\title{
ESTUDIO DE COLUMNAS REACTIVAS BASADAS EN EL EMPLEO DE HIERRO CERO-VALENTE PARA LA ELIMINACIÓN DE CONTAMINANTES EN AGUA
}

Tesis doctoral presentada por

\section{Eliana Berardozzi}

ante la Facultad de Ingeniería de la Universidad Nacional de La Plata para acceder al grado académico de

\section{DOCTOR EN INGENIERIA}
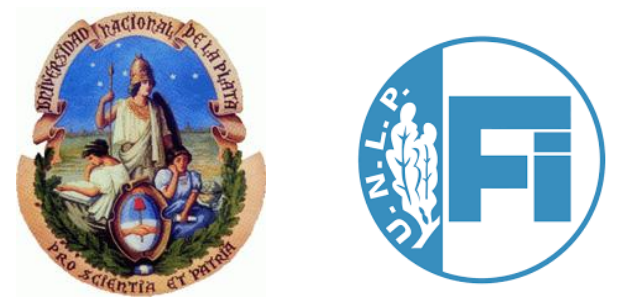

Dirección de tesis:

Dr. Fernando S. García Einschlag

Jurado de tesis:

Dra. Mónica Farfan Torres

Dra. Cristina Zalazar

Dra. Nora Bértola

Fecha de la defensa oral y pública:

5 de Abril de 2019 


\section{RESUMEN}

Muchos de los estudios sobre la técnica de Hierro Cero-Valente se han centrado en sistemas batch. Sin embargo, desde un punto de vista práctico, las tecnologías de separación y purificación basadas en procesos heterogéneos generalmente emplean sistemas continuos. Por lo tanto, para facilitar el proceso de escalado generalmente son necesarios ensayos de laboratorio utilizando columnas operadas en modo continuo. Si bien los sistemas continuos basados en el empleo de ZVI han mostrado efectividad para la remoción de diferentes contaminantes, en ensayos a largo plazo generalmente se observa: por un lado una disminución en la conductividad hidráulica de las columnas y por otro una pérdida de la reactividad del lecho. Por estos motivos es de gran importancia estudiar el comportamiento a largo plazo de columnas reactivas basadas en el empleo de Hierro Cero-Valente.

Para esto en el capítulo 2 se comienza realizando una descripción del material y la metodología utilizados a lo largo del trabajo y un resumen del marco teórico en el cuál se basa la tesis relacionado con reactores tubulares y lechos rellenos. En el capítulo 3 se exponen los resultados de las primeras pruebas realizadas utilizando columnas reactivas con $\mathrm{ZVI}$, y ensayos adicionales y complementarios realizados.

El estudio del desempeño de estos sistemas para distintas condiciones operativas, con el objeto de optimizar la eficiencia de remoción de diferentes contaminantes representa el eje central de la tesis y los resultados experimentales obtenidos utilizando columnas reactivas de pequeña escala (RSSCT) se detallan en el capítulo 4. En este capítulo se analiza también la posibilidad de utilizar diferentes fuentes alternativas de ZVI. En el capítulo 5 se emplean distintas técnicas de análisis multivariado y modelos matemáticos que permiten interpretar los resultados obtenidos utilizando RSSCT y poder predecir el comportamiento del sistema.

A lo largo del capítulo 6 se detalla el diseño de plantas de tratamiento para la remoción de arsénico que incluyen todos los procesos unitarios necesarios para la obtención de agua apta para consumo humano y el escalado de los procesos en columna para caudales de hasta $4 \mathrm{~m}^{3} /$ día. Utilizando estas plantas se estudia el comportamiento del sistema a largo plazo, otro de los objetivos de esta tesis. En el capítulo 7 se presentan los resultados de las pruebas de campo realizadas con matrices de agua reales contaminadas utilizando las plantas diseñadas para las diferentes escalas de tratamiento.

Finalmente, en el capítulo 8 se discuten los resultados obtenidos utilizando columnas de pequeña escala para la remoción de cromo hexavalente. 


\section{Índice}

RESUMEN

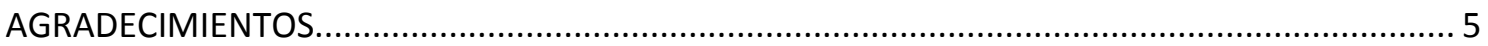

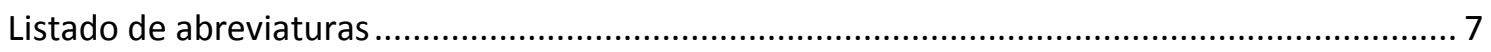

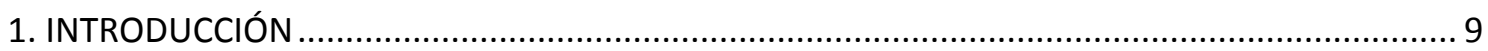

1.1 TECNOLOGÍAS BASADAS EN EL EMPLEO DE HIERRO PARA LA REMEDIACIÓN AMBIENTAL9

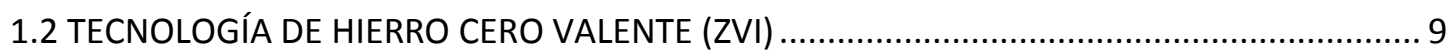

1.2.1 Mecanismos de remoción de arsénico mediante ZVI .............................................. 11

1.2.2 Mecanismos de remoción de $\mathrm{Cr}(\mathrm{VI})$ mediante $\mathrm{ZVI}$................................................... 12

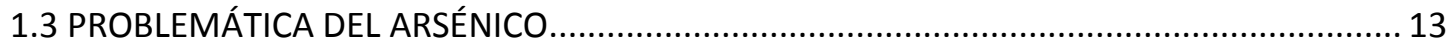

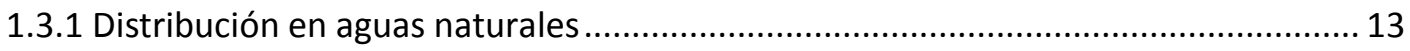

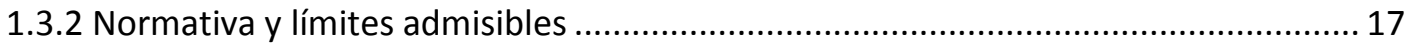

1.3.3 Efectos en la salud y principales rutas de exposición ............................................... 18

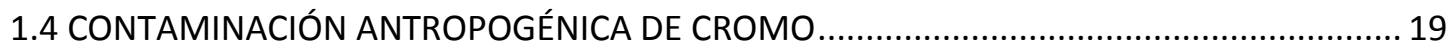

1.5 MÉTOdOS PARA LA MITIGACÓN DE LA PROBLEMÁTICA DEL ARSÉNICO EN AGUA DE

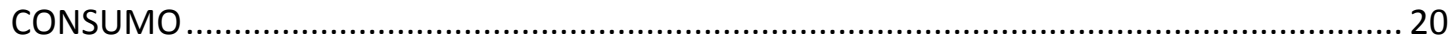

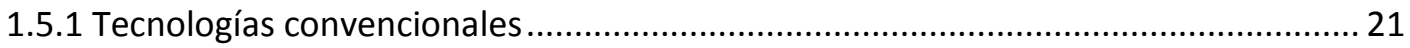

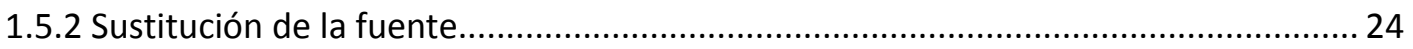

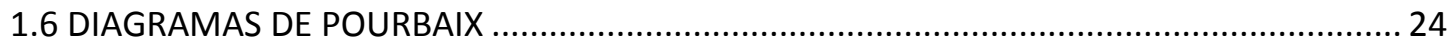

1.6.1 Diagramas de Pourbaix en sistemas Fe/ $\mathrm{H}_{2} \mathrm{O}, \mathrm{As} / \mathrm{H}_{2} \mathrm{O}$ y $\mathrm{Cr} / \mathrm{H}_{2} \mathrm{O}$............................... 25

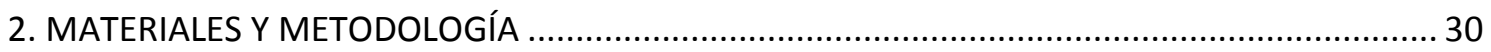

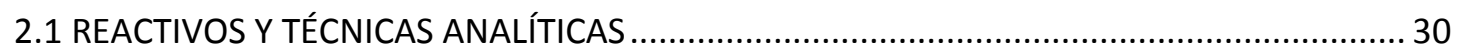

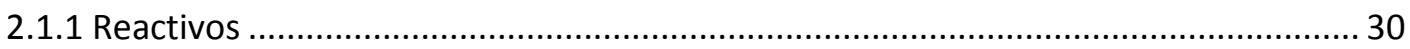

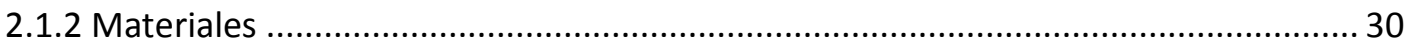

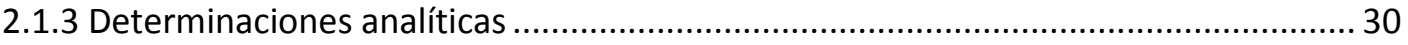

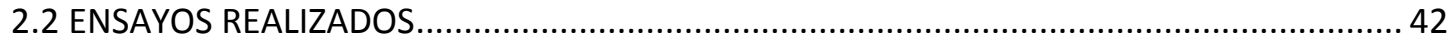

2.2.1 Estudios de captación de arsénico en reactores discontinuos (batch) ...................... 42

2.2.2 Sistemas de lecho fijo. Remoción de contaminantes en columnas rellenas .............. 43

2.2.3 Comportamiento hidrodinámico de lechos rellenos con ZVI..................................... 46

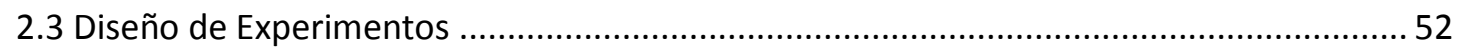

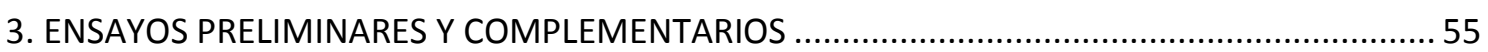

3.1 ENSAYOS PRELIMINARES DE REMOCIÓN. EFECTO DEL pH ............................................ 56

3.2 ENSAYOS PRELIMINARES. EFECTO DE LAS VARIABLES OPERATIVAS ................................57 


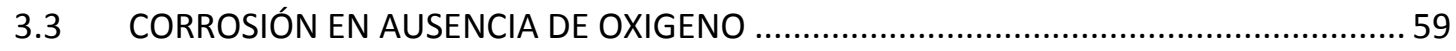

3.3.1 Ensayos preliminares de dos columnas en serie..................................................... 59

3.3.2 Corrosión en atmósfera de nitrógeno ………………........................................ 62

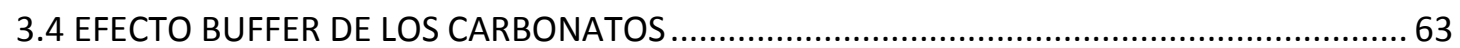

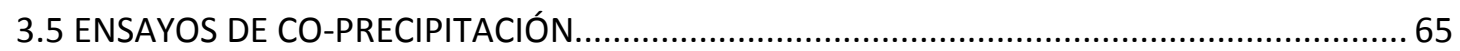

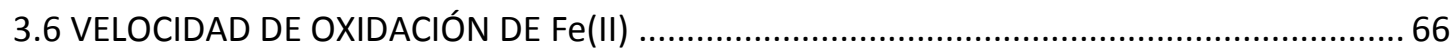

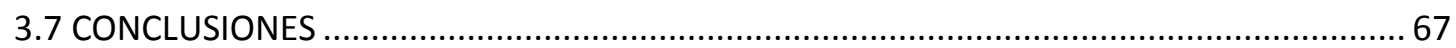

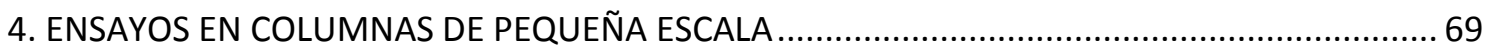

4.1 ESTUDIO DE LAS VARIABLES OPERATIVAS: ENSAYOS RÁPIDOS EN COLUMNAS REACTIVAS

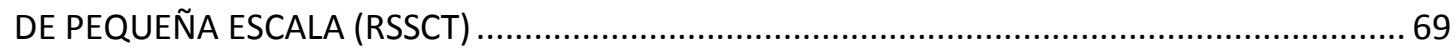

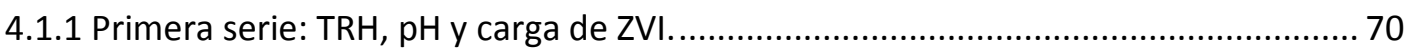

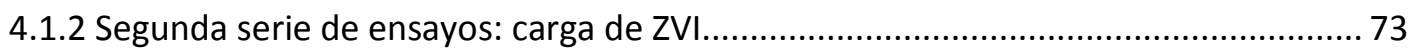

4.1.3 Tercera serie de ensayos: efecto de densidad del lecho ......................................... 75

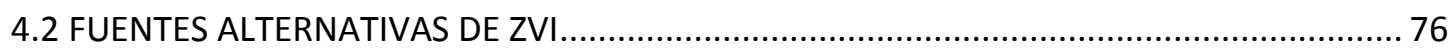

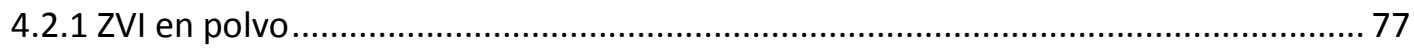

4.2.2 Granallas de acero al carbono ................................................................................. 79

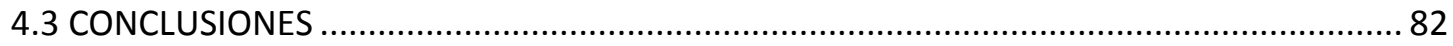

5. ESTRATEGIAS PARA ANÁLISIS, INTERPRETACIÓN Y MODELADO DE LOS DATOS OBTENIDOS

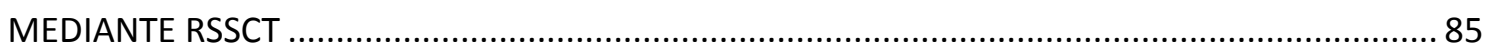

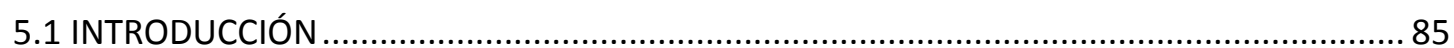

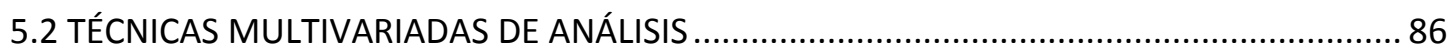

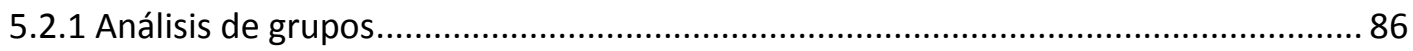

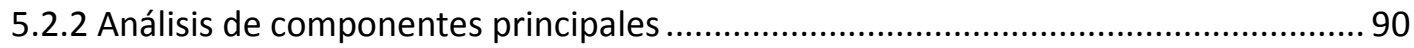

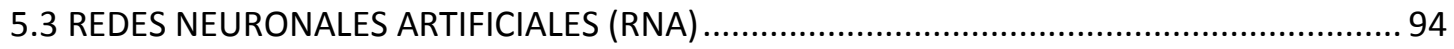

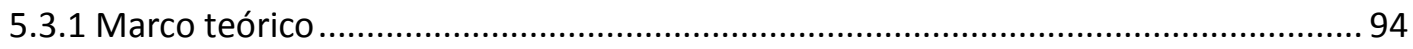

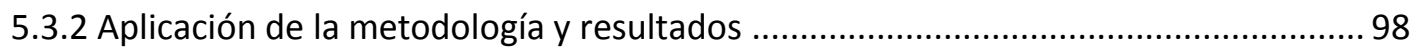

5.3.3 Análisis de sensibilidad de redes neuronales....................................................... 113

5.4 DESARROLLO DE UN MECANISMO SIMPLIFICADO PARA EL MODELADO DE LOS

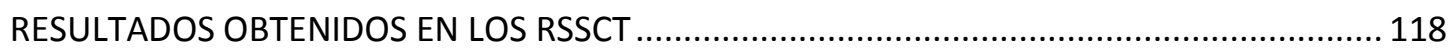

Resolución numérica del modelo simplificado ................................................................. 121

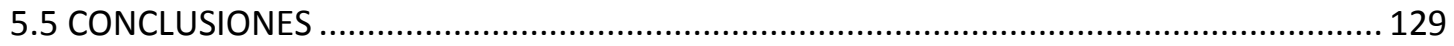

6. DISEÑO DE PLANTAS DE TRATAMIENTO PARA LA ELIMINACIÓN DE ARSÉNICO EN AGUA .. 132

6.1 INSTALACIÓN PARA LA REALIZACIÓN DE ENSAYOS A ESCALA REAL .............................. 132

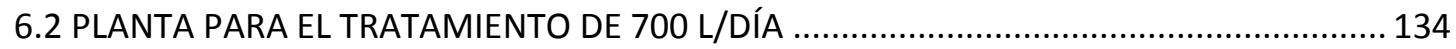

6.2.1 Resultados eficiencia pruebas de laboratorio................................................... 137 
6.2.2 Variación de la conductividad hidráulica 141

6.2.3 Resultados DTR columna grande 144

6.3 PLANTA PARA EL TRATAMIENTO DE $2 \mathrm{M}^{3}$ /DÍA .............................................. 147

6.4 PLANTA PARA EL TRATAMIENTO DE 4 M3/DÍA................................................... 151

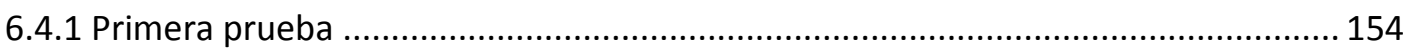

6.4.2 Segunda prueba .................................................................................. 156

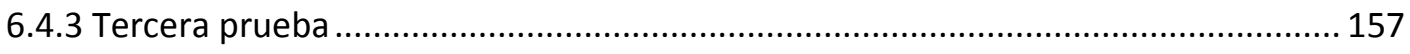

6.5 CARACTERIZACIÓN DE RESIDUOS OBTENIDOS DEL PROCESO DE TRATAMIENTO .......... 159

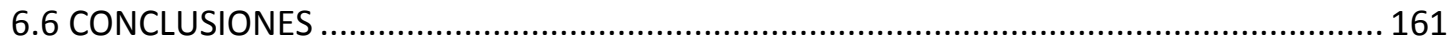

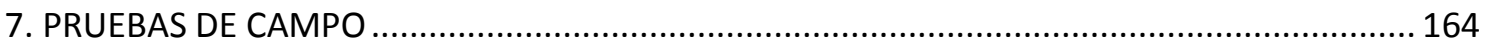

7.1 PRIMERA PRUEBA DE CAMPO, GRAL. RODRIGUEZ ............................................. 164

Adecuación e instalación del prototipo .............................................................. 165

7.2 SEGUNDA PRUEBA DE CAMPO, CASTELLI ......................................................... 167

7.2.1 Resultados primer ensayo en Castelli ............................................................. 171

7.2.2 Resultados segundo ensayo en Castelli .......................................................... 171

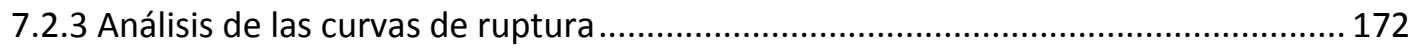

7.3 TERCERA PRUEBA DE CAMPO, VERÓNICA ...................................................... 174

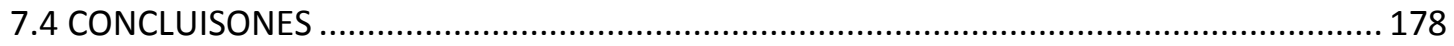

8. ENSAYOS DE PEQUEÑA ESCALA PARA LA REMOCIÓN DE Cr(VI) .................................. 180

8.1 ENSAYOS PRELIMINARES EN BATCH ............................................................. 180

8.1.1 Reacción en fase homogénea ..................................................................... 180

8.1.2 Reacción heterogénea.......................................................................... 181

8.2 ENSAYOS RÁPIDOS EN COLUMNAS REACTIVAS DE PEQUEÑA ESCALA (RSSCT)............. 183

8.2.1 Efecto del TRH y el pH ....................................................................... 183

8.2.2 Efecto de la densidad del relleno ................................................................ 184

8.2.3 Especiación del Cromo eluido ............................................................... 185

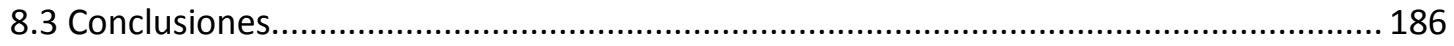

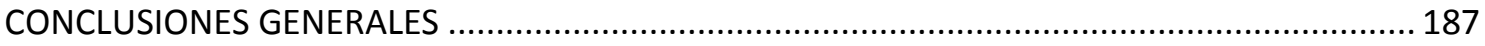

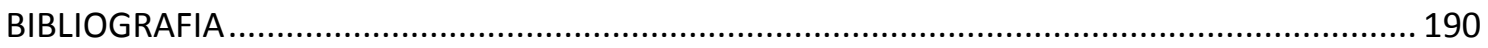

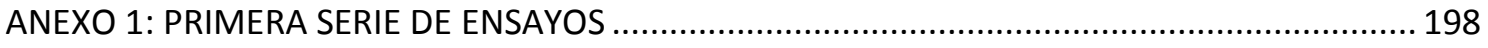

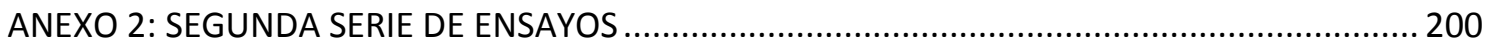

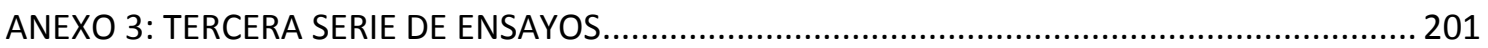




\section{AGRADECIMIENTOS}

El presente trabajo de tesis es el resultado de varios años de trabajo durante los que conté con el apoyo de una gran cantidad de personas e instituciones a los cuales quiero agradecer.

Al sistema de educación pública y gratuita argentino, por haberme permitido estudiar y al cuál debo todas mis etapas de formación.

Al CONICET y al INIFTA por haberme permitido ingresar al sistema científico.

A todas las instituciones que financiaron este trabajo de tesis: CONICET, UNLP, Secretaría de Políticas Universitarias, Facultad de Ingeniería, Departamento de Hidráulica y UIDET Hidromecánica.

A todas las personas del ex LIS por haberme recibido y ayudado en mis comienzos en el laboratorio.

A todo el personal docente y no docente del Departamento de Hidráulica y a Hidromecánica por haberme abierto sus puertas y brindado su ayuda tanto administrativa como en la construcciones de modelos a lo largo de todos estos años. En especial a Hugo por todas las horas de viaje y charlas compartidas así como toda su ayuda técnica.

A Alejandra y Joaquín por darnos el primer impulso para salir a realizar las primeras pruebas fuera de la Facultad. A Patricia y Alfredo por habernos recibido en su casa y colaborar en las pruebas.

A la cooperativa de Castelli (CUECCA) y a FEDECOBA por su colaboración en nuestra segunda prueba de campo.

A la Cooperativa de agua de Verónica y a FEDECAP por habernos abierto sus puertas en este último período. En particular a Luis por seguir impulsando nuestros avances.

A todo el primer piso por compartir materiales, festejos y hacer más a menos los días en el INIFTA.

Al Laboratorio de Simulación y Control de Procesos de la Universidad de San Pablo por su introducción a las redes neuronales.

A Gaby por tantos años de aprender juntas. Su ayuda durante las pruebas en la Facultad resultó imprescindible. A todos los chicos que participaron del proyecto, Lucas, Vicente, David y Belén muchas gracias.

A todos los PAOs por bancarme todos estos años. A Andrés por su amistad y conocimientos compartidos, su sabiduría y ayuda experimental fue fundamental para transitar los primeros años el laboratorio. A Bruno por alegrar nuestras horas en el INIFTA y por su amistad. A Sofi, Mariana, Fede, Agus y Lisandro por los lindos momentos compartidos. A Lisandro también por su colaboración experimental. 
A Cecilia y a Sergio por su apoyo constante a lo largo de estos años y por tenerme siempre en cuenta.

A mi familia que me enseñó que con esfuerzo todo se logra. Gracias por su apoyo incondicional.

En especial a Seba que, pese a nuestras discusiones, todo lo que sé lo aprendí de él. Se preocupó por compartir todos sus conocimientos y por mi formación de un pensamiento crítico. Gracias a su sabiduría, paciencia y apoyo incondicional este trabajo pudo ser posible. 
Berardozzi

\section{Listado de abreviaturas}

ZVI: hierro cero valente (zero valent iron).

HFO: oxihidróxidos de hierro (hydrous iron oxides).

CL: capa de corrosión (corrosion layer).

MTZ: zona de trasferencia de masa (mass transfer zone).

DTR: curva de distribución de tiempos de residencia.

RFP: reactor de flujo pistón.

MDA: modelo de dispersión axial.

MTS: modelo de tanques en serie.

VR: variables respuesta.

VI: variables independientes.

RSSCT: ensayos rápidos en columnas reactivas en pequeña escala (rapid small scale column test).

TRH: tiempo de residencia hidráulico.

Tr: tiempo de reacción.

$\rho_{\mathrm{l}}:$ densidad del lecho.

PC: componente principal.

RNA: red neuronal artificial.

LS: conjunto de datos de aprendizaje (learning set).

TS: conjunto de datos de prueba (test set).

MLP: múltiples capas perceptron (multi layer perceptron).

MSE: error cuadrático medio.

E: desviación cuadrática.

$Q_{d}$ : caudal de diseño.

$Q_{m}$ : caudal promedio experimental.

FLA: filtro lento de arena. 


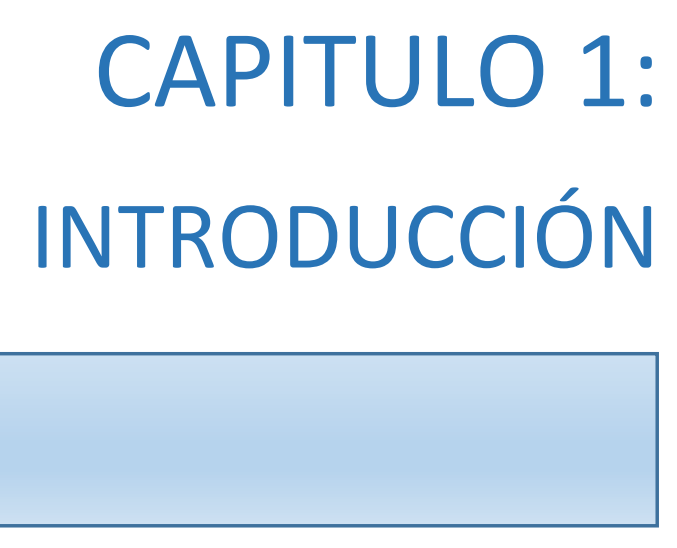




\section{INTRODUCCIÓN}

\subsection{TECNOLOGÍAS BASADAS EN EL EMPLEO DE HIERRO PARA LA REMEDIACIÓN AMBIENTAL}

La alta tasa de deterioro de los recursos naturales es una preocupación mundial en las últimas décadas. En consecuencia, se han creado legislaciones destinadas a reforzar la protección y remediación de suelos y fuentes de agua contaminadas. Además, el reconocimiento de que varios métodos de tratamiento tradicionales no son sostenibles en muchas situaciones, ha llevado a un crecimiento en el desarrollo de tecnologías alternativas para el tratamiento de la tierra suelos y aguas. Varias de estas técnicas utilizan hierro y sus productos minerales para eliminar o estabilizar diferentes tipos de contaminantes [1].

El hierro es uno de los elementos más abundantes en la corteza terrestre, y en la naturaleza predomina en dos estados de oxidación: Fe(II) y $\mathrm{Fe}(\mathrm{III})$. El hierro cero valente, $\mathrm{Fe}(0)$, también se puede encontrar bajo condiciones ambientales y geológicas específicas. Las reacciones relacionadas con este metal juegan un papel importante en una serie de procesos ambientales. En este contexto, las diferentes formas minerales de hierro influyen en la movilidad, distribución y degradación de los contaminantes debido a su capacidad de actuar como agentes reductores, adsorbentes o precipitantes. Se sabe que los oxihidróxidos (HFO) de hierro amorfos frescos son adsorbentes particularmente eficaces de una amplia gama de contaminantes [2-4].

Las tecnologías para remediación ambiental basadas en el empleo de hierro se suelen dividir en dos grupos: i) las tecnologías que utilizan hierro como adsorbente, coprecipitante o agente inmovilizador de diferentes contaminantes, y ii) las que usan hierro como donor de electrones para reducir químicamente distintos contaminantes. Sin embargo, es necesario aclarar que muchas tecnologías involucran ambos tipos de procesos.

La adsorción se asocia con la acumulación de contaminantes sobre la superficie de un sólido, mientras que la precipitación se debe a la formación espontánea de precipitados. La coprecipitación es un mecanismo de eliminación inespecífico en el que especies extrañas quedan atrapadas en una matriz sólida formada por oxo/hidróxidos amorfos [5-7]. La reducción química se refiere a una reacción en la que el contaminante gana uno o más electrones y se transforma en una especie menos tóxica o con menor movilidad [5].

\subsection{TECNOLOGÍA DE HIERRO CERO VALENTE (ZVI)}

Entre las técnicas alternativas introducidas en las últimas décadas se encuentran aquellas basadas en el uso de hierro cero valente (cero valent iron, ZVI). Estas tecnologías han aparecido como una solución prometedora porque presentan una relación eficiencia/costo muy favorable y pueden implementarse utilizando 
materiales simples y ampliamente disponibles. Su uso se relacionó inicialmente con aplicaciones en barreras reactivas permeables (ZVI PRB) para la remediación de aguas subterráneas in situ [8]. Estas se han instalado en todo el mundo y, en la mayoría de los casos, funcionaron satisfactoriamente [9-10], por lo que la tecnología se amplió para su uso en sistemas de filtros ex-situ.

En las últimas dos décadas se han publicado numerosos trabajos que demuestran que la técnica $\mathrm{ZVI}$ puede emplearse con éxito para remover diversos contaminantes incluyendo especies de arsénico [11-13], $\mathrm{NO}_{3}^{-}$[15], $\mathrm{NO}_{2}^{-}$, cromo hexavalente [16], metales pesados [17] y compuestos orgánicos tanto halogenados [12] como nitrados [14][18].

Las tecnologías basadas en ZVI pueden implicar una variedad de vías de eliminación de contaminantes que incluyen tanto transformaciones químicas directas (reducción/oxidación) [19,20] como procesos físicos (adsorción/coprecipitación) [21]. Recientemente se ha señalado que la importancia relativa de los fenómenos involucrados puede depender fuertemente no solo de la naturaleza del contaminante objetivo, sino también de las condiciones de operación [19] [22].

El hierro metálico en contacto con el agua es inestable y se corroe espontáneamente. La corrosión acuosa del hierro se produce esencialmente a través de un proceso electroquímico cuya hemi reacción anódica es la producción de especies ferrosas [23].

La oxidación de $\mathrm{Fe}(0)$ puro en medios ácidos $(\mathrm{pH}<4)$ generalmente está vinculada a la reducción de $\mathrm{H}^{+}$[7], mientras que la reducción del $\mathrm{O}_{2}$ disuelto es el proceso catódico principal a valores de $\mathrm{pH}$ casi neutros [7]. La estequiometria global de estos últimos procesos puede representarse mediante las ecuaciones 1.1 y 1.2.

$\mathrm{Fe}(0)+2 \mathrm{H}^{+} \rightarrow \mathrm{Fe}(\mathrm{II})+\mathrm{H}_{2}$

$\mathrm{Fe}(0)+2 \mathrm{H}^{+}+1 / 2 \mathrm{O}_{2} \rightarrow \mathrm{Fe}(\mathrm{II})+\mathrm{H}_{2} \mathrm{O}$

El mecanismo asociado a la producción de $\mathrm{H}_{2}$ implica etapas de transferencia monoelectrónica con la formación de hidrógeno atómico adsorbido $(\mathrm{H} \bullet)$ como especie intermedia [24]. Por otro lado, se cree que la reducción electroquímica del oxígeno disuelto se produce o bien mediante un proceso que involucra 4 e-para producir directamente $\mathrm{H}_{2} \mathrm{O}$ sobre el hierro desnudo [25] (ecuación 1.2) o mediante dos reducciones consecutivas de $2 \mathrm{e}^{-}$, con la formación de $\mathrm{H}_{2} \mathrm{O}_{2}$ como intermediario sobre superficies de hierro cero recubiertas por una capa de corrosión [19-21,25] (ecuaciones 1.3 y 1.4 ).

$\mathrm{Fe}(0)+2 \mathrm{H}^{+}+\mathrm{O}_{2} \rightarrow \mathrm{Fe}(\mathrm{II})+\mathrm{H}_{2} \mathrm{O}_{2}$

$\mathrm{Fe}(0)+2 \mathrm{H}^{+}+\mathrm{H}_{2} \mathrm{O}_{2} \rightarrow \mathrm{Fe}(\mathrm{II})+2 \mathrm{H}_{2} \mathrm{O}$

Además del $\mathrm{H}^{+} \mathrm{y} \mathrm{O}_{2}$, otras especies también pueden actuar como aceptores de electrones. Dependiendo de la composición de la fase acuosa, estas especies pueden incluir $\mathrm{Cr}(\mathrm{VI}), \mathrm{NO}_{3}{ }^{-}, \mathrm{H}_{2} \mathrm{O}_{2}, \mathrm{Fe}(\mathrm{III})$, nitrocompuestos, azo compuestos e incluso el $\mathrm{H}_{2} \mathrm{O}$ $[5,7]$. Las tazas de corrosión en los sistemas $\mathrm{ZVI} / \mathrm{H}_{2} \mathrm{O}$ están condicionadas por el hecho de que las especies de $\mathrm{Fe}$ (II) también pueden oxidarse produciendo $\mathrm{Fe}$ (III) (ecuación 1.5). 
$\mathrm{Fe}(\mathrm{II})+1 / 4 \mathrm{O}_{2}+\mathrm{H}^{+} \rightarrow \mathrm{Fe}(\mathrm{III})+1 / 2 \mathrm{H}_{2} \mathrm{O}$

Por otro lado, algunos autores [3,5,14] proponen la reacción heterogénea de reducción del $\mathrm{Fe}(\mathrm{III})$ en contacto con el $\mathrm{ZVI}$ según:

$\mathrm{Fe}(0)+2 \mathrm{Fe}(\mathrm{III}) \rightarrow 3 \mathrm{Fe}(\mathrm{II})$

Las especies férricas son bastante insolubles por encima de $\mathrm{pH} 4$ y su precipitación generalmente conduce a la formación de una capa de corrosión (CL, corrosion layer) en la superficie del ZVI [18,22]. Esta capa está compuesta inicialmente por una gran variedad de hidróxidos porosos que con el paso del tiempo se transforman en óxidos menos porosos por deshidratación (ec 1.7 a 1.9) [5,26-27].

$$
\begin{aligned}
& \mathrm{Fe}(\mathrm{III})+3 \mathrm{H}_{2} \mathrm{O} \leftrightarrow \mathrm{Fe}(\mathrm{OH})_{3}+3 \mathrm{H}^{+} \\
& \mathrm{Fe}(\mathrm{OH})_{3} \leftrightarrow \mathrm{FeO}(\mathrm{OH})+\mathrm{H}_{2} \mathrm{O} \\
& 2 \mathrm{FeO}(\mathrm{OH}) \leftrightarrow \mathrm{Fe}_{2} \mathrm{O}_{3}+\mathrm{H}_{2} \mathrm{O}
\end{aligned}
$$

La estructura precisa de la CL depende también de la composición de la fase acuosa y de las condiciones hidrodinámicas. Los productos de corrosión generalmente incluyen estas especies férricas $\left(\mathrm{Fe}_{2} \mathrm{O}_{3} / \mathrm{FeOOH} / \mathrm{Fe}(\mathrm{OH})_{3}\right)$ pero también pueden incluir especies ferrosas $\left(\mathrm{FeO} / \mathrm{Fe}(\mathrm{OH})_{2}\right)$ y compuestos mixtos de hierro de diferente valencia $\left(\mathrm{Fe}_{3} \mathrm{O}_{4} / \mathrm{GreenRust}\right)$ y $[24,38]$.

Aunque las capas de corrosión son estructuras microscópicamente heterogéneas que evolucionan con el tiempo, pueden considerarse películas estratificadas que cambian gradualmente de compuestos ferrosos, que dominan la composición de la capa interna (adyacente a la superficie de metal reductor), hacia especies férricas, que dominan la composición de la capa externa (junto a la especie oxidante presente en la fase acuosa). Es importante resaltar que, dependiendo de su estructura y composición, la capa de corrosión puede disminuir sustancialmente tanto la reactividad [18] como la eficiencia de utilización [1] del ZVI. Por lo tanto, la investigación del papel de capas pasivas bajo diferentes condiciones operacionales es de gran preocupación para las aplicaciones prácticas del hierro metálico [28,29].

\subsubsection{Mecanismos de remoción de arsénico mediante ZVI}

Los mecanismos de eliminación de As mediante la técnica de hierro cero valente implican varias etapas secuenciales que involucran especies de Fe en distintos estados de oxidación. En la primera etapa, el ZVI se oxida a Fe(II) por diferentes mecanismos dependiendo de las condiciones de operación. Para aguas que contienen oxígeno disuelto, la oxidación de $\mathrm{ZVI}$ se acopla a la reducción de $\mathrm{O}_{2}$ (ecuación 1.2), mientras que en los medios anóxicos la oxidación de $\mathrm{ZVI}$ produce $\mathrm{H}_{2}$ a través de la reducción de $\mathrm{H}^{+}$(ecuación 1.1). La última reacción es particularmente importante en medios ácidos y para soluciones electrolíticas de alta conductividad.

En presencia de $\mathrm{O}_{2}$, el $\mathrm{Fe}$ (II) generado se oxida a $\mathrm{Fe}(\mathrm{III})$ en forma parcial o total dependiendo del $\mathrm{pH}$ de la solución. Las especies de Fe(III) se pueden encontrar en 
solución como óxidos férricos hidratados coloidales (HFO) y/o sobre la superficie de partículas de ZVI formando la $\mathrm{CL}$. Para los sistemas de $\mathrm{ZVI} / \mathrm{H}_{2} \mathrm{O}$, la función de los productos de corrosión en el mecanismo de eliminación de arsénico puede ser doble: el arsénico puede quedar atrapado dentro de la fase en crecimiento de oxi/hidróxidos de hierro (coprecipitación) o puede ser atraído electrostáticamente hacia la superficie de los productos de corrosión para finalmente formar complejos superficiales (adsorción).

La posibilidad de eliminar simultáneamente especies de As(III) y de As(V) es una de las ventajas de los tratamientos basados en ZVI operados en condiciones aeróbicas. Esto parece ser posible por dos razones. Por un lado, el mecanismo de coprecipitación involucrado en el proceso de eliminación ha sido identificado como un proceso inespecífico. Por otro lado, en aguas ricas en oxígeno, la reducción de oxígeno disuelto produce intermedios reactivos ( $\mathrm{p}$. Ej. $\mathrm{HO}_{2} / \mathrm{O}_{2}{ }^{--}, \mathrm{H}_{2} \mathrm{O}_{2}, \mathrm{HO} \cdot$ ) que favorecen la oxidación de $\mathrm{As}(\mathrm{III})$ a $\mathrm{As}(\mathrm{V})[30,31]$ y esta última especie es mucho más fácil de ser adsorbida por los productos de corrosión.

La adsorción de $\mathrm{As}(\mathrm{V})$ sobre óxidos férricos es más eficiente que la de As(III) debido a valores de pK más bajos asociados a la primera especie. Dado que la eficiencia de adsorción está influenciada por la capacidad de desprotonación del sorbato y que el valor de pK del arsenito es mayor que el del arseniato, a valores de $\mathrm{pH}$ neutros la absorción de las formas desprotonadas de arseniato $\left(\mathrm{H}_{2} \mathrm{AsO}_{4}^{-}, \mathrm{HAsO}_{4}{ }^{-2}\right)$ es mucho más eficiente que la captación de la forma protonada del arsenito $\left(\mathrm{H}_{2} \mathrm{AsO}_{3}\right)$ [32].

Teniendo en cuenta la complejidad de los mecanismos de remoción involucrados, no resulta sencillo diseñar sistemas de tratamiento basados en esta técnica. Además, debe considerarse que los cambios dinámicos en el comportamiento del lecho de hierro, debidos a la formación y transformación de productos de corrosión que componen la CL durante la vida útil del sistema, generalmente causan una notable reducción de la eficiencia del proceso. Por lo tanto, la optimización general del sistema requiere una comprensión profunda de varios procesos fisicoquímicos coexistentes.

\subsubsection{Mecanismos de remoción de $\mathrm{Cr}(\mathrm{VI})$ mediante ZVI}

Diferentes métodos se encuentran disponibles para la eliminación del cromo hexavalente en aguas contaminadas. La mayoría de ellos incluye la reducción química a $\mathrm{Cr}$ (III) seguida de etapas de precipitación, adsorción, procesos de separación biológica o de membrana. La reducción química a $\mathrm{Cr}$ (III) seguida de precipitación es la técnica más utilizada para la descontaminación de aguas residuales contaminadas con $\mathrm{Cr}(\mathrm{VI})$. Los agentes reductores comúnmente utilizados son el sulfato ferroso, el dióxido de azufre y los sulfitos de sodio. El principal inconveniente de este tipo de tratamientos es el alto costo de los productos químicos utilizados para la reducción y la precipitación. Por este motivo, en los últimos años, ha surgido un gran interés en la investigación de materiales de bajo costo que puedan sustituir a los agentes reductores tradicionales [33]. 
Uno de los métodos de interés para la reducción in situ de metales activos presentes en agua subterránea contaminada es la técnica ZVI [31]. El mecanismo de eliminación de $\mathrm{Cr}(\mathrm{VI})$ por parte del ZVI involucra la oxidación de $\mathrm{Fe}(0)$ a $\mathrm{Fe}(\mathrm{II})$ y $\mathrm{Fe}(\mathrm{III})$, junto con la reducción de $\mathrm{Cr}(\mathrm{VI})$ a $\mathrm{Cr}(\mathrm{III})$, y la posterior precipitación de un sólido poco soluble.

Mientras que en condiciones extremadamente ácidas a $\mathrm{pH}<2.5$ el $\mathrm{H}^{+}$es el aceptor de electrones dominante, a $\mathrm{pH}>2.5$ el $\mathrm{Cr}(\mathrm{VI})$ resulta ser el aceptador de electrones dominante que contribuye a la corrosión de ZVI [34].

Estudio previos han demostrado que a pH menor a 5.36 y concentración de $\mathrm{Cr}(\mathrm{VI})$ por debajo de $53 \mathrm{ppm}$ el $\mathrm{Cr}(\mathrm{VI})$ pueden eliminarse de la solución por reducción a $\mathrm{Cr}(\mathrm{III})$, de acuerdo con [35]:

$$
\begin{aligned}
& 2 \mathrm{HCrO}_{4}^{-}+3 \mathrm{Fe}(0)+14 \mathrm{H}^{+} \rightarrow 2 \mathrm{Cr}(\mathrm{III})+3 \mathrm{Fe}(\mathrm{II})+8 \mathrm{H}_{2} \mathrm{O} \\
& \mathrm{HCrO}_{4}^{-}+3 \mathrm{Fe}^{2+}+7 \mathrm{H}^{+} \rightarrow \mathrm{Cr}(\mathrm{III})+3 \mathrm{Fe}(\mathrm{III})+4 \mathrm{H}_{2} \mathrm{O}
\end{aligned}
$$

Mientras que a $\mathrm{pH}$ mayores a 5.36 las reacciones correspondientes quedarían definidas de la siguiente forma:

$$
\begin{aligned}
& 2 \mathrm{CrO}_{4}{ }^{2-}+3 \mathrm{Fe}(0)+8 \mathrm{H}_{2} \mathrm{O} \rightarrow 2 \mathrm{Cr}(\mathrm{III})+3 \mathrm{Fe}(\mathrm{II})+16 \mathrm{OH}^{-} \\
& \mathrm{CrO}_{4}{ }^{2-}+3 \mathrm{Fe}^{2+}+4 \mathrm{H}_{2} \mathrm{O} \rightarrow \mathrm{Cr}(\mathrm{III})+3 \mathrm{Fe}(\mathrm{III})+8 \mathrm{OH}^{-}
\end{aligned}
$$

En condiciones moderadas de $\mathrm{pH}$ (entre $\mathrm{pH} 5$ y 11), la eliminación de $\mathrm{Cr}(\mathrm{III})$ puede ocurrir a través de la precipitación de $\mathrm{Cr}(\mathrm{OH})_{3}$ o la coprecipitación de hidróxidos u oxo-hidróxidos mixtos de $\mathrm{Fe}(\mathrm{III})-\mathrm{Cr}$ (III) [34,36] según las ecuaciones 1.14 y 1.15:

$$
\begin{aligned}
& (1-x) \mathrm{Fe}^{3+}+x \mathrm{Cr}^{3+}+3 \mathrm{H}_{2} \mathrm{O} \rightarrow \mathrm{Cr}_{x} \mathrm{Fe}_{(1-\mathrm{x})}(\mathrm{OH})_{3}+3 \mathrm{H}^{+} \\
& (1-x) \mathrm{Fe}^{3+}+x \mathrm{Cr}^{3+}+2 \mathrm{H}_{2} \mathrm{O} \rightarrow \mathrm{Cr}_{x} \mathrm{Fe}_{(1-\mathrm{x})}(\mathrm{OOH})+3 \mathrm{H}^{+}
\end{aligned}
$$

donde el valor de x varía entre 0 y 1 .

\subsection{PROBLEMÁTICA DEL ARSÉNICO}

\subsubsection{Distribución en aguas naturales}

El arsénico es un elemento natural de la corteza terrestre que ocupa el $20^{\circ}$ lugar en abundancia y se encuentra ampliamente distribuido en el medio ambiente. Desde su aislamiento en el año 1250 este elemento ha sido un centro de controversia en la historia humana. Se ha utilizado en varios campos tanto en medicina, como agricultura, ganadería, electrónica, y metalurgia. Hoy en día es bien reconocido que el consumo de arsénico, incluso en niveles muy bajos, conduce a la carcinogénesis. 


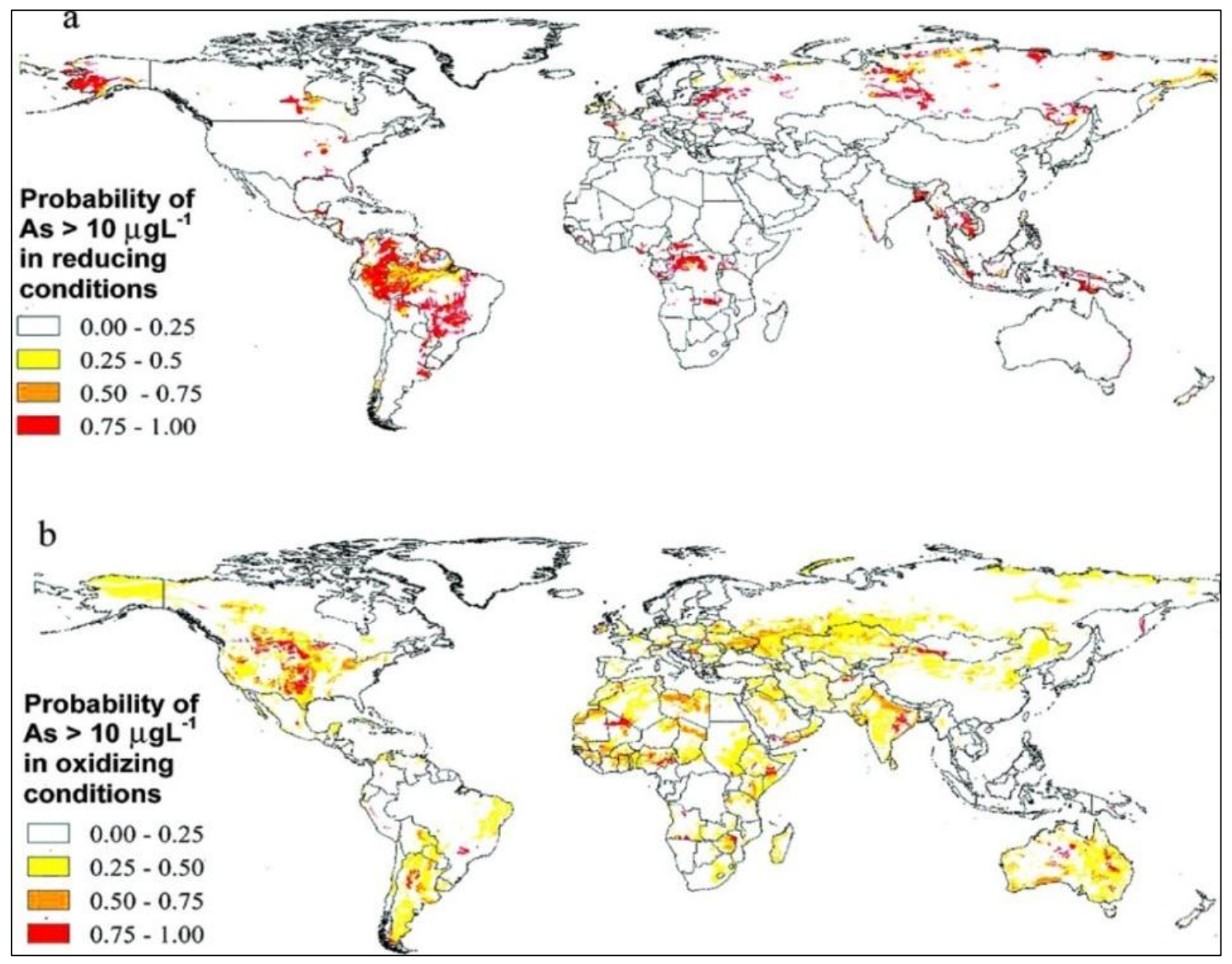

Figura 1.1. Modelado de la probabilidad global de contaminación geogénica de arsénico en aguas subterráneas para (a) condiciones reductivas del agua subterránea, y (b) condiciones oxidativas/alto $\mathrm{pH}$ [37].

El alto contenido de arsénico en aguas naturales es un problema mundial. Más de 226 millones de personas se encuentran expuestas a este contaminante a lo largo de 120 países. Uno de los países con mayor contenido de arsénico en sus fuentes de agua es la India. Países como Nepal, China, Mongolia, Myanmar, Tailandia, Taiwán, Vietnam, Camboya, Sri Lanka, Pakistán, Afganistán, Japón, Hungría, Ghana, México, Bolivia y Argentina también se encuentran altamente afectados por la toxicidad del arsénico. Asimismo existen estudios donde se informa que el contenido de arsénicos en agua va más allá del límite seguro en diferentes regiones de Irán, Australia, Nueva Zelanda, partes de la Unión Europea, Islandia, Brasil, Canadá y los Estados Unidos [38]. En la Figura 1.1 se presenta un mapa global donde se observa la probabilidad de obtener concentraciones de arsénico en aguas subterráneas mayores a $0.01 \mathrm{mg} / \mathrm{L}$ en condiciones tanto oxidantes como reductivas.

La Ilanura Chaco-Pampeana se encuentra entre las áreas del mundo más grandes identificadas con altos contenidos de arsénico en el agua subterránea [39,40]. Argentina fue el primer país de América Latina desde donde se informó la presencia de arsénico en las aguas subterráneas. En la Figura 1.2 se puede observar un mapa con las principales zonas afectadas por alto contenido de arsénico en nuestro país. La información disponible sobre la presencia de arsénico en aguas superficiales y subterráneas del territorio argentino responde a estudios parciales, realizados en distintas áreas del país. Este mapa publicado por el Ministerio de Educación señala 
áreas que corresponden a un nivel de arsénico en agua superior al límite establecido por la OMS $(0.01 \mathrm{mg} / \mathrm{L})$ junto a la densidad poblacional $\left(\mathrm{hab} / \mathrm{km}^{2}\right)$. Las zonas con presencia de arsénico están definidas a nivel de macro escala por lo que el análisis no puede ser extensivo a escalas menores. La variabilidad del contenido de arsénico en aguas subterráneas es muy grande, su distribución varía en forma vertical y horizontal, lo que demuestra una gran complejidad para determinar su presencia y lograr su predicción. En muchas ocasiones pozos cercanos presentan una gran diferencia en sus concentraciones de As.

Actualmente se estima que el área afectada por la presencia de arsénico en Argentina cubre aproximadamente $10^{6} \mathrm{~km}^{2}$ y que la población en áreas con aguas subterráneas contaminadas con As se eleva a alrededor de 4 millones de personas [39-41]. Las provincias más afectadas son Córdoba, Santiago del Estero, Chaco, Salta, Jujuy, Tucumán, Santa Fe y La Pampa, siendo las tres primeras las provincias con más altas concentraciones. Por otro lado, es importante tener en cuenta los contenidos de arsénico en la Provincia de Buenos Aires, ya que en la misma habita más de un tercio de la población del país.

La distribución de arsénico en la Provincia de Buenos Aires [42] se muestra en la Figura 1.3. A partir de este mapa se desprende que el $87 \%$ del territorio provincial tiene agua subterránea que supera la norma provincial vigente $(0,05 \mathrm{mg} / \mathrm{L})$ y sólo el $3 \%$ de los pozos muestreados cuenta con agua subterránea apta para consumo humano según el límite de la OMS $(0,01 \mathrm{mg} / \mathrm{L})$. Las regiones que registran los tenores más elevados (mayores a 0,1 mg/L), ocupan el $29 \%$ de la superficie de la Provincia y coinciden con zonas vecinas a la Bahía Samborombón, gran parte de la Pampa Arenosa y la totalidad de la región en forma de bastón, al Sur de Bahía Blanca. 


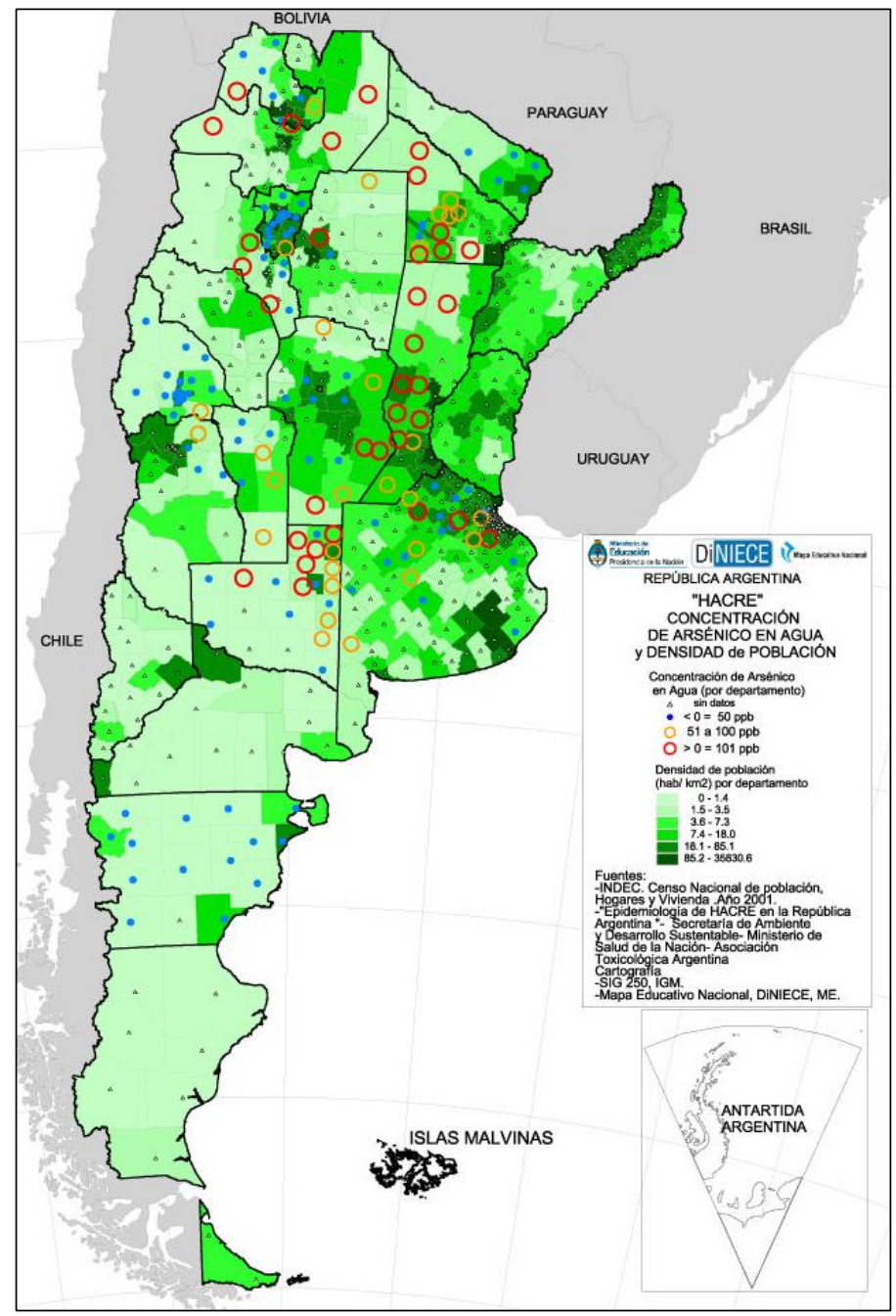

Figura 1.2. Distribución de concentración de arsénico y densidad poblacional en Argentina.

La mayor parte del contenido de As en las aguas subterráneas de la planicie Chaco-Pampeana tiene origen natural. El arsénico está presente en la mayoría de las rocas y se moviliza por procesos de disolución natural, actividad biológica, reacciones geoquímicas y emisiones volcánicas. A pesar de que los problemas ambientales relacionados con el arsénico se deben principalmente a su movilidad bajo condiciones naturales, algunas actividades antropogénicas como la minería, la combustión de combustibles fósiles, el uso de pesticidas arsenicales, la aplicación de herbicidas y el empleo de desecantes en cultivos podrían crear impactos adicionales [43].

El As es un metaloide que puede presentarse en aguas formando parte tanto de especies orgánicas como inorgánicas. Se reconoce que las especies arsenicales inorgánicas solubles son más perjudiciales que las orgánicas, siendo las especies con As(III) más tóxicas que las que poseen $\mathrm{As}(\mathrm{V})$. Las condiciones redox predominantes para los acuíferos argentinos van desde moderadamente reductoras a oxidantes, por lo que las especies de $\mathrm{As}(\mathrm{V})$ son la principal fuente de contaminación con arsénico en el agua subterránea de nuestro país. En este contexto, las especies más comunes de arsénico inorgánico, que a menudo se encuentran en los suministros de agua para un 
rango de $\mathrm{pH}$ entre 6 y 9 , son arseniatos $\left(\mathrm{HAsO}_{4}{ }^{2-}\right.$ y $\left.\mathrm{H}_{2} \mathrm{AsO}_{4}{ }^{-}\right)$y ácido arsenioso $\left(\mathrm{H}_{3} \mathrm{AsO}_{3}\right)$ [44].

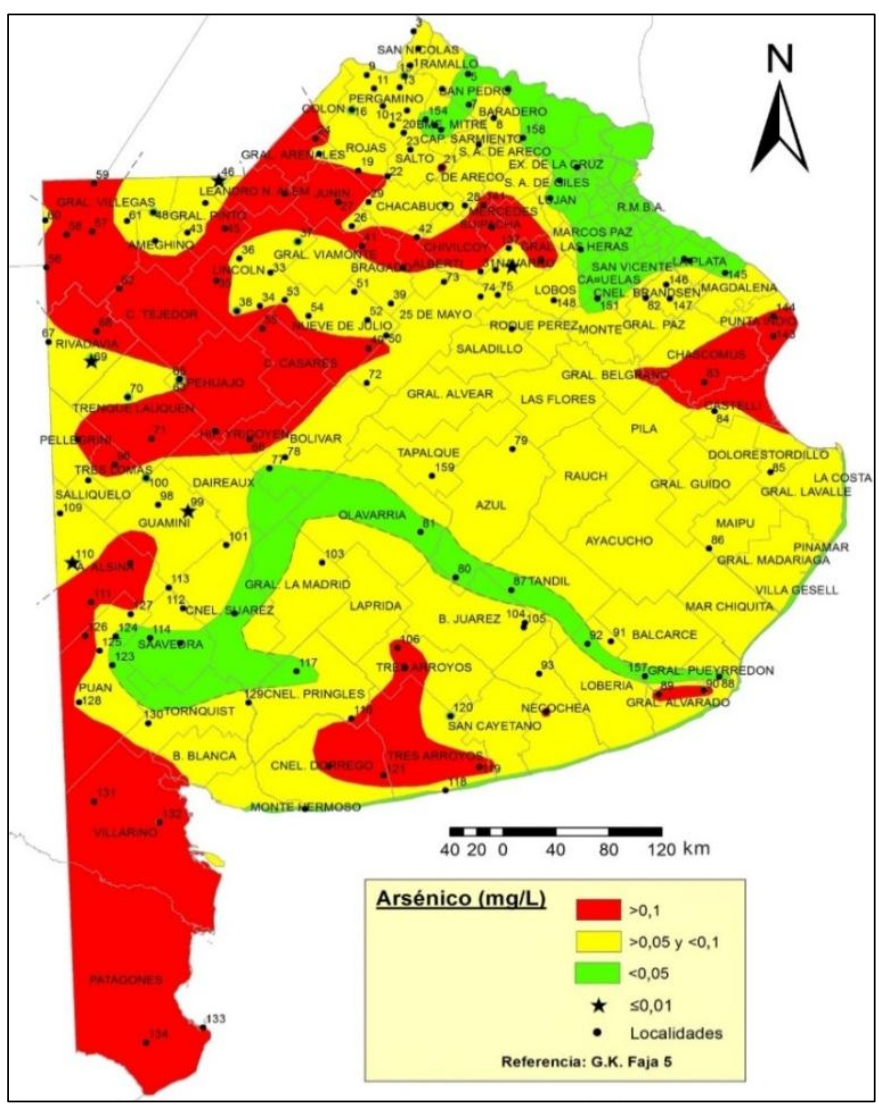

Figura 1.3. Distribución del contenido de arsénico en el agua subterránea de la provincia de Buenos Aires [42].

\subsubsection{Normativa y límites admisibles}

Las normas sobre potabilidad, así como sobre la calidad de la mayoría de los alimentos, han ido evolucionando hacia umbrales más estrictos a través del tiempo. Desde el año 1993 la OMS ha adoptado como límite máximo permisible para el As en agua potable un valor de $10 \mathrm{ppb}(0,01 \mathrm{mg} / \mathrm{L})$ [45], sin embargo, muchos países han conservado el límite anterior de la OMS de 50 ppb (0.05 mg L) como su estándar [41].

En nuestro país existen diferencias en las normativas respecto al contenido de As en el agua potable en diferentes provincias. Además, las normativas han ido modificándose durante las últimas décadas. Por ejemplo, en la Provincia de Buenos Aires el Decreto 6553 del año 1974 señalaba como valor aconsejable <0,01 mg/L, como valor aceptable hasta $0,01 \mathrm{mg} / \mathrm{L}$ y como valor tolerable hasta $0,1 \mathrm{mg} / \mathrm{L}$. Esta normativa se modificó en 1996, mediante la Ley 11.820, vigente en la actualidad, que estableció sólo un límite tolerable de $0,05 \mathrm{mg} / \mathrm{L}(50 \mu \mathrm{g} / \mathrm{L})$. Sin embargo, frente a los 0,05 mg/L de la Provincia de Buenos Aires, La Pampa adopta 0,15 mg/L, Santa Fe 0,1, Córdoba y Río Negro 0,05 mg/L y Entre Ríos 0,01 mg/L [42]. De esta forma, varias 
provincias tienen pendiente de concreción un convenio con el Código Alimentario Argentino (CAA), entidad que establece como límite tolerable $0,01 \mathrm{mg} / \mathrm{L}(10 \mu \mathrm{g} / \mathrm{L})$ para el agua potable de suministro público y agua potable de uso domiciliario y para agua de bebida envasada. Este mismo código, por otro lado, establece un valor máximo de $0,2 \mathrm{mg} / \mathrm{L}(200 \mu \mathrm{g} / \mathrm{L})$ para agua mineral natural.

El cumplimiento del límite permisible de arsénico en el agua potable ha sido un proceso gradual en los países en desarrollo. Con frecuencia, los límites permitidos se han fijado de acuerdo con la tecnología asequible en cada país. El problema del agua potable contaminada con arsénico ha sido mitigado, en algunas áreas urbanas medianas y grandes de América Latina con suministro centralizado de agua, mediante la instalación de plantas de tratamiento o aprovechando recursos hídricos alternativos. Sin embargo, existen pocas soluciones disponibles para la mitigación del arsénico en poblaciones rurales y pequeñas. Los métodos a pequeña escala y domésticos para eliminar el arsénico del agua para beber en América Latina han sido revisados recientemente [41]. Para estos sectores de población, el desarrollo de tecnologías alternativas y de bajo costo es de suma importancia.

\subsubsection{Efectos en la salud y principales rutas de exposición}

El arsénico puede producir tanto intoxicaciones agudas como crónicas. Las intoxicaciones agudas, de menor recurrencia, pueden presentarse por ingestión o inhalación. Ente los principales efectos de este tipo de intoxicación se encuentran náuseas, vómitos, diarrea, efectos cardiovasculares y encefalopatía [46].

La intoxicación crónica es la de mayor impacto. El As ingerido en pequeñas concentraciones en el agua de bebida por un largo período de tiempo es absorbido mediante vía sanguínea, metabolizado y acumulado, preferentemente en pulmones, hígado, riñones, piel, dientes, pelos y uñas. Los trastornos característicos que resultan de la exposición crónica son: engrosamiento de palmas y plantas (queratodermia), aumento de la pigmentación de la piel (hiperqueratosis) y aparición de cáncer cutáneo. Además, son bastante frecuentes los cánceres de pulmón y de laringe. El As también puede dañar al sistema nervioso, con manifestaciones que comienzan con hormigueo y entumecimiento de plantas y palmas, y continúan con una neuritis diseminada y dolorosa de las extremidades superiores e inferiores [47-51].

Las principales rutas de exposición de las personas y mayor amenaza para la salud pública derivada del consumo de agua provienen de fuentes de agua subterráneas con elevados contenidos de arsénico. Los cultivos irrigados con agua contaminada y los alimentos preparados con agua contaminada se presentan como fuentes secundarias. El pescado, los mariscos, la carne, las aves de corral, los productos lácteos y los cereales también pueden ser fuentes dietéticas de arsénico, aunque la exposición a estos alimentos suele ser mucho menor en comparación con la exposición a través de la ingesta de agua subterránea contaminada [46]. 


\subsection{CONTAMINACIÓN ANTROPOGÉNICA DE CROMO}

El cromo es el sexto elemento más abundante en la corteza terrestre. Generalmente se encuentra en pequeñas cantidades asociado a otros metales, particularmente en minerales que contienen hierro o plomo tales como cromita $\left(\mathrm{FeCr}_{2} \mathrm{O}_{4}\right)$ o crocoita $\left(\mathrm{PbCrO}_{4}\right)$. El cromo tiene una amplia variedad de usos industriales. Entre las tres más importantes se puede mencionar: (1) la industria metalúrgica, para la fabricación de acero inoxidable y varias aleaciones metálicas; (2) las industrias químicas, en tintes y pigmentos, cromado, curtido de cuero y preservación de la madera; y (3) la producción de materiales refractarios, incluyendo ladrillos refractarios de magnesita-cromo para revestimientos de hornos metalúrgicos y cromita granular para varias otras aplicaciones resistentes al calor.

El cromo es un contaminante común del agua subterránea y del suelo, particularmente en áreas industriales, y es el segundo contaminante inorgánico más abundante en aguas subterráneas en sitios de disposición de desechos peligrosos. Las concentraciones típicas de cromo en el agua natural oscilan entre 0,5 y $10 \mu \mathrm{g} / \mathrm{L}$. En Argentina, sin embargo, se encontraron concentraciones de Cr total de 20 a 230 $\mu \mathrm{g} / \mathrm{L}$ en acuíferos de la llanura pampeana [44]. La contaminación del agua subterránea puede ocurrir debido a la lixiviación del cromo proveniente de desechos sólidos dispuestos sobre el suelo, incluidos los desechos mineros o las filtraciones de lagunas industriales. Sin embargo la presencia de cromo en agua y suelo se debe principalmente a las liberaciones permitidas o accidentales de efluentes de procesos industriales que utilizan cromo en sus operaciones.

Los estados de oxidación de cromo van desde +2 a +6 , pero solo +3 y +6 son los estados estables que se encuentran generalmente en el medio ambiente, dependiendo de las condiciones redox locales [52]. El Cr(III) es el estado de oxidación más común en el medio ambiente y la mayoría del $\mathrm{Cr}(\mathrm{VI})$ que se encuentra es el resultado de emisiones domésticas e industriales. Los procesos geoquímicos determinan la especiación, el transporte, y el destino del cromo en el medio ambiente. Tanto en agua dulce como en ambientes marinos, la hidrólisis y la precipitación son los procesos más importantes que determinan el destino ambiental del cromo, mientras que la adsorción y la bioacumulación son relativamente menores. Dado que el $\mathrm{Cr}(\mathrm{III})$ y el $\mathrm{Cr}(\mathrm{VI})$ tienen diferentes solubilidades y afinidades por las superficies minerales, la movilidad del cromo dependerá en gran medida de su especiación redox. El $\mathrm{Cr}$ (III) se encuentra en gran parte inmóvil en el ambiente y solo se puede movilizar formando complejos con el carbono orgánico disuelto. Los compuestos de $\mathrm{Cr}(\mathrm{VI})$ pueden reducirse a $\mathrm{Cr}(\mathrm{III})$ en presencia de ciertas especies de hierro y materia orgánica oxidable, sin embargo, el $\mathrm{Cr}(\mathrm{VI})$ es generalmente estable y móvil en aguas naturales donde hay bajas concentraciones de materiales reductores.

Además de afectar la movilidad del cromo en el medio ambiente, la especiación del cromo es importante para distinguir los posibles riesgos sobre la salud humana. Las principales rutas de la exposición al cromo incluyen la inhalación, el contacto con la piel, los ojos o la ingestión. El $\mathrm{Cr}$ (III) es un nutriente esencial en la dieta que se requiere para mantener un eficiente metabolismo de glucosa, lípidos y proteínas, para la integridad vascular $[53,54]$ y que exhibe un bajo nivel de toxicidad crónica [54]. No 
existe evidencia que indique que el $\mathrm{Cr}$ (III) puede causar cáncer en humanos o animales y la USEPA lo ha identificado en el Grupo D, no clasificable como carcinógeno en humanos. El $\mathrm{Cr}(\mathrm{VI})$ es mucho más tóxico que el $\mathrm{Cr}(\mathrm{III})$, tanto para exposiciones agudas como crónicas. La USEPA ha clasificado al $\mathrm{Cr}(\mathrm{VI})$ en el Grupo A, conocido carcinógeno humano cuando la vía de exposición es por inhalación y como un posible carcinógeno por la vía oral de exposición. El $\mathrm{Cr}(\mathrm{VI})$ causa daño celular por su papel como fuerte agente oxidante y por su capacidad de penetrar las membranas biológicas. Está asociado con el riesgo de cáncer y daño tanto renal como hepático. Además el ácido crómico, los dicromatos y otros compuestos de $\mathrm{Cr}(\mathrm{VI})$ son poderosos irritantes para la piel y pueden ser corrosivos. Por lo tanto, la eliminación del $\mathrm{Cr}(\mathrm{VI})$ tanto en efluentes acuosos industriales como en fuentes de agua subterránea resulta un paso importante en la mitigación de los problemas asociados a este metal.

En nuestro país el CAA, establece como límite tolerable de $\mathrm{Cr} 0,05 \mathrm{mg} / \mathrm{L}$ tanto para el agua potable de suministro público y uso domiciliario como para agua de bebida envasada. En la Provincia de Buenos Aires la ley 11.820, vigente en la actualidad fija el mismo límite. Con respecto al límite de descarga de efluentes, esta misma ley establecía, en un principio, una concentración máxima de 0,5 mg/L para el vertido tanto en cursos de aguas superficiales como de mar. Posteriormente mediante la resolución 336 del año 2003 este parámetro fue modificado desglosando cromo total de cromo hexavalente y estableciendo valores máximos de $2 \mathrm{mg} / \mathrm{L}$ y $0,2 \mathrm{mg} / \mathrm{L}$, respectivamente, para descargas en colectoras cloacales, conductos pluviales o cuerpos de agua superficiales.

En Argentina el margen sur de la costa del Río de la Plata es una de las principales zonas expuestas a variedad de contaminantes que a menudo tienen concentraciones mucho más altas que las establecidas por la ley. En esta zona las mayores cantidades de cromo se descargan por los ríos Matanza-Riachuelo (590 kg/día) y Luján (340 kg/día) y los canales Sarandí (270 kg/día) y Santo Domingo (190 $\mathrm{kg} / \mathrm{día}$ ). En consecuencia, se ha registrado valores del orden de 80-100 $\mu \mathrm{g} / \mathrm{L}$ en muestras de agua de áreas cercanas a estas descargas [55,56]. En la zona del río Matanza -Riachuelo las principales fuentes puntuales de contaminación por cromo están asociadas a la industria del curtido.

\subsection{MÉTODOS PARA LA MITIGACÓN DE LA PROBLEMÁTICA DEL ARSÉNICO EN AGUA DE CONSUMO}

La provisión de fuentes de agua alternativas libres de arsénico y la instalación de sistemas de tratamiento luego de la extracción del agua son los dos principales medios de mitigación en regiones severamente afectadas por el problema del arsénico. 


\subsubsection{Tecnologías convencionales}

Las tecnologías convencionales para remover arsénico se basan en una serie de procesos químicos y físicos básicos que pueden aplicarse solos o combinados y en secuencia: oxidación/reducción, precipitación/coprecipitación, coagulación-filtración, adsorción e intercambio iónico, exclusión física, tecnologías de membrana, métodos biológicos, etc. [57-59]. Dependiendo del nivel de recursos de la región afectada y del grado de contaminación de la fuente de provisión de agua disponible, diferentes alternativas pueden resultar viables y/o convenientes.

En general las tecnologías de remoción de As son más eficientes cuando el elemento está presente en el estado pentavalente ya que predominan las especies oxianiónicas que son más fácil de remover. Por ello, muchos procesos requieren de una primera etapa de oxidación.

La oxidación se lleva a cabo generalmente por aireación, ozonización, aplicación de peróxido de hidrógeno, permanganato de potasio, cloración, rayos UV o por actividad microbiana [58,60]. El proceso de preoxidación puede incrementar significativamente el costo del proceso de tratamiento dada la dificultad en el transporte, almacenamiento y manipulación por la alta corrosividad y toxicidad de algunos de los agentes oxidantes [60]. Por otro lado, la cloración del agua con alto contenido de carbono orgánico puede producir compuestos órgano-clorados peligrosos en el agua. El permanganato de potasio es de bajo costo y ampliamente disponible, por lo que puede resultar una opción viable.

\subsubsection{Adsorción}

Varios adsorbentes se han utilizado a lo largo de la historia para la adsorción de arsénico. Entre los adsorbentes convencionales se encuentran la alúmina activada, el hidróxido de hierro granular, GFH® [63], el óxido de hierro granular (Bayoxide $₫$, GFO), la arena recubierta con óxido de hierro (IOCS), la ferrihidrita (FH), el carbón activado, etc. Entre las mayores desventajas que presenta la aplicación de adsorbentes tradicionales se pueden mencionar la rápida saturación de muchos materiales y, en los casos en que los mismos pueden ser regenerados, la generación de grandes volúmenes de efluentes contaminados. En la Tabla 1.1 se lista la capacidad de adsorción de diferentes adsorbentes naturales y comerciales más utilizados. 
Tabla 1.1. Capacidad máxima de adsorción de $\mathrm{As}(\mathrm{V})$ de algunos adsorbentes comerciales y naturales.

\begin{tabular}{|l|c|c|}
\hline Compuesto & $\begin{array}{c}\text { Capacidad } \\
(\mathbf{m g ~ A s}(\mathbf{V}) / \mathbf{g})\end{array}$ & Referencias \\
\hline Laterita natural & 0,565 & {$[64]$} \\
\hline Limaduras de hierro & $0,6-45$ & {$[65-67]$} \\
\hline Hidróxido de hierro granular (GHF) & 8 & {$[63]$} \\
\hline Suelo rojo & 0,514 & \multirow{2}{*}{} \\
\hline Arena recubierta con óxido de hierro (IOCS) & 0,043 & \\
\hline Ferrihidrita & 0,25 & \\
\hline
\end{tabular}

Algunos investigadores han aplicado suelo rojo; bio-adsorbentes o bioadsorbentes modificados como polvo de palo de yute, polvo de caña de azúcar, cascara de huevo en polvo, polvo de jacinto de agua, cáscara de arroz, pluma de pollo, etc. La aplicación de nanomateriales de óxidos de hierro, cobre, plata o aluminio, nanocompuestos de titanio o carbono y nanotubos de carbono como adsorbentes son cada vez más prometedores hoy en día. La escasez de material de sujeción adecuado para nano-adsorbentes dificulta la aplicación con éxito de estos materiales a gran escala debido a los grandes costos asociados a los procesos de filtración y separación del nanomaterial de la solución [69].

Los sistemas de adsorción incluyen, además del correspondiente filtro con el material absorbente, sistemas de pretratamiento (oxidación, ajuste de $\mathrm{pH}$, etc.) y sistemas de postratamiento (desinfección, ajuste final de $\mathrm{pH}$, etc.). A pesar de su simplicidad, la principal desventaja de estos métodos es que por lo general no alcanzan a reducir la concentración de As a niveles aceptables [70].

\subsubsection{Coagulación/floculación-precipitación y filtración}

Los coagulantes son agentes que desestabilizan las partículas coloidales al neutralizar las cargas. La neutralización de las cargas de las partículas elimina las fuerzas repulsivas que actúan entre ellas y, por lo tanto, permite que las partículas se aglomeren. Finalmente los aglomerados precipitan debido a la gravedad cuando su peso supera la fuerza de flotación que actúa sobre ellos. Los floculantes son aditivos que aumentan el tamaño y estabilizan los coágulos formando flóculos, que posteriormente son sedimentados o filtrados con mayor facilidad. En el proceso de coagulación-precipitación, debido a la aplicación de coagulantes y/o floculantes, las formas de arsénico solubles terminan formando parte de sólidos insolubles que luego precipitan. La coagulación-precipitación debe estar seguida por un proceso de filtración adecuado. Sin filtración, la eliminación de arseniato es de alrededor de $30 \%$, mientras que si se utilizan filtros de arena, la eliminación de arseniato mejora a más del $96 \%$ [58]. 
El sulfato de aluminio, el policloruro de aluminio, el cloruro férrico y sulfato férrico son algunos de los coagulantes utilizados comúnmente. $\mathrm{El} \mathrm{pH}$ del agua tiene una gran influencia en la eficiencia de la coagulación-precipitación y el pH óptimo para el proceso de coagulación-precipitación varía con el tipo de coagulante utilizado. Los derivados del aluminio funcionan de manera más eficiente a $\mathrm{pH}$ neutro, mientras que las sales de hierro pueden funcionar de manera eficiente en un amplio rango de $\mathrm{pH}$ [71]. Los principales inconvenientes de este proceso incluyen la generación de lodos tóxicos y la baja eficiencia de eliminación de As (III).

\subsubsection{Procesos basados en membranas (ósmosis inversa/nanofiltración/ electrodiálisis)}

Las membranas son barreras que permiten el paso selectivo de algunos constituyentes de una mezcla a través de ellas, mientras bloquean el paso de otros componentes. El movimiento del agua de alimentación a través de una membrana puede estar determinado por factores tales como un gradiente de presión, la concentración de los componentes en el agua de alimentación, el potencial eléctrico de la membrana, el caudal de agua de alimentación, la temperatura y las propiedades químicas del agua de alimentación (como el pH, el carbono orgánico disuelto, la naturaleza de constituyentes, etc.) o el tipo de membrana [60].

Dependiendo del tamaño del poro, los procesos de filtración por membrana impulsados por presión generalmente se clasifican como: microfiltración (MF) (tamaño de poro de membrana 0,1-10 mm), ultrafiltración (UF) (tamaño de poro de membrana 0,01-0,1 mm), nanofiltración (NF) (poro de membrana tamaño 0,001-0,01 mm) y ósmosis inversa $(\mathrm{Ol})$ (tamaño de poro de membrana $\sim 0,0001 \mathrm{~mm}$ ).

La MF y UF que utilizan membranas de baja presión no son del todo adecuadas, ya que las especies de As son muy pequeñas y pueden atravesar las membranas. Por el contrario, la nanofiltración (NF) o la ósmosis inversa (OI), que utilizan membranas de alta presión (75-250 psi o incluso superiores) resultan las más adecuadas. Estas últimas dos tecnologías son muy efectivas en la eliminación de As $(V)$ (con eficiencias entre 91 y 99\%), pero no tan efectivos para la eliminación de As(III) (con eficiencias entre 20 y 55\%). Además, en estos casos la oxidación no es conveniente ya que pequeñas trazas de oxidantes residuales pueden dañar las membranas [72].

La OI es una tecnología desalinizadora, no específica, en la que se aplica una presión externa para invertir el flujo osmótico natural y forzar la transferencia del agua desde una solución salina concentrada a través de la membrana semipermeable. Esta tiene una superficie microporosa que rechaza las impurezas pero permite el paso de agua. La membrana rechaza especialmente iones polivalentes, siendo apropiada para oxianiones de As. El tratamiento es eficiente para un amplio rango de valores de $\mathrm{pH}$ (3-11). En el proceso interfieren altas concentraciones de sólidos en suspensión, la materia orgánica, los ácidos húmicos, amonio, metano, y aniones tales como carbonatos, sulfatos y nitrito. En consecuencia, en la mayoría de los casos, se requiere un pretratamiento del agua que ingresa al equipo de ósmosis inversa para evitar el deterioro prematuro de las membranas. 
Entre las principales desventajas de esta tecnología deben considerarse las altas tasas de rechazo, el considerable consumo eléctrico y los altos costos tanto de inversión inicial como de operación (recambio de membranas). Además, en áreas de bajos recursos o donde el agua es escasa no es conveniente el empleo de esta tecnología debido al mayor riesgo de ensuciamiento de las membranas. Finalmente, es importante tener en consideración que la Ol no solo elimina el As sino también otros iones, alterando la composición química y las propiedades organolépticas del agua de bebida [57]. Por lo tanto en la práctica, resulta necesario la mezcla de agua tratada con agua cruda para alcanzar los niveles de iones requeridos. Pese a esto, la Ol es una de las tecnologías más utilizadas.

\subsubsection{Sustitución de la fuente}

Las opciones propuestas en este caso incluyen la realización de pozos profundos, pozos tubulares a distintas profundidades $u$ otras opciones de fuentes alternativas de agua tales como recoger agua de lluvia. Sin embargo, con excepción de los pozos tubulares, la aceptación de muchas de estas alternativas por parte de pequeñas comunidad es muy baja. [73,74]. Por otra parte, perforar a profundidades mayores a $100 \mathrm{~m}$ suele ser costoso.

Como alternativa surge la identificación y abordaje de acuíferos seguros. El proyecto SASMIT [75] brinda un enfoque sistemático de bajo costo para la identificación de acuíferos seguros y la provisión de agua de bebida a las comunidades expuestas a altos niveles de As. El mismo se basa en tener en cuenta el color de los sedimentos de los acuíferos. Sin embargo, estudios preliminares realizados en aguas subterráneas del cono aluvial del Río Dulce (Ilanura ChacoPampeana de Argentina) muestran que no resulta sencillo implementar esta estrategia en nuestro país debido a condiciones y fuentes de As muy diferentes [57].

En nuestro país la construcción de acueductos para el abastecimiento de agua superficial, que por lo general se encuentra libre de arsénico, es una de las opciones analizadas en varios casos. Otra de las opciones evaluadas para minimizar el consumo de agua contaminada por parte de la población es la utilización de una doble red para sistemas de agua centralizados, en estos casos el agua con menor contenido de arsénico es reservada únicamente para la ingesta y cocción de alimentos.

\subsection{DIAGRAMAS DE POURBAIX}

Los diagramas de Pourbaix o diagramas E-pH (o pE-pH) consisten en la representación gráfica de las regiones donde predominan cada especie de un metal a una determinada condición de potencial y pH en condiciones de equilibrio (Figura 4). El diagrama tiene en cuenta los equilibrios químicos y electroquímicos para definir el dominio de estabilidad termodinámica de las soluciones de electrolito (normalmente acuosas) y de las diferentes especies químicas relacionadas al metal, por ejemplo, óxidos, hidróxidos e hidruros. Tales diagramas pueden construirse a partir de cálculos 
basados en la ecuación de Nernst y en las constantes de equilibrio de los distintos equilibrios involucrados.

Hay tres tipos generales de líneas en los diagramas de Pourbaix, cada una representa un equilibrio entre dos especies: líneas horizontales indican reacciones con dependencia solamente del potencial, líneas verticales indican reacciones con dependencia solamente del $\mathrm{pH}$ y las líneas oblicuas indican reacciones con dependencia tanto del potencial como del $\mathrm{pH}$. En los diagramas suelen presentarse dos líneas discontinuas señaladas como a y $b$, que delimitan la zona donde el agua es estable. Por encima de la línea "a" (condiciones oxidantes), el agua se descompone por oxidación desprendiendo oxígeno en forma de gas. Por debajo de la línea "b" (condiciones reductoras), el agua se descompone por reducción generando hidrógeno gaseoso.

Estos diagramas son muy útiles para el análisis de procesos de corrosión porque permiten saber si en determinadas condiciones de potencial y $\mathrm{pH}$ el metal se corroerá o no. En las zonas donde la especie química termodinámicamente estable es el metal $\left(\mathrm{Me}^{0}\right)$, este no será atacado y si en el medio hay presentes iones del mismo metal tenderán a depositarse como $\mathrm{Me}^{0}$. Estas zonas se clasifican como zonas de inmunidad. Las zonas donde las fases estables son especies disueltas son las zonas de corrosión. Finalmente, las condiciones que llevan a la formación de productos sólidos (CL) que se depositan sobre la superficie del metal y son capaces de producir un impedimento del proceso de corrosión se denominan zonas de pasividad.

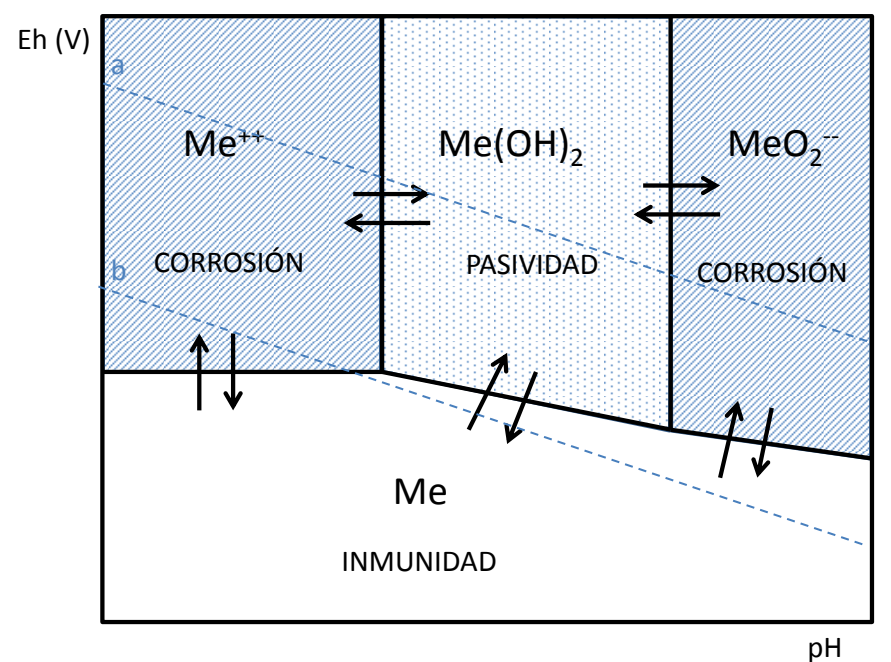

Figura 1.4. Diagrama de Pourbaix genérico para un metal Me. Zonas de corrosión.

\subsubsection{Diagramas de Pourbaix en sistemas $\mathrm{Fe} / \mathrm{H}_{2} \mathrm{O}, \mathrm{As} / \mathrm{H}_{2} \mathrm{O}$ y $\mathrm{Cr} / \mathrm{H}_{2} \mathrm{O}$}

Las posibles reacciones y las especies predominantes en sistemas $\mathrm{Fe} / \mathrm{H}_{2} \mathrm{O}$, As $/ \mathrm{H}_{2} \mathrm{O}$ y $\mathrm{Cr} / \mathrm{H}_{2} \mathrm{O}$ se pueden ver en las Figuras 5 a 7 . Los diagramas fueron construidos utilizando el programa HSC Chemistry 6 a partir de los valores de energía libre de Gibbs de formación de las principales especies que se muestran en la Tabla 
1.2. Estos valores coinciden con datos bibliográficos reportados por varios autores $[76,77]$.

Tabla1.2. Energía libre de Gibbs de formación de las principales especies acuosas y sólidos para los sistemas $\mathrm{Fe}-\mathrm{H}_{2} \mathrm{O}, \mathrm{As}-\mathrm{H}_{2} \mathrm{O}$ y $\mathrm{Cr}-\mathrm{H}_{2} \mathrm{O}$ a $25^{\circ} \mathrm{C}$ y 1 bar.

\begin{tabular}{|c|c|c|c|c|c|}
\hline Especie & $\Delta \mathbf{G}(\mathrm{Kcal} / \mathrm{mol})$ & Especie & $\Delta \mathbf{G}(\mathrm{Kcal} / \mathrm{mol})$ & Especie & $\Delta \mathbf{G}(\mathrm{Kcal} / \mathrm{mol})$ \\
\hline $\mathrm{Fe}(\mathrm{OH})_{2}$ & -117.578 & $\mathrm{AsO4}^{3-}$ & -154.923 & $\mathrm{Cr}^{3+}$ & -49.333 \\
\hline $\mathrm{Fe}(\mathrm{OH})_{3}$ & -168.638 & $\mathrm{H}_{3} \mathrm{AsO}_{3}$ & -152.867 & $\mathrm{Cr}^{2+}$ & -39.419 \\
\hline $\mathrm{Fe}^{3+}$ & -4.107 & $\mathrm{H}_{3} \mathrm{AsO}_{4}$ & -183.070 & $\mathrm{CrO}_{4}{ }^{2-}$ & -173.95 \\
\hline $\mathrm{Fe}^{2+}$ & -21.875 & $\mathrm{HASO}_{4}{ }^{2-}$ & -170.752 & $\mathrm{Cr}_{2} \mathrm{O}_{3}$ & -251.699 \\
\hline $\mathrm{FeOH}^{2+}$ & -57.830 & $\mathrm{H}_{2} \mathrm{AsO}_{3}{ }^{1-}$ & -140.272 & $\mathrm{Cr}(\mathrm{OH})_{4}{ }^{1-}$ & -251.612 \\
\hline & & $\mathrm{H}_{2} \mathrm{AsO}_{4}{ }^{1-}$ & -179.989 & $\mathrm{HCrO}_{4}{ }^{1-}$ & -182.791 \\
\hline
\end{tabular}

Como se puede observar en la Figura 1.5, dado que el Fe(0) es un donador de electrones fuerte, es estable solo para valores de Eh por debajo de $-0,6$ volts. En ausencia de oxígeno el $\mathrm{Fe}(0)$ reacciona con agua para formar $\mathrm{Fe}(\mathrm{II})$ e hidrógeno gaseoso. Los valores de Eh asociados a los equilibrios entre los pares redox $\mathrm{As}(\mathrm{V}) / \mathrm{As}(\mathrm{III})$ y $\mathrm{As}(\mathrm{III}) / \mathrm{As}(0)$ (Figura 1.6) son más altos que el correspondiente al par $\mathrm{H}_{2} \mathrm{O} / \mathrm{H}_{2}$, lo que indica que tanto las especies de $\mathrm{As}(\mathrm{V})$ como las de As (III) son aceptores de electrones más fuertes que el agua. Por lo tanto, el análisis de los diagramas Eh-pH muestra que, desde un punto de vista termodinámico, As(V) y As(III) pueden ser reducidos a $\mathrm{As}(0)$ por parte del $\mathrm{Fe}(0)$. Sin embargo, es necesario recordar que las especies predominantes y las reacciones predichas por el diagrama son válidas en condiciones de equilibrio y las velocidades de algunas reacciones redox, en particular aquellas que involucran varios electrones, pueden ser muy bajas debido a las altas energías de activación involucradas.

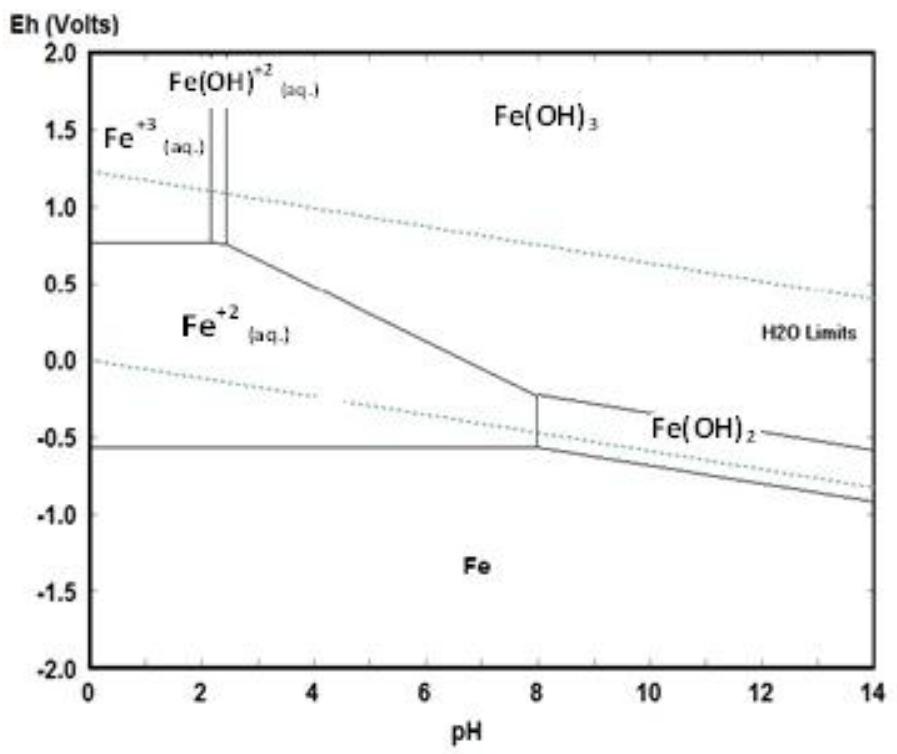

Figura 1.5 .Diagrama de Pourbaix para el sistema $\mathrm{Fe}-\mathrm{H}_{2} \mathrm{O}$ a $25^{\circ} \mathrm{C}$ y 1 bar. Fe total: $1 \mathrm{e}^{-3} \mathrm{M}$. 
El $\mathrm{As}(\mathrm{V})$ es el estado de oxidación estable cuando el potencial es mayor a 0 Volts aproximadamente. En el diagrama de la Figura 1.6 se puede observar porqué el As(V) es más fácil de remover que el As(III). En el rango de pHs neutros y en condiciones oxidantes tales como las dominantes en presencia de oxígeno disuelto, el $\mathrm{As}(\mathrm{V})$ existe en las formas oxoaniónicas con cargas negativas $\mathrm{H}_{2} \mathrm{AsO}_{4}^{-}$y $\mathrm{HAsO}_{4}^{-2}$. Para estos mismos rangos de Eh-pH (Figura 1.5) las especies de hierro predominantes cuentan con carga positiva favoreciendo la atracción electrostática entre las especies de $\mathrm{As}(\mathrm{V})$ y $\mathrm{Fe}(\mathrm{III})$. Sin embargo en el rango de Eh donde el As(III) resulta ser el estado de oxidación estable, y para valores de $\mathrm{pH}$ menores a 9, predomina la especie neutra $\mathrm{H}_{3} \mathrm{AsO}_{3}$.

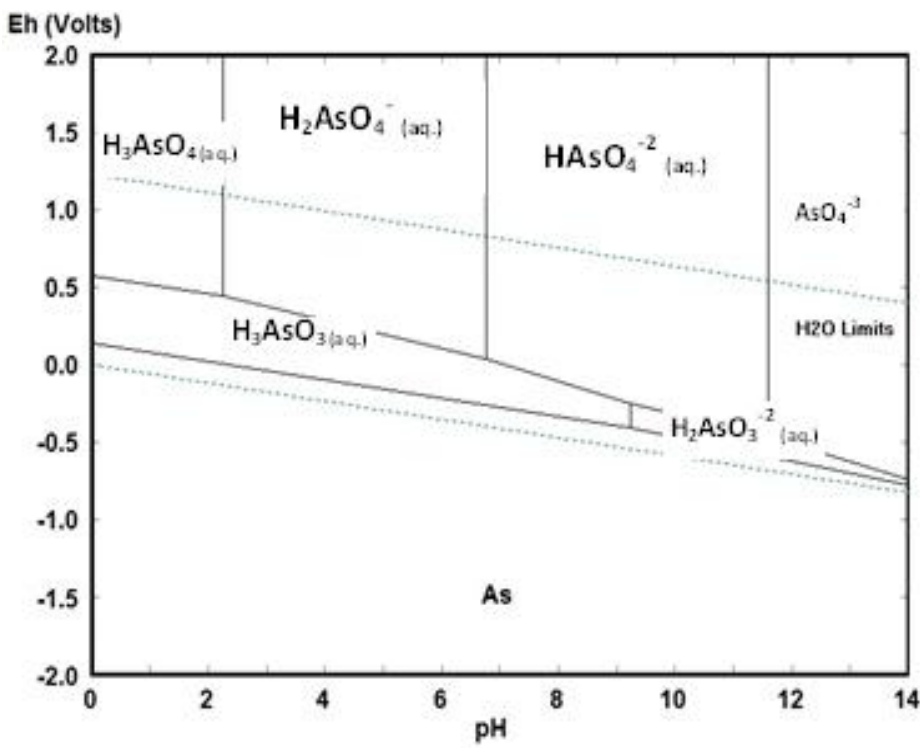

Figura 1.6 .Diagrama de Pourbaix para el sistema As- $\mathrm{H}_{2} \mathrm{O}$ a $25^{\circ} \mathrm{C}$ y 1 bar. As total: $4 \mathrm{e}^{-6} \mathrm{M}$.

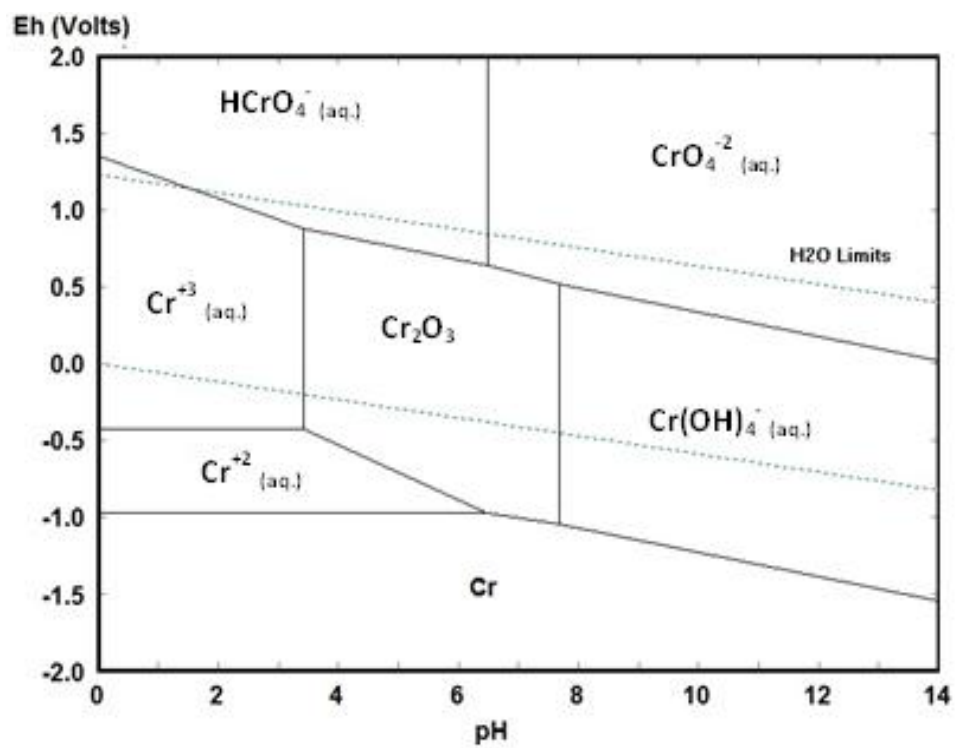

Figura 1.7 .Diagrama de Pourbaix para el sistema $\mathrm{Cr}-\mathrm{H}_{2} \mathrm{O}$ a $25^{\circ} \mathrm{C}$ y 1 bar. $\mathrm{Cr}$ total: $1 \mathrm{e}^{-4} \mathrm{M}$. 
Como se muestra en la Figura 1.7, el cromo hexavalente en sus formas $\mathrm{HCrO}_{4}{ }^{-}$ y $\mathrm{CrO}_{4}{ }^{-2}$ es estable en condiciones oxidativas (alto $\mathrm{Eh}$ ) y/o alto $\mathrm{pH}$, mientras que el cromo trivalente en sus formas $\mathrm{Cr}^{3+}, \mathrm{Cr}_{2} \mathrm{O}_{3}$ y $\mathrm{Cr}(\mathrm{OH})^{-4}$ es estable en la mayoría de las condiciones de $\mathrm{Eh}$ a $\mathrm{pH}$ bajo y condiciones más reductoras a un $\mathrm{pH}$ más alto. La inestabilidad del $\mathrm{Cr}(\mathrm{VI})$ a $\mathrm{pH}$ bajo demuestra que el cromato es un fuerte agente oxidante, lo que significa que el $\mathrm{Cr}(\mathrm{VI})$ puede reducirse fácilmente en estas condiciones. De modo similar a lo que ocurre con el ZVI, la presencia de cromo metálico es inusual porque las especies tanto de $\mathrm{Cr}(\mathrm{VI})$ como de $\mathrm{Cr}(\mathrm{III})$ son termodinámicamente estables en presencia de oxígeno atmosférico. 
CAPITULO 2:

MATERIALES Y METODOLOGÍA 


\section{MATERIALES Y METODOLOGÍA}

\subsection{REACTIVOS Y TÉCNICAS ANALÍTICAS}

\subsubsection{Reactivos}

Durante el desarrollo de este trabajo de tesis se realizaron experimentos utilizando como reactivos arseniato de sodio $\mathrm{Na}_{2} \mathrm{HAsO}_{4} .7 \mathrm{H}_{2} \mathrm{O}$, trióxido de arsénico $\mathrm{As}_{2} \mathrm{O}_{3}$, dicromato de potasio $\mathrm{K}_{2} \mathrm{Cr}_{2} \mathrm{O}_{7}$, hidróxido de sodio $\mathrm{Na}(\mathrm{OH})$, acetato de sodio $\mathrm{CH}_{3} \mathrm{COONa}$, 1,5-difenilcarbazida $\mathrm{C}_{15} \mathrm{H}_{14} \mathrm{~N}_{4} \mathrm{O}$, azida de sodio $\mathrm{NaN}_{3}$, fluoruro de potasio $\mathrm{KF}$, tiocianato de potasio $\mathrm{KSCN}$, permanganato de potasio $\mathrm{KMnO}_{4}$ (calidades Reactivo Analítico, marca Anedra), sulfato de hierro (II) y amonio $\mathrm{Fe}\left(\mathrm{NH}_{4}\right)_{2}\left(\mathrm{SO}_{4}\right)_{2} \cdot 6 \mathrm{H}_{2} \mathrm{O}$, sulfato de hierro (III) y amonio $\mathrm{Fe}\left(\mathrm{NH}_{4}\right)\left(\mathrm{SO}_{4}\right)_{2}$, dietilditiocarbamato de plata AgDDTC, yoduro de potasio IK, ácido ascórbico $\mathrm{C}_{6} \mathrm{H}_{8} \mathrm{O}_{6}$, molibdato de amonio $\mathrm{Mo}_{7} \mathrm{O}_{24}\left(\mathrm{NH}_{4}\right)_{6} .4 \mathrm{H}_{2} \mathrm{O}$, potasio antimonil tartrato $\mathrm{Sb}_{2} \mathrm{C}_{8} \mathrm{H}_{4} \mathrm{~K}_{2} \mathrm{O}_{12} .3 \mathrm{H}_{2} \mathrm{O}$ (calidades $\mathrm{RA}$ (ACS), marca Anedra), ofenantrolina $\mathrm{C}_{12} \mathrm{H}_{8} \mathrm{~N}_{2} \cdot \mathrm{H}_{2} \mathrm{O}$ (calidad $\mathrm{RA}$ (ACS) marcas Anedra y Biopack), ácido clorhídrico $36.5-38 \% \mathrm{HCl}$, cloruro estañoso $\mathrm{SnCl}_{2} .2 \mathrm{H}_{2} \mathrm{O}$, cinc granulado $\mathrm{Zn}$, morfolina, ácido sulfúrico $98 \% \mathrm{H}_{2} \mathrm{SO}_{4}$ (calidades Pro-análisis (ACS), marca Cicarelli) y acetato de plomo $\mathrm{Pb}\left(\mathrm{CH}_{3} \mathrm{COO}\right)_{2} \cdot 3 \mathrm{H}_{2} \mathrm{O}$ (alta pureza, marca Biopack). En todos los casos los compuestos fueron usados sin previa purificación y las soluciones fueron preparadas utilizando agua de calidad milli-Q o destilada.

\subsubsection{Materiales}

Se utilizaron, sin tratamiento previo, tres tipos de materiales comercialmente disponibles como fuentes de ZVI: hierro en polvo (Anedra, Fe $>98 \%$ ), lana de acero (Mapavirulana®, C 0,076-0,84 \%, P 0,015-0,018 \%, S 0,011-0,014 \%, Mn 0,810-0,86 $\%$, Si 0,115-0,146 \%) y granallas de acero (Fe 98,1-97,1\%, C 0,8-1,2 \%, Mn 0,6-1,2 $\%$, Si $0,4 \%, \mathrm{P}<0,05 \%, \mathrm{~S}<0,05 \%$ ). El área superficial específica, determinadas por la adsorción de $\mathrm{N}_{2}$ a $-195^{\circ} \mathrm{C}$ (método BET), para el hierro en polvo fue de $0,67 \mathrm{~m}^{2} / \mathrm{g}$. Por otro lado, las granallas utilizadas son de forma esférica y tienen un diámetro comprendido en el intervalo $1,4-1,7 \mathrm{~mm}$.

\subsubsection{Determinaciones analíticas}

\subsubsection{Espectrofotometría UV/vis}

En el presente trabajo de Tesis se emplearon varias técnicas colorimétricas para la cuantificación de diferentes especies en solución. Los espectros de absorción UV-visible fueron registrados utilizando los espectrofotómetros UV-1800 Shimadzu y UV-Vis Agilent Cary 60. Asimismo, se realizaron lecturas de absorbancia para una sola longitud de onda utilizando un espectrofotómetro ChromTech modelo UV-1800. En la Tabla 2.1 se resumen las características de estos tres equipos. Para las determinaciones se usaron celdas de cuarzo de $0,2 \mathrm{~cm}, 1,0 \mathrm{~cm}$ y $10 \mathrm{~cm}$ de camino 
óptico. Las soluciones con absorbancias mayores a 1.5 fueron previamente diluidas para evitar la pérdida de linealidad en las determinaciones.
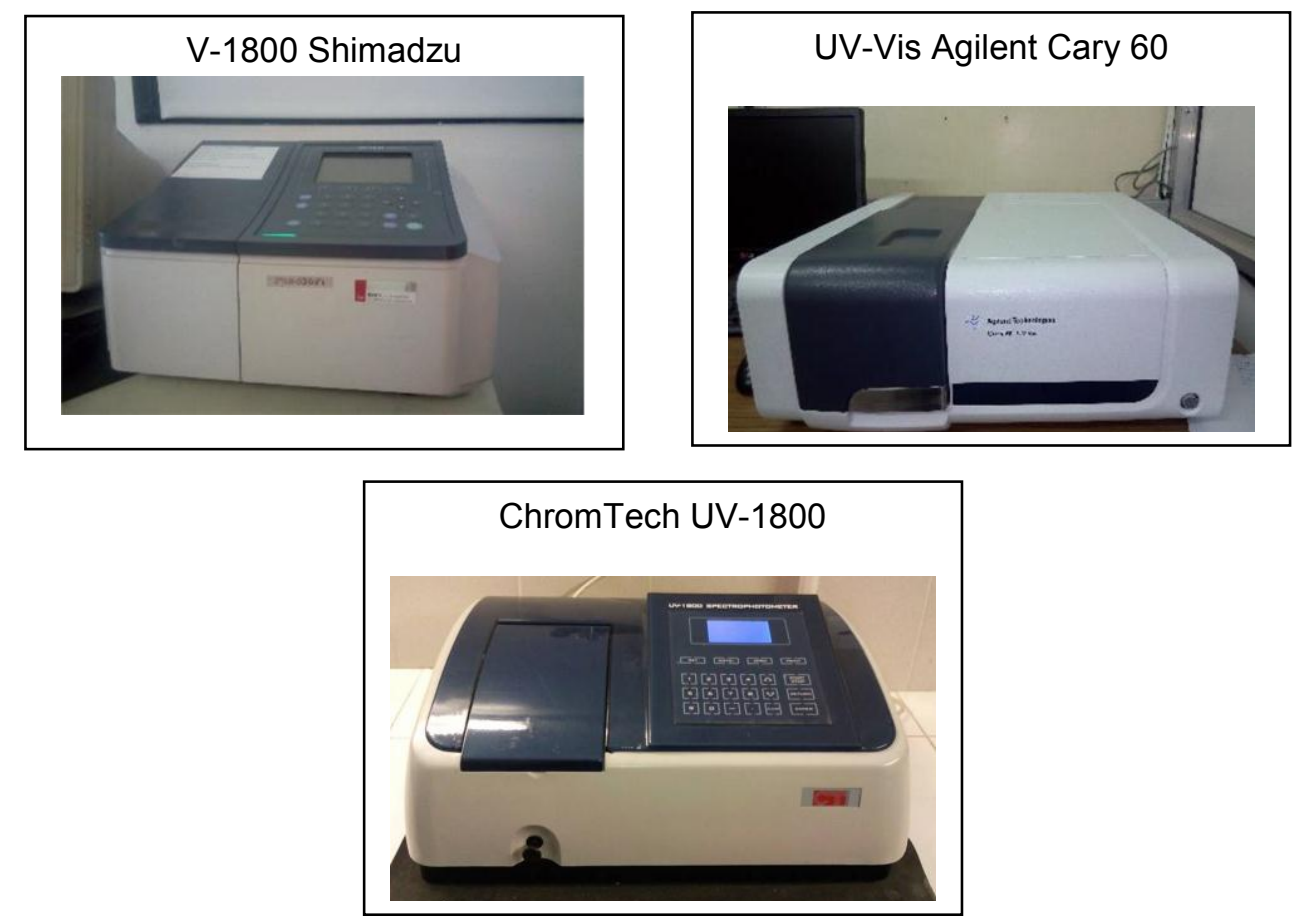

Figura 2.1. Espetofotómetros utilizados.

Tabla 2.1. Características de los espectrofotómetros utilizados informadas por el proveedor.

\begin{tabular}{|c|c|c|c|}
\hline & UV-1800 Shimadzu & UV-Vis Agilent Cary 60 & ChromTech UV-1800 \\
\hline Sistema fotométrico & Doble haz & Barrido & Simple haz \\
\hline Intervalo espectral & $190 \mathrm{~nm}-1100 \mathrm{~nm}$ & $190 \mathrm{~nm}-1100 \mathrm{~nm}$ & $190 \mathrm{~nm}-1100 \mathrm{~nm}$ \\
\hline Ancho de la rendija & $1 \mathrm{~nm}$ & $1.5 \mathrm{~nm}$ & $2 \mathrm{~nm}$ \\
\hline Tipo de lámpara & $\begin{array}{l}\text { Deuterio (D2) y } \\
\text { halógeno (W1) }\end{array}$ & Flash Xenón & Tungsteno y deuterio \\
\hline Intervalo fotométrico & - 4 a 4 Abs & - 4 a 4 Abs & - 0,3 a 3 Abs \\
\hline Exactitud espectral & $\pm 0,3 \mathrm{~nm}$ & $\pm 0,5 \mathrm{~nm}$ & $\pm 0,8 \mathrm{~nm}$ \\
\hline \multirow{2}{*}{$\begin{array}{l}\text { Reproducibilidad } \\
\text { espectral }\end{array}$} & $\pm 0,1 \mathrm{~nm}$ & $\pm 0,1 \mathrm{~nm}$ & $0,5 \mathrm{~nm}$ \\
\hline & UV-1800 Shimadzu & UV-Vis Agilent Cary 60 & ChromTech UV-1800 \\
\hline Ruido fotométrico & $\pm 0,0005$ Abs & $\pm 0,0001 \mathrm{Abs}$ & - \\
\hline $\begin{array}{l}\text { Exactitud } \\
\text { fotométrica }\end{array}$ & $\pm 0,006 \mathrm{Abs}$ & $\pm 0,005$ Abs (NIST $930 \mathrm{D})$ & $\pm 0,3 \% \mathrm{~T}$ \\
\hline $\begin{array}{l}\text { Estabilidad de la } \\
\text { línea de base }\end{array}$ & $\pm 0,0006$ Abs & $\begin{array}{l}<1.0 \%(198 \mathrm{~nm}) \\
<0,05 \%(220 \mathrm{~nm}) \\
<0,05 \%(370 \mathrm{~nm})\end{array}$ & $\pm 0,002 \mathrm{~A} / \mathrm{h}(500 \mathrm{~nm})$ \\
\hline
\end{tabular}




\subsubsection{Determinación de arsénico en agua}

En el desarrollo de este trabajo las determinaciones de arsénico en aguas fueron realizadas utilizando diferentes métodos colorimétricos: el método de dietilditiocarbamato de plata, el método del azul de molibdeno y test comerciales de tiras reactivas.

\section{Método de dietilditiocarbamato de plata}

El método colorimétrico que emplea dietilditiocarbamato de plata (AgDDTC) se basa en la reducción del $\mathrm{As}(\mathrm{V})$ a arsina $\left(\mathrm{H}_{3} \mathrm{As}\right)$ y en la formación de un complejo coloreado entre esta especie y el AgDDTC. Esta técnica consta de una serie de pasos que se llevan a cabo utilizando un tren de recipientes de vidrio que en conjunto se denomina aparto de Gutzeit modificado (Figura 2.2).

En primer lugar el $\mathrm{As}(\mathrm{V})$ es reducido a $\mathrm{As}(\mathrm{III})$ (ecuación 2.1) utilizando cloruro estañoso $\left(\mathrm{SnCl}_{2}\right)$ en presencia de yoduro de potasio $(\mathrm{IK})$ y ácido clorhídrico $(\mathrm{HCl})$. Luego en contacto con zinc ( $\mathrm{Zn})$ en medio ácido el $\mathrm{As}(\mathrm{III})$ se transforma en arsina (ecuaciones 2.2 y 2.3) en el recipiente generador de Gutzeit.

$$
\begin{aligned}
& \mathrm{AsO}_{4}{ }^{3-}+2 \mathrm{H}^{+}+2 \mathrm{Cl}^{-}+\mathrm{SnCl}_{4}{ }^{2-} \rightarrow \mathrm{AsO}_{3}{ }^{3-}+\mathrm{H}_{2} \mathrm{O}+\mathrm{SnCl}_{6}{ }^{2-} \\
& \mathrm{Zn}^{0}+2 \mathrm{H}^{+} \rightarrow \mathrm{Zn}^{2+}+\mathrm{H}_{2(\mathrm{~g})} \\
& \mathrm{AsO}_{3}{ }^{3-}+3 \mathrm{H}^{+}+3 \mathrm{H}_{2(\mathrm{~g})} \rightarrow \mathrm{AsH}_{3(\mathrm{~g})}+3 \mathrm{H}_{2} \mathrm{O}
\end{aligned}
$$

El gas generado, antes de ser absorbido en la solución de dietilditiocarbamato de plata, pasa a través de un algodón colocado en el tubo lavador e impregnado en acetato de plomo $\left(\mathrm{Pb}\left(\mathrm{H}_{3} \mathrm{C}_{2} \mathrm{O}_{2}\right)_{2}\right)$ para eventualmente remover el sulfuro de hidrógeno que podría generarse en presencia de especies de azufre y producir interferencias (ecuación 2.4).

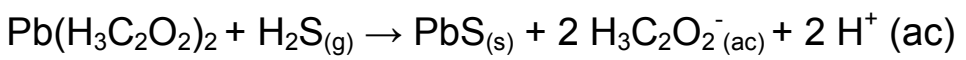

La arsina formada posteriormente reacciona con el AgDDTC (ecuación 2.5) que se encuentra disuelto en un solvente orgánico (puede emplearse efedrina, cloroformo o piridina) colocado en el tubo adsorberdor (Figura 2.2) formando un complejo rojizo soluble, que se detecta fotométricamente a $535 \mathrm{~nm}$ y cuya contribución a la absorbancia es proporcional a la concentración de arsénico presente en la muestra.

$2 \mathrm{H}_{3} \mathrm{As}_{(\mathrm{g})}+6 \mathrm{Ag}(\mathrm{DDTC})_{(\mathrm{d})} \rightarrow 6 \mathrm{Ag}_{(\mathrm{d})}+2 \mathrm{As}(\mathrm{DDTC})_{3(\mathrm{~d})}$

Las determinaciones fueron realizadas utilizando $100,0 \mathrm{~mL}$ de muestra según el procedimiento detallado en el "Standard Methods for the examination of water and wastewater" [78]. Las curvas de calibración correspondientes se realizaron empleando soluciones patrón de arseniato de sodio de diferente concentración. A partir de los valores de absorbancia obtenidos se determinó un coeficiente de extinción molar, a 
$535 \mathrm{~nm}$, de $225120 \mathrm{~L} \mathrm{~mol}^{-1} \mathrm{~cm}^{-1}$. El límite de detección del método es de 0,010 mg As/L.
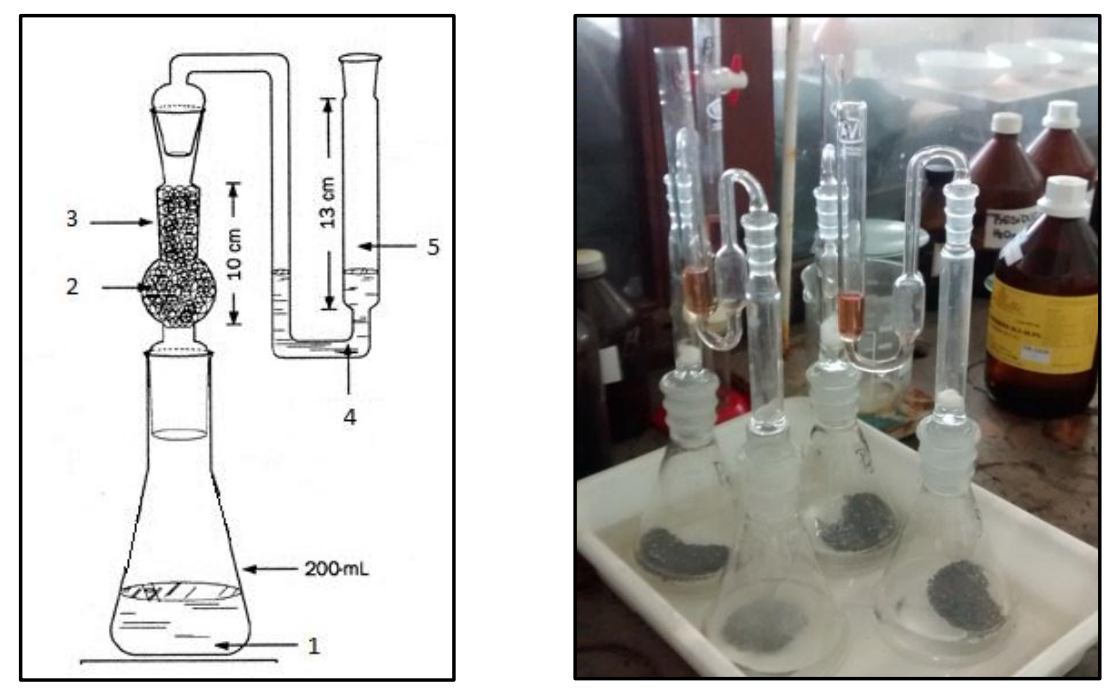

Figura 2.2. Izquierda: esquema aparato de Gutzeit: 1-matraz generador con muestra y granallas de zinc, 2- algodón impregnado en acetato de plomo, 3- tubo lavador, 4 - solución de dietilditiocarbamato de plata, 5- tubo adsorbedor. Derecha: foto de los equipos utilizados.

\section{Método de azul de molibdeno}

Dado que el fosfato y el arseniato presentan propiedades químicas similares, el arseniato puede determinarse por la mayoría de los métodos utilizados para la determinación de (orto)fosfato. Uno de los utilizados es el basado en la formación del complejo antimonil-fosfomolibdato. Este complejo se reduce con ácido ascórbico dando una especie que absorbe fuertemente en el infrarrojo. Johnson fue el primero en publicar este método, que luego fue modificado por Pilson, para la determinación de arsénico en agua [79-81]. Esta técnica presenta ciertas ventajas respecto a la técnica colorimétrica de dietilditiocarbamato de plata, entre ellas se destacan la no generación de productos tóxicos como la arsina y la menor complejidad del material de vidrio utilizado.

Puesto que el $\mathrm{As}(\mathrm{V})$ forma el complejo mencionado y el As(III) no, el primer paso de esta técnica para la determinación de As total consiste en la oxidación del As(III) a As(V). Luego, en presencia de ácido ascórbico y una solución complejante de molibdato de amonio, se forma el complejo de antimonil-arsenomolibdato y se determina la intensidad mediante la lectura de la absorbancia a $860 \mathrm{~nm}$.

Para soluciones que pueden presentar interferencia por la presencia de fosfatos, la cuantificación de arsénico se realiza a partir de la diferencia entre la absorbancia de una alícuota de la muestra pre-tratada para oxidar el As(III) (absorbancia debida a fosfato y As) y otra alícuota pre-tratada para reducir el As(V) (absorbancia debida a fosfato solamente). Si bien esta técnica no se encuentra incluida en el Standard Methods, diferentes autores han publicado métodos para la estandarización de esta técnica con pequeñas variaciones. Los reactivos utilizados y 
los pasos seguidos para la determinación de arsénico total mediante esta técnica son los siguientes:

1. Soluciones a utilizar:

- Solución de ácido ascórbico al $10 \% \mathrm{~m} / \mathrm{v}$.

- Solución oxidante: $\mathrm{KMnO}_{4} 1 \mathrm{mM}$

- Solución de $\mathrm{H}_{2} \mathrm{SO}_{4} 9 \mathrm{M}$.

- $\quad$ Solución de molibdato: $13 \mathrm{~g}$ de $\left(\mathrm{NH}_{4}\right)_{6} \mathrm{Mo}_{7} \mathrm{O}_{24} . .4 \mathrm{H}_{2} \mathrm{O}$ en $100 \mathrm{~mL}$ de agua con 5 $\mathrm{mL}$ de $\mathrm{H}_{2} \mathrm{SO}_{4} 9 \mathrm{M}$.

- $\quad$ Solución de potasio antimonil-tartrato: $0,35 \mathrm{~g} \mathrm{~K}(\mathrm{SbO}) \mathrm{C}_{4} \mathrm{H}_{4} \mathrm{O}_{6} \cdot 1 / 2 \mathrm{H}_{2} \mathrm{O}$ en $100 \mathrm{~mL}$ de agua con $5 \mathrm{~mL}$ de $\mathrm{H}_{2} \mathrm{SO}_{4} 9 \mathrm{M}$.

- $\quad$ Solución de arsénico patrón de 1000 ppm

2. Preparación de solución complejante: mezclar la solución de molibdato, la de potasio antimonil-tartrato y llevar a volumen final de $500 \mathrm{~mL}$ con solución de $\mathrm{H}_{2} \mathrm{SO}_{4} 9$ M. Esta solución se puede conservar dos meses refrigerada y en frasco color caramelo.

3. Colocar $40 \mathrm{~mL}$ de muestra en un matraz de $50 \mathrm{~mL}$, agregar $2 \mathrm{~mL}$ de solución oxidante y dejar reaccionar $15 \mathrm{~min}$.

4. Agregar $1 \mathrm{~mL}$ de la solución de ácido ascórbico preparada en el momento. $\mathrm{Y}$ luego $2 \mathrm{~mL}$ de solución complejante. Dejar reaccionar durante 70 minutos y leer la absorbancia a $860 \mathrm{~nm}$ en celda de camino óptico de $10 \mathrm{~cm}$.

5. Preparación de la curva de calibración: preparar soluciones patrón con concentraciones de As en el rango de $0-200$ ppb y tratar como se describe en los pasos anteriores.

Con los valores de absorbancia obtenidos de la curva de calibración se obtuvo un coeficiente de extinción molar a $860 \mathrm{~nm}$ de $25100 \mathrm{~L} \mathrm{~mol}-1 \mathrm{~cm}-1$. El límite de detección del método es de 0,010 mg As/L.

La longitud de onda para la cual el complejo presenta su máximo de absorción fue determinada a partir del análisis de los espectros de la soluciones patrones en el rango de $600-900 \mathrm{~nm}$. El tiempo de reacción óptimo se determinó a partir de la obtención cada 5 min del espectro de uno de los patrones para tiempos de reacción entre 20 y 90 minutos.

\section{Método de tiras reactivas}

Los denominados "test kit As" se basan en la metodología colorimétrica y son semi-cuantitativos. Las desventajas que presentan son: una relativamente baja sensibilidad en la medición, ya que depende de la comparación visual del operador, deficiente reproductibilidad, peligros potenciales para el operador ante la exposición a 
productos de reacción tóxicos (gas arsina), y la generación de residuos peligrosos. Como ventajas se destacan la detección de arsénico a un costo bajo por unidad de determinación, la rapidez de la medición y la posibilidad de realizar determinaciones en campo.

El fundamento de estos test consiste en convertir los compuestos arsenicales presentes en el agua en gas arsina, mediante el contacto con polvo de zinc y ácido en polvo. La $\mathrm{H}_{3} \mathrm{As}$ generada, al tomar contacto con una banda de papel embebida en bromuro de mercurio produce un cambio de color, desde blanco a marrón, pasando por tonos amarillos según la concentración de As que contenga la muestra.

En este trabajo se utilizaron tests de dos firmas comerciales. En primer lugar se utilizaron kits de Arsénico 10 Quantofix ${ }^{\circledR}$ de Macherey-Nagel. Este kit posee los siguientes rangos de detección: $0-0,01-0,025-0,05-0,1$ y 0,5 mg/l. Luego se utilizó el método colorimétrico con tiras de ensayo y reactivos As MQuant ${ }^{\mathrm{TM}}$ de la marca Merck con los siguientes rangos de detección: 0,005 - 0,010 - 0,025 - 0,05 0,10 - 0,25 - 0,50 mg/L As. En ambos casos se realizaron las determinaciones siguiendo los pasos detallados en los respectivos manuales de instrucciones. En la Figura 2.3 se pueden ver imágenes de los test kits utilizados.
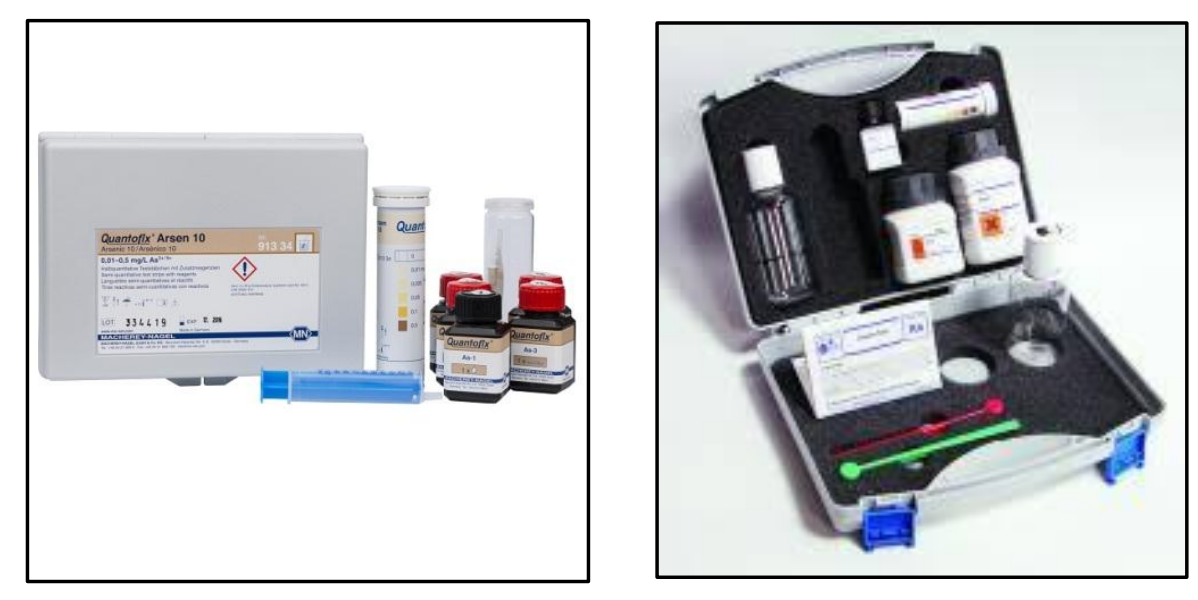

Figura 2.3. Izquierda: Kit para determinación de As marca Macherey-Nagel. Derecha: Kit para determinación de As marca Merck.

\subsubsection{Determinación de hierro}

Para la cuantificación del contenido de Fe en solución, en todos los casos se utilizaron técnicas colorimétricas para diferenciar entre especies de $\mathrm{Fe}(\mathrm{II})$ y $\mathrm{Fe}(\mathrm{III})$. En los casos donde fue necesario evitar la oxidación de las especies de Fe(II), por parte del oxígeno disuelto, las muestras fueron recogidas en matraces de $10 \mathrm{~mL}$ conteniendo $5 \mathrm{~mL}$ de una solución de $\mathrm{HCl}$ en agua destilada de $\mathrm{pH} 4$. 
Determinación de Fe(II). Método colorimétrico de o-fenantrolina modificado

La cuantificación de la concentración $\mathrm{Fe}(\mathrm{II})$ en las muestras fue realizada empleando el método colorimétrico de o-fenantrolina modificado. El fundamento del método se basa en la formación de un complejo estable de color rojo-anaranjado entre el $\mathrm{Fe}(\mathrm{II})$ y la o-fenantrolina. Los reactivos utilizados y los pasos seguidos se detallan a continuación:

1. Soluciones a utilizar:

- Solución de o-fenantrolina 0,018 M

- Solución buffer de acetato de sodio y ácido acético 0,7 M

- Solución de NaF o KF 0,02 M.

- $\quad$ Solución patrón de $\mathrm{Fe}(\mathrm{II}): \mathrm{Fe}\left(\mathrm{NH}_{4}\right)_{2}\left(\mathrm{SO}_{4}\right)_{2} \cdot 6 \mathrm{H}_{2} \mathrm{O} 0,001 \mathrm{M}$

2. Solución complejante: Colocar iguales cantidades de las soluciones de ofenantrolina, buffer y solución de NaF. Conservar refrigerada.

3. Colocar en tubo de ensayo $1 \mathrm{~mL}$ de la solución complejante y $2 \mathrm{~mL}$ de muestra. El complejo es formado de manera inmediata y la intensidad de color permanece estable por varias horas. Medir absorbancia con una celda de $1 \mathrm{~cm}$ de camino óptico a $510 \mathrm{~nm}$.

4. Preparar soluciones de diferente concentración de Fe(II) utilizando la solución patrón y realizar la curva de calibración siguiendo los puntos antes indicados.

Con los valores de absorbancia obtenidos de la curva de calibración se obtuvo un coeficiente de extinción molar a $510 \mathrm{~nm}$ de $8336 \mathrm{I} \mathrm{mol}^{-1} \mathrm{~cm}^{-1}$.

\section{Determinación de Fe(III). Método colorimétrico del tiocianato.}

El ión férrico reacciona con el tiocianato formando distintos complejos solubles, de color rojo intenso, por lo que la cuantificación de este complejo es una de las técnicas más utilizadas para la determinación de concentraciones de hierro. El complejo que predomina en solución depende tanto de la concentración del tiocianato como del pH. Al aumentar la concentración de tiocianato, aumenta la longitud de onda correspondiente al máximo de absorción. Dependiendo de la concentración de tiocianato empleada predominará un complejo diferente: en soluciones diluidas el complejo $\mathrm{Fe}(\mathrm{SCN})^{2+}$ prevalece mientras que para soluciones concentradas $(>0,15 \mathrm{M})$ predomina el complejo $\mathrm{Fe}(\mathrm{SCN})_{2}{ }^{+}[82,83]$. Para la aplicación de esta técnica es importante también la presencia de ácidos fuertes (ácido clorhídrico o nítrico) para evitar la hidrólisis del ion férrico.

1. Soluciones a utilizar:

- $\quad$ Solución complejante: $\mathrm{KSCN} 3 \mathrm{M}$ acidificada con $\mathrm{HCl} 1 \% \mathrm{p} / \mathrm{v}$

- Solución patrón de $\mathrm{Fe}(\mathrm{III}): \mathrm{Fe}\left(\mathrm{NH}_{4}\right)\left(\mathrm{SO}_{4}\right)_{2}$ 0,001 M 
2. Colocar en tubo de ensayo $1 \mathrm{~mL}$ de la solución complejante y $2 \mathrm{~mL}$ de muestra. El máximo de la intensidad del color se produce luego de 15 min de poner en contacto ambas soluciones y permanece estable por un período de aproximadamente $30 \mathrm{~min}$. Medir absorbancia con una celda de $1 \mathrm{~cm}$ de camino óptico a $480 \mathrm{~nm}$.

3. Preparar soluciones de diferente concentración de Fe(III) utilizando la solución patrón y realizar la curva de calibración siguiendo el procedimiento antes indicado.

A partir de los valores de absorbancia obtenidos de la curva de calibración se obtuvo un coeficiente de extinción molar a $480 \mathrm{~nm}$ de $10517 \mathrm{I} \mathrm{mol}^{-1} \mathrm{~cm}^{-1}$.

Determinación de $\mathrm{Cr}(\mathrm{IV})$. Método colorimétrico.

Este método colorimétrico se basa en la reacción del cromo hexavalente con 1,5-difenilcarbazida en medio ácido, que da lugar a la formación de un compuesto de color rojo violeta. La reacción del cromo (VI) con la difenilcarbazida es una reacción redox en la cual el $\mathrm{Cr}(\mathrm{VI})$ se reduce a $\mathrm{Cr}(\mathrm{III})$ y el reactivo se oxida a difenilcarbazona, que rápidamente forma un complejo de color rojo-violeta con el $\mathrm{Cr}(\mathrm{III})$ naciente. Si al $\mathrm{Cr}$ (III) acuoso se le añade el reactivo difenilcarbazona no hay reacción y no se origina coloración, esto se debe a la gran inercia del acuocomplejo del $\mathrm{Cr}$ (III) que impide que la reacción ocurra. La intensidad del complejo es medida fotométricamente a una longitud de onda de $540 \mathrm{~nm}$ y la absorbancia es proporcional a la concentración de cromo en la muestra. Para determinar cromo total, la muestra debe ser sometida a digestión ácida y oxidación con permanganato de potasio, previo a la reacción con la difenilcarbazida [78]. Los reactivos utilizados y los pasos seguidos se detallan a continuación:

1. Soluciones a utilizar:

- Solución de 1,5-difenilcarbazida al $50 \% \mathrm{~m} / \mathrm{v}$.

- $\quad$ Solución buffer de ácido sulfúrico 1:1.

- $\quad$ Solución patrón de $\mathrm{Cr}(\mathrm{IV}) 500 \mathrm{mg} / \mathrm{l}\left(\mathrm{K}_{2} \mathrm{Cr}_{2} \mathrm{O}_{7}\right)$.

2. Colocar en tubo de ensayo $5 \mathrm{~mL}$ de muestra y $0,05 \mathrm{~mL}$ de ácido sulfúrico 1:1. Agitar para mezclar bien y verificar que le pH sea cercano a 2 .

3. Añadir $0,1 \mathrm{~mL}$ de solución de difenilcarbazida, agitar y dejar reposar 5 a 10 minutos.

4. Preparar soluciones de diferente concentración de $\operatorname{Cr}(\mathrm{IV})$ utilizando la solución patrón y realizar la curva de calibración siguiendo los puntos antes indicados.

Con los valores de absorbancia registrados en la curva de calibración se obtuvo un coeficiente de extinción molar a $543 \mathrm{~nm}$ de $45879 \mathrm{~L} \mathrm{~mol}^{-1} \mathrm{~cm}^{-1}$. 


\subsubsection{Determinación y control de pH}

Las determinaciones de $\mathrm{pH}$ en el laboratorio se realizaron empleando dos $\mathrm{pH}$ metros. Uno de los instrumentos utilizados fue de la firma Radiometer (modelo PHM220) conectado a un electrodo de vidrio combinado con una referencia interna de $\mathrm{Ag} / \mathrm{AgCl}$ y un puente salino de $\mathrm{KCl}$ saturado. En forma alternativa se empleó un $\mathrm{pH}$ metro de la marca Thermo Scientific (modelo Orion 3 Star), conectado a un electrodo combinado (con referencia $\mathrm{Ag} / \mathrm{AgCl}$ y cuerpo de epoxi) de la misma marca.

En las plantas piloto la medición y regulación del pH se realizó utilizando un equipo dosificador con control de $\mathrm{pH}$ incorporado marca AQUATRON (modelo $\mathrm{pH}-\mathrm{CP}$ 07/05). El sistema consiste en una bomba a diafragma, un controlador de $\mathrm{pH}$ proporcional, un sensor de nivel de líquido utilizado para la regulación y un electrodo de $\mathrm{pH}$ marca Sensorex (modelo S250C).

La calibración de todos los pH-metros fue realizada empleando buffers comerciales de pH 4.01, 7.00 y 10.0 de la firma Anedra. La regulación de los valores de $\mathrm{pH}$ en las diferentes experiencias fue realizada utilizando soluciones de $\mathrm{HCl}$ de diferentes concentraciones suministradas por las marcas Cicarrelli y Merck.
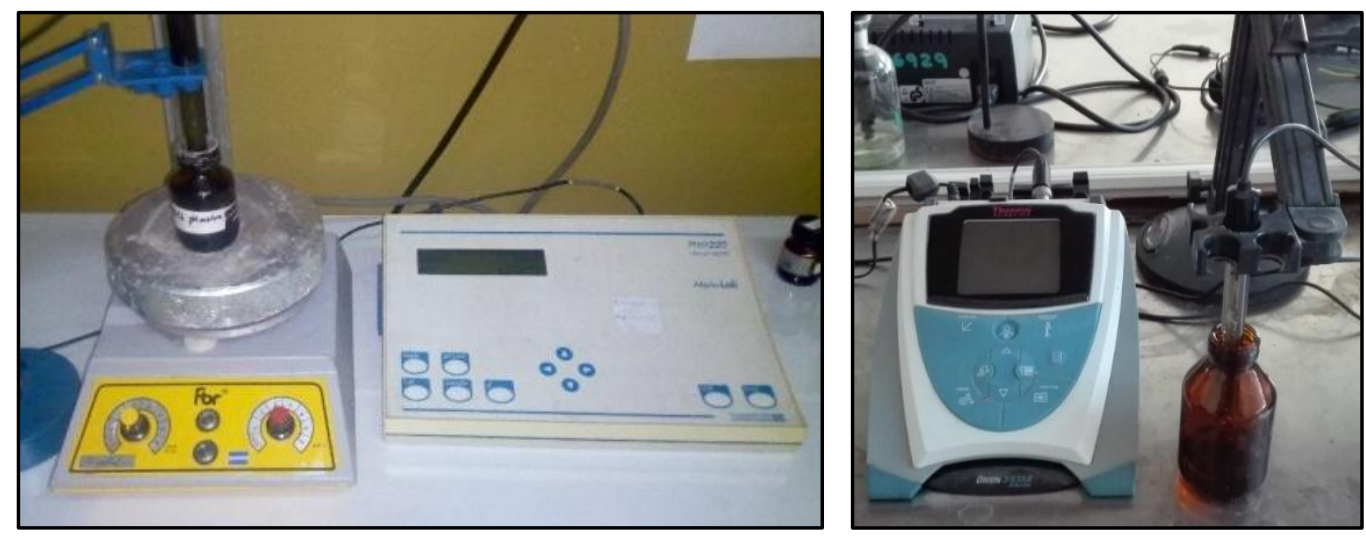

Figura 2.4. Izquierda: $\mathrm{pH}$ metro marca Radiometer. Derecha: $\mathrm{pH}$ metro marca Orion Thermo Scientific.

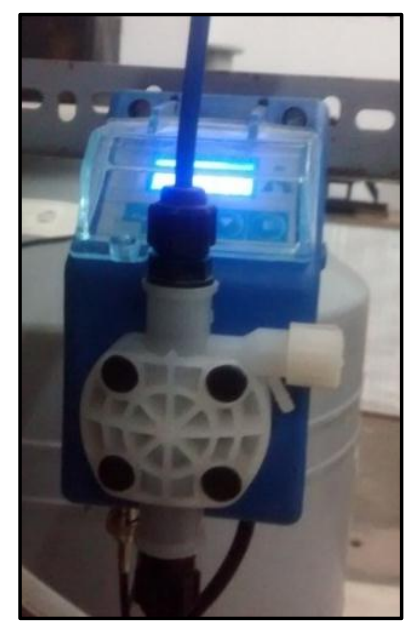

Figura 2.5. Bomba para la regulación y control de pH marca Acquatron. 


\subsubsection{Determinación de oxígeno disuelto y ORP}

En muchos de los ensayos realizados en sistemas continuos de pequeña escala se determinó el contenido de oxígeno disuelto en la solución efluente de las columnas reactivas. Para esto se utilizó una celda de flujo acoplada a la salida de las columnas que consta de un cilindro de acrílico con una entrada lateral en la parte superior y una salida lateral en la parte inferior (Figura 2.6). En la parte superior se colocó el sensor empleado para la determinación sumergiéndolo en la celda de flujo y sellado de manera hermética para impedir el derrame de líquido o el intercambio gaseoso.

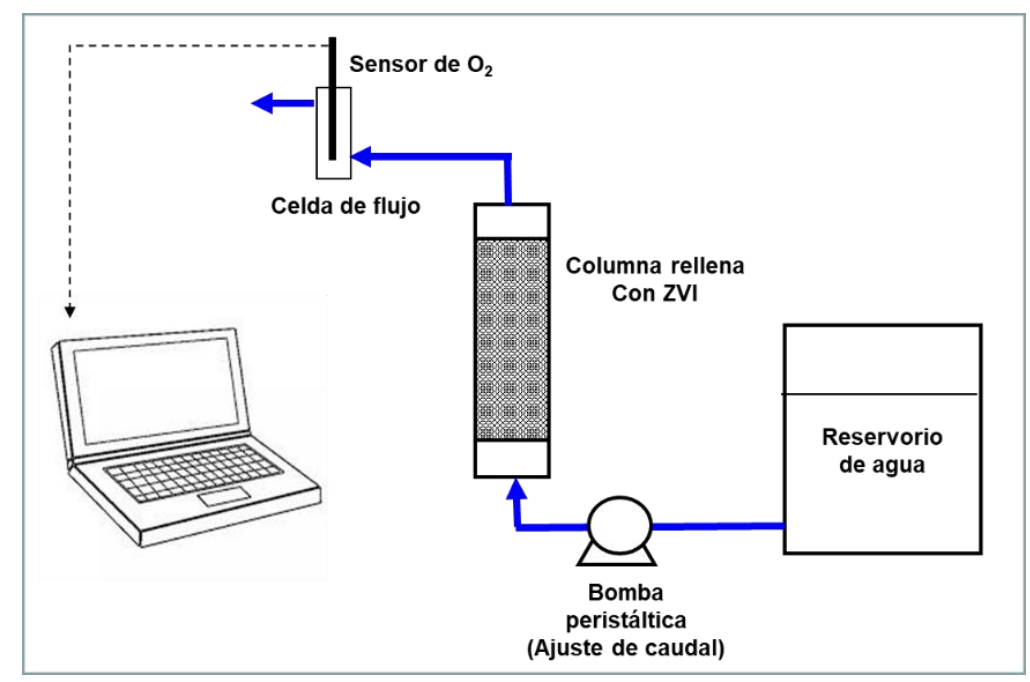

Figura 2.6. Esquema de instalación de sensor de oxígeno.

Se trabajó con dos tipos de sensores de oxígeno, un sensor electroquímico de membrana selectiva marca Orion modelo 081010MD donde la lectura se realizó de manera directa en el display de la consola (Thermo Orion 850A+). El otro sensor utilizado fue un dispositivo óptico YSI ProODO cuya medida se basa en el quenching de la fluorescencia de un colorante en presencia de oxígeno disuelto. En ese caso el registro de las medidas se realizó de manera continua conectando el instrumento a una PC utilizando un software Data Manager provisto por el fabricante.
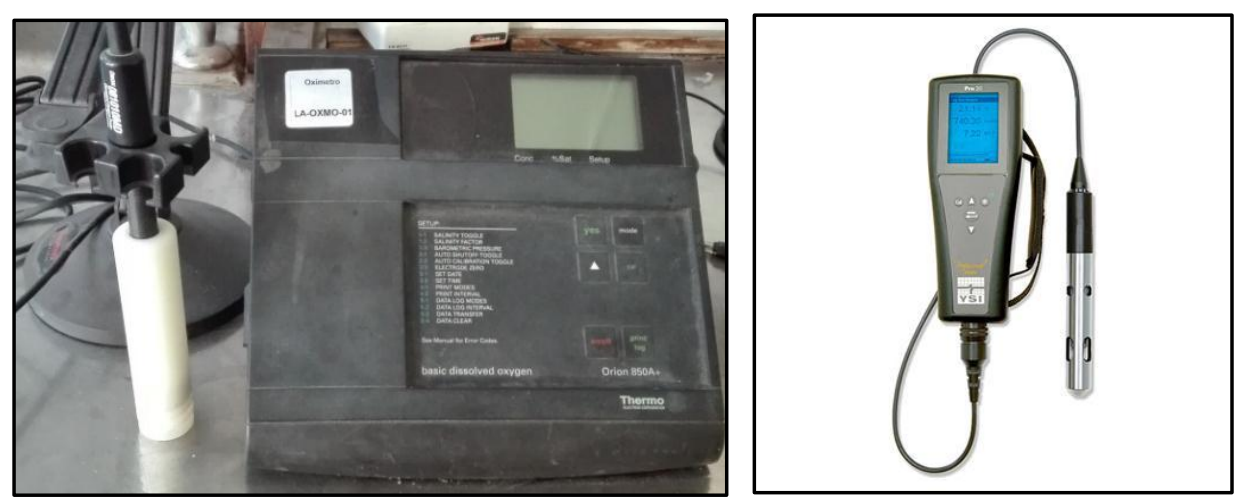

Figura 2.7. Izquierda: electrodo para la determinación de oxígeno de membrana selectiva y consola marca Thermo Orion. Derecha: sensor óptico de oxígeno YSI ProODO. 
Para el monitoreo de la plantas piloto también se realizaron medidas de potencial de óxido reducción (ORP) en las soluciones de salida de las columnas. Para esto se colocó una T estándar de pvc de $3 / 4$ " en la cañería de salida con un accesorio porta-electrodo. En el momento de realizar las determinaciones se colocó el electrodo de ORP, se dejó estabilizar durante 30 minutos y se realizó la lectura del potencial. Se trabajó con un medidor/controlador digital de ORP Altronix 4802 provisto de un electrodo combinado para ORP Alpha PO-50 con cuerpo plástico, punta de platino y referencia de $\mathrm{Ag} / \mathrm{AgCl}$.

\subsubsection{Determinación de conductividad, turbiedad y color}

Para caracterizar las muestras de agua utilizadas se realizaron determinaciones de conductividad. Este tipo de medida también fue utilizado para estudiar la distribución del fluido en el interior de las columnas reactivas utilizando IK como trazador (ver sección 2.2.3). Las medidas fueron realizadas utilizando un conductímetro portátil LaMotte CON 6 PLUS.

En diferentes ensayos realizados fueron necesarias realizar determinaciones de color y turbiedad tanto en efluentes como en corrientes de proceso. Para eso se utilizó un medidor de turbiedad de mesada marca LaMotte modelo LTC3000we. EI mismo fue calibrado utilizando los patrones de turbiedad provistos por el fabricante del equipo.
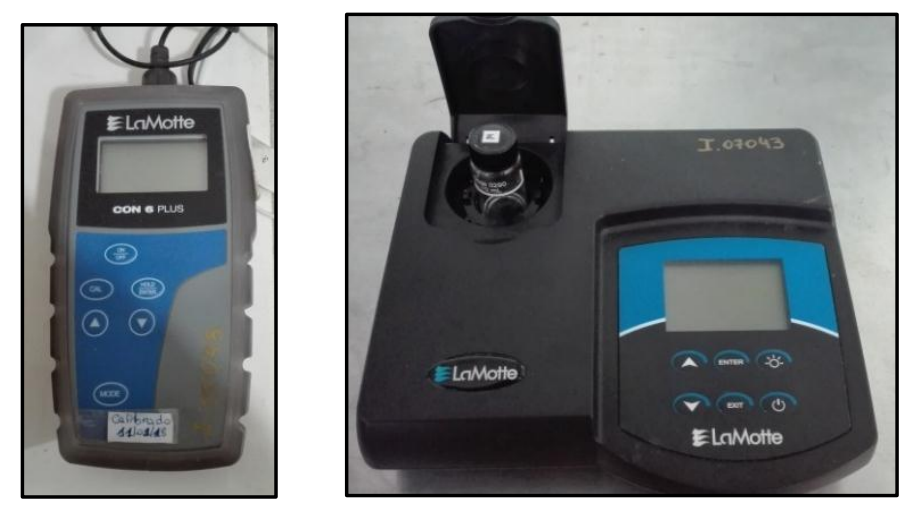

Figura 2.8. Conductímetro (izq.) y turbidímetro de mesada (der.) utilizados marca LaMotte.

\subsubsection{Determinación de sólidos en efluentes líquidos}

Para determinar la cantidad de sólidos presentes en efluentes generados por parte del proceso de remoción se realizaron determinaciones según el Standard Methods (SM) [78]. En la Figura 2.9 se puede observar una clasificación de los sólidos en agua. En este caso se realizaron medidas de sólidos totales (SM 2540 A), sólidos suspendidos totales (SM 2540 D) y sólidos sedimentables (SM 2540 F). Para llevar a cabo los procedimientos se utilizó un sistema de filtración con bomba de vacío, balanza gravimétrica, estufa de secado a $103-105^{\circ} \mathrm{C}$ marca SanJor modelo SL30S y conos Imhoff. 


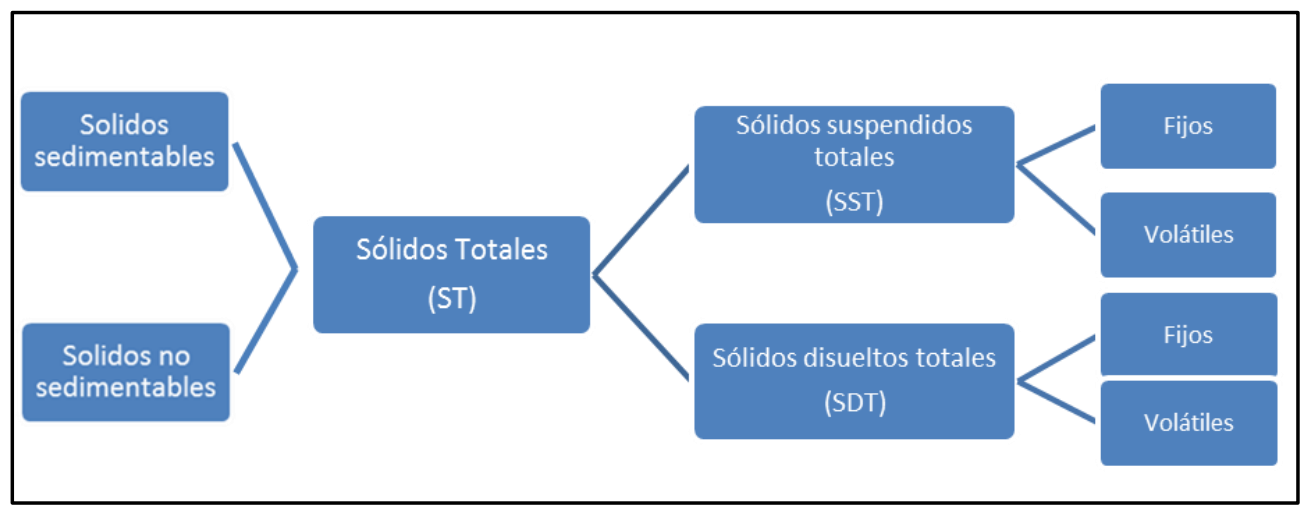

Figura 2.9. Clasificación de sólidos en aguas residuales y efluentes.

\subsubsection{Determinación de peligrosidad de efluentes líquidos}

Para evaluar la peligrosidad de los residuos generados por la planta piloto, el efluente generado en el proceso se sometió a un proceso de filtración con filtro de 0,22 $\mu \mathrm{m}$ y posteriormente se analizaron ambas fracciones por separado: filtrado y retenido.

Para determinar la posibilidad de vertido o no del líquido filtrado generado se analizó el contenido de arsénico según la técnica de azul de molibdeno antes detallada. Luego se comparó el resultado obtenido con el valor máximo permitido según la reglamentación vigente. La resolución 336/2003 establece como máximo 0,5 $\mathrm{mg} / \mathrm{L}$ de As para descarga en colectora cloacal, conducto pluvial o cuerpo de agua superficial.

La fracción retenida por el filtro se consideró como barro y se analizó según lo indicado por el Decreto 831/94 de residuos peligrosos que reglamenta la Ley 24.051. Según esta ley se define como barros "cualquier residuo sólido, semisólido o líquido generado en una planta de tratamiento de aguas residuales, sea municipal, provincial o nacional o industrial, planta de purificación de agua para consumo, o instalación de control de contaminación de efluentes gaseosos. No se consideran barros los efluentes de las plantas de tratamiento de aguas residuales." Esta ley indica en el Anexo IV que para determinar si un barro es peligroso por lixiviación una de las pruebas que debe realizarse es el ensayo conocido como "Toxicity Characteristic Leaching Procedure (procedimiento de toxicidad característica de lixiviación, TCLP)" desarrollado por la US EPA. Este procedimiento evalúa las características tóxicas y cuantifica el grado de lixiviación de contaminantes bajo determinadas condiciones de laboratorio a partir de residuos sólidos. En consecuencia, se siguió el procedimiento descripto por la norma US EPA Method 1311. Brevemente, el ensayo consiste en poner en contacto el residuo con una solución de $\mathrm{H}_{2} \mathrm{SO}_{4}$ y $\mathrm{HNO}_{3}$ a temperatura y agitación controladas $\left(25^{\circ} \mathrm{C}\right.$ y $\left.30 \pm 2 \mathrm{rpm}\right)$ por un tiempo de $18 \pm 2$ horas en un agitador rotacional (Figura 2.10). El extracto líquido obtenido después de la lixiviación es analizado para determinar si presenta elementos considerados como peligrosos. El límite máximo admisible en el lixiviado es de 100 veces el límite máximo aceptable para el agua potable. En este caso, considerando el límite de $0,010 \mathrm{mg} / \mathrm{L}$ de As para el agua de consumo según el CAA, se analizó el contenido de As y se adoptó como límite máximo aceptable un valor de $1,0 \mathrm{mg} / \mathrm{L}$. 


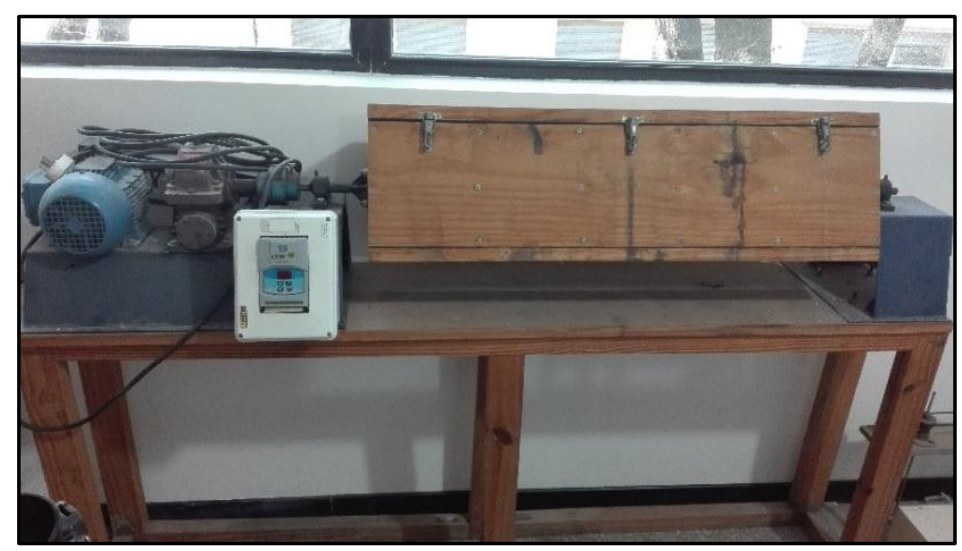

Figura 2.10. Agitador rotacional utilizado para realizar el ensayo de lixiviación TCLP.

\subsection{ENSAYOS REALIZADOS}

\subsubsection{Estudios de captación de arsénico en reactores discontinuos (batch)}

El conocimiento de los factores que gobiernan los aspectos cinéticos y de equilibrio de la adsorción es crítico para el diseño de plantas de tratamiento eficientes. Muchos de los estudios relacionados con la eliminación de contaminantes por procesos de adsorción se han llevado a cabo en modo de operación discontinua (Batch), con el fin de evaluar la eficiencia del adsorbente, las capacidades de adsorción y la cinética de adsorción [64,84]. Dado que, en los sistemas basados en el empleo de ZVI, la eliminación de especies solubles se debe a su interacción con superficies sólidas, generalmente se aplican modelos cuantitativos de adsorción para describir la captación del arsénico. La cantidad de arsénico eliminado por unidad de masa de un sólido dado (q) y la eficiencia de captación (\% R) son los principales parámetros que caracterizan los sistemas Batch y se emplean tanto en estudios de equilibrio como en estudios cinéticos [85].

Varios investigadores han analizado las tasas de eliminación de arsénico en presencia de diferentes materiales absorbentes. En general, se llevan a cabo experimentos en batch para determinar el tiempo de reacción requerido para alcanzar el equilibrio de adsorción y los datos experimentales habitualmente se evalúan usando diferentes modelos cinéticos simples. Sin embargo, se debe enfatizar que, debido a la heterogeneidad de las superficies involucradas y a la influencia de los fenómenos de transporte, los modelos cinéticos simples no siempre son capaces de describir con precisión los procesos de adsorción que involucran materiales porosos. Por ejemplo, en los experimentos batch es bastante frecuente observar una fase rápida inicial seguida de una fase mucho más lenta. La adsorción de un soluto por un adsorbente poroso implica tres pasos consecutivos: (i) transporte del adsorbato desde el seno de la solución a la superficie externa del adsorbente, (ii) transporte del adsorbato dentro de los poros del adsorbente (difusión intrapartícula), y (iii) adsorción en la superficie interna de los poros del material adsorbente. Dado que la importancia relativa de cada paso puede depender tanto de las condiciones operativas (velocidad de flujo, temperatura y concentración de adsorbato) como de las características del adsorbente 
(tamaño de partícula, afinidad adsorbente-adsorbato y porosidad de la fase sólida), los modelos simples solo brindan una descripción aproximada de las velocidades de eliminación de los contaminantes.

\subsubsection{Sistemas de lecho fijo. Remoción de contaminantes en columnas rellenas}

A pesar de que los resultados en condiciones batch pueden usarse para una caracterización preliminar de sistemas adsortivos, los parámetros cinéticos y de equilibrio obtenidos en condiciones discontinuas no necesariamente proporcionan datos precisos para el proceso de escalado. La mayoría de los procesos de separación y purificación que emplean la tecnología de adsorción utilizan columnas de flujo continuo [86,87]. La operación de lecho fijo constituye una configuración apropiada para aplicaciones a gran escala ya que asegura la máxima fuerza impulsora posible para el proceso de adsorción. Comenzando en la entrada, la zona del adsorbente saturado se extiende gradualmente a lo largo de la columna, con el adsorbato finalmente eluyendo de la columna. El proceso se lleva a cabo hasta que la concentración de contaminantes en el efluente excede el nivel permisible, denominada concentración de ruptura $(\mathrm{Cr})$. Esta condición se define como punto o tiempo de ruptura del lecho (Tr) [86-88]. Dado que el objetivo principal en el diseño de las columnas es predecir cuánto efluente puede ser tratado o cuánto durará el lecho, es necesario realizar pruebas de flujo continuo de lecho fijo tanto a escala de laboratorio como a escala piloto.

\subsubsection{Zona de transferencia de materia y curvas de ruptura}

En los sistemas de adsorción de lecho empacado, el flujo de agua contaminada crea un frente de onda, conocido como zona de transferencia de masa (mass transfer zone, MTZ), que se mueve desde la entrada hacia la salida del lecho a medida que aumenta el tiempo de operación del sistema. Detrás de la MTZ, el absorbente está completamente agotado, dentro de la MTZ, el grado de saturación del absorbente varía de 100 a 0 por ciento, y más allá del borde superior de la MTZ queda el absorbente no utilizado. Tal como se muestra en la Figura 2.11, la MTZ viaja a través de la columna hasta que alcanza el extremo de salida, después de lo cual el lecho alcanza su punto de ruptura.

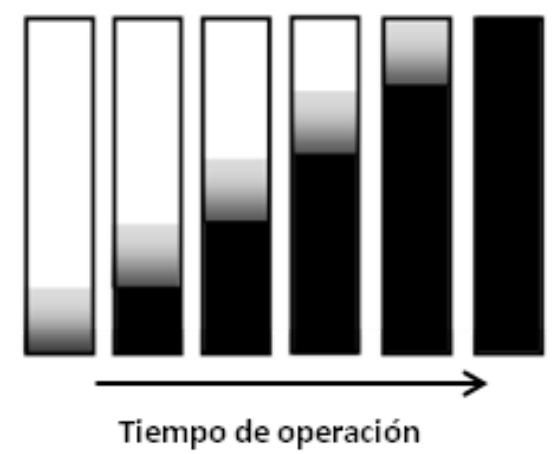

Figura 2.11. Representación de la MTZ para diferentes tiempos de operación. 
El comportamiento dinámico de los sistemas de flujo continuo de lecho fijo se describe en términos de las denominadas curvas de ruptura, obtenidas trazando los valores de $\mathrm{C} / \mathrm{C}_{0}$ en la salida del sistema en función del tiempo de tratamiento o del volumen pasado por la columna. Las curvas de ruptura generalmente muestran un perfil típico en forma de S. Para un contaminante dado, tanto el tiempo necesario para alcanzar el punto de ruptura como la pendiente hasta el punto de agotamiento dependen de las propiedades del lecho fijo así como de las condiciones de operación. La Figura 2.12 representa una curva de ruptura típica y se indica los puntos de ruptura y agotamiento.

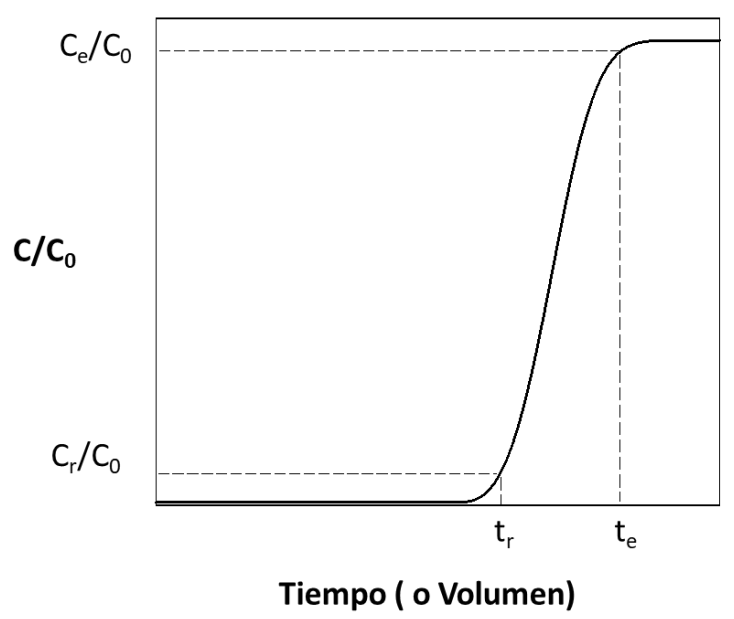

Figura 2.12. Curva de ruptura típica.

La naturaleza de las curvas de ruptura depende no solo del tipo de isoterma de adsorción que gobierna el equilibrio estático, sino también de cuestiones cinéticas relacionadas con la transferencia de masa hacia y a través del adsorbente en la columna [89]. Dado que la adsorción desde la fase móvil al lecho fijo es un proceso de transferencia de masa entre las fases líquida y sólida, la cinética del proceso puede estar controlada mediante varios procesos independientes tales como la difusión en la película, la difusión intrapartícula y la cinética de quimisorción [90].

La descripción cuantitativa de la evolución de la zona de transferencia de masa (MTZ) involucra la resolución de sistemas de ecuaciones diferenciales parciales y generalmente requiere del empleo de métodos de simulación numérica. Por lo tanto, se han desarrollado varios modelos matemáticos simples para predecir el comportamiento dinámico de columnas de lecho fijo. Las suposiciones principales y las ecuaciones que describen los perfiles de avance para los modelos simplificados de uso frecuente se enumeran en la Tabla 2.2 ([85-91] y las referencias allí incluidas).

Uno de los modelos más utilizados es el de Bohart-Adams. Varios autores han observado las tendencias generales predichas por el modelo de Bohart-Adams ya que se encontró que $t_{r}$ y $V_{r}$ aumentan con el aumento de $Z[85,92,93]$ y disminuyen con el aumento de $C_{0}[89,92,94]$ o con el aumento de la velocidad de flujo $[95,96]$. Finalmente, en general se observa que la pendiente de las curvas de ruptura basadas en el tiempo aumenta con $\mathrm{C}_{0}[85]$. 
Tabla 2.2. Ecuaciones simplificadas para el modelado de curvas de ruptura. ${ }^{*}$

\begin{tabular}{|c|c|c|}
\hline Modelo & Curva de ruptura & $\begin{array}{l}\text { Principales } \\
\text { suposiciones }\end{array}$ \\
\hline Bohart-Adams & $\frac{C}{C_{0}}=\frac{1}{1+\exp \left(\frac{k_{A B} \cdot N_{o} \cdot Z}{v_{\text {Filt }}}-k_{A B} \cdot C_{0} \cdot t\right)}$ & $\begin{array}{l}\text { Sin dispersión axial. Tasa de } \\
\text { adsorción controlada por la } \\
\text { reacción de superficie entre el } \\
\text { adsorbato y la capacidad de } \\
\text { adsorbente residual. }\end{array}$ \\
\hline Thomas & $\frac{C}{C_{0}}=\frac{1}{1+\exp \left(k_{T}\left(q_{o} m_{c}-C_{0} V_{e f f}\right) / Q\right)}$ & $\begin{array}{l}\text { Condiciones de flujo pistón. } \\
\text { Isoterma de Langmuir y cinética } \\
\text { de segundo orden. Resistencia a } \\
\text { la transferencia de masa en la } \\
\text { película y difusión intrapartícula } \\
\text { ausentes. }\end{array}$ \\
\hline Yoon-Nelson & $\frac{C}{C_{0}}=\frac{\exp \left[k_{Y N} \times(t-\tau)\right]}{1+\exp \left[k_{Y N} \times(t-\tau)\right]}$ & $\begin{array}{l}\text { La disminución en la probabilidad } \\
\text { de que ocurra la adsorción es } \\
\text { proporcional a la probabilidad de } \\
\text { que el adsorbato atraviese el } \\
\text { lecho. Es un modelo muy conciso } \\
\text { y no requiere información sobre } \\
\text { las características del adsorbente. }\end{array}$ \\
\hline Wolborska & $\frac{C}{C_{0}}=\exp \left(\frac{\beta_{a} C_{0}}{N_{o}} t-\frac{\beta_{a} Z}{v_{\text {Filt }}}\right)$ & $\begin{array}{l}\text { Ecuación general de transferencia } \\
\text { de masa. Coeficiente cinético } \\
\text { dependiente del caudal. }\end{array}$ \\
\hline Clark & $\frac{C}{C_{0}}=\left(\frac{1}{1+A e^{-r t}}\right)^{1 / n-1}$ & $\begin{array}{l}\text { Coeficiente de transferencia de } \\
\text { masa en combinación con la } \\
\text { isoterma de Freundlich. }\end{array}$ \\
\hline
\end{tabular}

*Los parámetros $\mathrm{k}_{\mathrm{AB}}, \mathrm{k}_{\mathrm{T}}, \mathrm{k}_{\mathrm{YN}}, \beta_{\mathrm{a}}$ y $\mathrm{r}$ están relacionados con la cinética del proceso de captación, mientras que los valores de $N_{0}, q_{0}, m_{c}, \tau, N_{0}$ y A están relacionados con la capacidad total de captación para cada modelo simplificado. Además, Z, $\mathrm{v}_{\mathrm{Filt}} \mathrm{y} \mathrm{Q}$ representan la altura del lecho, la velocidad de filtración y el caudal volumétrico, respectivamente.

Teóricamente, los valores de $\mathrm{k}_{\mathrm{AB}}$ y $\mathrm{N}_{0}$ deberían ser independientes de las condiciones de funcionamiento. Sin embargo, debe tenerse en cuenta que el transporte de materia en lechos fijos puede ser bastante complejo ya que como se mencionó anteriormente las velocidades de absorción pueden estar limitadas por la resistencia a la transferencia de materia en la película de la interfaz líquido-sólido, la difusión intrapartícula o la adsorción. La etapa de adsorción es típicamente rápida, mientras que las otras dos resistencias dependen del caudal y del tamaño de partícula, respectivamente. Por lo tanto, la pendiente de las curvas de ruptura puede depender no solo de los valores de $\mathrm{C}_{0}$, sino también de la velocidad de flujo, la longitud de la columna y las propiedades del lecho. Además, aunque en principio el modelo asume que la capacidad total de adsorción debe ser una constante independiente de las 
condiciones de operación, se ha informado que $N_{0}$ puede disminuir $[93,65]$, permanecer constante [98] o aumentar [94] al incrementar el caudal de trabajo. En este contexto debe tenerse en cuenta que si bien los modelos simplificados pueden usarse para describir tendencias generales, pueden no ser capaces de proporcionar descripciones precisas de las curvas de ruptura experimentales para una amplia gama de condiciones operativas.

Pese a que los procesos de remoción de arsénico en columnas rellenas con ZVI no son puramente adsortivos, la obtención de curvas de rupturas y el modelado de estas utilizando las ecuaciones simplificadas propuestas permiten caracterizar y evaluar en forma comparativa el comportamiento de las columnas en los diferentes ensayos realizados. En el caso de lechos reactivos un modelo completo debería incluir (además de la difusión en la película líquido-sólido, la difusión intrapartícula y la adsorción) una etapa previa de difusión en la capa de productos de corrosión (CL). De esta manera, el peso relativo de cada una de estas resistencias puede ir variando con el paso del tiempo de vida del lecho debido a modificaciones en la extensión y la naturaleza de la CL.

\subsubsection{Pruebas rápidas en columnas de pequeña escala (RSSCT)}

La metodología de RSSCT fue desarrollada originalmente para probar la eficiencia de remoción de compuestos orgánicos sobre carbón activado granular. En este enfoque, desarrollado por Crittenden et al. [98,99], el comportamiento dinámico de la columna de tamaño completo o piloto se simula mediante el uso de una columna más pequeña llena de partículas adsorbentes de menor tamaño. Debido a la similitud de los procesos de transferencia de masa y las características hidrodinámicas, los datos obtenidos en los sistemas con pequeñas columnas y a escala piloto están correlacionados [99]. Por lo tanto, los ensayos en laboratorio utilizando RSSCT resultan rápidos y económicos permitiendo así reducir el tiempo y los costos asociados con los estudios piloto [100]. En particular, el uso de RSSCT puede ser muy útil para evaluar diferentes condiciones operativas u optimizar procesos para diferentes calidades de agua.

\subsubsection{Comportamiento hidrodinámico de lechos rellenos con ZVI}

En general, es sabido, que la acumulación de productos de corrosión a lo largo de la columna afecta significativamente la estabilidad de los sistemas basados en ZVI al disminuir la conductividad hidráulica de los lechos. Por este motivo, los cambios en parámetros característicos de las columnas tales como porosidad $(\Phi)$, conductividad hidráulica $(K)$ y distribución de tiempos de residencia (DTR), tienen una influencia significativa en la eficiencia de los lechos fijos utilizados en los sistemas de tratamiento de agua. Si bien los dos primeros parámetros afectan principalmente al volumen tratado por unidad de tiempo y/o los costos de bombeo asociados, la DTR afecta directamente los procesos fisicoquímicos involucrados y, por lo tanto, tiene un impacto directo en la eficiencia de eliminación de contaminantes. 


\subsubsection{Conductividad hidráulica}

La evaluación de la conductividad hidráulica de las columnas reactivas basadas en ZVI es un parámetro importante para el diseño de sistemas efectivos de tratamiento del agua [101]. Los métodos de permeabilidad de carga descendente y de carga constante son los procedimientos más utilizados para las determinaciones de conductividad hidráulica en columnas y filtros de laboratorio [102-104]. En el desarrollo del presente trabajo de Tesis se ha empleado el método de carga constante que consiste en el uso de un permeámetro de nivel constante y la aplicación de la ley de Darcy. Esta ley experimental describe de manera sencilla la circulación de un fluido a lo largo de un medio poroso (Figura 2.13) y establece que la velocidad en los poros es proporcional al gradiente hidráulico adimensional $(\mathrm{dH} / \mathrm{L})$.

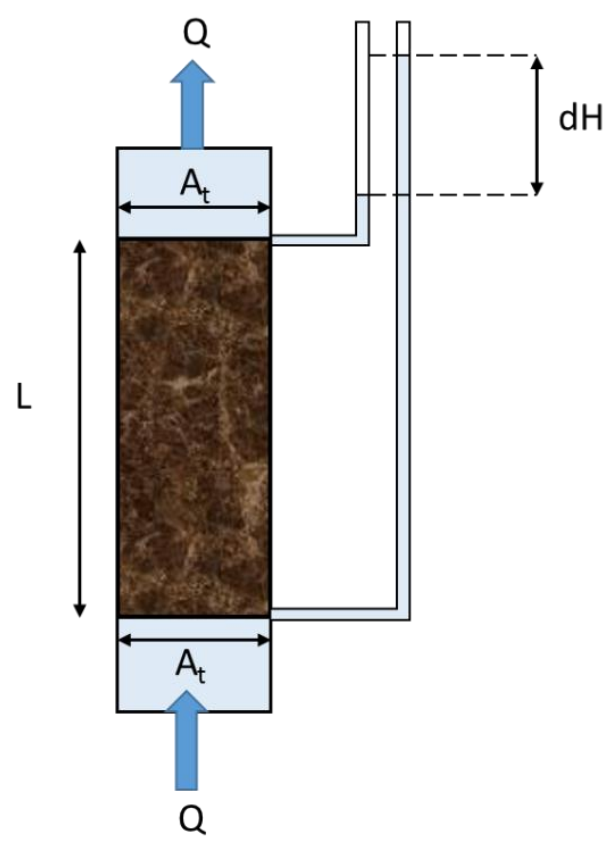

Figura 2.13. Representación esquemática del flujo de una fluido a través un medio poroso.

La ecuación utilizada, tanto para la evaluación experimental puntual de este parámetro así como para el seguimiento de su evolución temporal a lo largo de la vida útil del lecho reactivo, es la siguiente:

$$
K=\frac{Q * L}{A_{t} * d H}
$$

donde $\mathrm{K}$ es la conductividad hidráulica ( $\mathrm{cm} / \mathrm{min}), \mathrm{Q}$ es el flujo volumétrico del fluido a través del lecho $\left(\mathrm{cm}^{3} / \mathrm{min}\right), L$ es la profundidad del lecho $(\mathrm{cm}), A_{t}$ es el área total de la sección transversal de la cama $\left(\mathrm{cm}^{2}\right)$ y $\mathrm{dH}$ es la pérdida de carga $(\mathrm{cm})$. La ley de Darcy falla para valores de $\mathrm{K}$ muy bajos y/o para altas tasas de flujo. El rango de validez corresponde a un número de Reynolds entre 1 y 10 . Se ha encontrado experimentalmente que, para garantizar que el número de Reynolds no exceda el 
último límite de validez, la caída de presión total en el permeámetro no debe ser mayor al $50 \%$ de la longitud total.

\subsubsection{Flujo no ideal}

El flujo en reactores reales siempre muestra desviaciones del comportamiento respecto a los modelos de flujo ideal. Esto se debe, entre otros motivos, a la recirculación de fluido, a la presencia de cortocircuitos y a la generación de zonas con un reducido recambio de la fase líquida (zonas muertas). Es recomendable evitar estas desviaciones, ya que reducen la eficacia del tratamiento y también distorsionan la información relativa a los parámetros cinéticos o fisicoquímicos necesarios para el diseño. Para la caracterización del comportamiento de los reactores de columna, se han propuesto diferentes estrategias. En este contexto, la evaluación de la función de distribución de probabilidad que describe el tiempo de residencia de cada elemento de fluido en el reactor (DTR) es de gran importancia [105]. El método experimental más utilizado para obtener la DTR es el método de estímulo-respuesta, que consiste en aplicar una perturbación en el equipo y analizar su respuesta a la salida del mismo. Por lo general la perturbación, consiste en la incorporación de una sustancia no reactiva (trazador) en la alimentación del reactor. El trazador debe poder detectarse fácilmente y no perturbar el flujo. La concentración, u otra propiedad relacionada con el trazador, es registrada a la salida del reactor como una función del tiempo y utilizada para la construcción de la DTR. Hay diferentes tipos de señales de estimulación; el más utilizado es el pulso corto.

Para que la DTR sea independiente de la cantidad de trazador utilizada, es conveniente representarla en forma estandarizada $(E)$. La curva $E(t)$ se puede determinar con los valores obtenidos a la salida del reactor de la siguiente manera:

$$
E(t)=\frac{C(t)}{\int_{o}^{\infty} C(t) d t}
$$

Entonces, el tiempo de residencia promedio (ec 2.8, 2.9) así como la varianza de la distribución (ec 2.10, 2.11) pueden obtenerse a partir de los datos experimentales:

$$
\begin{aligned}
\bar{t} & =\frac{\int_{o}^{\infty} t * C(t) d t}{\int_{o}^{\infty} C(t) d t} \cong \frac{\sum t_{i} * C_{i} * \Delta t_{i}}{\sum C_{i} * \Delta t_{i}} \\
\bar{t} & =\int_{o}^{\infty} t * E(t) d t \cong \sum t_{i} * E_{i} * \Delta t_{i} \\
\sigma^{2} & =\frac{\int_{o}^{\infty}(t-\bar{t})^{2} * C(t) d t}{\int_{o}^{\infty} C(t) d t}=\frac{\int_{o}^{\infty} t^{2} * C(t) d t}{\int_{o}^{\infty} C(t) d t}-\bar{t}^{2} \cong \frac{\sum t_{i}^{2} * C_{i} * \Delta t_{i}}{\sum C_{i} * \Delta t_{i}}-\bar{t}^{2} \\
\sigma^{2} & =\int_{o}^{\infty} t^{2} * E(t) d t-\bar{t}^{2} \cong \sum t_{i}^{2} * E_{i} * \Delta t_{i}-\bar{t}^{2}
\end{aligned}
$$

En el caso de un reactor de lecho relleno, la discrepancia entre el tiempo de residencia obtenido a partir de la relación entre el volumen del reactor y el caudal 
volumétrico $\left(t_{m}\right)$ y el tiempo medio obtenido de la ecuación $2.8(\bar{t})$ da una idea de la magnitud de las desviaciones respecto del flujo pistón debidas a la presencia de cortocircuitos y zonas muertas. Para estudiar y comparar curvas DTR correspondientes a diferentes tamaños de reactor o caudales de operación generalmente la función $E$ se expresa en función del tiempo adimensional $\theta$.

$$
\begin{aligned}
& \theta=\frac{t}{\bar{t}} \\
& E(\theta)=\frac{C(\theta)}{\int_{o}^{\infty} C(\theta) d \theta}=E(t) * \bar{t}
\end{aligned}
$$

\section{El modelo de dispersión}

Dado el diseño seleccionado para la planta de tratamiento desarrollada en nuestro laboratorio, el modelo más simple para describir el patrón de flujo dentro del lecho reactivo es el modelo ideal de Reactor de Flujo Pistón (RFP). Este se caracteriza por un mezclado perfecto en la dimensión radial y ningún tipo de dispersión en la dimensión axial. En un RFP ideal, el tiempo de residencia para todos los elementos de fluido dentro del reactor debe ser el mismo.

Normalmente, los sistemas reales se apartan de este comportamiento. Los modelos de flujo no ideal son útiles para representar el flujo en recipientes reales. Existen diferentes tipos de modelos dependiendo de si el patrón real de guarda similitud con el correspondiente a un tanque agitado con mezclado perfecto, un flujo pistón o alguna condición intermedia. Para los reactores tubulares, existen dos modelos para explicar las desviaciones del flujo respecto al RPF: el modelo de dispersión axial (MDA) y el modelo de tanques en serie (MTS). Estos modelos se aplican a diferentes situaciones que incluyen el flujo turbulento en tuberías, el flujo laminar en tubos muy largos, el flujo en lechos compactos, etc. [106]. Para el análisis del comportamiento de la columna ZVI probada, el modelo MDA es mucho más apropiado que el modelo MTS.

EI MDA es un modelo empleado principalmente para reactores tubulares que solo difiere del flujo pistón en el hecho de adicionar una contribución de tipo dispersivo en sentido axial, definido por una ecuación análoga a la de la ley de Fick [107]. Asumiendo la validez de este modelo, el balance de material para un trazador viene dado por:

$$
\frac{\partial \mathrm{C}}{\partial \mathrm{t}}=-\mathrm{u} \frac{\partial \mathrm{C}}{\partial \mathrm{z}}+\mathrm{D} \frac{\partial^{2} \mathrm{C}}{\partial \mathrm{z}^{2}}
$$

donde $\mathrm{D}$ es el coeficiente de dispersión axial, que es un parámetro diferente del coeficiente de difusión molecular y permite describir la evolución de la distribución de solutos a lo largo del eje longitudinal de la columna. Reordenando parámetros, en forma adimensional se obtiene la ecuación diferencial básica

$$
\frac{\partial C}{\partial \theta}=\left(\frac{D}{u L}\right) \frac{\partial^{2} C}{\partial \zeta}-\frac{\partial C}{\partial \zeta}
$$


donde $\theta=\frac{t}{\bar{t}}$ y $\zeta=\frac{z}{L}$. El parámetro adimensional $\left(\frac{D}{u L}\right)$ se denomina módulo de dispersión del recipiente y cuantifica la extensión de la dispersión axial en relación al transporte advectivo. Valores de este parámetro tendiendo a cero representan pequeñas desviaciones del flujo pistón, mientras que valores altos representan una gran dispersión y en estas condiciones el sistema se asemeja más bien a un tanque agitado.

\section{Grados de dispersión y condiciones de contorno}

La ecuación del MDA puede ser ajustada para diferentes grados de dispersión y condiciones de contorno. Si se inyecta un pulso Gaussiano de trazador ideal, la dispersión dentro del recipiente provoca la ampliación de la curva de DTR. Para grados de dispersión bajos $\left(\frac{D}{u L}<0,01\right)$, la curva no cambia su forma y la resolución de la ecuación 21 produce una familia de curvas Gaussianas. Para grandes desviaciones del flujo de pistón $\left(\frac{\boldsymbol{D}}{\boldsymbol{u} \boldsymbol{L}}>0,01\right)$, la DTR se amplía significativamente y cambia su forma, dando como resultado curvas asimétricas. Además, las soluciones matemáticas de la última ecuación diferencial dependen de las condiciones de contorno, por lo que el comportamiento del trazador justo en la entrada y salida de la columna también determina la forma de las curvas $E(\theta)$.

La Figura 2.13 muestra las formas de las curvas $E(\theta)$ para diferentes grados de dispersión. Los perfiles muestran que a medida que aumenta el número de dispersión del recipiente, la DTR se amplía sustancialmente.

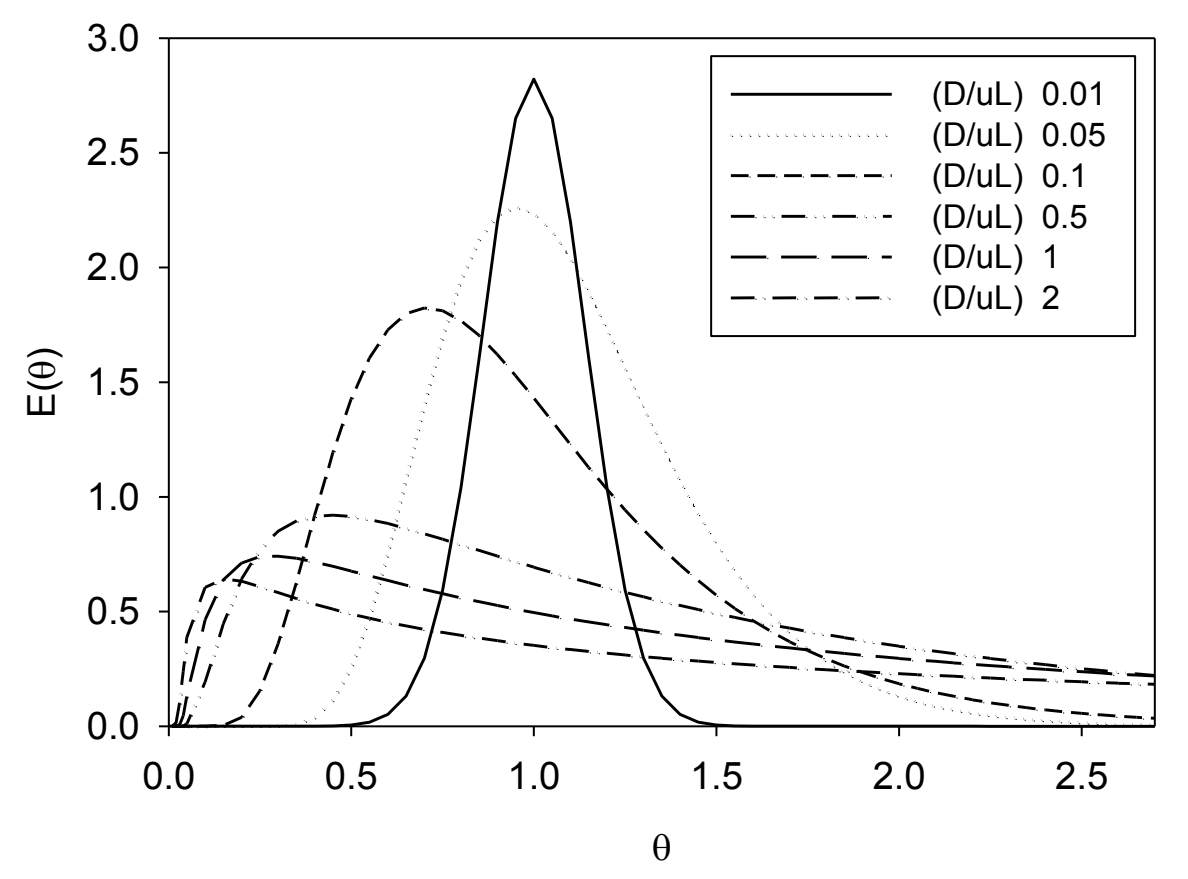

Figura 2.13.Curvas $E(\theta)$ para diferentes grados de dispersión.

Las condiciones de contorno afectan significativamente a la solución del MDA e incluyen: i) condiciones de contorno cerrado, donde se supone que la dispersión solo ocurre dentro del recipiente, y el fluido entra y sale como un flujo de pistón; ii) 
condiciones de contorno abierto, que consideran que hay dispersiones antes de que el trazador ingrese y luego de que abandone el buque; y iii) combinaciones entre ambos.

Suponiendo una función $\delta$-Dirac para el impulso inyectado (pulso perfecto), la señal a la salida del sistema se puede obtener a partir de la solución de la ecuación 2.15 usando diferentes condiciones de contorno. Las expresiones analíticas se resumen en la Tabla 2.3.

Tabla 2.3. Expresiones analíticas para diferentes condiciones de contorno [108].

\begin{tabular}{|c|c|}
\hline & Expresión analítica \\
\hline $\begin{array}{l}\text { Pequeños grados de } \\
\text { dispersión }\left(\frac{D}{u L}<0,01\right)\end{array}$ & $\begin{array}{c}E(\theta)=\sqrt{\frac{1}{4 \frac{\boldsymbol{D}}{\boldsymbol{u} \boldsymbol{L}} \pi}} \exp \left[-\frac{(1-\theta)^{2}}{4 \frac{\boldsymbol{D}}{\boldsymbol{u} \boldsymbol{L}}}\right] \\
\bar{\theta}_{E}=1 \quad \sigma_{E}^{2}=2 \frac{\boldsymbol{D}}{\boldsymbol{u} \boldsymbol{L}}\end{array}$ \\
\hline $\begin{array}{l}\text { Grandes desviaciones } \\
\text { del flujo pistón } \\
\left(\frac{D}{u L}>0,01\right)\end{array}$ & \\
\hline Recipiente abierto & $\begin{array}{c}E(\theta)=\sqrt{\frac{1}{4 \frac{D}{\boldsymbol{u} \boldsymbol{L}} \theta}} \exp \left[-\frac{(1-\theta)^{2}}{4 \frac{\boldsymbol{D}}{\boldsymbol{u} \boldsymbol{L}} \theta}\right] \\
\bar{\theta}_{E \infty}=1-2 \frac{\boldsymbol{D}}{\boldsymbol{u} \boldsymbol{L}} \quad \sigma_{E \infty}^{2}=2 \frac{\boldsymbol{D}}{\boldsymbol{u} \boldsymbol{L}}+8\left(\frac{\boldsymbol{D}}{\boldsymbol{u} \boldsymbol{L}}\right)^{2}\end{array}$ \\
\hline Recipiente cerrado & $\begin{array}{l}\text { No hay expresión analítica para } E(\theta) \\
\bar{\theta}_{E}=1 \quad \sigma_{E}^{2}=2 \frac{\boldsymbol{D}}{\boldsymbol{u} \boldsymbol{L}}-2\left(\frac{\boldsymbol{D}}{\boldsymbol{u} \boldsymbol{L}}\right)^{2}\left[1-e^{-\frac{\boldsymbol{u} \boldsymbol{L}}{\boldsymbol{D}}}\right]\end{array}$ \\
\hline $\begin{array}{l}\text { Recipiente cerrado } \\
\text { (con dispersión a la } \\
\text { entrada)- abierto }\end{array}$ & $\begin{aligned} E(\theta)=\sqrt{\frac{1}{\pi \frac{D}{\boldsymbol{u} \boldsymbol{L}} \theta}} \exp \left[-\frac{1}{4 \frac{D}{\boldsymbol{u} \boldsymbol{L}} \theta}\right] \\
\quad-\frac{1}{2 \frac{\boldsymbol{D}}{\boldsymbol{u} \boldsymbol{L}}} \exp \left[\frac{\boldsymbol{u} \boldsymbol{L}}{\boldsymbol{D}}\right\rfloor \operatorname{erfc}\left[\sqrt{\frac{1}{\theta \frac{D}{\boldsymbol{u} \boldsymbol{L}}}} \frac{1+\theta}{2}\right]\end{aligned}$ \\
\hline $\begin{array}{l}\text { Recipiente cerrado } \\
\text { (sin dispersión a la } \\
\text { entrada)-abierto }\end{array}$ & $E(\theta)=\sqrt{\frac{1}{4 \pi \frac{\boldsymbol{D}}{\boldsymbol{u} \boldsymbol{L}} \theta^{3}}} \exp \left[-\frac{(1-\theta)^{2}}{4 \frac{\boldsymbol{D}}{\boldsymbol{u} \boldsymbol{L}} \theta}\right]$ \\
\hline
\end{tabular}

En capítulos siguientes se determinaran experimentalmente las curvas de distribución de tiempos de residencia y se hará uso de la expresión analítica de la Tabla 2.3 que resulte más adecuada y ajuste mejor los resultados para calcular el coeficiente de dispersión y caracterizar el flujo en el sistema. 


\subsection{Diseño de Experimentos}

Un diseño experimental o diseño estadístico de experimentos (DEE) consiste en una serie de pruebas en las cuales se inducen cambios deliberados en los factores de un proceso o sistema, de manera que sea posible observar o identificar las causas de los cambios en las respuestas del sistema [109,110]. El DEE se utiliza principalmente para el desarrollo de modelos empíricos y se basa en la aplicación de técnicas estadísticas para seleccionar la estrategia experimental óptima que permita obtener la información buscada con el mínimo coste y, al mismo tiempo, garantizar la máxima fiabilidad en las conclusiones que se obtengan. Esta metodología posee su propio lenguaje y es necesario su conocimiento para poder utilizarlo y comprenderlo a fin de obtener conclusiones adecuadas. Entre los términos más importantes se destacan [111]:

- Factor: es la variable controlable o independiente que es estudiada en el experimento. Esta puede ser cualitativa (cambios en el equipo, métodos, material utilizado) o cuantitativa (temperatura, presión, concentración, tiempo).

- Niveles: si el factor es cuantitativo los niveles corresponderán a los valores numéricos que tomará el factor durante el diseño. En cambio, si el factor es cualitativo los niveles serán por ejemplo $\mathrm{V}$ (verdadero) o $\mathrm{F}$ (falso).

- Combinación: es la asignación de un solo nivel a un factor o de varios niveles a todos los factores de una corrida experimental.

- Corrida experimental: implementación de cada una de las combinaciones.

- Variable de respuesta: es la variable de interés sobre la que se analizará la significancia de los factores.

- Efecto: es el cambio de la variable de respuesta por el cambio del nivel de un factor.

Los objetivos principales de los diseños experimentales son:

- Determinar cuáles factores tienen mayor influencia en la respuesta de un determinado sistema.

- Determinar el mejor nivel de los factores controlables que influyen en la respuesta, de manera que, esta tome un valor cercano al nivel nominal deseado.

- Determinar la mejor combinación de factores controlables que ayuden a reducir la variabilidad de la respuesta.

- Establecer la combinación óptima de los factores controlables, con el objetivo de minimizar los efectos de los factores incontrolables.

Para cumplir con estos objetivos se emplea la siguiente metodología:

1. Identificar los factores que pueden influir en la variable respuesta y proponer un modelo

2. Realizar el experimento, tomando las observaciones necesarias

3. Estimar los parámetros del modelo

4. Contrastar si los factores influyen en la respuesta 
5. Si los factores influyen en la respuesta, detectar dónde radican las diferencias

6. Si algún factor no influye, simplificar el modelo y repetir los pasos anteriores

7. Realizar la diagnosis del modelo mediante el análisis de los residuos.

Existen diferentes tipos de diseños de experimentos dependiendo de la cantidad de recursos con los que se cuente y la complejidad del modelo que se quiera utilizar. Los diseños de tipo factorial permiten estudiar los efectos que varios factores pueden tener en una o más respuestas. Por lo general se puede ejecutar el diseño factorial completo o una fracción del diseño. Un diseño factorial completo es un diseño en el cual se miden las variables respuestas para todas las combinaciones de niveles de los factores. El número de corridas necesarias para un diseño completo de $R$ niveles por factor es $R^{k}$, donde $k$ es el número de factores. Un diseño fraccionado es un diseño en el cual solo se realiza un subconjunto seleccionado o "fracción" de las corridas experimentales incluidas en el diseño factorial completo.

La mayoría de los DEE cumplen con dos características: i) son ortogonales, es decir, la varianza de la respuesta esperada, en cualquier punto de la región experimental, se puede expresar como la suma ponderada de las varianzas de los parámetros estimados del modelo, y ii) son invariantes por rotación lo que garantiza que el diseño proporcione estimaciones igualmente precisas en todas las direcciones. En la Tabla 2.4 se describen brevemente algunos de los DEE más utilizados.

Tabla 2.4. Diseños de experimentos más utilizados [109-112].

\begin{tabular}{|c|c|c|}
\hline Diseño & $\begin{array}{l}\text { Número de } \\
\text { puntos }\end{array}$ & Descripción \\
\hline $\begin{array}{l}\text { Diseño factorial } \\
\text { con dos niveles }\end{array}$ & $N=2^{k}$ & $\begin{array}{l}\text { Es un diseño ortogonal muy simple que posee } \\
\text { como desventaja que considera solo dos niveles } \\
\text { para cada factor. }\end{array}$ \\
\hline $\begin{array}{l}\text { Diseño factorial } \\
\text { fraccionado }\end{array}$ & $\begin{array}{l}N=2 \mathrm{k}-\mathrm{p} \\
\text { Donde } \mathrm{p} \text { implica la } \\
\text { fracción del diseño } \\
\text { factorial }\end{array}$ & $\begin{array}{l}\text { Es una fracción del diseño factorial de dos } \\
\text { niveles. Son una opción adecuada cuando los } \\
\text { recursos son limitados o el número de factores } \\
\text { incluidos en el diseño es grande. }\end{array}$ \\
\hline $\begin{array}{l}\text { Diseño central } \\
\text { compuesto }\end{array}$ & $N=2^{k}+2^{*} k+n_{0}$ & $\begin{array}{l}\text { Consiste en una parte factorial, en una cantidad } \\
\mathrm{n}_{0} \text { de puntos centrales y en una parte axial que } \\
\text { corresponde a dos puntos axiales en los ejes } \\
\text { correspondientes a cada uno de los factores } \\
\text { situados a una distancia } \alpha \text {. Depende del valor de } \\
\mathrm{n}_{0} \text { para ser ortogonal y es invariante por rotación } \\
\text { si } \alpha=\sqrt[4]{2^{k}}\end{array}$ \\
\hline $\begin{array}{l}\text { Diseño factorial } \\
\text { en tres niveles }\end{array}$ & $N=3^{k}$ & $\begin{array}{l}\text { Es un diseño ortogonal sencillo que considera } \\
\text { tres niveles para cada factor }\end{array}$ \\
\hline $\begin{array}{l}\text { Diseño de matriz } \\
\text { de Doehlert }\end{array}$ & $N=k^{2}+k+n_{0}$ & $\begin{array}{l}\text { Se caracteriza por considerar distinto número de } \\
\text { niveles para cada factor y que todos los puntos } \\
\text { equidistan del experimento central. Permite } \\
\text { extender el dominio mediante el agregado de otro } \\
\text { factor. }\end{array}$ \\
\hline
\end{tabular}


CAPITULO 3:

ENSAYOS PRELIMINARES $Y$ COMPLEMENTARIOS 


\section{ENSAYOS PRELIMINARES Y COMPLEMENTARIOS}

A lo largo de los capítulos del presente trabajo de tesis se describen los resultados obtenidos del estudio de una metodología basada en el empleo de hierro cero Valente $(\mathrm{ZVI})$ para la remoción de contaminantes en agua en sistemas continuos. Dependiendo del contaminante y de las condiciones operativas, los mecanismos de remoción pueden diferir entre precipitación, co-precipitación, reducción electroquímica o una combinación de los procesos anteriores. Sin embargo en todos los casos el proceso global consta de una serie de etapas en común.

El sistema básico involucra tres etapas: en primer lugar el agua atraviesa un reactor tubular lleno de $\mathrm{Fe}(0)$ donde esta especie se oxida a $\mathrm{Fe}(\mathrm{II})$. En simultáneo, parte del $\mathrm{Fe}(\mathrm{II})$ formado es oxidado a $\mathrm{Fe}$ (III) debido a la presencia de oxígeno disuelto en el agua que ingresa al sistema. Posteriormente, el Fe(II) soluble que eluye de la columna es oxidado en un segundo módulo que opera con una concentración de oxígeno constante cercana a 8 ppm mediante un sistema de aireación. Las especies férricas y ferrosas generadas en el sistema forman óxidos mixtos que a valores de $\mathrm{pH}$ cercanos a la neutralidad son insolubles. Finalmente, para remover los sólidos generados en los módulos anteriores se utiliza una última etapa de separación física para obtener finalmente agua clarificada (Figura 3.1).

Los estudios presentados en los capítulos 3 y 4 se enfocan principalmente en la primera etapa, que consiste en un reactor tubular de lecho fijo relleno de ZVI y constituye el objetivo principal de estudio de esta tesis.

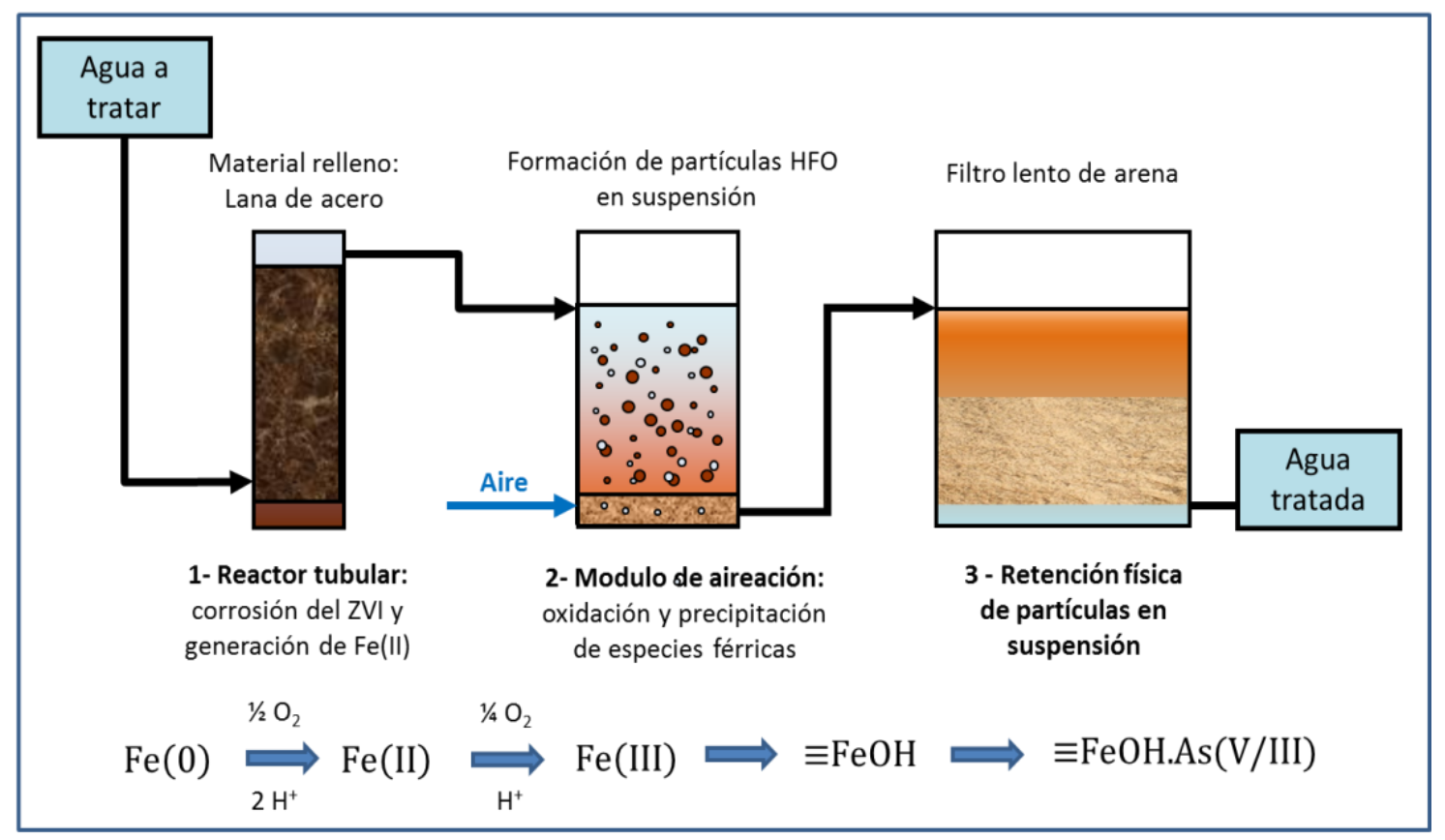

Figura 3.1. Esquema del proceso de tratamiento continuo de agua basado en la técnica de hierro cero Valente (ZVI). 


\subsection{ENSAYOS PRELIMINARES DE REMOCIÓN. EFECTO DEL pH}

Se realizaron ensayos preliminares para evaluar el potencial de la técnica ZVI para la remoción de As en una matriz de agua real y analizar el efecto del $\mathrm{pH}$ sobre el desempeño del sistema.

Las pruebas fueron llevadas a cabo en modo continuo utilizando una columna de vidrio $\left(\mathrm{d}_{\mathrm{i}}=3.8 \mathrm{~cm}\right.$ y $\left.\mathrm{L}=11.3 \mathrm{~cm}\right)$, rellena con $15 \mathrm{~g}$ de lana de acero comercial $\mathrm{y}$ operada con un TRH de 16 min. Como solución de trabajo se utilizó agua de pozo de una vivienda rural de la localidad de Gral Rodriguez (provincia de Buenos Aires) contaminada con $120 \mathrm{ppb}$ de As. El ajuste de $\mathrm{pH}$ se realizó con $\mathrm{HCl} 1 \mathrm{~N}$. La eficiencia del proceso se determinó midiendo los contenidos Fe(II), Fe(III) y arsénico tanto en la entrada como en la salida de las columnas reactivas. La determinación de arsénico fue realizada luego de oxidar y filtrar la muestra con el fin de eliminar las especies insolubles de hierro generadas por la corrosión del ZVI.

En primer lugar se realizó un ensayo con una matriz de agua cruda cuyo $\mathrm{pH}$ fue 8.8. En la Figura 3.2 se pueden ver los resultados obtenidos. La primera determinación (8.8 ini) se realizó al finalizar la estabilización del sistema (7 volúmenes de lecho). La segunda determinación fue realizada luego de 6 horas de operación. Los resultados muestran que en la primera determinación, con el material de relleno nuevo, se obtiene un porcentaje de remoción del orden del $50 \%$. Esto se debe principalmente a restos de óxidos de $\mathrm{Fe}(\mathrm{III})$ presentes en el material de partida. Luego de 6 hs de operación el porcentaje de remoción cae a 0 ya que a este $\mathrm{pH}$ de operación no se observa oxidación del ZVI ni generación de Fe(II). Posteriormente se realizó un ensayo similar pero haciendo una corrección previa del $\mathrm{pH}$ a un valor de 7.5. Como puede observarse, en estas condiciones luego de 6 horas de operación el sistema continua operando con un porcentaje de remoción del $60 \%$ gracias a la generación de una pequeña cantidad de $\mathrm{Fe}(\mathrm{II})$. Finalmente, para los ensayos realizados con la misma matriz de agua cruda pero acidificada a un $\mathrm{pH}$ inicial de $\mathrm{pH} 6.5$ muestran un notable incremento en la generación de $\mathrm{Fe}(\mathrm{II})$ permitiendo así alcanzar porcentajes de remoción superiores al 95\%.

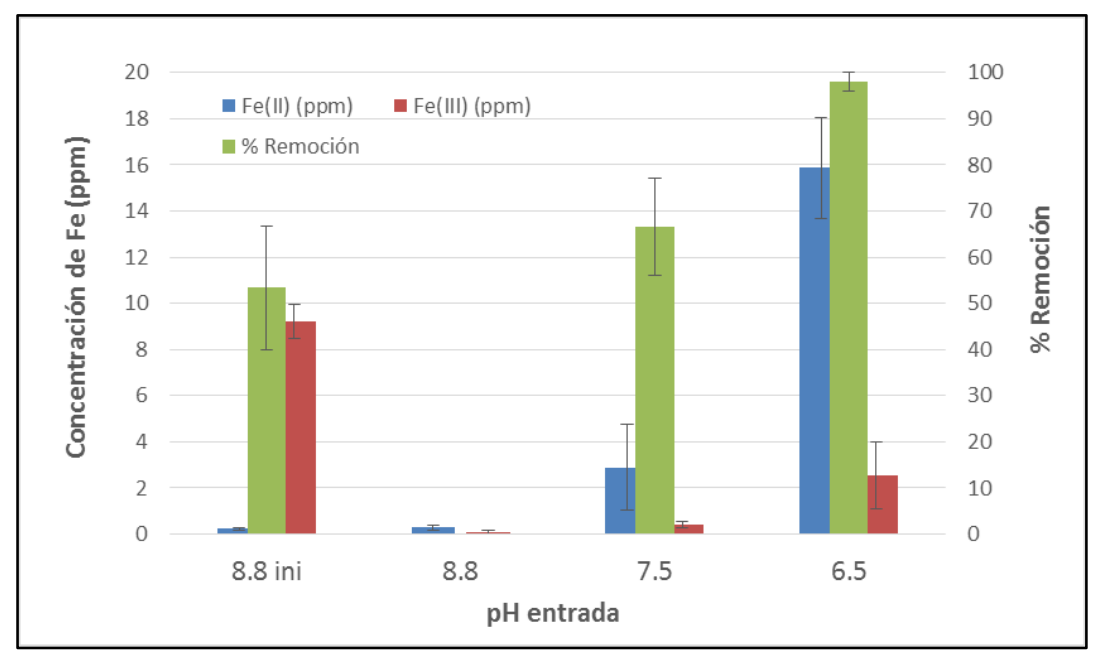

Figura 3.2. Ensayos preliminares de remoción ( $C_{i} 120$ ppb de As, $m_{z v i} 15$ g, TRH 15 min). 


\subsection{ENSAYOS PRELIMINARES. EFECTO DE LAS VARIABLES OPERATIVAS}

Se acepta ampliamente que la eficacia del tratamiento de los sistemas continuos basados en el empleo de ZVI depende principalmente de la naturaleza de la fuente de $\mathrm{Fe}(0)$ utilizada y de las condiciones operativas de la columna [101]. En particular, las características fisicoquímicas del agua de entrada y el tiempo de residencia hidráulica $(\mathrm{TRH})$ se encuentran entre las condiciones operativas que más influyen en el desempeño del proceso en general.

Con respecto al primer punto, la composición química del agua contaminada determina el grado de corrosión, la especiación del hierro y el tipo de interacciones del contaminante con los productos de la corrosión. Varios autores han investigado el efecto de la presencia de diferentes iones, el $\mathrm{pH}$ y el contenido de oxígeno en la eficiencia de eliminación del arsénico [113,114]. Las reacciones involucradas en los sistemas $\mathrm{ZVI} /$ agua son complejas y altamente dependientes tanto del $\mathrm{pH}$ como del contenido de oxígeno disuelto.

Existen diferentes posturas respecto al efecto ejercido por diferentes iones sobre el proceso de remoción de arsénico. Algunos autores encontraron que aniones tales como cloruro, carbonato, nitrato, fosfato, sulfato y borato inhiben la eliminación de arsénico en diferentes grados [114]. Sin embargo, otros estudios afirman que el fosfato, el silicato y el molibdato compiten fuertemente con el arsénico por los sitios de adsorción, mientras que el sulfato y el cloruro no lo hacen [115]. Esto se debe posiblemente a que en muchos casos los efectos estudiados son dependientes de las concentraciones con las que se trabaje.

Por otro lado, en todo proceso de tratamiento continuo, el caudal volumétrico determina el tiempo de retención hidráulica (TRH) del agua dentro de cada una de las unidades de la planta. Para el lecho de ZVI, el TRH define la extensión del contacto sólido-líquido y, por lo tanto, debe ser suficiente para lograr la oxidación del ZVI a $\mathrm{Fe}(\mathrm{II})$ utilizando como oxidante al oxígeno disuelto, presente de forma natural en el agua a tratar. EI TRH en la segunda etapa, que se opera bajo una atmósfera saturada de aire, debe permitir la oxidación completa del Fe(II) eluido de la primera unidad y favorecer la coagulación, floculación y precipitación de las especies formadas de $\mathrm{Fe}(\mathrm{III})$ como oxihidróxidos de hierro.

En este contexto y debido a que el contenido de hierro en la solución es uno de los parámetros de diseño principales, se llevaron a cabo varios estudios para analizar los procesos de corrosión en columnas de pequeña escala rellenas de ZVI. Los experimentos tuvieron como objetivo cuantificar el efecto de las variaciones del TRH, el $\mathrm{pH}$ de la entrada, la masa de ZVI y la densidad del lecho sobre el comportamiento del sistema reactivo.

El primer grupo de ensayos preliminares fue realizado con dos objetivos: i) definir el rango de variación de tiempos de residencias (TRH) sobre los cuales trabajar en los ensayos rápidos con pequeñas columnas (RSSCT), ii) realizar un análisis preliminar acerca del efecto de la densidad del lecho en el desempeño de los 
sistemas. Las pruebas se realizaron en modo continuo utilizando una columna de vidrio $\left(d_{i}=3.8 \mathrm{~cm}\right)$ rellena de lana de acero comercial (Mapavirulana ${ }^{\circledR}$ ) y alimentada con agua de red saturada en aire (8-8.5 ppm de oxígeno) mediante un tanque elevado. Estos ensayos se realizaron con TRHs comprendidos entre 0,25 y 40 min empleando densidades del lecho entre 0,01 y $0,10 \mathrm{~g} / \mathrm{cm}^{3}$. Para caracterizar el comportamiento del lecho reactivo en las diferentes condiciones operativas analizadas se midieron los contenidos de $\mathrm{Fe}(\mathrm{II}), \mathrm{Fe}(\mathrm{III})$ y oxígeno a la salida de las columnas. El contenido de oxígeno se midió en línea usando una celda de flujo ubicada a la salida de la columna, mientras que el contenido de Fe se evaluó inmediatamente después de muestrear el efluente de la columna. La toma de datos para cada condición operativa fue realizada luego de la estabilización del sistema (aproximadamente 7 veces el TRH).

Los resultados más relevantes se muestran en las Figuras 3.3 a 3.5. Las mayores variaciones se registraron en el rango de TRH por debajo de los $10 \mathrm{~min}$. Puede observarse que dentro de este rango de operación el aumento del TRH produce una mayor generación de $\mathrm{Fe}(\mathrm{II})$ y un aumento en el consumo de oxígeno por parte del lecho para una dada densidad de empaquetamiento (Figura 3.3). Para un tiempo de residencia de $10 \mathrm{~min}$, el consumo de oxigeno es prácticamente total, incluso para bajos grados de compactación. Por otro lado, en estas condiciones se observa un aumento de la taza de generación de $\mathrm{Fe}$ (II) con el aumento de la densidad del lecho (Figura 3.4). Además, para bajos TRH (menores a $1 \mathrm{~min}$ ) se aprecia un aumento del consumo de oxígeno con el aumento de la densidad del lecho (Figura 3.5). Finalmente, cabe destacar que, para ninguna de las condiciones operativas seleccionadas se pudo observar una tendencia clara en el contenido de $\mathrm{Fe}$ (III) generado (datos no mostrados).

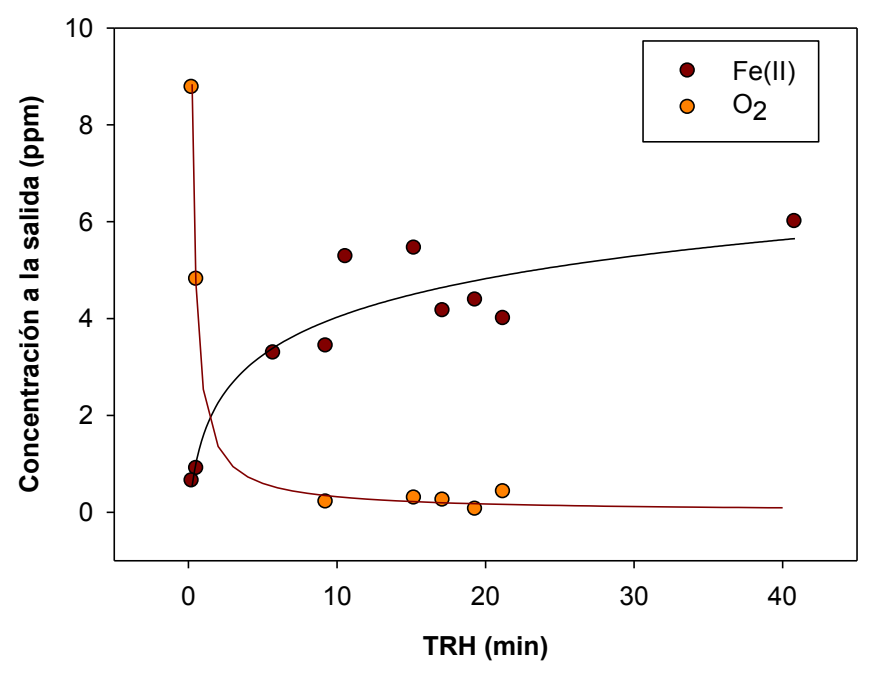

Figura 3.3. Efecto del tiempo de residencia hidráulico (TRH) sobre la generación de Fe(II) y el consumo de oxígeno (Densidad del lecho: $0,05 \mathrm{~g} / \mathrm{cm}^{3}$, $\mathrm{pH}$ de entrada: 7 ). 


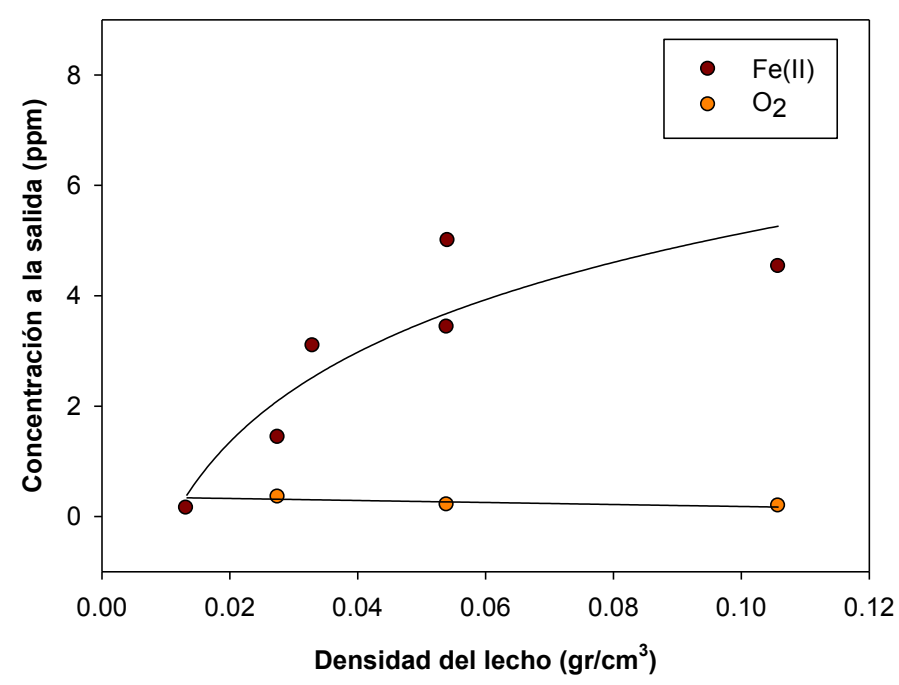

Figura 3.4. Efecto de la densidad del lecho sobre la generación de Fe(II) y el consumo de oxígeno (TRH: $10 \mathrm{~min}, \mathrm{pH}$ de entrada: 7).

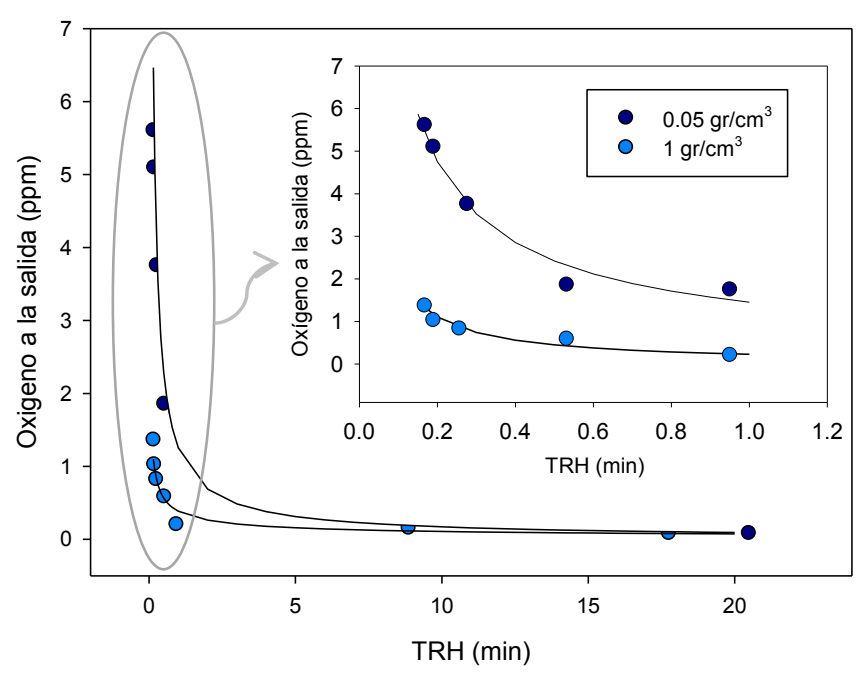

Figura 3.5. Efecto de la densidad del lecho y el TRH sobre el consumo de oxígeno para bajos valores de TRH.

\subsection{CORROSIÓN EN AUSENCIA DE OXIGENO}

\subsubsection{Ensayos preliminares de dos columnas en serie}

Con el fin de determinar si la oxidación del ZVI es significativa en ausencia de oxígeno a pH neutro (ec. 1.1), se realizó una nueva serie de experimentos para evaluar el efecto de la concentración de oxígeno en la generación de diferentes especies de hierro. Esta serie de ensayos también fue utilizada para realizar una nueva evaluación del efecto de variables operativas tales como: $\mathrm{TRH}$, densidad del lecho y $\mathrm{pH}$ inicial sobre la generación de las diferentes especies de hierro. Las pruebas se realizaron en modo continuo utilizando dos columnas de vidrio ( $\mathrm{di}=3.8 \mathrm{~cm}$ $\mathrm{L}=23 \mathrm{~cm}$ ) rellenas de lana de acero comercial y conectadas en serie. Los procesos se 
monitorearon midiendo los contenidos $\mathrm{Fe}(\mathrm{II}), \mathrm{Fe}(\mathrm{III}), \mathrm{pH}$ y oxígeno, tanto en la entrada como en la salida de ambas columnas reactivas. Para el caso de $\mathrm{Fe}(\mathrm{II})$ y $\mathrm{Fe}(\mathrm{III})$, se discriminó en cada caso hierro "total" de hierro "filtrable". El esquema del sistema utilizado se muestra en la Figura 3.6.

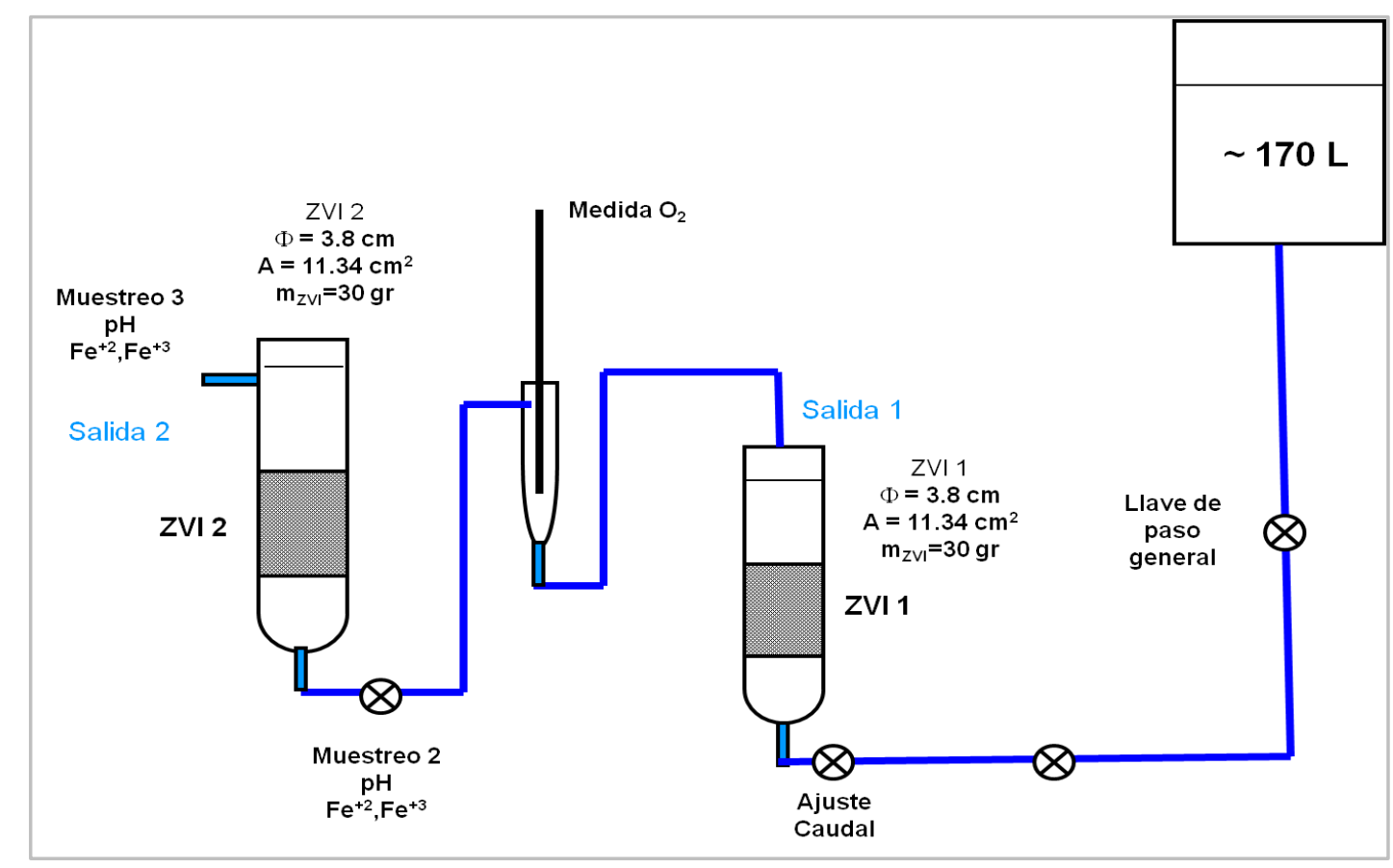

Figura 3.6. Esquema del sistema utilizado para los ensayos realizados con dos columnas en serie.

Las concentraciones de $\mathrm{Fe}(\mathrm{II})$ y de $\mathrm{Fe}(\mathrm{III})$ obtenidas se presentan en las Figuras 3.7 y 3.8, respectivamente. Los resultados incluyen 2 puntos de muestreo (P2: salida de la primer columna y P3: salida de la segunda columna), 2 valores de pH de entrada (6.5 y 7.5), 2 tiempos de residencia $(0,9$ y $17.4 \mathrm{~min})$ y 2 densidades de lecho $\left(0,05\right.$ y $\left.0,1 \mathrm{~g} / \mathrm{cm}^{3}\right)$. 

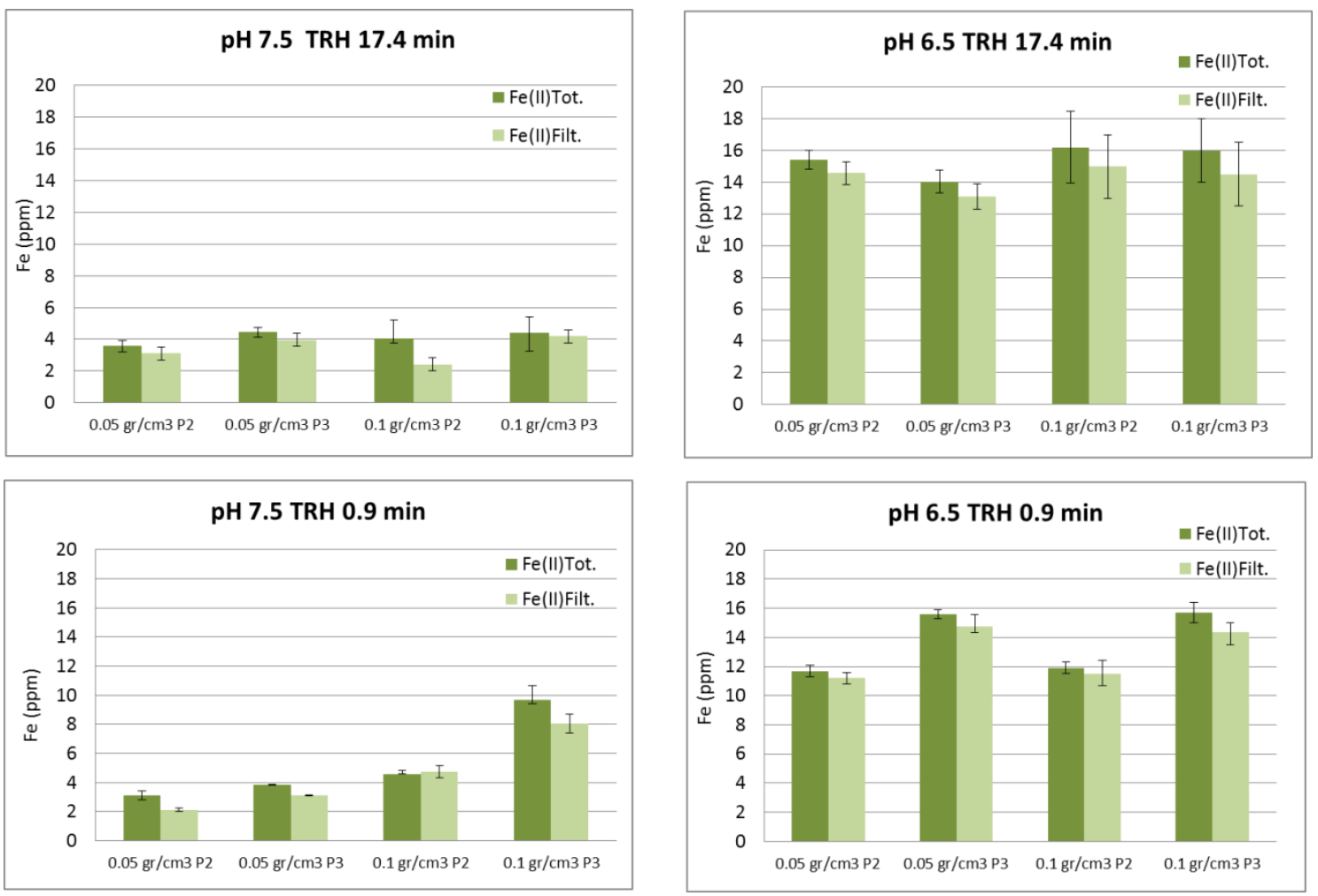

Figura 3.7. Contenido de $\mathrm{Fe}(\mathrm{II})(\mathrm{mg} / \mathrm{L})$ a la salida de cada columna (P2 y P3), para distintos TRH (0,9 y $17.4 \mathrm{~min})$ y densidad de lecho $\left(0,05\right.$ y $\left.0,1 \mathrm{~g} / \mathrm{cm}^{3}\right)$.
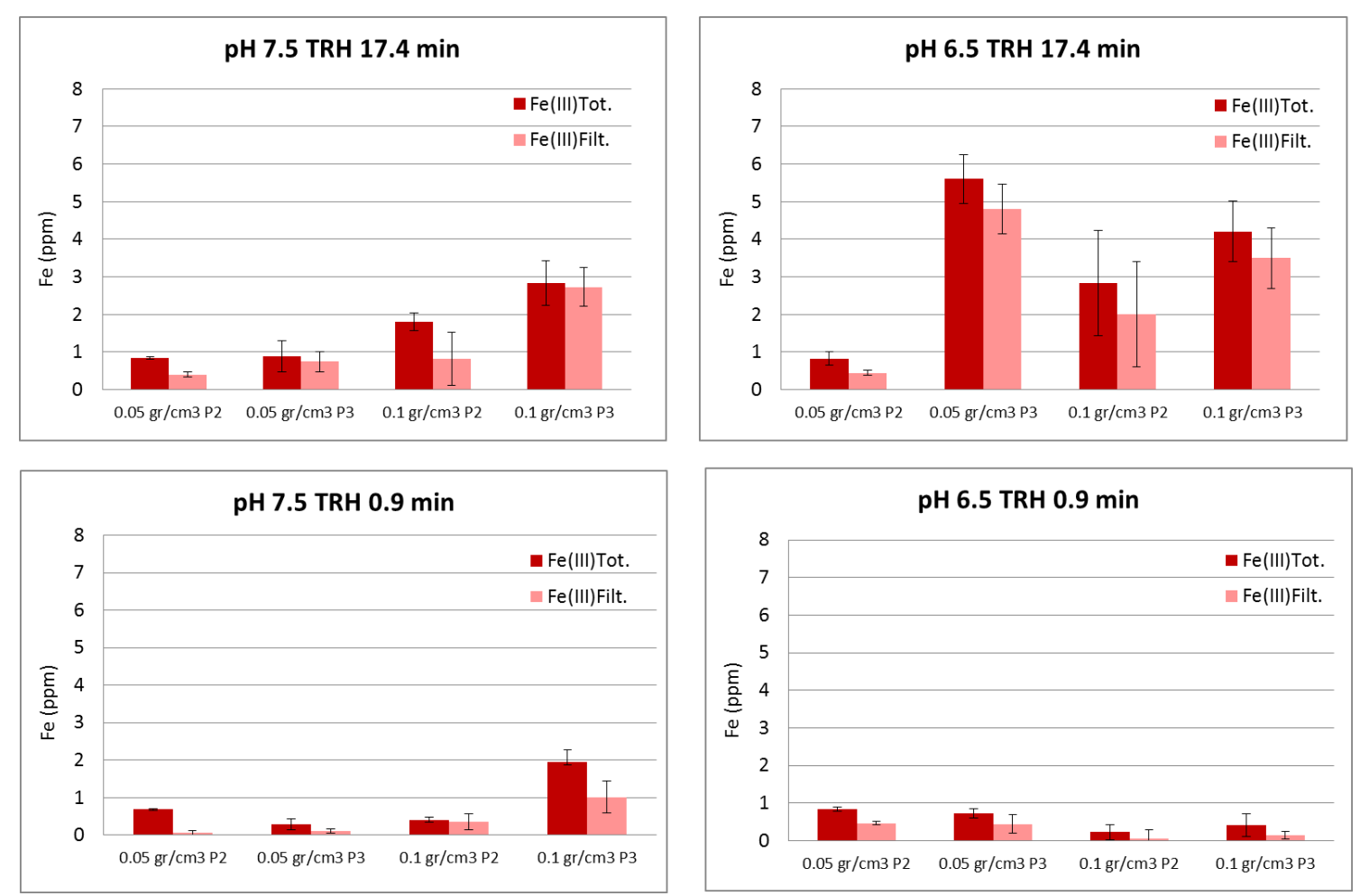

Figura 3.8. Contenido de Fe(III) (mg/l) a la salida de cada columna (P2 y P3), para distintos $\operatorname{TRH}(0,9$ y $17.4 \mathrm{~min})$ y densidad de lecho $\left(0,05\right.$ y $\left.0,1 \mathrm{~g} / \mathrm{cm}^{3}\right)$. 
El análisis de los valores obtenidos indica que la oxidación de $\mathrm{Fe}(0)$ produce tanto $\mathrm{Fe}(\mathrm{II})$ como $\mathrm{Fe}(\mathrm{III})$, siendo las concentraciones de $\mathrm{Fe}(\mathrm{II})$ mayores que las de $\mathrm{Fe}(\mathrm{III})$, especialmente a $\mathrm{pH}$ 6.5. Para los ensayos realizados con altos tiempos de residencia (caudal $15 \mathrm{~mL} / \mathrm{min}$ ) en los que el oxígeno es consumido en su totalidad por la primera columna (oxígeno a la salida $<1 \mathrm{ppm}$ ), la comparación entre los contenidos de hierro obtenidos en la entrada y la salida de la segunda columna (P2 y P3) no muestra diferencias significativas. Esto sugiere que, una vez agotado el oxígeno disuelto, la oxidación de $\mathrm{Fe}(0)$ por efecto del solvente es despreciable para valores de $\mathrm{pH}$ cercanos a la neutralidad. En contraste, para bajos tiempos de residencia (caudal $300 \mathrm{~mL} / \mathrm{min}$ ) en general se observa un aumento de la concentración de $\mathrm{Fe}$ (II) entre los puntos de muestreo 2 y 3 debido a un consumo incompleto del oxígeno disuelto en la primera columna (oxígeno a la salida 0,2 y $1.74 \mathrm{ppm}$ para las masas de 30 y $15 \mathrm{~g}$ respectivamente).

Por otra parte, los resultados muestran la disminución del $\mathrm{pH}$ incrementa las concentraciones de $\mathrm{Fe}(\mathrm{II})$. Este comportamiento sugiere un incremento de la fracción de oxígeno involucrada en la oxidación de $\mathrm{Fe}(0)$ a $\mathrm{Fe}(\mathrm{II})$ y una disminución de la fracción de oxígeno involucrada en la oxidación de Fe(II) a Fe(III).

\subsubsection{Corrosión en atmósfera de nitrógeno}

Con el objeto de estudiar el efecto del pH en procesos de corrosión en sistemas continuos en ausencia de oxígeno se realizaron ensayos con agua libre de oxígeno disuelto. Para esto, previo a la realización de los ensayos, se burbujeó de manera continua nitrógeno durante 30 minutos. Los ensayos se realizaron utilizando una columna de vidrio de $2.15 \mathrm{~cm}$ de diámetro y $8.3 \mathrm{~cm}$ de largo. La misma fue rellena con $3 \mathrm{~g}$ de lana de acero. La solución fue bombeada a través del lecho utilizando una bomba peristáltica conectada al recipiente contenedor de agua con burbujeo continuo de nitrógeno. La cantidad de oxígeno remanente en la solución fue del orden de 0,6 ppm. Se trabajó con soluciones de $\mathrm{pH}$ entre 4 y 7 , para tres tiempos de residencia (caudales) diferentes. Luego de estabilizar los sistemas (7 TRHs) para cada condición operativa se tomaron muestras para la determinación de $\mathrm{Fe}(\mathrm{II})$ y $\mathrm{Fe}(\mathrm{III})$ por triplicado. Los resultados obtenidos se muestran en la Figura 3.9. Puede observarse que la generación de $\mathrm{Fe}(\mathrm{II})$ es apreciable solamente para soluciones con un $\mathrm{pH}$ inicial de 4, es relativamente baja para $\mathrm{pH} 5$ y 6 y nula para los ensayos realizados a $\mathrm{pH}$. Tal como se esperaba, en ausencia de oxígeno disuelto la generación de $\mathrm{Fe}$ (III) fue casi nula para todos los valores de $\mathrm{pH}$. Parte del $\mathrm{Fe}(\mathrm{III})$ detectado posiblemente ya se encuentre presente en la superficie del material de relleno, que es utilizado tal cuál se recibe, y es arrastrado hacia el exterior de la columna durante los ensayos. Por último, en la Figura 3.10 se comparan los resultados obtenidos a pH 4 en ensayos realizados utilizando condiciones equivalentes pero en presencia de oxígeno. Estos muestran que la generación de $\mathrm{Fe}(\mathrm{II})$ a $\mathrm{pH} 4$ a través del mecanismo presentado por la ec. 1.1 (sin oxígeno) es mucho menor que la generada al acoplar los dos procesos (ec. 1.1 y 1.2). También se observa que en el primer caso el proceso resulta mucho menos sensible a la variación del tiempo de residencia hidráulico. 

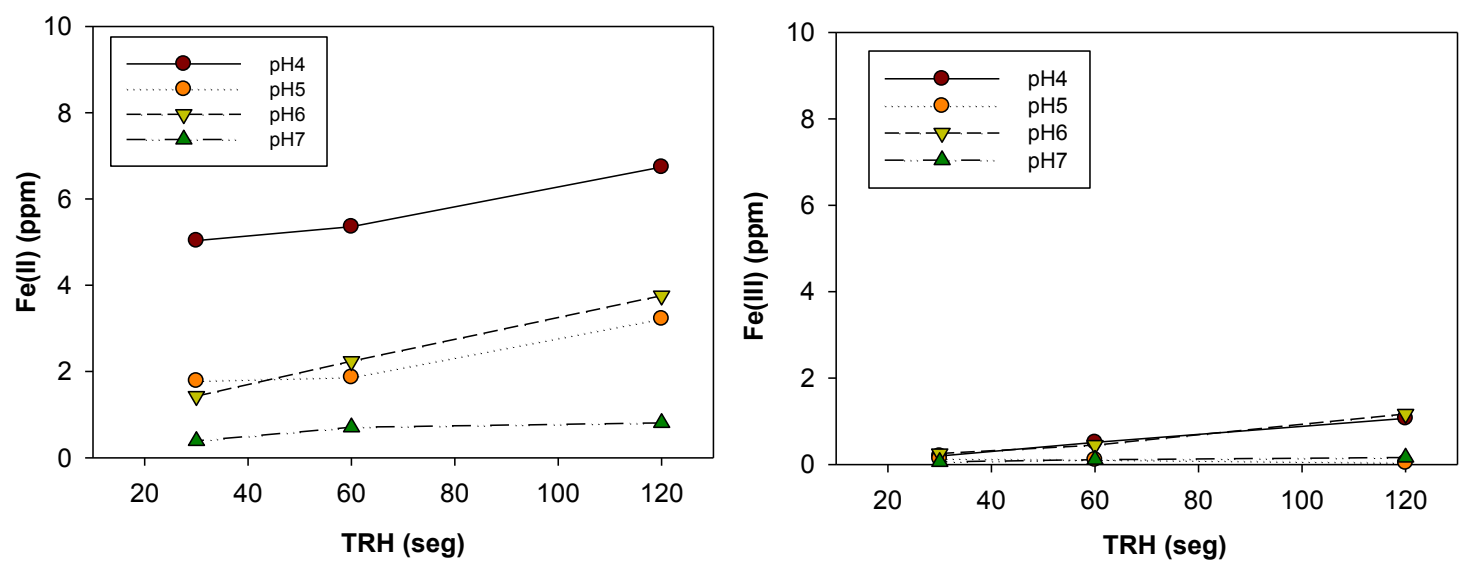

Figura 3.9. Generación de Fe(II) (izq.) y Fe(III) (der.) a la salida del sistema en una columna alimentada con agua purgada de oxígeno ( $\mathrm{pH}: 4$ a 7$)$.

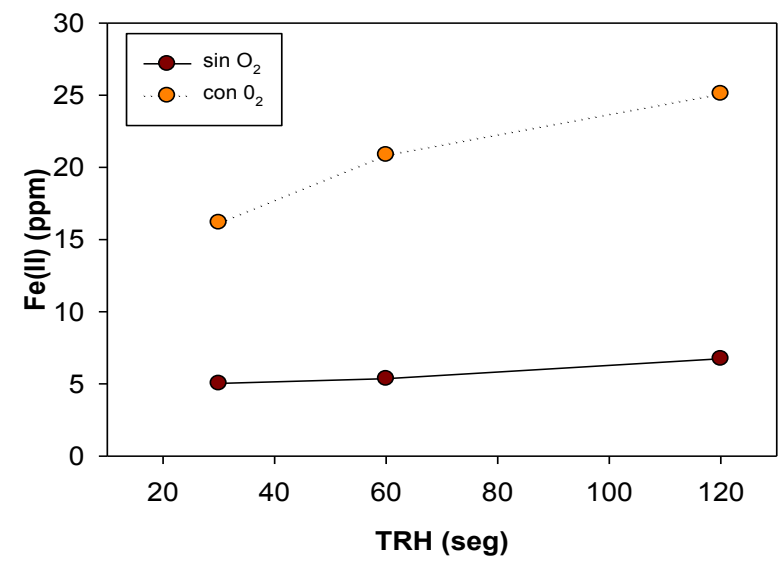

Figura 3.10. Comparación del Fe(II) generado en presencia y ausencia de oxígeno $(\mathrm{pH}=4)$.

\subsection{EFECTO BUFFER DE LOS CARBONATOS}

Los valores experimentales de $\mathrm{pH}$ registrados a la salida del sistema muestran que el aumento de $\mathrm{pH}$ es menor al estimado considerando la cantidad de $\mathrm{OH}$ generada de acuerdo con las estequiometrias de las reacciones asociadas a la corrosión del ZVI. Esto se debe, en parte, a la presencia de carbonatos y otras especies que contribuyen al efecto buffer de las aguas naturales utilizadas durante los ensayos [116].

Con el fin de establecer un modelo sencillo para explicar el comportamiento de los valores de $\mathrm{pH}$ en el efluente de las columnas, podemos asumir en principio un sistema cerrado donde no hay intercambio con la fase gaseosa. En estas condiciones, las reacciones ácido base más importantes sugieren la consideración de las siguientes especies en equilibrio: $\mathrm{CO}_{2}(\mathrm{aq}), \mathrm{H}_{2} \mathrm{CO}_{3}, \mathrm{HCO}_{3}{ }^{-}, \mathrm{CO}_{3}{ }^{-}, \mathrm{H}^{+}$y $\mathrm{OH}^{-}$. Estas especies están relacionadas mediante las siguientes ecuaciones:

$\mathrm{H}_{2} \mathrm{CO}_{3} \leftrightarrow \mathrm{HCO}_{3}^{-}+\mathrm{H}^{+} \quad \mathrm{K} 1=\frac{\left[\mathrm{H}^{+}\right]\left[\mathrm{HCO}_{3}{ }^{-}\right]}{\left[\mathrm{H}_{2} \mathrm{CO}_{3}\right]}$ 


$$
\begin{array}{lr}
\mathrm{HCO}_{3}{ }^{-} \leftrightarrow \mathrm{CO}_{3}{ }^{=}+\mathrm{H}^{+} & K 2=\frac{\left[\mathrm{H}^{+}\right]\left[\mathrm{CO}_{3}{ }^{-}\right]}{\left[\mathrm{HCO}_{3}{ }^{-}\right]} \\
\mathrm{H}_{2} \mathrm{O} \leftrightarrow \mathrm{OH}^{-}+\mathrm{H}^{+} & \mathrm{Kw}=\left[\mathrm{OH}^{-}\right]\left[\mathrm{H}^{+}\right]
\end{array}
$$

La concentración total y las concentraciones individuales vienen dadas por:

$$
\begin{aligned}
& \mathrm{C}_{\mathrm{T}}=\left[\mathrm{H}_{2} \mathrm{CO}_{3}\right]+\left[\mathrm{HCO}_{3}{ }^{-}\right]+\left[\mathrm{CO}_{3}{ }^{-}\right] \\
& {\left[\mathrm{H}_{2} \mathrm{CO}_{3}\right]=C_{T} * \alpha_{0} \quad \alpha_{0}=\left(1+\frac{K_{1}}{\left[\mathrm{H}^{+}\right]}+\frac{K_{1} K_{2}}{\left[\mathrm{H}^{+}\right]^{2}}\right)^{-1}} \\
& {\left[\mathrm{HCO}_{3}{ }^{-}\right]=C_{T} * \alpha_{1} \quad \alpha_{1}=\left(\frac{\left[\mathrm{H}^{+}\right]}{K_{1}}+1+\frac{K_{2}}{\left[\mathrm{H}^{+}\right]}\right)^{-1}} \\
& {\left[\mathrm{CO}_{3}{ }^{-}\right]=C_{T} * \alpha_{2} \quad \alpha_{2}=\left(\frac{\left[\mathrm{H}^{+}\right]^{2}}{K_{1} K_{2}}+\frac{\left[\mathrm{H}^{+}\right]}{K_{2}}+1\right)^{-1}}
\end{aligned}
$$

Por otro lado, teniendo en cuenta la definición de alcalinidad, o capacidad de una solución para neutralizar ácidos, la condición de electro neutralidad exige que:

$$
[\mathrm{Alk}]=\left[\mathrm{HCO}_{3}^{-}\right]+2\left[\mathrm{CO}_{3}{ }^{=}\right]+\left[\mathrm{OH}^{-}\right]-\left[\mathrm{H}^{+}\right]
$$

En este caso, dado el rango de trabajo de $\mathrm{pH}$ es posible considerar solo la primera disociación (ec. 3.1). La titulación con ácido o base de la solución de trabajo hasta un punto equivalente de $\mathrm{pH}$ apropiado puede utilizarse como un buen método para la determinación de los valores de $C_{T}$. Así, para el caso de la titulación con un ácido fuerte, y considerando solo la primera disociación, tenemos:

$$
[\mathrm{Alk}]=\left[\mathrm{HCO}_{3}^{-}\right]+\left[\mathrm{OH}^{-}\right]-\left[\mathrm{H}^{+}\right]+\mathrm{C}_{\mathrm{A}}
$$

donde $C_{A}$ es la concentración analítica del ácido. Teniendo en cuenta además que:

$$
C_{T}=[\mathrm{Alk}]=\left[\mathrm{HCO}_{3}{ }^{-}\right]+\left[\mathrm{H}_{2} \mathrm{CO}_{3}\right]
$$

obtenemos la expresión:

$$
C_{T} \alpha_{0}=\frac{K w}{\left[H^{+}\right]}-\left[H^{+}\right]+C_{A}
$$

A partir del ajuste de la ecuación 3.11 a los datos de $\mathrm{pH}$ obtenidos para diferentes $C_{A}$ (Figura 3.9) y teniendo en cuenta el valor de $\mathrm{K}_{1}$ de $4.9 \times 10^{-7}$ reportado en la bibliografía, se determinó el valor de $C_{T}$ para el agua de red utilizada, obteniéndose un valor de $1.310^{-3} \mathrm{M}$. Los mismos valores de $\mathrm{K}_{1}$ y $C_{T}$ fueron obtenidos aplicando el método de Gran a la curva de titulación de la solución de trabajo con $\mathrm{HCl}$ (datos no mostrados). Dado que el objetivo en este caso es poder obtener un modelo sencillo que permita tener en cuenta las reacciones ácido-base que controlan la variación de $\mathrm{pH}$, no se profundizará en el uso de estos parámetros y los valores obtenidos resultan suficientes para poder acoplar estas reacciones a las involucradas en el proceso. 


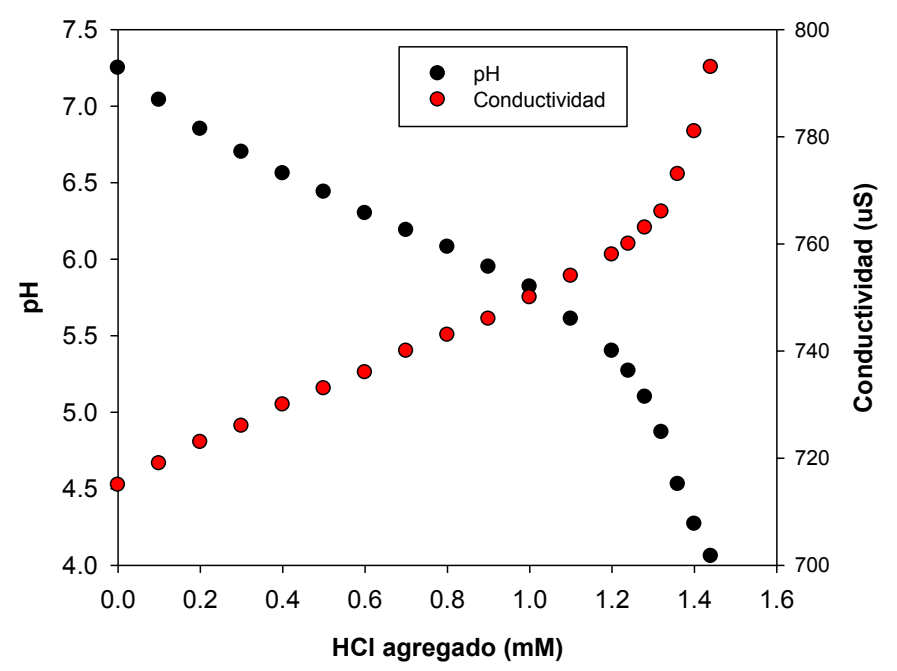

Figura 3.9. Curva de titulación acidimétrica de la solución de trabajo con $\mathrm{HCl}(1 \mathrm{M})$.

\subsection{ENSAYOS DE CO-PRECIPITACIÓN}

Con el objetivo de verificar la eficiencia del proceso de co-precipitación en la remoción de arsénico se realizaron diferentes ensayos en batch. Se prepararon varias soluciones con un volumen total de $500 \mathrm{~mL}$ a pH 5 con un contenido de $\mathrm{As}(\mathrm{V})$ de $0,350 \mathrm{ppm}$ a las cuales se les agregó una cantidad variable de solución madre de $\mathrm{Fe}$ (II) de $50 \mathrm{ppm}$ para obtener concentraciones finales entre 0,5 y $15 \mathrm{ppm}$ de $\mathrm{Fe}$ (II). Posteriormente, la oxidación de $\mathrm{Fe}(\mathrm{II})$ a $\mathrm{Fe}(\mathrm{III})$ por parte del oxígeno disuelto fue acelerada mediante el agregado de $\mathrm{Na}(\mathrm{OH})$ hasta obtener un $\mathrm{pH}$ 8. El proceso de precipitación del hierro es completado mediante el burbujeo de aire durante 30 minutos a cada uno de las soluciones. Luego de este período, se verificó la ausencia de Fe(II) en solución mediante su determinación colorimétrica.

Una vez finalizados estos ensayos las muestras fueron filtradas (nylon de 0,45 $\mu \mathrm{m})$ y se determinó el contenido de $\mathrm{As}(\mathrm{V})$ en el filtrado. Los resultados obtenidos se muestran en la Figura 3.10. Se puede observar que para concentraciones iniciales de $\mathrm{Fe}(\mathrm{II})$ superiores a $4 \mathrm{ppm}$ el porcentaje de remoción de As(V) es superior al $85 \%$.

Este resultado es muy importante para el monitoreo de sistemas continuos diseñados para eliminar As mediante el empleo de técnica ZVI. En consecuencia, la realización de controles periódicos del contenido de $\mathrm{Fe}$ (II) a la salida de las columnas reactivas permite evaluar en forma directa la eficiencia del sistema para la remoción del As mediante procesos de co-precipitación. 


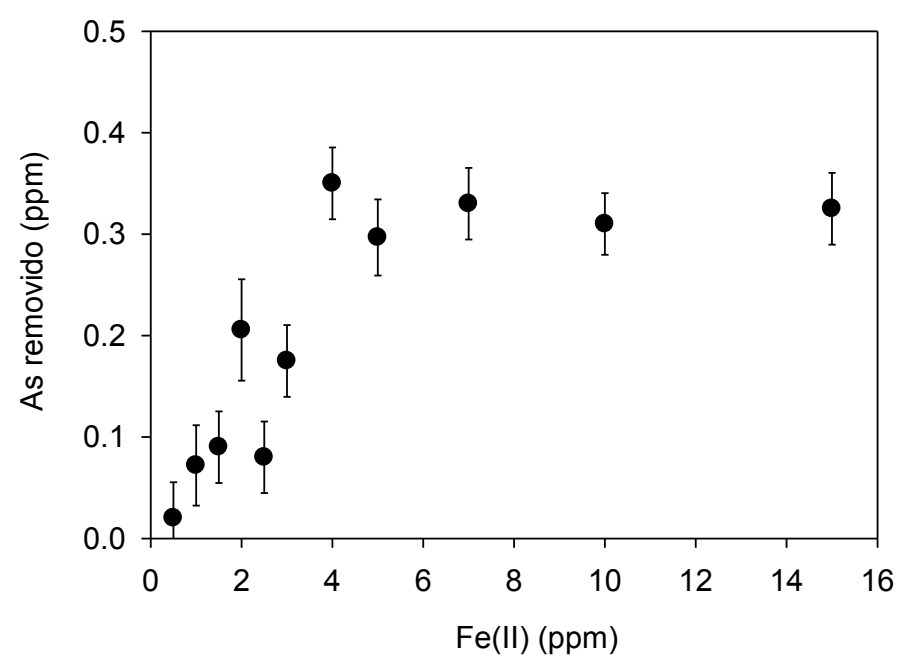

Figura 3.10. Ensayo de remoción de As por co-precipitación $\left(C_{i}\right.$ 0,35 ppm As $\left.(V)\right)$.

\subsection{VELOCIDAD DE OXIDACIÓN DE Fe(II)}

A fin de estimar el tiempo de residencia hidráulico necesario para la oxidación de $\mathrm{Fe}(\mathrm{II})$ a $\mathrm{Fe}(\mathrm{III})$, en la segunda etapa del proceso de tratamiento, se realizaron ensayos de oxidación de $\mathrm{Fe}(\mathrm{II})$ en condiciones de concentración de oxígeno controlada $(8.5 \mathrm{ppm})$. Para esto se prepararon soluciones de patrón de $\mathrm{Fe}(\mathrm{II})$ de 10 ppm a pH 7 y se comenzaron los ensayos burbujeando las soluciones con aire. Se tomaron muestras en el intervalo de 0 a 60 minutos de reacción y se determinaron los contenidos de $\mathrm{Fe}(\mathrm{II})$. Los resultados presentados en la Figura 3.11 permiten estimar un TRH mínimo de 30 minutos para la segunda etapa del proceso. Utilizando los primeros 5 puntos experimentales se calculó la velocidad inicial de oxidación de $\mathrm{Fe}(\mathrm{II})$ obteniéndose un valor promedio de $8.42 \times 10^{-6} \mathrm{M} \mathrm{seg}^{-1}$.

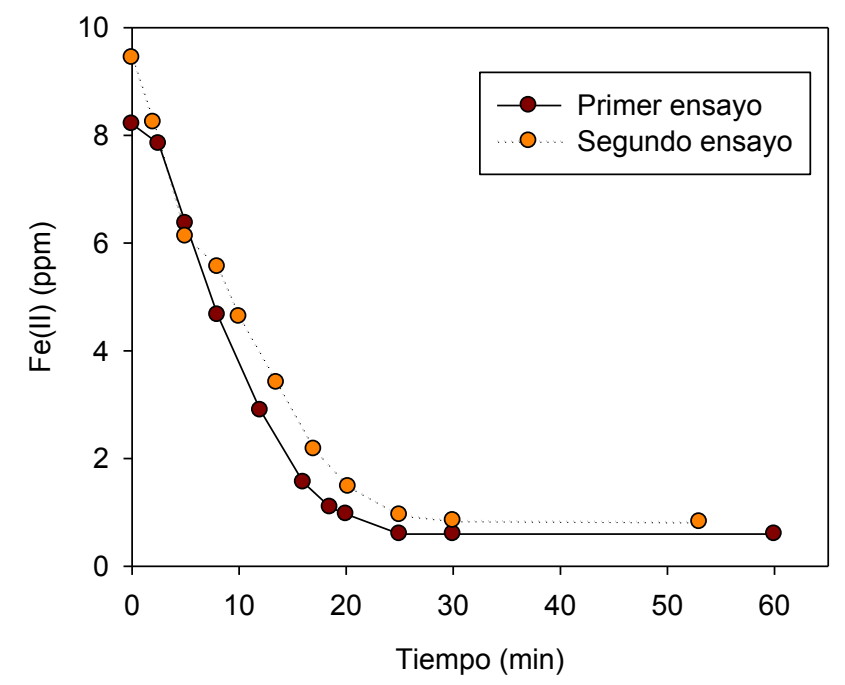

Figura 3.11. Velocidad de oxidación de Fe(II) $\left(\mathrm{C}_{\mathrm{i}} 10 \mathrm{ppm} \mathrm{Fe}(\mathrm{II})\right)$. 


\subsection{CONCLUSIONES}

Los primeros ensayos, para la remoción de arsénico, realizados utilizando una matriz de agua real sugieren que para valores de $\mathrm{pH}$ superiores a 8.5 , típicos de algunas fuentes de agua subterránea, la remoción de este contaminante es prácticamente nula. Sin embrago, la corrección del pH hasta valores del orden de 6.5 permite aumentar significativamente las velocidades de corrosión y con esto obtener tasas de remoción superiores al $95 \%$. Esto se traduce en un aumento en el consumo de oxígeno y en una mayor generación de especies de Fe(II) en solución al disminuir el $\mathrm{pH}$.

Con respecto a las tasas de consumo de oxígeno y de generación de Fe(II), para tiempos inferiores de residencia por debajo de los $10 \mathrm{~min}$, se observa que ambas se incrementan al aumentar la densidad del relleno o el TRH. Por otro lado, se observa que la generación de especies ferrosas es prácticamente nula en ausencia de oxígeno.

Los ensayos de coprecipitación muestran que se requiere un cantidad mínima de 4 ppm de $\mathrm{Fe}(\mathrm{II})$ para obtener porcentajes de remoción de arsénico superiores al $85 \%$. Por otra parte, el análisis de las cinéticas de oxidación de Fe(II) muestra que para lograr una oxidación completa de $\mathrm{Fe}(\mathrm{II})$ a $\mathrm{Fe}(\mathrm{III})$ y optimizar la segunda etapa del tratamiento resulta necesario un tiempo de residencia de al menos 30 minutos. 
CAPITULO 4:

ENSAYOS EN COLUMNAS DE PEQUEÑA ESCALA 


\section{ENSAYOS EN COLUMNAS DE PEQUEÑA ESCALA}

\subsection{ESTUDIO DE LAS VARIABLES OPERATIVAS: ENSAYOS RÁPIDOS EN COLUMNAS REACTIVAS DE PEQUEÑA ESCALA (RSSCT)}

Con el objeto de optimizar la eficiencia de remoción de diferentes contaminantes en los sistemas de tratamiento y teniendo en cuenta que el desempeño de los mismos depende fuertemente del comportamiento de los lechos reactivos, se han realizado ensayos empleando columnas reactivas de pequeña escala (RSSCT). En el esquema 4.1 se presentan los módulos involucrados en el sistema de tratamiento así como los procesos fisicoquímicos más importantes asociados a cada etapa.

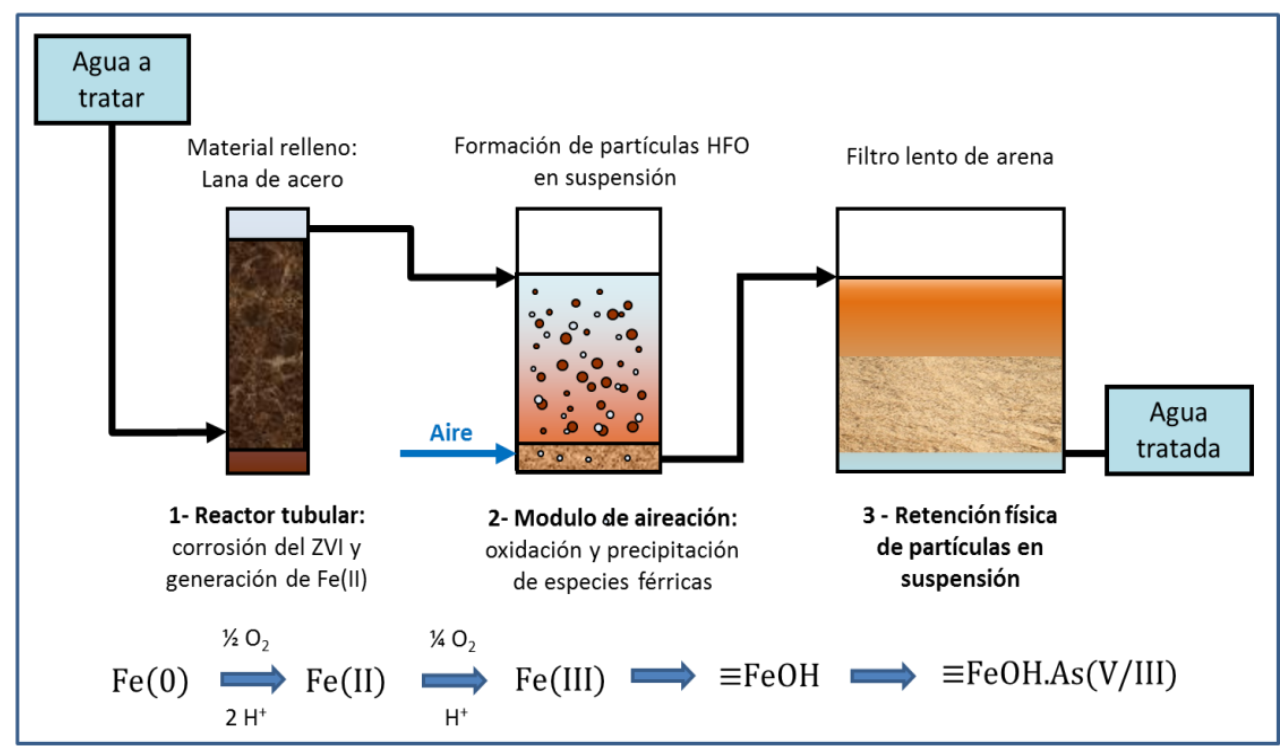

Figura 4.1. Esquema del proceso de tratamiento continuo de agua basado en la técnica de hierro cero Valente $(\mathrm{ZVI})$.

Estudios preliminares han demostrado que la concentración de Fe(II) a la salida de la columna es un parámetro clave para la optimización de los procesos de remoción. Debido a que este parámetro es altamente dependiente de las condiciones operativas, es necesario para evaluar correctamente la aplicabilidad de la técnica el análisis detallado de su comportamiento en diferentes situaciones.

Para estudiar en detalle el efecto de las variables independientes (tiempo de residencia hidráulico ( $T R H)$, carga de $Z \mathrm{VI}, \mathrm{pH}$ de entrada y densidad del lecho) sobre las variables de respuesta (producción de $\mathrm{Fe}(\mathrm{II})$ y $\mathrm{Fe}(\mathrm{III})$, $\mathrm{pH}$ de salida y consumo de oxígeno) se plantearon tres diseños experimentales para la realización de ensayos de corta duración utilizando columnas reactivas de pequeña escala (RSSCT). Los diseños fueron realizados en el rango de TRHs para el que se observaron variaciones significativas de las variables respuesta durante los ensayos preliminares. 
Tal como se describe en detalle en el Cap II, en la preparación de las soluciones de trabajo se utilizó agua de red, cuyo $\mathrm{pH}$ inicial fue ajustado a distintos valores utilizando $\mathrm{HCl} 0,1 \mathrm{M}$. Las columnas se alimentaron mediante una bomba peristáltica que permite regular el caudal del fluido. En todos los ensayos, a la salida de la columna se realizaron determinaciones de $\mathrm{Fe}(\mathrm{III}), \mathrm{Fe}(\mathrm{II}), \mathrm{pH}$ y oxígeno disuelto. Las determinaciones fueron realizadas luego de la estabilización del sistema (7 volúmenes de poro). Para la determinación de diferentes especies de hierro y de $\mathrm{pH}$ a la salida se tomaron muestras por triplicado. Las concentraciones de $\mathrm{Fe}$ (III) y $\mathrm{Fe}$ (II) se cuantificaron colorimétricamente, a través de los complejos formados con KSCN y ofenantrolina respectivamente. Las determinaciones de oxígeno disuelto a la salida se realizaron acoplando una celda de flujo a la salida de la columna con un sensor óptico para oxígeno disuelto.

\subsubsection{Primera serie: TRH, pH y carga de ZVI.}

La primera serie de ensayos fue realizada para evaluar el efecto del $\mathrm{TRH}$, el $\mathrm{pH}$ y la carga de ZVI sobre las variables respuesta. Las corridas fueron diseñadas con tiempos de residencia entre 5 y 120 segundos. Se utilizaron columnas rellenas con cantidades variables de lana de acero (entre 0,5 y $2 \mathrm{~g}$ ) manteniendo constantes la densidad del lecho $\left(0,1 \mathrm{~g} / \mathrm{cm}^{3}\right)$ y el diámetro de la columna $(1 \mathrm{~cm})$.

Se planteó un diseño factorial de experimentos con tres factores y diferente número de niveles por factor. En la Tabla 4.1 se muestran los niveles empleados para cada factor. Como resultado se obtuvieron 72 condiciones experimentales para ensayar. En el Anexo 1 se detallan los resultados obtenidos para todas las condiciones operativas ensayadas en esta serie.

Tabla 4.1. Condiciones experimentales correspondientes a la primera serie de ensayos.

\begin{tabular}{|c|c|c|c|c|c|c|}
\hline Factor Nivel & 1 & 2 & 3 & 4 & 5 & 6 \\
\hline m ZVI & $0,5 \mathrm{~g}$ & $1 \mathrm{~g}$ & $2 \mathrm{~g}$ & & & \\
\hline pH & 4 & 5 & 6 & 7 & & \\
\hline HRT & $120 \mathrm{seg}$ & $60 \mathrm{seg}$ & $30 \mathrm{seg}$ & $20 \mathrm{seg}$ & $10 \mathrm{seg}$ & $5 \mathrm{seg}$ \\
\hline
\end{tabular}

En las Figuras 4.2 a 4.8 se presentan resultados representativos de las principales tendencias observadas de esta serie de ensayos. En particular, las Figuras 4.2 a 4.4 muestran los efectos del $\mathrm{TRH}$, el pH de entrada y la carga de ZVI en la generación de especies de $\mathrm{Fe}(\mathrm{II})$ y $\mathrm{Fe}(\mathrm{III})$, mientras que las Figuras 4.5 a 4.8 presentan los efectos de las mismas variables operativas sobre la tasa de consumo de oxígeno disuelto y el valor de $\mathrm{pH}$ registrado a la salida de la columna. 

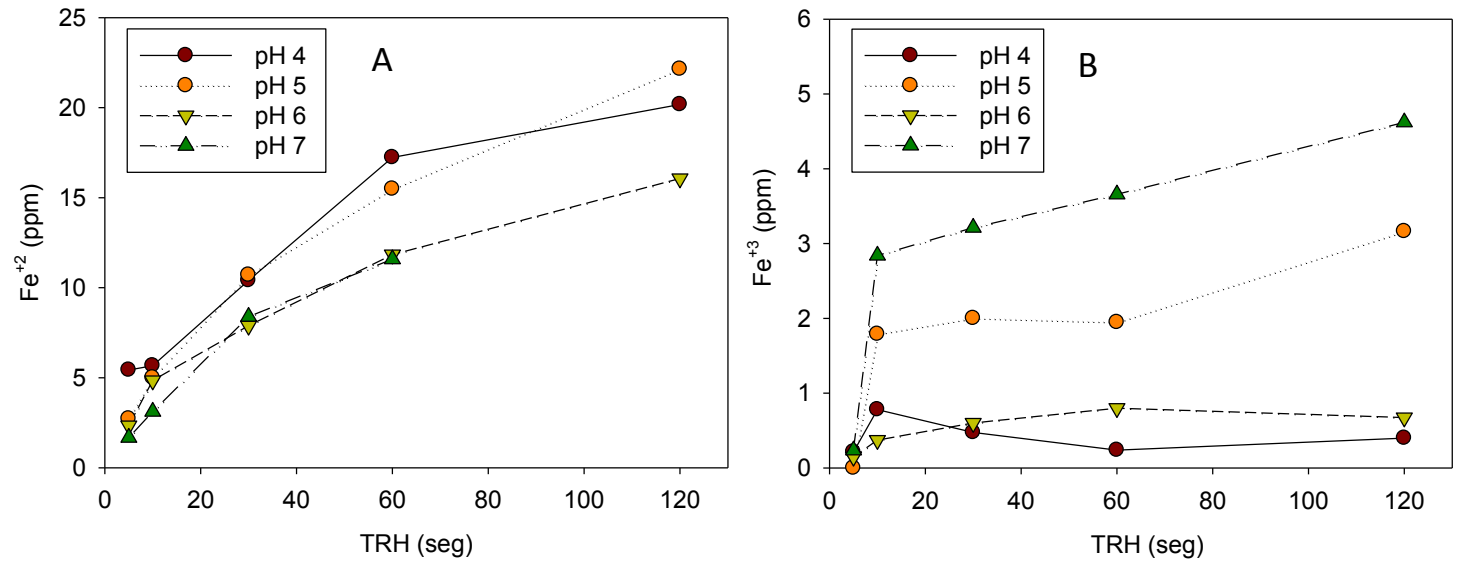

Figura 4.2. Efecto del TRH en la generación de especies de: $A) \mathrm{Fe}^{2+}$ y $\left.\mathrm{B}\right) \mathrm{Fe}^{3+}\left(\mathrm{m}_{\mathrm{zvl}}=1 \mathrm{~g}\right)$.
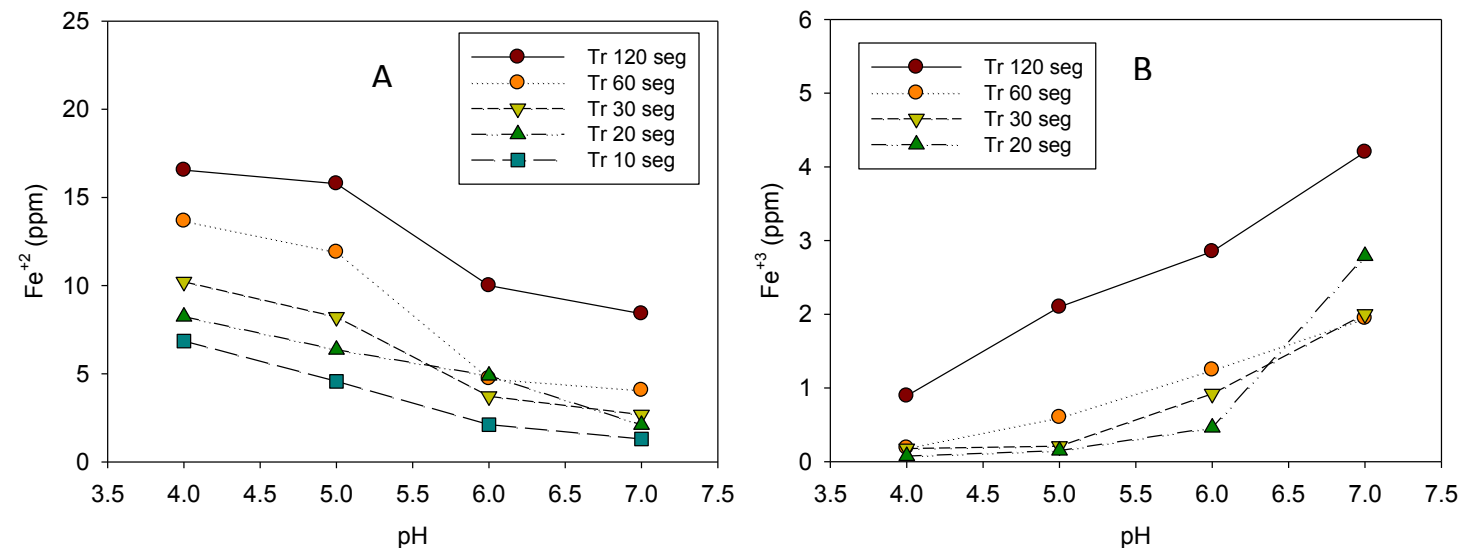

Figura 4.3. Efecto del $\mathrm{pH}$ de entrada en la generación de especies de: A) $\mathrm{Fe}^{2+}$ y B) $\mathrm{Fe}^{3+}$ $\left(\mathrm{m}_{\mathrm{zvl}}=0.5 \mathrm{~g}\right)$.
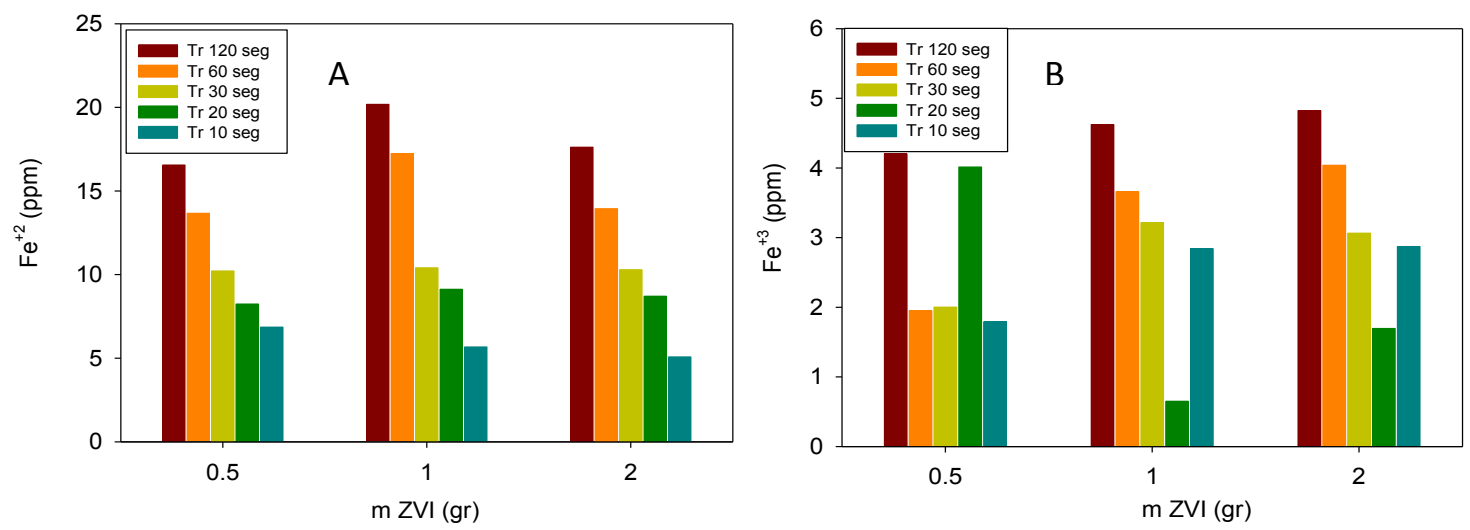

Figura 4.4. Efecto de la masa de ZVI en la generación de especies de: $\mathrm{A}) \mathrm{Fe}^{2+}(\mathrm{pH} 4)$ y B) $\mathrm{Fe}^{3+}$ $(\mathrm{pH} 7)$. 

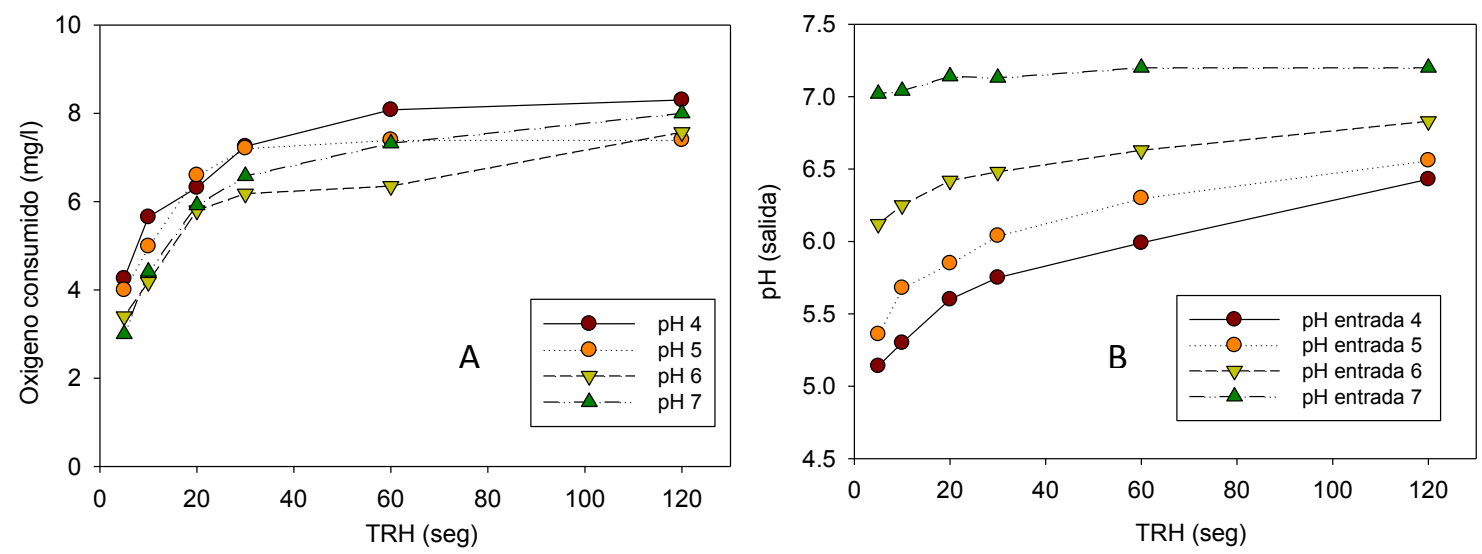

Figura 4.5. Efecto del TRH en: A) el consumo de oxígeno y $\mathrm{B}) \mathrm{pH}$ de salida ( $\left.\mathrm{m}_{\mathrm{zvl}}=1 \mathrm{~g}\right)$.

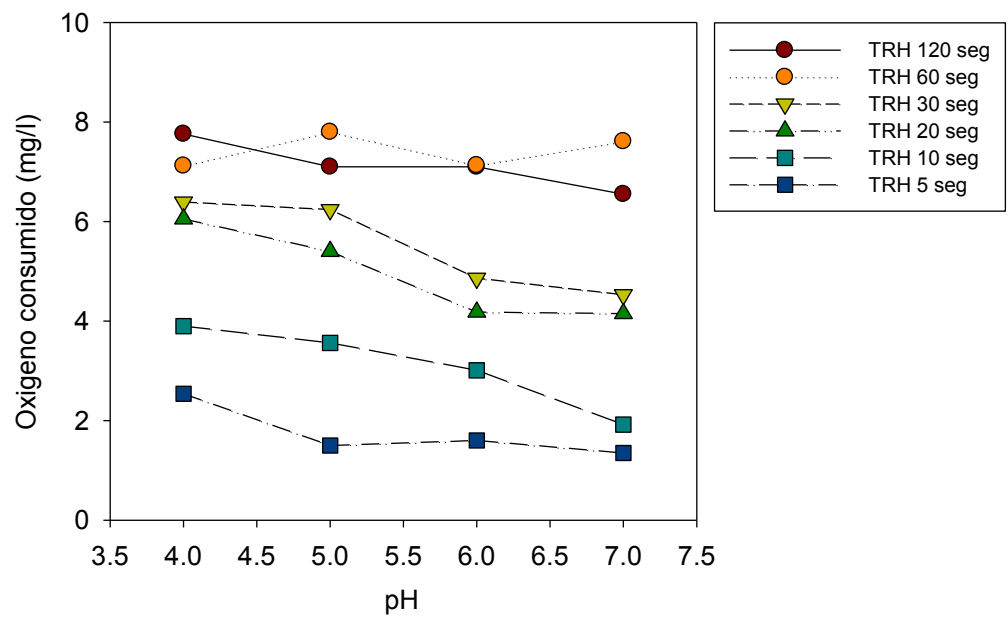

Figura 4.6. Efecto del $\mathrm{pH}$ de entrada en el consumo de oxígeno $\left(\mathrm{m}_{\mathrm{zvl}}=0,5 \mathrm{~g}\right)$.

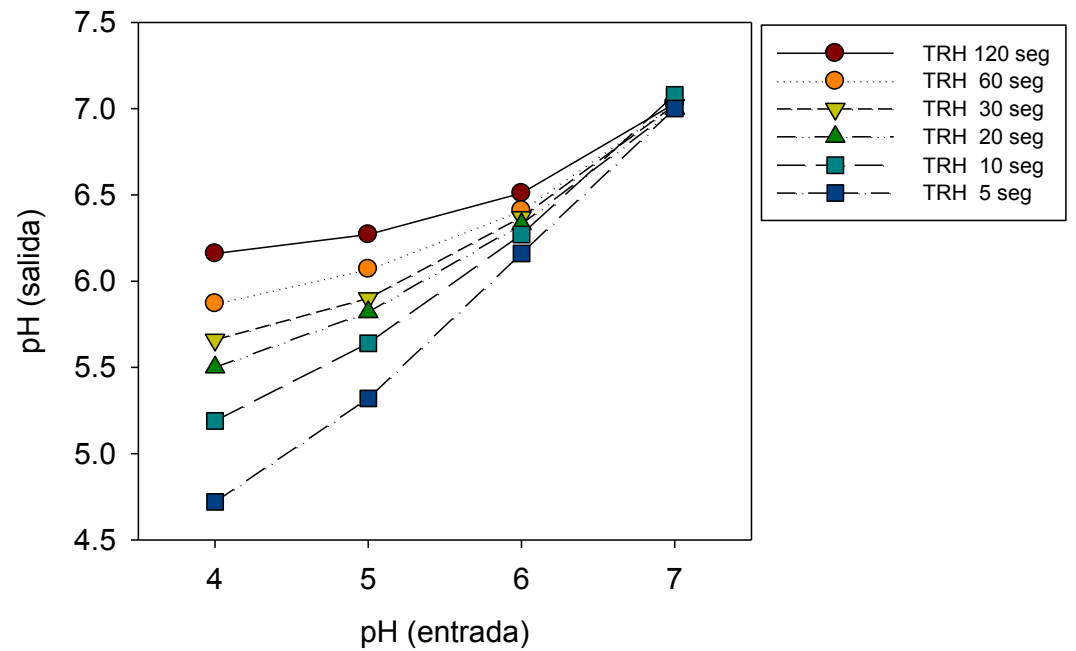

Figura 4.7. Efecto del $\mathrm{pH}$ de entrada en el $\mathrm{pH}$ de salida $\left(\mathrm{m}_{\mathrm{zvl}}=0,5 \mathrm{~g}\right)$. 

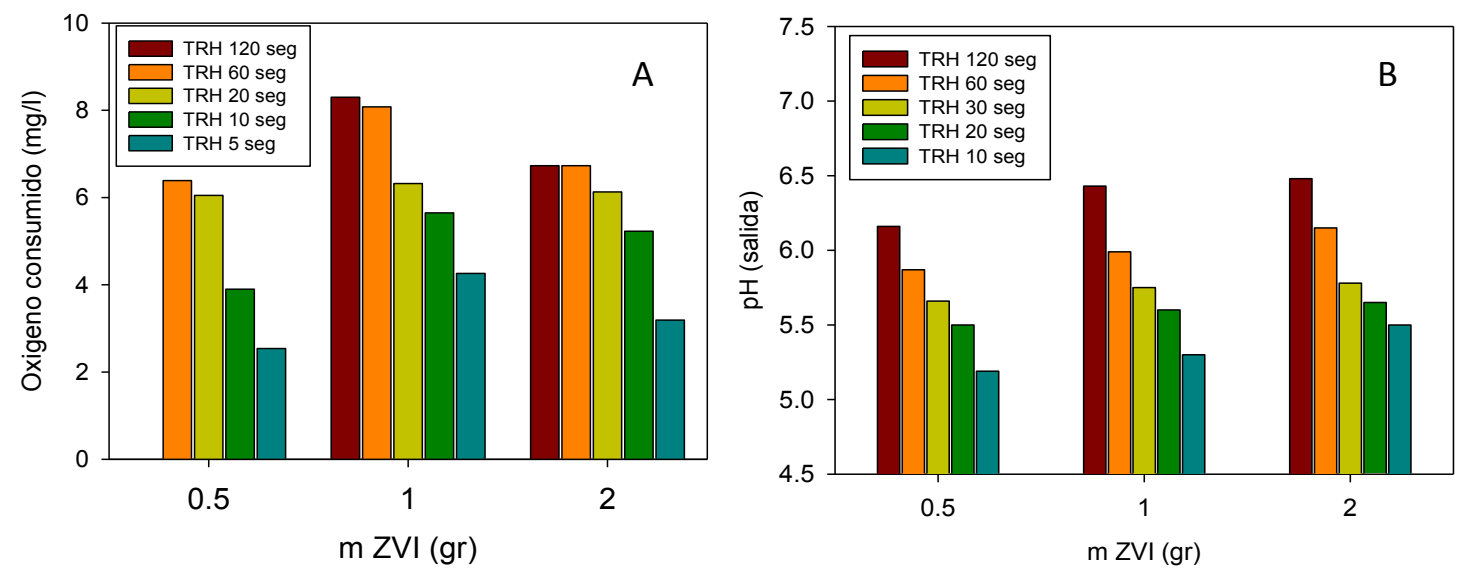

Figura 4.8. Efecto de la carga de ZVI en: A) el consumo de oxígeno y B) $\mathrm{pH}$ de salida ( $\mathrm{pH}$ 4).

Los resultados muestran que los niveles de Fe(II) claramente aumentan con el $\mathrm{TRH}$ en el rango de trabajo seleccionado y disminuyen al aumentar el $\mathrm{pH}$. Por otra parte, la generación de especies de Fe(III) también se ve favorecida por el aumento de la TRH en el intervalo de operación, aunque esto se puede observar solamente para valores de $\mathrm{pH}$ altos ya que sólo en estas condiciones la cantidad de $\mathrm{Fe}(\mathrm{III})$ generada es significativa.

Por otro lado, de acuerdo con lo esperado, el consumo de oxígeno disuelto aumenta en forma notable con el TRH. Por otro lado, para bajos TRH ( $\leq 30 \mathrm{seg}$ ) disminuye levemente al aumentar el $\mathrm{pH}$ del afluente. Sin embargo, para altos TRH ( $\geq 60 \mathrm{seg}$ ) el oxígeno consumido prácticamente no varía con el $\mathrm{pH}$. Finalmente, los valores de $\mathrm{pH}$ registrados en la salida de la columna aumentan con $\mathrm{TRH}$ y el $\mathrm{pH}$ de entrada, pero la diferencia entre los valores de $\mathrm{pH}$ de entrada y salida disminuye con el aumento del $\mathrm{pH}$ de entrada, de acuerdo con las tendencias informadas previamente [28]. Con respecto a efecto de la carga de ZVI, para los tres niveles adoptados en esta primera serie de ensayos no se pudo observar un efecto claro de este factor sobre las variables de respuesta.

\subsubsection{Segunda serie de ensayos: carga de ZVI}

Con el objetivo de estudiar con mayor detalle el efecto de la carga de ZVI sobre las variables antes analizadas, se realizó una nueva serie de ensayos a $\mathrm{pH} 4$ con mayor número de niveles para la carga de ZVI. Como resultado de este diseño se obtuvieron 25 condiciones experimentales adicionales (Anexo 2). En la Tabla 4.2 se muestran las condiciones experimentales empleadas, mientras que en las Figuras 4.9 y 4.10 se presentan los resultados registrados.

Tabla 4.2. Condiciones correspondientes a la segunda serie de ensayos $(\mathrm{pH} 4)$.

\begin{tabular}{|c|c|c|c|c|c|}
\hline Factor Nivel & 1 & 2 & 3 & 4 & 5 \\
\hline m ZVI & $0,2 \mathrm{~g}$ & $0,5 \mathrm{~g}$ & $0,8 \mathrm{~g}$ & $1,2 \mathrm{~g}$ & $1,6 \mathrm{~g}$ \\
\hline HRT & $60 \mathrm{seg}$ & $30 \mathrm{seg}$ & $15 \mathrm{seg}$ & $10 \mathrm{seg}$ & $5 \mathrm{seg}$ \\
\hline
\end{tabular}



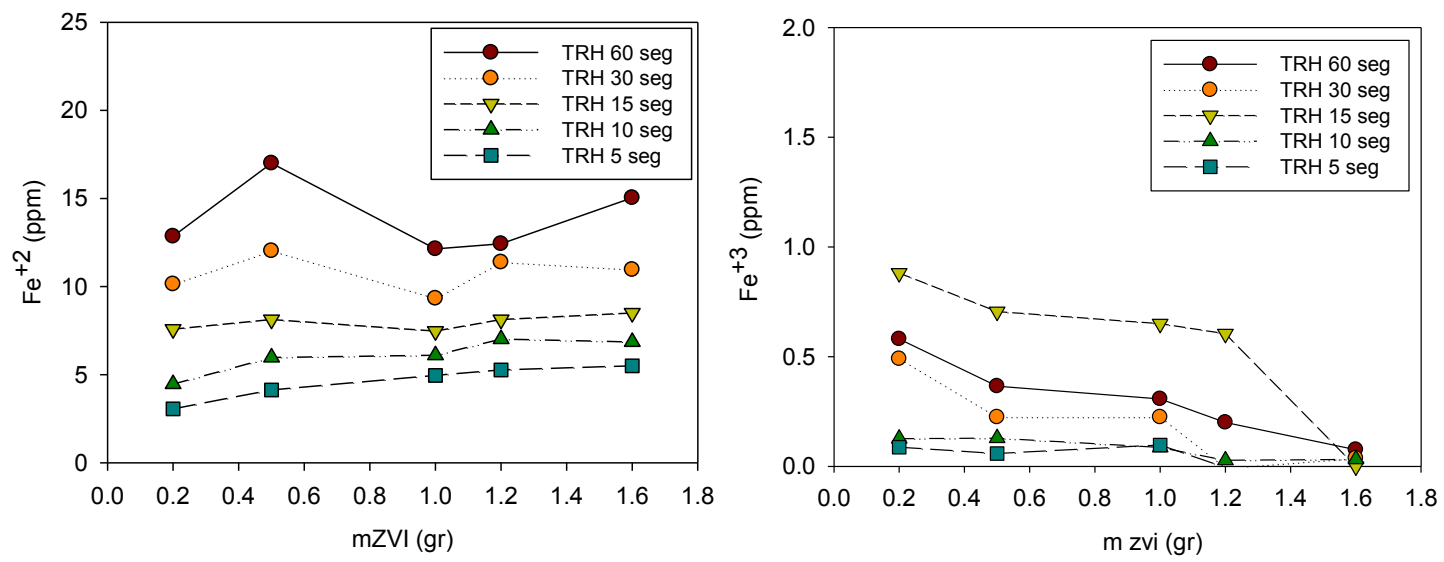

Figura 4.9. Efecto de la carga de ZVI en la generación de especies de $\mathrm{Fe}^{2+}$ y Fe ${ }^{3+}\left(\mathrm{pH}_{4}\right.$ ).

La carga de ZVI no parece tener un efecto marcado en la generación de especies de hierro. Con el aumento de la carga de ZVI se observa un pequeño aumento en la generación de $\mathrm{Fe}(\mathrm{II})$ para tiempos de residencia bajos y una cierta disminución en el contenido de Fe(III) para los tiempos de residencia mayores. Sin embargo, dado que esta serie de ensayos fue realizada a $\mathrm{pH} \mathrm{4}$, los contenidos de $\mathrm{Fe}$ (III) son muy bajos en todos los casos y no resulta posible establecer conclusiones categóricas.
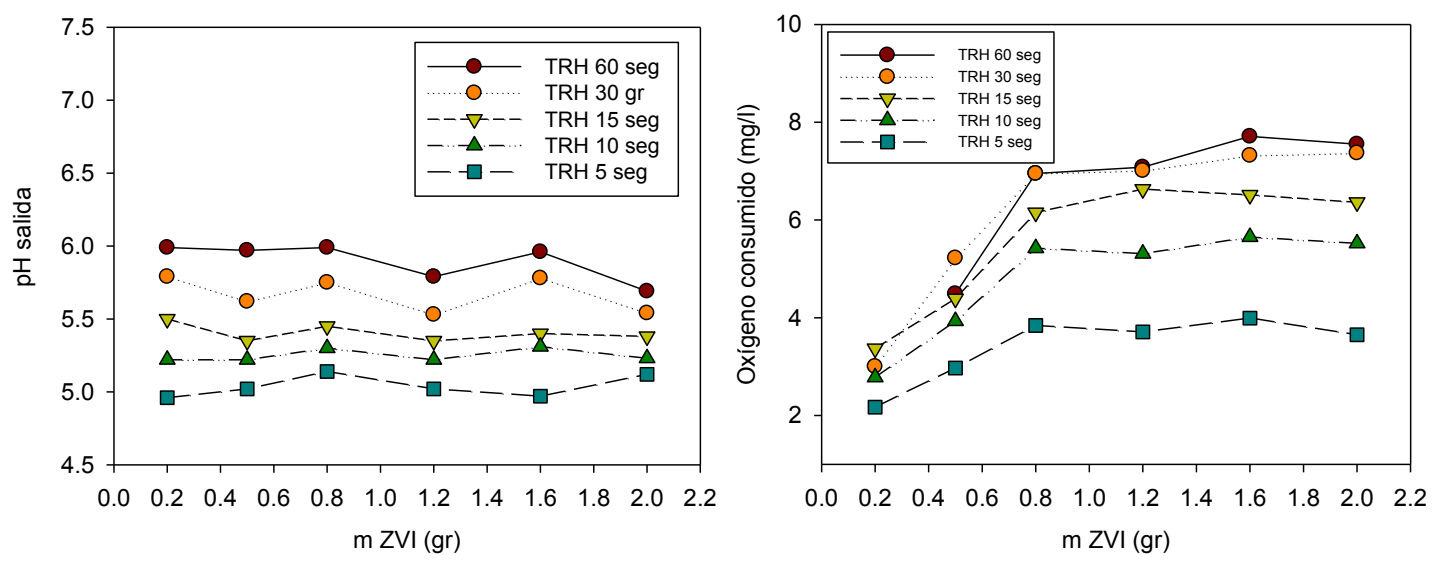

Figura 4.10. Efecto de la carga de ZVI en el consumo de oxígeno y $\mathrm{pH}$ de salida ( $\mathrm{pH} 4)$.

El pH de salida no muestra una dependencia significativa con el contenido de ZVI. En contraste, se observa un claro aumento del consumo de oxígeno al incrementar la carga de ZVI hasta valores de masa del orden de $1 \mathrm{~g}$. Para cargas mayores a $1 \mathrm{~g}$, el consumo de oxigeno resulta prácticamente independiente de la masa del lecho reactivo y solo depende significativamente del tiempo de residencia. Estos resultados indican que para cargas del lecho superiores a $1 \mathrm{~g}$, la velocidad de reacción no está limitada por la disponibilidad de $\mathrm{Fe}(0)$. 


\subsubsection{Tercera serie de ensayos: efecto de densidad del lecho}

Dado que en todos los ensayos anteriores la densidad del lecho se mantuvo constante, se realizó una serie adicional de ensayos para evaluar el efecto de este factor sobre las variables de respuesta.

Las corridas se realizaron con $\mathrm{pH} 4$ a la entrada utilizando $2 \mathrm{~g}$ de ZVI y variando el largo del empaquetamiento. Como resultado del diseño se obtuvieron 28 condiciones experimentales a ensayar (Anexo 3). En la Tabla 4.3 se presentan las condiciones experimentales utilizadas.

Tabla 4.3. Condiciones experimentales tercera serie de ensayos, efecto la densidad del lecho a $\mathrm{pH} 4$ y $\mathrm{mZVI} 2 \mathrm{~g}$.

\begin{tabular}{lccccccc}
\multicolumn{1}{c}{ Nivel } & $\mathbf{1}$ & $\mathbf{2}$ & $\mathbf{3}$ & $\mathbf{4}$ & $\mathbf{5}$ & $\mathbf{6}$ & $\mathbf{7}$ \\
Factor & & & & & & & \\
\hline $\mathbf{G ~ ( g / c m 3 ) ~}$ & 0,100 & 0,221 & 0,509 & 0,749 & & & \\
TRH & $120 \mathrm{seg}$ & $60 \mathrm{seg}$ & $30 \mathrm{seg}$ & $15 \mathrm{seg}$ & $10 \mathrm{seg}$ & $5 \mathrm{seg}$ & $2.5 \mathrm{seg}$ \\
\hline
\end{tabular}

Las tendencias registradas se muestran en las figuras 4.11 a 4.13. Para bajos valores de TRH se puede observar un leve aumento de las variables de respuesta con el aumento del gado de compactación. Por otro lado, para altos tiempos de residencia no se observan efectos significativos de la densidad de empaquetamiento del material.

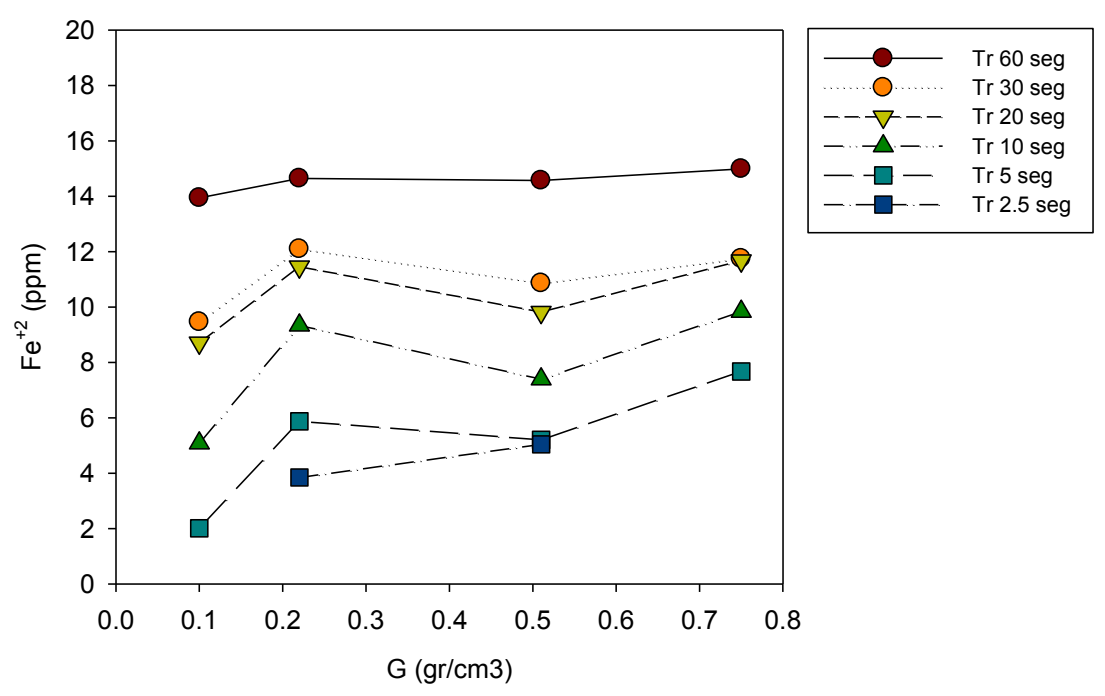

Figura 4.11. Efecto del gado de compactación en la generación de $\mathrm{Fe}^{2+}$ (entrada pH 4). 


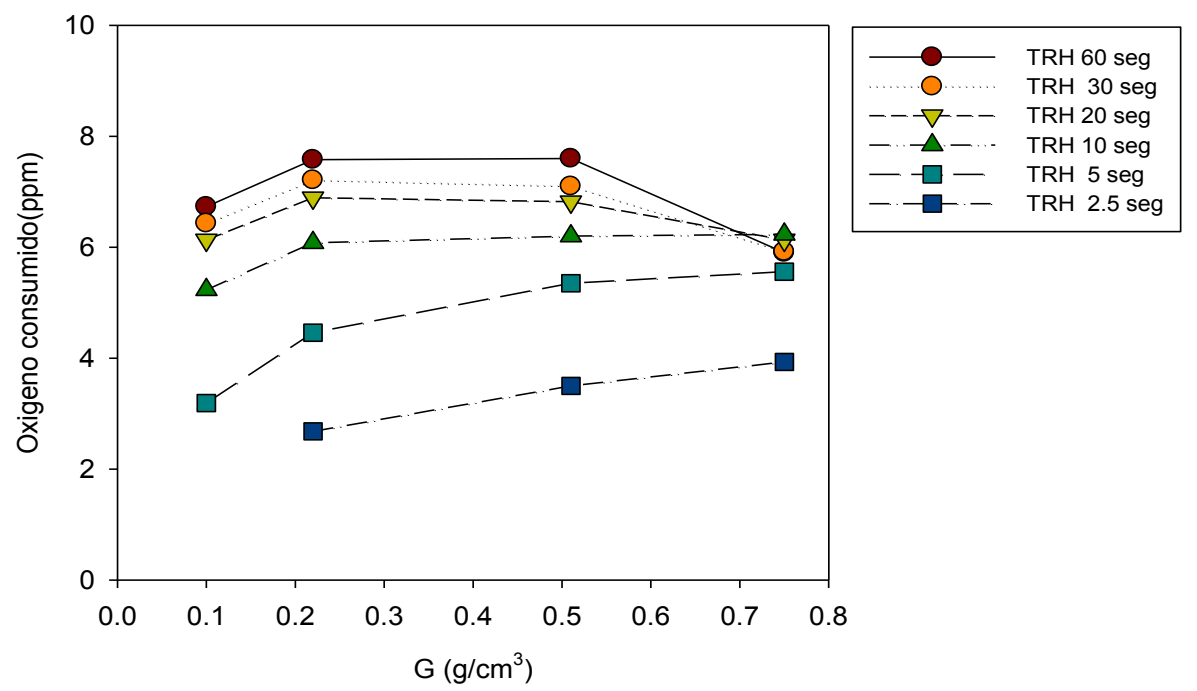

Figura 4.12. Efecto del grado de compactación en el consumo de oxígeno (entrada pH 4).

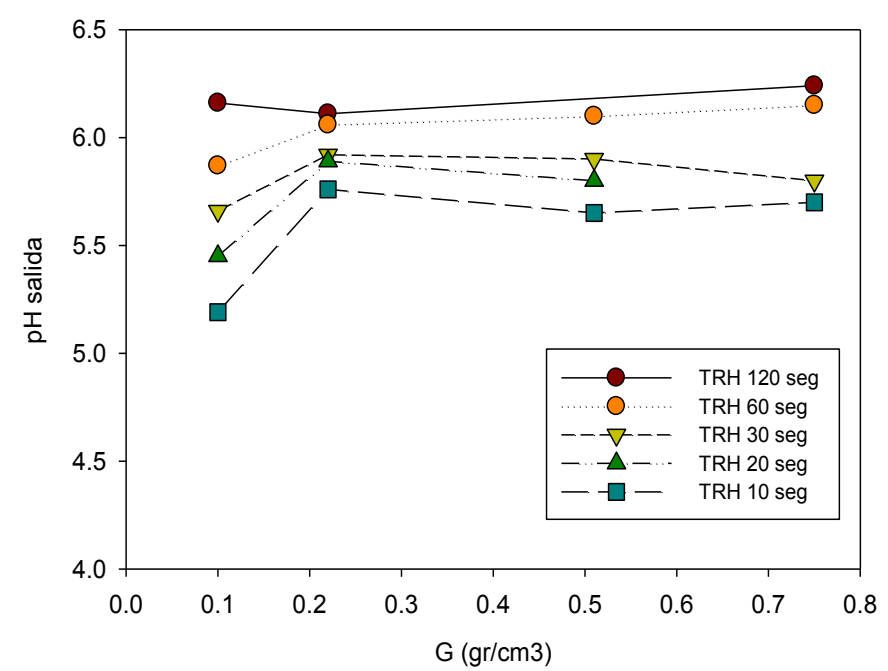

Figura 4.13. Efecto del grado de compactación en el pH de salida (entrada pH 4).

\subsection{FUENTES ALTERNATIVAS DE ZVI}

Entre los objetivos del plan de tesis se planteó evaluar la eficiencia de distintas fuentes de ZVI. Además, si bien los ensayos preliminares mostraron que el empleo de lana de acero como fuente de ZVI presenta numerosas ventajas, los estudios evidenciaron ciertas dificultades para obtener lechos uniformes y con características reproducibles tanto respecto de su comportamiento hidráulico como respecto de su reactividad. En este contexto, de manera similar a lo realizado en las columnas en las RSCT utilizando lana de acero, se estudió lo potencialidad de emplear ZVI en polvo o granallas de acero como materiales reactivos alternativos. Para esto se realizaron ensayos utilizando columnas de vidrio para evaluar la producción de especies resultantes de la corrosión y caracterizar hidráulicamente el comportamiento de estos rellenos 


\subsubsection{ZVI en polvo}

Los ensayos utilizando como material reactivo el ZVI en polvo, descripto en el Capítulo 2, fueron realizados utilizando una columna de vidrio con las dimensiones que se muestran en la Figura 4.14. Como relleno se utilizó una mezcla $50 \%$ en peso ZVI en polvo y $50 \%$ arena. La arena es utilizada como material inerte para minimizar el contacto entre partículas de ZVI, ya que, de no utilizarse, como resultado del proceso de expansión durante la corrosión se generan lechos demasiado compactos y con una conductividad hidráulica muy baja. La muestra de arena fue pre-tratada mediante un enjuague con ácido sulfúrico y posterior lavado con agua destilada hasta verificar $\mathrm{pH} 7$ en el líquido de enjuague. Por último fue secada en estufa. EI ZVI en polvo fue utilizado sin tratamiento previo. Como soporte y base del relleno se utilizó lana de vidrio y otros tipos de arena pre-tratada de manera similar. En la Figura 4.14 se muestra un esquema de la disposición del lecho y en la Tabla 4.4 se detallan las características granulométricas de cada fracción del lecho.

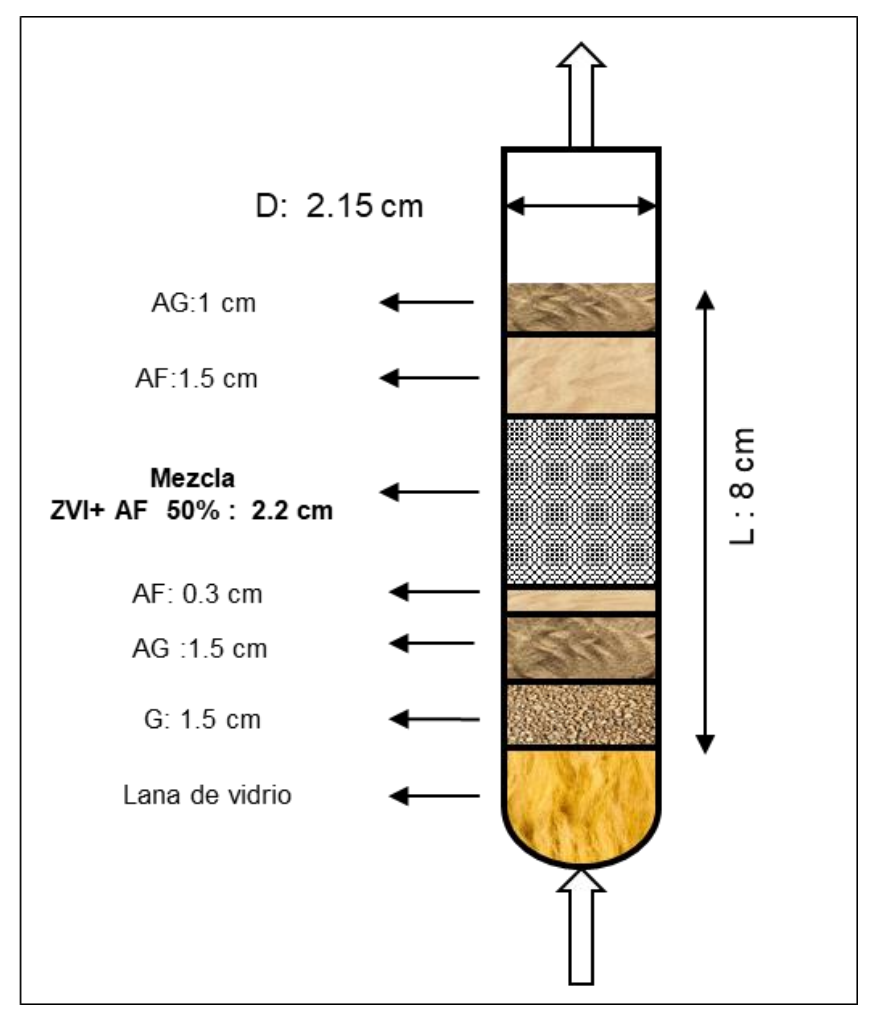

Figura 4.14. Composición y dimensiones columna rellena de ZVI en polvo.

Tabla 4.4. Características de los materiales utilizados para la columna rellena con ZVI en polvo.

\begin{tabular}{cc|c|c}
\hline & & $\mathbf{D}_{\text {ef }}(\mathbf{m m})^{*}$ & $\mathbf{C u}^{* *}$ \\
\hline Grava & $(\mathrm{G})$ & 2,89 & 1,79 \\
\hline Arena gruesa & $(\mathrm{AG})$ & 1,34 & 1,80 \\
Arena fina & $(\mathrm{AF})$ & 0,17 & 1,85 \\
\hline Polvo ZVI & $\mathrm{ZVI}$ & $<0,09$ & - \\
\hline
\end{tabular}

${ }^{*} D_{\text {ef: }}$ diámetro efectivo de las partículas

${ }^{* *} \mathrm{Cu}$ : coeficiente de uniformidad 
Generación de iones de Fe y efecto del TRH

Se trabajó con agua de red a pH 7 y se realizaron determinaciones de $\mathrm{Fe}(\mathrm{II})$ y $\mathrm{Fe}$ (III) por triplicado siguiendo la metodología antes descripta. Se utilizó una bomba peristáltica para la circulación del líquido a tratar a través del relleno. En primer lugar se analizó el tiempo que demora el sistema en estabilizarse realizando determinaciones en función del tiempo para tiempos de residencia promedio de 2 minutos. Los perfiles de la Figura 4.15 revelan que el sistema demora más de 100 volúmenes de poro en estabilizar y que las concentraciones de los iones relacionados con los productos de corrosión son muy bajas, por debajo de las 2 ppm de Fe total.

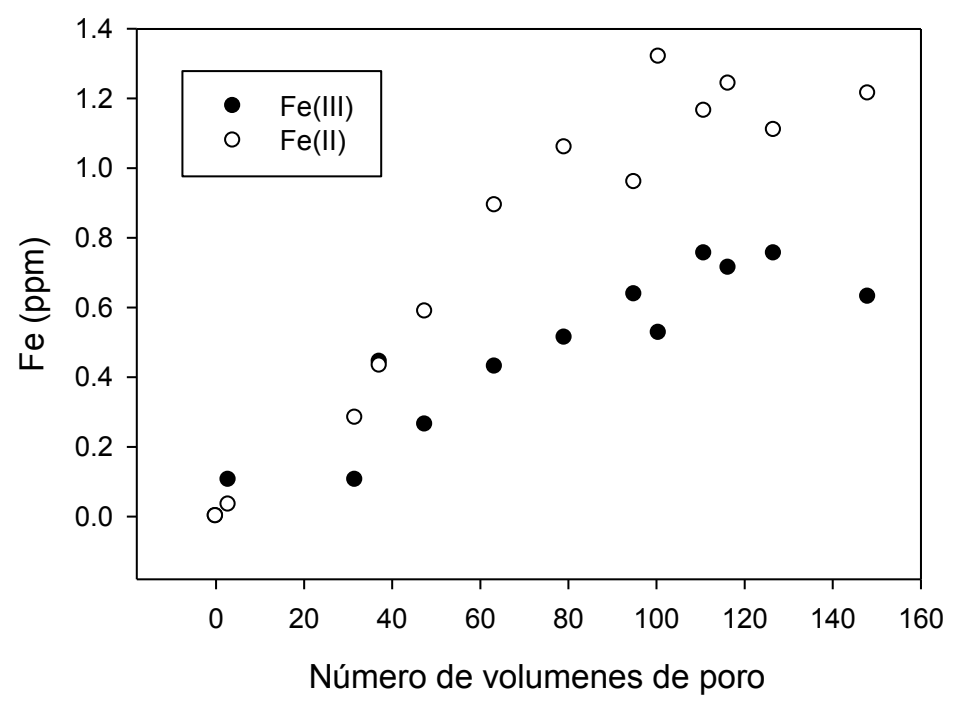

Figura 4.15. Generación de iones Fe en columna rellena de ZVI en polvo.

Por otro lado, se estudió el efecto del tiempo de residencia (TRH) sobre la generación de especies de hierro en solución (Tabla 4.5). Puede observarse que las concentraciones varían muy poco con el tiempo de residencia, menos del $10 \%$, y en todos los casos son muy bajas. Cabe destacar que resultó imposible evaluar tiempos de residencia menores ya que velocidades de flujo mayores a $5 \mathrm{~cm} / \mathrm{min}$ provocan la fluidización del relleno o la generación de canales preferenciales.

Tabla 4.5. Efecto del TRH sobre la generación de Fe para columnas rellenas con ZVI en polvo.

\begin{tabular}{c|c|c}
\hline TRH (min) & Fe(II) (ppm) & Fe(III) (ppm) \\
\hline 1.03 & 1,25 & 0,34 \\
1.03 & 1,34 & 0,25 \\
1.35 & 1,41 & 0,26 \\
1.80 & 1,33 & 0,30 \\
1.90 & 1,34 & 0,51 \\
4.50 & 1,30 & 0,35 \\
\hline Promedio & $1,30 \pm 0,05$ & $0,33 \pm 0,09$ \\
\hline
\end{tabular}


Conductividad hidráulica

Con el objetivo de comparar el comportamiento del ZVI en polvo con la lana de acero se realizaron determinaciones de conductividad hidráulica con lechos de pequeña escala y de iguales dimensiones. Las conductividades hidráulicas se determinaron según el método de permeámetro de carga constante y la ecuación 2.6. Los resultados se presentan en la Tabla 4.6 y la figura 4.16.

Tabla 4.6. Comparación de conductividades hidráulicas en columnas rellenas con ZVI en forma de lana de acero y polvo.

\begin{tabular}{l|c|c|c}
\hline & & Lana de acero & ZVI en polvo \\
\hline Largo (cm) & 8,3 & & \\
Diámetro (cm) & 2,15 & & \\
Pendiente (Q vs dH) & & 34,61 & 0,10 \\
K (cm/min) & & 79,13 & 0,22 \\
\hline
\end{tabular}
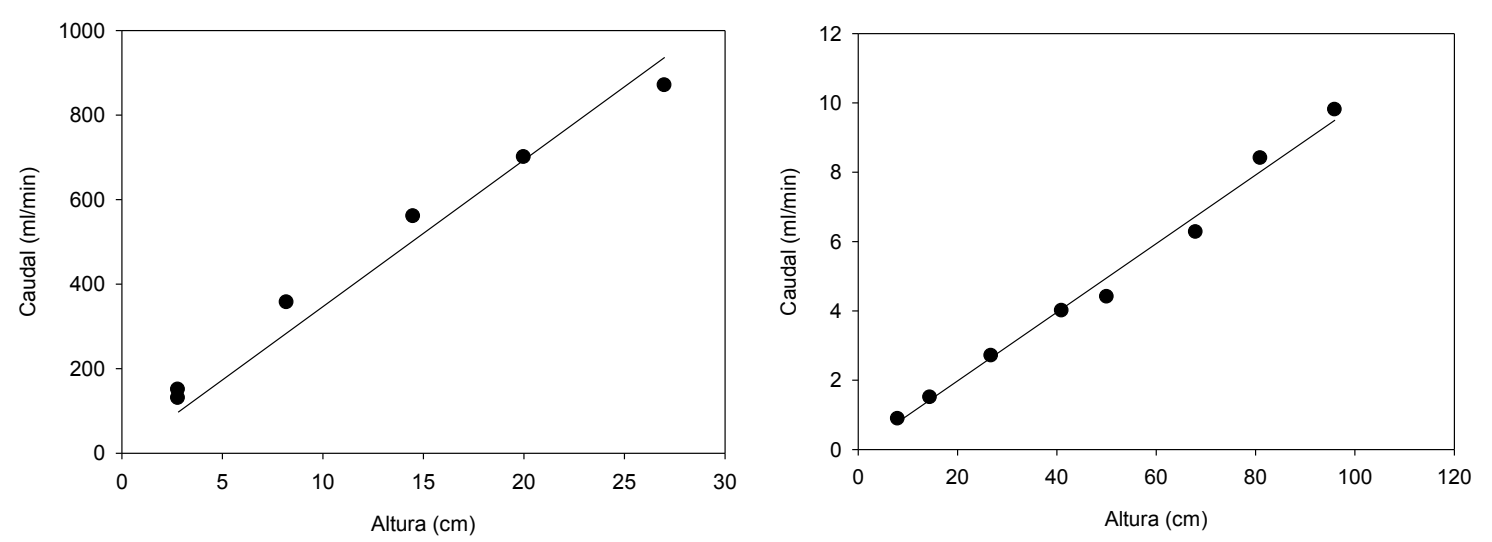

Figura 4.16. Determinación de la conductividad hidráulica de columnas en pequeña escala (izquierda: lana de acero, derecha: ZVI en polvo).

Los valores muestran que la conductividad hidráulica inicial del relleno con ZVI en polvo es dos órdenes de magnitud menor que columnas de características similares pero rellenas con lana de acero. Esto se presenta como una gran desventaja para la utilización de rellenos con $\mathrm{ZVI}$ en polvo a escala piloto puesto que serían necesarias presiones muy altas para alcanzar caudales iniciales de trabajo aceptables. Además, debe tenerse en cuenta que los lechos reactivos van perdiendo porosidad con el volumen tratado, incrementando así los inconvenientes desde el punto de vista hidráulico.

\subsubsection{Granallas de acero al carbono}

Otra opción evaluada fue el empleo de granallas de acero al carbono como posible fuente relleno para el lecho reactivo. Para evitar los problemas de conductividad hidráulica antes discutidos, se seleccionaron granallas esféricas del mayor tamaño disponible para obtener un lecho con la mayor porosidad posible. 
Generación de iones de Fe

Nuevamente se utilizó agua de red y una bomba peristáltica para la circulación a través del lecho. En este caso se trabajó con una columna de $1 \mathrm{~cm}$ de diámetro interno, al igual que en los RSCT realizados con lana de acero como material reactivo, y valores de $\mathrm{pH}$ de entrada 6 y 7 . Se observó el efecto de los factores TRH y pH de entrada sobre las variables respuesta tales como la generación de especies de $\mathrm{Fe}$ (II) y $\mathrm{Fe}(\mathrm{III})$ en solución y el pH de salida. Los resultados (Figura 4.17) muestran tendencias similares a las obtenidas con lana de acero. Cabe aclarar que los datos obtenidos con granallas de acero fueron representados en función de un tiempo de residencia aparente, calculado en función del caudal y el volumen total del lecho. Sin embargo, a diferencia de lo que ocurre para las columnas rellenas con lana de acero, el tiempo de residencia real para las granallas es un $58 \%$ menor debido a que la porosidad del lecho en este caso fue aproximadamente 0,42 .
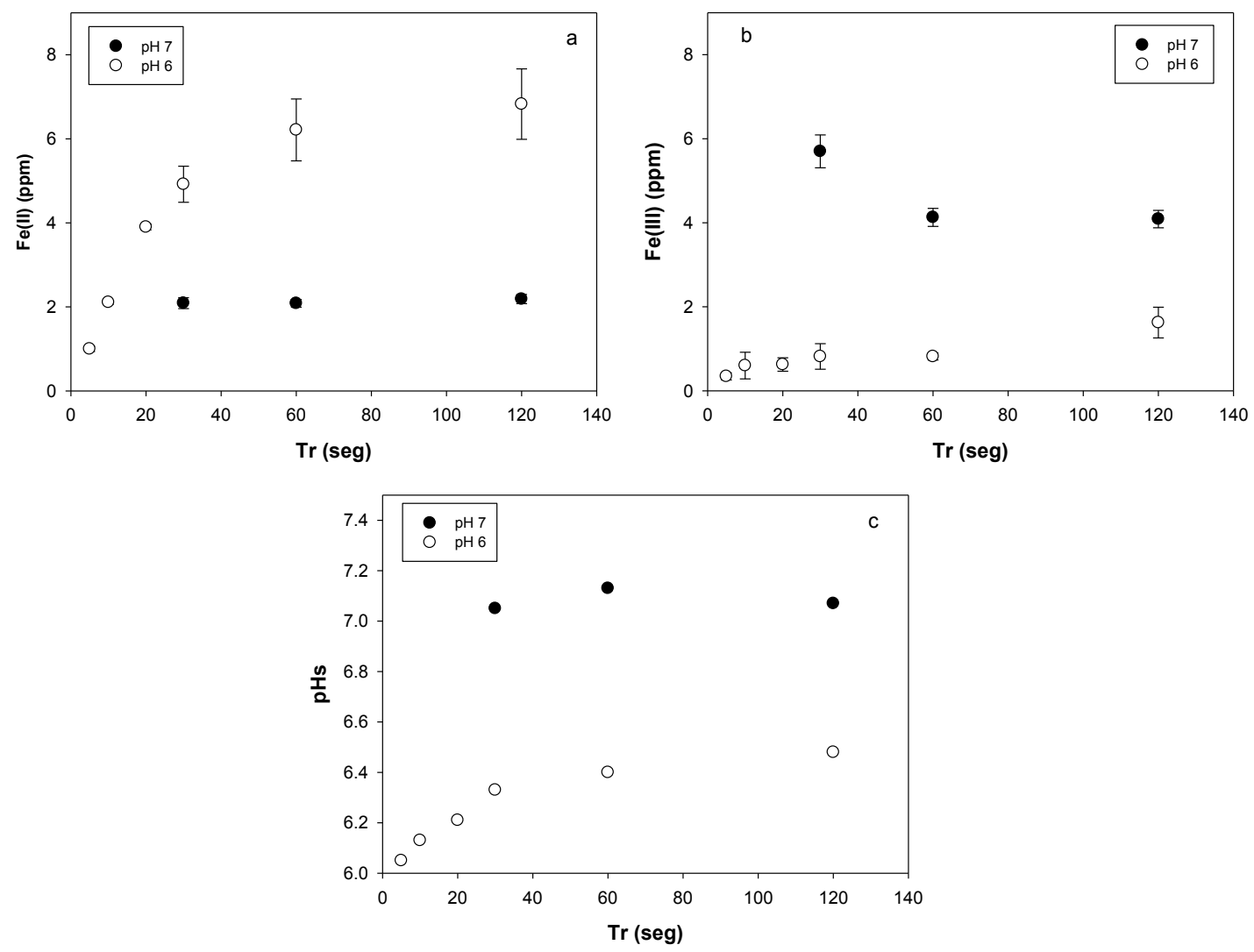

Figura 4.17. Efecto de las variables operativas para pequeñas columnas rellenas con granallas de acero al carbono $\left(\mathrm{m}_{\mathrm{zvl}}=45 \mathrm{~g}\right)$.

Al disminuir el $\mathrm{pH}$ de entrada se puede observar un aumento en la generación de $\mathrm{Fe}(\mathrm{II})$, una disminución de la generación de $\mathrm{Fe}(\mathrm{III})$ y un aumento de la variación del $\mathrm{pH}$. Asimismo se puede observar que el tiempo de residencia tiene mucho mayor impacto en las respuestas a $\mathrm{pH} 6$ que a $\mathrm{pH}$ 7. Finalmente cabe mencionar que los contenidos de $\mathrm{Fe}(\mathrm{II})$ registrados a $\mathrm{pH} 7$, del orden de 2 ppm, son muy cercanos al 
límite mínimo necesario para la remoción de As determinado en los ensayos preliminares.

Ensayo en pequeña escala de larga duración

Con el objetivo de verificar el potencial de este tipo de lechos para la remoción de arsénico se realizó un ensayo a largo plazo durante 40 días. Se trabajó con una columna de $3.5 \mathrm{~cm}$ de diámetro interno y agua de red. En la Tabla 4.7 se resumen las condiciones experimentales. Para el seguimiento del desempeño del lecho se realizaron determinaciones diarias de $\mathrm{Fe}(\mathrm{II})$ y As total. Los resultados se muestran en la Figura 4.18. Dado que solo se trabajó con la columna reactiva, la determinación de As fue realizada luego de oxigenar y filtrar la muestra tomada a la salida del lecho. Este último procedimiento permite simular los procesos que ocurrirían en los módulos 2 y 3 del prototipo completo.

Tabla 4.7. Condiciones empleadas en experimento a largo plazo realizado con el lecho de granallas de acero.

\begin{tabular}{l|l|l|l}
\hline Diámetro interno $\mathbf{( c m )}$ & 3,50 & Masa de ZVI (g) & 640 \\
\hline Longitud (cm) & 17,5 & As entrada (ppm) & 0,25 \\
\hline $\operatorname{Tr}(\mathbf{m i n})$ & 10,0 & pH entrada & 7,00 \\
\hline
\end{tabular}
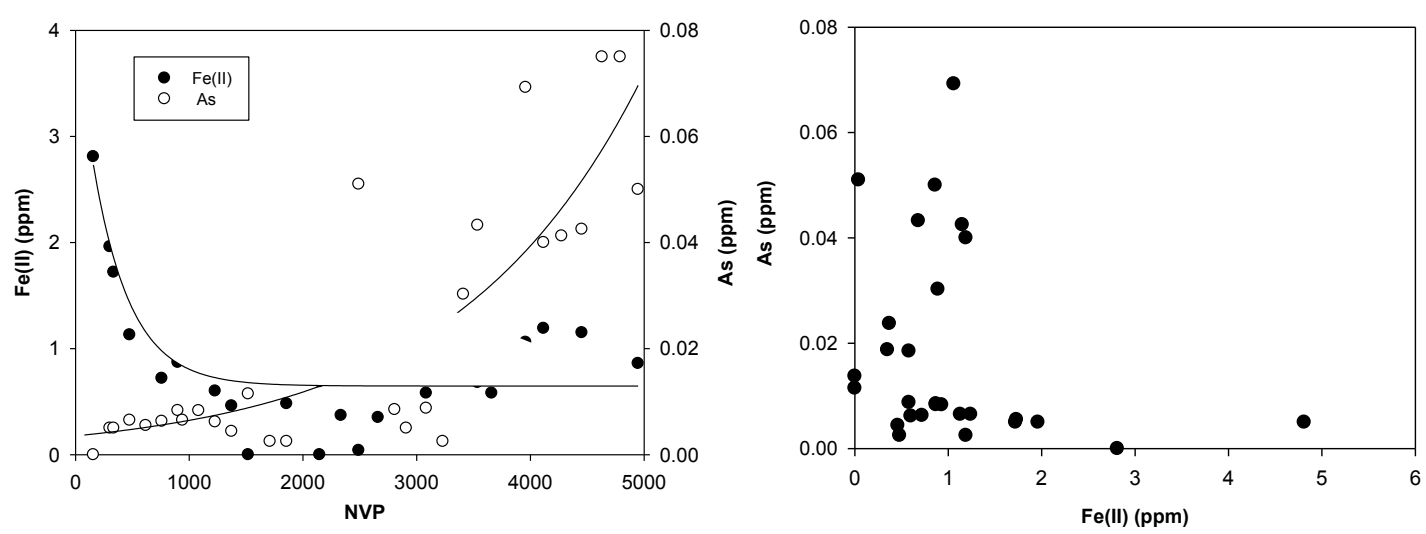

Figura 4.18. Izquierda: Generación de $\mathrm{Fe}(\mathrm{II})$ y contenido de $\mathrm{As}(\mathrm{V})$ a la salida de la columna rellena con granallas de acero en función del número de volúmenes de poro. Derecha: $\mathrm{As}(\mathrm{V})$ en función de $\mathrm{Fe}(\mathrm{II})$ a la salida de la columna.

Pese a las fluctuaciones observadas en los valores registrados, se puede ver que la concentración de $\mathrm{Fe}(\mathrm{II})$ a la salida de la columna cae rápidamente por debajo de $1 \mathrm{ppm}$. Por este motivo las concentraciones de As comienzan a superar el límite de $0,01 \mathrm{ppm}$ y se alcanza el punto de ruptura. A partir de los valores presentados en la Figura 4.17 se estableció un punto de ruptura cercano a los 1500 volúmenes de poro, equivalente a un volumen total tratado de $370 \mathrm{~L}$, lo que arroja un rendimiento cercano a $0,6 \mathrm{~L}$ tratados por $\mathrm{g}$ de $\mathrm{ZVI}$, valor significativamente menor que los $35 \mathrm{~L}$ por g de ZVI 
promedio registrados en los ensayos de larga duración realizados utilizando la misma masa de lana de acero (Sección 6.2.1).

\section{Conductividad hidráulica}

Durante el ensayo de larga duración con la columna rellena con granallas de acero al carbóno en pequeña escala se realizaron también determinaciones de conductividad hidráulica siguiendo la metodología antes descripta. En paralelo se montó una prueba en la planta piloto con una columna rellena también con granallas. Dado que la conductividad hidráulica disminuyó rápidamente en ambos casos (Tabla 4.7), y la planta fue diseñada para la circulación de fluido por gravedad, al cabo de 5 días resultó imposible hacer circular el caudal de diseño de $500 \mathrm{~mL} / \mathrm{min}$. En el caso de la planta piloto, el caudal máximo alcanzado fue de $80 \mathrm{~mL} / \mathrm{min}$ para una altura de tanque disponible de 2 metros debido al bajo valor de conductividad obtenido.

Tabla 4.7. Conductividad hidráulica de lechos rellenos con granallas.

\begin{tabular}{l|ccc|c}
\hline & \multicolumn{3}{|c|}{ Columna chica } & $\begin{array}{c}\text { Columna } \\
\text { grande }\end{array}$ \\
\hline Número de volúmenes de poro & 720 & 1872 & 3600 & \\
\hline $\mathbf{Q}=$ caudal $(\mathbf{c m} 3 / \mathbf{m i n})$ & 13,8 & 10,6 & 7,7 & 15,9 \\
\hline $\mathbf{L}=$ longitud $(\mathbf{c m})$ & 17,5 & 17,5 & 17,5 & 40 \\
\hline $\mathbf{A}=$ área de la sección transversal $\left(\mathbf{c m}^{2}\right)$ & 9,62 & 9,62 & 9,62 & 132,73 \\
\hline $\mathbf{H}=$ carga constante de la columna de agua $\mathbf{( c m )}$ & 18 & 35 & 30,5 & 38 \\
\hline $\mathbf{K}=$ conductividad hidráulica $\mathbf{( c m / m i n )}$ & 1,395 & 0,552 & 0,457 & 0,126 \\
\hline
\end{tabular}

\subsection{CONCLUSIONES}

Las conclusiones obtenidas a partir de los ensayos presentados en este capítulo se resumen a continuación:

- De los ensayos RSSCT se observa un aumento en la generación de Fe(II), en el consumo de oxígeno y en la variación del pH tanto con el aumento del TRH como con la disminución del $\mathrm{pH}$. Con respecto a la generación de $\mathrm{Fe}(\mathrm{III})$, esta aumenta con el TRH y disminuye con la disminución del pH. La masa de ZVI en la columna rellena no parece influir de manera significativa en ninguna de las variables respuesta. Para bajos valores de TRH se observa un leve aumento de las variables respuesta con el aumento del grado de compactación.

- Los ensayos realizados utilizando ZVI en forma de polvo muestran valores de $\mathrm{Fe}$ (II) a la salida de la columna menores a $2 \mathrm{ppm}$, valor significativamente menor que lo observado para condiciones experimentales similares utilizando lana de acero. La conductividad hidráulica de este material también resulta mucho más baja que para la lana de acero siendo estas de 0,22 y 79,13 
$\mathrm{cm} / \mathrm{min}$ respectivamente y este resultado condiciona severamente la aplicación del ZVI en polvo a escalas mayores a la de laboratorio.

- Los resultados obtenidos utilizando granallas de acero muestran cantidades iniciales de $\mathrm{Fe}(\mathrm{II})$ a $\mathrm{pH} 7$ suficientes para la remoción de As. Sin embargo, debido a la rápida disminución de concentración de $\mathrm{Fe}(\mathrm{II})$ a la salida de la columna, a la importante caída en la conductividad hidráulica y el bajo rendimiento en relación a la lana de acero, este material no resulta eficiente para su aplicación en sistemas continuos de dimensiones y características de diseño similares a las ensayadas en el presente trabajo de Tesis. 
CAPITULO 5:

ESTRATEGIAS PARA ANÁLISIS, INTERPRETACIÓN Y MODELADO DE LOS DATOS OBTENIDOS MEDIANTE RSSCT 


\section{ESTRATEGIAS PARA ANÁLISIS, INTERPRETACIÓN Y MODELADO DE LOS DATOS OBTENIDOS MEDIANTE RSSCT}

\subsection{INTRODUCCIÓN}

A lo largo de este capítulo se utilizarán diferentes estrategias para analizar y modelar los datos obtenidos mediante la metodología de RSSCT. Dada la complejidad de los mecanismos de los procesos fisicoquímicos involucrados, que ocurren en simultáneo durante la oxidación de lechos rellenos con ZVI, la aplicación de modelos duros para el estudio de los resultados obtenidos no resulta sencilla. Por este motivo y dado que el análisis de datos involucra relaciones complejas entre más de dos variables, el análisis multivariado resulta una buena opción para realizar una primera interpretación de los resultados.

Las técnicas multivariadas son métodos estadísticos que permiten observar y cuantificar relaciones entre variables. Estas técnicas pueden hacer uso de tabulación cruzada, correlación parcial o regresiones múltiples, e introducir nuevas variables para establecer vínculos entre los factores (variables independientes) y las respuestas (variables dependientes). Esto proporciona una imagen global y una mayor prueba de significancia en comparación con las técnicas univariadas tradicionalmente empleadas. Existen diferentes técnicas a utilizar dependiendo de la naturaleza de los datos y del tipo de asociación bajo análisis. En la primera parte de este capítulo, para realizar un análisis preliminar de los datos obtenidos mediante la metodología de RSSCT, se emplearán matrices de correlación, análisis por grupos y componentes principales. Estas técnicas permitirán establecer, por un lado, que variables tanto independientes como dependientes presentan similitud entre sí y, por otro lado, cuales son las variables independientes que mayor influencia presentan en la variabilidad de las respuestas observadas.

En la segunda parte de este capítulo se utilizará la metodología de Redes Neuronales Artificiales (RNA) para el modelado de los datos obtenidos. Las RNA son algoritmos diseñados para emular la forma en que el cerebro humano procesa la información y aprende. Este procedimiento de modelado, que se encuentra dentro de las metodologías del tipo "análisis basado en los datos" ("data-driven analysis"), es utilizado para describir sistemas dinámicos y se presenta como una técnica prometedora, especialmente para conjuntos de datos que tienen relaciones no lineales. Con los datos previamente registrados se construirán diferentes RNA y se estudiará la capacidad de cada una para predecir los valores experimentales de las distintas variables respuesta para la totalidad de los experimentos. La RNA que presente los mejores resultados se utilizará por un lado para simular los perfiles obtenidos, y por otro para construir superficies de respuesta que permitan visualizar el efecto de las distintas variables independientes sobre las distintas variables respuesta. Por último, se realizará un análisis de sensibilidad del modelo obtenido con el objeto de obtener información sobre la importancia relativa de cada variable. Esta estrategia de análisis constituye una metodología relativamente rápida y útil para obtener información que permita tomar decisiones específicas orientadas a la optimización del proceso. 
Cabe destacar que, pese a sus ventajas, los modelos neuronales tienen inconvenientes, entre los que se destacan los siguientes: i) son poco explicativos respecto a los principios físicos y químicos que rigen la dinámica del sistema por tratarse de modelos tipo caja-negra ii) la posibilidad de incorporar información previa en el modelo es muy limitada iii) no permiten realizar extrapolaciones. Por estas razones, como última estrategia se utilizarán modelos duros basados en las distintas reacciones involucradas en el proceso para el modelado de los datos obtenidos. Esta metodología permitirá obtener información acerca de las cinéticas y los mecanismos involucrados en los procesos de corrosión estudiados.

\subsection{TÉCNICAS MULTIVARIADAS DE ANÁLISIS}

\subsubsection{Análisis de grupos}

\subsubsection{Marco teórico}

El análisis de grupos o "cluster analysis" es una técnica estadística destinada a identificar y clasificar datos o variables, en grupos con determinadas características similares. Esto implica que: i) cada grupo es homogéneo con respecto a determinada característica, ii) las observaciones de un grupo deben ser diferentes de las observaciones de otros grupos respecto a la misma característica [117].

Para un caso general, en el que se considere una muestra con $\mathbf{n}$ datos de un conjunto de $\mathbf{p}$ variables, $X_{1}, X_{2}, \ldots, X_{p}$ los datos se clasificaran en $\mathbf{g}$ grupos, siguiendo las siguientes etapas:

1. Seleccionar la medida de similitud o tipo de distancia entre datos a utilizar.

2. Definir la técnica de agrupamiento a ser adoptada (jerárquica o no jerárquica).

3. Seleccionar un criterio de similitud entre grupos.

4. Obtener el dendrograma de resultados e interpretar los resultados obtenidos.

\section{Medida de similitud entre los datos}

Existen varios criterios para la medida de distancia entre datos. Las más comunes derivan de la expresión general denominada "distancia de Minkowisky". En la Tabla 5.1 se muestran los criterios de similitud más frecuentemente empleados El cálculo de las distancias entre todas las observaciones o variables resulta en una "matriz de similitud", D (simétrica, pxp, cuya diagonal principal es igual a cero). Además de la matriz $D$, se puede emplear la matriz de correlación $R$ (pxp) se puede utilizar como medida de distancia. La matriz $\mathrm{R}$ se emplea principalmente para casos que involucren agrupaciones de variables (en este caso la diagonal principal está compuesta por unos). Una vez construida la matriz de similitud, el siguiente punto consiste en definir cómo utilizar sus valores para formar grupos. 
Tabla 5.1. Criterios de similitud entre datos.

\begin{tabular}{|c|c|}
\hline Distancia & Definición \\
\hline Minkowisky & $D_{i j}=\left[\sum_{k=1}^{p}\left(\left|x_{i k}-x_{j k}\right|\right)^{n}\right]^{\frac{1}{n}}$ \\
\hline Euclediana & $D_{i j}=\left[\sum_{k=1}^{p}\left(\left|x_{i k}-x_{j k}\right|\right)^{2}\right]^{\frac{1}{2}}$ \\
\hline Manhattan & $D_{i j}=\sum_{k=1}^{p}\left(\left|x_{i k}-x_{j k}\right|\right)$ \\
\hline $\begin{array}{c}\text { Estadística o de } \\
\text { Mahalanobis }\end{array}$ & $D_{i j}=\left(X_{i}-X_{k}\right)^{T} \operatorname{Cov}\left(X_{i}-X_{k}\right)$ \\
\hline $\begin{array}{c}\text { Coeficiente de } \\
\text { correlación }\end{array}$ & $\left(\begin{array}{c}\sum_{j k}^{n}=\frac{\sum_{i j} z_{j k}}{n-1}=\frac{\sum_{i=1}^{n}\left(x_{i j}-\overline{x_{j}}\right)\left(x_{i k}-\overline{x_{k}}\right)}{(n-1) s_{j} s_{k}} \\
\\
\text { (donde } s_{j} y s_{k} \text { representan la raíz cuadrada de la } \\
\left.\text { varianza de las variables } X_{j} y X_{k}\right)\end{array}\right.$ \\
\hline
\end{tabular}

\section{Técnicas de agrupación}

Las técnicas de construcción de los grupos de datos se dividen en jerárquicas y no jerárquicas. Las técnicas jerárquicas se basan en el ordenamiento de las distancias, que se inicia a partir de la distancia menor detectada en la matriz D. Los datos son agrupados secuencialmente y, en cada etapa, se forma un nuevo grupo que involucra dos o más grupos anteriores, según una escala de distancia entre grupos. Brevemente, se parte de un número inicial de grupos igual al número de objetos a ser agrupados y los objetos se van agrupando sucesivamente hasta llegar a un único grupo que contiene todos los objetos. La agrupación sucesiva de objetos, que pueden ser observaciones, variables o grupos, se hace según criterios de similitud entre grupos. Los criterios más utilizados se muestran en la Tabla 5.2.

La información obtenida en cada paso del proceso de agrupamiento puede ser visualizada gráficamente en un dendrograma. El dendrograma es un diagrama de árbol que muestra los grupos que se forman al crear conglomerados. El nivel de similitud, o la distancia, se ubica en el eje vertical y las diferentes observaciones o variables se especifican en el eje horizontal.

Las técnicas no jerárquicas, que no se detallarán en el presente trabajo, parten de un número prefijado de grupos (denominadas semillas) y agrupan los datos según criterios de homogeneidad y de heterogeneidad entre ellos. 
Tabla 5.2. Criterio de similitud entre grupos utilizados en las técnicas de agrupación jerárquica.

\begin{tabular}{|l|l|l|}
\hline \multicolumn{1}{|c|}{ Tipo de criterio } & \\
\hline $\begin{array}{l}\text { Conexión simple, o vecino más cercano } \\
\text { ("single-linkage, nearest-neighbor"): la } \\
\text { distancia entre dos grupos es representada } \\
\text { por la distancia entre los dos objetos más } \\
\text { cercanos de los dos grupos. }\end{array}$ & $\begin{array}{l}\text { Conexión completa, o vecino más lejano } \\
\text { ("complete-linkage, farthest-neighbor"): la } \\
\text { distancia entre dos grupos es representada } \\
\text { por la distancia entre los dos objetos más } \\
\text { alejados de los dos grupos. }\end{array}$ \\
\hline $\begin{array}{l}\text { Conexión media ("average-linkage"): } \\
\text { considera la distancia entre dos grupos } \\
\text { representada por la media de las distancias } \\
\text { entre todos los pares posibles de } \\
\text { combinaciones de objetos de los dos grupo. }\end{array}$ & \\
\hline $\begin{array}{l}\text { Método del centroide: considera la distancia } \\
\text { entre dos grupos representada por la } \\
\text { distancia entre los centroides de cada grupo. }\end{array}$
\end{tabular}

\subsubsection{Aplicación de la metodología y resultados}

Con la ayuda el software estadístico Minitab ${ }^{\circledR} 17$ [118]. se realizó el agrupamiento de variables siguiendo la técnica jerárquica de agrupación simple, utilizando el coeficiente de correlación como medida de distancia entre datos. Los datos fueron ingresados en forma matricial colocando tanto las variables independientes como las variables respuesta en columnas y los experimentos $\mathrm{u}$ observaciones en filas. En las Figuras 5.1 a 5.3 pueden observarse los dendrogramas obtenidos al aplicar este tipo de análisis a los datos correspondientes a cada una de las series de ensayos descriptas en el capítulo 4. 


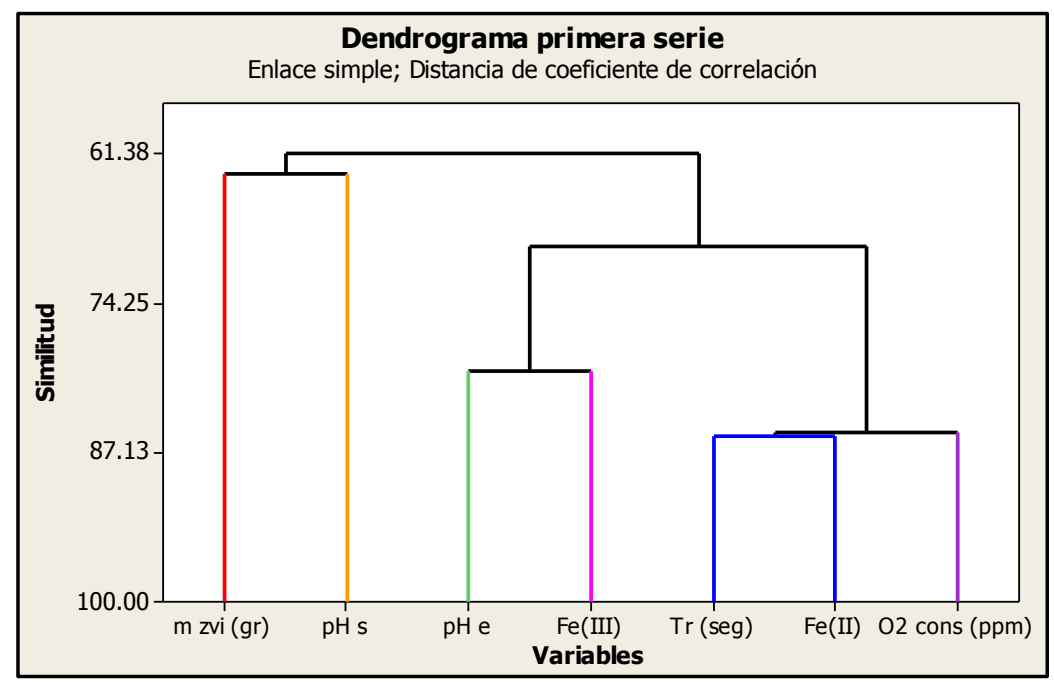

Figura 5.1. Dendrograma obtenido para la primera serie de ensayos $\left(\delta_{\mathrm{ap}}=0,1 \mathrm{gr} / \mathrm{cm}^{3}\right)$.

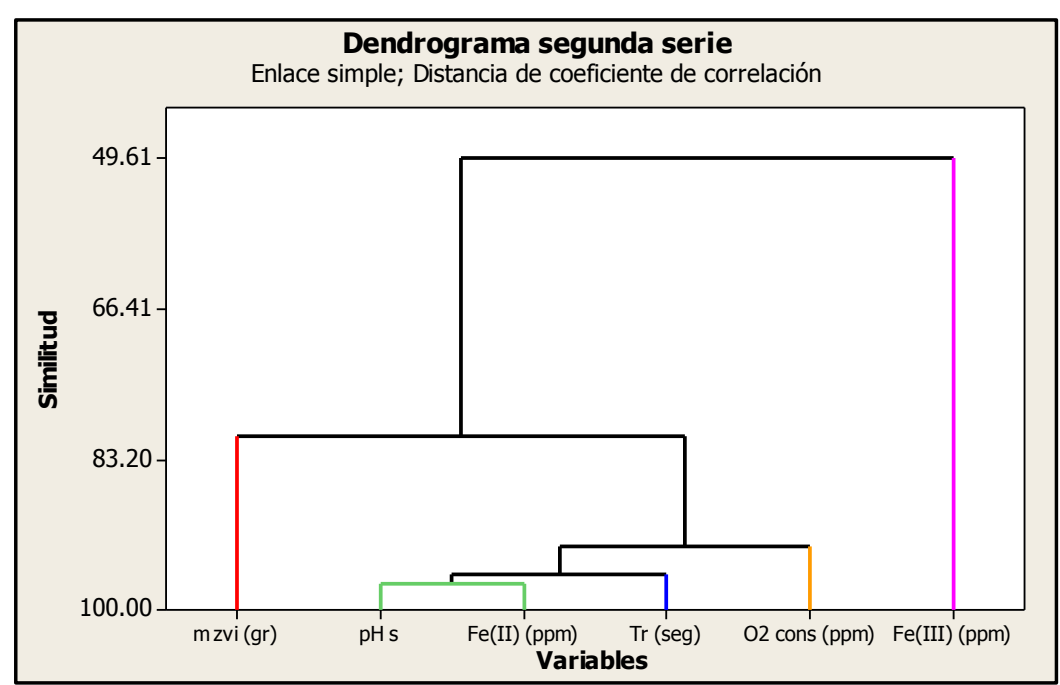

Figura 5.2. Dendrograma obtenido para la segunda serie de ensayos $\left(\mathrm{pHe}=4, \delta_{\mathrm{ap}}=0,1 \mathrm{gr} / \mathrm{cm}^{3}\right)$.

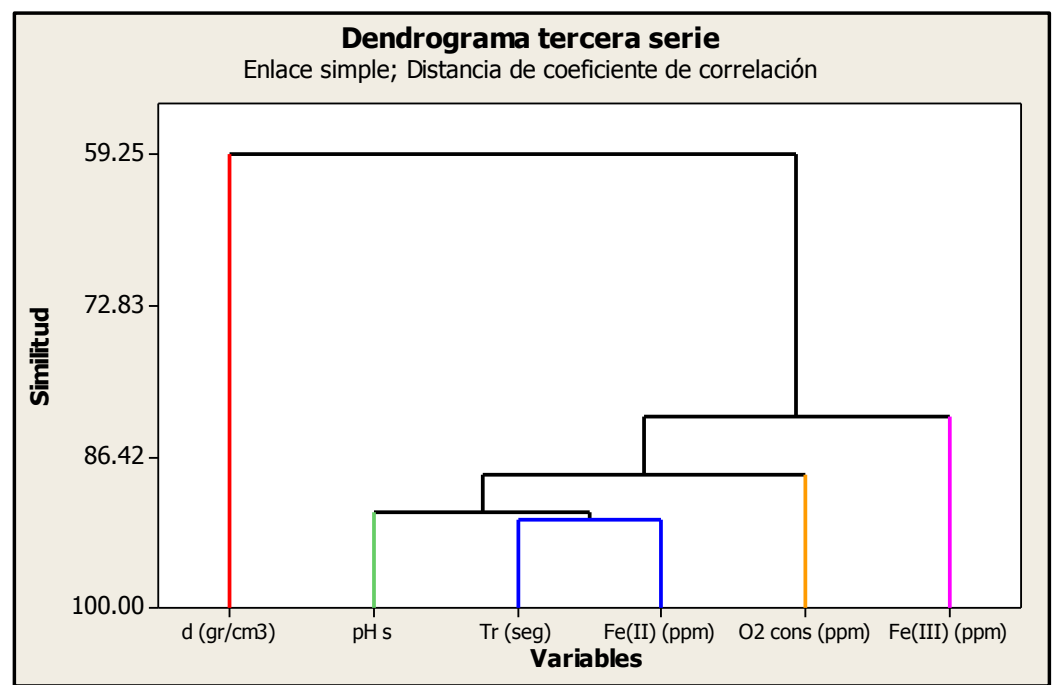

Figura 5.3. Dendrograma obtenido para la tercera serie de ensayos $\left(\mathrm{pH}=4, \mathrm{~m}_{\mathrm{zvl}}=2 \mathrm{gr}\right)$. 
Tal como se describió en el Capítulo 4, la primera serie de ensayos fue diseñada para estudiar el efecto de las variables independientes masa de $\mathrm{ZVI}$, pH de entrada y TRH sobre las variables de respuesta. El dendrograma obtenido (Figura 5.1) muestra que el mayor grado de similitud se registra entre el TRH y las variables respuesta $\mathrm{Fe}(\mathrm{II})$ y oxígeno consumido por lo que este factor es el que presenta la mayor influencia sobre el desempeño global del sistema. Por otra parte, la masa de ZVI resulta la variable operativa que menos influye para esta serie de ensayos.

El análisis de los conglomerados obtenidos para la segunda serie de ensayos (Figura 5.2) permite extraer las siguientes conclusiones: i) la variable respuesta $\mathrm{Fe}(\mathrm{III})$ muestra una correlación muy pobre con respecto al resto de las variables analizadas, por lo que no sería una variable importante para la descripción del comportamiento dinámico del sistema, ii) se confirma que también para esta serie de ensayos la masa de ZVI presenta una influencia mucho menor que el TRH sobre el desempeño del sistema.

Finalmente, el dendrograma correspondiente a la tercera serie de ensayos indica que las variables de respuesta no presentan una dependencia significativa con la densidad del lecho (Figura 5.3).

\subsubsection{Análisis de componentes principales}

\subsubsection{Marco teórico}

Un problema central en el análisis de datos que involucran muchas variables, como los obtenidos durante este trabajo de tesis, es la reducción de la dimensionalidad. Si es posible describir con precisión los valores de $\mathrm{p}$ variables por un subconjunto $r<p$ de ellas, se habrá reducido la dimensión del problema a costa de perder una parte de la información.

El análisis de componentes principales (PCA) es un método matemático bilineal que, dadas $\mathbf{n}$ observaciones de $\mathbf{p}$ variables, tiene como objetivo analizar si es posible representar adecuadamente esta información con un número menor $\mathbf{m}(m<p)$ de variables construidas como combinaciones lineales de las originales [119]. Esto permite representar óptimamente las observaciones de un espacio general pdimensional en un espacio de menor dimensión. La estrategia de esta metodología se basa en la transformación de las variables originales, en general correlacionadas, en nuevas variables no-correlacionadas, facilitando así la interpretación de los datos.

La obtención de componentes principales consiste en obtener los pesos $\mathbf{w}_{\mathbf{k j}}$, con $\mathrm{k}$ y j variando de $1 \mathrm{a} \mathrm{p}$, del siguiente sistema de $\mathrm{p}$ ecuaciones:

$$
\begin{gathered}
e_{1}=w_{11} * X_{1}+w_{12} * X_{2}+\cdots+w_{1 p} * X_{p} \\
e_{2}=w_{21} * X_{1}+w_{22} * X_{2}+\cdots+w_{2 p} * X_{p} \\
\vdots \\
e_{p}=w_{p 1} * X_{1}+w_{p 2} * X_{2}+\cdots+w_{p p} * X_{p}
\end{gathered}
$$


dónde:

$\mathrm{e}_{1}$ a $\mathrm{e}_{\mathrm{p}}$ : son los componentes principales, que generalmente son ordenados en orden decreciente en cuanto a su participación en la varianza de los datos

$\mathrm{w}_{\mathrm{kj}}$ : representan los pesos de la variable j sobre el componente $\mathrm{k}$ ("component loadings")

Los pesos se estiman de modo que se cumplen las siguientes restricciones:

1) El primer componente, $e_{1}$, cubre la fracción máxima de la varianza total de los datos del sistema. El segundo componente, $e_{2}$, cubre la fracción máxima del resto de la varianza total del sistema no incluido en el primer componente y así sucesivamente. De esta forma se obtiene una secuencia de componentes, $e_{1}$ a $e_{p}$, en orden decreciente de importancia (el número máximo de componentes es igual a $p$ ).

2) Normalización: $w_{k 1}^{2}+w_{k 2}^{2}+\cdots+w_{k p}^{2}=1$ con $\mathrm{k}=1, \ldots, \mathrm{p}$

Con esta condición los vectores asociados a los loadings se normalizan y se adopta para evitar que los valores numéricos de los pesos afecten a la varianza representada por un dado componente en relación a los demás.

3) Ortogonalidad: $w_{k 1} * w_{j 1}+w_{k 2} * w_{j 2}+\cdots+w_{k p} * w_{j p}=0 \quad$ con $k \neq j$

Esta condición garantiza que los loadings obtenidos no estén correlacionados.

El objetivo de los algoritmos de cálculo de componentes principales es obtener $\mathrm{w}_{\mathrm{kj}}$ respetando las restricciones 1 a 3 . Matemáticamente esto se logra diagonalizando la matriz de covarianza de los datos de modo de obtener sus autovalores y autovectores [98,99].

\subsubsection{Aplicación de la metodología y resultados}

Utilizando el software estadístico Minitab se realizó el análisis por componentes principales de los valores obtenidos para las variables respuesta en las diferentes series de ensayos. Los datos fueron ingresados en forma matricial, colocando las variables respuesta en columnas y los experimentos $u$ observaciones en filas. La Tabla 5.3 muestra los autovalores de la matriz covarianza junto con las varianzas asociadas a cada uno de ellos, mientras que la Tabla 5.4 presenta las proyecciones (coeficientes) de cada uno de los autovectores sobre las variables originales.

Tabla 5.3. Autovalores de la matriz de correlación de las variables respuesta.

\begin{tabular}{lcccc}
\hline & PC1 & PC2 & PC3 & PC4 \\
\hline Autovalor & 2,0073 & 1,4661 & 0,2923 & 0,2343 \\
Fracción de la varianza explicada & 0,502 & 0,367 & 0,073 & 0,059 \\
Varianza acumulada & 0,502 & 0,868 & 0,941 & 1 \\
\hline
\end{tabular}


Tabla 5.4. Matriz de pesos para los 4 componentes.

\begin{tabular}{lcccc}
\hline Variable & PC1 & PC2 & PC3 & PC4 \\
\hline Fe(II) (ppm) & 0,44 & $-0,586$ & $-0,029$ & $-0,68$ \\
$\mathbf{F e}($ III) (ppm) & 0,445 & 0,562 & 0,66 & $-0,224$ \\
$\mathbf{p H}_{\mathbf{s}}$ & 0,569 & $-0,392$ & 0,188 & 0,698 \\
$\Delta \mathbf{O}_{\mathbf{2}}$ (ppm) & 0,534 & 0,432 & $-0,727$ & 0,004 \\
\hline
\end{tabular}

La Tabla 5.3 muestra que más del $85 \%$ de la varianza total de los resultados experimentales obtenidos puede explicarse empleando sólo dos factores. A partir de la matriz de pesos (coeficientes) de los 2 primeros componentes se obtuvo un gráfico con la ubicación de los experimentos en el nuevo plano de variables definido por PC1 (eje horizontal) y PC2 (eje vertical). Este gráfico se replicó cuatro veces, uno por cada factor. En cada caso se identificó con diferentes colores a los distintos niveles de cada factor para poder observar su efecto sobre la distribución de los scores en el plano PC1-PC2.

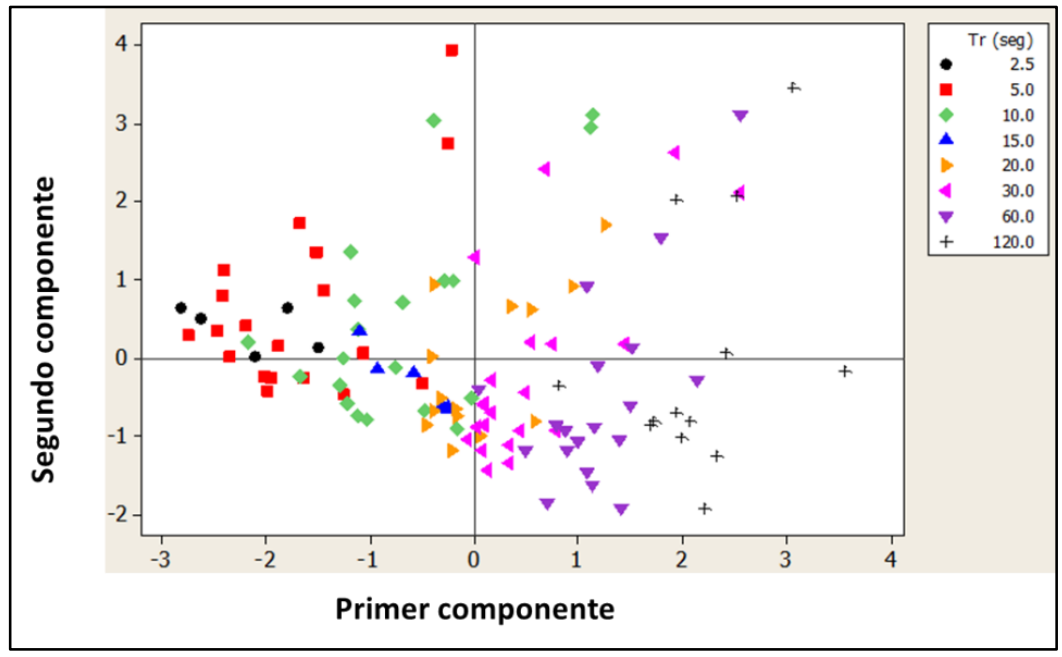

Figura 5.4. Gráfico de los primeros dos componentes, VI: TRH.

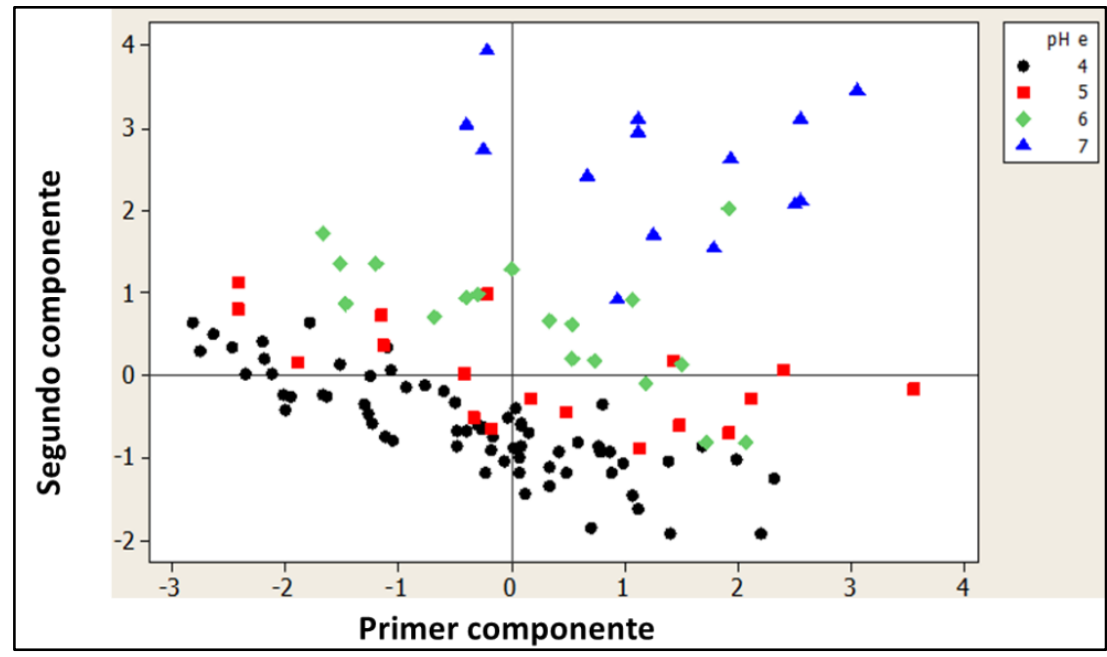

Figura 5.5. Gráfico de los primeros dos componentes, Vl: $\mathrm{pH}$. 


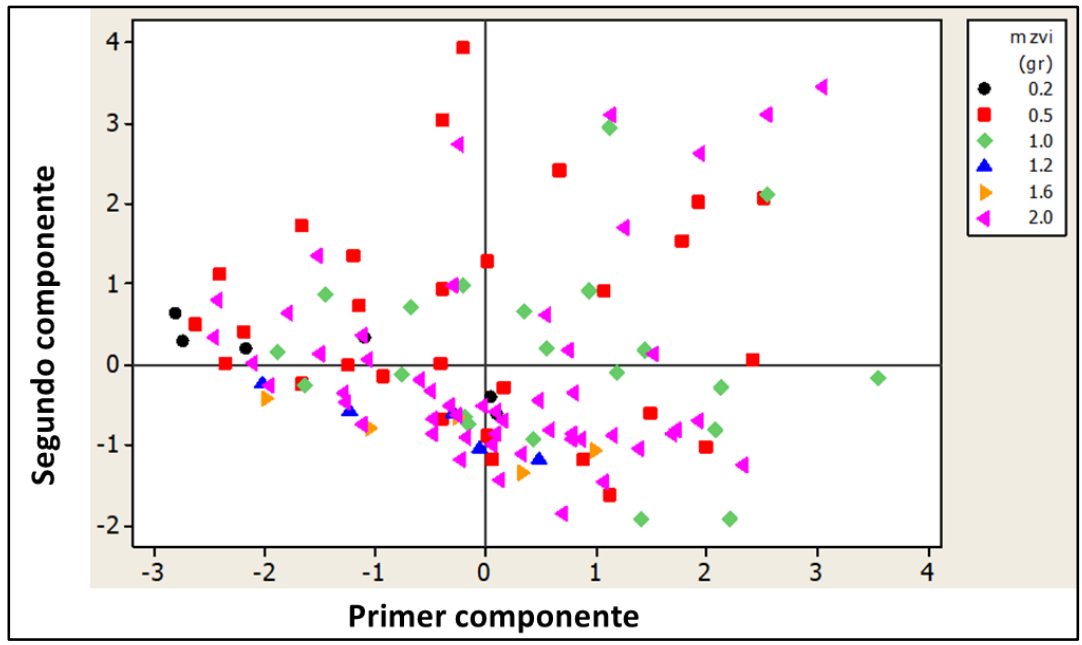

Figura 5.6. Gráfico de los primeros dos componentes, VI: masa.

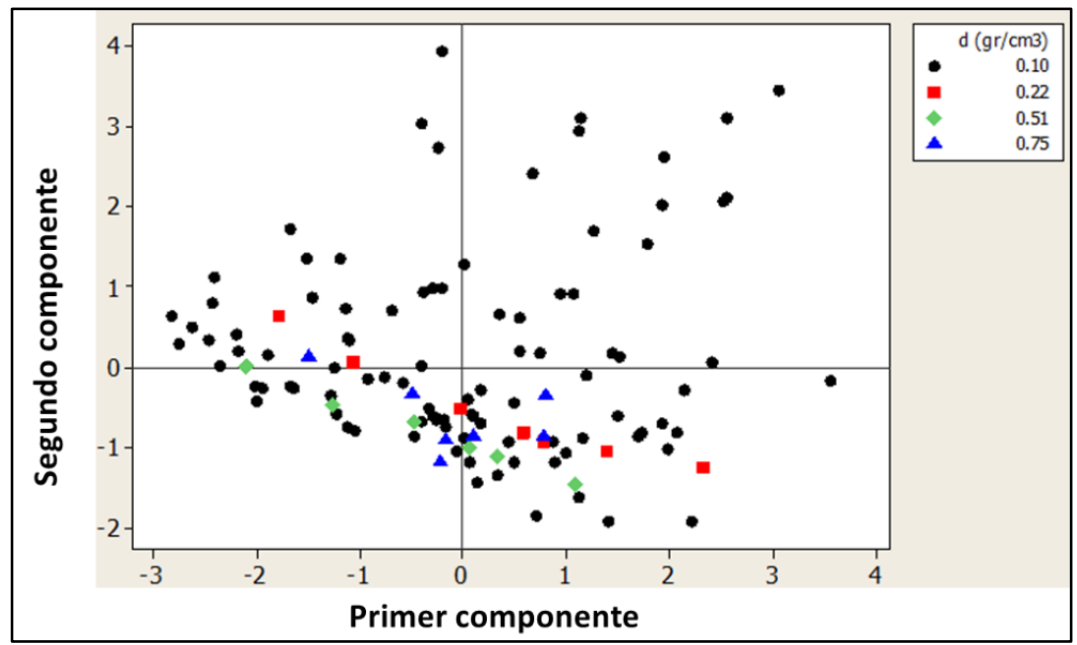

Figura 5.7. Gráfico de los primeros dos componentes, VI: densidad del lecho.

Como se puede observar en la Figura 5.4 el tiempo de residencia se encuentra fuertemente correlacionado con el primer componente principal, indicando que la mayor fracción de la varianza de los datos se asociada a esta variable operativa. Por otro lado, el pH de entrada muestra una clara relación con el segundo componente principal (Figura 5.5), por lo que es una de las variables que también influye significativamente en el comportamiento del sistema.

Cabe destacar que, la comparación del mecanismo propuesto (Cap 1, Reacciones 1.1 a 1.6) con las proyecciones de cada una de las 4 variables de respuesta sobre los 2 ejes abstractos sugiere que el PC1 refleja mayormente las contribuciones asociadas a las reacciones 1 y 2 (y en alguna medida también la 5), mientras que el PC2 tiene una importante contribución de la reacción 5 (y en alguna medida también de la reacción 6 ).

Por último, las Figuras 5.6 y 5.7 muestran que la masa total de ZVI y la densidad del relleno no se correlacionan directamente con ninguno de los dos 
primeros componentes principales, por lo que su influencia en la variabilidad de las respuestas observadas puede considerarse de relevancia menor.

\subsection{REDES NEURONALES ARTIFICIALES (RNA)}

\subsubsection{Marco teórico}

Las RNA son estructuras lógicas que tratan de simular ciertas características propias del cerebro humano tales como la capacidad de memorizar y de adquirir conocimiento mediante el entrenamiento. Una RNA se forma a partir de uno o varios elementos de procesamiento denominados neuronas o perceptrones, los cuales se conectan mediante coeficientes, que constituyen la estructura neural, y se organizan en capas $[120,121]$.

La neurona artificial es la unidad básica de procesamiento de las RNA y posee ciertas características funcionales. Como en el caso de una neurona biológica, una neurona artificial recibe estímulos de entrada que pueden venir del exterior o de la conexión con otras neuronas. La información de entrada que recibe la neurona se puede definir con el vector de entradas $(X)$ :

$$
X=\left[x_{1} x_{2} \ldots x_{n}\right]
$$

Este vector es modificado por un vector $W$ de pesos. Los productos de esta operación se suman para producir la entrada neta S (ec 5.1). Luego, la activación o no de la neurona depende de lo que se denomina función de activación $\mathrm{f}(\mathrm{S})$. Para ello, la entrada neta se evalúa en esta función y se obtiene la salida $O$, la cual se puede propagar hacia otras neuronas o resultar la salida final de la red. Este proceso se ilustra en la Figura 5.8.

$$
S_{j}=\sum_{i=1}^{n} W_{i j} X_{i}+W_{n+1} j
$$

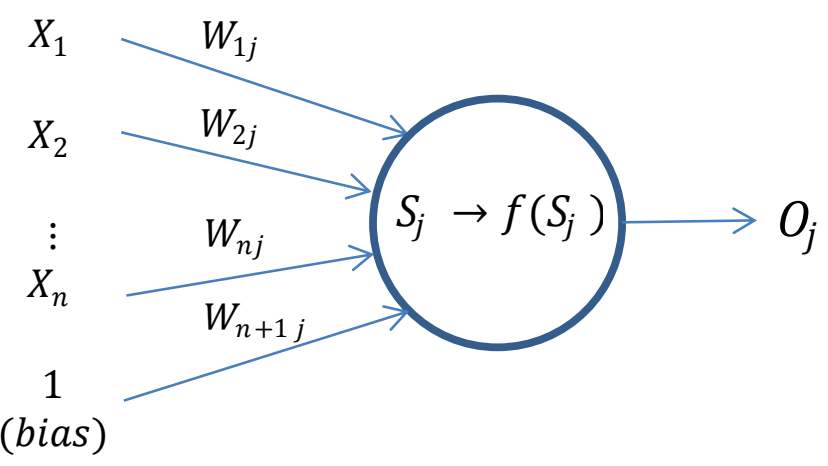

Figura 5.8. Estructura de una neurona artificial. 
La función de activación es una creación matemática utilizada para poder aplicar las RNA a diversidad de problemas reales. En la Tabla 20 se muestran los tipos de funciones de activación más utilizadas.

Tabla 5.5. Funciones de activación utilizadas en neuronas artificiales.

\begin{tabular}{|l|c|c|}
\hline Nombre & \multicolumn{1}{|l|}{ Función } & Rango \\
\hline Identidad & Si $S_{j} \leq a f\left(S_{j}\right)=S_{j}$ & {$[-\infty,+\infty]$} \\
\hline Escalón & Si $S_{j}>a f\left(S_{j}\right)=1$ & {$[0,+1]$} \\
\hline Escalón fuerte & Si $S_{j} \leq a f\left(S_{j}\right)=-1$ & {$[-1,+1]$} \\
\hline Sineal $S_{j}>a f\left(S_{j}\right)=1$ & {$[-\infty,+\infty]$} \\
\hline Sigmoidal & $f\left(S_{j}\right)=a S_{j}+b$ & {$[0,+1]$} \\
\hline Gaussiana & $f\left(S_{j}\right)=\frac{1}{1+e^{-S_{j}}}$ & {$[0,+1]$} \\
\hline $\begin{array}{l}\text { Tangente } \\
\text { hiperbólica }\end{array}$ & $f\left(S_{j}\right)=e^{-S_{j}{ }^{2}}$ & {$[-1,+1]$} \\
\hline
\end{tabular}

La capacidad de procesamiento y la aplicabilidad de una RNA están vinculadas al grado de interconexión entre neuronas. La conexión entre las neuronas está relacionada con la forma en que las salidas se encuentran enlazadas a las entradas de otras nuevas neuronas. La señal de salida de una determinada neurona puede ser la entrada para otra neurona o una entrada a sí misma. De acuerdo con esta condición las redes neuronales se clasifican en dos grupos: cíclicas y acíclicas.

En una red acíclica la información se dirige en un sentido único desde el inicio hacia el final, sin tener ningún retorno y se denominan "feedforward neural networks" (Figura 5.9). Este tipo de redes se utiliza para realizar mapeos no lineales entre los datos de entrada y salida.

Por otro lado, en una red cíclica los arcos o conexiones pueden retornar hacia neuronas anteriores. Este tipo de redes se denominada recurrente o "feedback neural networks" (Figura 5.9). Dada su complejidad, este tipo de redes no ha sido muy utilizado y se encuentra aún en etapa de estudio e investigación. 

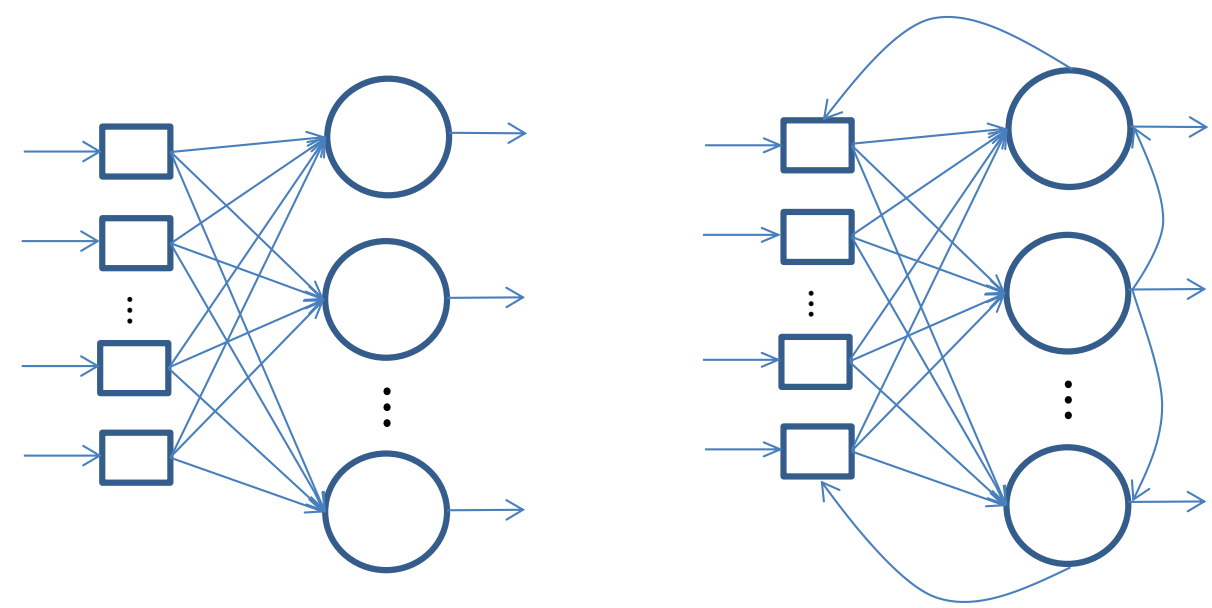

Figura 5.9. RNA sin retorno o "feedforward" (izquierda) y cíclicas o "feedback" (derecha).

La distribución de neuronas dentro de una RNA se realiza formando niveles o capas (de un número determinado de neuronas cada una) por lo que otra forma de clasificar a las RNA es como redes monocapa o como redes multicapa.

Existen diferentes modelos de redes multicapa. Uno de los primeros y más conocidos es el modelo llamado Multilayer Perceptron (MLP), que básicamente consiste en una red de tipo feedforward de tres o más capas (Figura 5.10). Dentro de una MLP, se pueden distinguir tres tipos de capas:

- Capa de entrada: es la capa que recibe las variables de entrada. Esta capa puede encargarse de estandarizar los valores del vector $X$. El número de elementos en la capa de entrada es igual al número de variables de entrada más el bias $(\mathrm{N}+1)$.

- Capas ocultas: son internas a la red y no tienen contacto directo con el exterior. El número de capas ocultas puede ser mayor a uno y el número de neuronas de cada capa $(\mathrm{NH}+1)$ puede variar. Cada neurona tiene una función de activación que usualmente es no lineal, continua y diferenciable. Las funciones de activación de tipo sigmoidal y la tangente hiperbólica son comúnmente utilizadas.

- Capas de salida: es el conjunto de neuronas que transfieren la información que la red ha procesado hacia el exterior. El número de elementos en la capa de salida es igual al número de variables de salida p. La función de activación este tipo de neuronas suele ser lineal. 


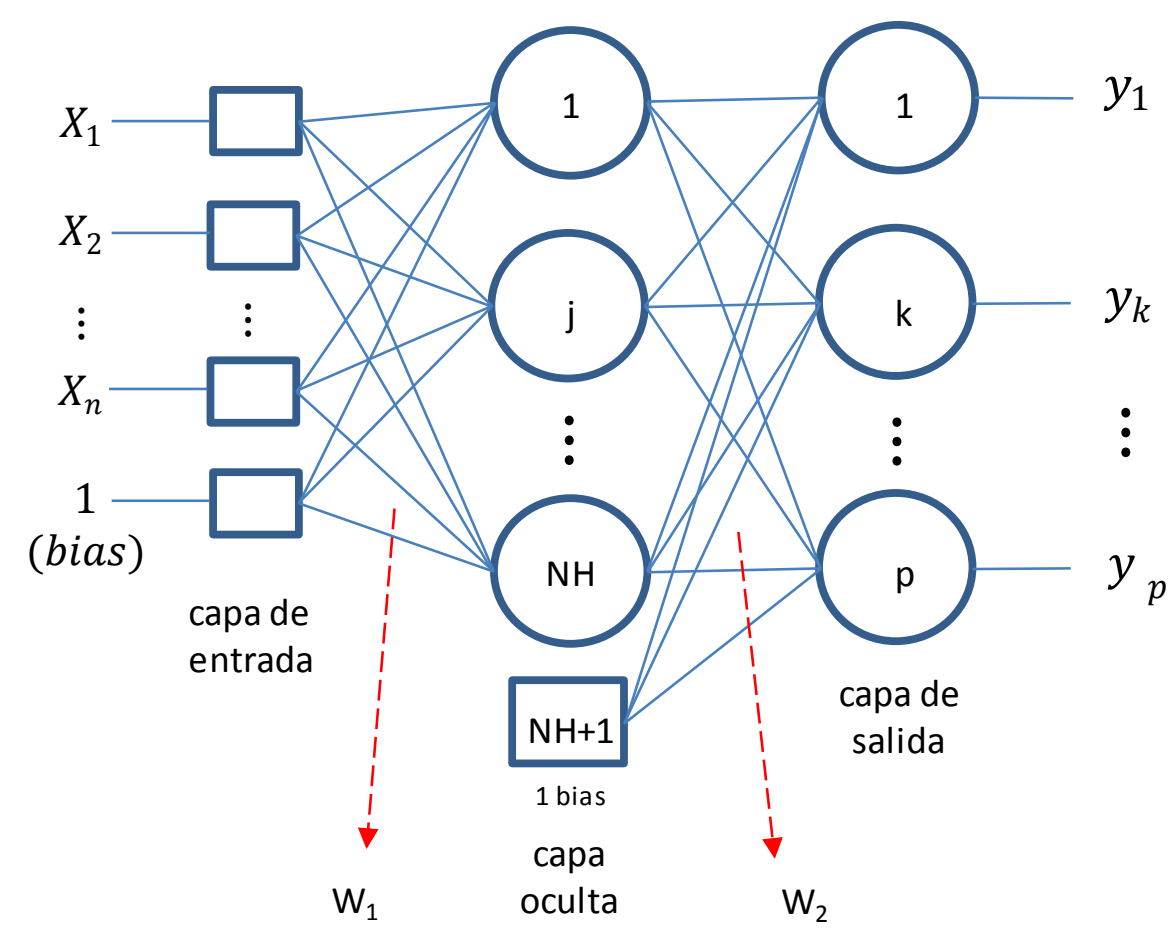

Figura 5.10. Estructura de una red neurona artificial MLP con una capa oculta.

Biológicamente, la información memorizada en el cerebro está relacionada con las intensidades de las conexiones sinápticas entre neuronas. En las redes neuronales artificiales, el conocimiento de la red está representado por las matrices de pesos de las conexiones entre las neuronas $\left(W_{1}\right.$ y $W_{2}$ en la Figura 5.10). Las matrices $W_{1}$ y $W_{2}$ se obtienen luego de un proceso de aprendizaje de la red a partir de los datos.

Uno de los procesos de aprendizaje es el denominado aprendizaje supervisado o por corrección de error. Este consiste en ajustar los pesos de las conexiones de la red en función de la diferencia entre los valores conocidos y los obtenidos en la salida de la red para el conjunto de datos de aprendizaje o entrenamiento (LS, learning set) $[122,123]$. Para un dado conjunto de patrones de aprendizaje el error global de la red se define como la desviación cuadrática que produce la red en sus diferentes neuronas de salida:

$$
E=\sum_{l=1}^{L} \sum_{k=1}^{p}\left(Y_{k, \text { calc }}{ }^{(l)}-Y_{k, \text { exp }}{ }^{(l)}\right)^{2}
$$

dónde:

L: número de observaciones en el conjunto de aprendizaje

$\mathrm{p}$ : número de neuronas en la capa de salida

$Y_{k, \text { calc }}{ }^{(l)}$ : valor de la variable respuesta calculado por la red

$Y_{k, \exp }{ }^{(l)}:$ valor de la variable respuesta esperado o experimental

El algoritmo de aprendizaje más reconocido como método efectivo para el entrenamiento de una RNA es el Backpropagation. Si bien este algoritmo puede presentar algunas dificultades para sortear mínimos locales, es uno de los más 
simples y difundidos para el entrenamiento de una RNA. Cuando se emplea Backpropagation, los pesos se calculan de acuerdo con la siguiente ecuación:

$$
W_{i, j}^{m+1}=W_{i, j}^{m}+\Delta W_{i, j}^{m}
$$

donde:

$W_{i, j}^{m+1}$ : valor actualizado del peso sináptico

$W_{i, j}^{m}$ : valor actual del peso sináptico

$\Delta W_{i, j}^{m}$ : variación del peso sináptico

Por otro lado, existen varias estrategias para evaluar los valores de $\Delta W_{i, j}^{m}$ durante el proceso de optimización entre los que se pueden mencionar el método del gradiente descendente, el algoritmo de Levenberg-Marquardt y métodos basados en gradientes conjugados [124]. Uno de los más utilizados es el método del gradiente descendente. En este caso el ajuste de los pesos se puede hacer de forma proporcional a la variación relativa del error que se obtiene al variar el peso correspondiente:

$$
\Delta W_{i, j}^{m}=\eta\left(-\frac{\partial E}{\partial W_{i, j}}\right)
$$

Donde: $\eta$ es el parámetro de aprendizaje o convergencia.

Con este algoritmo, cada vez que se realizan cambios a los pesos de la red, se asegura el descenso por la superficie del error hasta encontrar el valle más cercano. Uno de los problemas que presenta este algoritmo de entrenamiento es que busca minimizar la función de error, pudiendo caer en un mínimo local o en algún punto estacionario. En consecuencia, en ciertos casos no se llega a encontrar el mínimo global de la función de error.

La velocidad de convergencia y la posibilidad de encontrar un mínimo global o local está asociada al parámetro de aprendizaje $\eta$, para el que normalmente se emplean valores del orden de 0,05 a 0,25. También se puede trabajar con el mismo algoritmo pero con $\eta$ variable en el proceso de aprendizaje con el fin de modificar el tamaño de la variación de los pesos $\Delta \mathrm{W}$ y acelerar la convergencia del algoritmo de aprendizaje.

El proceso de cálculo sigue hasta que el valor de $\mathrm{E}$ de la red cumpla con un criterio de tolerancia o se alcance el número máximo de iteraciones. En el caso de las RNA el valor de $E$ que finaliza el proceso de cálculo es evaluado en un conjunto de datos independientes al de entrenamiento denominado test set (TS).

\subsubsection{Aplicación de la metodología y resultados}

\subsubsection{Desarrollo de redes neuronales}

Luego de realizar un análisis preliminar del efecto de las variables de entrada (factores) sobre las variables salida (respuestas) mediante el análisis de la matriz de 
correlación, el análisis de conglomerados y el análisis por componentes principales, se utilizó la metodología de las RNA para modelar al sistema definido por 4 variables de entrada o independientes y 4 variables de salida o dependientes (Tabla 5.6).

Tabla 5.6. Variables de entrada y salida para el modelado mediante RNAs.

\begin{tabular}{ll}
\hline Variables de entrada: & Variables de salida: \\
\hline Densidad del lecho $\left(\mathrm{gr} / \mathrm{cm}^{3}\right)$ & Concentración de $\mathrm{Fe}(\mathrm{II})$ a la salida $(\mathrm{ppm})$ \\
Masa de $\mathrm{ZVI}(\mathrm{gr})$ & Concentración de Fe(III) a la salida $(\mathrm{ppm})$ \\
$\mathrm{pH}$ de entrada & $\mathrm{pH}$ a la salida \\
\hline Tiempo de residencia hidráulico $(\mathrm{seg})$ & Oxigeno consumido a lo largo del lecho $(\mathrm{ppm})$ \\
\hline
\end{tabular}

A partir de un total de 125 experimentos u observaciones el objetivo fue obtener el mejor ajuste utilizando redes del tipo MLP con una sola capa oculta. Las redes construidas a lo largo del capítulo serán identificadas mediante tres índices que indican el número de neuronas en cada una de las capas: RNA ( N NH P), donde $\mathrm{N}$ es el número de neuronas de la capa de entrada, $\mathrm{NH}$ el número de neuronas de la capa oculta y $\mathrm{P}$ el número de neuronas de la capa de salida.

En el presente estudio se consideraron dos opciones de modelado posibles:

- una red única con 4 variables de entrada y 4 variables de salida para el modelado de todas las variables respuesta,

- un conjunto de 3 redes, una por cada serie de experimentos, con 4 variables de entrada y 4 variables de salida cada una,

Para cada opción de modelado se determinó el número de neuronas de la camada oculta $(\mathrm{NH})$ que minimiza el error entre el valor experimental y el valor predicho por la red para las variables respuesta en el conjunto de datos del test set.

\subsubsection{Entrenamiento de redes neuronales}

Empleo de una red única para el modelado de todas las series de ensayos

Para el entrenamiento de la red única se utilizó el software Neuro14 [125] desarrollado por el LSCP (Laboratorio de Simulación y Control de Procesos) de la Universidad de San Pablo. Este programa utiliza el método de Backpropagation y actualiza los pesos según el algoritmo del gradiente descendente.

Para cada ejecución el programa requiere del ingreso de la siguiente información: número de variables de entrada $(N)$, número de variables salida $(P)$, número de experimentos del learning test $(\mathrm{NL})$, número de experimentos del test set (NT), número de neuronas de la camada oculta $(\mathrm{NH})$, número de iteraciones máximas $(\mathrm{NI})$, parámetro de aprendizaje $(\eta)$ y dos grupos de experimentos (LS y TS) con valores de entrada y salida.

El conjunto de NL experimentos es utilizado para ajustar los parámetros de la simulación y el conjunto NT de experimentos es utilizado para estimar el valor 
predictivo de los parámetros ajustados. Los experimentos correspondientes al TS deben poseer, para sus variables entradas, valores en el interior del intervalo del dominio de todos los experimentos. El valor de $\eta$, que corresponde al tamaño de paso de cada iteración, puede ser un constante o variable. En este último caso se indica un valor inicial, uno mínimo y uno máximo.

Luego de cada simulación el programa reporta:

- Ios valores del error cuadrático medio del LS (MSEL) y del TS (MSET) y el valor de $\eta$ cada 100 iteraciones

- las matrices de pesos de la camada oculta y salida correspondiente al paso de iteración donde MSEL es mínimo

- las matrices de pasos de la camada oculta y salida correspondiente al paso de iteración donde MSET es mínimo

- las matrices de comparación $\mathrm{y}_{\text {cal }}$ - $\mathrm{y}_{\text {exp }}$ calculas con los pesos de la camada oculta y salida correspondiente al paso de iteración donde MSEL es mínimo

- las matrices de comparación y $y_{\text {cal }}$-yexp calculas con los pesos de la camada oculta y salida correspondiente al paso de iteración donde MSET es mínimo.

Cabe destacar que para cada opción de modelado, además de los valores de $\mathrm{NH}$, también se variaron los parámetros de aprendizaje: el factor de ajuste ( $\eta$ ) y el número máximo de iteraciones ( $\mathrm{NI}$ ). Naturalmente, la calidad de los ajustes obtenidos puede depender de los tres parámetros mencionados anteriormente. En este sentido vale la pena destacar que, si bien al incrementar el número de neuronas es posible reducir los errores cuadráticos medios, como regla general la cantidad de neuronas en la red debe ser lo más baja posible para evitar problemas de ajuste excesivo o sobre parametrización.

Inicialmente se seleccionó $\mathrm{NL}=90$ y $\mathrm{NT}=35$ y se configuró una RNA $(4, \mathrm{NH}, 4)$. Luego de una serie de simulaciones con diferentes valores de $\mathrm{NH}, \eta$ y $\mathrm{NI}$ se observó un grupo claro de "outliers" en el conjunto de datos del TS (Figura 5.11 a y d). Dado que los outliers detectados correspondían a un día específico de experimentos, este grupo de datos fue eliminado del conjunto a utilizar. Por otro lado, los gráficos de $y_{\text {calc }}$ versus $y_{\text {exp }}$ para los experimentos correspondientes al TS muestran un ajuste muy pobre para los valores de $\mathrm{Fe}(\mathrm{III})$ (Figura $5.11 \mathrm{~b}$ ). Como ya se discutió previamente, es muy posible que este resultado se deba a que las variaciones en esta variable son muy poco significativas y no pueden atribuirse de manera sencilla a cambios en los factores. Por este motivo, se decidió realizar una nueva red con 3 variables de salida, descartando al $\mathrm{Fe}(\mathrm{III})$ como variable respuesta a analizar. 

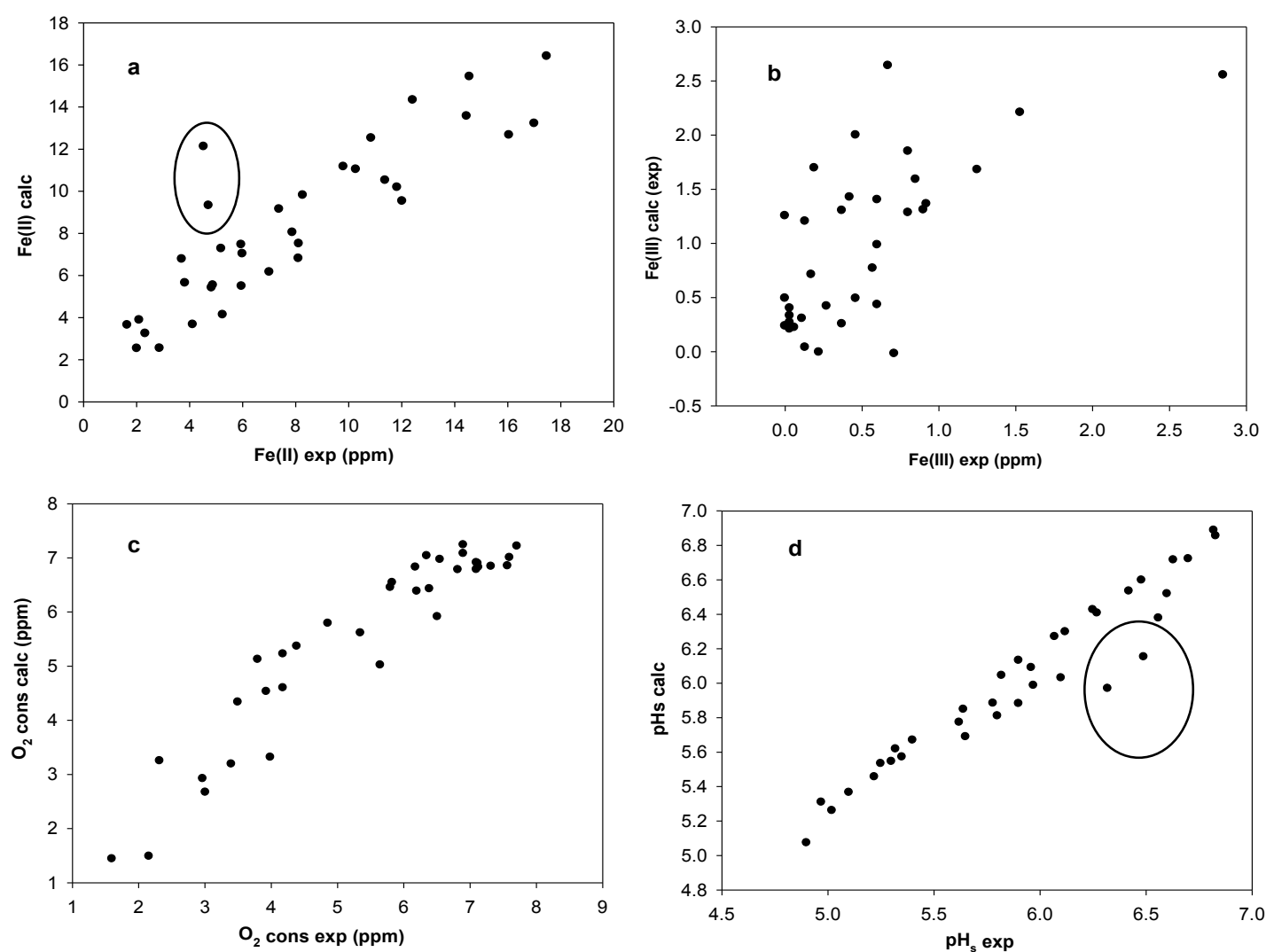

Figura 5.11. Gráfico de los valores obtenidos de las variables respuesta mediante una red neuronal única con $\mathrm{N}=4, \mathrm{NH}=5$ y $\mathrm{P}=4$ para el conjunto de datos del TS.

Con un nuevo grupo de NL= 84 experimentos y NT=35 se construyó una RNA $(4, \mathrm{NH}, 3)$. Se realizaron ajustes preliminares variando $\mathrm{NH}$ de 5 a 12, $\mathrm{NI}$ de 20000 a 500000 , y empleando valores de $\eta$ tanto constantes como variables para el intervalo entre 0,01 y 0,5 . Los mejores ajustes fueron obtenidos utilizando $\eta$ constante. Posteriormente, fijando los valores de $\eta=0,02$ y de $\mathrm{Nl}=500000$, se analizó el comportamiento del MSEL y MSET al aumentar $\mathrm{NH}$. Los resultados obtenidos muestran en este caso que, para $\eta$ constante, al aumentar $\mathrm{NH}$ el error disminuye y el ajuste mejora.

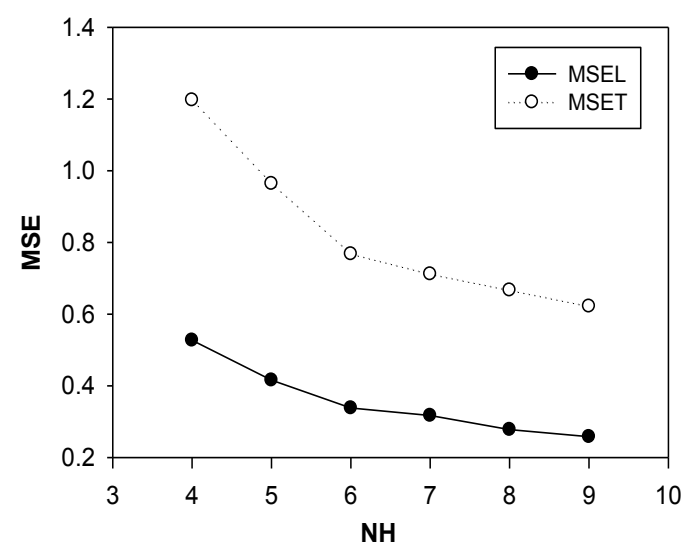

Figura 5.12. Evolución de los errores cuadráticos medios del LS (MSEL) y del TS (MSET) en función del número de neuronas de la camada oculta $(\mathrm{NH})$ para $\mathrm{N}=4, \mathrm{P}=3, \eta=0,02$ y $\mathrm{NI}=500000$. 
Como puede observarse en la Figura 5.12, al aumentar el $\mathrm{NH}$ ambos errores disminuyen en un comienzo rápidamente para luego hacerlo lentamente. Finalmente, se seleccionó $\mathrm{NH}=7$ ya que al aumentar este parámetro la disminución en el MSET es menor al $10 \%$.

Como resultado del entrenamiento se obtuvieron las matrices de pesos $W_{1}$ y $\mathrm{W}_{2}$ que permitieron la simulación de los valores de las variables respuesta para todas las condiciones experimentales ensayadas. Con 7 neuronas en la capa oculta, se calculó un total de 59 pesos: 35 entre la entrada y las capas ocultas (4 pesos más un "bias" para cada neurona de la capa oculta) y 24 entre las capas ocultas y de salida (7 pesos más un "bias" por cada neurona de la capa de salida). Los pesos correspondientes obtenidos con el software Neuro14 se muestran en la Figura 5.13. Estos pesos corresponden a los valores que conducen a la mínima desviación cuadrática para la simulación en el TS.

$W_{1}=\left[\begin{array}{ccccccc}-0.494 & -4.84 & -0.285 & 0.848 & 0.118 & -2.09 & 0.611 \\ -14.8 & -0.675 & 1.630 & -1.71 & -0.975 & 1.370 & 3.090 \\ 4.280 & 1.070 & 0.264 & -1.42 & 1.780 & -0.0592 & -3.81 \\ -2.73 & -9.80 & -0.247 & 1.280 & 2.340 & 22 & 1.62 \\ 0.930 & 0.940 & 0.946 & 0.578 & 0.717 & 0.4890 & 0.996\end{array}\right] \quad W_{2}=\left[\begin{array}{rrr}-1.66 & -2.21 & -4.96 \\ -2.42 & -6.78 & -2.08 \\ -10.3 & -5.70 & 1.13 \\ -8.83 & -1.04 & -1.86 \\ 9.08 & -1.48 & 5.63 \\ 2.69 & 8.87 & 2.41 \\ 4.33 & -2.47 & -7.23 \\ 0.562 & 0.895 & 0.521\end{array}\right]$

Figura 5.13. Matrices de pesos de la RNA construida.

La Fig. 5.14 muestra la comparación entre valores calculados y experimentales de las variables de salida tanto para el conjunto de aprendizaje como de prueba, usando la RNA $(4,7,3)$. El ajuste es relativamente bueno si se tiene en cuenta el elevado número de observaciones, la cantidad de variables intervinientes en el proceso y la compleja interacción entre ellas.
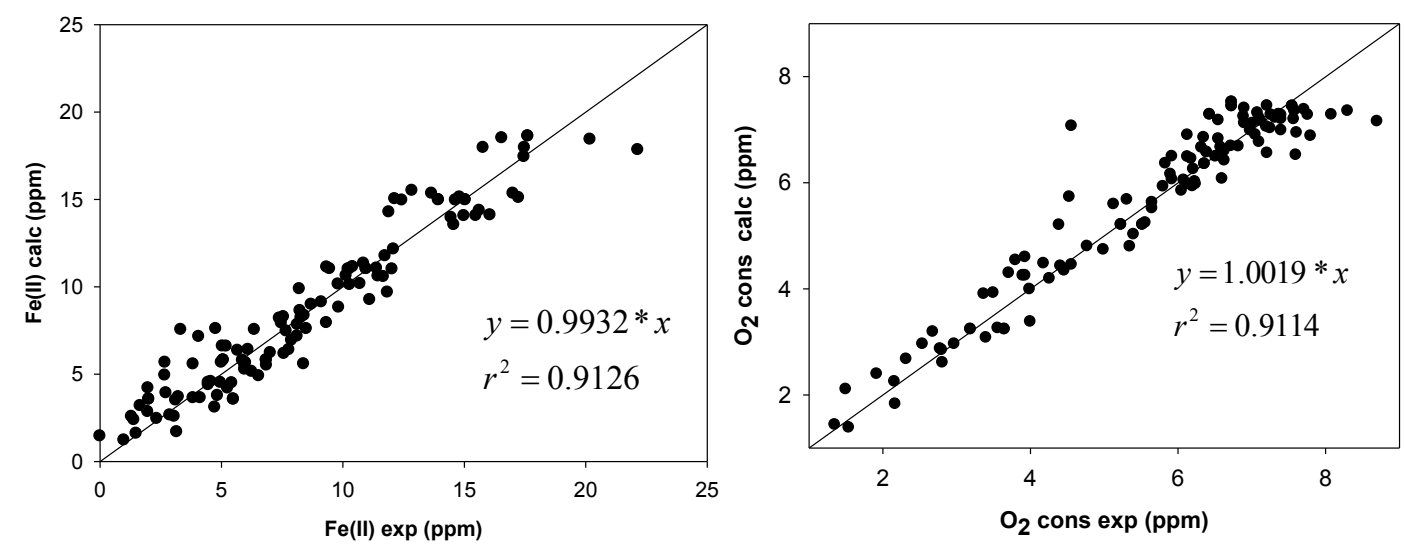

Figura 5.14 (a). Gráfico de los valores obtenidos de las variables respuesta mediante una red neuronal única con $\mathrm{NH}=7$ para todos los valores experimentales. 


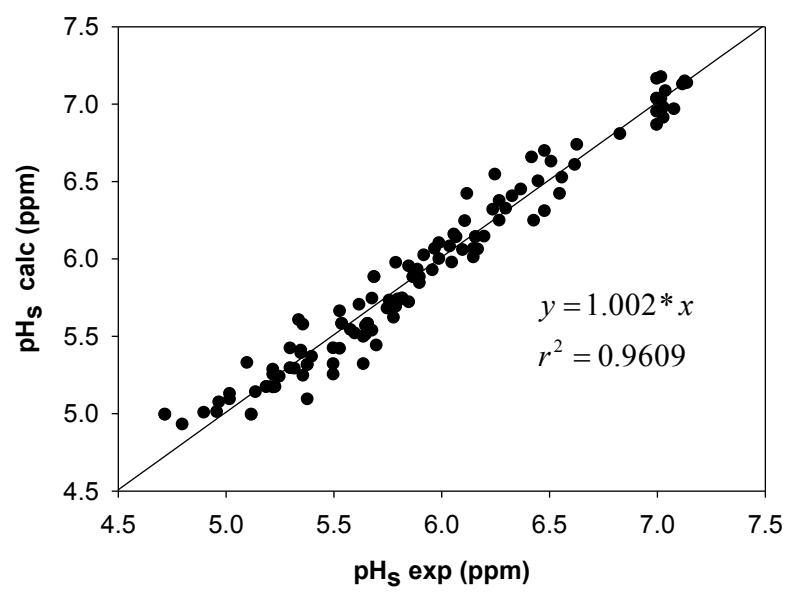

Figura 5.14 (b). Gráfico de los valores obtenidos de las variables respuesta mediante una red neuronal única con $\mathrm{NH}=7$ para todos los valores experimentales.

Empleo de una red para el modelado de cada serie de ensayos

La alternativa planteada previamente permite simular de manera correcta los resultados obtenidos para los experimentos realizados. Sin embargo, no puede utilizarse para predecir el comportamiento del sistema en la diferentes condiciones $u$ observar tendencias para todo el dominio definido por los valores máximos y mínimos de los factores controlados ya que no se trabajó con un diseño capaz de arrojar información estadísticamente válida para el dominio experimental completo. Por lo tanto, como una opción alternativa de modelado los datos experimentales correspondientes a cada serie de ensayos realizada fueron analizados empleando tres redes neuronales diferentes. Dado que cada serie individual representa a un diseño experimental del tipo factorial completo, esta nueva organización de los resultados en tres redes diferentes permitió realizar una evaluación más clara las tendencias generales.

En este caso el diseño de las redes fue realizado utilizando la aplicación Neural Net Fitting de Matlab. Para el ingreso de los datos las matrices de variables de entrada y salida fueron previamente adimensionalizadas. A diferencia del programa Neuro14, en este caso se utilizó para el aprendizaje el algoritmo de Levenberg-Marquardt. Además, como se mencionó previamente, los datos fueron separados en tres sets: entrenamiento, validación y test.

En esta aplicación los experimentos u observaciones fueron asignados de manera aleatoria en cada uno de los sets. Del total de observaciones de cada serie, el $75 \%$ se asignó al set de entrenamiento, el $15 \%$ al de validación y el $10 \%$ al de test. El set de entrenamiento y el de validación cumplen los mismos roles que el LS y el TS en el programa Neuro14. Los datos del test set no tienen ningún efecto en el entrenamiento $\mathrm{y}$, por lo tanto, proporcionan una medida independiente del desempeño de la red después del entrenamiento.

Para seleccionar la red que presente el mejor ajuste se plantearon redes MLP con una sola capa oculta y valores de $\mathrm{NH}$ comprendidos entre 2 y 10 . Se realizaron 15 entrenamientos de cada red. A partir de los resultados obtenidos, se eligió el valor de 
$\mathrm{NH}$ y las matrices de pesos que presentaron el menor valor del MSE para el conjunto de datos del test set en cada una de las series.

La figura 5.15 muestra que, exceptuando algunos "outliers", para las variables respuesta $\left(\mathrm{Fe}(\mathrm{II}), \mathrm{O}_{2}\right.$ consumido y diferencia de $\mathrm{pH}$ ) se obtuvieron muy buenos ajustes entre los valores experimentales y los correspondientes valores calculados para todo el conjunto de datos utilizando tres redes independientes
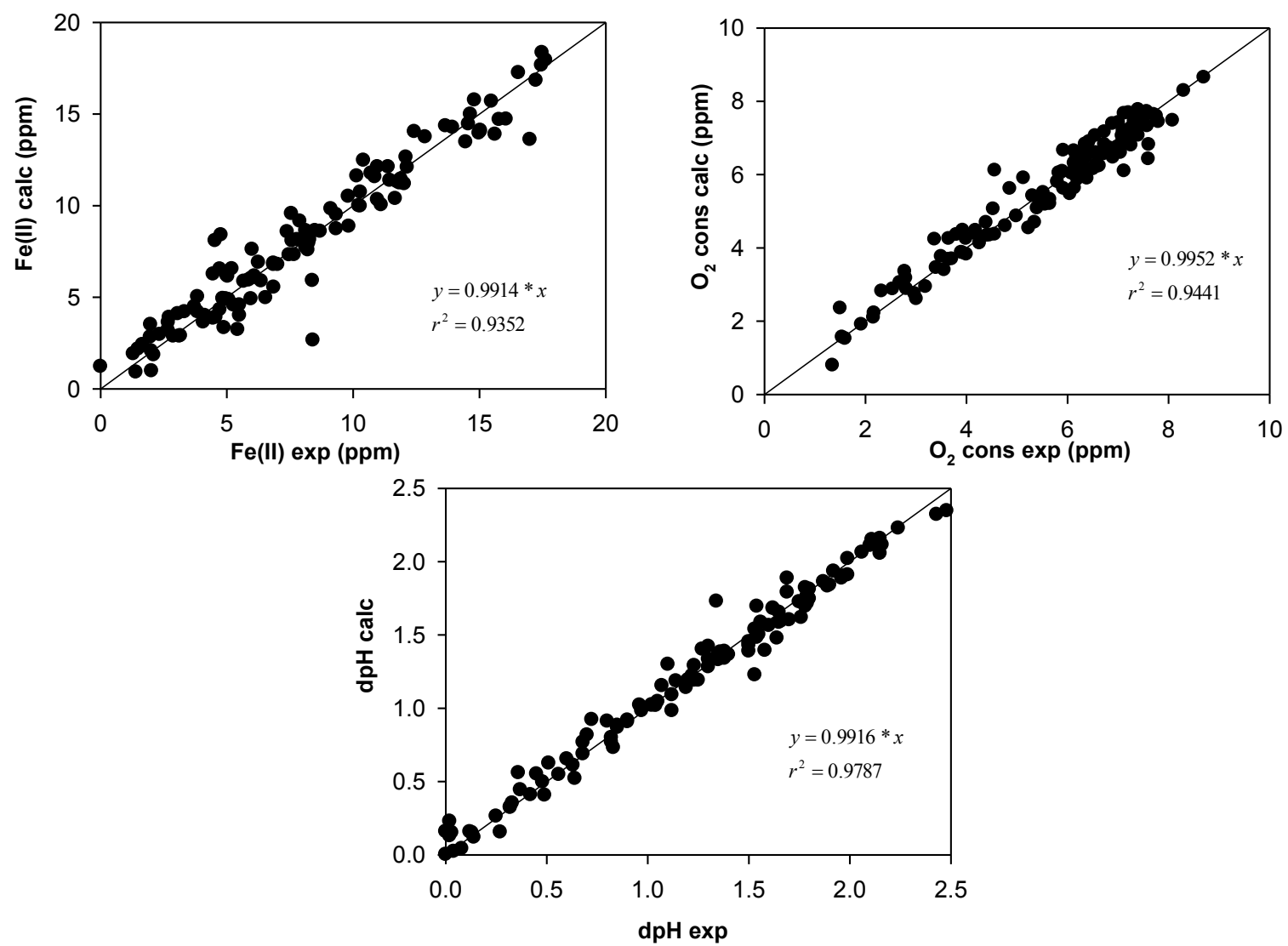

Figura 5.15. Gráfico de los valores obtenidos de las variables respuesta mediante tres redes independientes en función de los correspondientes valores experimentales (1era serie: RNA $(3,7,3)$, 2da serie: RNA $(2,4,3)$, 3ra serie: RNA $(2,4,3)$ ).

Una vez obtenidas las tres redes que permitieron obtener un buen ajuste de los datos experimentales, estas redes fueron utilizadas para simular el comportamiento del sistema en todo el dominio experimental estudiado.

\subsubsection{Simulación de los valores de las variables de respuesta}

Primera serie de experimentos

Los pesos correspondientes a la RNA $(3,7,3)$ construida para la primera serie de experimentos se muestran en las matrices $W_{1}$ y $W_{2}$ de la Figura 5.16. Utilizando estas matrices se trabajó con una rutina de Matlab que permite construir la RNA de tres capas y obtener la simulación de los resultados. La utilización de esta rutina 
permite predecir el comportamiento del sistema bajo cualquier condición operativa dentro del rango experimental estudiado en esta serie.

$$
W_{1}=\left[\begin{array}{ccccccc}
-0.0412 & -6.1598 & 0.0691 & 0.3853 & 0.9303 & 4.9854 & -2.9544 \\
0.7180 & -0.0689 & -0.7366 & 0.7307 & -1.7893 & -0.0708 & 0.0143 \\
-0.7095 & -3.1959 & -0.8939 & -0.051 & -0.0325 & -2.2603 & -1.5793 \\
0.2538 & 2.3945 & 1.1643 & 0.4465 & 0.8749 & -1.2395 & -4.8806
\end{array}\right]
$$$$
W_{2}=\left[\begin{array}{ccc}
-0.9124 & 0.4598 & -0.5275 \\
-1.0703 & -2.5592 & -0.7486 \\
0.6131 & -0.164 & 0.5794 \\
0.8756 & -0.7428 & -0.7167 \\
0.3436 & -0.0329 & -0.105 \\
-1.4329 & -2.4696 & -0.6512 \\
-0.6132 & -2.708 & -0.5154 \\
-1.3893 & -1.7497 & -0.7227
\end{array}\right]
$$

Figura 5.16. Matrices de pesos de la RNA construida para la primera serie de ensayos $(\mathrm{NH}=7, \mathrm{Nexp}=67)$.

En la Figura 5.17 se muestran las superficies de respuesta para las tres variables de salida analizadas $\left(\mathrm{Fe}(\mathrm{II}), \mathrm{O}_{2}\right.$ consumido y diferencia de $\mathrm{pH}$ ) construidas mediante la RNA propuesta para los ensayos realizados con una masa de ZVI de $1 \mathrm{~g}$ a diferentes TRHs y $\mathrm{PH}$ de entrada. Las superficies permiten visualizar el importante efecto del TRH sobre las tres variables respuesta. Por otro lado, se observa que el pH de entrada afecta a la generación de $\mathrm{Fe}(\mathrm{II})$ y a la variación del $\mathrm{pH}$ pero prácticamente no afecta al consumo de oxígeno.
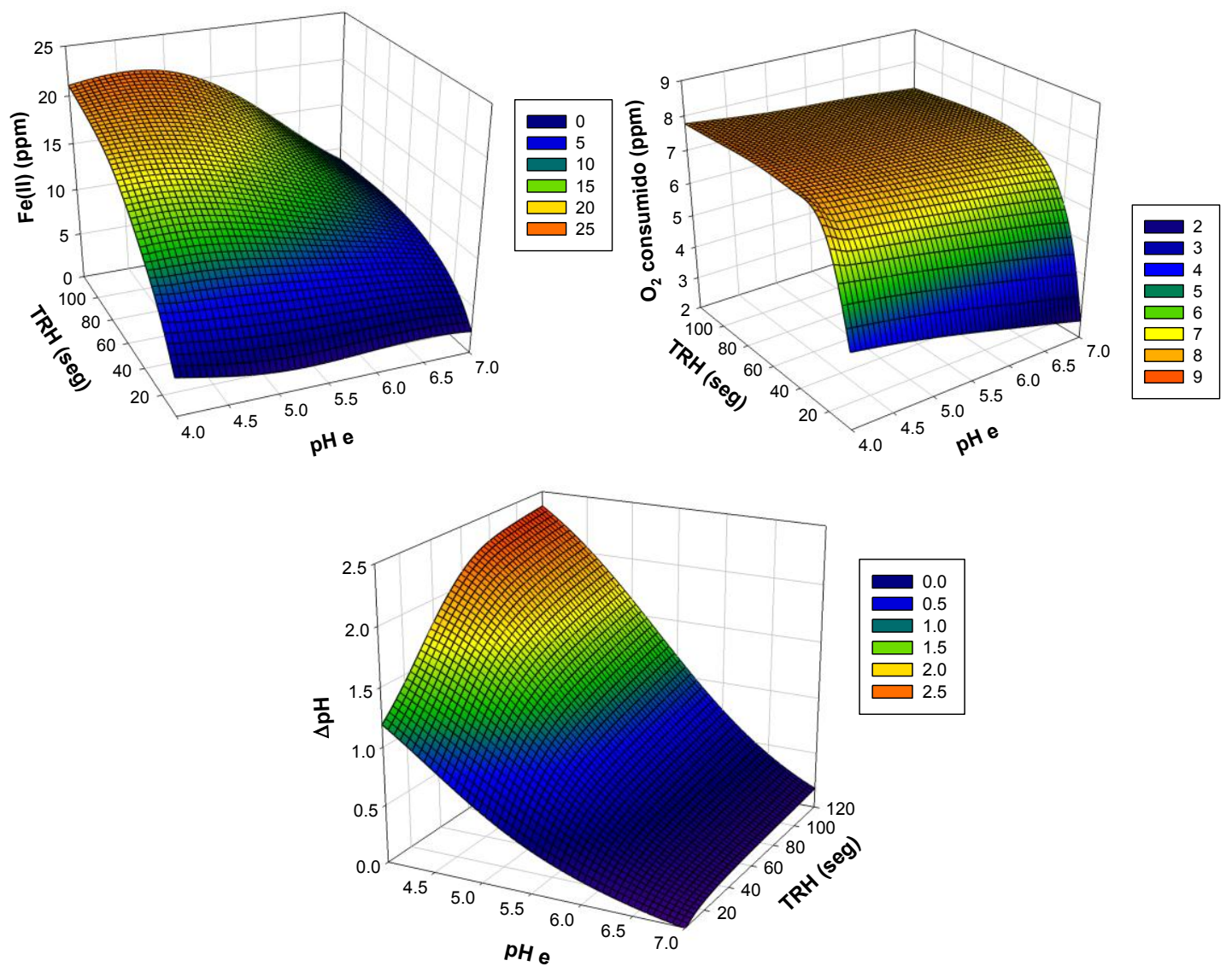

Figura 5.17. Superficies de respuesta construidas a partir de la RNA $(3,7,3)$ ( $\left.m_{z v l} 1 \mathrm{gr}\right)$. 
En los gráficos de la Figura 5.18 a 5.20 se pueden observar los perfiles de la simulación de las variables respuestas ( $\mathrm{Fe}(\mathrm{II}), \mathrm{O}_{2}$ consumido y diferencia de $\mathrm{pH}$ ) en función del tiempo de residencia hidráulico para todas las condiciones de operación correspondientes a la primera serie de ensayos. Con fines comparativos, se incluyen también los valores experimentales (puntos). Puede observarse un buen ajuste de las tendencias generales para casi todas las series de datos, aunque se destacan algunas particularidades del ajuste. Para valores altos TRH se observa cierta curvatura en los perfiles simulados cuando en realidad los datos experimentales sugieren un comportamiento más suave. Esta dificultad de la red para predecir correctamente el comportamiento del sistema parece incrementarse al aumentar el $\mathrm{pH}$. Es posible que, al haber una menor densidad de datos experimentales en la región de altos TRHs, la red este ajustando en parte al error experimental asociado a los datos del conjunto de condiciones analizado.
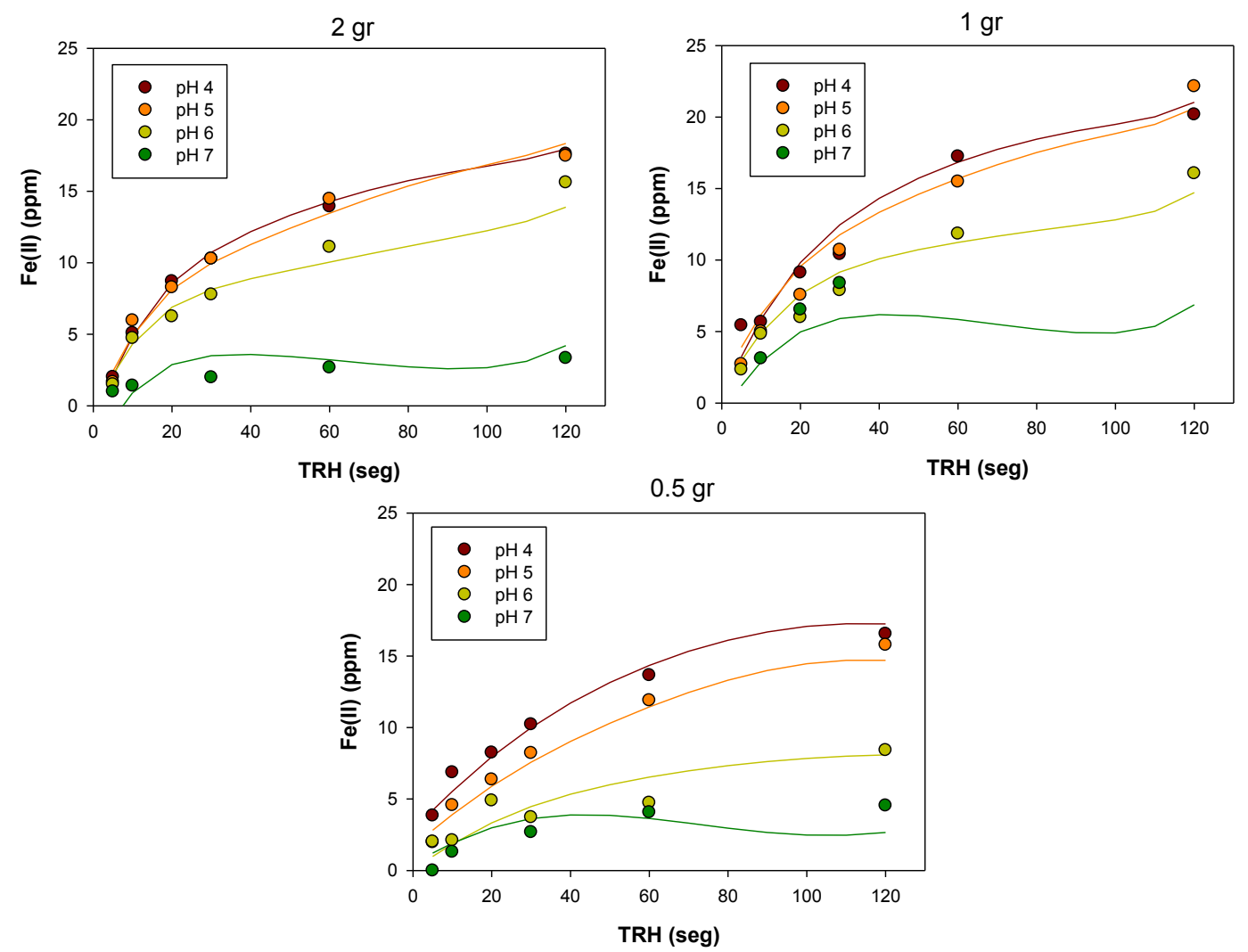

Figura 5.18. Perfiles de Fe(II) en función del TRH para las tres masas de ZVI utilizadas y los 4 pHs de entrada: datos experimentales (puntos) y valores calculados utilizando la RNA $(3,7,3)$ (línea continua). 

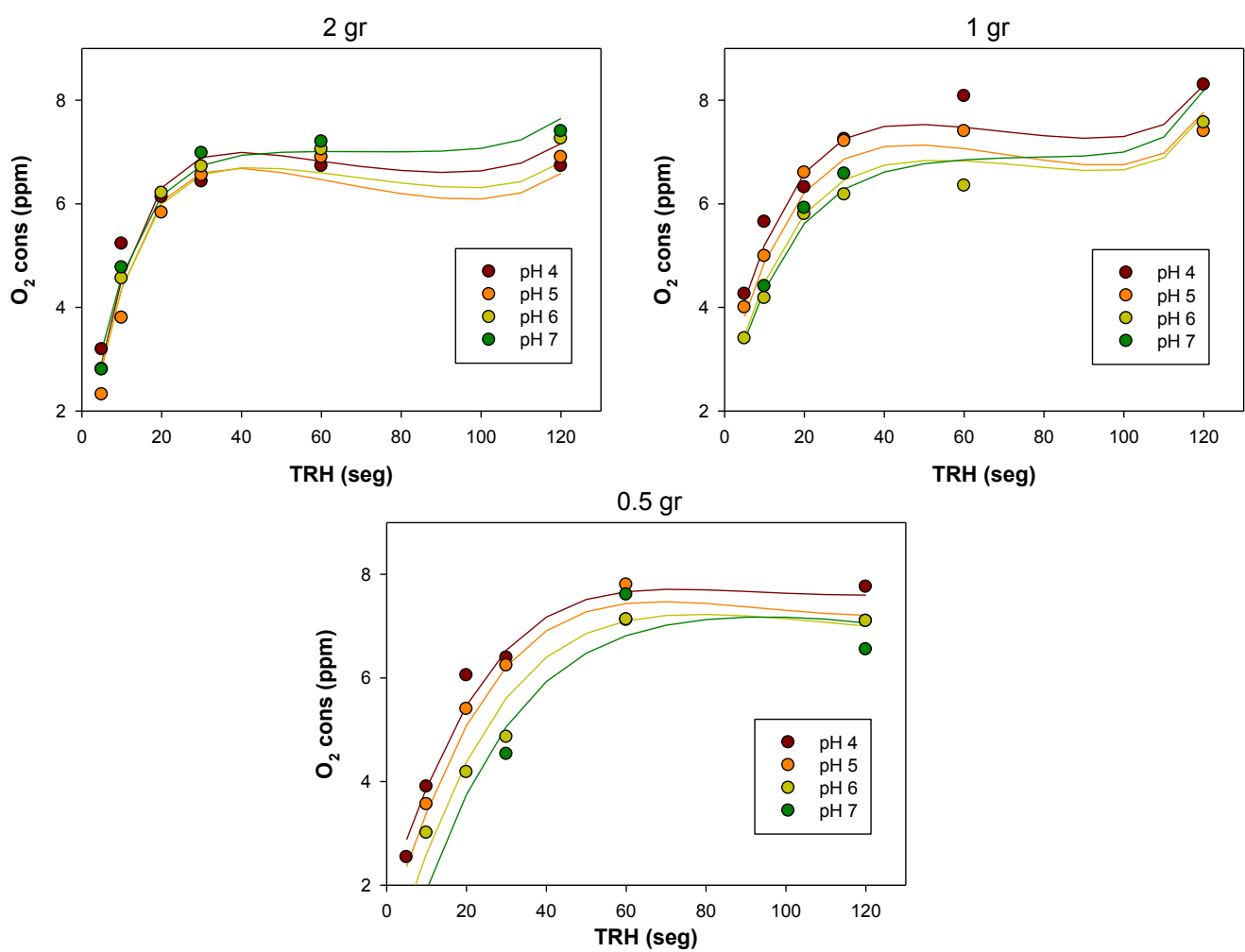

Figura 5.19. Perfiles de oxígeno consumido en función del TRH para las tres masas de ZVI utilizadas y los $4 \mathrm{pHs}$ de entrada: datos experimentales (puntos) y valores calculados utilizando la RNA $(3,7,3)$ (línea continua).
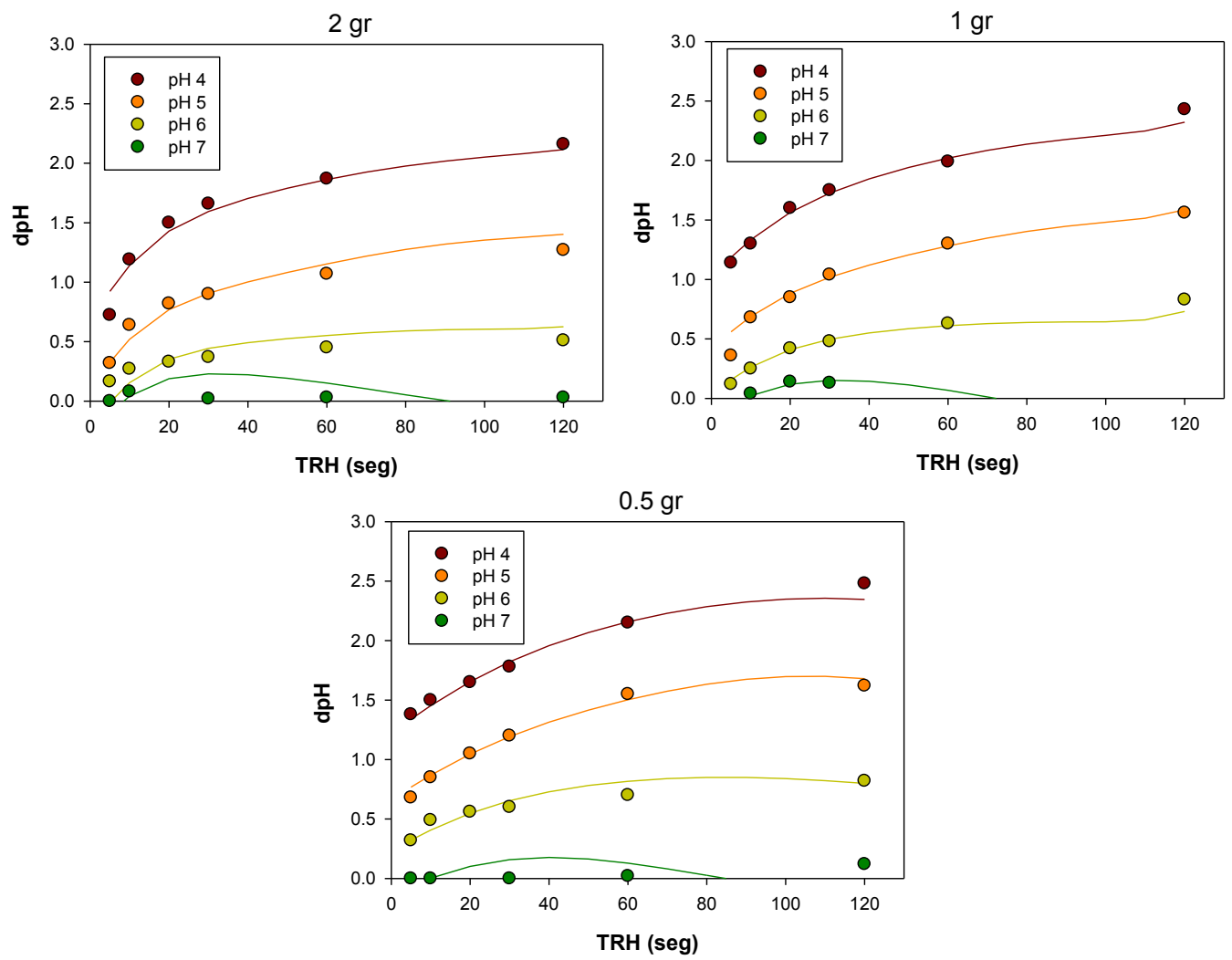

Figura 5.20. Diferencia entre el pH de entrada y salida en función del TRH para las tres masas de ZVI utilizadas y los $4 \mathrm{pHs}$ de entrada: datos experimentales (puntos) y valores calculados utilizando la RNA $(3,7,3)$ (línea continua). 
Segunda serie de experimentos

Las matrices de pesos utilizadas para la construcción de la RNA $(2,4,3)$, correspondiente a la segunda serie de ensayos se muestran en la Figura 5.21. Por otra parte, en la Figura 5.22 se representan las diferentes variables respuesta en función del tiempo de residencia hidráulico para todas las condiciones de operación correspondientes a la segunda serie de ensayos. Finalmenye, en la Figura 5.23 se incluyen las superficies de respuesta obtenidas a partir de la RNA diseñada para esta serie.

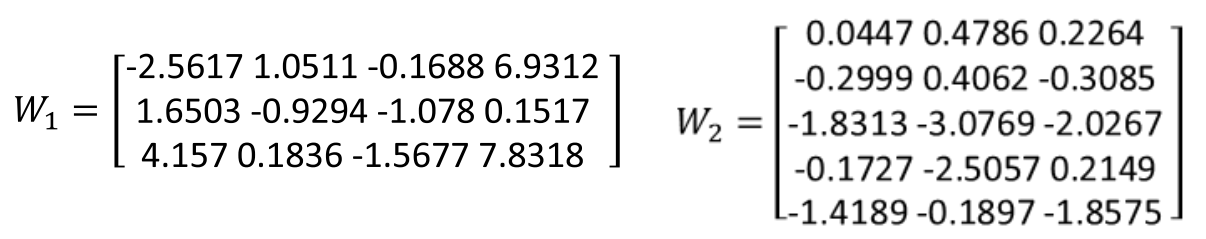

Figura 5.21. Matrices de pesos de la RNA construida para la segunda serie de ensayos $(\mathrm{NH}=4, \mathrm{Nexp}=27)$.

Los perfiles simulados muestran una aceptable concordancia con las tendencias generales mostradas por los datos experimentales y describen correctamente el efecto del TRH sobre las distintas variables respuesta. Sin embargo, en las superficies que se muestran en la Figura 5.23 para el $\mathrm{Fe}$ (II) generado y la variación del $\mathrm{pH}$ se observa una depresión abrupta cercana a los de $2 \mathrm{~g}$ de ZVI. Esto se debe, posiblemente, a que la masa de ZVI no influye significativamente sobre estas variables de respuesta y al agregar un número elevado de neuronas en la capa oculta la red tiende a ajustar el error experimental de los datos utilizados en el training set.
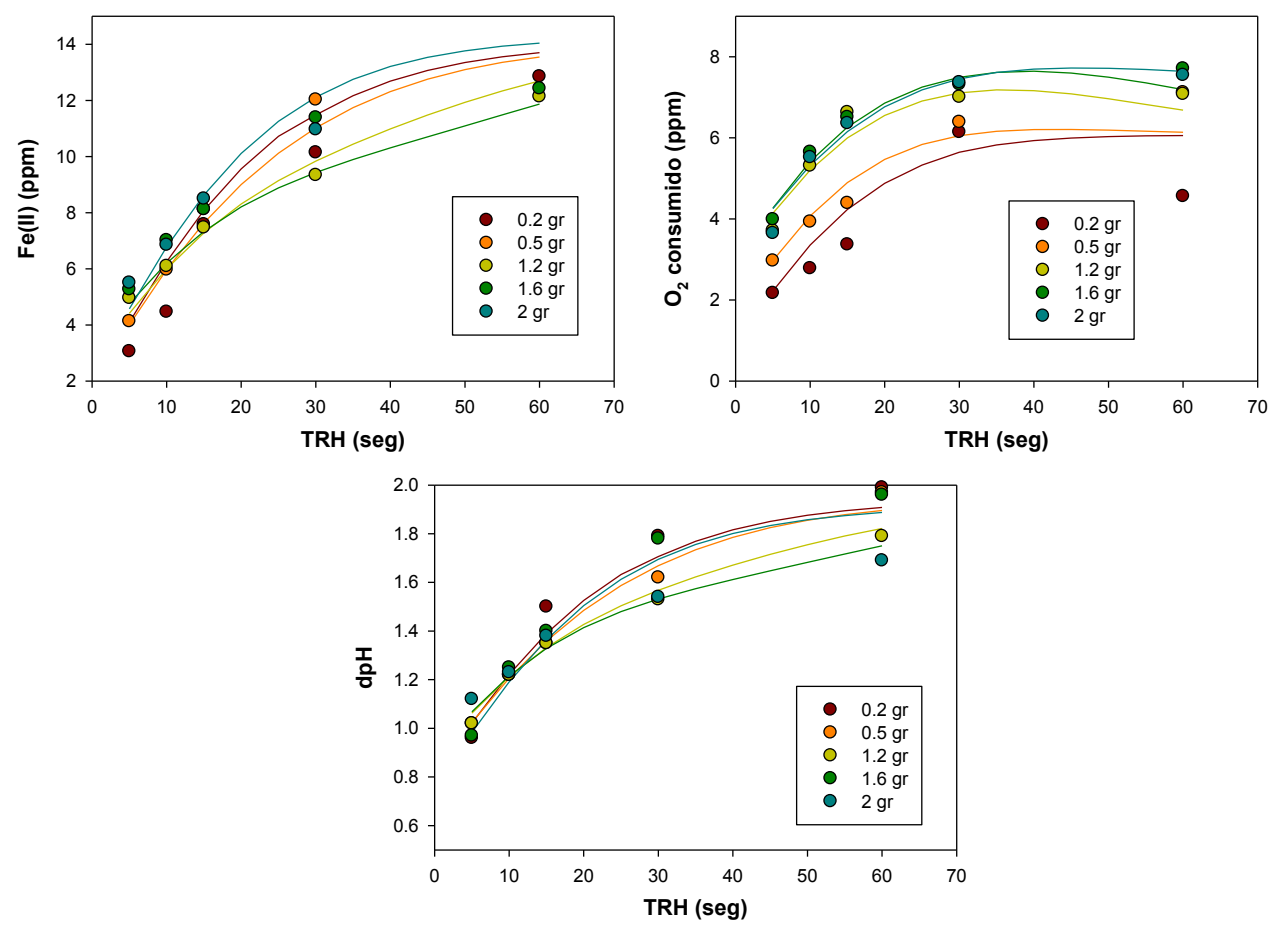

Figura 5.22. Perfiles de las distintas variables respuesta en función del TRH para las diferentes masas de ZVI utilizadas: datos experimentales (puntos) y valores calculados utilizando la $\mathrm{RNA}(2,4,3)$ (línea continua) ( $\mathrm{pH}$ de entrada: 4 ). 

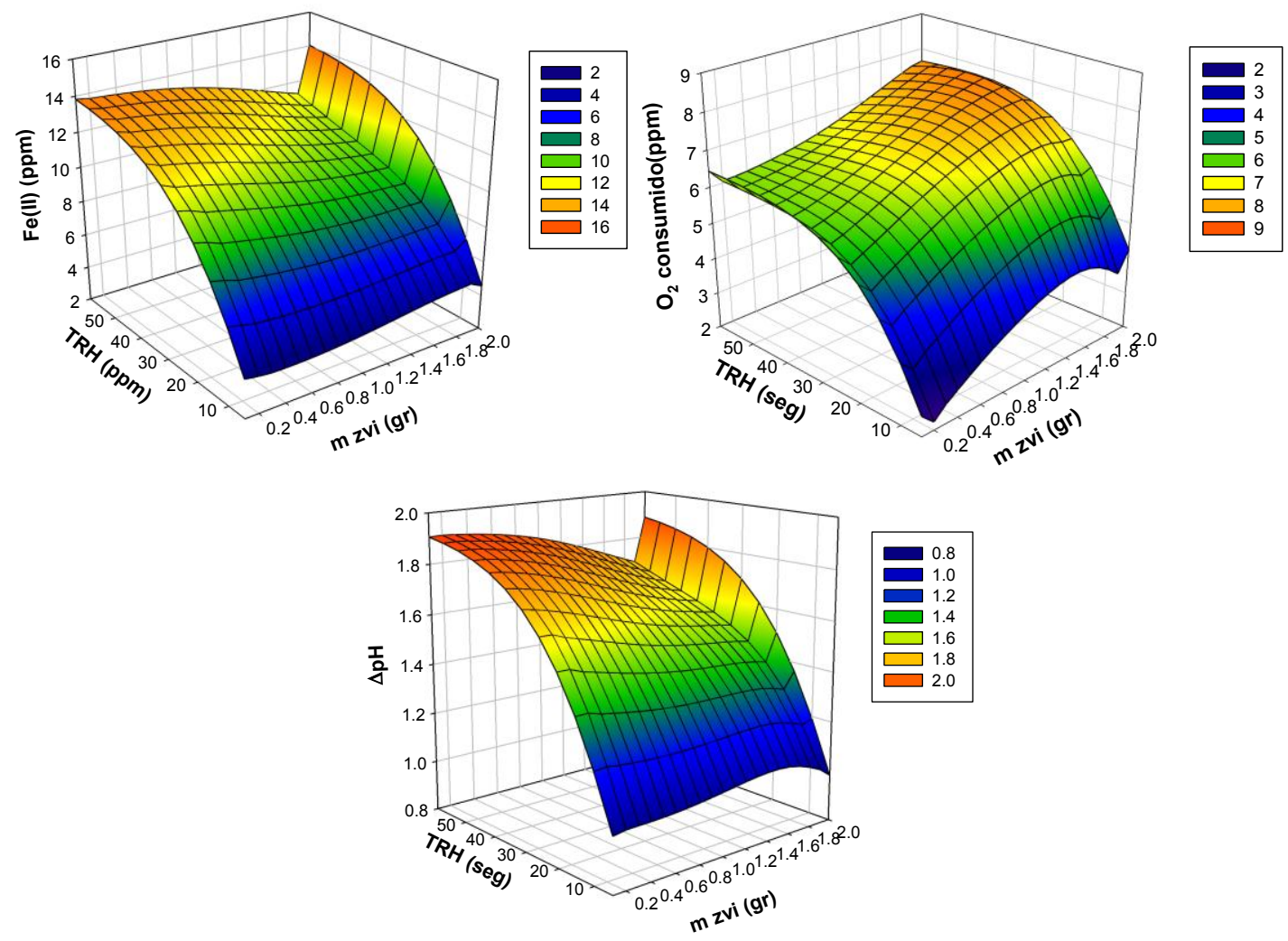

Figura 5.23. Superficies de respuesta construidas a partir de la $\operatorname{RNA}(2,4,3)$ diseñada para la segunda serie de ensayos $(\mathrm{pH} 4)$.

En este contexto cabe destacar que existen diferentes criterios para determinar el número máximo de neuronas en cada capa oculta $(\mathrm{NH})$ y no obtener un ajuste excesivo [126]. Algunas reglas empíricas mencionan que "el tamaño óptimo de la capa oculta suele estar entre el tamaño de la capa de entrada y el tamaño de la capa de salida" [127]. Por otra parte, hay una regla adicional que ayuda a resolver este tipo de problemas. Esta indica que el límite superior para el número de neuronas ocultas que no resultará en un ajuste excesivo es $[126,128]$ :

$$
N H=\frac{N s}{\alpha *(N+P)}
$$

Donde:

$\mathrm{N}$ : número de neuronas en la capa de entrada.

$P$ : número de neuronas en la capa de salida.

Ns: número de observaciones en el set de datos de entrenamiento.

$\alpha$ : factor de escala arbitrario usualmente entre 2-10.

Si se aplica la ec 5.5 para la construcción de una RNA a partir de los datos correspondientes a la segunda serie de ensayos, se obtiene que el número de neuronas en la capa oculta $(\mathrm{NH})$ debe ser como máximo 2 en este caso. Las superficies obtenidas mediante una RNA $(2,2,3)$ (Figura 2.24) son similares a las mostradas en la Figura 5.23 pero sin presentar las depresiones antes mencionadas. Esto representa una evidencia adicional que apoya la hipótesis de que, en el dominio 
experimental analizado, para masas del lecho superiores a $0,5 \mathrm{~g}$ la carga de ZVI no influye significativamente en la generación de Fe(II) ni en la variación del pH.
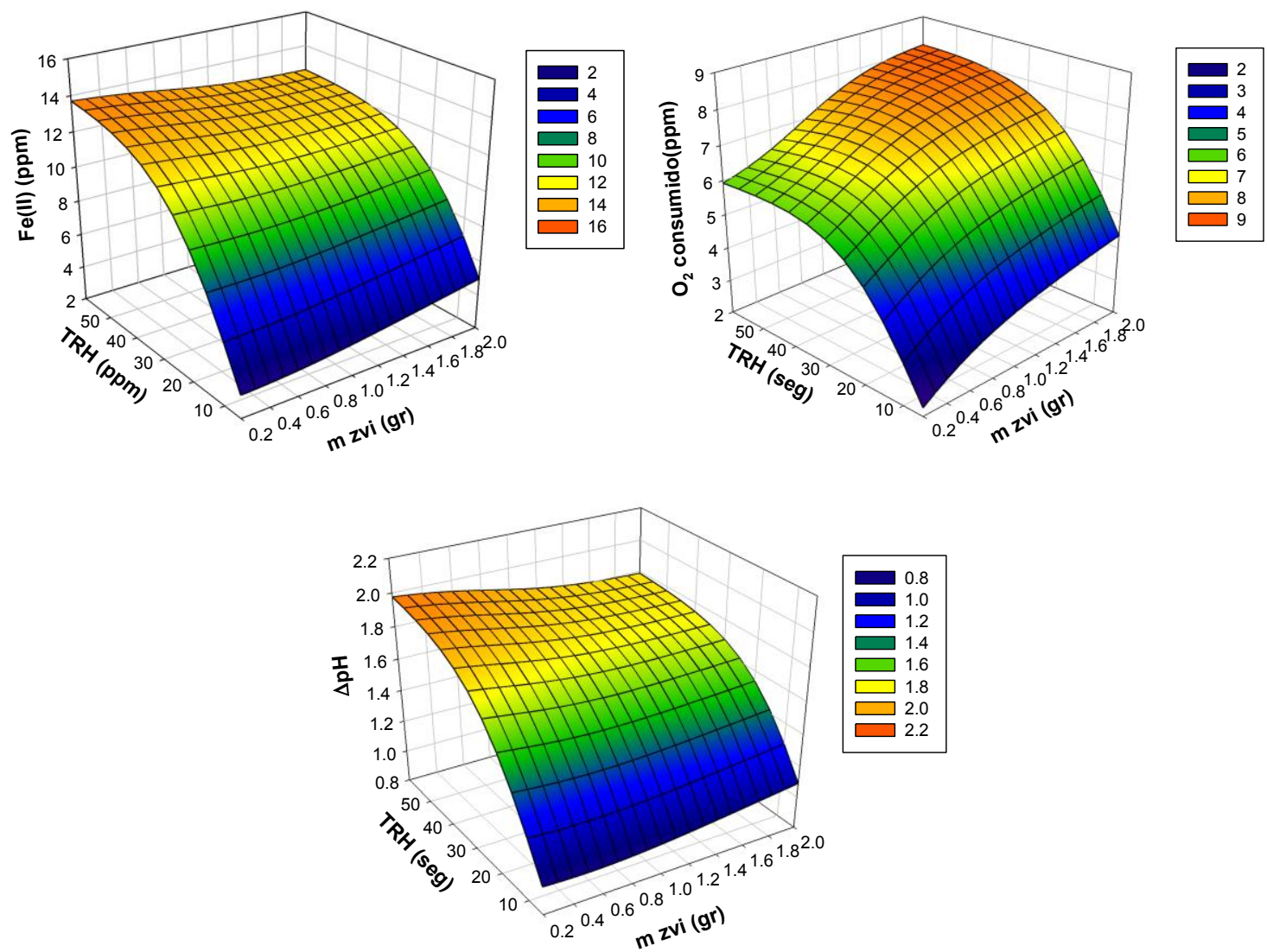

Figura 5.24. Superficies de respuesta construidas a partir de la RNA $(2,2,3)$ diseñada para la segunda serie de ensayos $(\mathrm{pH} 4)$.

Tercera serie de experimentos

En la Figura 5.25 se presentan las matrices de pesos obtenidas para la tercera RNA. Nuevamente se construyó una rutina para graficar los perfiles de las diferentes variables respuestas ( $\mathrm{Fe}(\mathrm{II}), \mathrm{O}_{2}$ consumido y diferencia de $\mathrm{pH}$ ) como funciones del tiempo de residencia hidráulico para todas las condiciones de operación ensayadas en la tercera serie. Las Figuras 5.26 y 5.27 muestran, al igual que para la segunda serie de ensayos, un efecto muy importante del TRH sobre las variables de respuesta. Cabe destacar que la inspección visual de los valores experimentales sugiere un comportamiento más suave que el previsto por la red y esto puede ser un indicio de un modelo con problemas de sobreparametrización. Sin embargo, el efecto del TRH es suficientemente importante como para que la tendencia general pueda apreciarse sin inconvenientes tanto a partir de los datos como a partir de las predicciones del modelo. En contraste,, la dependencia con la densidad del lecho prevista por la RNA en algunos casos presenta un comportamiento demasiado errático y, como en el caso de la red anterior, es muy probable que la red esté ajustando una parte importante del error experimental asociado a los datos. 


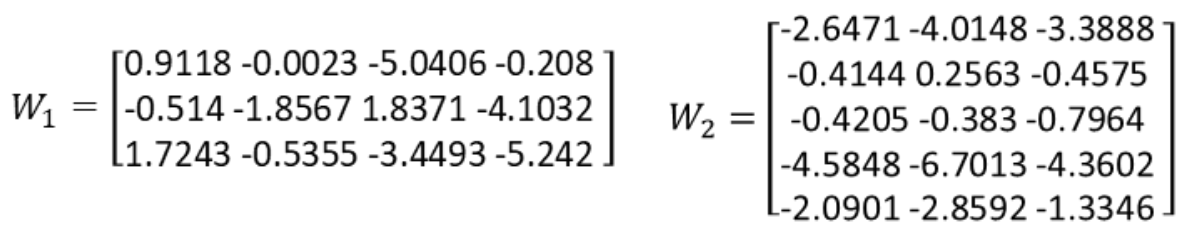

Figura 5.25. Matrices de pesos de la RNA construida para la tercera serie de ensayos que minimiza el error del test set $(\mathrm{NH}=4, \mathrm{Nexp}=25)$.
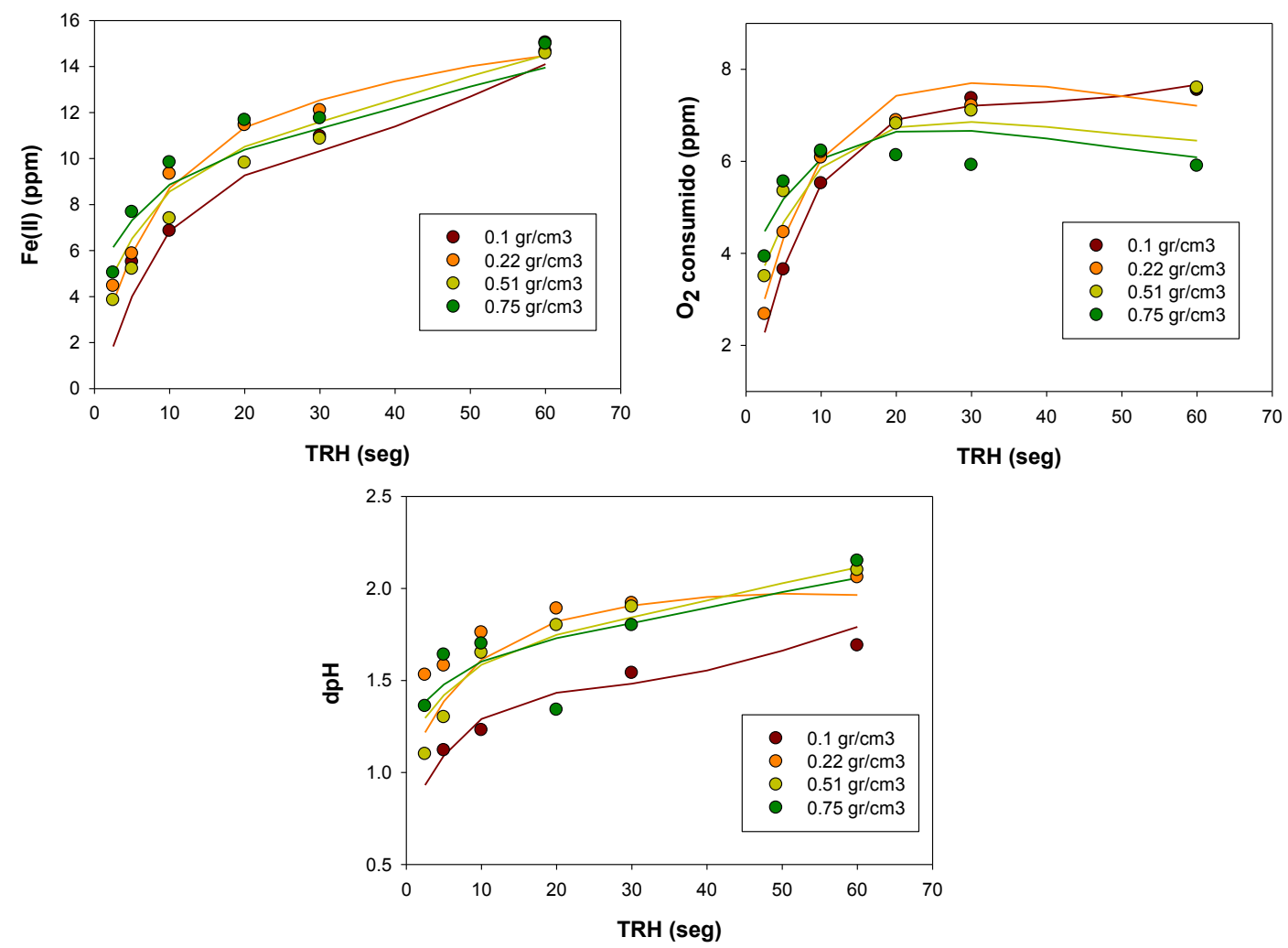

Figura 5.26. Comportamiento de las distintas variables respuesta en función del TRH para las diferentes densidades de lecho utilizadas: datos experimentales (puntos) y valores calculados utilizando la RNA $(2,4,3)$ (línea continua) (pH de entrada: 4 ). 

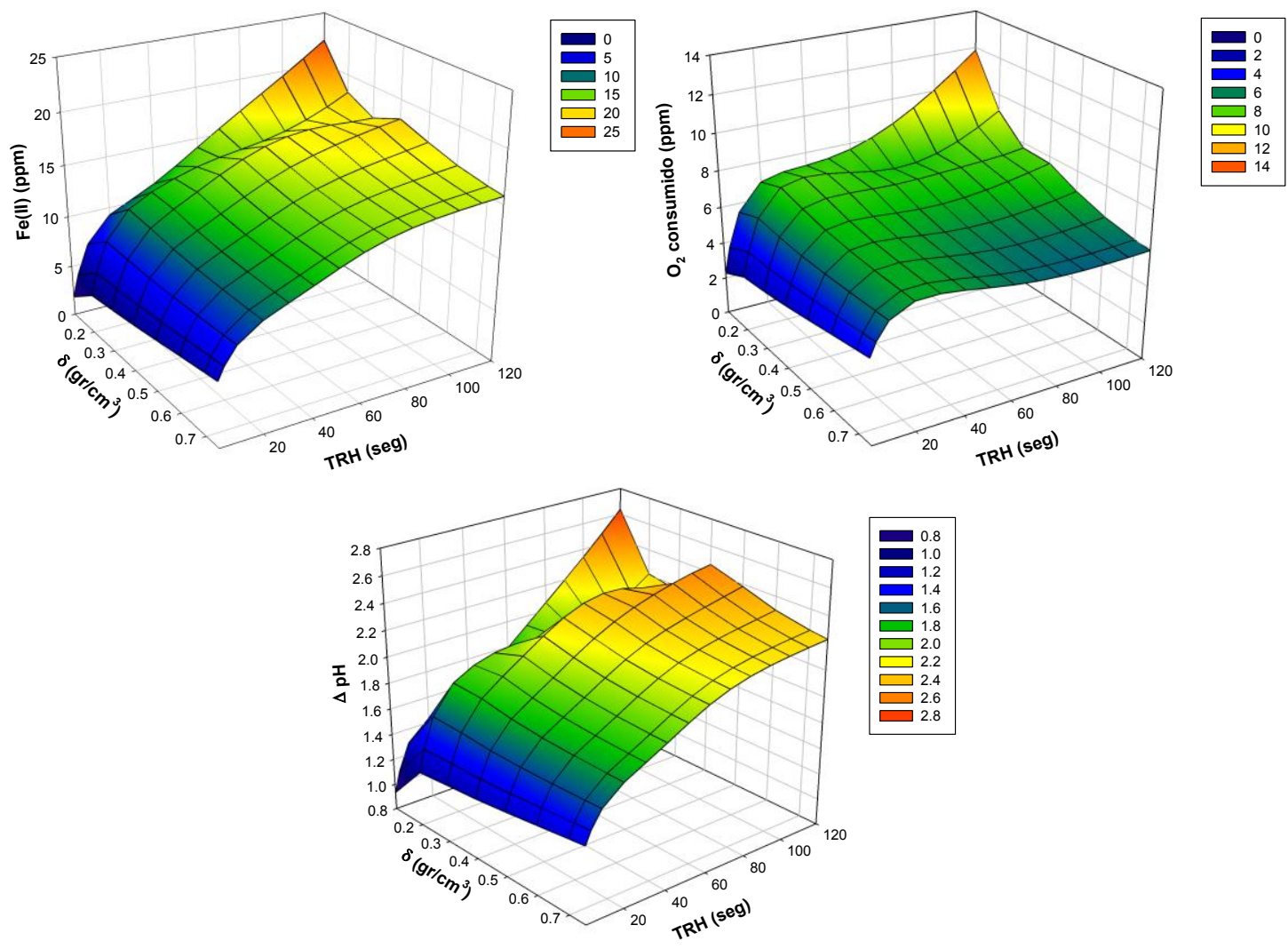

Figura 5.27. Superficies de respuesta construidas a partir de la RNA $(2,4,3)$ diseñada para la tercera serie de ensayos $(\mathrm{pH} 4)$.

Debido a los problemas de sobre parametrización exhibidos en las figuras 5.26 y 5.27 nuevamente se aplicó la ecuación 5.5 para limitar el valor de $\mathrm{NH}$. En este caso también se obtuvo un valor de 2 para el número máximo de neuronas en la capa oculta que permite evitar problemas de sobreajuste. Los gráficos muestran que la densidad del lecho no influye en ninguna de las variables respuesta analizadas (Figura 5.28).
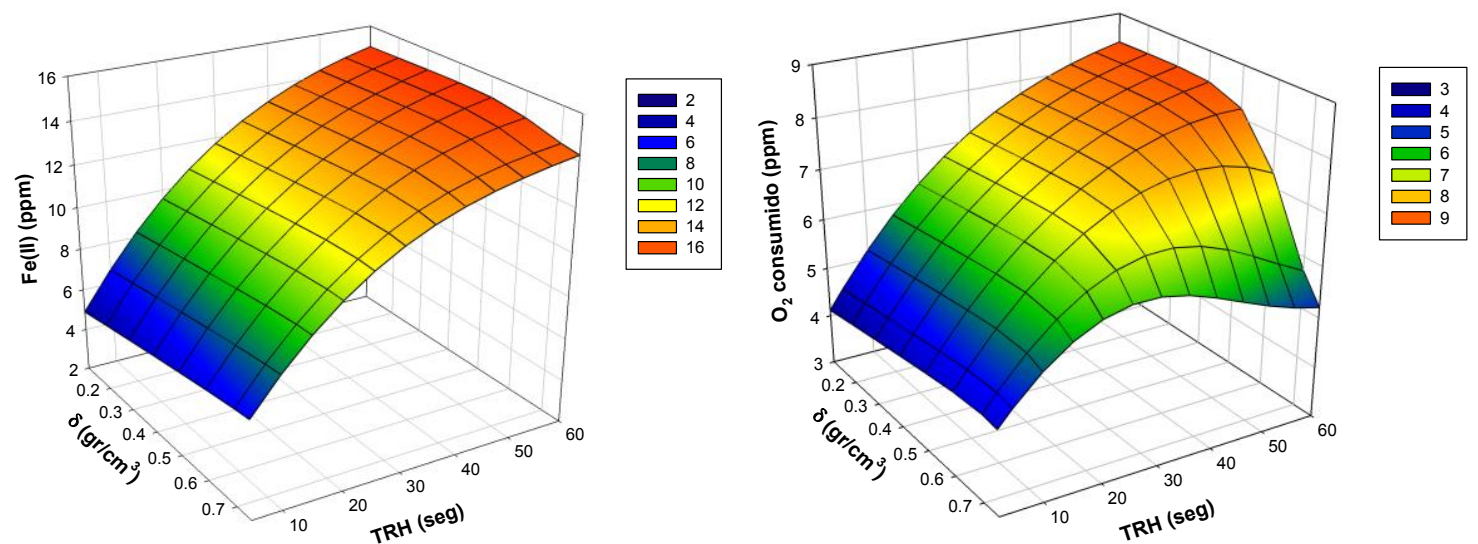

Figura 5.28 (a). Superficies de respuesta construidas a partir de la RNA $(2,2,3)$ diseñada para la tercera serie de ensayos $(\mathrm{pH} 4)$. 


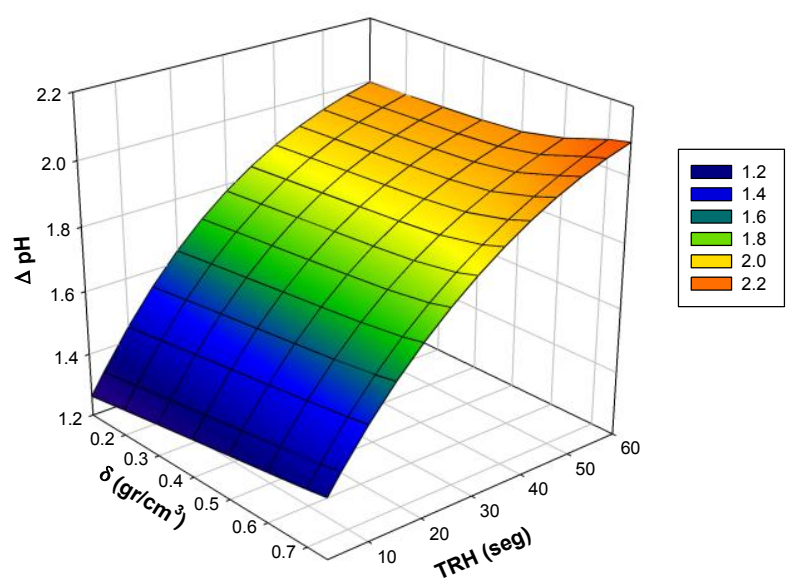

Figura 5.28 (b). Superficies de respuesta construidas a partir de la RNA $(2,2,3)$ diseñada para la tercera serie de ensayos $(\mathrm{pH} 4)$.

\subsubsection{Análisis de sensibilidad de redes neuronales}

\subsubsection{Marco teórico}

Método HIPR

Los modelos de RNA configurados se utilizaron luego para evaluar la importancia relativa de las variables de entrada (factores) en la predicción de la las variables respuesta experimentalmente observadas. Esta evaluación se basó en el análisis del efecto que tiene una perturbación impuesta a las entradas del modelo sobre los valores de las respuestas predichas por la red, de acuerdo con el método de aleatorización de parámetros de entrada ("Holdback Input Parameter Randomization method", HIPR) propuesto por Kemp et al [129].

El método HIPR es una variante mejorada del denominado "Método de perturbación" y consiste en realizar la evaluación del efecto que tiene el empleo de conjuntos de datos que han sido alterados sobre la predicción que realiza el modelo de RNA. El proceso de evaluación incluye la aleatorización secuencial de las variables de entrada de manera de poder deducir la importancia relativa de cada una de ellas en los valores de las respuestas calculados por la red neuronal.

Una vez que un modelo RNA ha sido optimizado, el método HIPR utiliza el conjunto de datos de prueba ("test set") para determinar la importancia relativa de las variables de entrada. El procedimiento establecido para estimar la sensibilidad de la RNA a los parámetros de entrada involucra la siguiente secuencia:

1) Realizar simulaciones secuenciales con la RNA, para el conjunto de datos de prueba, pero reemplazando los valores de un parámetro de entrada por valores aleatorios distribuidos uniformemente en el intervalo sobre el cual la red fue originalmente entrenada. 
2) Calcular el error cuadrático medio (MSE) de la RNA para cada variable respuesta cuando se ha presentado un conjunto alterado de datos en el que uno de los parámetros de entrada ha sido reemplazado por valores aleatorios.

3) Repetir este procedimiento $R$ veces alterando el mismo parámetro de entrada y calcular el MSE promedio.

4) Repetir el procedimiento para cada uno de los parámetros de entrada, sustituyendo, en cada serie, los valores originales por valores aleatorios distribuidos uniformemente en el dominio mapeado por la red.

Para evaluar el error cuadrático medio $\left(\mathrm{MSE}_{\mathrm{k}, \mathrm{i}, \mathrm{r}}\right)$ en cada una de las $\mathrm{R}$ iteraciones se emplea la ec. 5.6, mientras que el error promedio asociado a cada parámetro $\left(\mathrm{MSE}_{\mathrm{k}, \mathrm{i}}\right)$ se estima mediante la ec. 5.7

$$
\begin{gathered}
M S E_{k, i, r}=\frac{1}{T} \sum_{l=1}^{T}\left(y_{k, c a l}{ }^{(l)}-y_{k, i, r}{ }^{(l)}\right)^{2} \\
\overline{M S E}_{k, i}=\frac{1}{R} \sum_{r=1}^{R} M S E_{k, i, r}
\end{gathered}
$$

Donde:

$\mathrm{k}$ : variables dependientes $(1, \ldots, \mathrm{p})$

i: variables independientes $(1, \ldots, N)$

I: observaciones $(1, \ldots, T)$

r: iteraciones de perturbación $(1, \ldots, R)$

$y_{k, c a l}{ }^{(l)}$ : valor calculado de la variable respuesta $\mathrm{k}$ para la observación I utilizando el valor original de variable de entrada $\mathrm{i}$

$y_{k, i, r}{ }^{(l)}$ : valor calculado de la variable respuesta k para la observación I en la iteración $r$ de la variable de entrada i aleatorizada

$\overline{M S E}_{k, i}$ : error cuadrático medio de la variable respuesta $\mathrm{k}$, para $\mathrm{R}$ perturbaciones en la variable de entrada $x_{i}$

El cociente entre el valor del MSE promedio calculado a partir de la aleatorización de los valores de una de las variables de entrada y el MSE del conjunto de datos original refleja la importancia relativa de esa variable de entrada sobre la predicción de la RNA. Si un parámetro no influye sobre la capacidad predictiva de la RNA, el MSE del conjunto de datos aleatorizado estará relativamente cerca del MSE del conjunto de datos originales. Si un parámetro contribuye fuertemente a la capacidad predictiva de la RNA, el MSE del conjunto de datos en el que se encuentra este parámetro aleatorizado será significativamente mayor que el MSE del conjunto de datos originales. 
El método antes descripto no permite diferenciar interacciones positivas o negativas entre parámetros de entrada y variables respuesta. Sin embargo, si en el algoritmo antes mencionado se evalúa la correlación en lugar del MSE, es posible identificar el tipo de interacción a partir del signo del valor obtenido. Las ecuaciones empleadas para evaluar la correlación son las siguientes:

$$
\begin{aligned}
& \operatorname{Corr}_{k, i, r}=\frac{1}{T} \sum_{l=1}^{T} \frac{\left(y_{k, i, r}{ }^{(l)}-y_{k, c a l}(l)\right)\left(x_{r, i}{ }^{(l)}-x_{i}{ }^{(l)}\right)}{\left(y_{\max , k^{-}}-y_{\min , k}\right)\left(x_{\max , i}-x_{\min , i}\right)} \\
& \overline{\operatorname{Corr}}_{k, i}=\frac{1}{R} \sum_{r=1}^{R} \operatorname{Corr}_{k, i, r}
\end{aligned}
$$

Dónde:

$x_{r, i}{ }^{(l)}$ : valor perturbado en la iteración $\mathrm{r}$ de la variable de entrada i en la observación I

$x_{i}{ }^{(l)}$ : valor original de la variable de entrada i en la observación I

$y_{\max , k}, y_{\max , k}$ : valores máximos y mínimos de la variable de salida $\mathrm{k}$

$x_{\max , i}, x_{\max , i}$ : valores máximos y mínimos de la variable de entrada i

$\overline{\operatorname{Corr}}_{k, i}$ : valor medio de la correlación $\operatorname{Corr}_{k, i}$ para la variable respuesta $\mathrm{k}$, para $\mathrm{R}$ perturbaciones en la variable de entrada $x_{i}$.

\subsubsection{Resultados}

La Figura 5.24 presenta los resultados del análisis HIPR aplicado a la RNA $(3,7,3)$ de la primera serie de ensayos después de 5000 perturbaciones aleatorias $(R)$ en cada variable de entrada. Tal como se esperaba, el análisis indicó efectos positivos importantes del TRH en la tasa de generación de Fe(II), en el consumo oxígeno y, en menor medida, en el aumento de $\mathrm{pH}$ a lo largo del lecho. Por otro lado se observa que un aumento del $\mathrm{pH}$ de entrada disminuye sustancialmente la variación del $\mathrm{pH}$ y moderadamente la generación de Fe(II). Finalmente, el análisis realizado sugiere que la masa de ZVI no tiene influencia en el desempeño del sistema ya que la aleatorización de este parámetro de entrada prácticamente no modifica a los valores de las variables respuesta predichos por la RNA.

La tendencia observada con respecto al efecto del TRH se confirma en los gráficos presentados en la Figura 5.25 , donde se muestran los resultados de la aplicación del método HIPR a la RNA $(2,4,3)$ diseñada para la segunda serie de ensayos. Por otra parte, si bien la masa de ZVI no presenta ninguna influencia sobre las respuestas $\mathrm{Fe}$ (II) generado y variación del $\mathrm{pH}$, el consumo de oxígeno muestra un incremento moderado con la carga de material reactivo en el lecho para la segunda serie de ensayos.

Finalmente, la aplicación de este método a la RNA $(2,4,3)$ diseñada para el conjunto de datos de la tercera serie de ensayos permitió confirmar las tendencias 
respecto del TRH y evaluar el efecto de la densidad del lecho sobre las distintas variables de respuesta. El análisis de la Figura 5.26 muestra efectos muy pequeños sobre la generación de $\mathrm{Fe}(\mathrm{II})$ y sobre el consumo de oxígeno, pero revela cierta influencia de la densidad de lecho sobre la variación del pH.

Cabe aclarar que se obtuvieron resultados similares utilizando redes a las cuales se limitó el número máximo de las neuronas en la capa oculta $(\mathrm{NH})$ según el criterio de la ec. 5.5 .

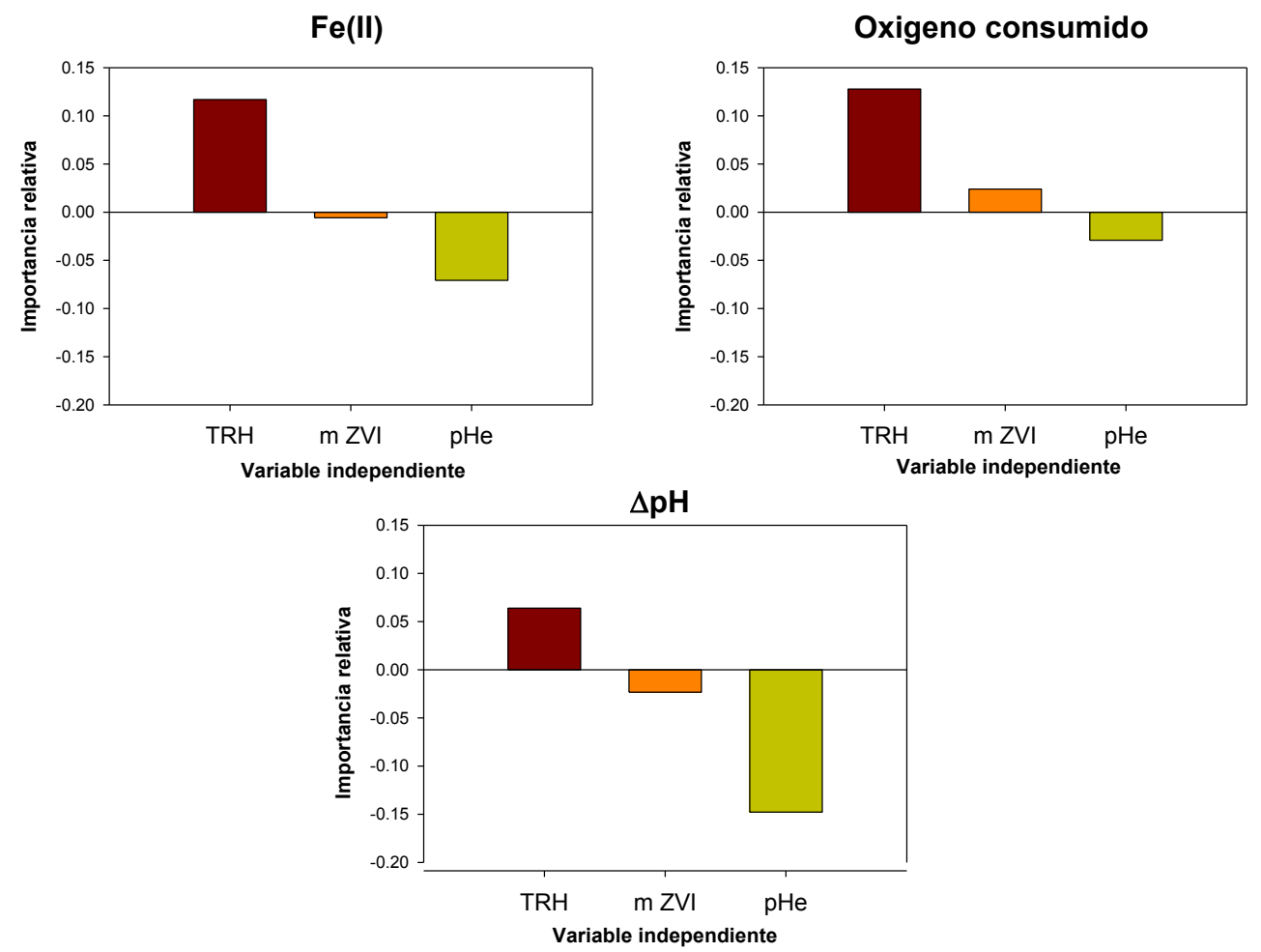

Figura 5.24. Importancia relativa de las variables independientes en estudio sobre las variables de respuesta basada en el resultado del método HIPR aplicado a la RNA correspondiente a la primera serie de ensayos. 

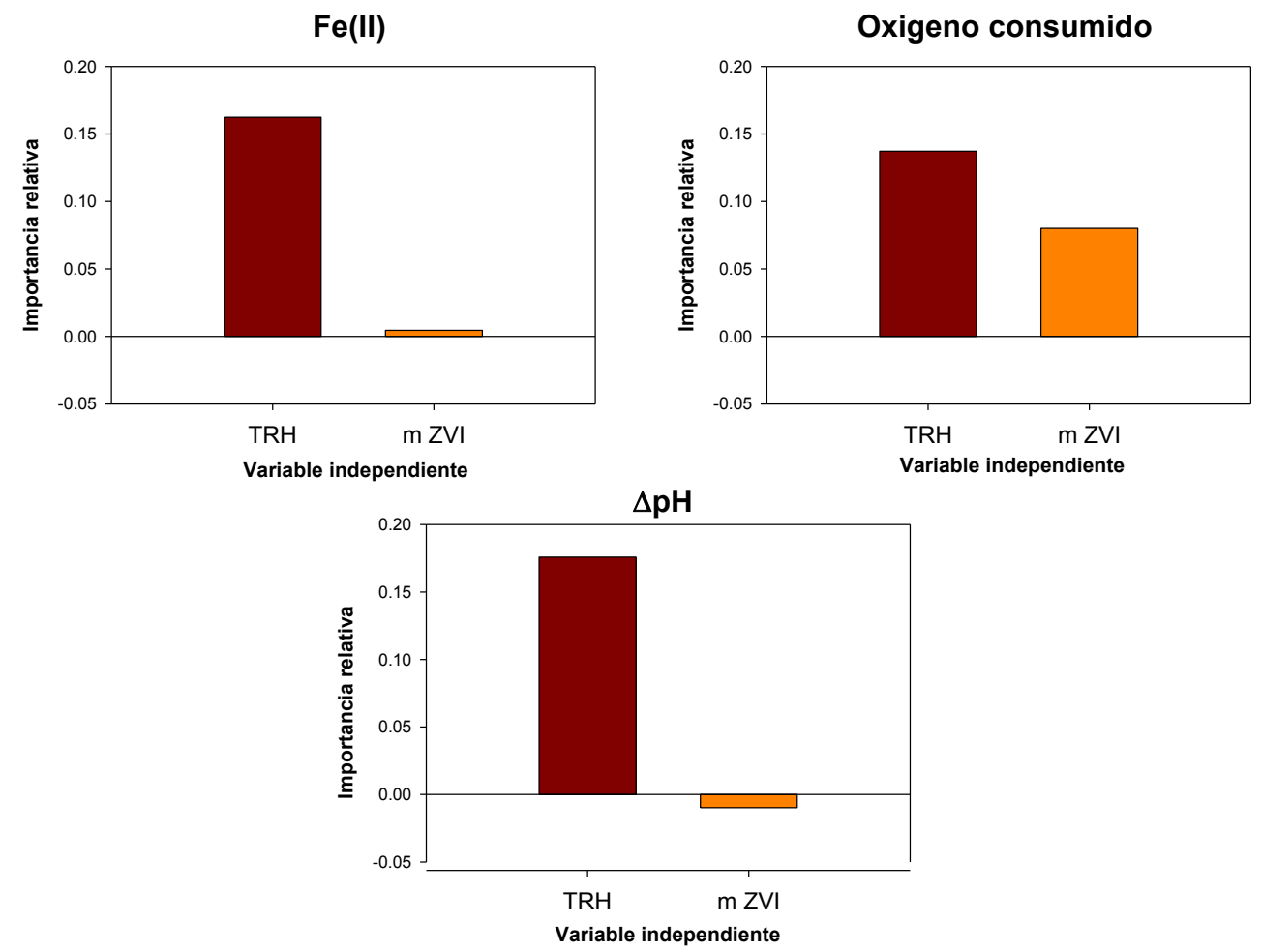

Figura 5.25. Importancia relativa de las variables independientes en estudio sobre las variables de respuesta basada en el resultado del método HIPR aplicado a la RNA correspondiente a la segunda serie de ensayos.
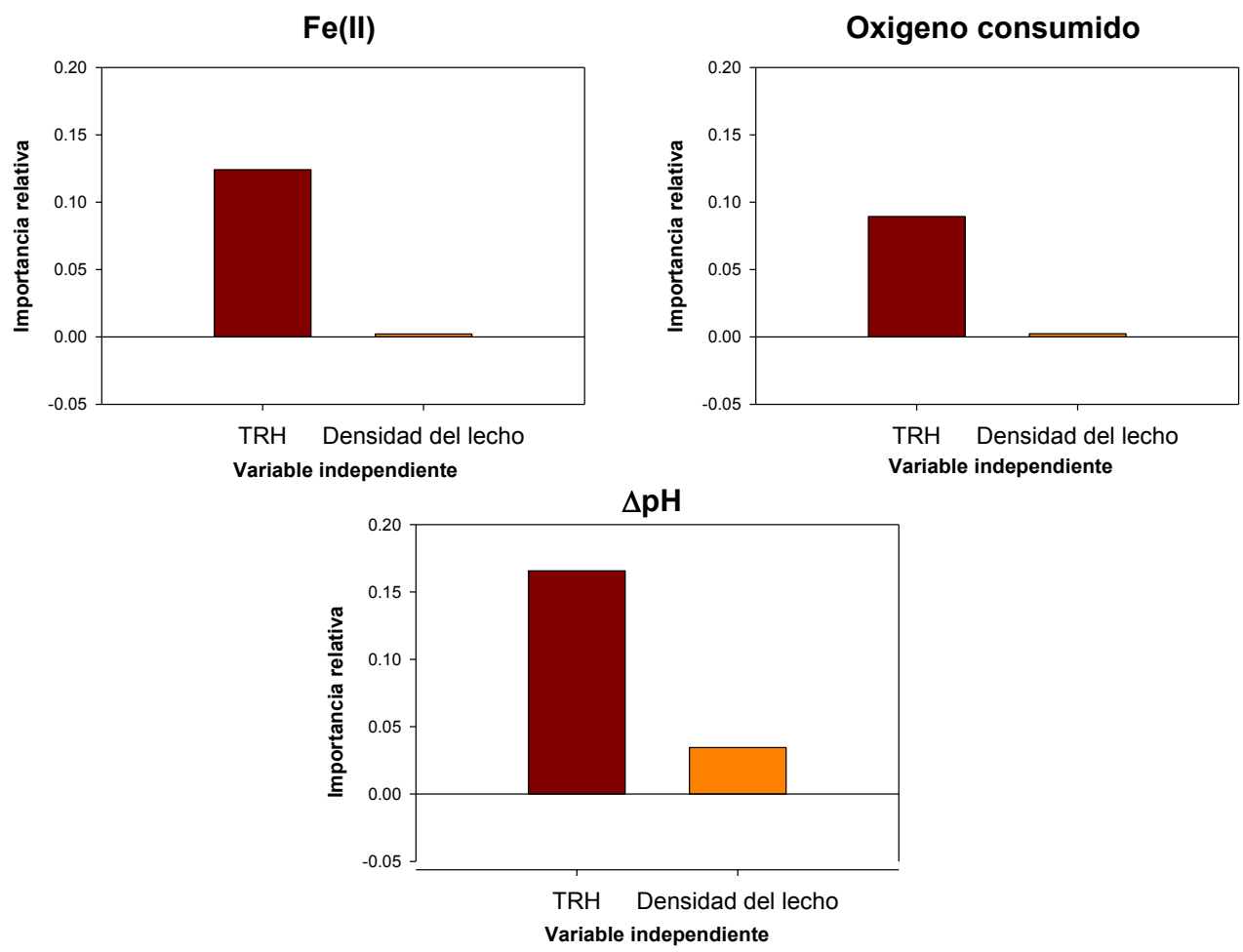

Figura 5.26. Importancia relativa de las variables independientes en estudio sobre las variables de respuesta basada en el resultado del método HIPR aplicado a la RNA correspondiente a la tercera serie de ensayos. 


\subsection{DESARROLLO DE UN MECANISMO SIMPLIFICADO PARA EL MODELADO DE LOS RESULTADOS OBTENIDOS EN LOS RSSCT}

Tal como se discutió en los capítulos anteriores, en los sistemas $\mathrm{ZVI} / \mathrm{H}_{2} \mathrm{O}$ pueden ocurrir varios procesos tanto físicos como químicos en forma simultánea. En particular, para el modelado completo de la fisicoquímica de este tipo de sistemas, sería necesario considerar no solamente las reacciones 1.1 a 1.9 presentadas en el Capítulo 1, sino también una serie de reacciones relacionadas con los procesos Fenton $[22,109]$ puesto que en presencia de oxígeno disuelto los sistemas basados en el empleo de ZVI producen tanto $\mathrm{Fe}(\mathrm{II})$ como $\mathrm{H}_{2} \mathrm{O}_{2}$. Además, el hecho de que varias de las reacciones químicas consideradas sean heterogéneas dificulta aún más el desarrollo de modelos cinéticos que tengan en cuenta todos los fenómenos involucrados debido a que en muchos casos las velocidades de reacción están controladas por no sólo por la naturaleza y reactividad de la superficie sino también por procesos de transferencia de materia.

Por otro lado, la información que se puede obtener a la salida de las columnas acerca de los procesos cinéticos que ocurren en el interior de las mismas es limitada. Por ejemplo, previamente discutimos que los niveles de $\mathrm{Fe}(\mathrm{III})$ registrados en el efluente de las columnas no presentan ninguna correlación evidente con las variables operativas (factores controlados). Ensayos posteriores mostraron que este comportamiento se debe a que la mayoría del Fe(III) formado precipita en el interior de las columnas. Además de las limitaciones asociadas a los niveles de $\mathrm{Fe}$ (III) registrados, debe considerarse que la cinética de algunas de las reacciones involucradas puede mostrar una dependencia muy fuerte con el $\mathrm{pH}$ del medio. Esto obstaculiza la obtención de información cinética confiable puesto que, dependiendo de las condiciones de trabajo, el $\mathrm{pH}$ puede presentar variaciones de hasta 2.5 unidades en el interior de las columnas. Finalmente cabe destacar que, debido a la naturaleza del material del relleno empleado, ligeras variaciones tanto en el empaquetamiento como en el nivel de envejecimiento de los lechos reactivos pueden resultar en diferencias significativas en los patrones de flujo en el interior de las columnas y por lo tanto en los valores de las variables de respuesta.

En consecuencia, el desarrollo de modelos fisicoquímicos que tengan en cuenta la totalidad de los procesos involucrados y puedan predecir el comportamiento dinámico del sistema estudiado bajo diferentes condiciones operativas resulta extremadamente difícil. Sin embargo, las técnicas de modelado "blando" utilizadas en este capítulo han permitido inferir que, pese a la complejidad de los sistemas estudiados, son relativamente pocos los fenómenos necesarios para explicar las tendencias generales observadas y reproducir el comportamiento global de los lechos rellenos con ZVI.

En este contexto, se encaró el desarrollo de un modelo fisicoquímico simplificado capaz de describir los rasgos más sobresalientes del sistema bajo estudio. Tomando en cuenta tanto las limitaciones relacionadas con las mediciones de Fe(III) como las dificultades asociadas a los cambios de $\mathrm{pH}$ en el interior de las columnas, el modelo simplificado se centró, por un lado, en la descripción de la estequiometria aparente del proceso global y, por otro, en la interpretación de los perfiles que se 
obtuvieron al representar los niveles de $\mathrm{O}_{2}$ y de $\mathrm{Fe}(\mathrm{II})$ registrados en función de tiempo de residencia hidráulico. A continuación se resumen los resultados más importantes en relación a los perfiles de $\mathrm{O}_{2}$ y de $\mathrm{Fe}$ (II) estudiados en el Capítulo 4:

1. Las concentraciones de $\mathrm{Fe}(\mathrm{II})$ a la salida de las columnas presentan una fuerte dependencia con el $\mathrm{pH}$ de entrada, siendo relativamente altas para valores de $\mathrm{pH}$ moderadamente ácidos ( $\mathrm{pH} 4$ y 5 ) y bajas para condiciones de $\mathrm{pH}$ cercanas a la neutralidad ( $\mathrm{pH} 6$ y 7 ) tal como se observa en la Figura $4.2 \mathrm{~A}$.

2. La variación del $\mathrm{pH}$ en el interior de las columnas disminuye al incrementar el $\mathrm{pH}$ del afluente (Figura 4.6). Además, los cambios de $\mathrm{pH}$ observados son menores que los esperados si se consideran los niveles de $\mathrm{Fe}(\mathrm{II})$ registrados y la estequiometria de las reacciones 1.1 y 1.2 .

3. Para columnas lo suficientemente largas (altos TRH), más de un $87 \%$ del oxígeno se consume en el interior de las mismas, quedando solo una pequeña fracción residual de oxígeno a la salida de las columnas. Además, los perfiles de $\mathrm{O}_{2}$ registrados en el efluente como función del TRH resultan prácticamente independientes del pH del afluente (Figuras 4.4 y 4.5 ).

4. Los perfiles de oxígeno consumido y de $\mathrm{Fe}(\mathrm{II})$ generado presentan un desfasaje con respecto a los $\mathrm{TRH}$, ya que los niveles de $\mathrm{Fe}(\mathrm{II})$ a la salida de las columnas (Figura 4.1 A) muestran un ligero incremento aún para valores de TRH en los que el oxígeno consumido llega a su valor máximo (Figura 4.4 A). Cabe señalar que este pequeño incremento en los niveles de $\mathrm{Fe}(\mathrm{II})$ para $\mathrm{TRH}$ en los cuales el $\mathrm{O}_{2}$ consumido permanece constante puede deberse a la contribución de dos fenómenos diferentes. En primer lugar debe tenerse en cuenta que dado que la oxidación del ZVI es un proceso heterogéneo, para que los cationes de $\mathrm{Fe}(\mathrm{II})$ formados en la capa de corrosión (CL) sean observados en el efluente de las columnas deben migrar hacia el seno de la solución. Por lo tanto, el consumo de oxígeno de la fase líquida y el ingreso de $\mathrm{Fe}(\mathrm{II})$ soluble a la misma no ocurren en forma simultánea . Por otro lado, además del $\mathrm{O}_{2}$ otras especies pueden oxidar al ZVI, entre ellas el propio solvente (Reacción 1.1) y las especies de Fe(III) presentes en la capa de corrosión (Reacción 1.6).

Teniendo en cuenta estas observaciones, se postula el siguiente conjunto de reacciones no elementales para explicar los procesos globales que ocurren durante el paso de agua a través de las columnas rellenas con $\mathrm{Fe}(0)$ :

$$
\begin{aligned}
& \mathrm{Fe}(0)+\mathrm{H}_{2} \mathrm{O}+\frac{1}{2} \mathrm{O}_{2} \stackrel{r A}{\rightarrow} \mathrm{Fe}(\mathrm{OH})_{2} \mathrm{CL} \\
& \mathrm{Fe}(0)+\frac{3}{2} \mathrm{H}_{2} \mathrm{O}+\frac{3}{4} \mathrm{O}_{2} \stackrel{r B}{\rightarrow} \mathrm{Fe}(\mathrm{OH})_{3} \mathrm{CL} \\
& \mathrm{Fe}(\mathrm{OH})_{2} \stackrel{r C}{\rightarrow} \mathrm{Fe}(\mathrm{II})_{a \mathrm{C}}+2 \mathrm{OH}^{-}
\end{aligned}
$$

En primer lugar el modelo planteado contempla dos vías alternativas para el consumo de $\mathrm{ZVI}$, dependiendo del estado de oxidación final alcanzado por el hierro $\left(R_{A}\right.$ y $\left.R_{B}\right)$. Puede apreciarse que la estequiometría aparente representada por $R_{B}$ 
engloba los procesos descriptos en el capítulo 1 mediante las reacciones denominadas $1.2,1.5$ y 1.7.

En segundo lugar, el mecanismo propuesto considera un tercer proceso $\left(R_{C}\right)$ en el cual el $\mathrm{Fe}^{2+}$ generado en la fase sólida por la transferencia de electrones desde el $\mathrm{Fe}(0)$ al oxígeno molecular es liberado al seno de la solución. Cabe destacar que, durante el proceso de corrosión, los cationes $\mathrm{Fe}^{2+}$ inicialmente se forman dentro de la estructura de oxi-hidróxidos sobre la superficie del ZVI. Posteriormente, estos cationes producidos en la reacción heterogénea deben migrar a través tanto de la capa de corrosión como de la película o film de difusión contra la interfaz sólido/líquido en la que se dará la transferencia de materia hasta el seno del fluido para el que se asume una composición homogénea.

Finalmente, el modelo considera que debido a la naturaleza del material de relleno empleado, resulta prácticamente imposible obtener lechos con un empaquetamiento completamente uniforme. En consecuencia, las columnas presentan canales preferenciales para el flujo de la fase acuosa que apartan sustancialmente al sistema de un régimen ideal de flujo pistón.

A partir de las reacciones planteadas, se deduce que la estequiometria aparente para el consumo de oxígeno dependerá de la prevalencia de una u otra vía $\left(R_{A} \circ R_{B}\right)$, siendo mayor el consumo de $\mathrm{O}_{2}$ por mol de $Z \mathrm{VI}$ oxidado cuanto mayor sea la proporción de $\mathrm{Fe}(\mathrm{III})$ producido. Vale la pena señalar que, de acuerdo con la información disponible en la literatura acerca de la cinética de la reacción 1.5 en este tipo de sistemas [14,22], se espera que la contribución del proceso global representado por $\mathrm{R}_{\mathrm{B}}$ sea fuertemente dependiente del $\mathrm{pH}$ de trabajo.

El análisis del mecanismo propuesto muestra que para el caso extremo donde todo el oxígeno fuera consumido por $\mathrm{R}_{\mathrm{A}}$ ( $\mathrm{pH}$ bajo) la máxima concentración de $\mathrm{Fe}(\mathrm{II})_{\mathrm{ac}}$ generado para un concentración de oxígeno a la entrada de $8 \mathrm{ppm}$ sería de $28 \mathrm{ppm}$. Por otro lado, si todo el oxígeno fuera consumido por $\mathrm{R}_{\mathrm{B}}$ ( $\mathrm{pH}$ alto), no debería detectarse $\mathrm{Fe}(\mathrm{II})_{\mathrm{ac}}$ a la salida de la columna. Dado que para todos los ensayos en los cuales el consumo de oxigeno fue total se registraron concentraciones de $\mathrm{Fe}(\mathrm{II})_{\mathrm{ac}}$ en el rango comprendido entre 3 y $22 \mathrm{ppm}$, los valores experimentales muestran que el comportamiento del sistema se encuentra dentro de los extremos previstos por las reacciones $R_{a}$ y $R_{B}$ Teniendo en cuenta el razonamiento anterior, en principio las fracciones de $Z \mathrm{VI}$ consumido tanto por la reacción $\mathrm{R}_{\mathrm{A}}$ como por la reacción $\mathrm{R}_{\mathrm{B}}$ pueden estimarse empleando las siguientes ecuaciones:

$$
f_{A}=\frac{F e(I I)_{a c}}{28 p p m} \quad f_{B}=1-f_{A}
$$

En este contexto, el estudio de los valores de $f_{A}$ y $f_{B}$ en función del $\mathrm{pH}$ del medio constituye una herramienta clave para evaluar los alcances del modelo.

Asimismo, cabe destacar que el mecanismo propuesto permite racionalizar las tendencias observadas experimentalmente sobre una base fisicoquímica. En términos cualitativos, los resultados obtenidos pueden explicarse de la siguiente manera: 
1. Las variaciones en los niveles de $\mathrm{Fe}(\mathrm{II})$ soluble, registrados a la salida de las columnas, pueden atribuirse a diferencias en las contribuciones relativas de las vías $R_{A}$ y $R_{B}$. En particular, debido a que la producción de $\mathrm{Fe}(\mathrm{II})$ decrece sustancialmente al aumentar el $\mathrm{pH}$ de trabajo, la contribución del proceso representado por $\mathrm{R}_{\mathrm{A}}$ prevalece en medio ácido mientras que la contribución del proceso representado por $\mathrm{R}_{B}$ predomina en medios neutros

2. Los mayores incrementos del $\mathrm{pH}$, entre el afluente y el efluente de las columnas, se registran cuando la proporción del ZVI que se transforma en $\mathrm{Fe}(\mathrm{II})$ es alta, es decir para aquellas condiciones $\left(\mathrm{pH}_{\mathrm{i}} 4.0\right.$ o 5.0) en las que predomina la secuencia $\mathrm{R}_{A} \rightarrow \mathrm{R}_{\mathrm{C}}$ (en la que se generan 2 moles de $\mathrm{OH}^{-}$por cada mol de $\mathrm{Fe}(\mathrm{II})$ producido). Por el contario, para valores de $\mathrm{pH}$ cercanos a la neutralidad $\left(\mathrm{pH}_{\mathrm{i}} 6.0 \circ 7.0\right)$, prevalece el proceso global representado por $\mathrm{R}_{\mathrm{B}}$ en el cual el ZVI se transforma en $\mathrm{Fe}(\mathrm{III})$ sin afectar la acidez del medio. Finalmente cabe destacar que, debido al efecto buffer que ejerce la matriz acuosa utilizada previamente descripto en la sección 3.4, las variaciones de $\mathrm{pH}$ observadas son siempre menores a las esperadas de acuerdo con la estequiometria global de la secuencia $R_{A} \rightarrow R_{C}$.

3. La velocidad de corrosión, y en consecuencia el consumo de oxígeno, solo estará limitada para masas de ZVI muy bajas, es decir cuando el número de sitios sobre la superficie del ZVI disponibles para la adsorción de oxígeno sea limitante. Además, los niveles residuales de $\mathrm{O}_{2}$ observados en el afluente pueden atribuirse al apartamiento del régimen de flujo pistón por parte de las columnas estudiadas. En efecto, debido a la presencia de canales preferenciales en el relleno, una fracción del oxígeno presente a la entrada de la columna siempre podrá atravesar el lecho sin tiempo suficiente para reaccionar. En este contexto puede asumirse que, de no existir canales de flujo preferenciales, para altos TRH el consumo de oxigeno hubiera sido total para todas las condiciones de $\mathrm{pH}$ ensayadas.

4. La diferencias en las escalas de TRH asociadas a los perfiles de $\mathrm{Fe}(\mathrm{II})$ y de $\mathrm{O}_{2}$ se deben a naturaleza heterogénea de la secuencia de procesos representada por $\mathrm{R}_{\mathrm{A}} \rightarrow \mathrm{R}_{\mathrm{C}}$ En particular, debido a la presencia de la $\mathrm{CL}$, el $\mathrm{Fe}^{2+}$ generado sobre la superficie del ZVI no es detectado inmediatamente en solución sino que requiere un cierto tiempo para migrar desde la $C L$ hasta la fase acuosa (proceso $\mathrm{R}_{\mathrm{C}}$ ). Por otro lado, si bien el oxígeno también necesita atravesar la $\mathrm{CL}$ y llegar a la superficie del ZVI para ser reducido, esta transferencia de masa limita la velocidad global del proceso y por lo tanto afecta en la misma medida tanto a la velocidad de consumo de $\mathrm{O}_{2}$ como a la velocidad de generación de $\mathrm{Fe}^{2+}$ en el interior de la capa de corrosión (CL).

\section{Resolución numérica del modelo simplificado}

Teniendo en cuenta el modelo descripto por las reacciones $R_{A}, R_{B}$ y $R_{C}$, se planteó el balance de materia para cada una de las especies solubles utilizando la siguiente ecuación de transporte de un soluto reactivo en una dimensión: 


$$
\left.\phi \frac{\partial C_{i}}{\partial t}=-v \frac{\partial C_{i}}{\partial z}+\frac{\partial}{\partial z}\left(\phi D \frac{\partial C_{i}}{\partial z}\right)+\phi R_{i} \quad \mathrm{i}=1, \ldots, \mathrm{Nc} \quad \text { (ec. } 5.11\right)
$$

donde $C_{i}$ es la concentración del soluto i en solución (mol. $\mathrm{I}^{-1}$ ), v es la velocidad lineal del fluido $\left(\mathrm{cm}^{-1} \mathrm{~s}^{-1}\right.$, D es un término que engloba la difusión molecular y la dispersión mecánica $\left(\mathrm{cm}^{2} . \mathrm{s}^{-1}\right), \phi$ es la porosidad del medio (adimensional) y $R_{\mathrm{i}}$ se denomina término fuente/sumidero de soluto (en mol. I $^{-1} \mathrm{~s}^{-1}$ ). Para el sistema bajo estudio, el valor de $R_{i}$ representa el balance entre las vías de producción/consumo de la i-esima especie y está asociado a reacciones tanto redox como de adsorción/desorción y/o disolución/precipitación. Finalmente Nc considera el número de especies a tener en cuenta y por lo tanto representa el número de ecuaciones diferenciales a resolver en forma simultánea.

Para facilitar la simulación numérica del modelo propuesto se realizaron algunas simplificaciones:

1. Dadas las bajas densidades de relleno empleadas, la porosidad inicial de los lechos fue muy cercana a la uno. Por otro lado, teniendo en cuenta que las escalas de tiempo utilizadas para los ensayos tipo RSSCT fueron muy cortas, el consumo de ZVI puede considerarse prácticamente despreciable. En este contexto se supuso un valor unitario y constante para la porosidad del medio durante los ensayos.

2. Las muestras utilizadas para las determinaciones fueron tomadas una vez que las columnas alcanzaron condiciones de estado estacionario (luego de eluidos 7 volúmenes de poro). Matemáticamente esto significa que el miembro izquierdo de las ecuaciones que gobiernan las especies cuyas concentraciones fueron registradas en la fase acuosa puede considerarse despreciable. Por lo tanto, luego de cierto tiempo con condiciones de contorno constantes, los términos transientes se anulan y los valores de $\mathrm{Ci}$ varían únicamente con la posición en el lecho (z).

3. Si bien a lo largo de la tesis se discute la influencia de los fenómenos de dispersión, para verificar si las tendencias generales descriptas por nuestro modelo son razonables como primera aproximación a la resolución del sistema se consideró un flujo tipo pistón ideal. Por lo tanto el término relacionado con la dispersión axial se supuso despreciable.

4. Para el dominio experimental estudiado las variables de respuesta no mostraron dependencias importantes con la masa de ZVI o con la densidad del empaquetamiento. En este contexto, y debido a la complejidad inherente a las reacciones heterogéneas, como primera aproximación se asumió que las leyes de velocidad para las reacciones $R_{A}$ y $R_{B}$ presentan orden cero respecto de la masa de $\mathrm{ZVI}$ y orden uno respecto de la concentración de oxígeno disuelto. Finalmente, dado que la reacción $\mathrm{R}_{\mathrm{C}}$ representa la transferencia de cationes $\mathrm{Fe}^{2+}$ desde el hidróxido ferroso de la capa de corrosión hacia la fase acuosa se asumió una dependencia de tipo Monod respecto a la masa de hidróxido ferroso. Esta ley cinética de tipo hiperbólico para la incorporación de $\mathrm{Fe}(\mathrm{II})$ a la solución se propone para reflejar el hecho de que la cinética de este proceso está controlada básicamente por el área de la capa de corrosión y no por su espesor. 
En base a estas suposiciones los balances de materia para $\mathrm{O}_{2}, \mathrm{Fe}(\mathrm{II})_{\mathrm{ac}}$, $\mathrm{Fe}(\mathrm{OH})_{2 \mathrm{LL}}$, y $\mathrm{Fe}(\mathrm{OH})_{3 \mathrm{CL}}$ resultan:

$$
\begin{aligned}
& v \frac{d C_{\mathrm{O}_{2}}}{d z}=-\frac{1}{2} r_{A}-\frac{3}{4} r_{B}=-\frac{1}{2} k_{A}(p H) C_{\mathrm{O}_{2}}-\frac{3}{4} k_{B}(p H) C_{O_{2}} \\
& v \frac{d C_{\mathrm{Fe}(\mathrm{II}) a c}}{d z}=r_{C}=k_{C} * \frac{m_{\mathrm{Fe}(\mathrm{OH})_{2} \mathrm{CL}}}{m_{\mathrm{Fe}(\mathrm{OH})_{2} C L}+\mathrm{Ks}} \\
& \frac{d m_{\mathrm{Fe}(\mathrm{OH})_{2} \mathrm{CL}}}{d t}=r_{A}-r_{C}=k_{A}(p H) C_{\mathrm{O}_{2}}-k_{C} * \frac{m_{\mathrm{Fe}(\mathrm{OH})_{2} C L}}{m_{\mathrm{Fe}(\mathrm{OH})_{2} C L}+\mathrm{KS}} \\
& \frac{d m_{\mathrm{Fe}(\mathrm{OH})_{3} \mathrm{CL}}}{d t}=r_{B}=k_{B}(p H) C_{\mathrm{O}_{2}}
\end{aligned}
$$

Es importante considerar que, a pesar de la simplicidad de las reacciones químicas propuestas, la resolución matemática del modelo planteado no resulta sencilla dado que deberían considerarse dos fases: una fase acuosa móvil y una fase sólida estacionaria. Tal como se ha descripto previamente, dado que las determinaciones experimentales sobre la fase móvil se realizaron en condiciones de estado estacionario, los términos transientes de las ecuaciones que gobiernan el comportamiento de las especies en solución pueden asumirse como despreciables. Sin embargo, para los balances de materia que involucran especies en la fase sólida deben considerarse necesariamente dos variables, la temporal $(t)$ y la espacial $(z)$.

En este contexto, para simplificar la resolución matemática del modelo planteado, como primera aproximación se optó por no modelar el comportamiento de la fase sólida. Con el fin de simular el comportamiento de la fase líquida, deben evaluarse tanto el consumo de $\mathrm{O}_{2}$ como la producción de $\mathrm{Fe}(\mathrm{II})$ y de $\mathrm{HO}^{-}$en solución. Es interesante señalar que la ecuación 5.12, que gobierna el consumo de oxígeno, puede resolverse sin necesidad de conocer las variables que caracterizan la fase

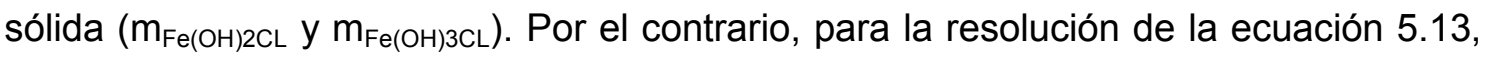
que gobierna el perfil de producción de Fe(II) en solución, resultaría necesario conocer los valores de $\mathrm{m}_{\mathrm{Fe}(\mathrm{OH}) 2 \mathrm{CL}}$ en la fase sólida. Por lo tanto, para describir de forma aproximada el comportamiento del $\mathrm{Fe}$ (II) en la fase móvil, se planteó que la velocidad de aparición de $\mathrm{Fe}(\mathrm{II})$ en solución está controlada por $\mathrm{r}_{\mathrm{A}}$ y por un factor de retardo que da cuenta del tiempo requerido para transportar los cationes $\mathrm{Fe}^{2+}$ desde la fase sólida hasta la solución $\left(R_{C}\right)$. Este tipo de estrategia es utilizada normalmente para cuantificar el reparto de un soluto entre un medio sólido poroso y una fase líquida móvil. En general el valor del coeficiente de retardo representa la proporción del soluto que queda atrapado temporalmente en la fase sólida. En el caso particular del modelo aquí planteado, la introducción del factor de retardo en la ecuación para el transporte de $\mathrm{Fe}(\mathrm{II})$ es una aproximación muy útil ya que permite incluir el efecto que el proceso $\mathrm{R}_{\mathrm{C}}$ tiene sobre el comportamiento del sistema sin la necesidad de considerar la fase sólida.

Teniendo en cuenta las aproximaciones previamente descriptas, se desarrolló un conjunto de herramientas de software en el entorno Matlab para la resolución 
numérica de las ecuaciones asociadas a la fase acuosa. A partir de la comparación entre los perfiles experimentales y los resultados de las simulaciones se ajustaron los valores de las constantes cinéticas $\mathrm{k}_{\mathrm{A}} \mathrm{y} \mathrm{k}_{\mathrm{B}}$ en función del $\mathrm{pH}$ (ver más adelante). Además, para la estimación del perfil de $\mathrm{pH}$ a lo largo del lecho se utilizaron las ecuaciones expuestas en la sección 3.4. En las Figuras 5.27 a 5.30 se muestran los perfiles espaciales simulados para una columna de $25.5 \mathrm{~cm}$ de largo, operada con velocidades lineales de $12.7 \mathrm{~cm} / \mathrm{min}$ y $6.35 \mathrm{~cm} / \mathrm{min}$ para valores de $\mathrm{pH}$ inicial de 4 a 7 .
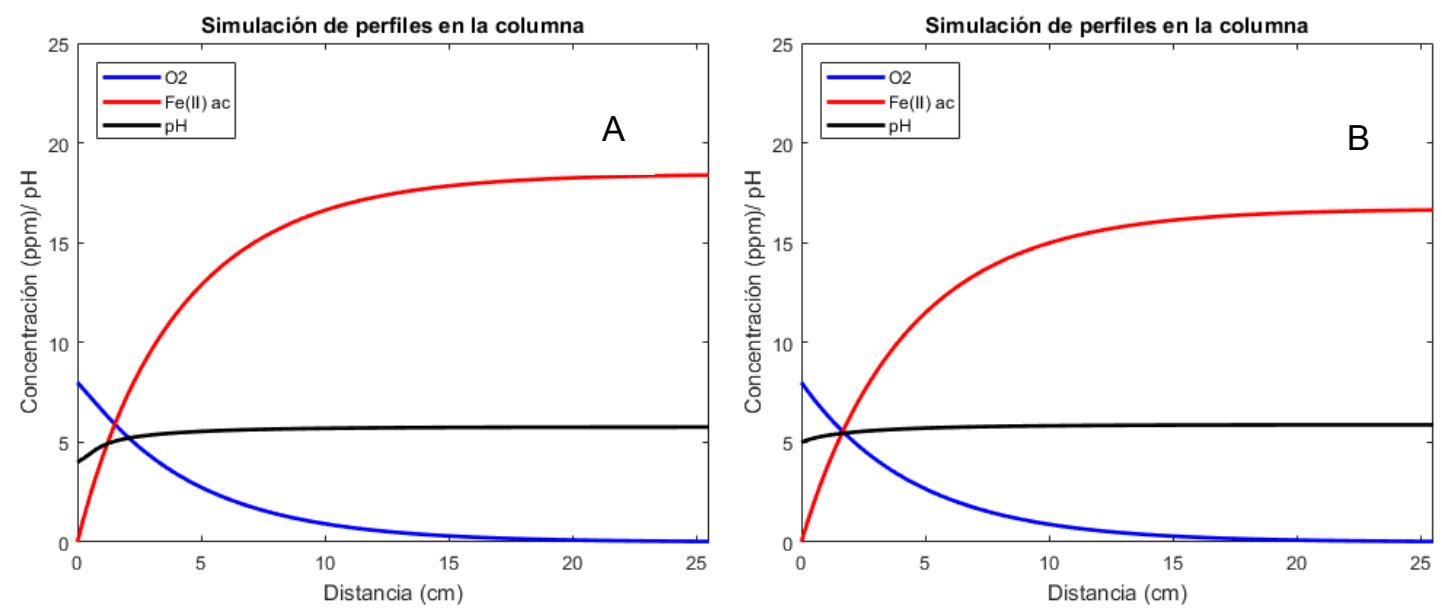

Figura 5.27. Simulación de los perfiles a lo largo de la columna para el modelo propuesto. $\mathrm{L}=25.5 \mathrm{~cm}, \mathrm{v}=12.7 \mathrm{~cm} / \mathrm{min}, \mathrm{pHi}=4(\mathrm{~A})$ y $\mathrm{pHi}=5(\mathrm{~B})$.
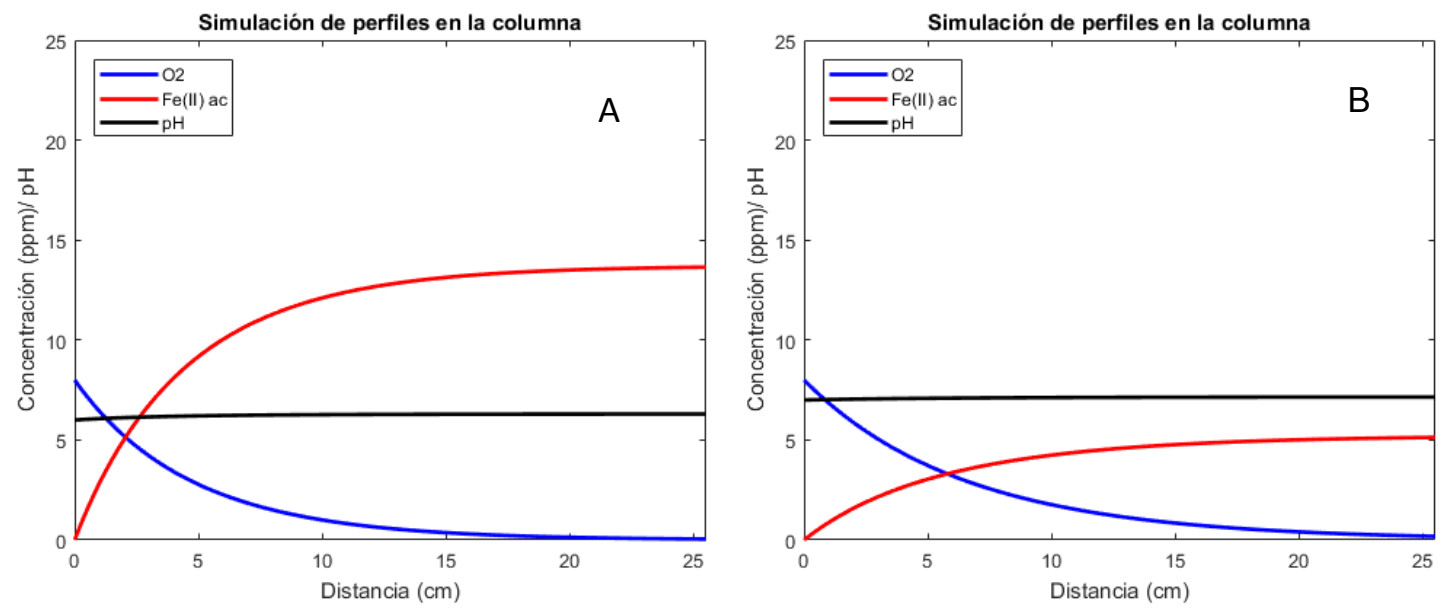

Figura 5.28. Simulación de los perfiles a lo largo de la columna para el modelo propuesto. $\mathrm{L}=25.5 \mathrm{~cm}, \mathrm{v}=12.7 \mathrm{~cm} / \mathrm{min}, \mathrm{pHi}=6(\mathrm{~A})$ y $\mathrm{pHi}=7(\mathrm{~B})$. 

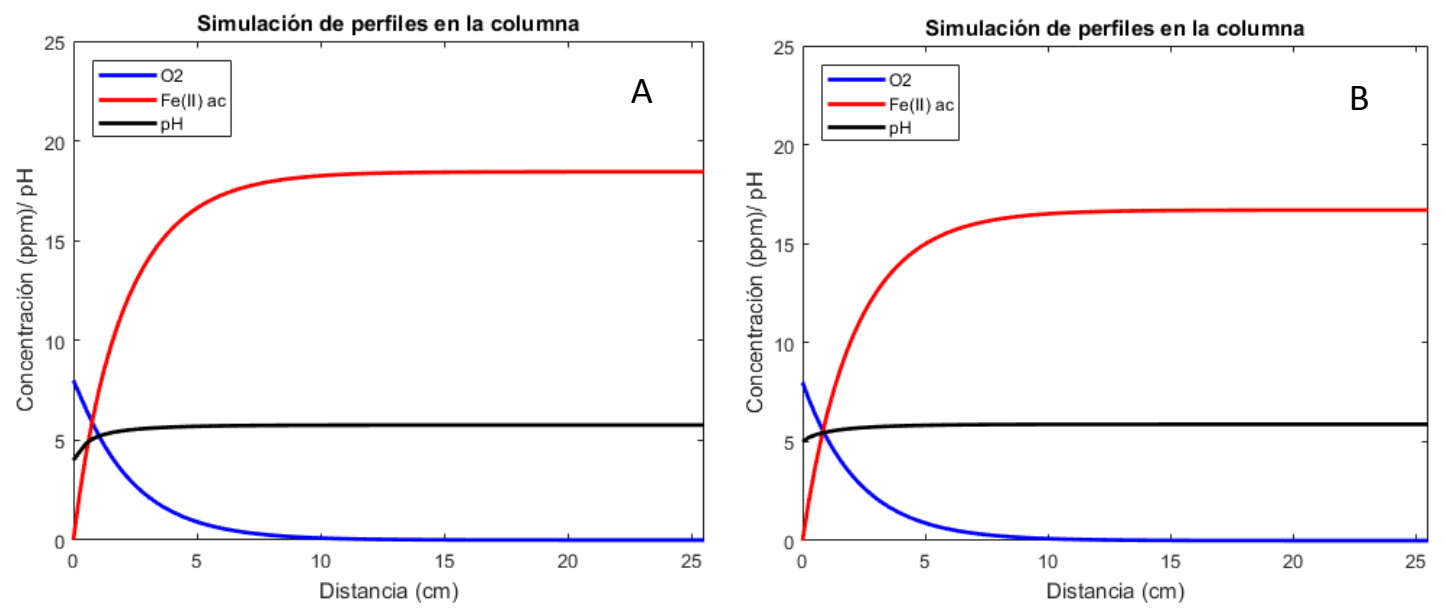

Figura 5.29. Simulación de los perfiles a lo largo de la columna ara el modelo propuesto. $L=$ $25.5 \mathrm{~cm}, \mathrm{v}=6.35 \mathrm{~cm} / \mathrm{min}, \mathrm{pHi}=4(\mathrm{~A})$ y $\mathrm{pHi}=5(\mathrm{~B})$.
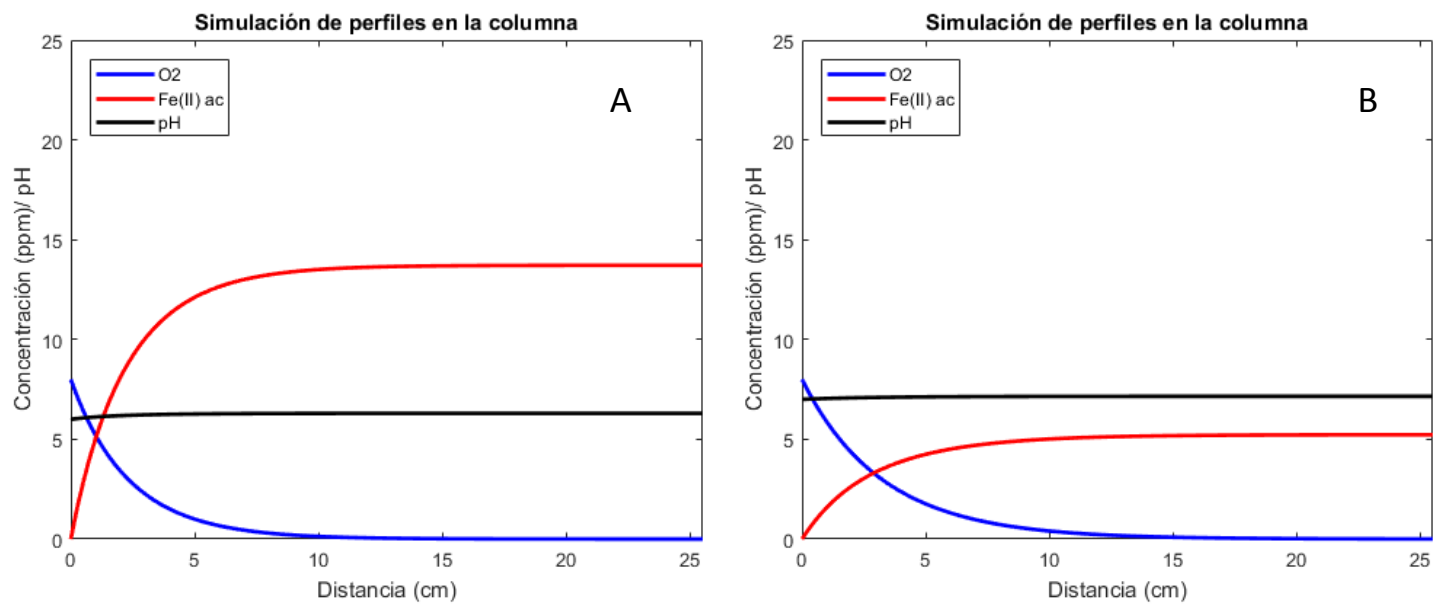

Figura 5.30. Simulación de los perfiles a lo largo de la columna ara el modelo propuesto. $L=$ $25.5 \mathrm{~cm}, \mathrm{v}=6.35 \mathrm{~cm} / \mathrm{min}, \mathrm{pHi}=6(\mathrm{~A})$ y $\mathrm{pHi}=7(\mathrm{~B})$.

Puede observarse que los perfiles simulados reproducen las diferencias de composición registradas entre el afluente y el efluente bajo diferentes condiciones operativas. El análisis de las velocidades de consumo de oxígeno por las reacciones $R_{A}$ y $R_{B}$ (datos no mostrados) revela que para valores $\mathrm{pH}$ bajos al ingreso de la columna, el peso de la reacción $R_{B}$ es prácticamente nulo y predomina el mecanismo descripto por $\mathrm{R}_{\mathrm{A}}$. No obstante, a medida que la fase móvil recorre la columna, debido al aumento de $\mathrm{pH}$ produce la corrosión, la velocidad de la reacción $\mathrm{R}_{B}$ crece notablemente y en consecuencia el peso relativo del proceso representado por $R_{A}$ disminuye. En otras palabras, las fracciones $f_{A}$ y $f_{B}$ previamente definidas (ec. 5.10) varían a lo a lo largo del lecho conforme varía el pH en el interior de la columna.

Finalmente, con el objeto de valorar la capacidad predictiva del conjunto de hipótesis y aproximaciones realizadas, se simularon las composiciones del efluente para una misma columna operada bajo distintas condiciones de $\mathrm{TRH}$ y $\mathrm{pH}$ de entrada. 
En este caso, para poder comparar las predicciones del modelo con los valores registrados experimentalmente a diferentes $\mathrm{TRH}$, las simulaciones se realizaron empleando un coeficiente de retardo para el Fe(II) dependiente del caudal de trabajo. Además, con el fin de contemplar las desviaciones del patrón de flujo real respecto al modelo de flujo pistón ideal, se introdujo en el modelo una distribución de tiempos de residencia (DTR) obtenida experimentalmente para columnas con características similares a las utilizadas en los ensayos RSSCT.

En las Figura 5.31 a 5.34 se contrastan los resultados experimentales con los valores calculados mediante las simulaciones.

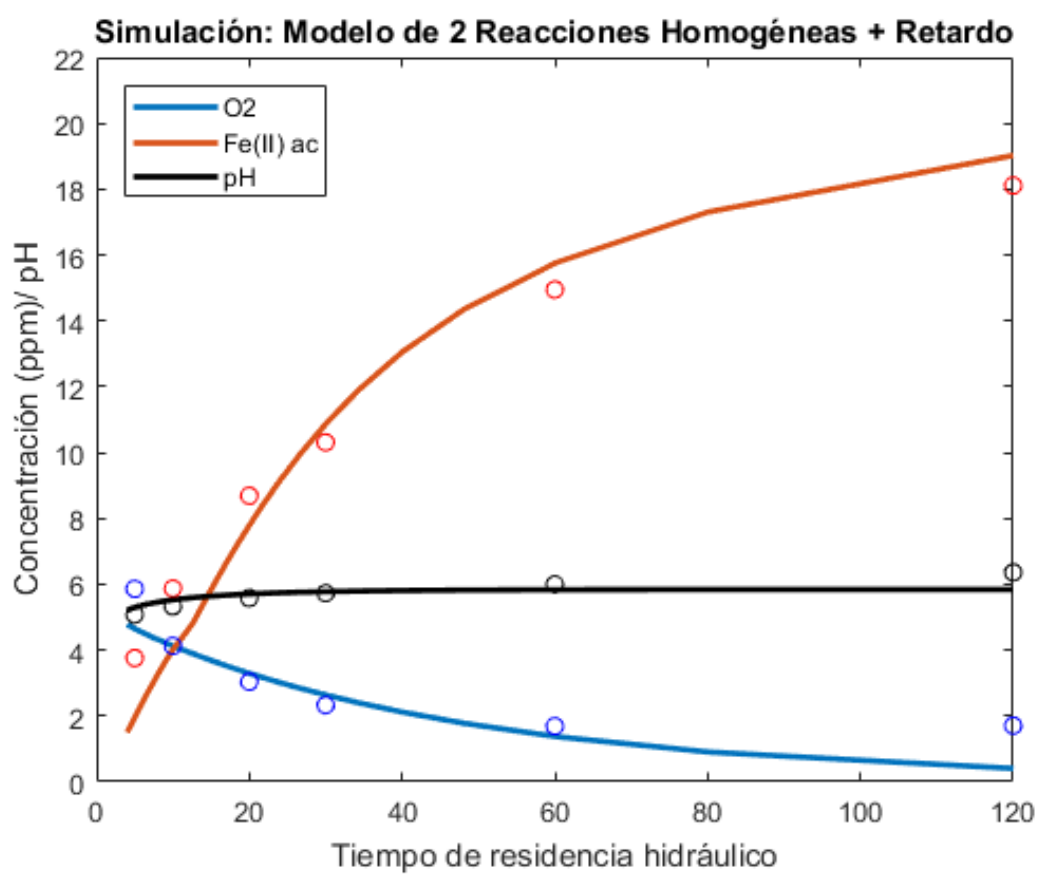

Figura 5. 31. Simulación de los resultados obtenidos mediante el modelo propuesto y comparación con los resultados experimentales para distintos $\mathrm{TRH}(\mathrm{pH}$ ingreso=4). 


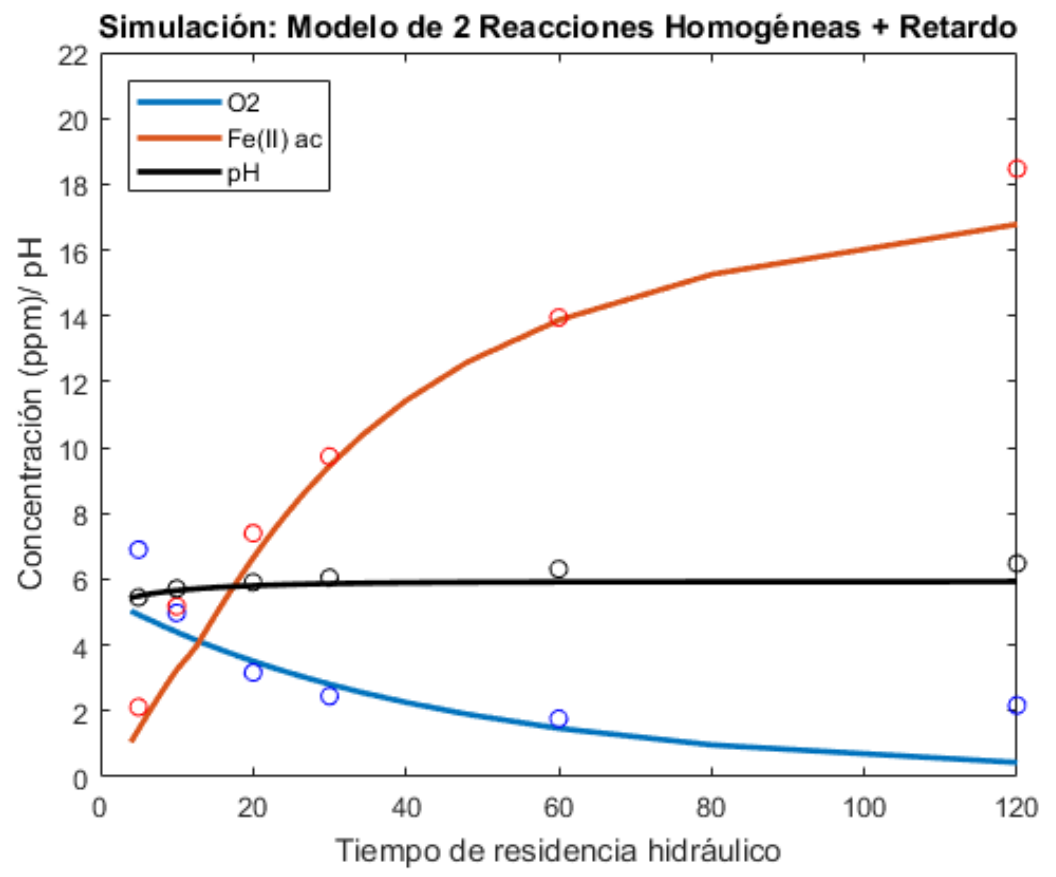

Figura 5. 32. Simulación de los resultados obtenidos mediante el modelo propuesto y comparación con los resultados experimentales para distintos $\mathrm{TRH}(\mathrm{pH}$ ingreso=5).

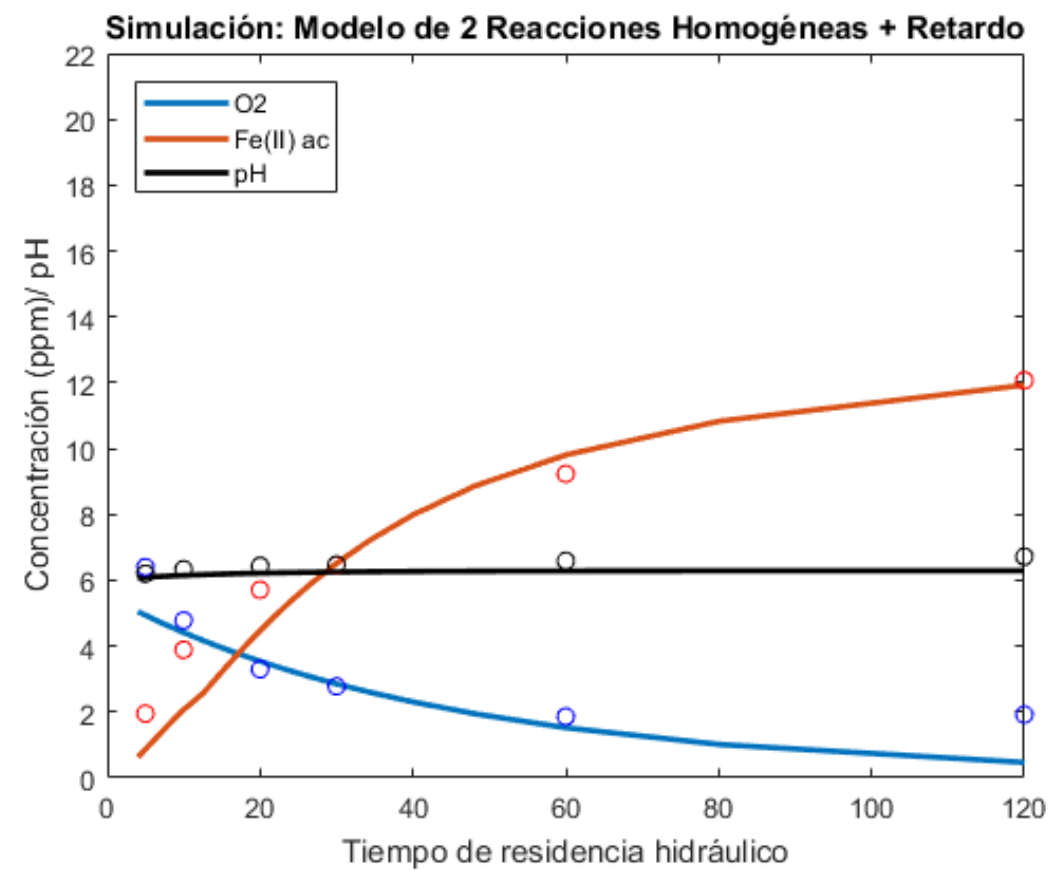

Figura 5. 33. Simulación de los resultados obtenidos mediante el modelo propuesto y comparación con los resultados experimentales para distintos $\mathrm{TRH}(\mathrm{pH}$ ingreso=6). 


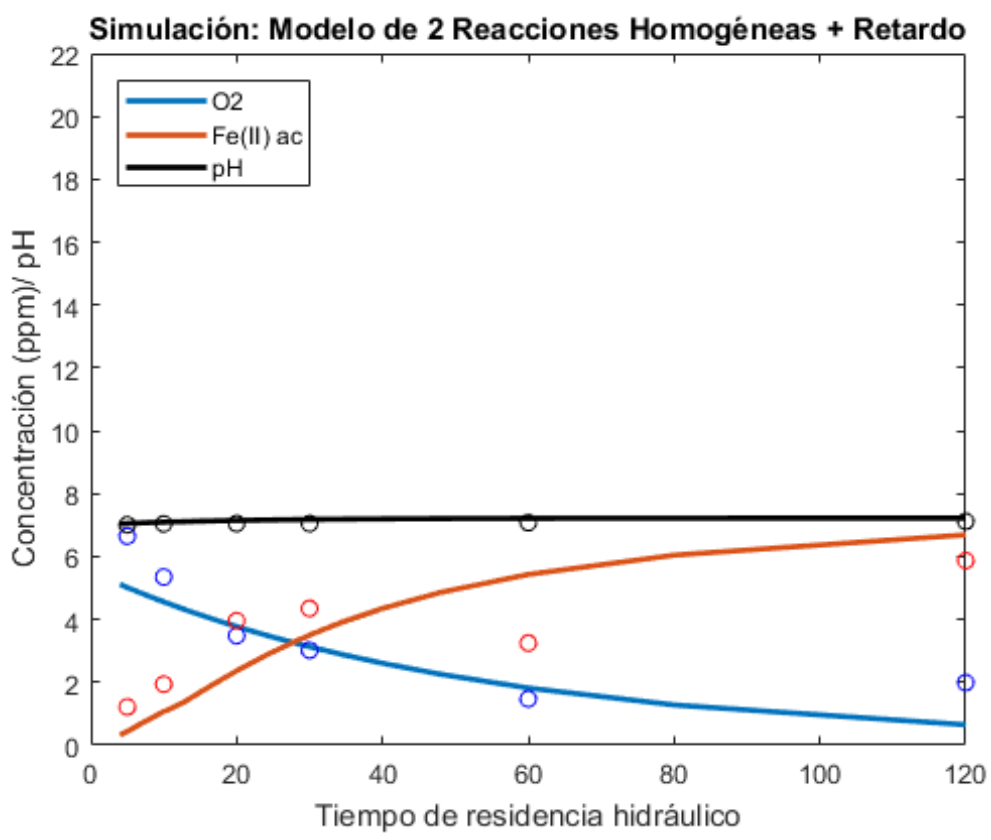

Figura 5. 34. Simulación de los resultados obtenidos mediante el modelo propuesto y comparación con los resultados experimentales para distintos $\mathrm{TRH}(\mathrm{pH}$ ingreso=6).

El análisis de los niveles de $\mathrm{O}_{2}$ simulados muestra que, si bien existen diferencias entre los perfiles calculados y los registrados experimentalmente, la introducción de una DTR al modelo permite considerar los efectos de dispersión hidrodinámica en el interior del lecho reactivo. En particular, la DTR permite dar cuenta de la existencia de canales preferenciales ya que predice contenidos de oxígeno superiores a cero, aún para tiempos de residencia hidráulicos en los cuales el consumo de $\mathrm{O}_{2}$ prácticamente alcanza su valor máximo.

Por otro lado, a partir de los valores obtenidos de la simulación es posible calcular las fracciones $f_{A}$ y $f_{B}$ (ec. 5.10) a la salida de la columna. Cabe aclarar que estos valores representan un valor aparente de lo que ocurre en el interior de la columna ya que, como consecuencia del incremento del $\mathrm{pH}$ a lo largo del lecho, el peso relativo de estas fracciones depende del avance en la columna. En la Figura 5.35 se compara la dependencia, con el $\mathrm{pH}$ de entrada, de los valores de $\mathrm{f}_{\mathrm{A}}$ calculados para un tiempo de residencia de $120 \mathrm{seg}$ con la registrada experimentalmente. Puede observarse que el modelo permite predecir correctamente la inversión de las fracciones $f_{A}$ y $f_{B}$ con la variación del $p H$, siendo predominante la primera para pHs bajos (4 y 5) y la segunda para $\mathrm{pH}$ neutro. 


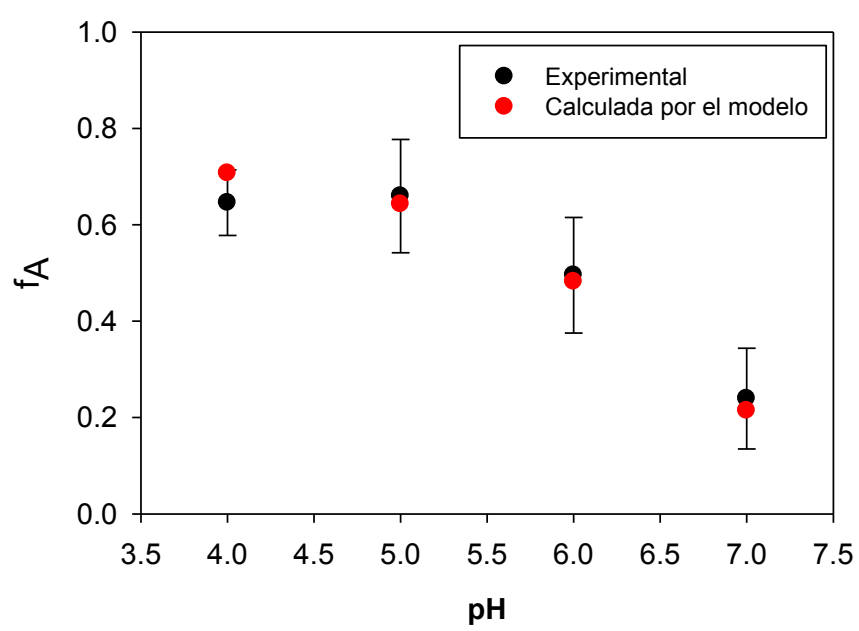

Figura 5.35. Fracción del ZVI consumida por el mecanismo $\mathrm{R}_{\mathrm{A}}$ para los diferentes $\mathrm{pH}$ de ingreso $(\mathrm{TRH}=120 \mathrm{seg})$.

El análisis de las Figuras 5.31 a 5.35 muestra que, a pesar de la sencillez del modelo fisicoquímico propuesto y de las aproximaciones realizadas para resolver matemáticamente las ecuaciones que describen los balances de materia, el modelo físico-matemático desarrollado logra capturar la esencia de los fenómenos químicos más relevantes presentes en el sistema. Esta herramienta permite reproducir las tendencias observadas en un amplio rango de valores de $\mathrm{pH}, \mathrm{TRH}$ y $\mathrm{ZVI}$, explicando así las razones del comportamiento del sistema bajo diferentes condiciones operativas. Actualmente, se trabaja en el refinamiento del modelo de manera de incluir tanto la fase móvil como las fases sólidas. En particular se abordará la resolución de los balances teniendo en cuenta las variables temporal y espacial, para poder calcular los perfiles de $\mathrm{Fe}(\mathrm{OH})_{2}$ y $\mathrm{Fe}(\mathrm{OH})_{3}$ acumulados en el interior de la columna y predecir tiempos de ruptura para diferentes condiciones operativas.

\subsection{CONCLUSIONES}

A lo largo de esta sección se presentó un análisis, interpretación y modelado de resultados correspondientes a 125 experimentos El análisis de los conglomerados muestra, como principal resultado, que la variable respuesta $\mathrm{Fe}(\mathrm{III})$ presenta una correlación muy pobre con respecto al resto de las variables analizadas. Asimismo, tanto esta técnica como el análisis mediante componentes principales indican que el $\mathrm{TRH}$ es el factor que presenta la mayor influencia sobre la variabilidad de los resultados observados en las variables respuesta. También se puede observar que el $\mathrm{pH}$ de entrada produce cierta influencia, la masa de ZVI presenta una influencia mucho menor sobre el desempeño del sistema y la densidad del lecho resulta la variable operativa que menos influye. Por otro lado, la metodología de componentes principales sugiere que el PC1, asociado a la mayor variabilidad de los resultados, refleja mayormente las contribuciones asociadas a las reacciones representadas en las ec. 1 y 2 (y en alguna medida también la 5), mientras que el PC2 tiene una importante contribución de la reacción 5 (y en alguna medida también de la reacción 6 ). 
El objetivo central de la sección correspondiente a redes neuronales fue obtener modelos predictivos que permitan reproducir el comportamiento del sistema y evaluar la importancia relativa de las condiciones operativas sobre las variables que caracterizan la corrosión de lechos reactivos rellenos con ZVI. Como variables independientes para las RNA se utilizaron el pH de entrada, el tiempo de residencia hidráulico (TRH), la masa de ZVI y la densidad del lecho. Por otra parte, como variables de salida (respuesta), que caracterizan el desempeño del lecho, se utilizaron: el consumo de oxígeno, el $\mathrm{pH}$ de salida (o alternativamente la variación del pH) y la concentración de $\mathrm{Fe}(\mathrm{II})$ en el efluente de las columnas. Cabe destacar que la concentración de $\mathrm{Fe}(\mathrm{III})$ fue descartada como variable de respuesta ya que los análisis preliminares mostraron una correlación muy pobre con el resto de las variables.

Las RNA diseñadas y seleccionadas para simular los datos obtenidos presentaron las siguientes características: (i) una sola capa oculta; (ii) una función de activación tangente hiperbólica en la capa oculta y una función lineal en la capa de salida, (iii) para su entrenamiento se empleó el algoritmo Levenberg-Marquardt. Como se discutió previamente, uno de los parámetros más importantes es el número de neuronas en la capa oculta $(\mathrm{NH})$. A partir de los ajustes obtenidos se puede observar que, cuando las variables de entrada influyen de manera significativa en el desempeño de las variables respuesta estudiadas, las RNAs obtenidas permiten predecir el comportamiento de lechos reactivos rellenos con ZVI a parir de las condiciones operativas en la totalidad del rango experimental analizado (primera serie). Sin embargo, cuando la variable de entrada a la RNA estudiada no influye de manera significativa la minimización del error conduce a seleccionar un número excesivo de neuronas en la capa oculta produciéndose así un sobreajuste de los datos. En este contexto, es recomendable limitar el valor de $\mathrm{NH}$ sobre la base de otros criterios.

Finalmente, considerando los resultados obtenidos en el análisis de sensibilidad permiten confirmar que el TRH presenta la más alta contribución para todas las arquitecturas neuronales empleadas. El pH de entrada se presenta como la segunda variable en importancia relativa, mientras que para el dominio experimental estudiado tanto la carga de ZVI como la densidad del lecho tienen un impacto muy poco significativo sobre el desempeño de las columnas.

Gracias al análisis de datos mediante modelos "blandos" se pudo postular un modelo fisicoquímico simplificado de tres reacciones, cuyas velocidades son $\mathrm{pH}$ dependientes. El mismo es capaz de englobar los fenómenos más relevantes que gobiernan el comportamiento del sistema. Sobre la base de esas tres reacciones se propuso un modelo matemático muy simple que permite predecir las tendencias generales observadas para los perfiles de $\mathrm{Fe}(\mathrm{II}), \mathrm{pH}$ y oxígeno a la salida de las columnas sobre una base racional. En comparación con los modelos blandos, el modelo propuesto nos brinda no solamente un análisis mucho más profundo de las razones del comportamiento del sistema sino también un excelente punto de partida para el desarrollo de modelos más completos que permitan interpretar los resultados obtenidos en columnas de mayor escala. 


\section{CAPITULO 6: DISEÑO DE PLANTAS DE TRATAMIENTO PARA LA ELIMINACIÓN DE ARSÉNICO}

EN AGUA 


\section{DISEÑO DE PLANTAS DE TRATAMIENTO PARA LA ELIMINACIÓN DE ARSÉNICO EN AGUA}

\subsection{INSTALACIÓN PARA LA REALIZACIÓN DE ENSAYOS A ESCALA REAL}

En base a la información obtenida en los diferentes ensayos realizados en el laboratorio, se diseñó una planta de tratamiento continuo para la remoción de arsénico. Se comenzó con un diseño básico inicial para el tratamiento de un caudal de $500 \mathrm{~mL} / \mathrm{min}$ y posteriormente se realizaron modificaciones con el objeto de facilitar el escalado del proceso a mayores caudales.

Una vez definido el diseño se construyeron diferentes prototipos para realizar ensayos a escala real usando como solución de trabajo tanto agua de red contaminada artificialmente como aguas subterráneas reales con altos contenidos de arsénico. En todos los casos, la construcción y montaje de la planta fue realizada en primera instancia en instalaciones del departamento de Hidráulica de la Facultad de ingeniería. Una vez realizadas diferentes de pruebas de mediano y largo plazo, los prototipos que mostraron un buen desempeño fueron trasladados a campo para evaluar su desempeño con matrices de agua real.

Para la realización de los ensayos a escala piloto en las instalaciones de la Facultad, se montó un sistema automático para la contaminación del agua de red utilizada como afluente. La estructura general utilizada se muestra en la Figura 6.1. El sistema, que permite operar los diferentes prototipos de manera continua durante las 24 horas del día, cuenta con un reservorio principal de 1100 I ubicado a nivel del piso y un tanque secundario de 400 I ubicado a una altura de 5 metros, similar a la altura de un tanque de agua domiciliario. El tanque superior incluye un flotante automático que, dependiendo del nivel, controla el funcionamiento de una bomba centrifuga $(0,75 \mathrm{HP})$ que eleva el agua desde el tanque principal al secundario. En el tanque principal el agua de red es contaminada artificialmente con una solución de As concentrada. Esta solución es dosificada utilizando una bomba a diafragma (Ares DS-6) que se enciende en paralelo a la bomba centrífuga de elevación. El tanque principal cuenta además con una entrada de agua de red donde el agua que ingresa es regulada con un flotante mecánico. 


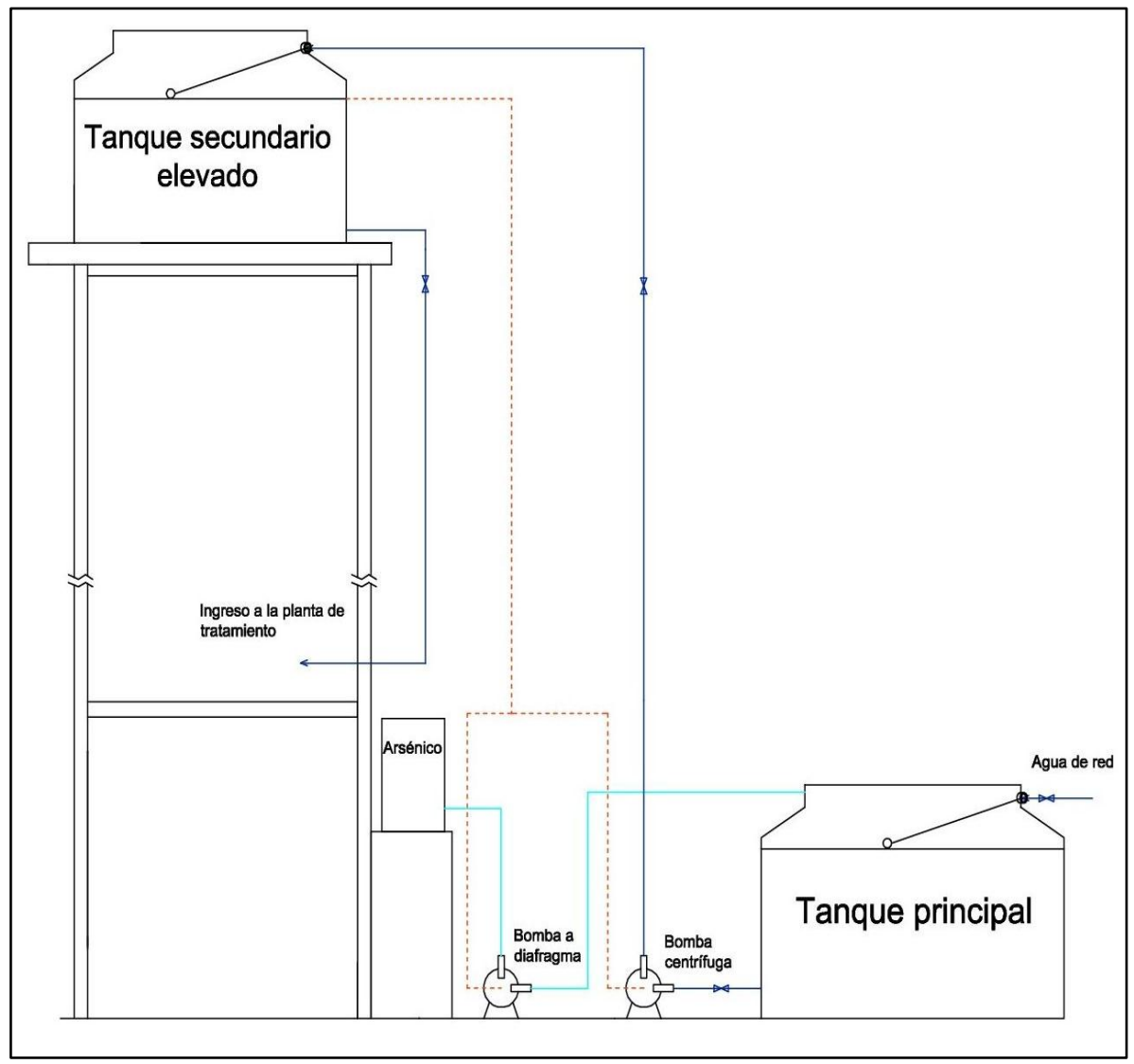

Figura 6.1. Instalación de la infraestructura dispuesta para la realización de pruebas a escala piloto.

Algunos de los ensayos en continuo fueron realizados controlando el $\mathrm{pH}$ al ingreso de la planta de tratamiento. Con este fin se acopló una bomba a diafragma para dosificar ácido mediante un controlador proporcional de $\mathrm{pH}$ incorporado. En la Figura 6.2 se observa un diagrama de la instalación del sistema de ajuste de pH automático. En primer lugar un pulso de solución de ácido es inyectado a la corriente de alimentación. El fluido ingresa luego a un mezclador estático en línea que genera un alto grado de mezclado entre la solución ácida y la corriente alimentada en un pequeño tramo de la cañería. Por último, el electrodo mide el $\mathrm{pH}$ de la solución resultante y en base a la lectura realizada calcula la frecuencia de bombeo. 


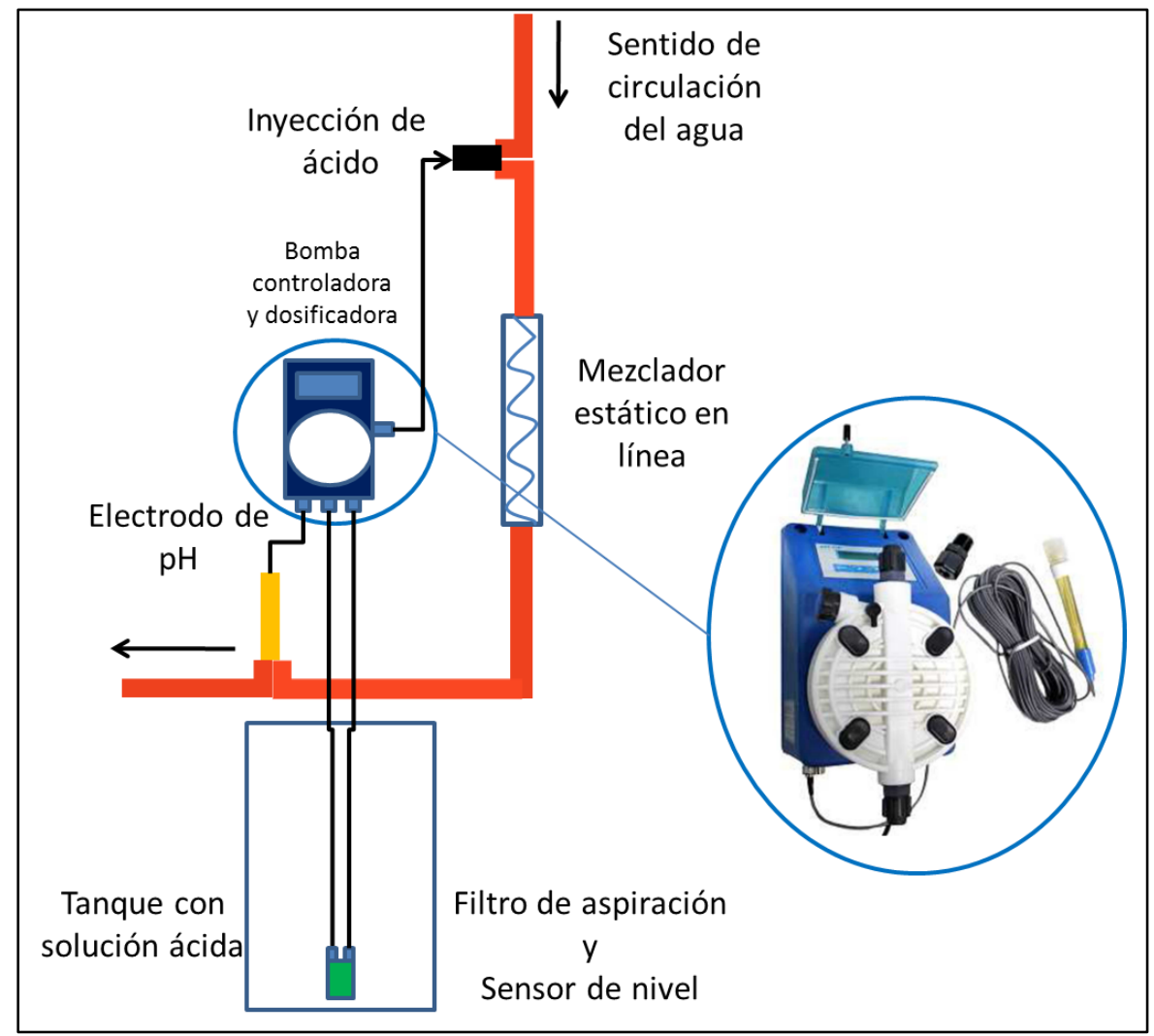

Figura 6.2. Sistema de regulación de pH en línea.

\subsection{PLANTA PARA EL TRATAMIENTO DE 700 L/DÍA}

Tomando en consideración tanto la información asociada con los procesos específicos involucrados en los sistemas ZVI/agua, como los conocimientos teóricos relacionados a los procesos convencionales de filtración, se desarrolló una planta completa de tratamiento a pequeña escala, basada en el uso de $\mathrm{Fe}(0)$. El prototipo fue diseñado para tratar, de manera continua, agua subterránea contaminada con As con un caudal de $500 \mathrm{~mL} / \mathrm{min}$. El principal objetivo en este caso fue desarrollar un sistema de operación simple con materiales económicos y disponibles fácilmente en el mercado. Dado que el prototipo fue pensado para ser utilizado a escala domiciliaria o de pequeñas grupos en comunidades dispersas, el diseño contempló requerimientos mínimos de energía eléctrica.

El sistema involucra tres etapas y funciona con un flujo de agua inducido por gravedad. Ubicada en un tanque elevado, el agua a tratar atraviesa en la etapa inicial un reactor tubular relleno con ZVI. Pese a que se pueden usar varias fuentes de ZVI, el material seleccionado fue la lana de hierro por presentar las ventajas que se detallan en el capítulo 3, ser económica y de fácil acceso. Para construir el lecho relleno, la lana de acero, comercializada en forma de paño continuo de $10 \mathrm{~cm}$ de ancho en rollos de $1.5 \mathrm{~kg}$, es cortada en rectángulos de largo igual al diámetro de la columna a empacar. Estos rectángulos son superpuestos en forma alternada formando un cilindro del diámetro de la columna y aproximadamente $20 \mathrm{~cm}$ de alto. Luego se colocan tantos cilindros como se requiera en el interior de una columna de pvc o acrílico verificando que no quede espacio entre el relleno y las paredes del recipiente. 
Como soporte se utiliza un plato perforado colocado $1 \mathrm{~cm}$ por encima de la cañería de ingreso de agua.

Como se explicó anteriromente, durante la primera etapa del proceso el ZVI reacciona con el oxígeno disuelto (OD) presente naturalmente en el agua produciendo especies de $\mathrm{Fe}(\mathrm{II})$ solubles. Al mismo tiempo, parte del $\mathrm{Fe}(\mathrm{II})$ formado también reacciona con OD para producir especies de $\mathrm{Fe}$ (III) que forman productos de corrosión capaces de co-precipitar o adsorber una fracción del As presente en el agua dentro de la columna. El paso de la solución desde la columna a la siguiente etapa es regulado por una válvula flotante ubicada en la entrada del módulo 2.

La segunda etapa consiste en un tanque de aireación/contacto para oxidar el $\mathrm{Fe}(\mathrm{II})$ soluble restante e inducir procesos adicionales de precipitación/coprecipitación que mejoran la eficiencia de eliminación de As. Para facilitar la nucleación y el crecimiento de las partículas, se utilizó grava en el fondo de esta unidad. Esta también incluye un fondo cónico con una llave para permite la descarga de los sólidos acumulados.

Finalmente, se incluyó como tercera etapa un filtro lento de arena para eliminar las especies precipitadas de hierro y obtener concentraciones totales de Fe y de As por debajo de los límites establecidos para agua potable $(0,3 \mathrm{ppm}$ y $10 \mathrm{ppb}$, respectivamente). El filtro de arena opera de manera descendente por gravedad con una velocidad de $0,5 \mathrm{~cm} / \mathrm{min}$ (que equivale a $0,3 \mathrm{~m} / \mathrm{h}$ ). Está construido con una capa de canto rodado como soporte, una capa media de grava, un lecho de arena y una membrana geotextil en la parte superior. El diseño del filtro fue seleccionado luego de varias pruebas con filtros ascendentes y descendentes con distintas configuraciones de relleno. Cabe destacar las pruebas mencionadas mostraron una gran tendencia de las partículas de oxi/hidroxidos de hierro generadas en estos sistemas a participar en procesos de cementación que conducen a la formación de capas muy poco permeables sobre la superficie del manto filtrante. La utilización del geotextil facilita las tareas de mantenimiento al permitir la limpieza de la parte superior del filtro donde se retiene la mayor parte de los óxidos de hierro generados.

La configuración de tres módulos fue establecida luego de numerosos ensayos realizados con diferentes plantas piloto en los que se evaluaron varias estrategias para el armado de los prototipos. Una de las principales dificultades que surgió en el desarrollo de las pruebas iniciales fue la imposibilidad de regular correctamente el caudal. Dada la variación en la conductividad hidráulica del lecho durante los primeros días de operación era necesario un ajuste constante de caudal. Para esta escala de trabajo, este problema fue resuelto mediante la colocación de la válvula flotante a la salida del primer módulo. De esta manera el sistema funciona con la columna rellena bajo presión, siendo la presión a la entrada la correspondiente a la altura del tanque elevado (3.5 $\mathrm{m}$ aproximadamente). Luego el caudal es regulado mediante la diferencia de nivel entre las segunda y tercer etapa.

En la Figura 6.3 se presenta una fotografía de una de las primeras configuraciones ensayadas. Se puede observar un sistema de regulación de caudal mediante un vertedero a la salida del primer módulo y un filtro lento de arena operado en forma ascendente. 


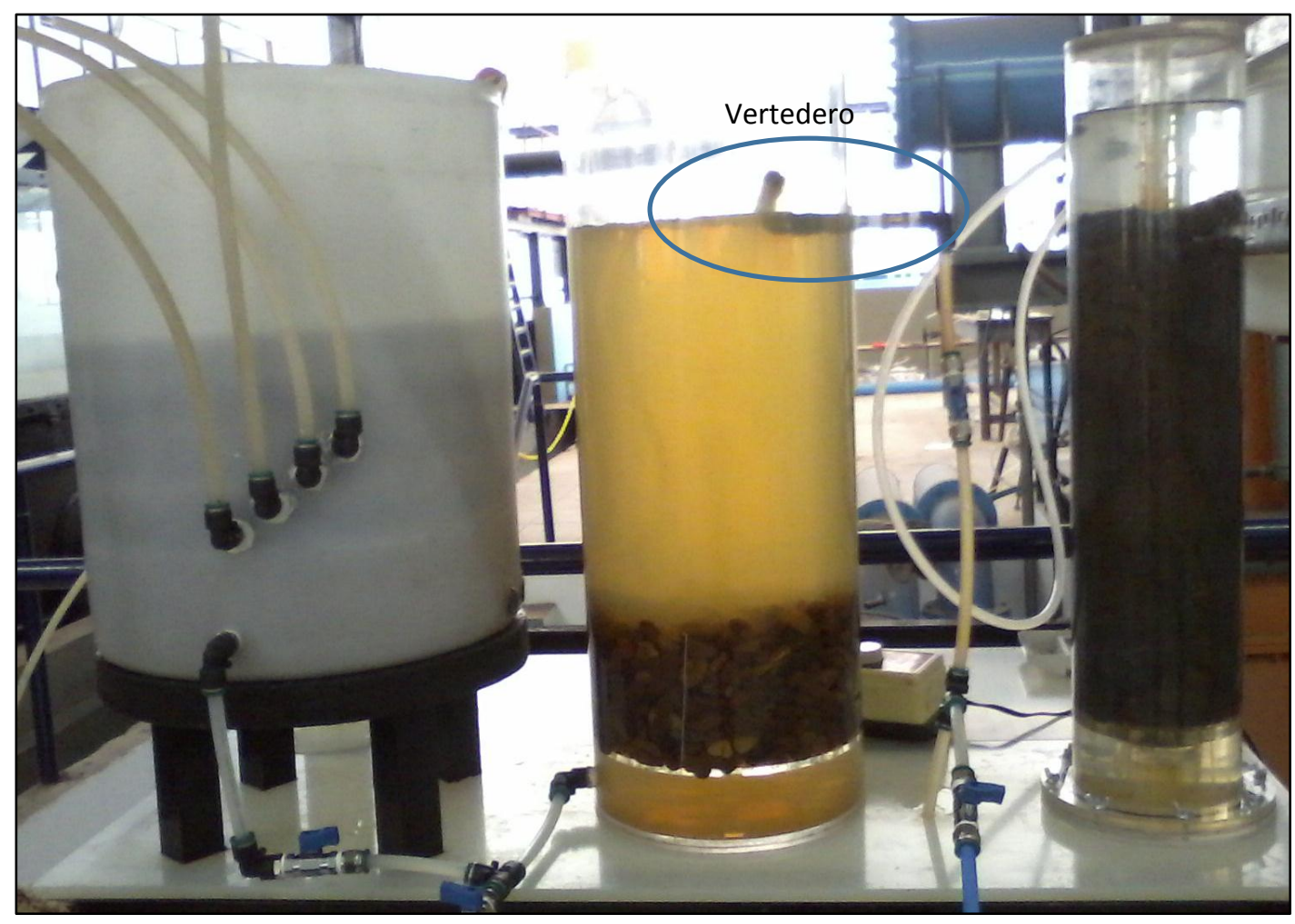

Figura 6.3. Fotografía de uno de los prototipos domiciliarios utilizados para la realización de ensayos a escala real en instalaciones de la Facultad ( $Q d=500 \mathrm{~mL} / \mathrm{min})$.

Las primeras pruebas con el prototipo de la Figura 6.3 mostraron algunos inconvenientes en la etapa final de filtrado. Por este motivo, se realizaron ensayos con diferentes configuraciones para el filtro lento de arena. Los resultados mostraron que cuando se emplea una configuración ascendente, pequeñas perturbaciones en el caudal de entrada pueden generar reiteradas fluidizaciones y favorecer el desarrollo de cortocircuitos (o bypases) en el manto filtrante. En consecuencia, con la finalidad de garantizar una mayor estabilidad hidráulica, para el diseño final se seleccionó la operación descendente.

La representación esquemática del diseño final adoptado para las pruebas de laboratorio en esta escala se muestra en la Figura 6.4. En la Tabla 6.1 se detallan las dimensiones y parámetros de diseño adoptados. 


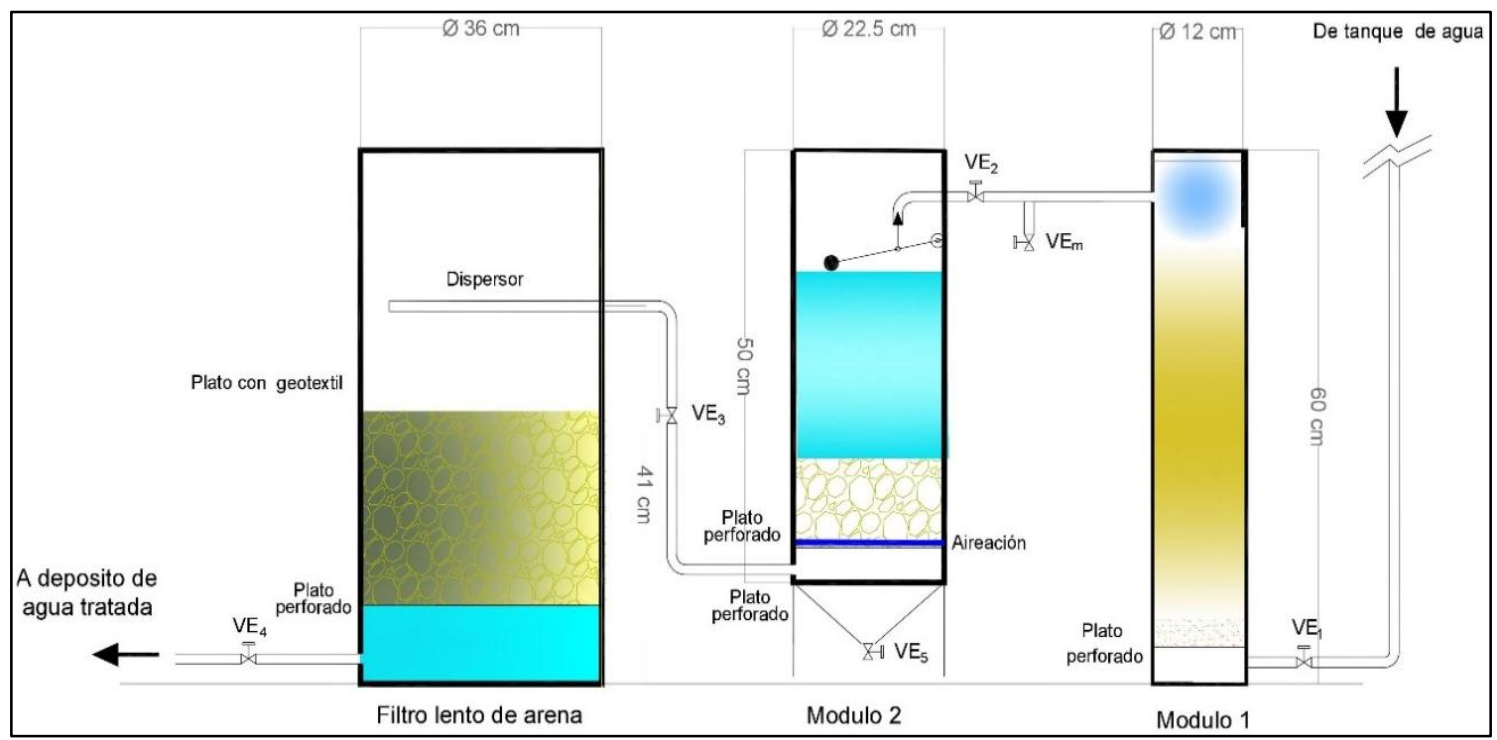

Figura 6.4. Diseño final del prototipo domiciliario ( $Q d=500 \mathrm{~mL} / \mathrm{min})$.

Tabla 6.1. Parámetros de diseño de la planta para el tratamiento de 700 L/día.

\begin{tabular}{|c|c|c|c|}
\hline & Columna & Módulo 2 & FLA \\
\hline$Q$ diseño (mL/min) & 500 & 500 & 500 \\
\hline Longitud del lecho (cm) & 45 & 40 & 30 \\
\hline Diámetro $(\mathrm{cm})$ & 12 & 22.5 & 36 \\
\hline Área $\left(\mathrm{cm}^{2}\right)$ & 113 & 398 & 1018 \\
\hline TRH (min) & 10,2 & 31,8 & 61,1 \\
\hline TRH calculado ensayos preliminares (min) & $>2$ & $>\mathbf{3 0}$ & \\
\hline Densidad del lecho $\left(\mathrm{gr} / \mathrm{cm}^{3}\right)$ & 0,069 & & \\
\hline velocidad (cm/min) & 4,42 & 1,26 & 0,49 \\
\hline velocidad $(\mathrm{m} / \mathrm{h})$ & 2,65 & 0,75 & 0,29 \\
\hline velocidad teórica recomendada $(\mathrm{m} / \mathrm{h})$ & & & $0,1-0,3$ \\
\hline
\end{tabular}

\subsubsection{Resultados eficiencia pruebas de laboratorio}

Con el objetivo de evaluar la eficiencia del proceso y el tiempo de servicio de la planta de tratamiento diseñada se realizaron pruebas piloto. Como solución de trabajo se utilizó agua de red de La Plata, de pH 7.2-7.5, artificialmente contaminada con $0,25 \mathrm{mg} / \mathrm{L}$ de $A s(V)$ y se utilizó una masa de lana de acero de $350 \mathrm{gr}$. Los parámetros empleados para monitorear el desempeño del prototipo fueron: $\mathrm{Fe}(\mathrm{II})$ y Fe(III) a la salida de cada módulo y As a la salida del sistema.

Se realizó un muestreo diario y con los datos obtenidos se construyó la curva de ruptura que se muestra Figura 6.5. Se puede observar un tiempo de ruptura cercano a 1370 horas y un volumen de ruptura de 16296 litros para el material reactivo para la prueba realizada empleando un caudal de trabajo promedio de $275 \pm 130$ 
$\mathrm{mL} / \mathrm{min}$. Superado este tiempo, el contenido de As en el efluente alcanza el límite máximo permitido por la OMS de 0,01 $\mathrm{mg} / \mathrm{l}$. Las determinaciones de hierro a la salida del primer módulo (Figura 6.6) indican que a partir de este momento el contenido de $\mathrm{Fe}$ (II) disminuye por debajo de $0,5 \mathrm{ppm}$ y el de $\mathrm{Fe}_{\text {Tot }}$ por debajo de $2 \mathrm{ppm}$. Estos resultados concuerdan con los mostrados en el Capitulo 3 y también sugieren que estos parámetros podrían emplearse para el control del proceso e indicación del agotamiento del lecho reactivo. Para verificar esta hipótesis, se realizaron dos nuevas pruebas adicionales. Durante la primera con un caudal promedio de $330 \mathrm{~mL} / \mathrm{min}$ se obtuvo un tiempo de ruptura de 1176 horas y un volumen de ruptura de 23324 litros. En la segunda con un caudal promedio de $380 \mathrm{~mL} / \mathrm{min}$ se obtuvo un tiempo de ruptura de 1000 horas y un volumen de ruptura de 23058 litros. En ambos casos se registraron concentraciones de $\mathrm{Fe}_{\text {Tot }}$ por debajo de $2 \mathrm{ppm}$ para tiempos superiores al de ruptura (Figura 6.7).

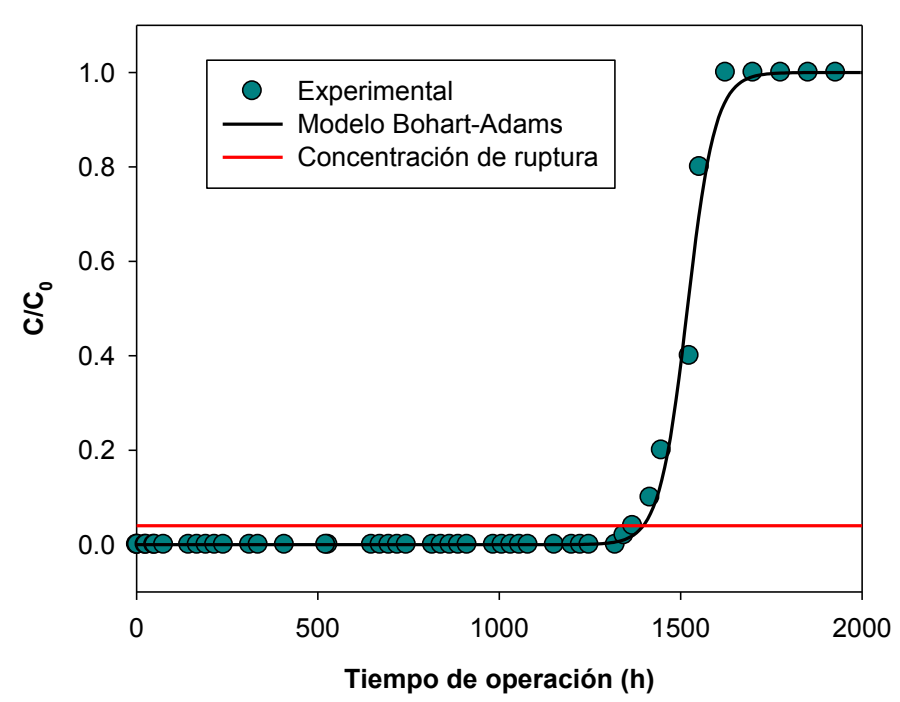

Figura 6.5. Curva de ruptura del primer prototipo $\left(\mathrm{Qm}=275 \mathrm{~mL} / \mathrm{min}, \mathrm{m}_{\mathrm{ZvI}}=350 \mathrm{gr}\right)$.

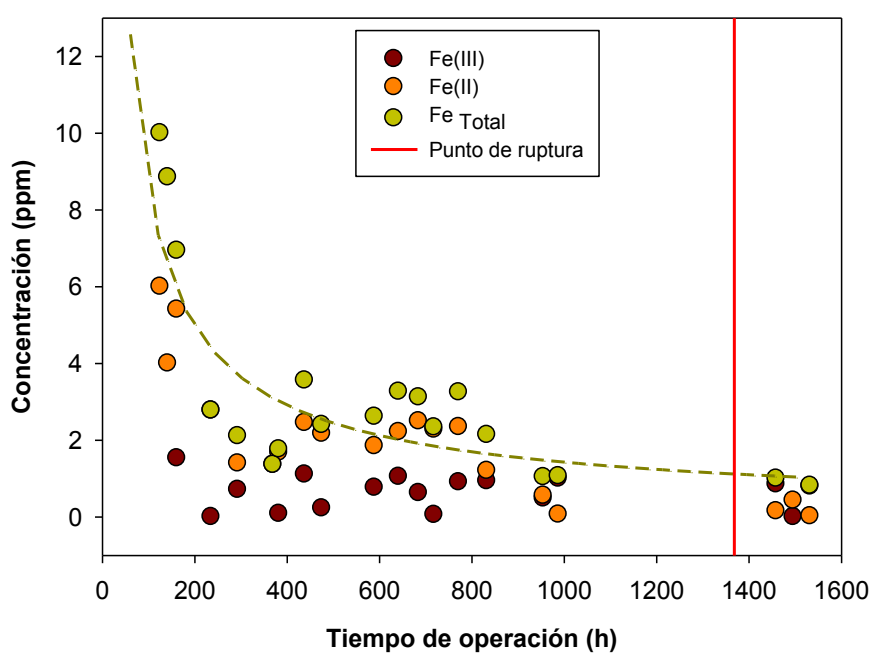

Figura 6.6. Concentración de Fe a la salida del reactor $\left(\mathrm{Qm}=275 \mathrm{~mL} / \mathrm{min}, \mathrm{m}_{\mathrm{zVI}}=350 \mathrm{gr}\right)$. 

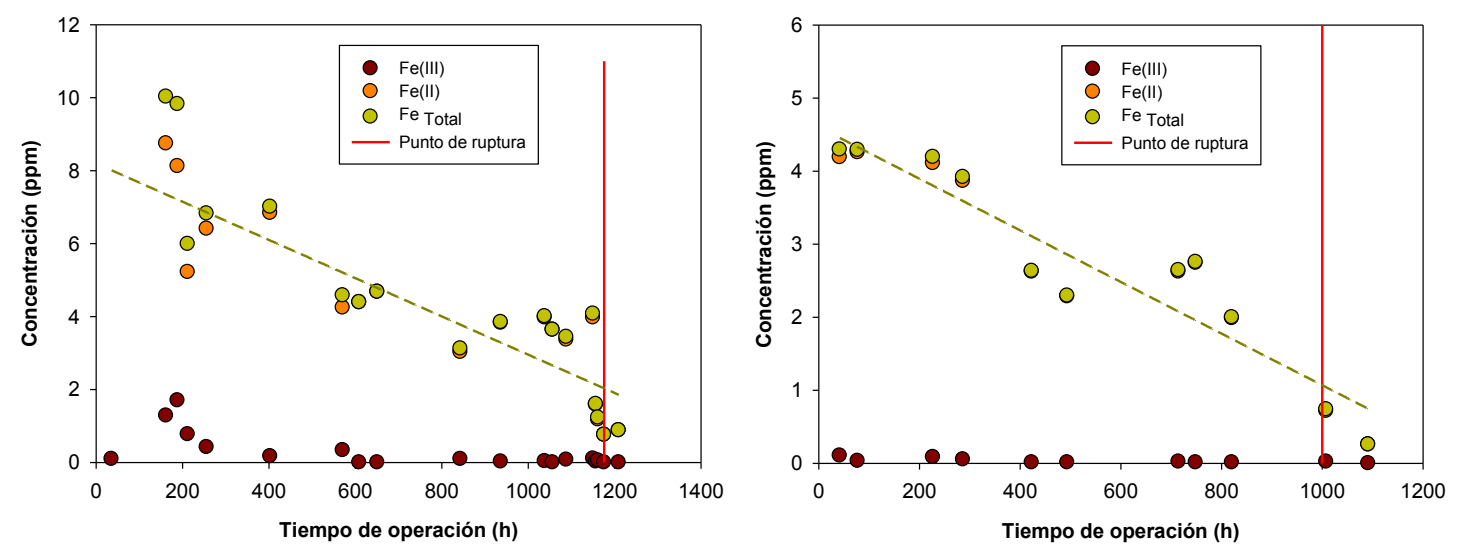

Figura 6.7. Concentración de Fe a la salida del reactor $\left(m_{\mathrm{zvI}}=350 \mathrm{gr}\right.$, izq. $Q \mathrm{~m}=330$, der. $\left.Q \mathrm{~m}=380 \mathrm{~mL} / \mathrm{min}\right)$.

Una segunda curva de ruptura fue obtenida utilizando el mismo prototipo y modificando las condiciones de operación. En este caso, se trabajó con un caudal promedio mayor al empleado en el ensayo de la Figura 6.5 , de $408 \mathrm{~mL} / \mathrm{min}$ y se controló el pH de entrada entre 6.5-7.0.

De acuerdo con lo que se esperaba, los resultados mostraron un tiempo de ruptura menor (Fig.15), cercano a 660 horas. Por otro lado, el volumen de ruptura registrado fue 19238 litros, levemente superior al de la prueba anterior a pesar de haber trabajado a un mayor caudal. Las determinaciones de hierro a la salida del primer módulo para este segundo ensayo (Fig. 16) muestran valores de $\mathrm{Fe}(\mathrm{II})$ a la salida del primer módulo bastante mayores que los del ensayo realizado sin control del $\mathrm{pH}$ de entrada. A pesar de esta clara diferencia, en este caso también se observa que para tiempos de operación mayores al tiempo de ruptura la concentración de $\mathrm{Fe}(\mathrm{II})_{\mathrm{F}} \mathrm{a}$ la salida del primer módulo está por debajo de las $0,5 \mathrm{ppm}$ y el lecho pierde la capacidad de remover el contaminante.
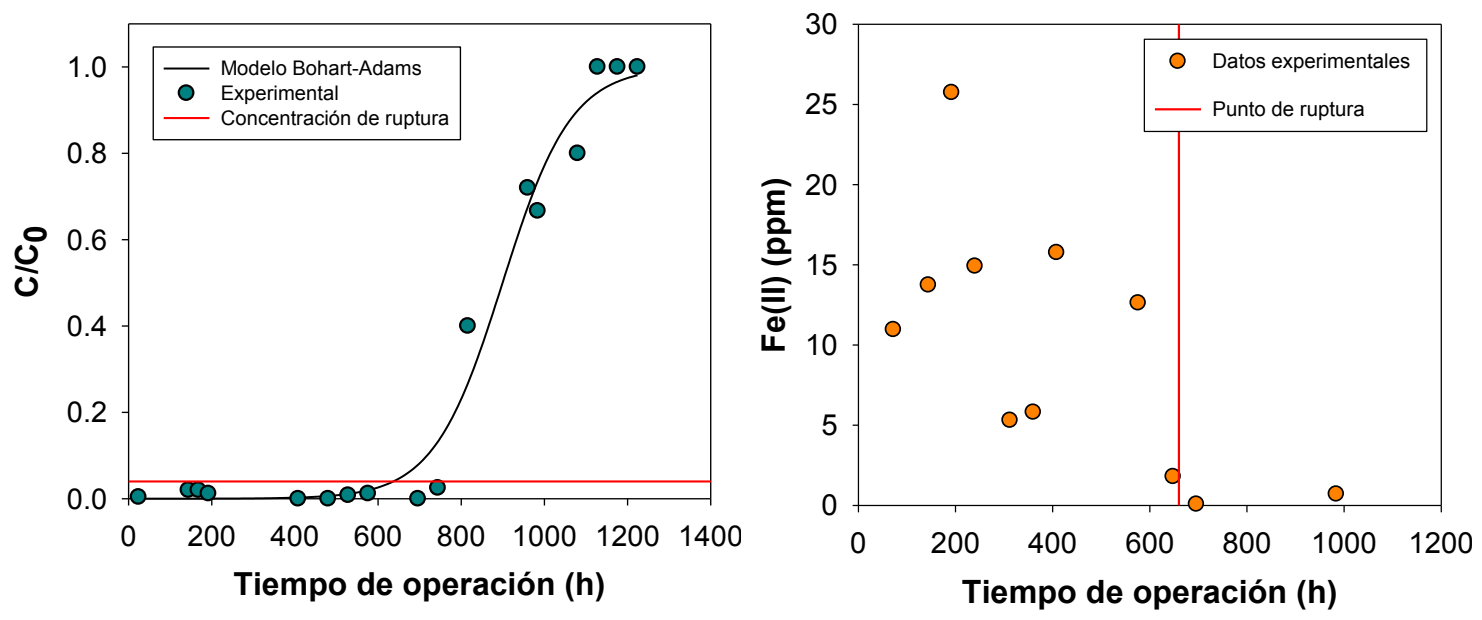

Figura 6.8. Curva de ruptura (izq.) y concentración de Fe a la salida del reactor (der.). $(\mathrm{Qm}=408 \mathrm{~mL} / \mathrm{min}, \mathrm{mZVl}=500 \mathrm{gr})$. 
Las curvas de ruptura obtenidas fueron ajustada utilizando el modelo de Bohart-Adams (ec. 6.1). A partir del conocimiento de las condiciones utilizadas para el ensayo: concentración de contaminante en la entrada $\left(C_{0}\right)$, velocidad de filtración $\left(v_{\text {filt }}\right)$ y largo del lecho (Z), el modelo simplificado de Bohart-Adams permite caracterizar el sistema estudiado mediante la estimación de sólo dos parámetros: $\boldsymbol{i}$ - la capacidad de la columna $\left(N_{0}\right)$, y ii- la constante cinética del lecho $\left(k_{a b}\right)$. En la Tabla 6.2 se muestran las condiciones operativas empleadas y los resultados del ajuste, que permiten caracterizar tanto la capacidad de la columna $\left(\mathrm{N}_{\circ}\right)$ como la constante cinética del lecho $\left(\mathrm{k}_{\mathrm{ab}}\right)$ para los dos ensayos realizados.

$$
\frac{C}{C_{0}}=\frac{1}{1+\exp \left(\frac{k_{a b} N_{0} Z}{v_{f i l t}}-k_{a b} C_{o} t\right)}
$$

Tabla 6.2 . Ajuste del modelo de Bohart-Adams para las dos curvas de ruptura obtenidas.

\begin{tabular}{|c|c|c|c|}
\hline Datos & & Parámetros calculados & \\
\hline Altura de lecho $(Z)$ & $45 \mathrm{~cm}$ & & \\
\hline Conc. de As a la entrada $\left(\mathrm{C}_{0}\right)$ & $0.25 \mathrm{mg} / \mathrm{l}$ & & \\
\hline \multicolumn{4}{|l|}{ Curva número 1} \\
\hline Masa de ZVI & $350 \mathrm{gr}$ & Máx. capacidad del lecho $\left(\mathrm{N}_{0}\right)$ & $972.85 \mathrm{mg} / \mathrm{l}$ \\
\hline Velocidad de filtración (Vfilt) & $115.27 \mathrm{~cm} / \mathrm{h}$ & Cte. Cinética del lecho $\left(\mathrm{K}_{\mathrm{ab}}\right)$ & $0.1044(\mathrm{mg} / \mathrm{l})^{-1} \mathrm{~h}^{-1}$ \\
\hline \multicolumn{4}{|l|}{ Curva número 2} \\
\hline Masa de ZVI & $500 \mathrm{gr}$ & Máx. capacidad del lecho $\left(\mathrm{N}_{0}\right)$ & $854.68 \mathrm{mg} / \mathrm{l}$ \\
\hline Velocidad de filtración (Vfiit) & $171.02 \mathrm{~cm} / \mathrm{h}$ & Cte. Cinética del lecho $\left(\mathrm{K}_{\mathrm{ab}}\right)$ & $0.0484(\mathrm{mg} / \mathrm{l})^{-1} \mathrm{~h}^{-1}$ \\
\hline
\end{tabular}

Como se puede ver la máxima capacidad del lecho difiere levemente pero en ambos ensayos resulta de orden de $900 \mathrm{mg} / \mathrm{L}$. En contraste, la constante cinética del lecho disminuye un $100 \%$ al aumentar la velocidad un $50 \%$. Esto se debe, posiblemente, a que al aumentar la velocidad el fluido pueden generarse canales preferenciales de paso que disminuyen el tiempo de contacto efectivo entre la solución y el material del relleno reduciendo así la probabilidad de que el contaminante quede retenido en el proceso..

Sin embargo, tal como se mencionó en la sección 2.2.2.2, el modelo simplificado de Bohart-Adams es estrictamente aplicable a lechos puramente adsortivos en los que la retención del contaminante se produce por adsorción sobre un lecho químicamente inerte. En el caso de los sistemas basados en el empleo de ZVI, el lecho fijo no es inerte y va modificándose con el tiempo de servicio debido a la acumulación de productos de corrosión, a la disminución de la superficie de ZVI disponible y a la caída de permeabilidad hidráulica del sistema. Por este motivo, los parámetros estimados empleando la ecuación 6.1 deben ser analizados con cautela. Un modelo completo de comportamiento del sistema reactivo requeriría no solamente la consideración de los cambios fisicoquímicos que ocurren en el lecho a lo largo del tiempo de servicio sino también la evaluación de cómo evolucionan las contribuciones relativas de los diferentes mecanismos de remoción de As a medida que el lecho se va 
modificando.

En la Tabla 6.3 se muestra un resumen de todas las pruebas realizadas con la planta piloto en las instalaciones de la Facultad para esta escala. Se trabajó con densidades de lecho comprendidas entre $0,052-0,134 \mathrm{gr} / \mathrm{cm}^{3}$ y valores de TRH entre 6 y 23,6 min. La primera prueba fue realizada sin control de $\mathrm{pH}(\mathrm{pH} \approx 7,3)$, mientras que para el resto de los ensayos se controló su valor de entrada en el rango 6,5-7,0. Puede apreciarse que, en los casos en los que se trabajó con control de $\mathrm{pH}$, el rendimiento obtenido se mantuvo en el orden de los 35 litros de agua tratada por cada gramo de ZVI utilizado. Teniendo en cuenta una concentración promedio a la entrada de 0,25 $\mathrm{mg} / \mathrm{L}$ de $\mathrm{As}(\mathrm{V})$ se obtiene una capacidad máxima de remoción de 8,75 mg As/g ZVI, valor superior al de muchos de los absorbentes reportados en la literatura (Tabla 1.1). Además, dentro del rango de condiciones en las cuales se trabajó, el rendimiento resultó ser prácticamente independiente del valor de las condiciones operativas utilizadas.

Tabla 6.3. Rendimiento obtenido en diferentes pruebas realizadas con la planta diseñada para el tratamiento de 720 L/día.

\begin{tabular}{|r|r|r|r|r|r|r|r|c|}
\hline Prueba & masa ZVI (gr) & $\begin{array}{c}\text { Densidad } \\
\text { del lecho } \\
\text { (gr/cm3) }\end{array}$ & $\begin{array}{c}\text { TRH } \\
\text { promedio } \\
\text { (min) }\end{array}$ & $\begin{array}{c}\text { Tiempo de } \\
\text { ruptura } \\
\text { (horas)* }\end{array}$ & $\begin{array}{c}\text { Volumen } \\
\text { de ruptura } \\
\text { (litros) }\end{array}$ & $\begin{array}{c}\text { Caudal } \\
\text { Días } \\
\text { operativos }\end{array}$ & $\begin{array}{c}\text { Rendimiento* } \\
\text { promedio } \\
\text { (ml/min) }\end{array}$ & $\begin{array}{c}\text { (litros } \\
\text { tratados/gr ZVI) }\end{array}$ \\
\hline 1 & 350 & 0.052 & 23.6 & 1370 & 16296 & 57 & 198.54 & 46.56 \\
\hline 2 & 500 & 0.078 & 27.9 & 1200 & 16625 & 50 & 230.90 & 33.25 \\
\hline 3 & 650 & 0.100 & 19.5 & 1176 & 23324 & 49 & 330.56 & 35.88 \\
\hline 4 & 650 & 0.100 & 17.0 & 1000 & 23058 & 42 & 381.25 & 35.47 \\
\hline 5 & 500 & 0.077 & 23.4 & 744 & 19238 & 31 & 430.96 & 38.48 \\
\hline 6 & 500 & 0.077 & 13.8 & 696 & 19432 & 29 & 465.33 & 38.86 \\
\hline 7 & 500 & 0.078 & 12.4 & 528 & 16491 & 22 & 520.55 & 32.98 \\
\hline 8 & 500 & 0.134 & 6.0 & 456 & 17078 & 19 & 624.20 & 34.16 \\
\hline
\end{tabular}

\subsubsection{Variación de la conductividad hidráulica}

Se realizó una prueba de laboratorio utilizando agua de red con la planta piloto de tres módulos para evaluar la variación de conductividad hidráulica de la columna reactiva con el tiempo de operación. Para esto, se acopló un permeámetro de carga constante en paralelo a la alimentación de la columna (Figura 6.9) y semanalmente se determinó la conductividad hidráulica del lecho reactivo. 


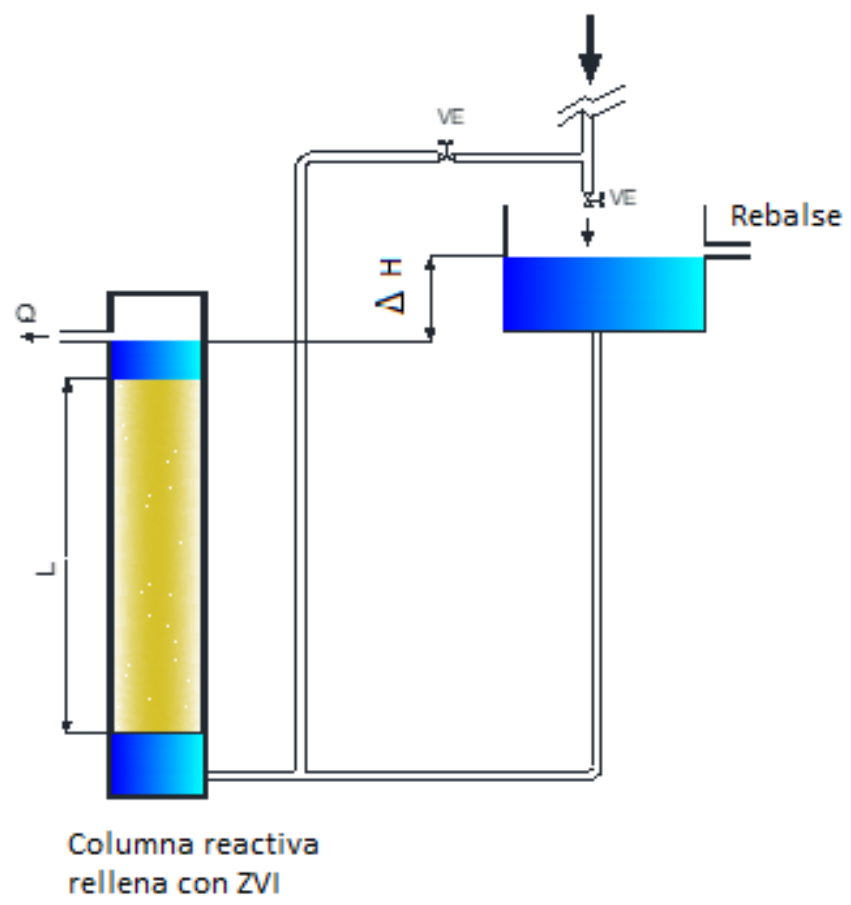

Figura 6.9. Permeámetro de carga constante acoplado a la columna.

Para determinar la conductividad hidráulica $(\mathrm{K})$ se aplicó la ley de Darcy. Tal como se describió en el capítulo 2, esta ley falla para valores de $\mathrm{K}$ muy bajos o para altas tasas de flujo y su rango de validez corresponde a un número de Reynolds entre 1 y 10. Experimentalmente se ha encontrado que, para garantizar que el número de Reynolds no exceda el último límite de validez, la caída de presión total en el permeámetro no debe ser mayor al $50 \%$ de la longitud total del lecho [130]. Teniendo en cuenta esto, antes de la evaluación de la evolución temporal de $\mathrm{K}$, se realizaron varias determinaciones del valor inicial de $K$ con diferentes niveles de agua $(\Delta H)$ para verificar el rango de aplicabilidad de la ley de Darcy al sistema estudiado. La Figura 6.10 muestra que la ley es válida para niveles de $\Delta H$ entre 8 y $40 \mathrm{~cm}$, ya que para este rango el caudal varía linealmente con la carga hidráulica aplicada.

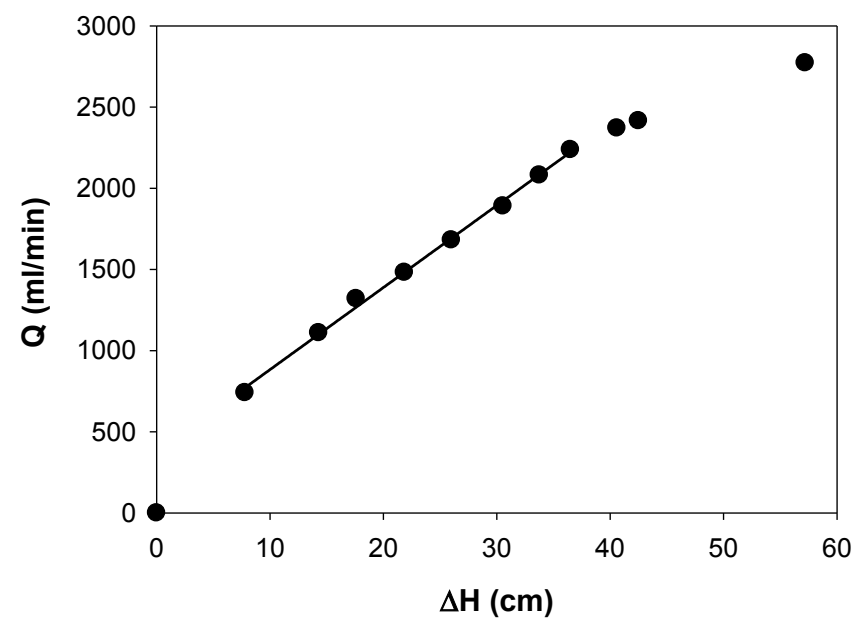

Figura 6.10. Determinación experimental del rango de valides de la Ley de Darcy. 
La Figura 6.11 muestra el comportamiento del valor de la conductividad hidráulica en función del volumen tratado. Los valores de $\mathrm{K}$ obtenidos disminuyen claramente con el volumen tratado, lo que sugiere que la disminución de la porosidad debida a los efectos de taponamiento que producen un aumento de la perdida de carga en el lecho con el volumen tratado.

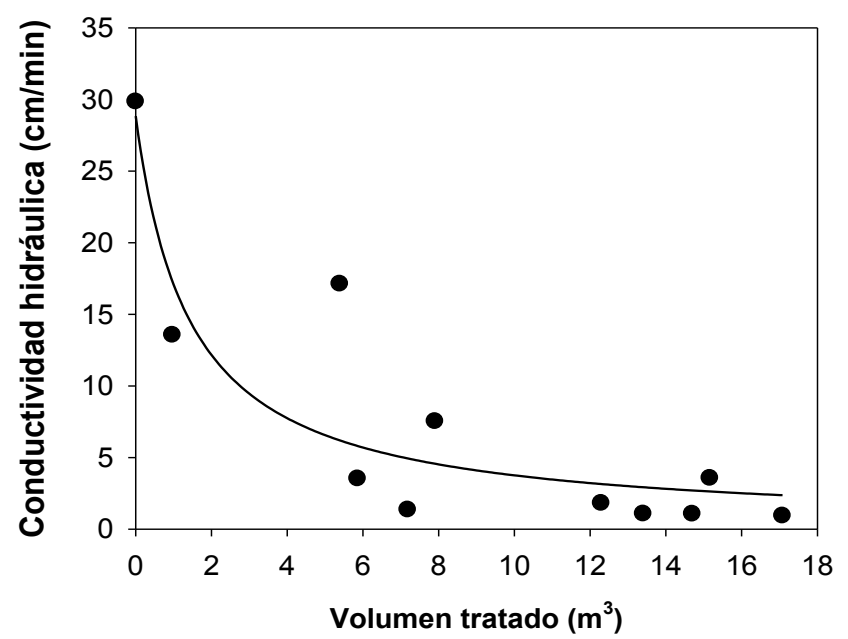

Figura 6.11. Evolución temporal de la conductividad hidráulica $(K)$ de la columna $\left(Q_{m}=520 \mathrm{~mL} / \mathrm{min}, \mathrm{m}_{\mathrm{zVI}}=500 \mathrm{~g}\right)$.

Teniendo en cuenta que este prototipo está diseñado para funcionar con una presión constante en la entrada de la columna, es de esperar una disminución del caudal en las etapas iniciales del proceso. Sin embargo, después de un período relativamente corto, los valores de $\mathrm{K}$ disminuyen suavemente, lo que permite una operación relativamente estable desde un punto de vista hidráulico. Cabe destacar que otros autores, que han empleado diferentes materiales de relleno, han encontrado reducciones mucho más pronunciadas en la conductividad hidráulica de las capas ZVI, en algunos casos de dos órdenes de magnitud [103].

Las posibles causas de obstrucción en lechos rellenos con ZVI operados con matrices de agua real son: precipitación de $\mathrm{CaCO}_{3}$, precipitación de especies de hierro, acumulación de $\mathrm{H}_{2}$ gaseoso en ambientes anóxicos, crecimiento de biofilms y acumulación de partículas suspendidas [101,131]. Dadas las condiciones operativas seleccionadas para las pruebas realizadas en nuestro laboratorio, la acumulación de $\mathrm{CaCO}_{3}$, la producción de $\mathrm{H}_{2}$ y el crecimiento de biofilms pueden ser considerados despreciables, por lo que la disminución de conductividad hidráulica resulta de la acumulación de productos expansivos de corrosión de hierro que conducen a la pérdida de permeabilidad [132]. Es importante tener en cuenta que, para aplicaciones de campo, las condiciones de operación deben seleccionarse adecuadamente para minimizar las causas obstrucción del lecho antes mencionadas. En la Figura 6.12 se compara el aspecto del relleno al inicio y al final de la prueba. 


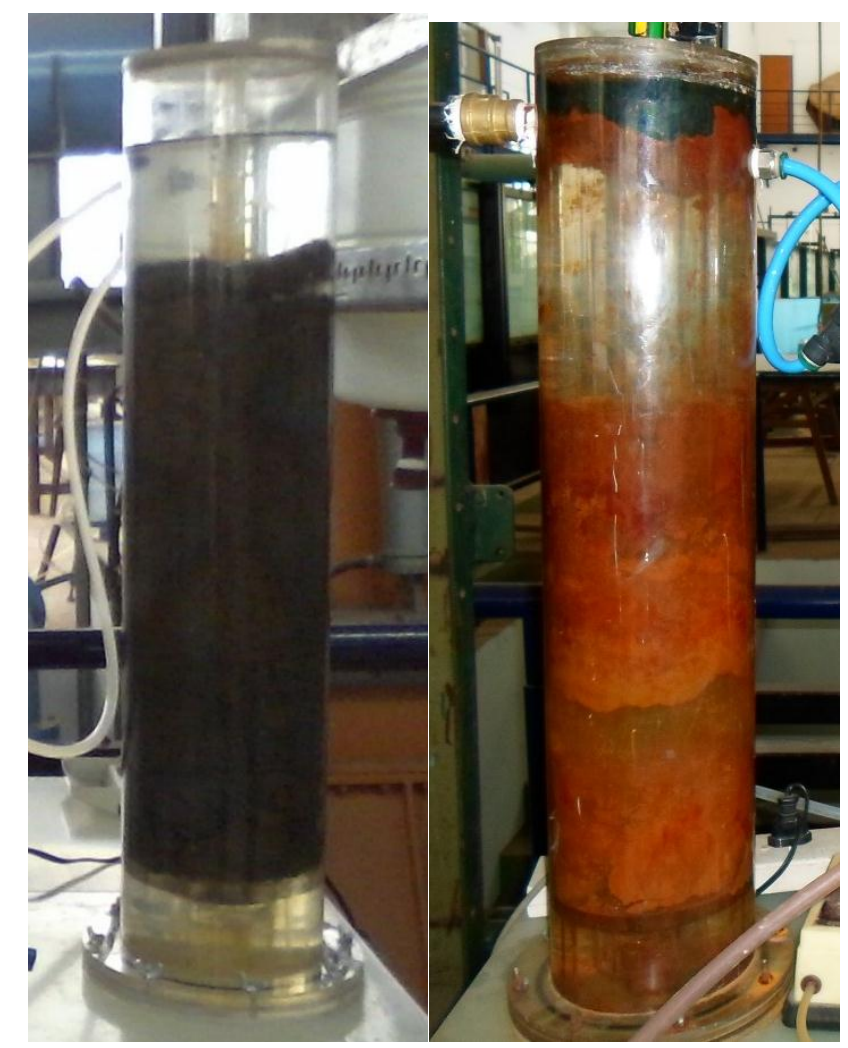

Figura 6.12. Aspecto del relleno de ZVI antes (izq.) y después del proceso de tratamiento (der.).

En la Figura 2 (derecha) se puede observar la acumulación de una gran cantidad de productos de corrosión luego de aproximadamente 30 días de operación. En la parte inferior, por donde ingresa el agua a tratar, prevalecen sólidos de color rojizo asociados principalmente a especies férricas. Esto se debe a que esta fracción del lecho se encuentra en contacto permanente con la solución de entrada que posee una mayor concentración de oxígeno. En la parte superior de la columna (salida) se observa un pequeño fragmento de productos de corrosión de color negro asociados mayormente a especies ferrosas. Esto se debe a la condición de anoxia en esta zona del reactor. La acumulación de estos sólidos con diferentes densidades produce una fragmentación del lecho y con ello la generación de canales preferenciales para el paso del fluido que conllevan a una pérdida significativa en la eficiencia del proceso de remoción.

\subsubsection{Resultados DTR columna grande}

Con el fin de caracterizar el patrón de flujo dentro de columna reactiva utilizada en el prototipo desarrollado, se aplicó el método estímulo respuesta. La curva de DTR se obtuvo utilizando IK como trazador para un caudal de operación de $600 \mathrm{~mL} / \mathrm{min}$. La misma se determinó experimentalmente midiendo la conductividad del fluido a la salida de la columna. Las mediciones se realizaron para cada una de las tres semanas de operación del prototipo con el fin de obtener la evolución temporal de los parámetros que caracterizan el comportamiento del flujo en el lecho reactivo (Tabla 6.4). 
Para cada prueba, en primer lugar se obtuvo el gráfico conductividad vs tiempo, el tiempo medio y la varianza. Con estos datos, se obtuvo el módulo de dispersión $\left(\frac{\boldsymbol{D}}{\boldsymbol{u} \boldsymbol{L}}\right)$, utilizando el modelo de dispersión axial y suponiendo que se trabajaba con grandes desviaciones respecto al flujo pistón (Tabla 6.4). Luego se comprobó que el comportamiento del sistema se encontraba dentro de este régimen $\left(\frac{\boldsymbol{D}}{\boldsymbol{u} \boldsymbol{L}}>0,01\right)$. Los resultados se muestran en la Tabla 6.4 .

Tabla 6.4. Parámetros característicos del modelo de dispersión axial calculados para el sistema estudiado.

\begin{tabular}{c|ccc}
\hline Parámetro & DTR semana 1 & DTR semana 2 & DTR semana 3 \\
\hline$\overline{\boldsymbol{t}}$ & 11,87 & 10,32 & 10,79 \\
$\boldsymbol{\sigma}^{\mathbf{2}}$ & 20,15 & 18,73 & 36,91 \\
$\boldsymbol{\sigma}_{\boldsymbol{\theta}}^{2}$ & 0,14 & 0,18 & 0,32 \\
\hline$\left(\frac{\boldsymbol{D}}{\boldsymbol{u}}\right) \mathrm{RA}^{*}$ & 0,058 & 0,069 & 0,110 \\
$\left(\frac{\boldsymbol{D}}{\boldsymbol{u} \boldsymbol{L}}\right) \mathbf{R C}^{* *}$ & 0,077 & 0,097 & 0,197 \\
\hline
\end{tabular}

${ }^{*}$ Condiciones de contorno de recipiente abierto (RA)

${ }^{* *}$ Condiciones de contorno de recipiente cerrado (RC)

Con los datos experimentales, se obtuvieron las curvas de $E_{t}$ y $E_{\ominus}$ y se ajustaron las expresiones analíticas para los modelos de grandes desviaciones de sistemas abiertos, sistemas cerrado-abierto y cerrado (sin dispersión)- abierto.

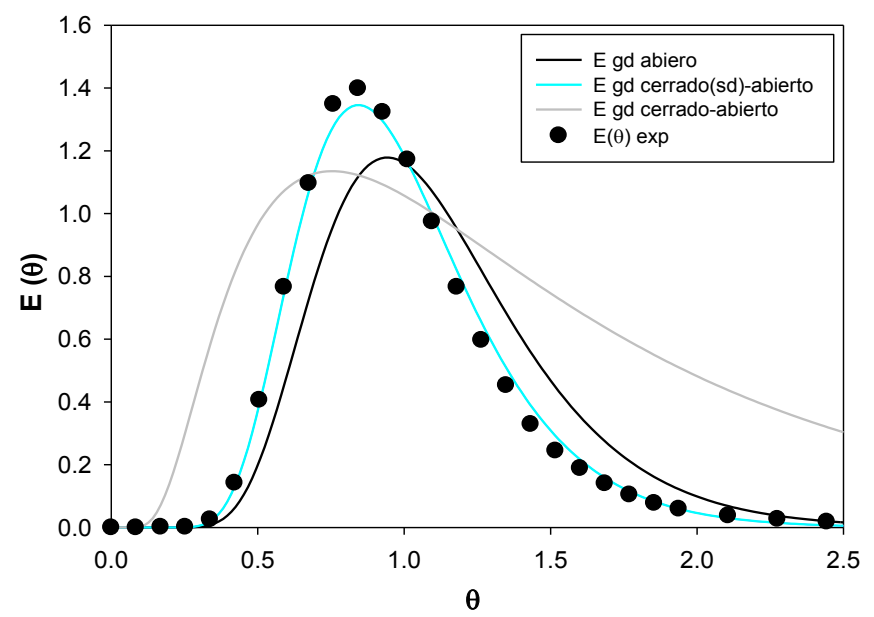

Figura 6.13. Selección del modelo hidrodinámico (DTR semana 1) 


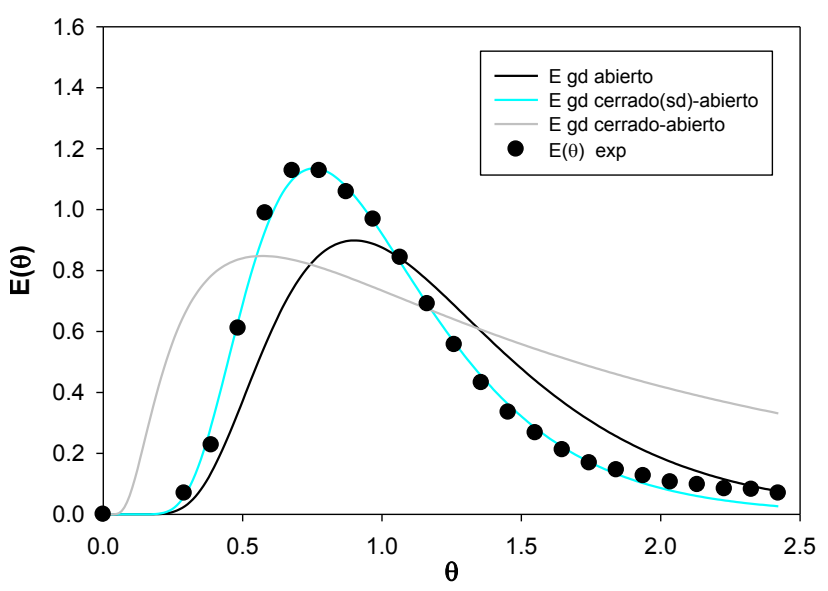

Figura 6.14. Selección del modelo hidrodinámico (DTR semana 2)

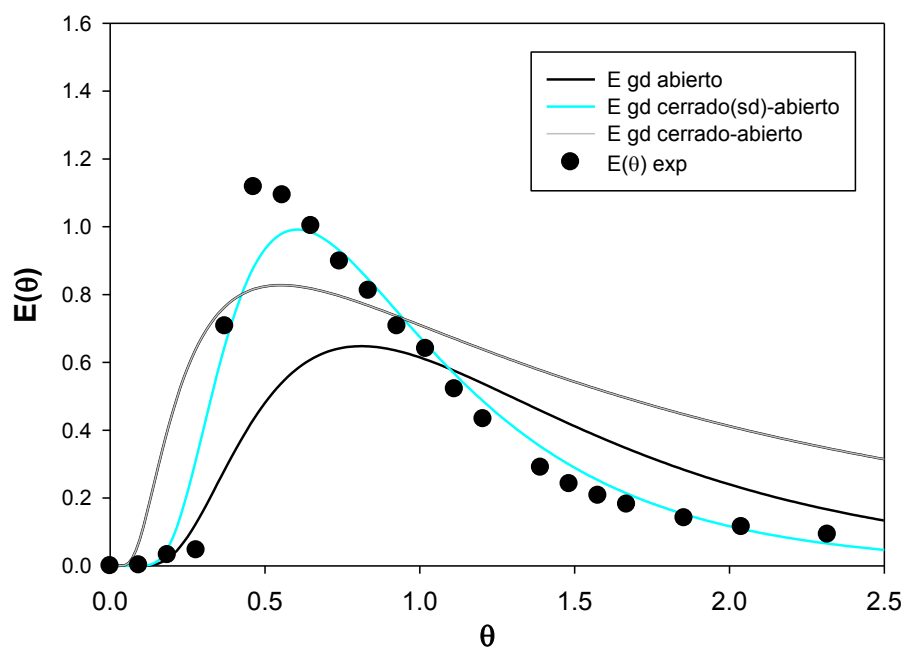

Figura 6.15. Selección del modelo hidrodinámico (DTR semana 3)

Las Figuras 6.13 a 6.15 muestran que la mejor descripción de los perfiles registrados se obtiene al utilizar la expresión para grandes desviaciones del flujo tipo pistón con condiciones de contorno correspondientes a un recipiente cerrado (sin dispersión a la entrada)-abierto. Este resultado concuerda con la situación experimental y el método de muestreo empleado para la medida de la conductividad. La Figura 6.16 muestra la evolución temporal de la DTR obtenida ajustando los datos experimentales con la ecuación mostrada en la última fila de la Tabla 2.3. Se puede ver claramente que al aumentar el tiempo de operación del lecho fijo la dispersión axial del fluido aumenta. Este comportamiento se puede atribuir a la aparición de vías de flujo preferencial y retro mezclado debido a la acumulación de productos de corrosión dentro de la columna y concuerda con lo que se observa en la imagen de la Figura 6.2. 


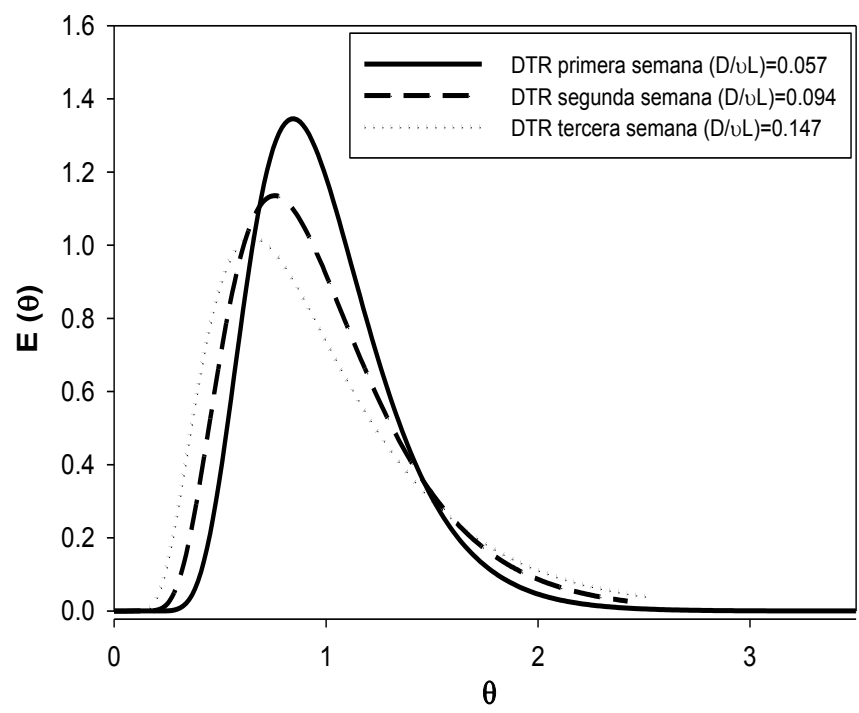

Figura 6.16. Evolución temporal de la DTR utilizando el modelo correspondiente a un sistema cerrado (sin dispersión) - abierto.

\subsection{PLANTA PARA EL TRATAMIENTO DE 2 M³/DÍA}

Dados los buenos resultados obtenidos para la planta de tratamiento de 700 L/día se trabajó en el escalo para el tratamiento de 2000 L/día de agua contaminada. La planta diseñada se muestra en las Figuras 6.17 y 6.18 , mientras que los parámetros constructivos se detallan en la Tabla 6.5. Esta unidad cuenta con dos columnas reactivas en paralelo (1), un módulo de aireación (2), un pre-filtro adicional de grava ascendente (3) y un filtro lento de arena (FLA) como última etapa (4).

El pre-filtro ascendente de grava se incorporó al diseño con el objetivo de disminuir la frecuencia en las tareas de limpieza del FLA. El mismo cuenta con un sistema de entrada de agua a presión para retro lavado descendente. Esta unidad cuenta también con un fondo cónico para el desalojo de lodos por parte del pre-filtro.

Tabla 6.5. Parámetros de diseño planta para el tratamiento de 2000 L/día.

\begin{tabular}{|c|c|c|c|c|}
\hline & Columnas & Módulo 2 & Prefiltro & FLA \\
\hline$Q$ diseño (mL/min) & 1500 & 1500 & 1500 & 1500 \\
\hline Longitud del lecho (cm) & 50 & 60 & 72 & 89 \\
\hline Diámetro (cm) & 14 & 41 & 34 & 55 \\
\hline Área $\left(\mathrm{cm}^{2}\right)$ & 154 & 1320 & 908 & 2376 \\
\hline TRH (min) & 10,3 & 52,8 & 43,6 & 141,0 \\
\hline TRH calculado ensayos preliminares ( $\mathrm{min}$ ) & $>2$ & $>30$ & & \\
\hline Densidad del lecho $\left(\mathrm{gr} / \mathrm{cm}^{3}\right)$ & 0,065 & & & \\
\hline velocidad (cm/min) & 4,87 & 1,14 & 1,65 & 0,63 \\
\hline velocidad $(\mathrm{m} / \mathrm{h})$ & 2,92 & 0,68 & 0,99 & 0,38 \\
\hline velocidad teórica recomendada $(\mathrm{m} / \mathrm{h})$ & & & $0,08-1$ & $0,1-0,3$ \\
\hline
\end{tabular}




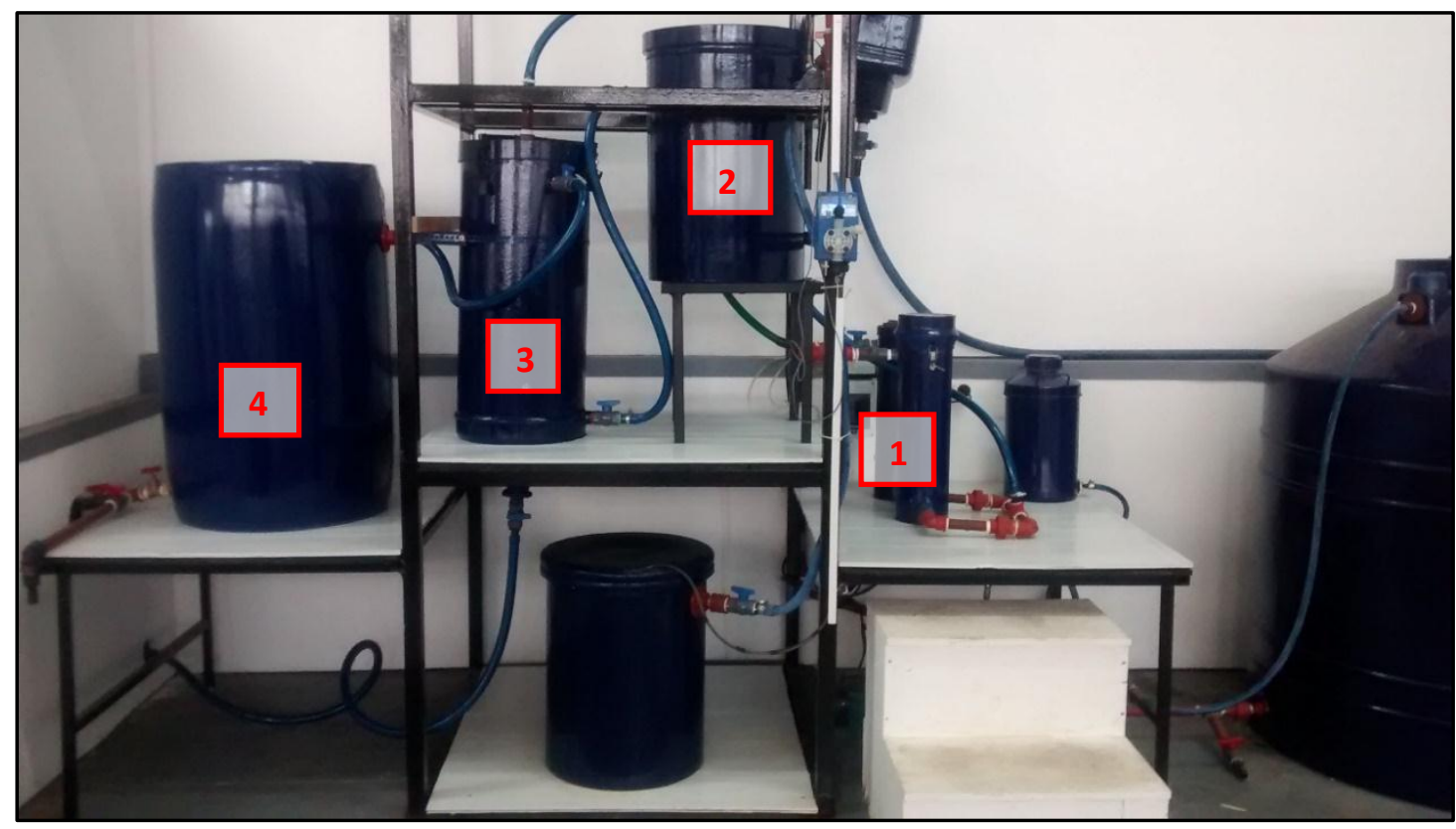

Figura 6.17. Fotografía de la planta utilizada para la realización de ensayos a escala real en instalaciones de la Facultad ( $\mathrm{Qd}=1500 \mathrm{~mL} / \mathrm{min})$.

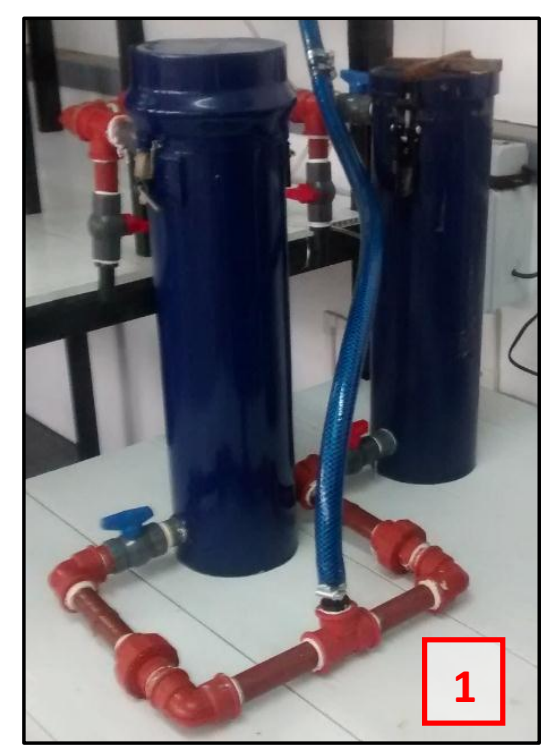

Figura 6.18. Detalle de las columnas conectadas en paralelo ( $\mathrm{Qd}=750 \mathrm{~mL} / \mathrm{min}$ por columna).

Se realizó una prueba piloto con un caudal inicial de $1500 \mathrm{~mL} / \mathrm{min}$. A las pocas horas de operar el prototipo se observó una notable diferencia entre los caudales de ambas columnas que operaban en paralelo. Esta dificultad se debió a un problema en el empaquetamiento inicial del relleno de los lechos reactivos y fue acrecentándose con el volumen tratado. De todas formas la prueba no fue interrumpida y se continuó con el monitoreo del desempeño mediante la determinación de $\mathrm{Fe}(\mathrm{II})$ y $\mathrm{Fe}$ (III) a la salida de cada columna, y en cada módulo de la planta, así como también del contenido de $\operatorname{As}(\mathrm{V})$ a la salida del sistema. Luego de 48 hs de operación el desempeño del sistema no fue completamente satisfactorio por lo que se redujo el 
caudal de trabajo. En la Tabla 6.6 se pueden observar las condiciones de operación efectivas a lo largo de esta prueba. Los bajos contenidos de $\mathrm{Fe}(\mathrm{II})$ a la salida de la columna numero 2 sugieren fuertemente que hubo algún problema con el empaquetamiento del material de relleno en este reactor que resultó en la presencia de canales preferenciales de flujo. Luego de 40 días de operación se dio por finalizado el ensayo.

Tabla 6.6. Condiciones de operación efectiva de la prueba realizada con la planta diseñada para el tratamiento de $2 \mathrm{~m}^{3} /$ día.

\begin{tabular}{|c|c|c|c|c|}
\hline & Columnas & Módulo 2 & Prefiltro & FLA \\
\hline Q promedio real (mL/min) & 760 & 760 & 760 & 760 \\
\hline Longitud del lecho $(\mathrm{cm})$ & 50 & 60 & 72 & 89 \\
\hline Diámetro $(\mathrm{cm})$ & 14 & 41 & 34 & 55 \\
\hline Área $\left(\mathrm{cm}^{2}\right)$ & 154 & 1320 & 908 & 2376 \\
\hline TRH (min) & 20,3 & 104,2 & 86,0 & 278,2 \\
\hline TRH calculado ensayos preliminares (min) & $>2$ & $>30$ & & \\
\hline Densidad del lecho $\left(\mathrm{gr} / \mathrm{cm}^{3}\right)$ & 0,065 & & & \\
\hline velocidad $(\mathrm{cm} / \mathrm{min})$ & 2,47 & 0,58 & 0,84 & 0,32 \\
\hline velocidad $(\mathrm{m} / \mathrm{h})$ & 1,48 & 0,35 & 0,50 & 0,19 \\
\hline velocidad teórica recomendada $(\mathrm{m} / \mathrm{h})$ & & & $0,08-1$ & $0,1-0,3$ \\
\hline
\end{tabular}

En la Figura 6.20 se muestra el contenido de $\mathrm{As}(\mathrm{V})$ a la salida del sistema a lo largo del tiempo de operación. Como se puede observar, el volumen de ruptura registrado, $20000 \mathrm{I}$, es de orden similar al de la primera planta piloto y este resultado también sugiere que una de las columnas no opero de manera correcta a lo largo de esta prueba. Para verificar esta hipótesis, se realizaron determinaciones de conductividad hidráulica en cada una de las columnas. La número 1 registró un valor de $0,15 \mathrm{~cm} / \mathrm{min}$ mientras que la columna 2 un valor de $1,9 \mathrm{~cm} / \mathrm{min}$. Esto confirma un "bypass" del fluido en el lecho de la columna número 2. Sobre la base de este resultado, como estrategia para intentar mitigar este problema en los sucesivos modelos se decidió colocar caudalímetros con regulación de paso en el ingreso de cada una de las columnas. 


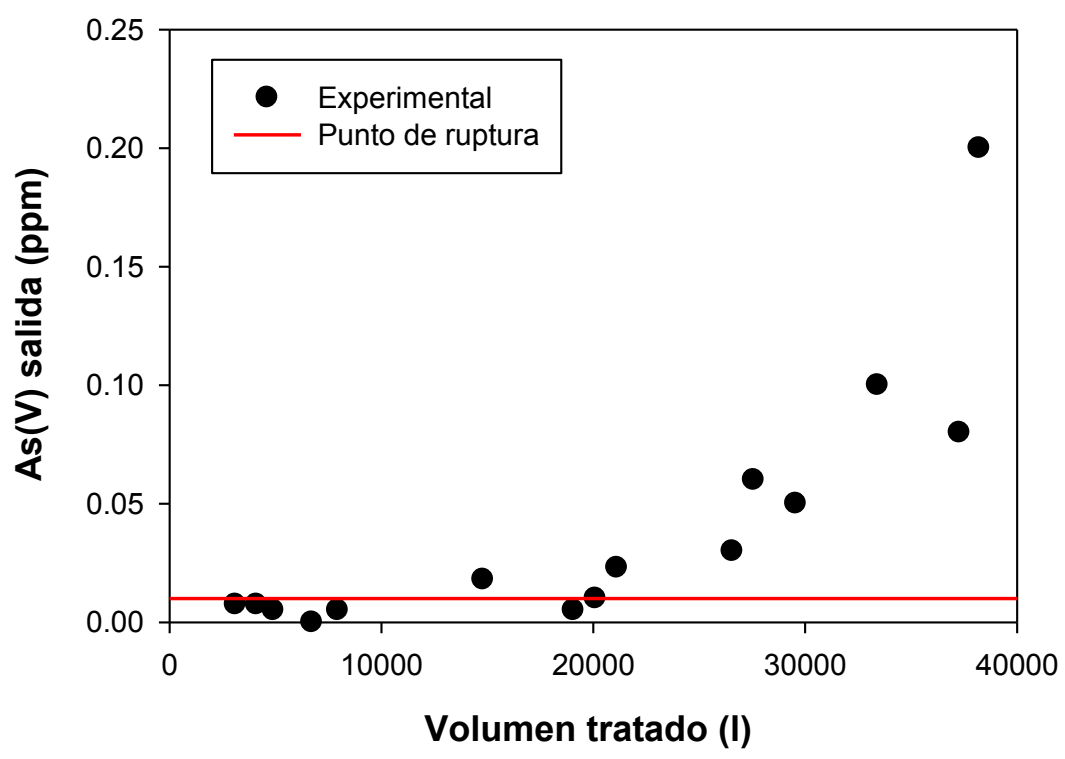

Figura 6.20. Concentración de $A s(V)$ a la salida del sistema para la planta diseñada pata el tratamiento de $2 \mathrm{~m}^{3} /$ día. As(V) entrada $=0,2 \mathrm{ppm}$. Qm= $760 \mathrm{~mL} / \mathrm{min}$.

En paralelo, para evaluar la eficiencia de las unidades de remoción del hierro generado, se realizaron determinaciones de turbiedad en las diferentes etapas del proceso. En la Tabla 6.7 se puede apreciar que el pre-filtro de grava remueve entre un 18 y $46 \%$ de la turbiedad total dependiendo el valor inicial de la misma, mientras que el FLA posteriormente conlleva a la remoción total de turbiedad.

Por último, la Figura 6.21 muestra la evolución temporal de la conductividad hidráulica del FLA. Se puede apreciar una reducción del $50 \%$ de la conductividad hidráulica del filtro al finalizar los 28 días de operación. Este período corresponde a la vida útil de relleno por lo que la inclusión del pre-filtro permite reducir sustancialmente las operaciones de mantenimiento.

Tabla 6.7. Eficiencia de remoción de turbiedad por parte del prefiltro y el FLA.

\begin{tabular}{|c|c|c|c|c|c|}
\hline \multirow[b]{2}{*}{$\begin{array}{l}\text { Litros } \\
\text { tratados }\end{array}$} & \multicolumn{5}{|c|}{ Turbiedad (NTU) } \\
\hline & Módulo 2 & Salida Prefiltro & $\begin{array}{l}\text { Porcentaje de } \\
\text { remoción prefiltro }\end{array}$ & $\begin{array}{c}\text { Salida } \\
\text { FLA }\end{array}$ & $\begin{array}{l}\text { Porcentaje de } \\
\text { remoción filtro }\end{array}$ \\
\hline & (NTU) & (NTU) & & (NTU) & \\
\hline 3000 & 42 & 34,2 & $18,6 \%$ & 0,57 & $80,1 \%$ \\
\hline 4900 & 49,9 & 26,6 & $46,7 \%$ & 0,55 & $52,2 \%$ \\
\hline 7900 & 33,8 & 19,4 & $42,6 \%$ & 0,20 & $56,8 \%$ \\
\hline Límite CAA & & & & 3 & \\
\hline
\end{tabular}




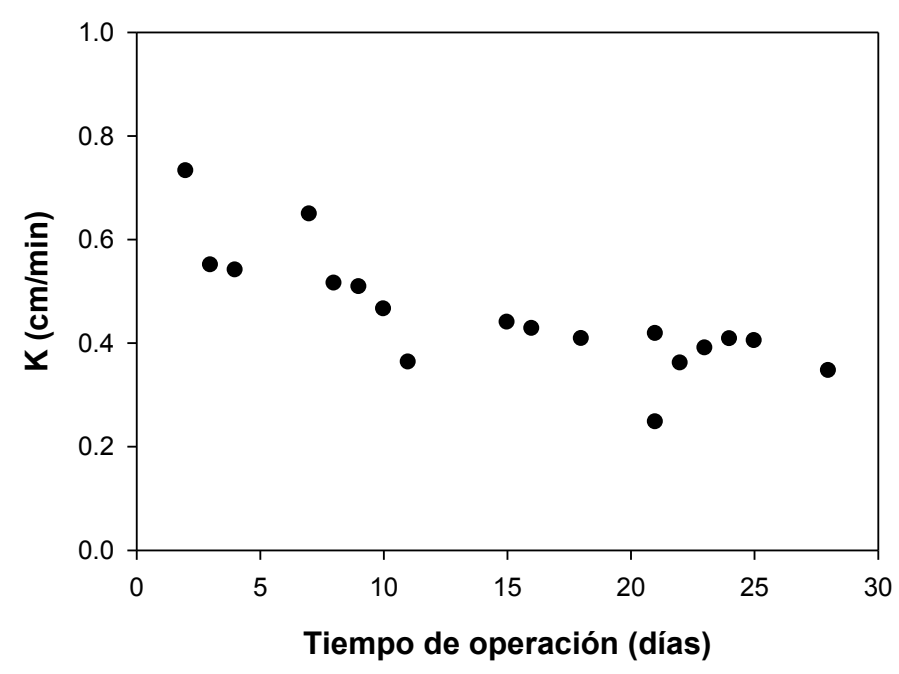

Figura 6.21. Evolución de la conductividad hidráulica de la columna rellena con ZVI con el tiempo de operación de la planta.

\subsection{PLANTA PARA EL TRATAMIENTO DE 4 M3/DÍA}

Con el objetivo de seguir ampliando el caudal de tratamiento y evaluar nuevas estrategias para el control de la eficiencia de la planta se construyó una unidad para el tratamiento de $4 \mathrm{~m}^{3}$ por día. La evolución del desempeño del sistema se realizó mediante determinaciones simultáneas de ORP a la salida de cada columna y de arsénico a la salida de la planta durante el tiempo de vida útil del relleno. En la Figura 6.22 se presenta un esquema de la planta construida mientras que las Figuras $6.23 \mathrm{y}$ 6.24 muestran fotos de su instalación en la Facultad. Como puede observarse, la planta cuenta con:

-sistema de regulación de $\mathrm{pH}$ automático

- dos columnas en paralelo (caudal de diseño por columna: $Q=1,5 \mathrm{~L} / \mathrm{min}$ )

-caudalímetros en la entrada de cada una de las columnas

- un módulo de aireación

-un pre-filtro rápido de grava operado a presión con recirculación

-un filtro lento de arena por gravedad

En la Tabla 6.8 se incluyen las dimensiones de la planta para el tratamiento de 4000 L/día. Debido a que el objetivo principal de este ensayo fue optimizar el funcionamiento de dos columnas en paralelo, no se tuvo en cuenta la velocidad recomendada para la operación del FLA. Por este motivo, fue necesario aumentar la frecuencia de limpieza de esta última etapa. 


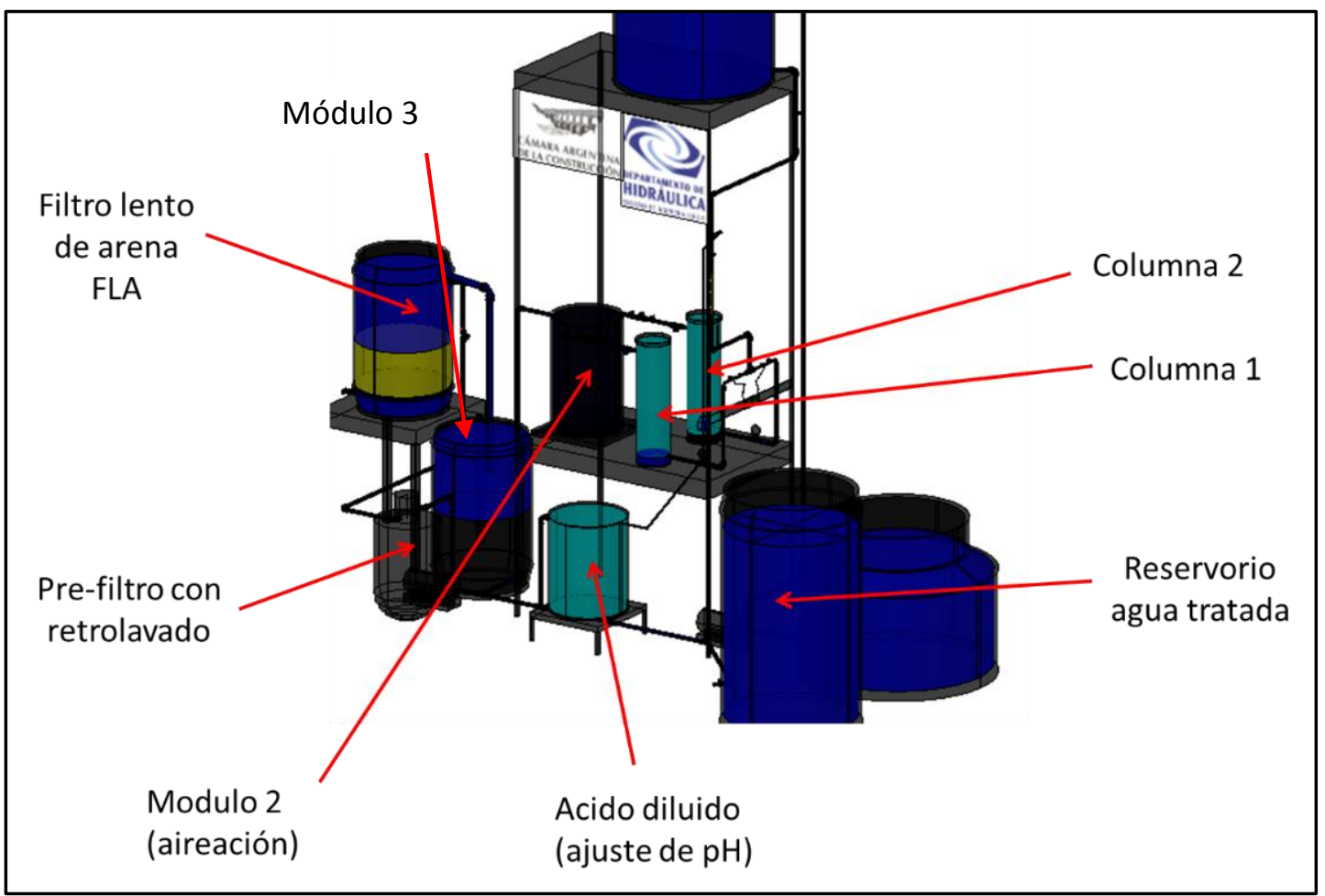

Figura 6.22. Esquema del diseño de la planta construida para el tratamiento de $4 \mathrm{~m}^{3} /$ día.

Tabla 6.8. Parámetros de diseño planta para el tratamiento de 4000 L/día.

\begin{tabular}{|c|c|c|c|c|}
\hline & Columnas & Módulo 2 & Módulo 3 & FLA \\
\hline Q promedio real (mL/min) & 1500 & 3000 & 3000 & 3000 \\
\hline Londitud del lecho (cm) & 70 & 60 & 89 & 89 \\
\hline Diámetro (cm) & 21 & 41 & 55 & 55 \\
\hline Aárea $\left(\mathrm{cm}^{2}\right)$ & 346 & 1320 & 2376 & 2376 \\
\hline TRH (min) & 16,2 & 26,4 & 70,5 & 70,5 \\
\hline TRH calculado ensayos preliminares (min) & $>2$ & $>30$ & & \\
\hline Densidad del lecho $\left(\mathrm{gr} / \mathrm{cm}^{3}\right)$ & 0,065 & & & \\
\hline velocidad (cm/min) & 4,33 & 2,27 & 1,26 & 1,26 \\
\hline velocidad $(m / h)$ & 2,60 & 1,36 & 0,76 & 0,76 \\
\hline velocidad teórica recomendada $(\mathrm{m} / \mathrm{h})$ & & & & $0,1-0,3$ \\
\hline
\end{tabular}




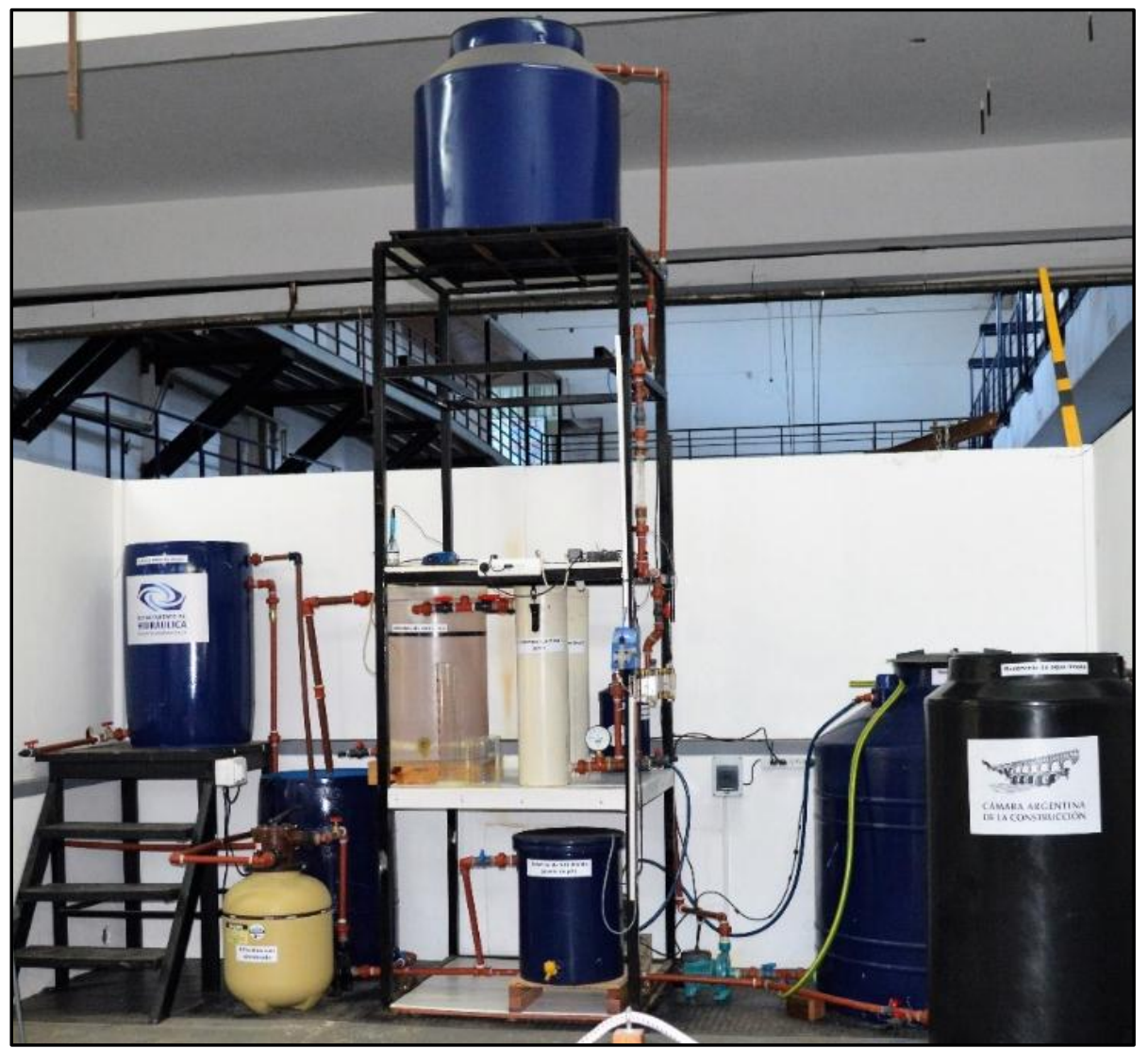

Figura 6.23. Planta para el tratamiento de $4 \mathrm{~m}^{3} /$ día de agua instalada en la Facultad.

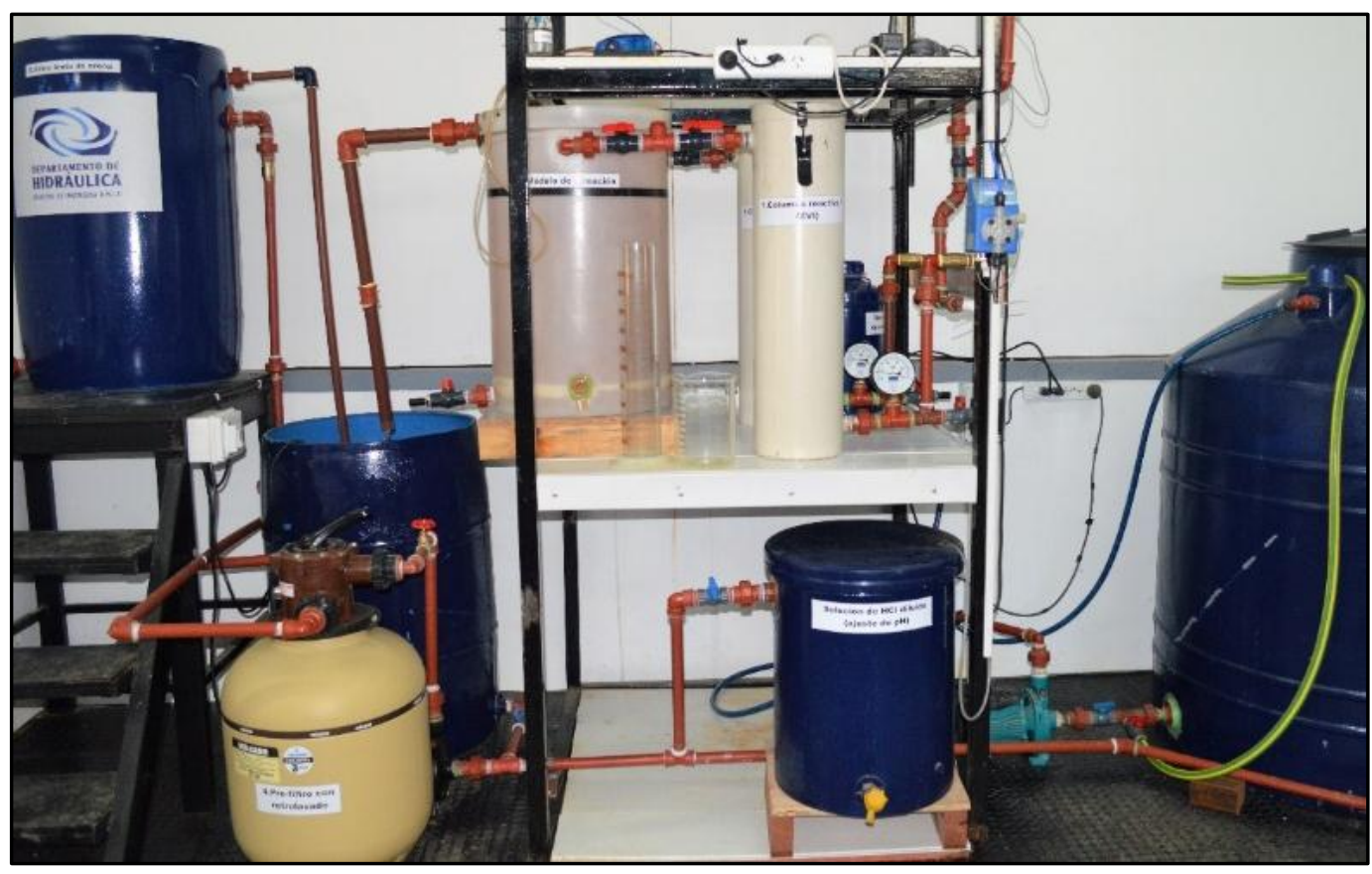

Figura 6.24. Planta para el tratamiento de $4 \mathrm{~m}^{3} /$ día de agua instalada en la Facultad. 


\subsubsection{Primera prueba}

Se rellenaron ambas columnas con $1500 \mathrm{~g}$ de ZVI cada una y se comenzó una prueba con un caudal de trabajo de $3000 \mathrm{~mL} / \mathrm{min}$. Las determinaciones de ORP se realizaron instalando un porta electrodo a la salida de cada columna y dejando estabilizar el sistema durante 30 minutos. Luego de un mes de operación se observó un buen desempeño del sistema, con concentraciones de As por debajo de $10 \mathrm{ppb}$ para un volumen superior a los $100 \mathrm{~m}^{3}$ tratados (Figura 6.25). Sin embargo, se registró una diferencia notable entre los perfiles de ORP registrados a las salidas de las columnas dispuestas en paralelo.

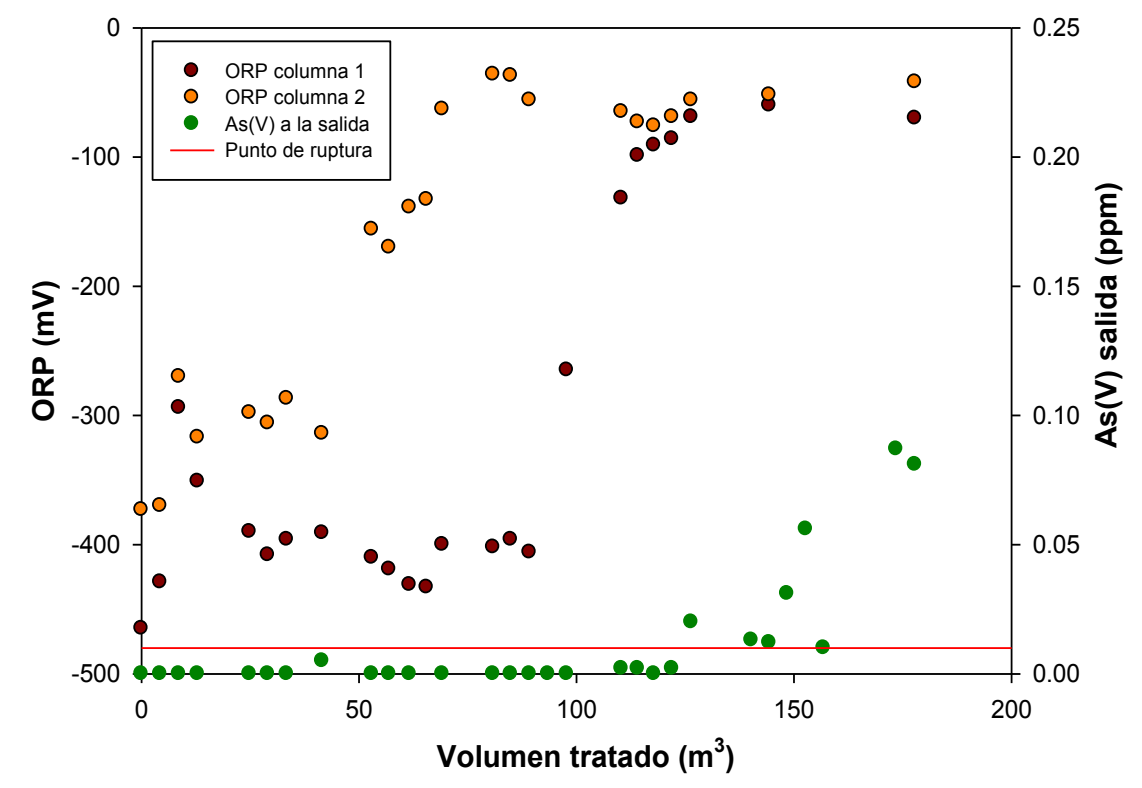

Figura 6.25. Perfiles de concentración de $A s(V)$ a la salida del sistema y de ORP a la salida de cada columna en función del volumen tratado $\left(Q_{d}=3000 \mathrm{~mL} / \mathrm{min}\right)$.

Para determinar si la diferencia en los perfiles de ORP registrados se debía a problemas de bypass en alguna de las columnas, se realizaron determinaciones de DTR en ambas columnas en simultáneo. La Figura 6.26 muestra una gran diferencia en el comportamiento de ambas columnas, comprobándose así que el pobre desempeño de la columna 2 estaba asociado a un canal preferencial o bypass en el relleno en la columna 2 generado posiblemente por un problema en el empacado. El tiempo de residencia efectivo de esta columna resultó aproximadamente de 3 a 5 minutos, mucho menor que el TRH de diseño (15 minutos). Cabe destacar que, dado el bajo tiempo de residencia promedio asociado a la columna 2, es esperable que tanto la velocidad de consumo de $\mathrm{O}_{2}$ disuelto como la producción de $\mathrm{Fe}(\mathrm{II})$ hayan resultado mucho menores que las correspondientes a la columna 1. Por lo tanto, como consecuencia de las diferencias en las tasas de corrosión de cada columna, los valores de ORP divergen y la columna 2 presenta un apartamiento prematuro del régimen de funcionamiento óptimo. 


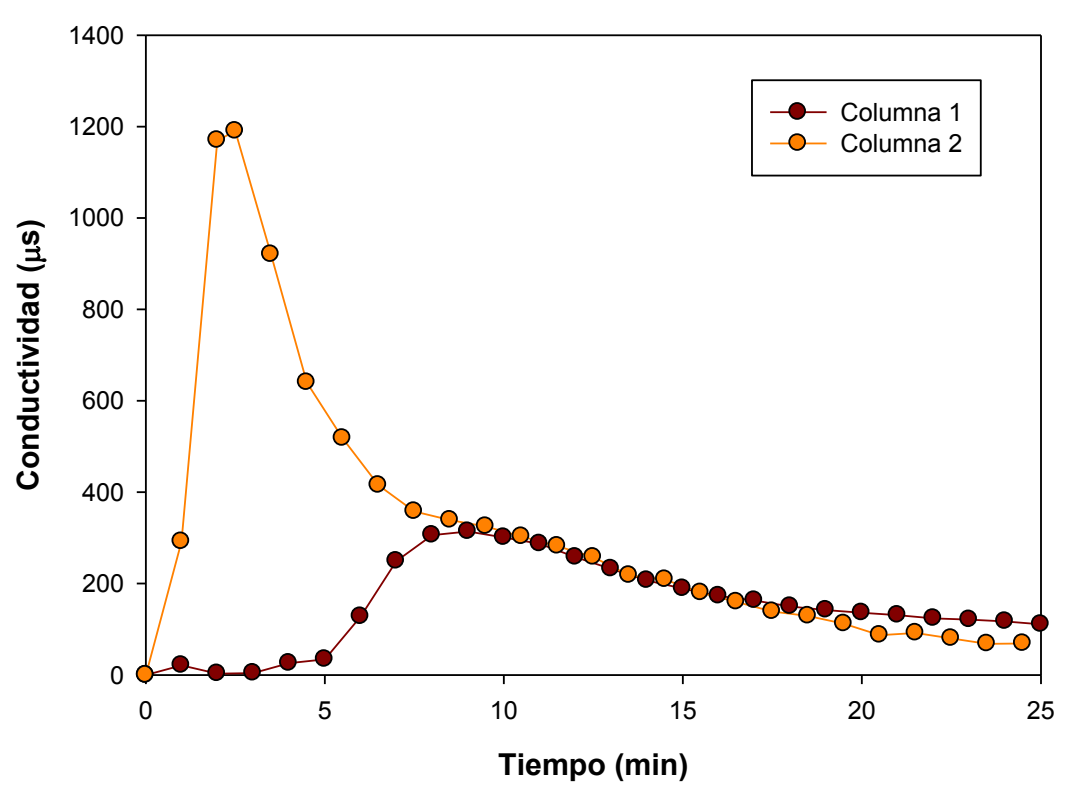

Figura 6.26. Curvas de conductividad vs. tiempo para un ensayo estimulo-respuestas correspondientes a las columnas reactivas luego de 30 días de operación.

Por otra parte, con el objetivo de verificar el funcionamiento de los procesos de de remoción de sólidos, se realizaron determinaciones de color y turbiedad para todas las etapas. Los resultados que se muestran en la Figura 6.27 permiten verificar un buen desempeño del filtro rápido de grava y del FLA para la remoción de color y turbiedad en esta escala de tratamiento. Por último, como señala la Figura 6.25 , el punto de ruptura del proceso de remoción se registra cuando los valores de ORP de ambas columnas superan los $-100 \mathrm{mV}$ aproximadamente. Los resultados de esta prueba muestran el potencial de las medidas de ORP a la salida de las columnas como instrumento de control de la eficiencia del proceso.
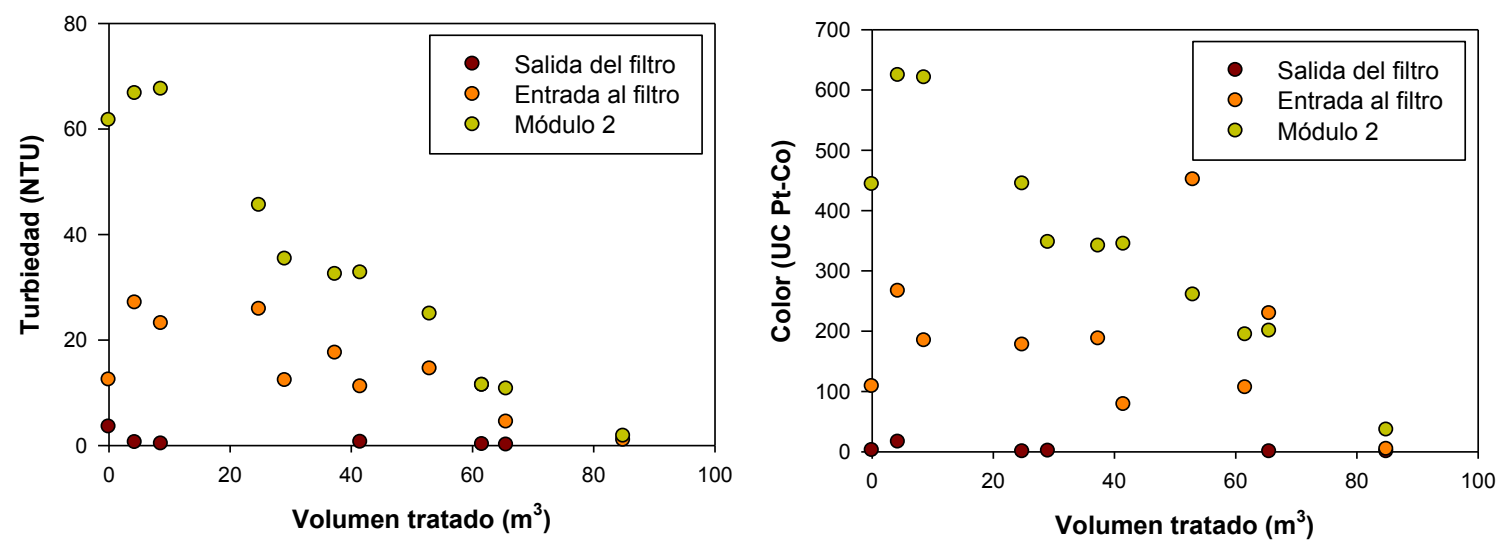

Figura 6.27. Remoción de turbiedad (izq.) y color (der.) por parte del pre-filtro rápido y el FLA. 


\subsubsection{Segunda prueba}

Con el fin de evaluar la utilidad de las medidas de ORP como herramienta para monitorear del desempeño de las columnas y observar su dependencia con el caudal de operación se realizó una segunda prueba con la misma planta. Antes del inicio de esta prueba, se procedió a la limpieza de todos los módulos y al remplazo del relleno de las columnas.

Las Figuras 6.28 y 6.29 muestran un buen desempeño de ambas columnas tanto desde el punto de vista fisicoquímico (ya que los valores de ORP se mantuvieron por debajo de $-100 \mathrm{mV}$ para ambas columnas) como hidráulico (ya que las DTR experimentales para ambas columnas fueron similares y los TRH calculados resultaron cercanos a los valores teóricos del diseño). Es interesante señalar que, de acuerdo a lo esperado, la columna con un TRH levemente inferior registra valores de ORP ligeramente mayores. Finalmente cabe destacar que, las determinaciones de As mostraron concentraciones del contaminante a la salida del sistema menores que 10 ppb confirmando así la eficiencia del proceso.

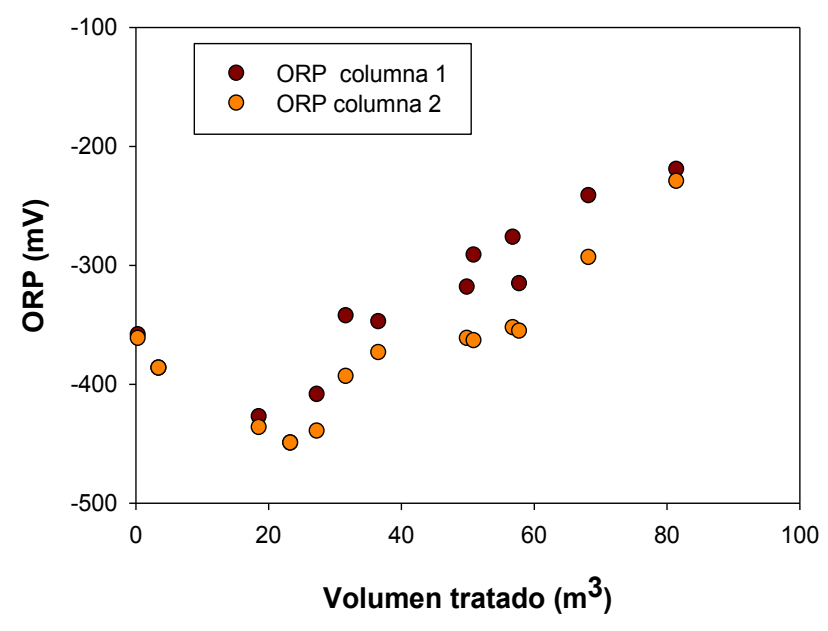

Figura 6.28. Variación del ORP a la salida de las columnas en función del volumen de agua tratado.

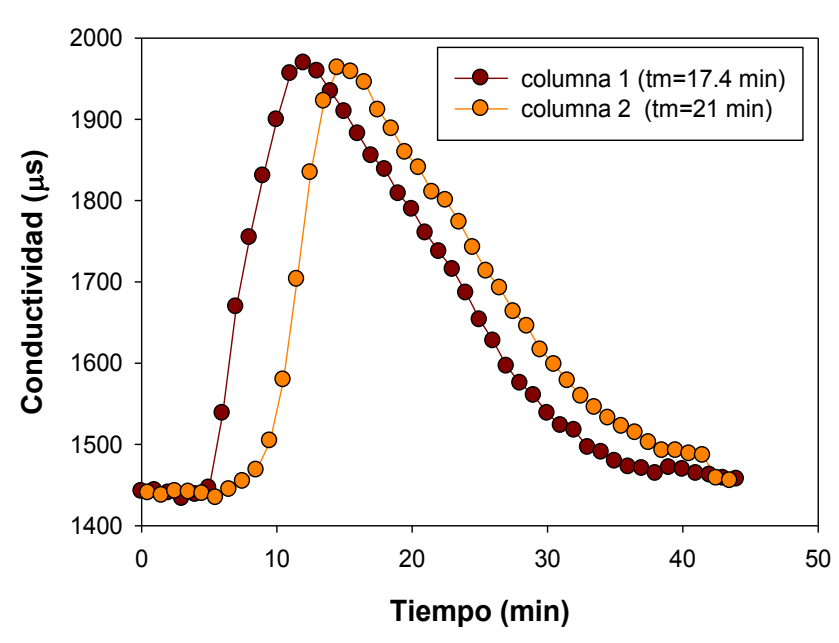

Figura 6.29 Curvas de conductividad vs. tiempo para un ensayo estimulo-respuestas correspondientes a las columnas reactivas luego de 30 días de operación. 
La Tabla 6.9 muestra la dependencia de los valores de ORP con el caudal de trabajo. Se puede verificar que el ORP a la salida de las columnas muestra una correlación muy fuerte con el volumen total de agua tratada pero no muestra una dependencia significativa con el caudal de operación dentro del rango experimental analizado.

Tabla 6.9 .Resultados de variación de ORP en función del caudal de operación.

\begin{tabular}{|r|r|r|}
\hline \multicolumn{1}{|c|}{ Caudal } & ORP $(\mathrm{mV})$ & Litros acumulados \\
\hline 3.3 & -360 & 4085 \\
\hline 5.2 & -364 & 9815 \\
6 & -337 & 17771 \\
8.4 & -80 & 28571 \\
2.7 & -87 & 32891 \\
\hline
\end{tabular}

\subsubsection{Tercera prueba}

Empleando la misma configuración, se realizó una nueva prueba con dos objetivos: i) evaluar si la medida de $\mathrm{pH}$ a la salida de las columnas podía emplearse como variable de control del proceso ii) identificar los principales mecanismos de remoción intervinientes. Para esto se observó la evolución del sistema mediante determinaciones de $\mathrm{pH}$ y ORP (ya verificada como una buena variable de control de eficiencia) a la salida de cada columna durante el tiempo de vida útil del relleno.

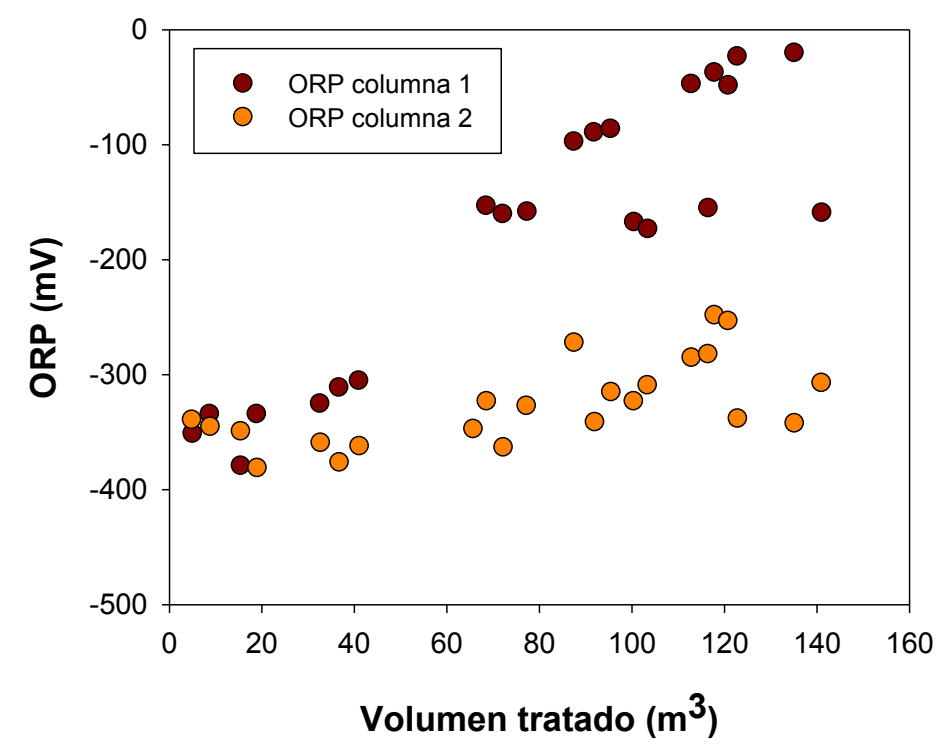

Figura 6.29. Variación del ORP a la salida de las columnas en función del volumen de agua tratado $\left(Q_{d}=3000 \mathrm{~mL} / \mathrm{min}\right)$. 


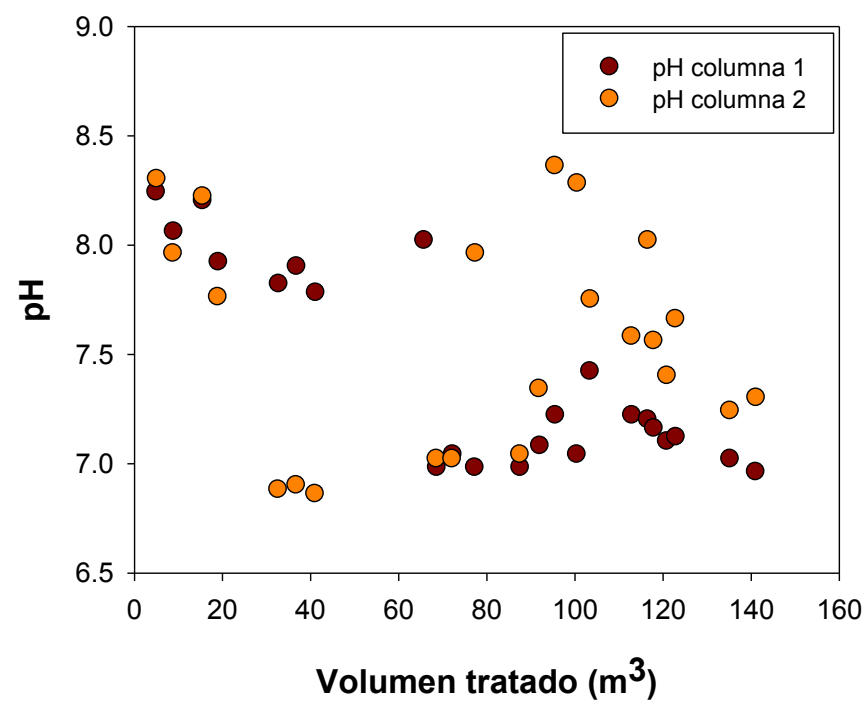

Figura 6.30. Variación del pH a la salida de las columnas en función del volumen de agua tratado $\left(Q_{d}=3000 \mathrm{~mL} / \mathrm{min}\right)$.

El análisis de las Figuras 6.29 y 6.30 muestra una cierta correlación entre las medidas de $\mathrm{pH}$ y de ORP. Para valores bajos de ORP $(<300 \mathrm{mV})$, en general se registran valores altos de $\mathrm{pH}(>7,5)$ lo que indica una alta tasa de corrosión y un buen desempeño de la columna. Por el contrario, altos valores de ORP y valores de $\mathrm{pH}$ cercanos a 7 indican un mal desempeño de los lechos que pueden estar relacionados tanto con problemas hidráulicos como con el agotamiento del material reactivo. Sin embargo, las tendencias observadas en las medidas de ORP parecen más claras que las de $\mathrm{pH}$. Los desempeños de cada columna en cuanto a la remoción de arsénico se muestran en la Tabla 6.10. Luego de 10 días de operación se detecta un mejor desempeño de la columna \#2 (menor ORP y mayor pH a la salida) en comparación con la columna \#1. Pese a esto, el valor de As a la salida del sistema se mantiene por debajo de las 50 ppb y en muchos casos por debajo de 10 ppb para concentraciones de As de entrada promedio de $150 \mathrm{ppb}$.

Teniendo en cuenta el segundo objetivo de esta prueba, para esclarecer los mecanismos de remoción que intervienen en el proceso se comparó el contenido de $\mathrm{As}_{\text {Tot }}$ a la salida de las columnas respecto al obtenido a la salida del sistema completo. Como se puede ver en la Tabla 6.10, más del $90 \%$ del As fue retenido por el lecho que funcionaba de manera correcta (columna \#2), lo que indica que el principal mecanismo de remoción involucra fenómenos de co-precipitación y de adsorción en el interior de la columna. Cabe destacar que los resultados muestran que la coprecipitación es dominante respecto de la adsorción porque cuando la concentración de $\mathrm{Fe}(\mathrm{II})$ en solución cae por debajo de $0,5 \mathrm{ppm}$ la remoción también lo hace. Si, por el contrario, la adsorción fuera el mecanismo dominante, con el paso del tiempo debería observarse un incremento del porcentaje de remoción debido a la acumulación de productos de corrosión en el interior del lecho. 
Tabla 6.10. Concentración de As a la salida de las columnas y del sistema.

\begin{tabular}{|c|c|c|c|c|}
\hline $\begin{array}{l}\text { Volumen } \\
\text { tratado (I) }\end{array}$ & $\begin{array}{l}A s_{\text {Tot }} \text { entrada } \\
(p p m)\end{array}$ & $\begin{array}{l}\text { As }_{\text {Tot }} \text { salida de la } \\
\text { columna } 1(\mathrm{ppm})\end{array}$ & $\begin{array}{l}\text { As }_{\text {Tot }} \text { salida de la } \\
\text { columna } 2(\mathrm{ppm})\end{array}$ & $\begin{array}{c}\mathrm{As}_{\text {Tot }} \text { salida } \\
\text { del sistema (ppm) }\end{array}$ \\
\hline 36683 & 0,27 & 0,00 & 0,01 & 0,00 \\
\hline 65465 & 0,18 & 0,03 & 0,01 & 0,01 \\
\hline 68794 & 0,29 & 0,25 & 0,00 & 0,00 \\
\hline 87600 & 0,39 & 0,13 & 0,02 & 0,02 \\
\hline 91995 & 0,45 & 0,45 & 0,03 & 0,03 \\
\hline 95732 & 0,54 & 0,32 & 0,01 & 0,04 \\
\hline 116614 & 0,43 & 0,26 & 0,01 & 0,01 \\
\hline 122935 & 0,63 & 0,16 & 0,02 & 0,02 \\
\hline 135258 & 0,31 & 0,16 & 0,01 & 0,03 \\
\hline
\end{tabular}

\subsection{CARACTERIZACIÓN DE RESIDUOS OBTENIDOS DEL PROCESO DE TRATAMIENTO}

Como resultado del proceso de tratamiento tres tipos de residuos fueron obtenidos en las diferentes unidades de la planta:

-un residuo semisólido proveniente de la columna reactiva, compuesto principalmente por productos de corrosión del hierro en diferentes estados de oxidación con la mayor parte del arsénico adsorbido/coprecipitado (FRE1)

-un residuo líquido proveniente de la limpieza de las unidades de pre-filtrado con sólidos en suspensión compuestos también por hierro, mayoritariamente bajo la forma de hidróxido férrico, y una pequeña fracción de arsénico (FRE2)

-un residuo sólido proveniente del raspado del filtro lento de arena compuesto principalmente de arena y hierro que puede contener también una pequeña fracción de arsénico (FRE3)

El análisis de la muestra de sólidos provenientes del residuo denominado FRE1 por espectroscopia de fotoelectrones emitidos por rayos x (XPS) arrojó un resultado de $12,5 \%$ de As (12,5 átomos de As por cada 100 de $\mathrm{Fe}$ ), lo que demuestra que una fracción del As presente en la solución queda adsorbido o co-precipita junto al hierro en el lecho reactivo.

En las Figuras 6.31 y 6.32 se muestra el contenido de sólidos de muestras tomadas semanalmente del efluente denominado FRE2. Como se puede observar el contenido de sólidos disminuye al aumentar el tiempo de vida del relleno debido a una disminución en la tasa de corrosión de hierro a medida que el lecho envejece. De todas formas, estas concentraciones pueden variar dependiendo la frecuencia de limpieza de esta unidad. Los valores máximos estipulados por el anexo II de la resolución 336/2003 son de 0 y $5 \mathrm{~mL} / \mathrm{L}$ para sólidos sedimentables a los 10 y $120 \mathrm{~min}$ respectivamente. Los resultados muestran, en casi todos los casos, valores superiores 
a los estipulados. Por este motivo, antes de su disposición, el efluente se deja decantar para luego disponer las dos fracciones por separado.

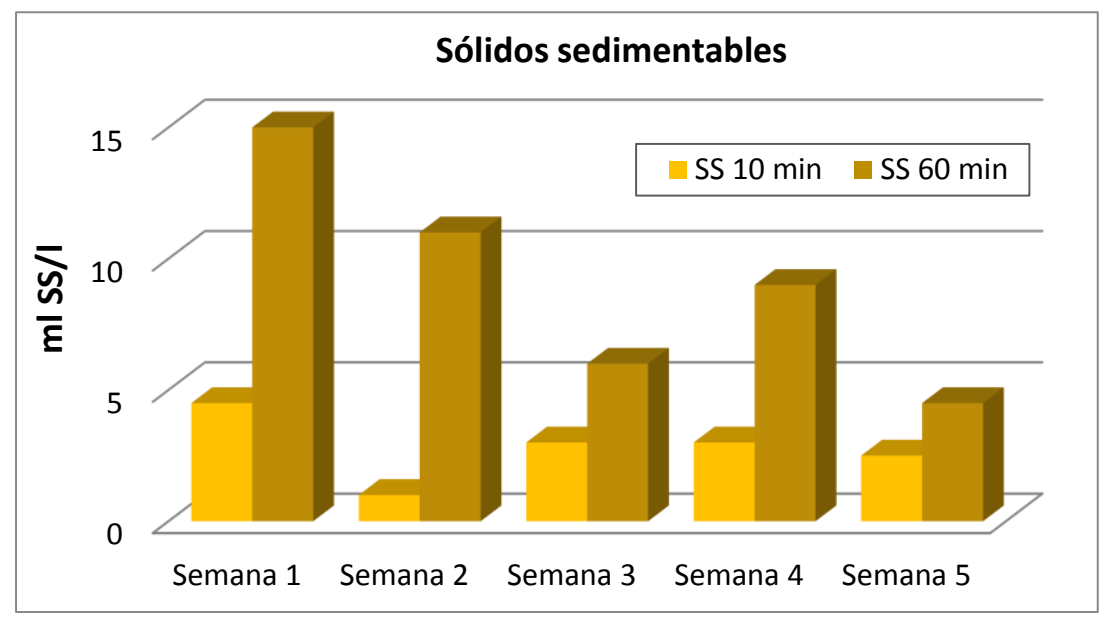

Figura 6.31. Solidos sedimentables en FRE2 en función de las semanas de operación de la planta de tratamiento.

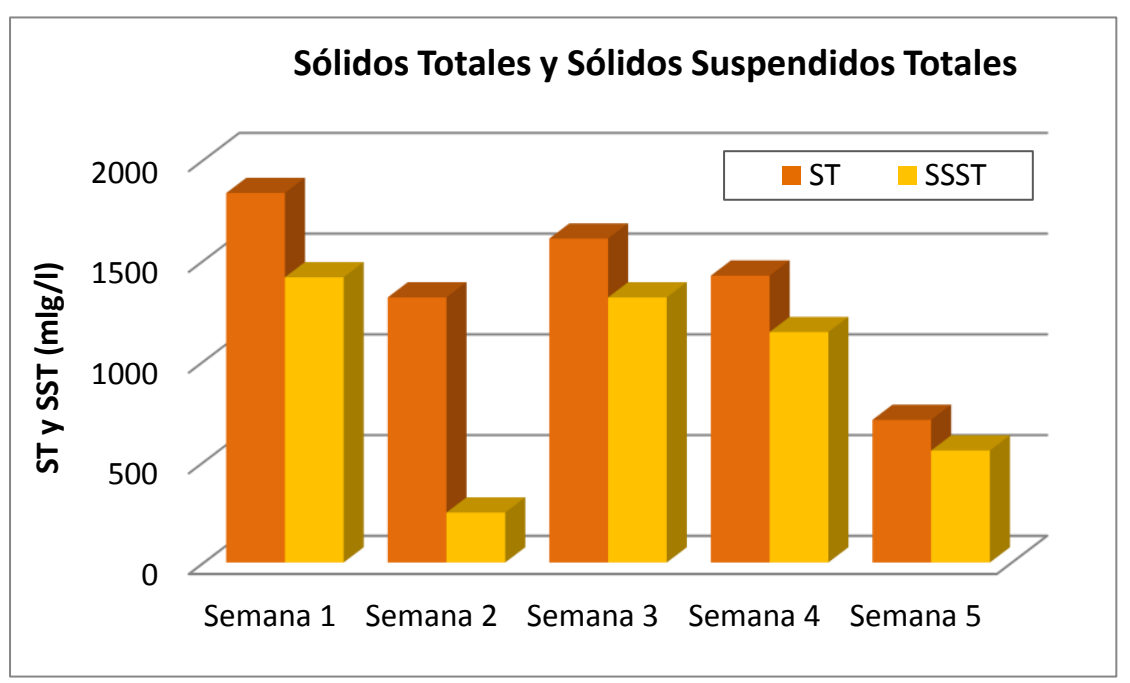

Figura 6.32. Sólidos totales y suspendidos totales en FRE2 en función de las semanas de operación de la planta de tratamiento.

Posteriormente, para evaluar la posibilidad de vuelco de la fracción sobrenadante (Iíquida) se determinó el contenido de $\mathrm{Fe}_{\text {Tot }}$ y $\mathrm{As}_{\text {Tot. }}$ Los valores presentados en la Tabla 6.10 se encuentran por debajo del límite máximo admisible por lo que esta fracción puede ser volcada directamente al sistema cloacal. Paralelamente, para determinar la peligrosidad del residuo sólido se realizó el test TCLP y se determinó el contenido de $\mathrm{Fe}_{\text {Tot }}$ y $\mathrm{As}_{\text {Tot }}$ en el lixiviado, luego del proceso de extracción. La Tabla 6.10 muestra que el contenido de estos elementos se encuentra dentro de los límites permitidos y por lo tanto el residuo puede ser dispuesto como no peligroso. 
Cabe destacar que a la fecha aún no se han realizado estudios similares sobre la fracción denominada FR3. Sin embargo, dado que esta fracción corresponde a sólidos muy similares a los de FR2 pero mezclados con la arena de la parte superior del filtro, es muy probable que este residuo también pueda ser dispuesto como no peligroso. Dado que se seguirá trabajando en este desarrollo, está previsto realizar más prueba relacionadas con la disposición de residuos.

Tabla 6.10. Valores y límites máximos de $\mathrm{Fe}_{\text {Tot }}$ y $\mathrm{As}_{\text {Tot }}$ en fracciones líquidas y lixiviados del sólido de FR2.

\begin{tabular}{l|r|r|c|r|}
\hline & \multicolumn{2}{|c|}{ As $_{\text {Tot }}(\mathbf{m g} / \mathbf{L})$} & \multicolumn{2}{c}{$\mathbf{F e}_{\text {Tot }}(\mathbf{m g} / \mathbf{L})$} \\
\hline & Determinado & Límite max. & Determinado & Límite max. \\
\hline Sobrenadante del residuo & 0,120 & 0,5 & $<0,3$ & 10 \\
\hline Lixiviado de sólidos & 0,117 & 1 & $<25$ & 30 \\
\hline
\end{tabular}

\subsection{CONCLUSIONES}

Los ensayos realizados en las instalaciones del Departamento de Hidráulica, con agua de red contaminada artificialmente con arsénico, sugieren que la tecnología desarrollada resultada eficiente para escalas de tratamiento entre 700 y 4000 L/día. En particular, para el prototipo de menor escala, el rendimiento obtenido se mantuvo en el orden de los 35 litros de agua tratada por cada gramo de ZVI utilizado y, dentro del rango analizado, el desempeño resultó ser prácticamente independiente de las condiciones operativas.

Los resultados sugieren que la remoción del contaminante involucra su coprecipitación y, en menor medida, su adsorción dentro de la columna rellena con ZVI. Los óxidos generados en el lecho reactivo son capaces de retener el As en su interior y así concentrar el mayor porcentaje de remoción en esta etapa. Asimismo, las determinaciones de As en el residuo proveniente de la segunda etapa del prototipo indican que la fracción de contaminante que no es retenido por la columna es coprecipitado junto al Fe que eluye de esta unidad y removido en las etapas siguientes.

La acumulación de productos de corrosión en la columna reactiva produce una rápida caída de la conductividad hidráulica del lecho. Sin embargo, este parámetro mantiene valores relativamente estables durante aproximadamente 20 días que resultan suficientes como para permitir la circulación de agua por gravedad, incluso para caudales de 4000 L/día.

El lecho se agota cuando la superficie de ZVI disponible se encuentra completamente saturada de productos de corrosión. A partir de este momento, la velocidad de corrosión disminuye sustancialmente y con esto el contenido de Fe(II) eluido. En consecuencia, el contenido de $\mathrm{Fe}(\mathrm{II})$ a la salida de la columna resultó una variable adecuada para indicar el agotamiento del lecho. Cabe destacar la importancia de este hallazgo debido a que la cuantificación del contenido de $\mathrm{Fe}(\mathrm{II})$ es más simple y más económica que la determinación del contenido de $\mathrm{As}(\mathrm{V})$. Asimismo, dado que el principal mecanismo de corrosión está relacionado al consumo de oxígeno por parte 
del ZVI, al agotarse el lecho la cantidad de oxígeno consumida por la columna reactiva también disminuye. Este hecho está ligado principalmente a la disminución de la $[\mathrm{Fe}(\mathrm{II})]$ en el efluente de las columnas y se ve reflejado en el aumento del potencial de reducción a la salida del reactor. Por lo tanto, la medida de los valores de ORP puede resultar de gran utilidad para el monitoreo on-line de la eficiencia del lecho. Los resultados obtenidos indican que potenciales superiores a $-100 \mathrm{mV}$ a la salida de la columna indican un lecho agotado que no es capaz de remover As.

Las determinaciones de la distribución de tiempos de residencia indicaron que una de las características más importantes a la hora diseñar el reactor es la homogeneidad y adecuado empaquetamiento del relleno. El formato particular de la lana de hierro, compuesta por hilos finos, hace que su correcta disposición en el reactor sea una de las claves para que el proceso resulte eficiente. La distribución del relleno debe ser tal que no se genere ningún tipo de canal preferencial para el paso del fluido. Esto representó una de las mayores dificultades para el escalado del proceso. En este contexto, y teniendo en cuenta las dimensiones de los "paños" de lana de hierro disponibles en el mercado, para poder incrementar los caudales de tratamiento fue necesario colocar, al menos, dos reactores rellenos en paralelo. Asimismo, esta configuración permitió que, en el caso de haber inconvenientes en el relleno de alguno de los reactores, el sistema de tratamiento continúe operando. En este caso, el $\mathrm{Fe}(\mathrm{II})$ generado por la columna que no presentó inconvenientes permitió la remoción de $\mathrm{As}(\mathrm{V})$ por parte de las unidades siguientes en el proceso por mecanismos de co-precipitación tal como se demostró en el capítulo 3.

Por último, es importante destacar que los residuos obtenidos en el proceso pueden ser dispuestos como "residuos no peligrosos". La separación por decantación de los efluentes provenientes de la etapa de limpieza de los módulos de aireación, prefiltrado y filtrado permite obtener un residuo líquido con concentraciones de As y de Fe lo suficientemente bajas como para permitir su vuelco en la red cloacal. Por otro lado, los resultados obtenidos del test de toxicidad TCLP indican que el sólido obtenido luego de la separación resulta estable y no tóxico dado el bajo contenido de As en el lixiviado, por lo que puede ser dispuesto como un "sólido no peligroso". 
CAPITULO 7:

PRUEBAS DE CAMPO 


\section{PRUEBAS DE CAMPO}

Con el objetivo de validar los resultados obtenidos con la planta piloto en las instalaciones de la Facultad, se realizaron pruebas de campo con los prototipos antes descriptos para diferentes escalas de tratamiento y empleando aguas subterráneas en distintas localidades de la Provincia de Buenos Aires.

\subsection{PRIMERA PRUEBA DE CAMPO, GRAL. RODRIGUEZ}

En septiembre de 2011 el Instituto de Investigación y Desarrollo Tecnológico para la Agricultura Familiar (IPAF, Región Pampeana) y la Agencia de Extensión Rural (AER, Moreno), ambos pertenecientes al INTA, realizaron un relevamiento de la infraestructura hídrica y usos del agua a pedido de productores tamberos de la Asociación de Familias Productoras de la Cuenca del Rio Lujan, quienes habían manifestado dudas respecto a la calidad de agua que consumían, en particular sobre el contenido de arsénico. El relevamiento incluyó la toma de muestras de agua de las perforaciones empleadas por los productores, tanto para consumo doméstico como para actividades productivas, localizadas en las zonas de General Rodríguez y Lujan (Pcia. de Buenos Aires). En todos los casos, los niveles de arsénico medidos fueron superiores a los valores guía establecidos por el CAA y la OMS (10 ppb).

A mediados de 2012, luego de analizar algunas de las tecnologías disponibles para la remoción de arsénico desarrolladas por distintas instituciones de la región, el IPAF acordó trabajar en articulación con la Facultad de Ingeniería (UNLP) para evaluar, junto a los productores, el desempeño de un prototipo desarrollado en la Facultad para una escala de tratamiento familiar de $500 \mathrm{~L} /$ día. La primera actividad junto a los productores consistió en una charla informativa sobre la problemática del arsénico en agua y sobre la técnica empleada para su remoción. En esa oportunidad se acordó instalar el prototipo en el establecimiento que presentó mayor concentración de arsénico, para lo cual se relevaron detalles de infraestructura de la vivienda (Figuras 7.1 y 7.2) y se tomaron muestras de agua para realizar análisis tanto fisicoquímicos como bacteriológicos con el objeto de caracterizar las aguas a tratar.

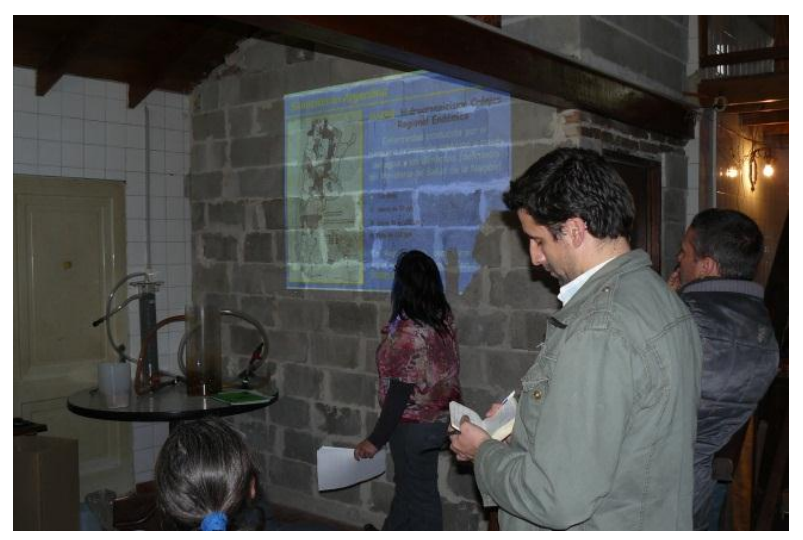

Figura 7.1. Primera visita realizada: charla informativa en Gral. Rodríguez. 


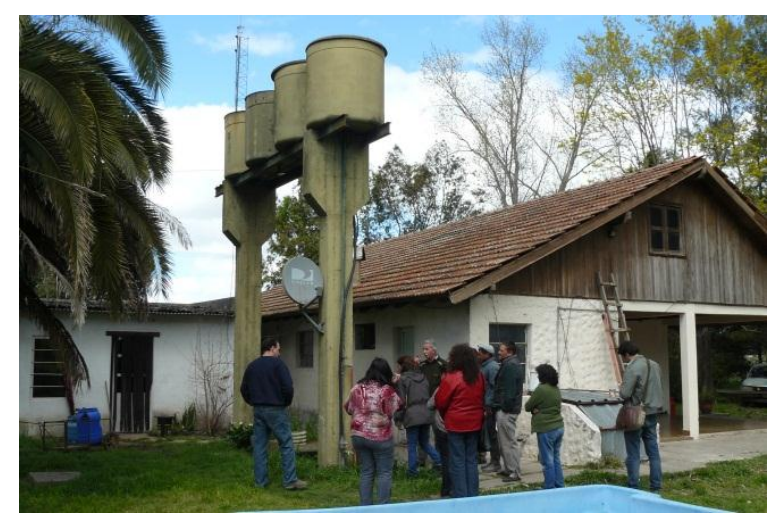

Figura 7.2. Primera visita realizada: relevamiento de información en Gral. Rodríguez.

\section{Adecuación e instalación del prototipo}

En base a los requerimientos del prototipo y a la infraestructura disponible en la casa de los productores donde posteriormente se probaría la planta, se analizaron diferentes posibilidades para la instalación. Finalmente se seleccionó el diseño más simple que permitiera la circulación del caudal deseado por gravedad y utilizando la carga hidráulica de un tanque elevado existente en el establecimiento (a una altura similar a la de una casa de familia de una planta). Esto se logró disponiendo los tres módulos, descriptos en el Capítulo 6, sobre una misma base de apoyo amurada a la base del tanque ubicado en el exterior de la vivienda. Los primeros dos módulos fueron realizados en acrílico y el filtro lento de arena en plástico.

El dispositivo fue instalado en marzo de 2013 y quedó en funcionamiento a modo de prueba (Figura 7.3). El agua tratada por el sistema fue recolectada en un tanque de 700 L para periódicamente analizar el contenido de arsénico, y eventualmente de hierro. Las tareas de seguimiento y registro de la eficiencia de remoción de As fueron realizadas por parte de los productores propietarios del establecimiento, a quienes se capacitó para la toma de muestras y para la determinación de arsénico mediante un kit de tiras reactivas (Figura 7.4). Asimismo, los propietarios del establecimiento fueron capacitados para realizar las tareas diarias de mantenimiento del prototipo y tomar las medidas necesarias en caso de desperfectos.

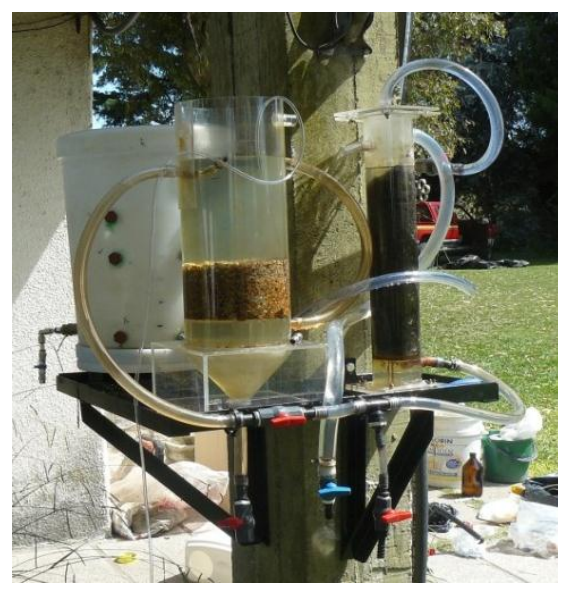

Figura 7.3. Segunda visita: instalación del prototipo As. 


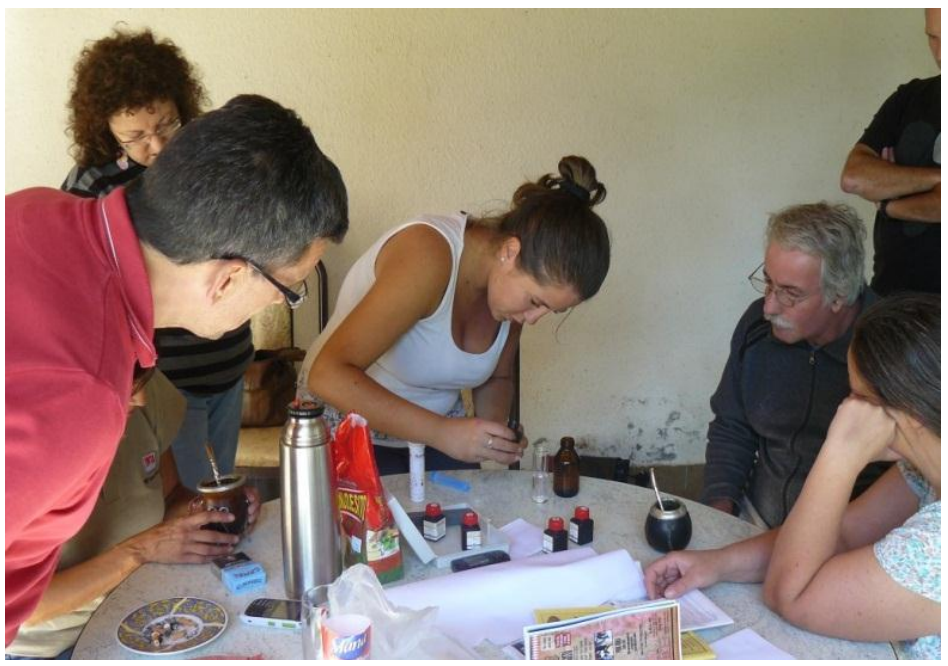

Figura 7.4. Segunda visita: capacitación para las determinaciones de As.

En el transcurso de las pruebas, se mantuvo contacto permanente con los productores, quienes regularmente informaron acerca de los niveles de remoción obtenidos y de distintos inconvenientes que fueron surgiendo. El primer problema relevante que presentó el sistema fue la abundante proliferación de algas y otros microorganismos en todos los módulos (Figura 7.5). Por este motivo, se realizó una nueva visita de relevamiento de la situación que resultó en una intervención para aislar el prototipo (Figura 7.6). En esta visita también se detectaron problemas de flujo asociados a la presencia de cortocircuitos (bypass) del fluido en el primer módulo, situación que se solucionó mejorando el empaquetamiento de la columna reactiva.
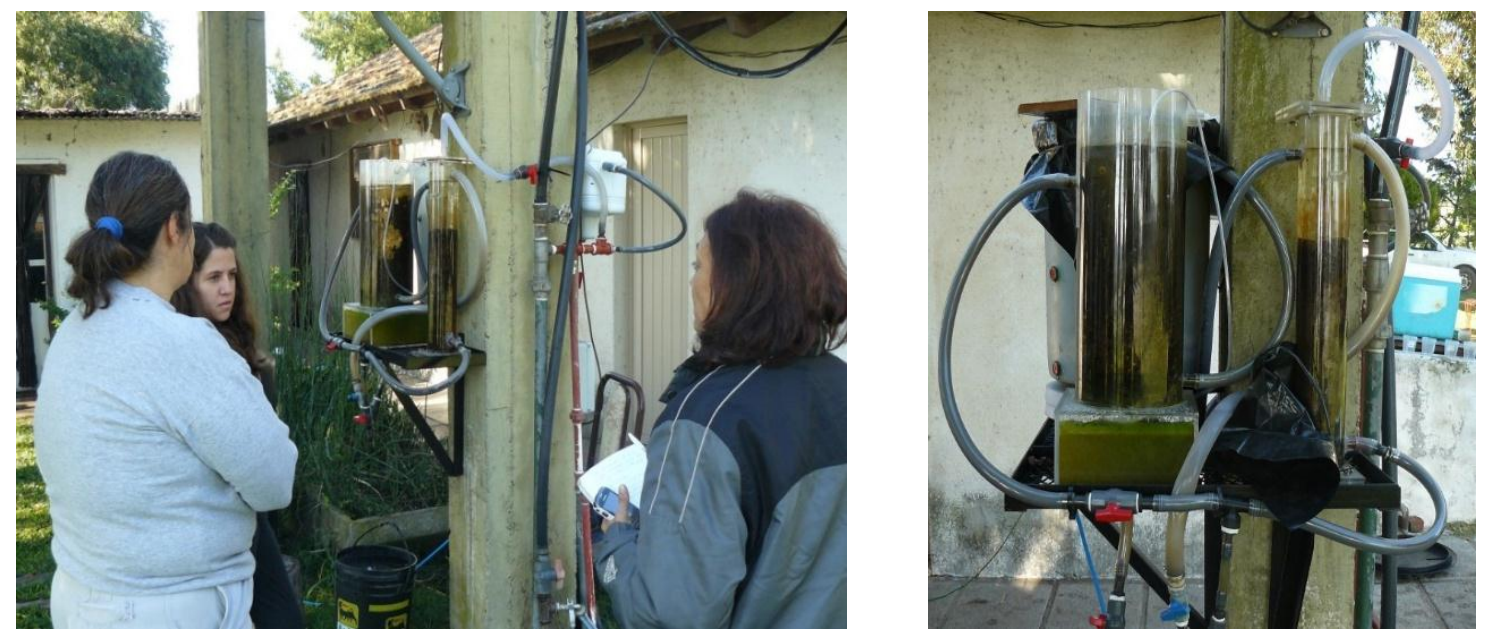

Figura 7.5. Proliferación de algas en el prototipo instalado en la vivienda de los productores de Gral. Rodriguez. 

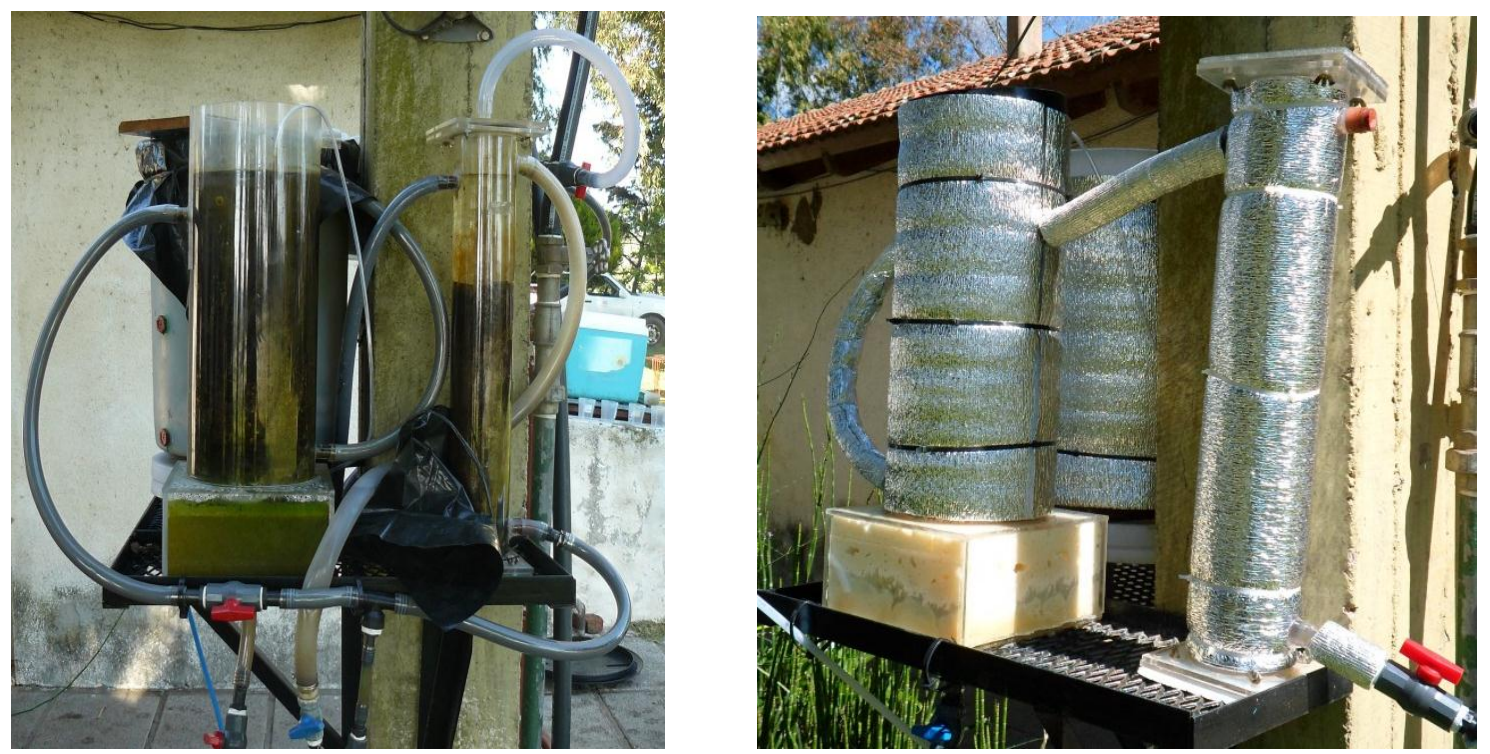

Figura 7.6. Aislación del prototipo instalado en la vivienda de los productores de Gral. Rodríguez.

Luego de solucionados los inconvenientes mencionados se programó una serie de visitas dado que los porcentajes de remoción detectados se encontraban por debajo de los valores esperados (<90\% remoción). En este contexto, se realizaron determinaciones de $\mathrm{Fe}_{\text {Tot }}$ a la salida de cada uno de los módulos. Las mismas permitieron corroborar que las eficiencias de remoción de As registradas resultaban insuficientes debido a una baja tasa de corrosión por parte del material reactivo. Se analizaron distintas variables que podían provocar este comportamiento. Luego de varios ensayos, tanto en campo como a nivel de laboratorio con matrices de agua provenientes de la perforación de los productores, se llegó a la conclusión de que las bajas tasas de corrosión observadas se correlacionaban con el alto $\mathrm{pH}$ del agua a tratar $(8,3$ - 8,5). Una vez identificada la causa de las deficiencias en el funcionamiento del prototipo, se procedió a evaluar diferentes alternativas para la incorporación de un sistema para la corrección del $\mathrm{pH}$ previo al ingreso del afluente a la primera columna.

\subsection{SEGUNDA PRUEBA DE CAMPO, CASTELLI}

Luego de analizar la factibilidad de escalar el proceso a mayores caudales y de implementar una etapa de medición/control de $\mathrm{pH}$, que requiere una mínima supervisión por parte de un operador, se evaluaron diferentes alternativas para la realización de una nueva prueba de campo. Considerando los caudales de trabajo alcanzados en las pruebas realizadas durante el primer cuatrimestre de 2015 en la Facultad se resolvió que el mejor destinatario para el prototipo modificado podría ser una pequeña comunidad o cooperativa de servicios de agua potable. Por este motivo se decidió trabajar en conjunto con personal de FEDECOBA (Federación de Cooperativas de Electricidad y Servicios de la Provincia de Buenos Aires Limitada) para realizar nuevas pruebas que permitieran verificar la eficacia y replicabilidad del proceso de tratamiento en otros sitios. 
Luego de analizar todos los municipios pertenecientes a FEDECOBA, en los cuales se detectaron altos contenidos de As para algunos de sus pozos, se seleccionó la Localidad de Castelli para la instalación de la nueva planta piloto. Las pruebas de campo fueron realizadas en la Cooperativa de Usuarios de Electricidad y de Consumo de Castelli (CUECCA) asociada a FEDECOBA. Afortunadamente, los integrantes de la cooperativa se mostraron muy interesados en probar esta nueva tecnología. Luego de una serie de reuniones y evaluaciones preliminares, el prototipo (Figuras 7.7 y 7.8 ) fue montado en las instalaciones pertenecientes al sector de Servicio de Agua Potable de la cooperativa, ubicadas bajo el tanque elevado de agua que abastece al casco urbano de la localidad de Castelli.

Se trabajó con agua proveniente de un pozo fuera de uso por su alto contenido de As ( 130 ppb). Diariamente se trasladó agua de este pozo para operar la planta de manera continua de lunes a viernes con un caudal de $700 \mathrm{~L} /$ día. Previo al inicio de las pruebas, se realizó un muestreo del pozo para su análisis y una capacitación de los operadores del sector aguas para la determinación de As con el kit de tiras reactivas y el monitoreo del prototipo (Figura 7.9).
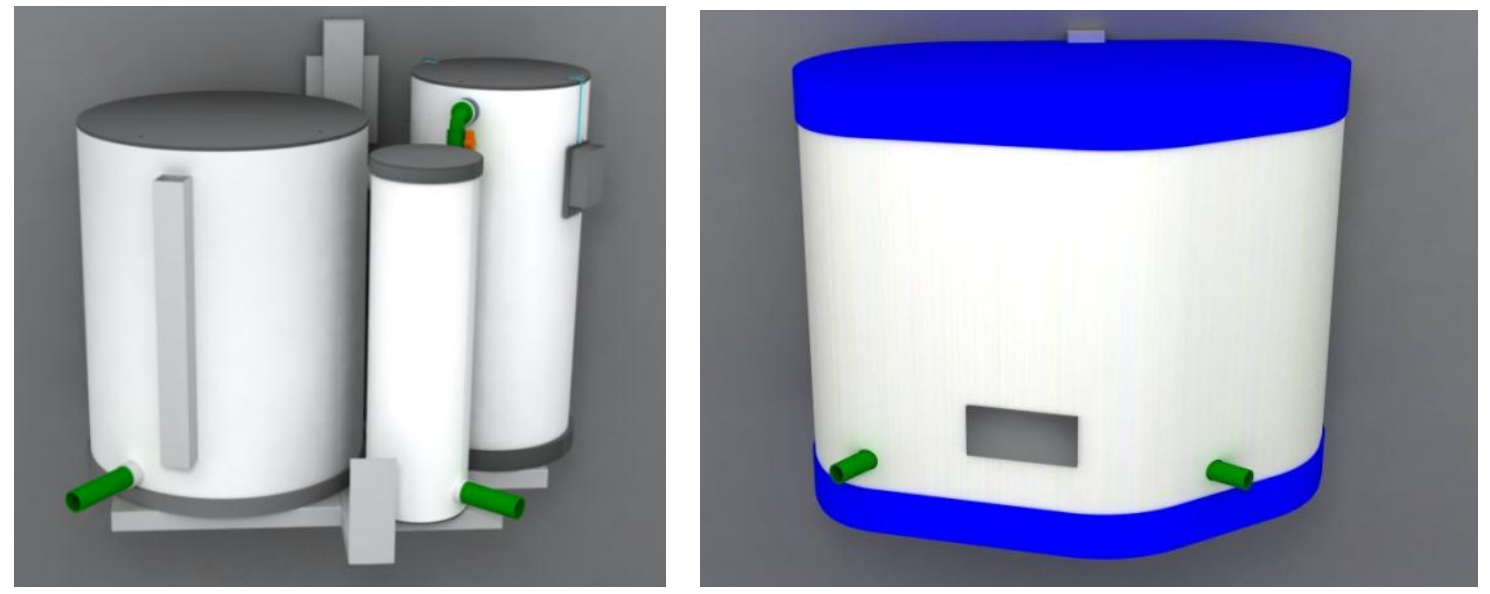

Figura 7.7. Esquema de la estructura interna del prototipo y vista exterior.

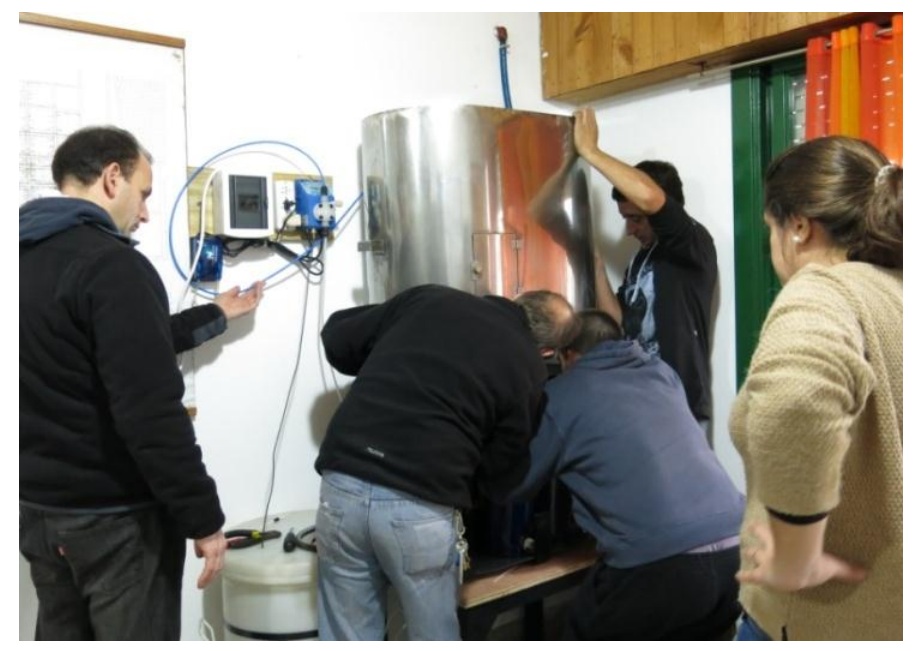

Figura 7.8. Instalación del prototipo en la localidad de Castelli. 

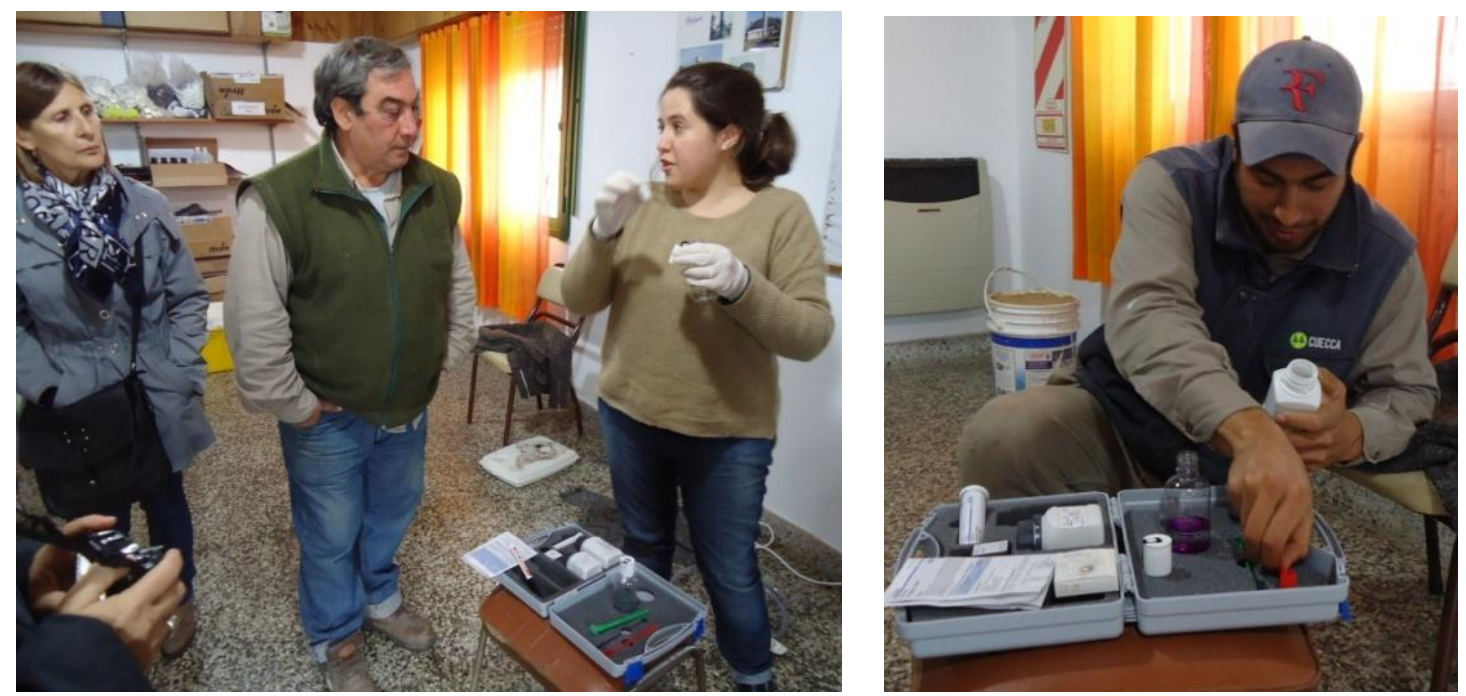

Figura 7.9. Capacitación de operadores del sector aguas de la cooperativa de Castelli.

Los ensayos fueron realizados utilizando el prototipo continuo descripto en el capítulo 6, diseñado para tratar caudales de 700 litros por día de agua. El caudal a tratar ingresa al sistema por gravedad desde un tanque elevado ubicado en el exterior, pasando por un sistema de corrección automática de $\mathrm{pH}$ mediante una bomba dosificadora de $\mathrm{HCl}$ previo al ingreso del agua al reactor. En el primer diseño, los 3 módulos se ubicaron sobre una misma base de apoyo cubiertos por una carcasa tal como se muestra en la Figura 7.8. Luego de la primera prueba, se realizaron modificaciones al sistema con el objeto de mejorar sus prestaciones y facilitar su operación. En la Figuras 7.10 y 7.11 se muestra un esquema del diseño del prototipo modificado así como también el equipo empleado durante la segunda prueba.

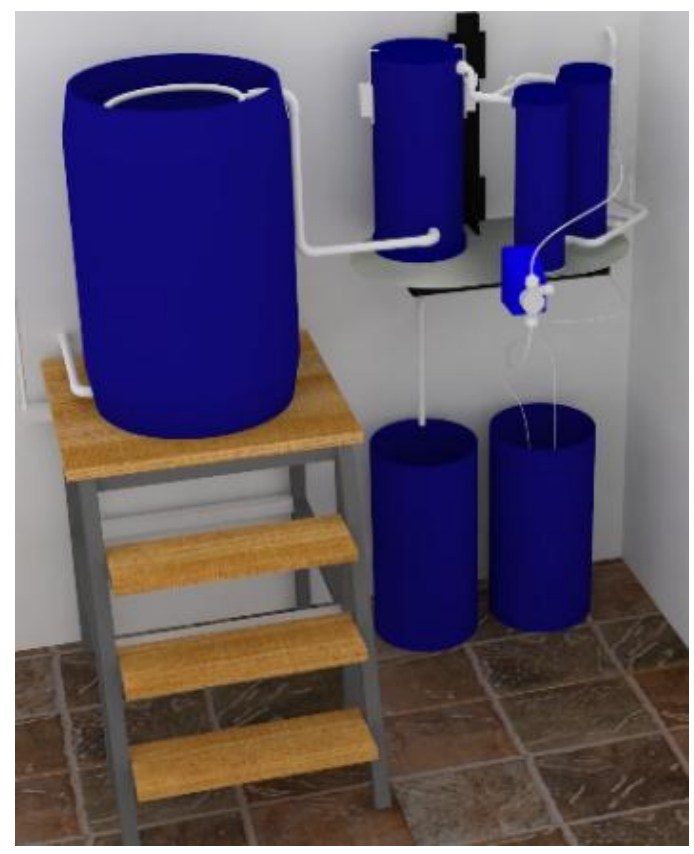

Figura 7.10. Esquema del segundo prototipo utilizado. 


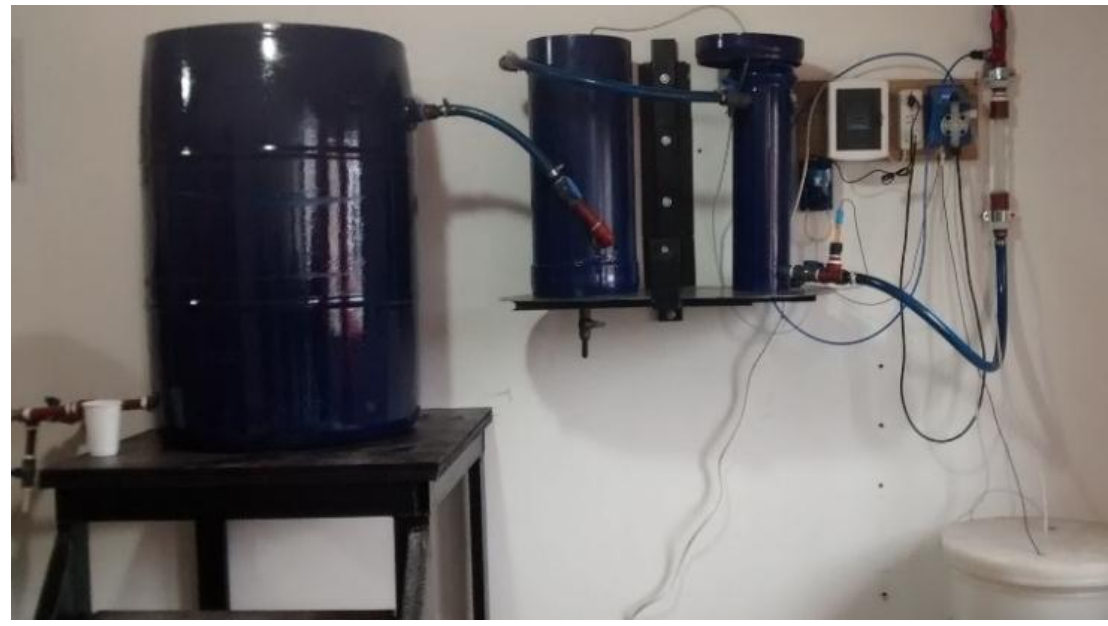

Figura 7.11. Foto del segundo prototipo utilizado.

En el transcurso de las pruebas se realizó un monitoreo diario del caudal por parte de los operadores quienes además, tres veces por semana, determinaron el contenido de As en campo y tomaron muestras de agua tratada para su posterior análisis en el laboratorio de la Facultad (donde se determinaron los niveles de As, $\mathrm{Fe}(\mathrm{II}), \mathrm{Fe}(\mathrm{III})$ y $\mathrm{Fe}$ total). Eventualmente, también se efectuaron muestreos para un análisis fisicoquímico completo del agua tratada por parte de un laboratorio externo. Los parámetros analizados y las técnicas mediante las cuales fueron realizadas las caracterizaciones fisicoquímicas completas se muestran en la Tabla 7.1.

Tabla 7.1. Parámetros fisicoquímicos determinados y técnicas utilizadas por el laboratorio externo.

\begin{tabular}{|c|c|c|c|}
\hline PARÁMETRO & MÉTODO & PARÁMETRO & MÉTODO \\
\hline $\mathrm{pH}$ & $\begin{array}{l}\text { SM M } 4500 \mathrm{H}-\mathrm{B} \\
\text { (Potenciométrico) }\end{array}$ & Sulfatos & $\begin{array}{l}\text { SM M } 4500 \text { SO4 -E } \\
\text { (Turbidimétrico) }\end{array}$ \\
\hline Conductividad & SM M 2510 B & Nitratos & $\begin{array}{c}\text { SM M } 4500 \text { NO3- -E } \\
\text { Espectrofotometría UV Vis }\end{array}$ \\
\hline Turbiedad & SM M 2130 B - Nefelométrico & Nitritos & $\begin{array}{l}\text { SM M 4500- NO2- -B } \\
\text { Espectrofotometría UV Vis }\end{array}$ \\
\hline Color & SM M 2120 B modificado & Fluoruros & $\begin{array}{l}\text { SM M } 4500 \text { F -D - } \\
\text { Espectrofotométrico }\end{array}$ \\
\hline Olor & SM 2150 - B - Organoléptico & Arsénico & $\begin{array}{l}\text { EPA SW } 846 \text { M 7061A - EAA } \\
\text { Generación de hidruros }\end{array}$ \\
\hline Aspecto & SM 2110 & Amonio & $\begin{array}{l}\text { SM M } 4500 \text { NH3 -C - } \\
\text { Espectrofotométrico }\end{array}$ \\
\hline $\begin{array}{l}\text { Sólidos totales } \\
\text { disueltos }\end{array}$ & SM M 2540 C - Gravimétrico & Hierro Total & SM M 3500 Fe - EAA \\
\hline Dureza & SM M 2340 C - Titulométrico EDTA & Manganeso & SM M 3111 Mn - EAA \\
\hline $\begin{array}{l}\text { Alcalinidad } \\
\text { Total }\end{array}$ & SM M 2320 B - Titulométrico & Fosfatos & SM 4500 P -21 st Ed \\
\hline Cloruros & SM M $4500 \mathrm{Cl}$ - B - Titulométrico & & \\
\hline
\end{tabular}




\subsubsection{Resultados primer ensayo en Castelli}

Durante el primer ensayo se detectaron algunos inconvenientes que fueron registrados para luego realizar las modificaciones necesarias. El acceso restringido al prototipo por la parte superior, originado por la carcasa, dificultó la limpieza del filtro. Además, la demanda de limpieza en las primeras semanas fue mayor a la esperada, problema originado por exceso de ácido durante los primeros días de operación. Ambos inconvenientes fueron completamente corregidos mediante la reubicación de la carcasa y la regulación adecuada del sistema de control de $\mathrm{pH}$.

Los resultados obtenidos durante la primera prueba mostraron que, pese a los problemas detectados, se pudo remover el arsénico del agua de pozo desde una concentración de 0,132 ppm hasta un valor por debajo de 0,01 ppm. La prueba se extendió por un período de aproximadamente 17 días empleando un caudal promedio de 700 L/día de agua. Los niveles de remoción alcanzados resultaron muy satisfactorios considerando que se trataba de la primera prueba realizada con agua real para este caudal de tratamiento y operando una planta con corrección automática del $\mathrm{pH}$ por parte de personal no especializado en la técnica de remoción.

Con respecto al contenido de hierro total en el agua tratada, durante los primeros 15 días se detectaron concentraciones por encima del límite permitido de 0,3 ppm a causa del exceso de ácido suministrado el sistema. Luego de realizar los ajustes necesarios, el contenido de este metal se mantuvo por debajo de 0,1 ppm.

\subsubsection{Resultados segundo ensayo en Castelli}

Tal como se mencionó previamente, a partir de las observaciones realizadas durante la primera prueba se incorporaron modificaciones al prototipo y se inició una nueva prueba de aproximadamente dos meses de duración, con un cambio del relleno de ZVI en la columna luego de transcurrido el primer mes. Las principales modificaciones implementadas consistieron en: i- la incorporación de un mezclador estático en línea luego de la inyección de ácido para disminuir y optimizar su consumo; ii- el cambio del filtro lento de arena en la etapa final por uno de mayor diámetro para aumentar su tiempo de operación; y iii- la eliminación de la carcasa para facilitar el acceso a los módulos y la limpieza del equipo.

Los resultados de la segunda prueba mostraron porcentajes de remoción del orden del 95-100\% durante dos períodos de 28 días. Los análisis externos también verificaron la eficiencia del proceso al obtener concentraciones de As por debajo del límite de detección para las dos muestras de agua tratada llevadas a analizar (Tabla 7.2). Con respecto al resto de las determinaciones realizadas, se puede observar que no se produjeron alteraciones en otros parámetros de calidad del agua a lo largo del tratamiento. En especial se verifica que el contenido de hierro se encuentra por debajo del límite máximo admisible. 
Tabla 7.2. Resultados del análisis fisicoquímico en muestras de agua sin tratar y tratadas durante la segunda prueba.

\begin{tabular}{|c|c|c|c|c|c|c|c|}
\hline Parámetros & $\begin{array}{c}\text { Sin } \\
\text { tratar } \\
15 / 5 / 15\end{array}$ & $\begin{array}{l}\text { Tratada } \\
11 / 5 / 15\end{array}$ & $\underset{\substack{\text { tratar } \\
28 / 12 / 15}}{\sin }$ & $\begin{array}{l}\text { Tratada } \\
\text { 28/12/15 }\end{array}$ & $\begin{array}{l}\text { Limite } \\
\text { CAA* }^{*}\end{array}$ & Unidad & $L^{* * *}$ \\
\hline pH & 8,0 & 6,96 & 8,5 & & $6,5-8,5$ & $\mathrm{U}$ de $\mathrm{pH}$ & 0,1 \\
\hline Conductividad & 793 & & 821 & 945 & - & $\mu \mathrm{mhos} / \mathrm{cm}$ & 1 \\
\hline Turbiedad & $<3$ & $<3$ & $<3$ & $<3$ & $<3$ & NTU & 3 \\
\hline Color & $<3$ & $<3$ & $<3$ & $<3$ & $<5$ & U de Color & 3 \\
\hline Olor & Inodoro & Inodoro & & & Inodoro & - & - \\
\hline $\begin{array}{l}\text { Sólidos totales } \\
\text { disueltos }\end{array}$ & & 585 & 522 & 552 & 1500 & $\mathrm{mg} / \mathrm{L}$ & 1 \\
\hline Dureza & 144 & 134 & 139 & 137 & 400 & $\mathrm{mg} \mathrm{CaCO}_{3} / \mathrm{L}$ & 1 \\
\hline Alcalinidad Total & 372 & - & 382 & 249 & - & $\mathrm{mg} \mathrm{CaCO} / \mathrm{L}$ & 1 \\
\hline Cloruros & 22 & 126 & 24 & 138 & 350 & $\mathrm{mg} / \mathrm{L}$ & 1 \\
\hline Sulfatos & 16 & 20 & 17 & 20 & 400 & $\mathrm{mg} / \mathrm{L}$ & 1 \\
\hline Nitratos & 13,9 & 14,4 & 14,9 & 11,5 & 45 & $\mathrm{mg} / \mathrm{L}$ & 0,5 \\
\hline Nitritos & 0,013 & 0,099 & 0,014 & $<0,005$ & 0,1 & $\mathrm{mg} / \mathrm{L}$ & 0,005 \\
\hline Fluoruros & 1,08 & 1,25 & 1,34 & 1,32 & & $\mathrm{mg} / \mathrm{L}$ & 0,03 \\
\hline Arsénico & 0,132 & $<0,003$ & 0,115 & $<0,003$ & 0,01 & $\mathrm{mg} / \mathrm{L}$ & 0,003 \\
\hline Amonio & $<0,1$ & 0,2 & 0,1 & 0,1 & 0,2 & $\mathrm{mg} / \mathrm{L}$ & 0,1 \\
\hline Hierro Total & & 0,112 & 0,024 & 0,042 & 0,3 & $\mathrm{mg} / \mathrm{L}$ & 0,006 \\
\hline Manganeso & & 0,238 & $<0,006$ & 0,012 & 0,1 & $\mathrm{mg} / \mathrm{L}$ & 0,006 \\
\hline Fosfatos & & & 0,43 & $<0,01$ & - & $\mathrm{mg} / \mathrm{L}$ & 0,01 \\
\hline
\end{tabular}

\subsubsection{Análisis de las curvas de ruptura}

El la Figura 7.12 se muestra la curva de ruptura construida a partir de los datos de concentración de arsénico a la salida de la columna durante la primera prueba, la concentración de entrada para este ensayo fue de $132 \mathrm{ppb}\left(\mathrm{C}_{0}\right)$. 


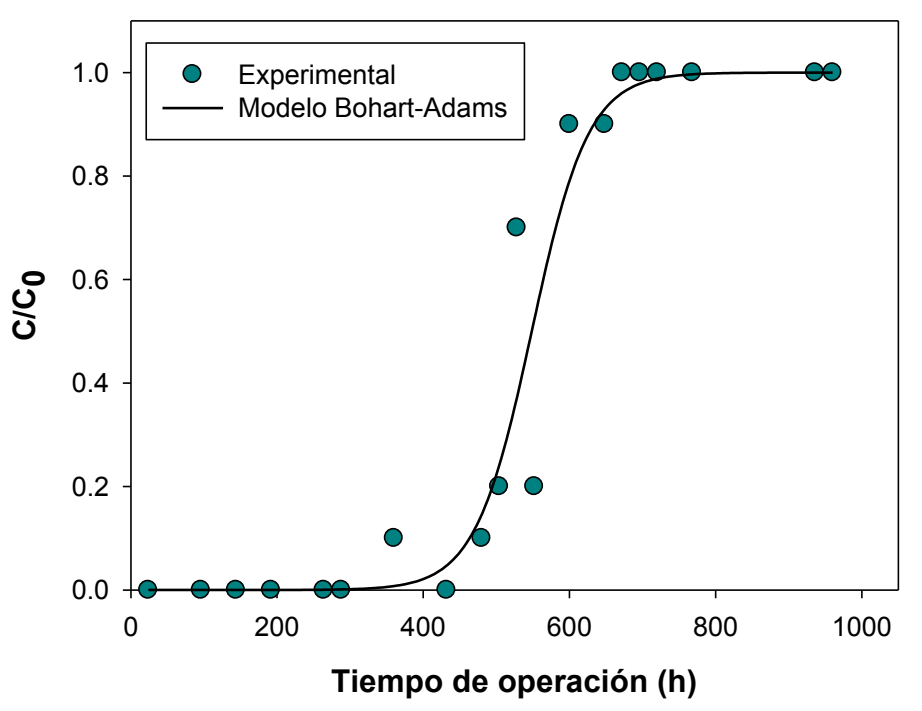

Figura 7.12. Curva de ruptura correspondiente a la primera prueba en la localidad de Castelli $\left(\mathrm{C}_{0}=132 \mathrm{ppb}\right)$.

Los valores experimentales de la curva de ruptura fueron ajustados utilizando el modelo de Bohart-Adams y los resultados se muestran en la Tabla 7.3. Como era esperable, dadas las diferencias en las respectivas matrices acuosas, los resultados de los parámetros obtenidos difieren ampliamente de los obtenidos para las pruebas de laboratorio.

Tabla 7.3. Ajuste de la primera curva de ruptura mediante el Modelo de Bohart-Adams.

\begin{tabular}{|c|c|c|c|}
\hline \multicolumn{2}{|l|}{ Datos } & \multicolumn{2}{|c|}{ Parámetros calculados } \\
\hline Altura de lecho (Z) & $45 \mathrm{~cm}$ & & \\
\hline Conc. de As a la entrada $\left(C_{0}\right)$ & $0,1 \mathrm{mg} / \mathrm{L}$ & & \\
\hline Masa de ZVI & $500 \mathrm{~g}$ & Máx. capacidad del lecho $\left(\mathrm{N}_{0}\right)$ & $170 \mathrm{mg} / \mathrm{L}$ \\
\hline Velocidad de filtración $\left(\mathbf{v}_{\text {filt }}\right)$ & $140 \mathrm{~cm} / \mathrm{h}$ & Cte. Cinética del lecho ( $\left.k_{\mathrm{ab}}\right)$ & $0,258(\mathrm{mg} / \mathrm{L})^{-1} \mathrm{~h}^{-1}$ \\
\hline
\end{tabular}

En la Figura 7.13 se comparan los tiempos de servicio correspondientes a los dos ensayos realizados. La primera curva de ruptura obtenida muestra un tiempo de servicio de 456 horas mientras para la segunda prueba la ruptura del lecho se produjo luego de 648 horas. Para mayores tiempos de servicio, el contenido de As en los efluentes medidos en cada prueba superó el límite permitido por la OMS (0,01 mg/L) (línea roja de la Figura 7.13). 


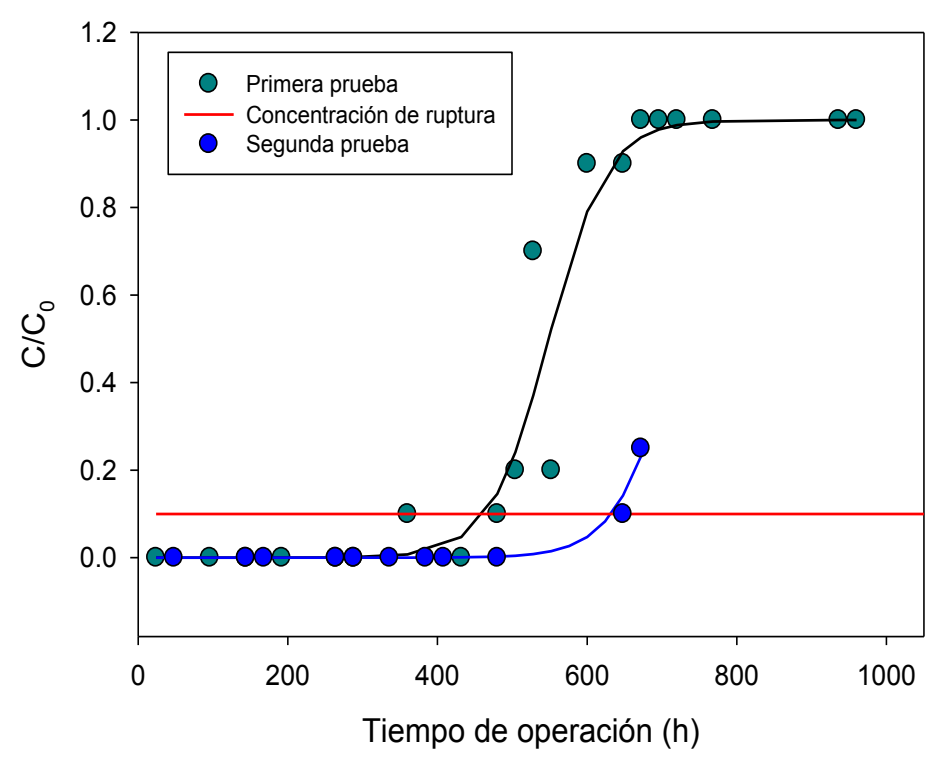

Figura 7.13. Comparación de tiempos de ruptura para las pruebas de campo realizadas en Castelli.

Tal como se describió en el Capítulo 6, ensayos previos realizados en nuestro laboratorio mostraron que para tiempos de operación por encima de los tiempos de ruptura, las concentraciones de $\mathrm{Fe}(\mathrm{II})$ a la salida del primer módulo son siempre menores a 0,5 ppm. En este contexto, cabe destacar que la alta tasa de consumo de ácido registrada durante el primer período de la primera prueba provocó una velocidad de corrosión mayor a la requerida, por este motivo no se obtuvo una producción de $\mathrm{Fe}(\mathrm{II})$ sostenida por parte del primer lecho y el tiempo de servicio en la primera prueba fue significativamente menor al esperado.

Dado que los resultados obtenidos fueron muy alentadores, se dispuso la posibilidad de realizar una nueva prueba de campo con un prototipo de mayor envergadura capaz de alcanzar caudales de tratamiento del orden de los $4 \mathrm{~m}^{3}$ diarios.

\subsection{TERCERA PRUEBA DE CAMPO, VERÓNICA}

Durante el año 2017 directivos de FEDECAP, Federación de Cooperativas de Agua Potable y Saneamiento de la Provincia de Buenos Aires, nos manifestaron su preocupación respecto del problema del arsénico y la necesidad, de pequeñas cooperativas de provisión de servicio de agua potable perteneciente a su Federación, de alcanzar el límite de 10 ppb en el agua para consumo. Por este motivo, se decidió trabajar en conjunto con la Federación para la realización las pruebas de campo correspondientes a la planta de tratamiento de $4 \mathrm{~m}^{3} /$ día descripta en el capítulo 6 .

Dada la envergadura de la planta de $4 \mathrm{~m}^{3} /$ día, se requiere cierta supervisión para su operación. Por lo tanto, para la realización de pruebas de campo fuera de la Facultad, se seleccionó la cooperativa de Verónica ya que dispone de personal 
capacitado para operar la planta. Cabe destacar que el contenido promedio de As en los pozos que emplea la cooperativa de Verónica está por debajo de las 50 ppb (del orden de las 35 a $45 \mathrm{ppb}$ ). En este sentido, de acuerdo con la normativa actualmente vigente en la provincia de Buenos Aires no sería necesaria la aplicación de un tratamiento para la eliminación de As. Sin embargo, teniendo en cuenta los niveles guía planteados por la OMS y el CAA, y tomando en consideración los resultados previos alcanzados por nuestro grupo de trabajo, el principal objetivo de esta prueba ha sido evaluar la capacidad para obtener un desempeño parejo de las dos columnas en paralelo, en cuanto a caudales de tratamiento y velocidad de corrosión, que permita garantizar concentraciones de As por debajo de $10 \mathrm{ppb}$.

La misma planta que durante el primer cuatrimestre de 2018 fue probada en la Facultad fue trasladada e instalada en la cooperativa de Verónica a principios de junio de 2018. En las instalaciones de la Cooperativa de Verónica la planta se alimenta desde un tanque elevado principal que distribuye el agua a la comunidad (Figuras 7.14 a 7.18). De acuerdo con el protocolo de trabajo establecido en experiencias anteriores, luego de instalada la planta se capacitó al personal de la Cooperativa en cuestiones relacionadas con los fundamentos de la técnica de remoción, las tareas de operación de la planta y las determinaciones analíticas requeridas para el monitoreo del proceso (Fig 7.16).

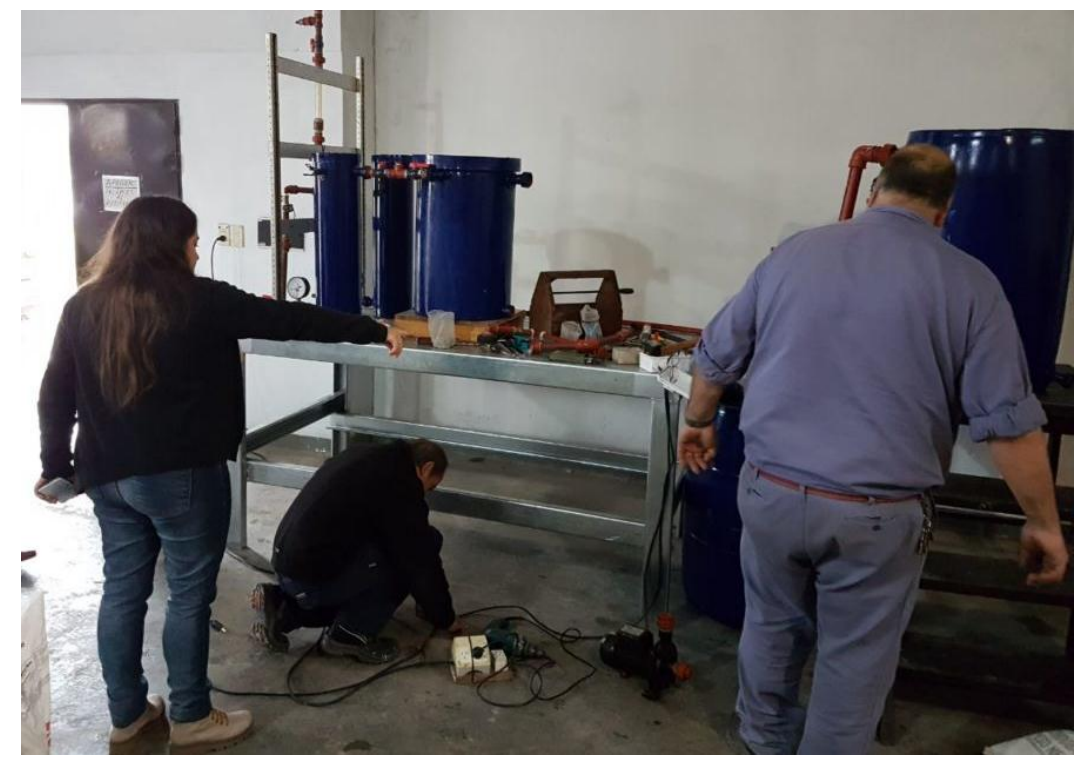

Figura 7.14. Montaje de la planta para el tratamiento de $4 \mathrm{~m}^{3} /$ día en la cooperativa de 

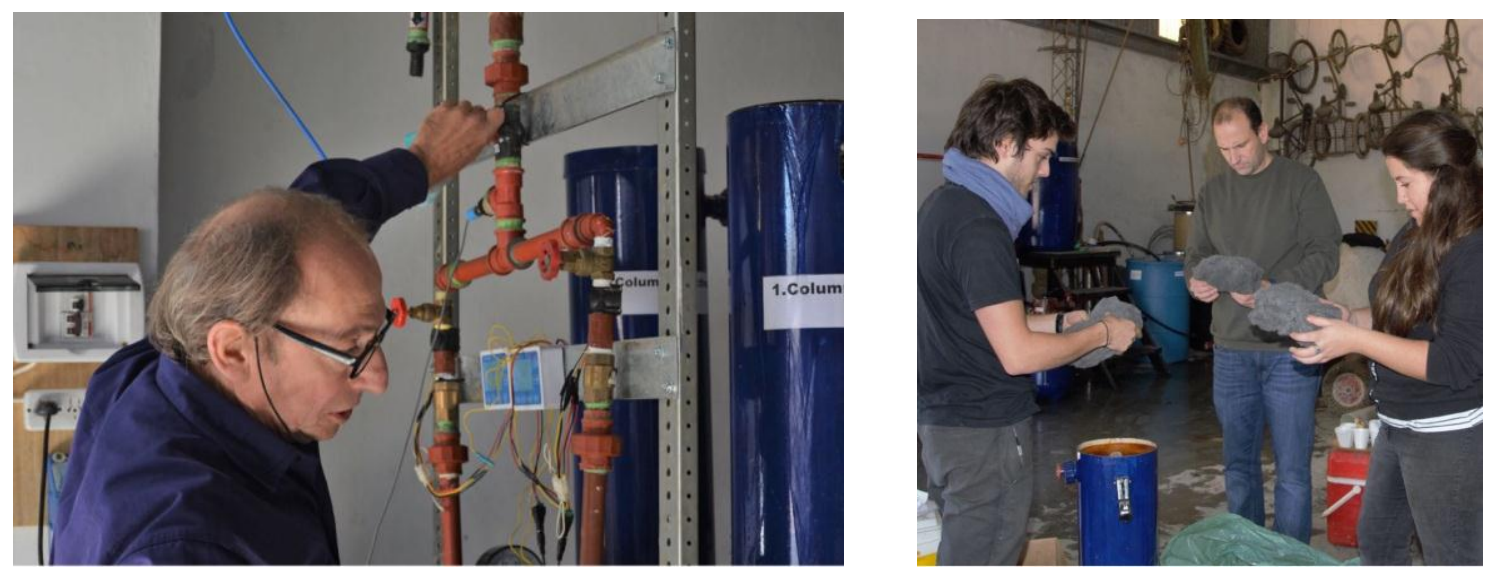

Figura 7.15. Montaje de la planta para el tratamiento de $4 \mathrm{~m} /$ día en la cooperativa de Verónica.

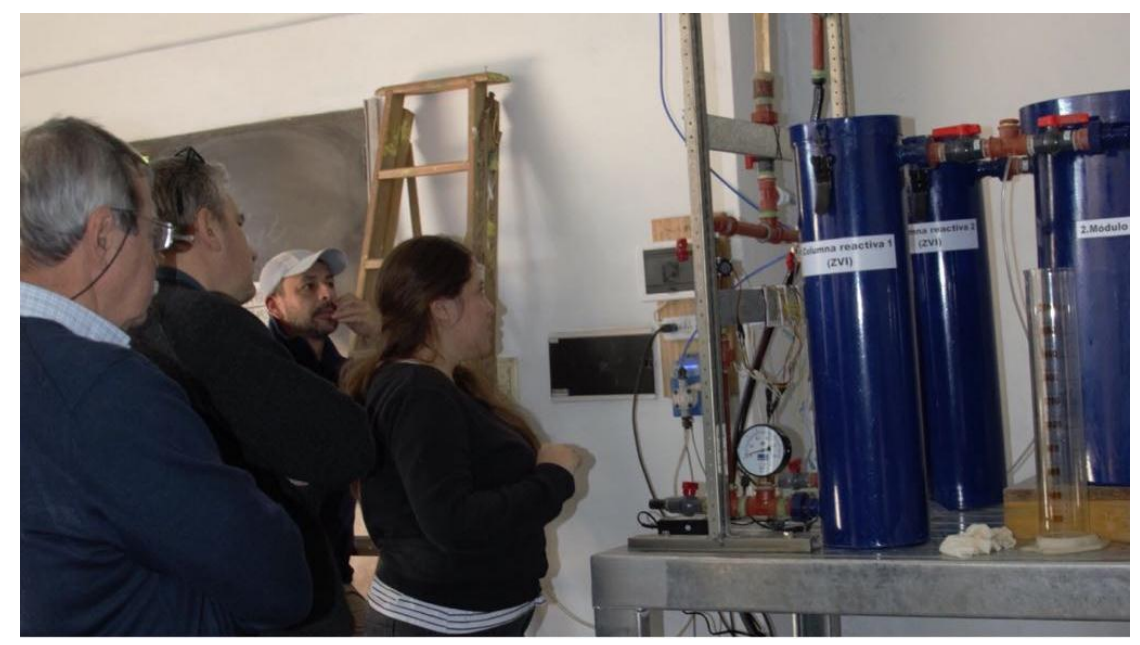

Figura 7.16. Capacitación del personal de la cooperativa de Verónica sobre operación y mantenimiento de la planta.

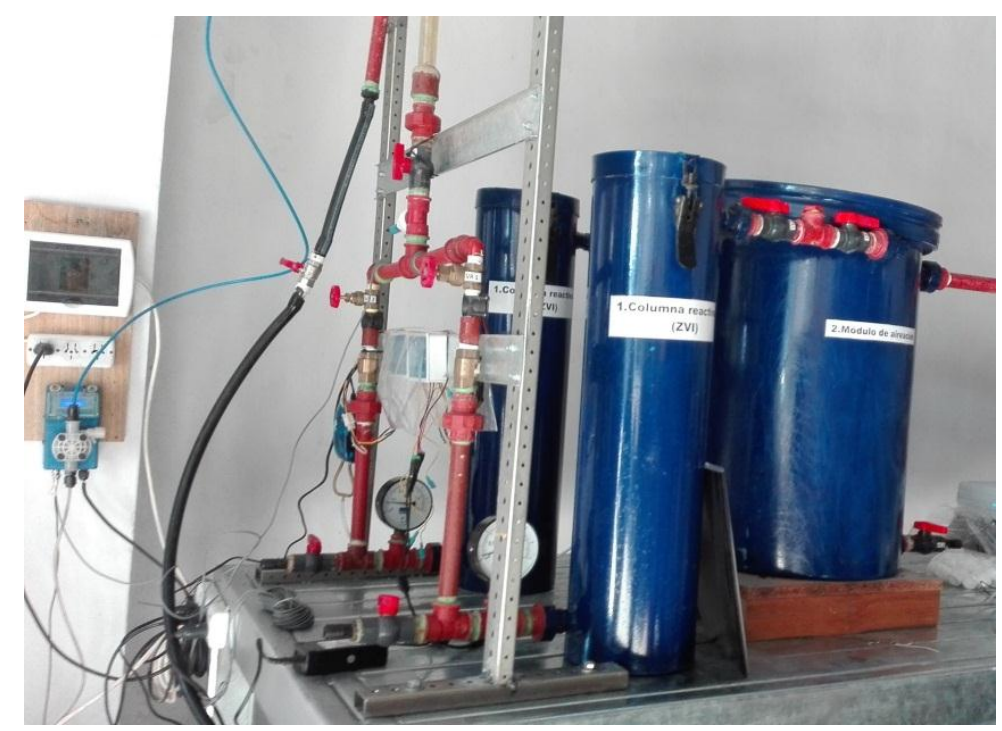

Figura 7.17. Planta para el tratamiento de $4 \mathrm{~m}^{3} /$ día instalada en la cooperativa de Verónica. 

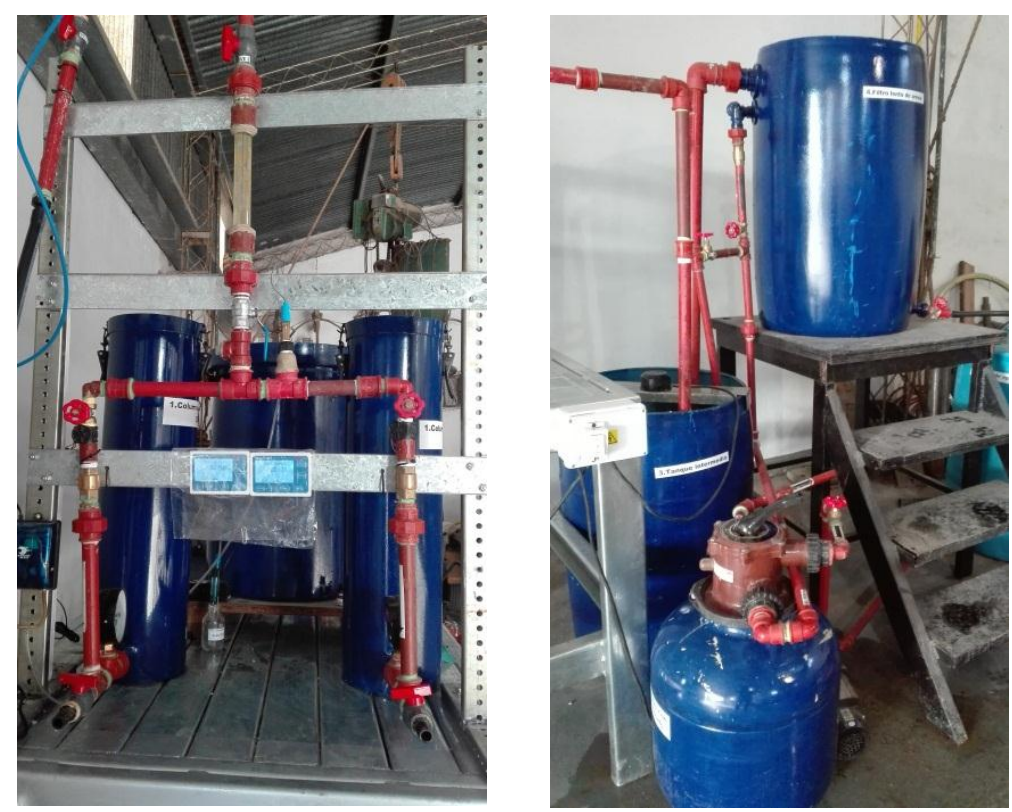

Figura 7.18. Planta para el tratamiento de $4 \mathrm{~m}^{3} /$ día instalada en la cooperativa de Verónica.

Durante la primera prueba fue posible obtener un desempeño similar de las dos columnas en parelelo. Este comportamiento fue verificado mediante mediciones de caudal y determinaciones de ORP. Sin embargo, surgieron algunas dificultades en las etapas posteriores relacionadas con los procesos de oxidación de especies ferrosas y de remoción de particulas en suspensión. Las determinaciones de $\mathrm{Fe}$ (II) y Fe(III) realizadas in situ mostraron que, dada las características propias del agua de la región, que aún se encuentran bajo estudio, la etapa de aireación resulta insuficiente para oxidar todo el $\mathrm{Fe}(\mathrm{II})$ que eluye de las columnas. Ensayos posteriores, realizados en nuestros laboratorios con agua proveniente de la cooperativa de Verónica, comprobaron esta tendencia. Para solucionar este inconveniente se adicionó un sistema de cloración y recirculación de la solución en el segundo módulo del prototipo. Esta modificación permitió resolver completamente el problema cinético asociado a la etapa de oxidación del Fe(II) que eluye de las columnas. Finalmente cabe señalar que, debido al alto caudal de operación de la planta, la cantidad de partículas generadas es muy grande y por lo tanto la etapa final de filtración lenta requiere actualmente tareas de mantenimineto muy frecuentes. En este sentido, nuestros esfuerzos durante el corriente año estarán dirigidos a la optimización de las etapas relacionadas con la separación física de partículas generadas por el proceso. 


\subsection{CONCLUSIONES}

Los ensayos realizados en Gral. Rodríguez permitieron evidenciar que la composición de algunas matrices de agua subterránea conlleva a tasas de corrosión del ZVI insuficientes para el tratamiento de la contaminación por arsénico. En particular, es interesante resaltar que este problema pudo ser detectado gracias las características químicas del agua subterránea de la región (con $\mathrm{pH}$ cercano a 8 y un nivel de alcalinidad mucho mayor que el del agua de red de la Facultad). En este contexto, la prueba de campo realizada motivó la implementación de modificaciones en el sistema de tratamiento que permiten optimizar su funcionamiento para un espectro más amplio de matrices acuosas posibilitando así la evaluación del proceso para aguas subterráneas de otras comunidades.

Las dos pruebas realizadas en Castelli arrojaron resultados satisfactorios. Desde el punto de vista técnico permitieron verificar, utilizando una matriz de agua natural, que una vez incorporado una pequeña corrección de $\mathrm{pH}$ a la entrada del sistema, el diseño básico y la técnica empleada son eficaces para remover contenidos de arsénico del orden de 100 a 150 ppb presentes en aguas subterráneas. Asimismo, los resultados de la prueba sugirieron la posibilidad de replicar la experiencia en diversas regiones de la provincia de Buenos Aires. Es importante señalar que la participación activa del personal de la cooperativa de Castelli resultó altamente productiva y el intercambio de información permitió solucionar varios inconvenientes que surgieron de la operación diaria del prototipo. Esto facilitó la implementación de mejoras sustanciales al prototipo para lograr un diseño más robusto y sencillo de operar.

Finalmente, las pruebas realizadas en la localidad de Verónica posibilitaron evaluar la viabilidad de emplear columnas reactivas operando en paralelo como estrategia para ampliar la capacidad de tratamiento. Estas pruebas también confirmaron la necesidad de realizar ensayos preliminares para poder adaptar el diseño a las características particulares de cada matriz acuosa a tratar. 
CAPITULO 8:

ENSAYOS EN COLUMNAS DE PEQUEÑA ESCALA PARA LA REMOCIÓN DE Cr(VI) 


\section{ENSAYOS DE PEQUEÑA ESCALA PARA LA REMOCIÓN DE Cr(VI)}

Una vez verificada la eficiencia de la técnica de ZVI para la remoción de arsénico pentavalente en ensayos a diferentes escalas tanto en el laboratorio como en campo (capítulos 6 y 7), se estudió el empleo de esta técnica para la remoción de $\mathrm{Cr}(\mathrm{VI})$ en fase acuosa. Para la descripción de los resultados se tendrán en cuenta las conclusiones obtenidas a partir del estudio de los sistemas $Z \mathrm{VI} / \mathrm{O}_{2} / \mathrm{H}_{2} \mathrm{O}$ desarrollados en los capítulos 3 a 5 .

\subsection{ENSAYOS PRELIMINARES EN BATCH}

Para verificar experimentalmente la potencialidad de la técnica para la remoción de $\mathrm{Cr}(\mathrm{VI})$ y determinar el orden de tiempos de reacción necesarios para obtener tasas de reducción del $\mathrm{Cr}(\mathrm{VI})$ significativas se realizaron una serie de ensayos preliminares. Las investigaciones preliminares comprendieron ensayos de reducción tanto en presencia de $\mathrm{Fe}(\mathrm{II})$ como único reductor como en sistemas $\mathrm{Fe}(0) / \mathrm{H}_{2} \mathrm{O}$ en los que la coexistencia de ambos reductores es inevitable. Estos estudios permitieron estimar tiempos de residencia hidráulicos para la realización de ensayos en modo continuo.

\subsubsection{Reacción en fase homogénea}

En primer lugar se relizaron ensayos en fase homogenea preparando una serie de soluciones en matraces de $25 \mathrm{~mL}$ con una cantidad inicial de $\mathrm{Cr}(\mathrm{VI})$ de 0,019 $\mathrm{mM}$ ( 1 ppm) y cantidades variables de Fe(II) entre 0 y $0,103 \mathrm{mM}(0$ a $5,75 \mathrm{ppm})$. El pH inicial de todas las solucines se ajustó a un valor de 3,5 $\pm 0,05$. Para cada mezcla de reacción se tomaron muestras para la determinación de las concentraciones de $\mathrm{Cr}(\mathrm{VI})$ y de $\mathrm{Fe}(\mathrm{II})$ para tiempos de contacto de 28 y 120 minutos. En las Figuras 8.1 y 8.2 se muestran los resultados obtenidos.

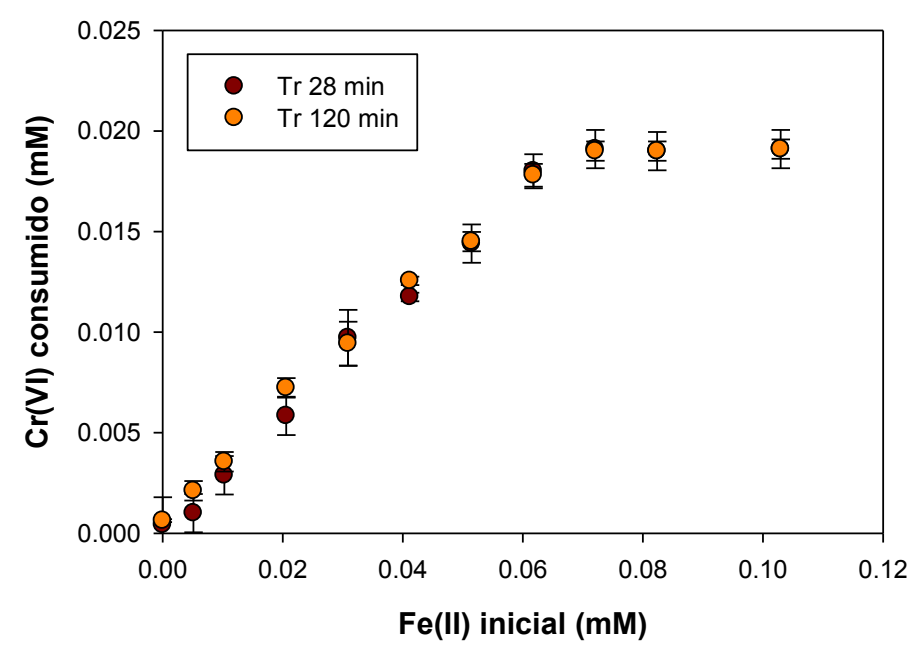

Figura 8.1. $\mathrm{Cr}(\mathrm{VI})$ consumido en función de la cantidad inicial de $\mathrm{Fe}(\mathrm{II})$ en solución $(\mathrm{Cr}(\mathrm{VI}) \mathrm{o}=0,019 \mathrm{mM})$. 
Como puede observarse en la Figura 8.1, las concentraciones obtenidas a los 28 minutos fueron practicamente iguales que las obtenidas a los 120 minutos por lo que se evaluó que media hora resulta sufciciente para alcanzar el equilibrio. Por otro lado, dada la relación estequiométrica (3 a 1) para la reducción del $\mathrm{Cr}(\mathrm{VI})$ por parte de $\mathrm{Fe}(\mathrm{II})$ (ec. 1.11), puede verificarse que la cantidad de $\mathrm{Cr}(\mathrm{VI})$ consumida corresponde a un consumo completo del $\mathrm{Fe}(\mathrm{II})$ colocado inicialmente ya que en todos los casos se obtuvieron rendimeintos superiores al $90 \%$. En principio, esto sugiere que para concentraciones iniciales por debajo de $0,06 \mathrm{mM}$ de $\mathrm{Fe}(\mathrm{II})$ se debería consumir la totalidad del agente reductor. Por otra parte, por encima de 0,06 $\mathrm{mM}$ de $\mathrm{Fe}(\mathrm{II})$, se esperaría un consumo total de $\mathrm{Cr}(\mathrm{VI})$ debido al exceso de agente reductor.Sin embargo, los resultados experimentales (Figura 8.2) muestran que el Fe(II) consumido es menor que el calculado según la cantidad de $\mathrm{Cr}(\mathrm{VI})$ reducido. En todos los casos el consumo es menor al $50 \%$ de lo esperado. Actualmente se están realizando ensayos complementarios para esclarecer las causas de este comportamiento.

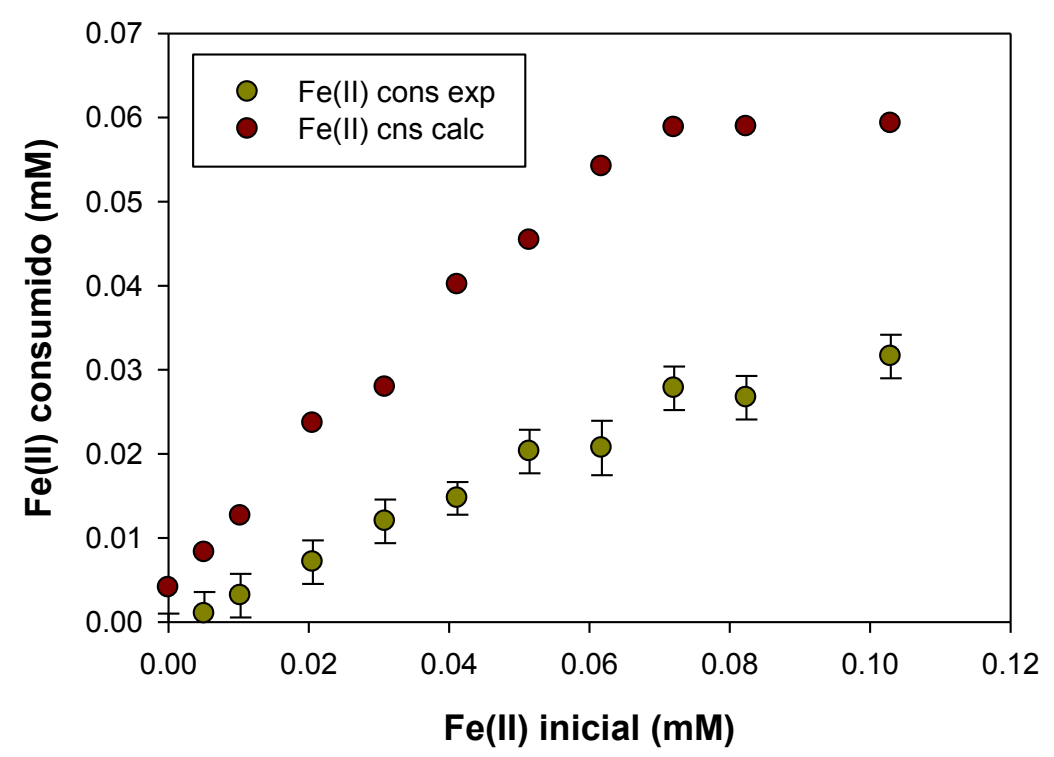

Figura 8.2. Fe(II) consumido en función de la cantidad inicial de Fe(II) en solución, valores determinados a partir de las medidas de $\mathrm{Fe}(\mathrm{II})$ realizadas (verde) y calculado en base al $\mathrm{Cr}(\mathrm{VI})$ consumido (marrón) ( $\mathrm{Cr}(\mathrm{VI}) \mathrm{o}=0,019 \mathrm{mM}, \mathrm{Tr}=120 \mathrm{~min})$.

\subsubsection{Reacción heterogénea}

Los ensayos en batch utilizando $\mathrm{ZVI}$ se realizaron en vasos de precipitados de $600 \mathrm{~mL}$ con una concentración inicial de $\mathrm{Cr}(\mathrm{VI})$ de 10 ppm y diferentes valores de $\mathrm{pH}$ inicial comprendidos entre 3 y 7 . En cada vaso se colocó un cilindro de lana de acero de $2 \mathrm{~g}$ con un diámetro similar al diámetro interno del vaso y se ubicó en el centro del vaso evitando el contacto con el aire. La solución se mantuvo en agitación durante 2 horas y se tomaron muestras de $5 \mathrm{~mL}$ cada 15 minutos para la determinación de $\mathrm{Cr}(\mathrm{VI})$. En las Figuras 8.3 y 8.4 se muestra la evolución de la concentración normalizada $\left(\mathrm{C} / \mathrm{C}_{0}\right)$ a lo largo del tiempo de reacción para los distintos $\mathrm{pHs}$ iniciales. Se puede observar claramente que la reducción de $\mathrm{Cr}(\mathrm{VI})$ fue muy rápida a $\mathrm{pH} 3$, donde se eliminó de la solución más del $95 \%$ del $\mathrm{Cr}(\mathrm{VI})$ en los primeros 15 minutos de 
reacción. Este proceso es significaticamente más lento a $\mathrm{pH} 7$ ya que son necesarias al menos 3 horas para una reducción completa. Para valores de $\mathrm{pH}$ inicial comprendidos entre 4 y 6 se observa un comportamiento intermedio pero dentro de este rango no se observan variaciones significativas.

En la Figura 8.4 se muestra de manera mas clara el efecto del $\mathrm{pH}$ sobre los porcentajes de reducción a diferentes tiempos de contacto. Para cada tiempo de reacción se observa que el contenido de $\mathrm{Cr}(\mathrm{VI})$ en solución disminuye a medida que el $\mathrm{pH}$ inicial disminuye. Este resultado se correlaciona en parte con la estequiometría de esta reacción (ec 1.8) ya que se requieren 7 moles de iones de hidrógeno para cada mol de $\mathrm{Cr}(\mathrm{VI})$. Asimismo, se ha reportado que la cinética es altamente dependiente de la concentración de $\mathrm{H}^{+}[33]$.

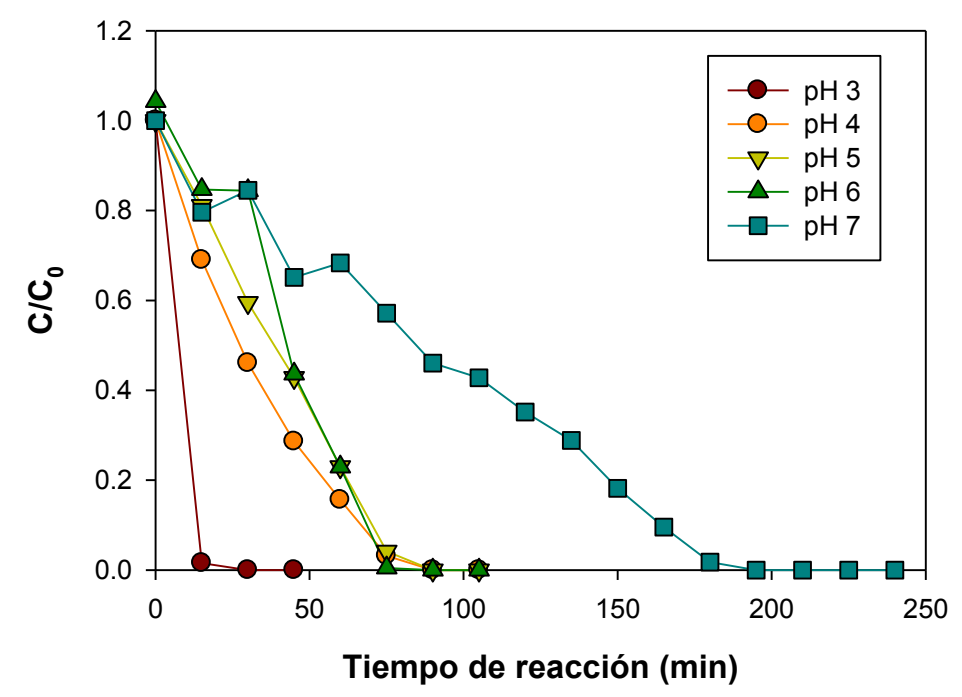

Figura 8.3. Evolución de la concentración de $\mathrm{Cr}(\mathrm{VI})$ normalizada para diferentes valores iniciales de $\mathrm{pH}$ de la solución $(\mathrm{Cr}(\mathrm{VI}) \mathrm{O}=10 \mathrm{ppm})$.

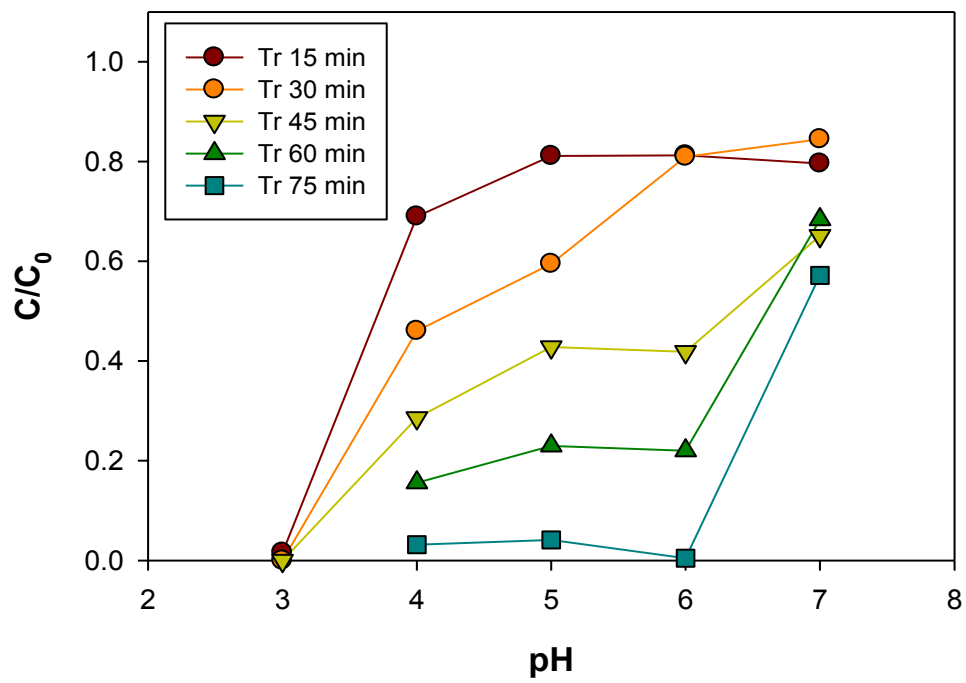

Figura 8.4. Efecto del pH sobre la concentración de $\mathrm{Cr}(\mathrm{VI})$ normalizada para diferentes tiempos de reacción $(\mathrm{Cr}(\mathrm{VI}) \mathrm{o}=10 \mathrm{ppm})$. 
Tabla 8.1. Concentraciones de Fe(II) y Fe(III) al finalizar la operación (Remoción 100\%).

\begin{tabular}{c|ccccc}
\hline & pH 3 & pH 4 & pH 5 & pH 6 & pH 7 \\
\hline Tiempo final (min) & 30 & 90 & 90 & 90 & 240 \\
\hline Fe(II) (ppm) & 65,0 & 7,44 & 6,13 & 7,67 & 0,04 \\
\hline Fe(III) (ppm) & 0,21 & 0,21 & 0,22 & 0,34 & 0,81 \\
\hline
\end{tabular}

En la Tabla 8.1 se muestra la concentración de $\mathrm{Fe}(\mathrm{II})$ y $\mathrm{Fe}(\mathrm{III})$ en solución al finalizar los ensayos. Al analizar las concentraciones de $\mathrm{Fe}$ (II) se observa una gran producción a $\mathrm{pH} 3$, una producción mucho menor en el rango de $\mathrm{pH}$ que va de 4 a 6 , y practicamente nada a $\mathrm{pH}$ 7. Esto se debe a que la oxidación de $\mathrm{Fe}(0)$ a $\mathrm{Fe}(\mathrm{II})$ mediada tanto por $\mathrm{Cr}(\mathrm{VI})$ como por $\mathrm{O}_{2}$ se ve favoreciada para bajos $\mathrm{pHs}$.

Teniendo en cuenta que la concentración inicial de $\mathrm{Cr}(\mathrm{VI})$ fue de 0,19 $\mathrm{mM}$ y que para todos los casos se alcanzó una remoción total del $\mathrm{Cr}(\mathrm{VI})$, puede observarse que la concentración de $\mathrm{Fe}$ generada para valores de $\mathrm{pH}$ entre 4 y 7 es sustancialmente menor que la esperada de 0,57 mM (31,9 ppm) si se considera que el único agente reductor del $\mathrm{Cr}(\mathrm{VI})$ es el $\mathrm{ZVI}$ de acuerdo con reacción (ec 1.10). Esto permite concluir que en el proceso de reducción en fase heterogenea intervienen como agentes reductores tanto el $\mathrm{Fe}(0)$ como el $\mathrm{Fe}(\mathrm{II})$ y que una fracción de los productos de corrosión gererados precipita sobre la superficie del ZVI formando así parte de la $\mathrm{CL}$. Esto se confirma si se observan las cantidades de $\mathrm{Fe}(\mathrm{II})$ y $\mathrm{Fe}(\mathrm{III})$ en solución a pH 7 , ya que aunque la cantidad de Fe en solución es practicamente nula se alcanza un remoción del $100 \%$ del $\mathrm{Cr}(\mathrm{VI})$.

\subsection{ENSAYOS RÁPIDOS EN COLUMNAS REACTIVAS DE PEQUEÑA ESCALA (RSSCT)}

Con el objetivo de estudiar el efecto de las variables operativas sobre la remoción de $\mathrm{Cr}(\mathrm{VI})$ en sistemas continuos usando $\mathrm{ZVI}$ se realizaron ensayos rápidos en columnas de pequeña escala (RSSCT). El orden de magnitud de los tiempos de residencia hidráulicos requeridos fue estimado a partir de los ensayos realizados en sistemas tipo batch utilizando lana de acero.

\subsubsection{Efecto del TRH y el pH}

La primera serie de ensayos fue realizada para evaluar el efecto del TRH y el $\mathrm{pH}$ sobre la remoción de $\mathrm{Cr}(\mathrm{VI})$. Dependiendo el $\mathrm{pH}$ de ingreso, que se varió en el rango de 3 a 5, las corridas fueron diseñadas con tiempos de residencia entre 0,25 y 16 minutos. Se utilizaron columnas rellenas con 5,33 g de virulana, densidad del lecho de $0,1 \mathrm{gr} / \mathrm{cm}^{3}$, diámetro de columna de $2,15 \mathrm{~cm}$ y largo de $14,68 \mathrm{~cm}$. Se trabajó con una concentración inicial de $\mathrm{Cr}$ de 10 ppm y el tiempo de residencia se modificó mediante la variación del caudal controlado mediante una bomba peristáltica. Las determinaciones fueron realizadas luego de la estabilización del sistema (7 volúmenes 
de poro). Para realizar las determinaciones se tomaron muestras por triplicado. La desviación estándar en las medidas menor a 0,10 ppm. En la Figura 8.5 se muestran los resultados obtenidos para la concentración normalizada de $\mathrm{Cr}(\mathrm{VI})$ a la salida de la columna.

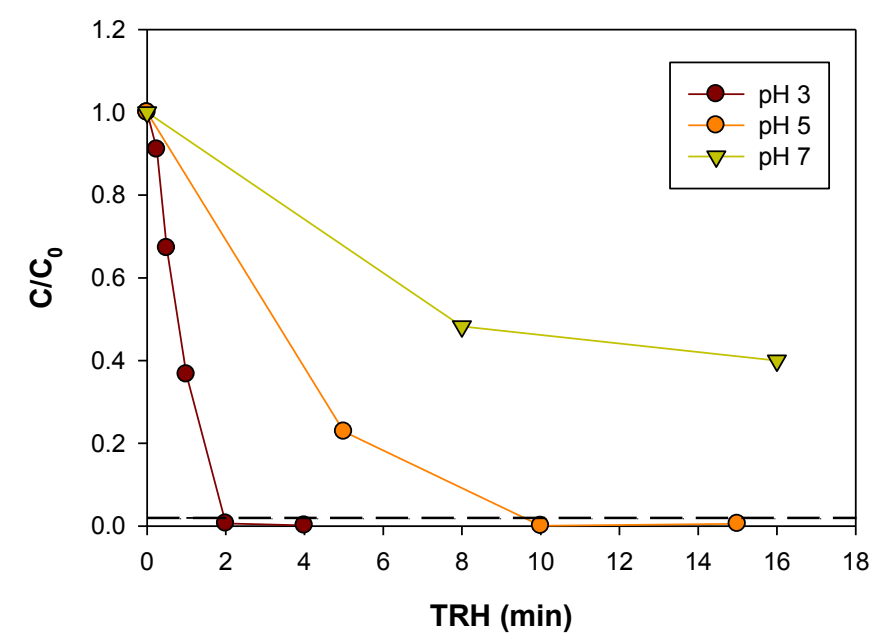

Figura 8.5. Efecto del TRH sobre la remoción de $\mathrm{Cr}(\mathrm{VI})$ para diferentes valores de $\mathrm{pH}$ de entrada $\left(C_{0}=10 \mathrm{ppm}, \mathrm{m}_{\mathrm{ZvI}}=2 \mathrm{gr}, \rho_{\mathrm{L}}=0,1 \mathrm{gr} / \mathrm{cm}^{3}\right)$.

Linea negra punteada: máxima concentración admisible para $\mathrm{Cr}(\mathrm{VI})$ para descarga de efluentes $(\mathrm{C} / \mathrm{Co}=0,02)$.

Como puede observarse, las tendencias son similares a las correspondientes a los sistemas tipo batch. Para una solución con pH 3 a la entrada de la columna, la reducción es muy rápida y se obtienen concentraciones de $\mathrm{Cr}(\mathrm{VI})$ por debajo del límite permisible para tiempos de residencia del orden de 2 minutos. En contraste, para afluentes con $\mathrm{pH} 7$ el proceso es muy lento y no se alcanza el valor límite dentro de la escala de TRHs analizados.

\subsubsection{Efecto de la densidad del relleno}

De manera similar al punto anterior se realizaron ensayos para estudiar el efecto de la densidad del relleno de lana de hierro sobre la reducción del $\mathrm{Cr}(\mathrm{VI})$. Las corridas fueron diseñadas con tiempos de residencia entre 2 y 16 minutos. Se trabajó con una concentración inicial de $\mathrm{Cr}(\mathrm{VI})$ igual a 10 ppm y pH 4 al ingreso. Se utilizaron columnas rellenas con $5,33 \mathrm{~g}$ de virulana y diámetro de columna de $2,15 \mathrm{~cm}$. Para variar la densidad se varió el largo del lecho relleno: $14,7 \mathrm{~cm}$ para la densidad de 0,1 $\mathrm{gr} / \mathrm{cm}^{3}$ y $5,51 \mathrm{~cm}$ para un densidad de $0,27 \mathrm{gr} / \mathrm{cm}^{3}$.

En la Figura 8.4 se muestra el efecto de la densidad del relleno sobre la remoción de $\mathrm{Cr}(\mathrm{VI})$. Para TRHs bajos, se observa una gran diferencia entre los resultados obtenidos para las dos densidades con un mayor grado de remoción para lechos más compactos. Estos resultados evidencian la naturaleza heterogénea del proceso ya que para bajos valores de TRH en principio se espera que la constante aparente de velocidad sea proporcional al área de ZVI expuesta y por lo tanto a mayor densidad de empaquetamiento mayor será la velocidad de remoción. 


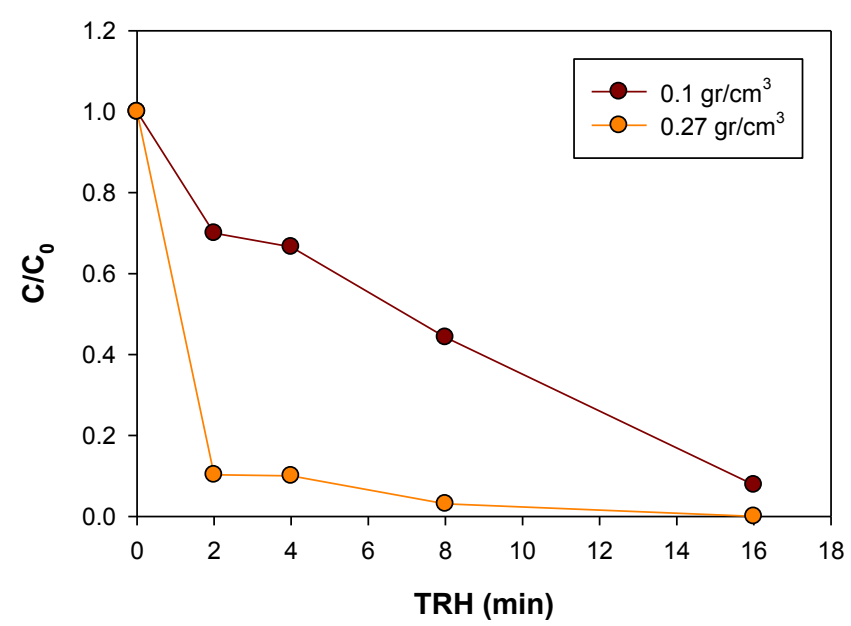

Figura 8.4. Efecto del TRH sobre la remoción de $\mathrm{Cr}(\mathrm{VI})$ para diferentes valores de denisdad del lecho ( $\mathrm{Co}=10 \mathrm{ppm}$, $\mathrm{pH}$ entrada=4).

\subsubsection{Especiación del Cromo eluido}

A fin de estudiar los mecanismos intervinientes en el proceso de remoción se realizaron ensayos con la metodología descripta en los puntos anteriores pero separando cada muestra obtenida para la determinación de cromo en 4 alicuotas. Dos de ellas fueron filtradas con filtro de nylon de 0,45 $\mu \mathrm{m}$ para determinar $\mathrm{Cr}$ total y $\mathrm{Cr}(\mathrm{VI})$ en solución ( $\mathrm{Cr}_{\text {TOт. }}$.aq y $\left.\mathrm{Cr}(\mathrm{VI}) \mathrm{aq}\right)$. Las dos restantes fueron utilizados para determinar $\mathrm{Cr}$ total y $\mathrm{Cr}(\mathrm{VI})$ total, tanto soluble como en suspensión $\left(\mathrm{Cr}_{\mathrm{TOT}}\right.$ y $\left.\mathrm{Cr}(\mathrm{VI})\right)$. En la Figura 8.5 se muestran los resultados obtenidos para una concentración de $10 \mathrm{ppm}$ y $\mathrm{pH} 4$ al ingreso y densidad de relleno del lecho de $0,27 \mathrm{gr} / \mathrm{cm}^{3}$.

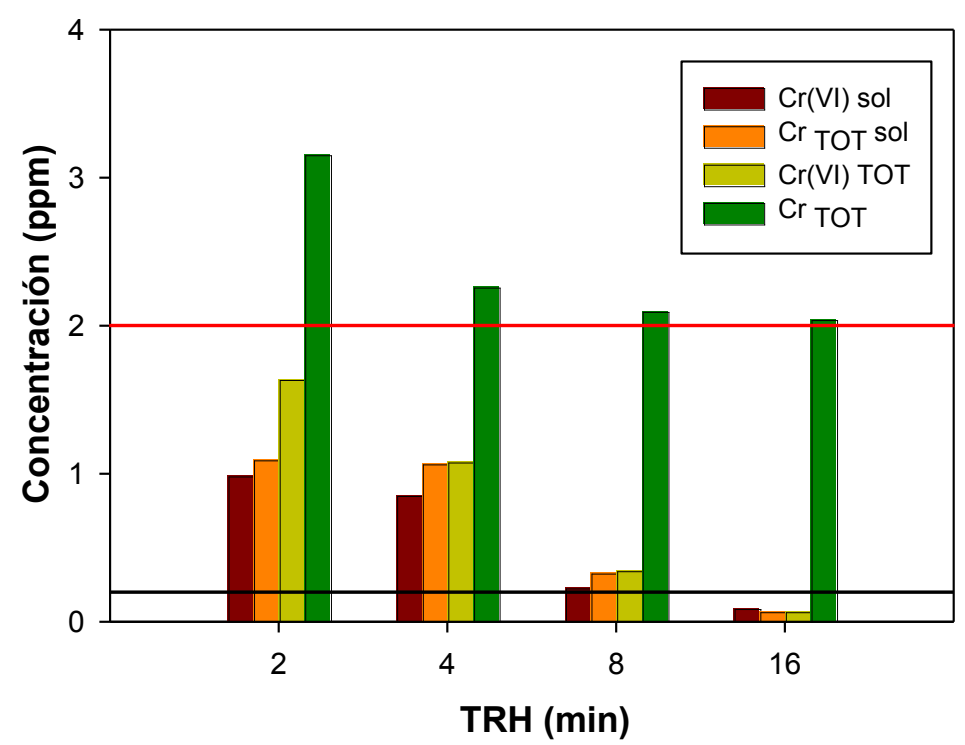

Figura 8.5. Especiación de $\mathrm{Cr}$ a la salida de la columna $\left(\mathrm{Co}=10 \mathrm{ppm}, \mathrm{pH}\right.$ entrada $\left.=4, \rho_{\mathrm{L}}=0,27 \mathrm{gr} / \mathrm{cm}^{3}\right)$.

Linea roja: máxima concentración admisible para $\mathrm{Cr}$ total para descarga de efluentes. Linea negra: máxima concentración admisible para $\mathrm{Cr}(\mathrm{VI})$ para descarga de efluentes. 
A partir del análisis de los resultados mostrados en la Figura 8.5 se pueden destacar varios puntos. En primer lugar se observa que para los 4 TRHs seleccionados más del $70 \%$ del Cr fue retenido en la columna, es decir, además de la reducción del $\mathrm{Cr}(\mathrm{VI})$ a $\mathrm{Cr}(\mathrm{III})$, la mayor parte de este contaminante queda adsorbido/co-precipitado en el interior de la columna, muy posiblemente atrapado en la CL. Sin embargo, teniendo en cuenta los valores límites, podemos observar que un proceso completo para la remoción de Cr debería contar con una columna con TRH superior a 16 min e incluir, luego del proceso reductivo con $\mathrm{ZVI}$, una etapa final de retención física para la remoción de partículas en suspensión dado que los valores de $\mathrm{Cr}_{\text {TOT }}$ superan levemente el valor máximo admisible.

Por otro lado para altas tasas de remoción y altos tiempos de residencia (TRHS 8 y 16) se observa que sólo una pequeña fracción del cromo logra atravesar la columna y la misma está compuesta principalmente por $\mathrm{Cr}(\mathrm{III})$ en suspensión. En contraste, para tiempos de residencia bajos, una proporción apreciable del contaminante atraviesa la columna y, además de $\operatorname{Cr}(\mathrm{III})$ en suspensión, se detecta también $\mathrm{Cr}(\mathrm{VI})$ en su forma soluble ya que las determinaciones de $\mathrm{Cr}(\mathrm{VI})_{\mathrm{aq}} \mathrm{y}$ de $\mathrm{Cr}_{\mathrm{TOT}}$ arrojan el mismo valor dentro del error experimental.

\subsection{Conclusiones}

Los resultados analizados en esta sección permiten corroborar la potencialidad de la técnica de ZVI para la remoción de $\mathrm{Cr}(\mathrm{VI})$. Los estudios preliminares tanto en batch como utilizando columnas rellenas indican una alta dependencia de la velocidad de reducción con el $\mathrm{pH}$, siendo esta favorable para bajos valores de $\mathrm{pH}$. Sin embargo, los resultados indican que un $\mathrm{pH}$ inicial de trabajo levemente ácido $(\mathrm{pH}$ 6) es suficiente para alcanzar tazas de reducción significativas para tiempos de reacción del orden de 90 minutos. Este resultado es relevante desde un punto de vista tecnológico porque permite la comparación de la eficacia de esta metodología con otras tecnologías de remoción de $\mathrm{Cr}(\mathrm{VI})$.

Con respecto a los mecanismos de remoción intervinientes, en los sistemas continuos podemos concluir que la reducción de $\mathrm{Cr}(\mathrm{VI})$ a $\mathrm{Cr}(\mathrm{III})$ se encuentra acoplada a procesos de co-precipitación/adsorción de especies de $\mathrm{Cr}$ (III) en el interior de la columna ya que la fracción de $\mathrm{Cr}$ que logra atravesar el lecho es muy baja.

Cabe destacar que los estudios realizados en los sistemas $\mathrm{ZVI} / \mathrm{Cr}(\mathrm{VI})$ muestran que muchos de los aspectos básicos que fueron comprendidos en los sistemas ZVI/As para columnas en modo de operación continuo son aplicables al desarrollo de tecnologías para la remoción de $\mathrm{Cr}(\mathrm{VI})$. 


\section{CONCLUSIONES GENERALES}

A lo largo del presente trabajo de tesis se describieron los resultados obtenidos a partir del estudio de una metodología basada en el empleo de hierro cero Valente (ZVI) para la remoción de contaminantes en agua en sistemas continuos. Dependiendo del contaminante y de las condiciones operativas, los mecanismos de remoción pueden diferir, sin embargo en todos los casos el proceso global consta de una serie de etapas en común. El sistema básico involucra tres etapas: en primer lugar el agua atraviesa un reactor tubular relleno de $\mathrm{Fe}(0)$ donde esta especie se oxida a $\mathrm{Fe}(\mathrm{II})$. En simultáneo, parte del Fe(II) formado es oxidado a Fe(III). Posteriormente, el $\mathrm{Fe}(\mathrm{II})$ soluble que eluye de la columna es oxidado en un segundo módulo mediante un sistema de aireación. Las especies generadas forman óxidos mixtos que, a valores de $\mathrm{pH}$ cercanos a la neutralidad, son insolubles por lo que se utiliza una última etapa de separación física para obtener finalmente agua clarificada.

Los estudios presentados en el capítulo 3 se enfocan principalmente en las primeras dos etapas. Los ensayos tipo batch, realizados en solución homogénea para evaluar la eficiencia del proceso de coprecipitación, indican que es necesaria una concentración de al menos 4 ppm de Fe(II) para remover el As(V). La comparación de este resultado con los valores obtenidos a la salida de las columnas, que muestran buenas eficiencias de remoción con solo $0,5 \mathrm{ppm}$ de $\mathrm{Fe}(\mathrm{II})$ soluble, sugiere que la presencia de puntos de nucleación y crecimiento en el interior de la columna favorece el proceso de coprecipitación incluso para concentraciones de sobresaturación menores a las testeadas en los sistemas batch. Por otra parte, el análisis de las cinéticas de oxidación de Fe(II) muestra que para lograr una oxidación completa de $\mathrm{Fe}(\mathrm{II})$ a $\mathrm{Fe}(\mathrm{III})$ y optimizar la segunda etapa del tratamiento resulta necesario un tiempo de residencia de al menos 30 minutos.

Para el análisis del efecto de las variables operativas sobre el desempeño de los lechos reactivos (primera etapa) se trabajó mediante la metodología de RSSCT utilizando lana de acero como material reactivo. Se estudió el efecto de los factores: $\mathrm{pH}$ de entrada, tiempo de residencia hidráulico (TRH), masa de ZVI y densidad del lecho. Como variables respuesta, que caracterizan el desempeño de las columnas, se utilizaron: el consumo de oxígeno, el pH de salida (o alternativamente la variación del $\mathrm{pH}$ ) y las concentraciones de $\mathrm{Fe}(\mathrm{II})$ y $\mathrm{Fe}(\mathrm{III})$ en el efluente de las columnas. Los resultados fueron interpretados con la ayuda tanto del análisis de conglomerados como del análisis de componentes principales. Asimismo, se emplearon redes neuronales artificiales para el desarrollo de modelos con la capacidad predictiva.

Las técnicas de modelo "blando" permitieron analizar con menor incertidumbre las tendencias generales y así identificar tanto las variables respuesta como los factores relevantes a la hora de analizar el desempeño del sistema. En particular, considerando los resultados obtenidos mediante el análisis de sensibilidad, aplicado a las RNA, se puede afirmar que el TRH presenta la mayor influencia sobre todas las variables respuesta. El $\mathrm{pH}$ de entrada se presenta como la segunda variable en importancia relativa, mientras que para el dominio experimental estudiado tanto la carga de ZVI como la densidad del lecho tienen un impacto muy poco significativo 
sobre el desempeño de las columnas. Cabe destacar que la concentración de $\mathrm{Fe}$ (III) fue descartada como variable respuesta del sistema ya que las variaciones observadas no resultaron significativas y no pueden atribuirse de manera directa a cambios en los factores.

Teniendo en cuenta estos resultados se pudo postular un modelo fisicoquímico simplificado de tres reacciones cuyas velocidades son $\mathrm{pH}$ dependientes que engloba los fenómenos más relevantes que gobiernan el comportamiento del sistema. El modelo planteado contempla, en primer lugar, dos vías alternativas para el consumo de $\mathrm{ZVI}$, dependiendo del estado de oxidación final alcanzado por el hierro $\left(\mathrm{Fe}^{2+} \mathrm{y}\right.$ $\left.\mathrm{Fe}^{3+}\right)$. El mecanismo propuesto además considera un tercer proceso en el cual el $\mathrm{Fe}^{2+}$ generado dentro de la CL posteriormente es liberado al seno de la solución. Sobre la base de estos tres procesos se propuso un modelo matemático muy simple que permite predecir las tendencias generales observadas para los perfiles de $\mathrm{Fe}(\mathrm{II}), \mathrm{pH}$ y oxígeno a la salida de las columnas sobre una base racional.

Con respecto al uso de fuentes de ZVI alternativas a la lana de acero, los ensayos realizados utilizando ZVI en forma de polvo muestran valores de $\mathrm{Fe}(\mathrm{II})$ a la salida de las columnas significativamente menor que los observados para condiciones experimentales similares para lechos con lana de acero. Los resultados obtenidos utilizando granallas de acero muestran cantidades iniciales de $\mathrm{Fe}(\mathrm{II})$ a $\mathrm{pH} 7$ suficientes para la remoción de As, sin embargo en estos sistemas se registró una rápida disminución de esta concentración. La conductividad hidráulica de lechos construidos con ZVI tanto en forma de polvo como de granallas resulta mucho más baja que para la lana de acero lo que condiciona severamente la aplicación de estos materiales a escalas mayores a la de laboratorio. Cabe señalar, que muchos autores proponen mezclar los materiales de ZVI con arena, utilizado como material inerte, para evitar el contacto entre partículas de ZVI y solucionar este problema. Sin embargo, para que esto resulte efectivo las partículas del material reactivo y del material inerte deben tener tamaños y formas similares. Esto resulta difícil para el ZVI en polvo por su bajo diámetro efectivo y también para las granallas de ZVI por su gran tamaño.

Las plantas de tratamiento continuo diseñadas, basadas en las tres etapas previamente mencionadas, resultaron eficientes para las diferentes escalas ensayadas en instalaciones de la Facultad. Los principales mecanismos de remoción se encuentran asociados a la co-precipitación de As dentro de la columna rellena con ZVI. El lecho se agota cuando la superficie de ZVI disponible se encuentra completamente saturada de productos de corrosión. A partir de este momento la velocidad de corrosión disminuye sustancialmente y con esto tanto el contenido de $\mathrm{Fe}$ (II) eluido como la cantidad de oxígeno consumida por la columna reactiva. Estos hechos se ven reflejados en el aumento del potencial de reducción a la salida del reactor y por este motivo la medida de ORP resulta de gran interés a la hora de diseñar sistemas de monitoreo on-line de la eficiencia de los lechos. Por otro lado, para el dominio experimental analizado, el rendimiento resultó ser prácticamente independiente de las condiciones operativas y se mantuvo en el orden de los 35 litros de agua tratada por cada gramo de ZVI utilizado.

La acumulación de productos de corrosión en la columna reactiva produce una rápida caída de la conductividad hidráulica del lecho. Sin embargo, este parámetro se mantiene relativamente estable durante aproximadamente 20 días y de un orden 
suficiente como para permitir la circulación de agua por gravedad. Las determinaciones de la distribución de tiempos de residencia indicaron que una de las características más importantes a la hora de montar el reactor es la homogeneidad y adecuado empaquetamiento del relleno con el objeto de evitar la formación de canales preferenciales para el paso del fluido.

Las pruebas de campo realizadas evidenciaron la necesidad de realizar ensayos preliminares para poder adaptar el diseño a las características particulares de cada matriz acuosa a tratar. También hay que destacar que la interacción y la participación activa de diferentes operadores, y posibles destinatarios de esta tecnología, ha permitido consolidar el diseño y mejorarlo para facilitar las tareas de operación y mantenimiento. Por último es importante mencionar que, según los estudios preliminares realizados hasta el momento, los residuos obtenidos del proceso pueden ser dispuestos como no peligrosos.

Los conocimientos adquiridos en los sistemas $\mathrm{ZVI} / \mathrm{H}_{2} \mathrm{O}$ y $\mathrm{ZVI} / \mathrm{As}$ permitieron analizar desde una perspectiva innovadora la eficiencia de la técnica ZVI para la remoción de $\mathrm{Cr}(\mathrm{VI})$. En el caso de este contaminante, los mecanismos de remoción se encuentran vinculados a la reducción a $\mathrm{Cr}$ (III) y posterior co-precipitación en el interior de la columna. Los resultados muestran que la eficiencia de este proceso se encuentra altamente influenciada por el $\mathrm{pH}$ de la solución a tratar. Sin embargo, desde el punto de vista tecnológico valores de $\mathrm{pH}$ levemente ácidos $(\mathrm{pH} \sim 6)$ requieren tiempos de reacción moderados que facilitan la aplicación de esta técnica en sistemas continuos.

En el marco de este trabajo de tesis se ha alcanzado un alto nivel de comprensión del funcionamiento de los lechos rellenos con ZVI que ha permitido estimar el comportamiento de columnas reactivas de diferente envergadura y bajo distintas condiciones operativas. En este contexto, se han ensayado diferentes prototipos completos con el fin de alcanzar caudales del orden de los $4 \mathrm{~m}^{3} / \mathrm{dí}$. Si bien los resultados obtenidos para estas escalas de tratamiento han sido alentadores, se ha observado que la principal limitación para la inmediata implementación de estas plantas se encuentra en la rápida saturación de las etapas finales de filtrado. Por este motivo, actualmente se está trabajando en el escalado y la optimización de las etapas de oxidación, contacto y filtrado, para garantizar su óptimo funcionamiento para escalas del orden de 1 a $2 \mathrm{~m}^{3} / \mathrm{h}$. 


\section{BIBLIOGRAFIA}

[1] A. B. Cundy, L. Hopkinson, and R. L. D. Whitby, "Use of iron-based technologies in contaminated land and groundwater remediation: A review," Sci. Total Environ., vol. 400, no. 1-3, pp. 42-51, 2008.

[2] L. B. Young and H. H. Harvey, "The Relative Importance of Manganese and Iron-Oxides and Organic-Matter in the Sorption of Trace-Metals By Surficial Lake-Sediments," Geochim. Cosmochim. Acta, vol. 56, pp. 1175-1186, 1992.

[3] L. C. Roberts, S. J. Hug, T. Ruettimann, M. Billah, A. W. Khan, and M. T. Rahman, "Arsenic Removal with Iron(II) and Iron(III) in Waters with High Silicate and Phosphate Concentrations," Environ. Sci. Technol., vol. 38, no. 1, pp. 307-315, 2004.

[4] X. Han, J. Song, Y. Li, S. Jia, W. Wang, and F. Huang, "As(III) removal and speciation of $\mathrm{Fe}$ (Oxyhydr)oxides during simultaneous oxidation of As(III) and Fe(II)," Chemosphere, vol. 147, pp. 337-344, 2016.

[5] C. Noubactep, "Processes of contaminant removal in ' $\mathrm{Fe} 0-\mathrm{H} 2 \mathrm{O}$ ' systems revisited: the Importance of co-precipitation," Environ. Sci., pp. 9-13, 2007.

[6] L. Gui, Y. Q. Yang, S. Jeen, R. W. Gillham, D. W. Blowes, and C. Noubactep, "Comment on "Reduction of chromate by granular iron in the presence," Appl. Geochemistry, vol. 24, no. 11, pp. 2206-2207, 2009.

[7] C. Noubactep, "A critical review on the process of contaminant removal in $\mathrm{Fe} 0-\mathrm{H} 2 \mathrm{O}$ systems," Environ. Technol., no. June 2014, pp. 909-920, 2008.

[8] S. F. O'Hannesin and R. W. Gillham, "Long-Term Performance of an in situ 'Iron Wall' for Remediation of VOCs," Ground Water, vol. 36, pp. 164-170, 1998.

[9] D. H. Phillips, T. Van Nooten, L. Bastiaens, M. I. Russell, K. Dickson, S. Plant, and R. M. Kalin, "Ten Year Performance Evaluation of a Field-Scale Fe0 Permeable Reactive Barrier Installed to Remediate TCE-Contaminated Groundwater," Environ. Sci. Technol., vol. 44, pp. 3861-3869, 2010.

[10] R. T. Wilkin, S. D. Acree, R. R. Ross, R. W. Puls, T. R. Lee, and L. L. Woods, "Fifteenyear assessment of a permeable reactive barrier for treatment of chromate and trichloroethylene in groundwater," Sci. Total Environ., vol. 468-469, pp. 186-194, 2014.

[11] N. Melitas, J.P. Wang, M. Conklin, P. O'Day, J. Farrell, “Understanding soluble arsenate removal kinetics by zerovalent iron”, Environ. Sci. Technol., vol. 36, pp. 2074-2081, 2002 (y referencias allí citadas).

[12] L. J. Matheson, P.G. Tratnyek, "Reductive dehalogenation of chlorinated methanes by iron metal”, Environ. Sci. Technol., vol. 28, pp. 2045-2053, 1994.

[13] S. J. Hug, O. Leupin, "Iron catalyzed oxidation of As(III) by oxygen and by hydrogen peroxide: $\mathrm{pH}$-dependent formation of oxidants in the Fenton reaction". Environ. Sci. Technol., vol. 37, pp. 2734-2742, 2003.

[14] J. M. Triszcz, A. Porta, and F. S. García, "Effect of operating conditions on iron corrosion rates in zero-valent iron systems for arsenic removal," Chem. Eng. J., vol. 150, pp. 431439, 2009.

[15] Yi-Ming Chen, Chi-Wang Li*, Shiao-Shing Chen, "Fluidized zero valent iron bed reactor for nitrate renoval", Chemosphere, vol. 59, pp. 753-759, 2005. 
[16] P. Mitra, D. Sarkar, S. Chakrabarti, B. K. Dutta, " Reduction of hexa-valent chromium with zero-valent iron: Batch kinetic studies and rate model", Chemical Engineering Journal, vol. 171, pp. 54-60, 2011.

[17] K. Komnitsas*, G. Bartzas, K. Fytas, I. Paspaliaris, "Long-term efficiency and kinetic evaluation of $\mathrm{ZVI}$ barriers during clean-up of copper containing solutions", Minerals Engineering, vol. 20, pp. 1200-1209, 2007.

[18] Y.H. Huang, T.C. Zhang, "Effects of dissolved oxygen on formation of corrosion products and concomitant oxygen and nitrate reduction in zero-valent iron systems with or without aqueous Fe ${ }^{2+”}$, Water Res., vol. 39, pp. 1751-1760, 2005.

[19] I.A. Katsoyiannis, T. Ruettimann, S.J. Hug, "pH dependence of fenton reagent generation and $\mathrm{As}$ (III) oxidation and removal by corrosion of zero valent iron in aerated water", Environ. Sci. Technol., vol. 42, pp. 7424-7430, 2008. doi:10.1021/es800649p.

[20] C.R. Keenan, D.L. Sedlak, "Factors Affecting the Yield of Oxidants from the Reaction of Nanoparticulate Zero-Valent Iron and Oxygen", Environ. Sci. Technol., vol. 42, pp. 12621267, 2008. doi: 10.1021/es7025664.

[21] C.R. Keenan, D.L. Sedlak, "Ligand-enhanced reactive oxidantgeneration by nanoparticulate zero-valent iron and oxygen", Environ. Sci. Technol., vol. 42, pp. 69366941, 2008. doi: 10.1021/es801438f\%0A.

[22] J. A. Donadelli, L. Carlos, A. Arques, and F. S. García Einschlag, "Kinetic and mechanistic analysis of azo dyes decolorization by ZVI-assisted Fenton systems: pHdependent shift in the contributions of reductive and oxidative transformation pathways," Appl. Catal. B Environ., vol. 231, no. December 2017, pp. 51-61, 2018.

[23] C. Noubactep, "Investigating the processes of contaminant removal in $\mathrm{Fe} / \mathrm{H} 2 \mathrm{O}$ systems", Korean J. Chem. Eng., vol. 29, pp. 1050-1056, 2012. doi:10.1007/s11814-0110298-8.

[24] J. Wang, J. Farrell, "Investigating the role of atomic hydrogen on chloroethene reactions with iron using Tafel analysis and electrochemical impedance spectroscopy", Environ. Sci. Technol., vol. 37, pp. 3891-3896, 2003. doi:10.1021/es0264605.

[25] V. Jovancicevic, J.O.M. Bockris, "The Mechanism of Oxygen Reduction on Iron in Neutral Solutions”, J. Electrochem. Soc., vol. 133, pp. 1797-1807, 1987. doi: 10.1149/1.2109021.

[26] C. Noubactep, "Characterizing the reactivity of metallic iron in $\mathrm{Fe} 0 / \mathrm{UVI} / \mathrm{H} 2 \mathrm{O}$ systems by long-term column experiments," Chem. Eng. J., vol. 171, no. 2, pp. 393-399, 2011.

[27] Benjamin Hildebrant, "Characterizing the Reactivity of Commercial Steel Wool for Water Treatment," 2018.

[28] X. Guo, Z. Yang, H. Liu, X. Lv, Q. Tu, Q. Ren, X. Xia, C. Jing, "Common oxidants activate the reactivity of zero-valent iron $(\mathrm{ZVI})$ and hence remarkably enhance nitrate reduction from water", Sep. Purif. Technol., vol. 146, pp. 227-234, 2015. doi:10.1016/j.seppur.2015.03.059.

[29] K.V.K. Ansaf, S. Ambika, I.M. Nambi, "Performance enhancement of zero valent iron based systems using depassivators: Optimization and kinetic mechanisms", Water Res., vol. 102, pp. 436-444, 2016.

[30] M. J. López-Muñoz, A. Arencibia, Y. Segura, and J. M. Raez, "Removal of As(III) from aqueous solutions through simultaneous photocatalytic oxidation and adsorption by $\mathrm{TiO} 2$ and zero-valent iron," Catal. Today, vol. 280, pp. 149-154, 2017.

[31] O. X. Leupin and S. J. Hug, "Oxidation and removal of arsenic (III) from aerated groundwater by filtration through sand and zero-valent iron," Water Res., vol. 39, pp. 1729-1740, 2005.

[32] K. Banerjee, R. P. Helwick, and S. Gupta, "A treatment process for removal of mixed inorganic and organic arsenic species from groundwater," Environ. Prog., vol. 18, no. 4, pp. $280-284,1999$. 
[33] M. Gheju and A. lovi, "Kinetics of hexavalent chromium reduction by scrap iron", vol. 135, no. 6 , pp. 66-73, 2006.

[34] M. Gheju, A. lovi, and I. Balcu, "Hexavalent chromium reduction with scrap iron in continuous-flow system Part 1: Effect of feed solution pH," vol. 153, pp. 655-662, 2008.

[35] M. Szabó, J. Kalmár, T. Ditrói, G. Bellér, G. Lente, N. Simic, and I. Fábián, "Equilibria and kinetics of chromium( $\mathrm{VI})$ speciation in aqueous solution - A comprehensive study from pH 2 to 11". Inorganica Chimica Acta, vol. 472, pp. 295-301, 2018. https://doi.org/10.1016/j.ica.2017.05.038

[36] S. Jeen, D. W. Blowes, and R. W. Gillham, "Performance evaluation of granular iron for removing hexavalent chromium under different geochemical conditions," Contam. Hydrol., vol. 95, pp. 76-91, 2008.

[37] H. Cao, X. Xie, Y. Wang, K. Pi, J. Li, and H. Zhan, "Predicting the risk of groundwater arsenic contamination in drinking water wells", 2018.

[38] J. Bundschuh, A. Pérez Carrera, and M. Litter. "Distribución del arsénico en las regiones ibérica e iberoamericana", CYTED, Argentina, 2008.

[39] H. B. Nicolli, J. M. Suriano, M. A. G. Peral, L. H. Ferpozzi, and O. A. Baleani, "Groundwater Contamination with Arsenic and Other Trace Elements in an Area of the Pampa , Province of Cordoba , Argentina," vol. 14, no. 1, pp. 3-16, 1989.

[40] P. L. Smedley, H. B. Nicolli, D. M. J. Macdonald, A. J. Barros, and J. O. Tullio, "Hydrogeochemistry of arsenic and other inorganic constituents in groundwaters from La Pampa, Argentina," Appl. Geochemistry, vol. 17, no. 3, pp. 259-284, 2002.

[41] J. Bundschuh, M. I. Litter, F. Parvez, G. Román-ross, H. B. Nicolli, J. Jean, C. Liu, D. López, M. A. Armienta, L. R. G. Guilherme, A. Gomez, L. Cornejo, L. Cumbal, R. Toujaguez, and C. Rica, "One century of arsenic exposure in Latin America: A review of history and occurrence from 14 countries," Sci. Total Environ., vol. 429, pp. 2-35, 2012.

[42] M. Auge, G. Espinosa, and L. Sierra, "Arsénico en el agua subterránea de la Provincia de Buenos Aires", 2013. https://doi.org/10.13140/RG.2.1.3333.4245.

[43] D. Mohan and C. U. Pittman, "Arsenic removal from water/wastewater using adsorbentsA critical review," J. Hazard. Mater., vol. 142, no. 1-2, pp. 1-53, 2007.

[44] S. S. Farías, V. A. Casa, C. Vázquez, L. Ferpozzi, G.N. Pucci and I. M. Cohen, "Natural contamination with arsenic and other trace elements in ground waters of Argentine Pampean Plain", Science of the Total Environment, vol. 309, no.1-3, pp. 187-199, 2003. https://doi.org/10.1016/S0048-9697(03)00056-1

[45] World Health Organization, "Guide lines for drinking-water qualitity recomendations, Second", Geneva, 1993.

[46] B. Kumar Mandal and K. T. Suzuki, "Arsenic round the world: a review," Talanta, vol. 58, pp. 201-235, 2002.

[47] D. G. Mazumder, "Chronic arsenic toxicity \& human health", Indian J. Med. Res., vol. 128, no. 4, pp. 436-447, 2008.

[48] O. F. Brouwer, W. Onkenhout, P.M. Edelbroek, J.F de Kom, F.A de Wolff and A.C. Peters, "Increased neurotoxicity of arsenic in methylenetetrahydrofolate reductase deficiency", Clin Neurol Neurosurg, vol. 94, no. 4, pp. 307-310, 1992.

[49] C.J Chen, C.W. Chen, M.M. Wu and T.L. Kuo, "Cancer potential in liver, lung, bladder and kidney due to ingested inorganic arsenic in drinking water", $\mathrm{Br} \mathrm{J}$ Cancer, vol. 66, no. 5, pp. 888-892. 1992. 
[50] C. Hopenhayn-Rich, M.L Biggs, A. Fuchs, R. Bergoglio, E.E. Tello, H. Nicolli and A.H. Smith, "Bladder cancer mortality associated with arsenic in drinking water in Argentina". Epidemiology, vol. 7, no. 2, pp. 117-124, 1996.

[51] M. Rahman, M. Tondel, S.A. Ahmad, I.A. Chowdhury, M. H. Faruquee and O. Axelson, "Hypertension and arsenic exposure in Bangladesh", Hypertension, vol. 33, no. 1, pp. 7478, 1999.

[52] M. Gheju, "Hexavalent chromium reduction with zero-valent iron (ZVI) in aquatic systems", vol. 222, no. 1-4, 2011.

[53] R. J. Irwin et al., "Environmental Contaminants Encyclopedia Chromium (VI) (Hexavalent Chromium) Entry", National Park Service Water, 1997.

[54] Agency for Toxic Substances and Disease Registry (ATSDR), "Toxicological Profile for Chromium", TP-7 US Department of Health and Human Services, Atlanta, GA, 2000.

[55] INA, "Evaluación de la calidad del agua en la Franja Costera Sur del Río de la Plata mediante modelación numérica". Instituto Nacional del Agua - Subsecretaría de Recursos Hídricos - Secretaría de Obras Públicas - República Argentina. Proyecto INA 1.207. Informe LHA 02-1, pp. 207-211, 2011.

[56] M. Licursi and N. Gómez, "Short-term toxicity of hexavalent-chromium to epipsammic diatoms of a microtidal estuary (Río de la Plata): Responses from the individual cell to the community structure," Aquat. Toxicol., vol. 134-135, pp. 82-91, 2013, y referencias allí citadas.

[57] Grupo AD-HOC Arsénico en agua, Red de Seguridad Alimentaria (RSA-CONICET). "Informe final", Argentina, 2018 y referencias allí citadas.

[58] M. I. Litter, M.E. Morgada and J. Bundschuh, "Possible treatments for arsenic removal in Latin American waters for human consumption", Environ Pollut, vol. 158, pp. 1105-1118, 2010.

[59] Proyecto S10068 y S10064 SECRETARIA DE OBRAS PUBLICAS; MINISTERIO DE PLANIFICACIÓN FEDERAL, INVERSIÓN PÚBLICA Y SERVICIOS.

[60] US EPA," Technologies and Costs for Removal of Arsenic from Drinking Water", 2000.

[61] B. Thomson, T. J. Cotter, and J. Chwirka, "Design and Operation of Point-of-Use Treatment System for Arsenic Removal," J. Environ. Eng., vol. 129, no. June, pp. 561564, 2003.

[62] T. S. Singh and K. K. Pant, "Equilibrium, kinetics and thermodynamic studies for adsorption of As(III) on activated alumina," Sep. Purif. Technol., vol. 36, no. 2, pp. 139147, 2004.

[63] M. Badruzzaman, P. Westerhoff, and D. R. U. Knappe, "Intraparticle diffusion and adsorption of arsenate onto granular ferric hydroxide (GFH)," Water Res., vol. 38, no. 18, pp. 4002-4012, 2004.

[64] A. Maiti, S. DasGupta, J. K. Basu, and S. De, "Batch and column study: Adsorption of arsenate using untreated laterite as adsorbent," Ind. Eng. Chem. Res., vol. 47, no. 5, pp. 1620-1629, 2008.

[65] N. P. Nikolaidis, G. M. Dobbs, and J. Lackovic, "Arsenic removal by zero-valent iron: field, laboratory and modeling studies," Water Res., vol. 37, no. 6, pp. 1417-1425, 2003.

[66] L. Doherty and E. Observatory, " Removal of Methylated Arsenic in Groundwater with Iron Filings”, vol. 39, no. 19, pp. 7662-7666, 2005. 
[67] S. Bang, G. P. Korfiatis, and X. Meng, "Removal of arsenic from water by zero-valent iron", Journal of Hazardous Materials, vol. 121, no. 1-3, pp. 61-67, 2005. https://doi.org/10.1016/j.jhazmat.2005.01.030

[68] Severn Trent Service, http://severntrentservices.com/

[69] S. Arpan and P. Biswajit, "The global menace of arsenic and its conventional remediation - A critical review," Chemosphere, vol. 158, pp. 37-49, 2016 y referencias allí citadas.

[70] G. Chaudhury, P. Chattopadhyay, R. Das, D. Muir, and P. "Singh, Sorption of Arsenate from Aqueous Solution with Manganic Ferric Oxyhydroxide". TMS, Warrendale, PA, USA, 2003.

[71] A.H Malik et al., "Perspectives of low cost arsenic remediation of drinking water in Pakistan and other countries", J. Hazard. Mater, vol. 168, no. 1, pp. 1-12, 2009.

[72] F. Fu, Q. Wang, "Removal of heavy metal ions from wastewaters: a review". J. Environ. Manag, vol. 92, no. 3, pp. 407-418, 2011.

[73] A. Ahmad et al., "Advanced Oxidation-Coagulation-Filtration (AOCF) - An innovative treatment technology for targeting drinking water with $<1 \mathrm{ug} / \mathrm{L}$ of arsenic", Buenos Aires, Argentina, 2014

[74] M. Hossain et al., "Sustainability of arsenic mitigation interventions - an evaluation of different alternative safe drinking water options provided in Matlab, an arsenic hot spot in Bangladesh", Frontiers in Environmental Science, pp. 3-30, 2015.

[75] P. Bhattacharya et al.,"Targeting arsenic-safe aquifers in regions with high arsenic groundwater and its worldwide implications (TASA)", Project Report, MISTRA. TRITA LWR Report 2015:01.

[76] P. Lu and C. Zhu, "Arsenic Eh-pH diagrams at $25^{\circ} \mathrm{C}$ and 1 bar," Environ. Earth Sci., vol. 62, no. 8, pp. 1673-1683, 2011.

[77] B. Beverskog, "Revised Diagrams for Iron At 25-300 ${ }^{\circ}$ C," Science, vol. 38, no. 12, pp. 2121-2135, 1996.

[78] American Public Health Association, "Standar Methods for examination of water and wastewater", 20 th edition, 1999.

[79] B. Serpaud and J. Bollinger, "Arsenite oxidation and arsenate determination by the molybdene blue method," vol. 61, pp. 267-276, 2003.

[80] R. K. Dhar, Y. Zheng, J. Rubenstone, and A. Van Geen, "A rapid colorimetric method for measuring arsenic concentrations in groundwater," vol. 526, pp. 203-209, 2004.

[81] M. Pilson, "Optimal acid concentration for arsenite oxidation," vol. 58, pp. 289-299, 1972.

[82] S. A. Lewin and R. S. Wagner, "The nature of iron(III) thiocyanate in solution," J. Chem. Educ., vol. 30, no. 9, p. 445, 1953, y referencias allí citadas.

[83] K. de Berg, M. Maeder, and S. Clifford, "A new approach to the equilibrium study of iron(III) thiocyanates which accounts for the kinetic instability of the complexes particularly observable under high thiocyanate concentrations," Inorganica Chim. Acta, vol. 445, pp. 155-159, 2016.

[84] C. Su and R. W. Puls, "Arsenate and arsenite removal by zerovalent iron: Kinetics, redox transformation, and implications for in situ groundwater remediation," Environ. Sci. Technol., vol. 35, no. 7, pp. 1487-1492, 2001. 
[85] F. S. G. Einschlag and J. M. Triszcz, "ARSENIC REMOVAL IN CONTINUOUS SYSTEMS USING ZERO - VALENT IRON FIXED BEDS", in Arsenic: Sources, Toxicity and Environmental Impact, capitulo 16, 2008 y referencias allí citadas.

[86] A. Wolborska, "External film control of the fixed bed adsorption," Chem. Eng. J., vol. 73, no. 2, pp. 85-92, 1999.

[87] C. Li, "Batch and Bench-Scale Fixed-Bed Column Evaluations of Heavy Metal Removals From Aqueous Solutions and Synthetic Landfill Leachate Using Low-Cost Natural Adsorbents," 2008.

[88] S. Kundu and A. K. Gupta, "As(III) removal from aqueous medium in fixed bed using iron oxide-coated cement (IOCC): Experimental and modeling studies," Chem. Eng. J., vol. 129, no. 1-3, pp. 123-131, 2007.

[89] M. Sarkar, A. Banerjee, P. P. Pramanick, and A. R. Sarkar, "Design and operation of fixed bed laterite column for the removal of fluoride from water," Chem. Eng. J., vol. 131, no. 1-3, pp. 329-335, 2007.

[90] E. A. Deliyanni, E. N. Peleka, and K. A. Matis, "Modeling the sorption of metal ions from aqueous solution by iron-based adsorbents," J. Hazard. Mater., vol. 172, no. 2-3, pp. 550-558, 2009.

[91] M. Trgo, N. V. Medvidovi, and J. Peri, "Application of mathematical empirical models to dynamic removal of lead on natural zeolite clinoptilolite in a fixed bed column," Indian $\mathrm{J}$. Chem. Technol., vol. 18, no. 2, pp. 123-131, 2011.

[92] V. C. Srivastava, B. Prasad, I. M. Mishra, I. D. Mall, and M. M. Swamy, "Prediction of breakthrough curves for sorptive removal of phenol by bagasse fly ash packed bed," Ind. Eng. Chem. Res., vol. 47, no. 5, pp. 1603-1613, 2008.

[93] D. Ranjan, M. Talat, and S. H. Hasan, "Rice polish: An alternative to conventional adsorbents for treating arsenic bearing water by up-flow column method," Ind. Eng. Chem. Res., vol. 48, no. 23, pp. 10180-10185, 2009.

[94] K. Komnitsas, G. Bartzas, K. Fytas, and I. Paspaliaris, "Long-term efficiency and kinetic evaluation of $\mathrm{ZVI}$ barriers during clean-up of copper containing solutions," Miner. Eng., vol. 20, no. 13, pp. 1200-1209, 2007.

[95] R.A. Hutchins, "New method simplifies design of activated carbon systems." Chem. Eng. 80,133-138,1973.

[96] D. C. K. Ko, J. F. Porter, and G. McKay, "Correlation-based approach to the optimization of fixed-bed sorption units," Ind. Eng. Chem. Res., vol. 38, no. 12, pp. 4868-4877, 1999.D.C.K. Ko, J.F. Porter, G. McKay, Ind. Eng. Chem. Res. 38, 4868-4877 (1999).

[97] Z. Aksu and F. Gönen, "Biosorption of phenol by immobilized activated sludge in a continuous packed bed: Prediction of breakthrough curves," Process Biochem., vol. 39, no. 5, pp. 599-613, 2004.

[98] J. C. Crittenden et al.,"Design of rapid small-scale adsorption tests for a constant diffusivity", Journal (Water Pollution Control Federation), pp. 312-319, 1986.

[99] J. C. Crittenden et al., "Design of rapid fixed-bed adsorption tests for nonconstant diffusivities", Journal of Environmental Engineering, vol. 113, no. 2, pp. 243-259,1987.

[100] J. C. Crittenden, P.S. Reddy, H. Arora, J. Trynoski, D.W. Hand, D.L. Perran, S. Summers, "Predicting GAC performance with rapid small-scale column tests." Journal of American Water Works Association, vol. 83, pp. 77-87,1991.

[101] R. Domga, F. Togue-kamga, C. Noubactep, and J. Tchatchueng, "Discussing porosity 
loss of Fe0 packed water filters at ground level," Chem. Eng. J., vol. 263, pp. 127-134, 2015.

[102] N. Moraci and P. S. Calabró, "Heavy metals removal and hydraulic performance in zerovalent iron/pumice permeable reactive barriers," J. Environ. Manage., vol. 91, no. 11, pp. 2336-2341, 2010.

[103] D. N. H. Beach, J. E. McCray, K. S. Lowe, and R. L. Siegrist, "Temporal changes in hydraulic conductivity of sand porous media biofilters during wastewater infiltration due to biomat formation," J. Hydrol., vol. 311, no. 1-4, pp. 230-243, 2005.

[104] D. Mishra and J. Farrell, "Evaluation of mixed valent iron oxides as reactive adsorbents for arsenic removal," Environ. Sci. Technol., vol. 39, no. 24, pp. 9689-9694, 2005.

[105] O. Levenspield, "Basics of Non-Ideal flow," in Chemical Reaction Engineering, Third Edit., John Wiley \& Sons, Inc., pp. 257-282, 1999.

[106] O. Levenspield, "The Dispersion Model," in Chemical Reaction Engineering, Third Edit., John Wiley \& Sons, Inc., pp. 293-320, 1999.

[107] A. Kołodziej, M. Jaroszy, H. Schoenmakers, K. Althaus, M. Kloeker, E. Geißler, and C. Ubler, "Dynamic tracer study of column packings for catalytic distillation", vol. 44, pp. 661-670, 2005.

[108] A. N. Colli, "Estudio teórico y experimental de las desviaciones de la idealidad en reactores electroquímicos", Universidad Nacional del Litoral, 2013.

[109] M. R. Costante, "Aplicación de métodos de Resolución Multivariada de Curvas para el estudio de las cinéticas y los mecanismos de degradación de colorantes en Procesos Avanzados de Oxidación", Universidad Nacional de La Plata, 2017.

[110] D. C. Montgomery. "Design and Analysis of Experiments", John Wiley \& Sons, 2008.

[111] L. Massart \& B. Vandeginste. Handbook of Qualimetrics Part A. pp. 519-556, 1995.

[112] J. Ferré, \& F. Rius, “Introducción al diseño estadístico de experimentos”, pp. 1-12, 1997.

[113] J. M. Triszcz, A. Porta, and F. S. García, "Effect of operating conditions on iron corrosion rates in zero-valent iron systems for arsenic removal," Chem. Eng. J., vol. 150, pp. 431439, 2009.

[114] M. Biterna, L. Antonoglou, E. Lazou, and D. Voutsa, "Arsenite removal from waters by zero valent iron: Batch and column tests," Chemosphere, vol. 78, no. 1, pp. 7-12, 2010.

[115] C. Su and R. W. Puls, "Arsenate and Arsenite Removal by Zerovalent Iron: Effects of Phosphate, Silicate, Carbonate, Borate, Sulfate, Chromate, Molybdate and Nitrate, Relative to Chloride," Environ. Sci. Technol., vol. 35, no. 22, pp. 4562-4568, 2001.

[116] W. Stumm and J. J. Morgan, Aquatic Chemistry: chemical equilibria and rates in natural waters, Third. John Wiley \& Sons, Inc., 1996.

[117] S. Sharma, Applied Multivariate Techniques. John Wiley \& Sons, Inc., 1997.

[118] Minitab 17. Recuperado de http://www.minitab.com/es-mx/products/minitab/free-trial/.

[119] Tauler, Roma. "Multivariate curve resolution applied to second order data", Chemometrics and intelligent laboratory systems, pp. 133-146, 1995. 
[120] M. T. Hagan, H. B. Demuth, M. H. Beale, and O. De Jesús, Neural Network Design, 2nd ed. 2014

[121] E. F. Caicedo Bravo and J. A. S. López, "Una aproximación práctica a las redes neuronales artificiales", 2009.

[122] S. Gob et al., "Modeling the kinetics of a photochemical water treatment process by means of artificial neural networks," Chem. Eng. Process., vol. 38, pp. 373-382, 1999.

[123] E. Oliveros, M. T. Maurette, and C. A. O. Nascimento, "Neural network modeling of the photocatalytic degradation of 2,4 -dihydroxybenzoic acid in aqueous solution Original articles," Analusis, vol. 26, pp. 326-332, 1998.

[124] L. Díaz-González, C. A. Hidalgo-Dávila, E. Santoyo, and J. Hermosillo-Valadez, "Evaluación de técnicas de entrenamiento de redes neuronales para estudios geotermométricos de sistemas geotérmicos," Rev. Mex. Ing. Química., vol. 12, no. 1, pp. 105-120, 2013.

[125] http://www.Iscp.pqi.ep.usp.br/

[126] https://stats.stackexchange.com/questions/181/how-to-choose-the-number-of-hiddenlayers-and-nodes-in-a-feedforward-neural-netw

[127] J. Heaton, Introduction to Neural Networks with Java, Second Ed. Heaton Research Inc, 2008.

[128] M. T. Hagan, H. B. Demuth, M. H. Beale, and O. De Jesús, Neural Network Design, 2nd ed. 2014.

[129] S. J. Kemp, P. Zaradic, and F. Hansen, "An approach for determining relative input parameter importance and significance in artificial neural networks," Ecol. Modell., vol. 204, no. 3-4, pp. 326-334, 2007.

[130] C. Espinosa, "Tema 3: Ley de Darcy", Hidráulica de Aguas Subterráneas y Su Aprovechamiento", 2006.

[131] P. D. Mackenzie, D. P. Horney, and T. M. Sivavec, "Mineral precipitation and porosity losses in granular iron columns," J. Hazard. Mater., vol. 68, no. 1-2, pp. 1-17, 1999.

[132] B. D. Btatkeu-k, H. Olvera-vargas, J. B. Tchatchueng, C. Noubactep and S. Caré, "Determining the optimum $\mathrm{Fe} 0$ ratio for sustainable granular $\mathrm{FeO}$ /sand water filters," Chem. Eng. J., vol. 247, pp. 265-274, 2014. 


\section{ANEXO 1: PRIMERA SERIE DE ENSAYOS}

\section{$\left(d_{i}\right.$ columna $\left.=1 \mathrm{~cm}, \delta=0.1 \mathrm{~g} / \mathrm{cm}^{3}\right)$}

\begin{tabular}{|c|c|c|c|c|c|c|c|c|c|}
\hline $\mathrm{m}_{\mathrm{ZvI}}(\mathrm{gr})$ & $\mathrm{pHe}$ & $\mathrm{pH} \mathrm{s}$ & TRH (seg) & $\mathrm{Q}\left(\mathrm{cm}^{3} / \mathrm{min}\right)$ & $\mathrm{O}_{2}$ e (ppm) & $\mathrm{O}_{2} \mathrm{~s}(\mathrm{ppm})$ & $\mathrm{O}_{2}$ cons $(\mathrm{ppm})$ & $\mathrm{Fe}(\mathrm{II})(\mathrm{ppm})$ & $\mathrm{Fe}(\mathrm{III})(\mathrm{ppm})$ \\
\hline \multirow[t]{24}{*}{2} & \multirow[t]{6}{*}{4} & 6.16 & 120 & 10 & 8.23 & 1.50 & 6.73 & 17.62 & 1.34 \\
\hline & & 5.87 & 60 & 20 & 8.23 & 1.50 & 6.73 & 13.94 & 0.86 \\
\hline & & 5.66 & 30 & 40 & 8.30 & 1.87 & 6.43 & 10.29 & 0.65 \\
\hline & & 5.50 & 20 & 60 & 8.30 & 2.17 & 6.13 & 8.70 & 0.13 \\
\hline & & 5.19 & 10 & 120 & 8.40 & 3.17 & 5.23 & 5.08 & 0.26 \\
\hline & & 4.72 & 5 & 240 & 8.40 & 5.21 & 3.19 & 2.01 & 0.59 \\
\hline & \multirow[t]{6}{*}{5} & 6.27 & 120 & 10 & 8.40 & 1.50 & 6.90 & 17.48 & 1.53 \\
\hline & & 6.07 & 60 & 20 & 8.40 & 1.50 & 6.90 & 14.46 & 0.85 \\
\hline & & 5.90 & 30 & 40 & 8.35 & 1.80 & 6.55 & 10.28 & 0.80 \\
\hline & & 5.82 & 20 & 60 & 8.35 & 2.52 & 5.83 & 8.28 & 0.13 \\
\hline & & 5.64 & 10 & 120 & 8.30 & 4.50 & 3.80 & 5.96 & 0.60 \\
\hline & & 5.32 & 5 & 240 & 8.30 & 5.98 & 2.32 & 1.66 & 0.27 \\
\hline & \multirow[t]{6}{*}{6} & 6.51 & 120 & 10 & 9.80 & 2.54 & 7.26 & 15.62 & 0.81 \\
\hline & & 6.45 & 60 & 20 & 9.00 & 1.95 & 7.05 & 11.11 & 1.46 \\
\hline & & 6.37 & 30 & 40 & 9.00 & 2.28 & 6.72 & 7.78 & 0.87 \\
\hline & & 6.33 & 20 & 60 & 9.00 & 2.79 & 6.21 & 6.25 & 1.15 \\
\hline & & 6.27 & 10 & 120 & 9.00 & 4.44 & 4.56 & 4.73 & 0.91 \\
\hline & & 6.17 & 5 & 240 & 9.00 & 6.19 & 2.81 & 1.49 & 0.35 \\
\hline & \multirow[t]{6}{*}{7} & 7.03 & 120 & 10 & 9.80 & 2.40 & 7.40 & 3.33 & 4.82 \\
\hline & & 7.03 & 60 & 20 & 9.03 & 1.24 & 7.20 & 2.67 & 4.04 \\
\hline & & 7.02 & 30 & 40 & 9.03 & 2.05 & 6.98 & 1.98 & 3.06 \\
\hline & & 7.00 & 20 & 60 & 9.03 & 2.40 & 6.63 & 3.23 & 1.69 \\
\hline & & 7.08 & 10 & 120 & 9.03 & 4.26 & 4.77 & 1.40 & 2.87 \\
\hline & & 7.00 & 5 & 240 & 9.00 & 6.20 & 2.80 & 0.99 & 1.57 \\
\hline \multirow[t]{24}{*}{1} & \multirow[t]{6}{*}{4} & 6.43 & 120 & 5 & 10.20 & 1.90 & 8.30 & 20.18 & 0.40 \\
\hline & & 5.99 & 60 & 10 & 9.65 & 1.57 & 8.08 & 17.24 & 0.24 \\
\hline & & 5.75 & 30 & 20 & 9.65 & 2.40 & 7.25 & 10.41 & 0.48 \\
\hline & & 5.60 & 20 & 30 & 9.65 & 3.33 & 6.32 & 9.12 & 0.37 \\
\hline & & 5.30 & 10 & 60 & 9.65 & 4.00 & 5.65 & 5.67 & 0.78 \\
\hline & & 5.14 & 5 & 120 & 10.04 & 5.78 & 4.26 & 5.43 & 0.21 \\
\hline & \multirow[t]{6}{*}{5} & 6.56 & 120 & 5 & 9.40 & 2.00 & 7.40 & 22.15 & 3.16 \\
\hline & & 6.30 & 60 & 10 & 9.50 & 2.10 & 7.40 & 15.48 & 1.95 \\
\hline & & 6.04 & 30 & 20 & 9.50 & 2.29 & 7.21 & 10.71 & 2.00 \\
\hline & & 5.85 & 20 & 30 & 9.50 & 2.90 & 6.60 & 7.56 & 0.00 \\
\hline & & 5.68 & 10 & 60 & 9.50 & 4.51 & 4.99 & 5.00 & 1.79 \\
\hline & & 5.36 & 5 & 120 & 9.20 & 6.73 & 2.47 & 2.72 & 0.00 \\
\hline & \multirow[t]{6}{*}{6} & 6.83 & 120 & 5 & 9.20 & 1.63 & 7.57 & 16.06 & 0.67 \\
\hline & & 6.63 & 60 & 10 & 8.40 & 2.05 & 6.35 & 11.84 & 0.80 \\
\hline & & 6.48 & 30 & 20 & 8.40 & 2.22 & 6.18 & 7.89 & 0.60 \\
\hline & & 6.42 & 20 & 30 & 8.40 & 2.60 & 5.80 & 6.00 & 0.90 \\
\hline & & 6.25 & 10 & 60 & 8.40 & 4.22 & 4.18 & 4.84 & 0.37 \\
\hline & & 6.12 & 5 & 120 & 9.30 & 5.90 & 3.40 & 2.34 & \\
\hline & \multirow[t]{6}{*}{7} & 7.20 & 120 & 5 & 8.86 & 0.86 & 8.00 & & 4.62 \\
\hline & & 7.20 & 60 & 10 & 8.86 & 1.54 & 7.32 & 3.00 & 3.66 \\
\hline & & 7.13 & 30 & 20 & 8.86 & 2.28 & 6.58 & 8.39 & 3.21 \\
\hline & & 7.14 & 20 & 30 & 8.86 & 2.94 & 5.92 & 6.54 & 0.65 \\
\hline & & 7.04 & 10 & 60 & 8.86 & 4.45 & 4.41 & 3.12 & 2.84 \\
\hline & & 7.02 & 5 & 120 & & & & 1.67 & 0.23 \\
\hline
\end{tabular}


PRIMERA SERIE DE ENSAYOS (continuación) $\left(d_{i}\right.$ columna $\left.=1 \mathrm{~cm}, \delta=0.1 \mathrm{~g} / \mathrm{cm}^{3}\right)$

\begin{tabular}{|c|c|c|c|c|c|c|c|c|c|}
\hline $\mathrm{m}_{\mathrm{zvI}}(\mathrm{gr})$ & $\mathrm{pHe}$ & $\mathrm{pHs}$ & TRH (seg) & $Q\left(\mathrm{~cm}^{3} / \mathrm{min}\right)$ & $\mathrm{O}_{2}$ e (ppm) & $\mathrm{O}_{2} \mathrm{~s}(\mathrm{ppm})$ & $\mathrm{O}_{2}$ cons $(\mathrm{ppm})$ & $\mathrm{Fe}(\mathrm{II})(\mathrm{ppm})$ & $\mathrm{Fe}(\mathrm{III})(\mathrm{ppm})$ \\
\hline \multirow[t]{24}{*}{0.5} & 4 & 6.48 & 120 & 2.5 & 9.50 & 1.74 & 7.76 & 16.55 & 0.89 \\
\hline & & 6.15 & 60 & 5 & 9.12 & 2.00 & 7.12 & 13.66 & 0.19 \\
\hline & & 5.78 & 30 & 10 & 9.12 & 2.73 & 6.39 & 10.22 & 0.18 \\
\hline & & 5.65 & 20 & 15 & 9.67 & 3.62 & 6.05 & 8.24 & 0.15 \\
\hline & & 5.50 & 10 & 30 & 9.12 & 5.22 & 3.90 & 6.86 & 0.34 \\
\hline & & 5.38 & 5 & 60 & 9.12 & 6.58 & 2.54 & 3.84 & 0.08 \\
\hline & 5 & 6.62 & 120 & 2.5 & 10.10 & 3.00 & 7.10 & 15.78 & 2.10 \\
\hline & & 6.55 & 60 & 5 & 9.50 & 1.70 & 7.80 & 11.90 & 0.60 \\
\hline & & 6.20 & 30 & 10 & 9.50 & 3.26 & 6.24 & 8.21 & 0.21 \\
\hline & & 6.05 & 20 & 15 & 9.50 & 4.10 & 5.40 & 6.36 & 0.21 \\
\hline & & 5.85 & 10 & 30 & 9.50 & 5.94 & 3.56 & 4.57 & 0.59 \\
\hline & & 5.68 & 5 & 60 & 9.50 & 8.00 & 1.50 & 1.97 & 0.15 \\
\hline & 6 & 6.82 & 120 & 2.5 & 8.70 & 1.60 & 7.10 & 4.54 & 2.85 \\
\hline & & 6.70 & 60 & 5 & 8.70 & 1.57 & 7.13 & 4.73 & 1.25 \\
\hline & & 6.60 & 30 & 10 & 8.70 & 3.84 & 4.86 & 3.72 & 0.92 \\
\hline & & 6.56 & 20 & 15 & 8.70 & 4.52 & 4.18 & 4.89 & 0.42 \\
\hline & & 6.49 & 10 & 30 & 8.70 & 5.69 & 3.01 & 2.11 & 0.19 \\
\hline & & 6.32 & 5 & 60 & 8.70 & 7.10 & 1.60 & 2.02 & 0.46 \\
\hline & 7 & 7.12 & 120 & 2.5 & 9.25 & 2.70 & 6.55 & 8.41 & 3.16 \\
\hline & & 7.02 & 60 & 5 & 9.25 & 1.64 & 7.61 & 4.07 & 1.95 \\
\hline & & 7.00 & 30 & 10 & 9.25 & 4.72 & 4.53 & 2.68 & 2.00 \\
\hline & & 7.00 & 20 & 15 & 9.25 & 5.10 & 4.15 & 2.10 & 4.01 \\
\hline & & 7.00 & 10 & 30 & 9.25 & 7.33 & 1.92 & 1.30 & 1.79 \\
\hline & & 7.00 & 5 & 60 & 9.25 & 7.10 & 2.15 & 1.00 & 2.79 \\
\hline
\end{tabular}




\section{ANEXO 2: SEGUNDA SERIE DE ENSAYOS}

\section{$\left(\mathrm{pH}\right.$ entrada $=4, \mathrm{~d}_{\mathrm{i}}$ columna $=1 \mathrm{~cm}, \delta=0.1 \mathrm{~g} / \mathrm{cm}^{3}$ )}

\begin{tabular}{|c|c|c|c|c|c|c|c|c|}
\hline m zvi (gr) & $\mathrm{pHs}$ & TRH (seg) & $\mathrm{Q}\left(\mathrm{cm}^{3} / \mathrm{min}\right)$ & $\mathrm{O}_{2}$ e (ppm) & $\mathrm{O}_{2} \mathrm{~s}$ (ppm) & $\mathrm{O}_{2}$ cons $(\mathrm{ppm})$ & $\mathrm{Fe}(\mathrm{II})(\mathrm{ppm})$ & $\mathrm{Fe}(\mathrm{III})(\mathrm{ppm})$ \\
\hline 0.2 & 5.99 & 60 & 2 & 10.14 & 5.58 & 4.56 & 12.85 & 0.58 \\
\hline 0.2 & 5.79 & 30 & 4 & 10.14 & 4.00 & 6.14 & 10.14 & 0.49 \\
\hline 0.2 & 5.5 & 15 & 8 & 8.62 & 5.25 & 3.37 & 7.58 & 0.88 \\
\hline 0.2 & 5.22 & 10 & 12 & 8.62 & 5.84 & 2.78 & 4.46 & 0.13 \\
\hline 0.2 & 4.96 & 5 & 24 & 8.62 & 6.45 & 2.17 & 3.06 & 0.09 \\
\hline 0.5 & 5.97 & 60 & 5 & 9.12 & 2.00 & 7.12 & 17.01 & 0.37 \\
\hline 0.5 & 5.62 & 30 & 10 & 9.12 & 2.73 & 6.39 & 12.03 & 0.22 \\
\hline 0.5 & 5.35 & 15 & 20 & 8.95 & 4.56 & 4.39 & 8.12 & 0.71 \\
\hline 0.5 & 5.22 & 10 & 30 & 8.95 & 5.02 & 3.93 & 5.97 & 0.13 \\
\hline 0.5 & 5.02 & 5 & 60 & 8.95 & 5.98 & 2.97 & 4.13 & 0.06 \\
\hline 0.8 & 6.07 & 60 & 8 & 8.60 & 1.65 & 6.95 & - & - \\
\hline 0.8 & 5.9 & 30 & 16 & 8.60 & 1.65 & 6.95 & - & - \\
\hline 0.8 & 5.4 & 15 & 32 & 8.60 & 2.45 & 6.15 & - & - \\
\hline 0.8 & 5.35 & 10 & 48 & 8.60 & 3.18 & 5.42 & - & - \\
\hline 0.8 & 5.01 & 5 & 96 & 8.60 & 4.76 & 3.84 & - & - \\
\hline 1.2 & 5.79 & 60 & 12 & 8.84 & 1.76 & 7.08 & 12.14 & 0.31 \\
\hline 1.2 & 5.53 & 30 & 24 & 8.84 & 1.83 & 7.01 & 9.34 & 0.22 \\
\hline 1.2 & 5.35 & 15 & 48 & 8.84 & 2.21 & 6.63 & 7.47 & 0.64 \\
\hline 1.2 & 5.22 & 10 & 72 & 8.84 & 3.53 & 5.31 & 6.10 & 0.09 \\
\hline 1.2 & 5.02 & 5 & 144 & 8.84 & 5.13 & 3.71 & 4.96 & 0.10 \\
\hline 1.6 & 5.96 & 60 & 16 & 9.05 & 1.34 & 7.71 & 12.43 & 0.57 \\
\hline 1.6 & 5.78 & 30 & 32 & 9.05 & 1.73 & 7.32 & 11.39 & 0.00 \\
\hline 1.6 & 5.4 & 15 & 64 & 9.05 & 2.54 & 6.51 & 8.13 & 0.60 \\
\hline 1.6 & 5.25 & 10 & 96 & 9.05 & 3.40 & 5.65 & 7.02 & 0.03 \\
\hline 1.6 & 4.97 & 5 & 192 & 9.05 & 5.06 & 3.99 & 5.26 & 0.00 \\
\hline 2 & 5.69 & 60 & 20 & 9.05 & 1.50 & 7.55 & 15.04 & 0.08 \\
\hline 2 & 5.54 & 30 & 40 & 9.05 & 1.68 & 7.37 & 10.96 & 0.04 \\
\hline 2 & 5.38 & 15 & 80 & 9.05 & 2.69 & 6.36 & 8.50 & 0.67 \\
\hline 2 & 5.23 & 10 & 120 & 9.05 & 3.53 & 5.52 & 6.85 & 0.03 \\
\hline 2 & 5.12 & 5 & 240 & 9.05 & 5.40 & 3.65 & 5.50 & 0.00 \\
\hline
\end{tabular}


ANEXO 3: TERCERA SERIE DE ENSAYOS

$\left(\mathrm{pH}\right.$ entrada $=4, \mathrm{~m}_{\mathrm{Zvl}}=2 \mathrm{~g}, \mathrm{~d}_{\mathrm{i}}$ columna $=1 \mathrm{~cm}$ )

\begin{tabular}{|c|c|c|c|c|c|c|c|c|c|}
\hline $\mathrm{L}(\mathrm{cm})$ & $\delta\left(\mathrm{gr} / \mathrm{cm}^{3}\right)$ & $\mathrm{pHs}$ & TRH (seg) & $\mathrm{Q}\left(\mathrm{cm}^{3} / \mathrm{min}\right)$ & $\mathrm{O}_{2}$ e $(p p m)$ & $\mathrm{O}_{2} \mathrm{~s}(\mathrm{ppm})$ & $\mathrm{O}_{2}$ cons $(\mathrm{ppm})$ & $\mathrm{Fe}(\mathrm{II})(\mathrm{ppm})$ & $\mathrm{Fe}(\mathrm{III})(\mathrm{ppm})$ \\
\hline \multirow[t]{6}{*}{25.46} & \multirow[t]{6}{*}{0.10} & 6.16 & 120 & 10.00 & 8.23 & 1.50 & 6.73 & 17.62 & 1.34 \\
\hline & & 5.69 & 60 & 20.00 & 9.05 & 1.50 & 7.55 & 15.04 & 0.08 \\
\hline & & 5.54 & 30 & 40.00 & 9.05 & 1.68 & 7.37 & 10.96 & 0.04 \\
\hline & & 5.38 & 15 & 80.00 & 9.05 & 2.69 & 6.36 & 4.77 & 0.67 \\
\hline & & 5.23 & 10 & 120.00 & 9.05 & 3.53 & 5.52 & 6.85 & 0.03 \\
\hline & & 5.12 & 5 & 240.00 & 9.05 & 5.40 & 3.65 & 5.50 & 0.00 \\
\hline \multirow[t]{7}{*}{11.5} & \multirow[t]{7}{*}{0.22} & 6.11 & 120 & 4.52 & 9.60 & 0.90 & 8.70 & 17.46 & 1.45 \\
\hline & & 6.06 & 60 & 9.03 & 8.68 & 1.10 & 7.58 & 14.64 & 0.88 \\
\hline & & 5.92 & 30 & 18.06 & 8.68 & 1.47 & 7.21 & 12.09 & 0.61 \\
\hline & & 5.89 & 20 & 27.10 & 8.68 & 1.79 & 6.89 & 11.45 & 0.59 \\
\hline & & 5.76 & 10 & 54.19 & 8.68 & 2.60 & 6.08 & 9.33 & 0.50 \\
\hline & & 5.58 & 5 & 108.39 & 8.68 & 4.22 & 4.46 & 5.87 & 0.39 \\
\hline & & 5.53 & 2.5 & 216.77 & 8.68 & 6.00 & 2.68 & 4.46 & 0.44 \\
\hline \multirow[t]{7}{*}{5} & \multirow[t]{7}{*}{0.51} & & 120 & 1.96 & 8.50 & & 8.50 & & \\
\hline & & 6.1 & 60 & 3.93 & 8.50 & 0.90 & 7.60 & 14.57 & 0.17 \\
\hline & & 5.9 & 30 & 7.85 & 8.50 & 1.40 & 7.10 & 10.86 & 0.03 \\
\hline & & 5.8 & 20 & 11.78 & 8.50 & 1.68 & 6.82 & 9.81 & 0.03 \\
\hline & & 5.65 & 10 & 23.56 & 8.50 & 2.30 & 6.20 & 7.39 & 0.03 \\
\hline & & 5.30 & 5 & 47.12 & 8.50 & 3.15 & 5.35 & 5.20 & 0.03 \\
\hline & & 5.1 & 2.5 & 94.25 & 8.50 & 5.00 & 3.50 & 3.84 & 0.11 \\
\hline \multirow[t]{7}{*}{3.4} & \multirow[t]{7}{*}{0.75} & 6.24 & 120 & 1.33 & 8.13 & 3.00 & 5.13 & 14.81 & 0.95 \\
\hline & & 6.15 & 60 & 2.67 & 8.13 & 2.23 & 5.90 & 14.99 & 0.53 \\
\hline & & 5.8 & 30 & 5.34 & 8.13 & 2.21 & 5.92 & 11.74 & 0.32 \\
\hline & & 5.34 & 20 & 8.00 & 8.13 & 2.00 & 6.13 & 11.67 & 0.37 \\
\hline & & 5.7 & 10 & 16.00 & 8.13 & 1.90 & 6.23 & 9.83 & 0.10 \\
\hline & & 5.64 & 5 & 32.00 & 8.13 & 2.57 & 5.56 & 7.67 & 0.41 \\
\hline & & 5.36 & 2.5 & 64.00 & 8.13 & 4.20 & 3.93 & 5.04 & 0.39 \\
\hline
\end{tabular}

